THE 1992 ERUPTIONS OF CRATER PEAK VENT, MOUNT SPURR VOLCANO, ALASKA

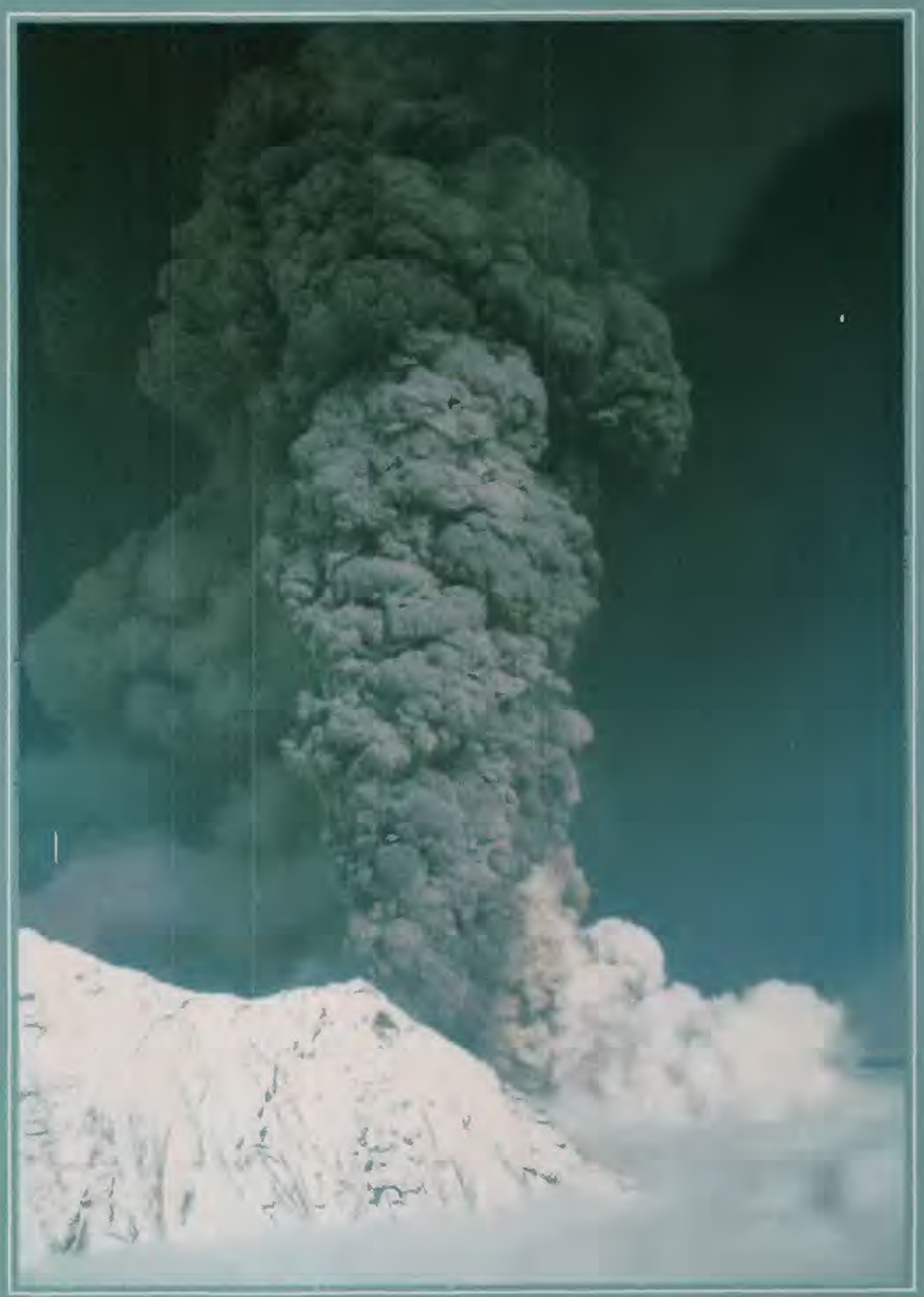

U.S. GEOLOGICAL SURVEY BULLETIN 2139 
Cover-Ash cloud rising from Crater Peak vent of Mount Spurr volcano, Alaska, during the eruption on August 18, 1992. Crater Peak is not visible in image. A pyroclastic flow that descended the volcano's flank produced the smaller steam and ash cloud shown at lower right of large cloud.

Photograph taken by Robert G. McGimsey. 


\title{
THE 1992 ERUPTIONS OF CRATER PEAK VENT, MOUNT SPURR VOLCANO, ALASKA
}

\author{
Terry E.C. Keith, Editor
}

U.S. GEOLOGICAL SURVEY BULLETIN 2139

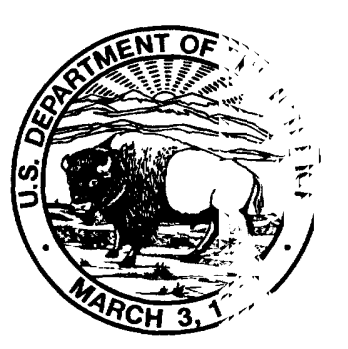




\title{
U.S. DEPARTMENT OF THE INTERIOR BRUCE BABBITT, Secretary
}

\author{
U.S. GEOLOGICAL SURVEY \\ Gordon P. Eaton, Director
}

For sale by

U.S. Geological Survey, Information Services

Box 25286, Federal Center

Denver, CO 80225

\begin{abstract}
Any use of trade, product, or firm names in this publication is for descriptive purposes only and does not imply endorsement by the U.S. Government

Cover designed by Glenn Schumacher

Text and illustrations edited by Carolyn Donlin
\end{abstract}

\author{
Library of Congress Cataloging-in-Publication Data \\ The 1992 eruptions of Crater Peak vent, Mount Spurr volcano, Alaska / \\ Terry E.C. Keith, editor. \\ p. cm. - (U.S. Geological Survey bulletin ; 2139) \\ Includes bibliographical references (p. $\quad$ ) ). \\ Supt. of Docs. no.: 1 19.3:2139 \\ 1. Spurr, Mount (Alaska)-Eruption, 1992. I. Keith, Terry E. C. \\ II. Series. \\ QE75.B9 \\ no. 2139 \\ [QE523.S73] \\ $557.3 \mathrm{~s}-\mathrm{dc} 20$ \\ [551.2' 1'097983] \\ 95-43967 \\ CIP
}


1. The 1992 Eruptions of Crater Peak Vent, Mount Spurr Volcano, Alaska: Chronology and Summary 1

By John C. Eichelberger, Terry E.C. Keith, Thomas P. Miller, and Christopher J. Nye

2. Real-time C-band Radar Observations of 1992 Eruption Clouds from Crater Peak, Mount Spurr Volcano, Alaska 19

By William I. Rose, Alexander B. Kostinski, and Lee Kelley

3. Tracking of 1992 Eruption Clouds from Crater Peak Vent of Mount Spurr Volcano, Alaska, Using AVHRR 27

By David J. Schneider, William I. Rose, and Lee Kelley

4. Explosive Emissions of Sulfur Dioxide from the 1992 Crater Peak Eruptions, Mount Spurr Volcano, Alaska 37

By Gregg J.S. Bluth, Courtney J. Scott, Ian E. Sprod, Charles C. Schnetzler, Arlin J. Krueger, and Louis S. Walter

5. Sulfur Dioxide Scrubbing During the 1992 Eruptions of Crater Peak, Mount Spurr Volcano, Alaska 47

By Michael P. Doukas and Terrence M. Gerlach

6. Chemistry of Crater Lake Waters Prior to the 1992 Eruptions of Crater Peak, Mount Spurr Volcano, Alaska 59

By Terry E.C. Keith, J. Michael Thompson, and Robert G. McGimsey

7. Tephra-fall Deposits from the 1992 Eruptions of Crater Peak, Mount Spurr Volcano, Alaska: A Preliminary Report on Distribution, Stratigraphy, and Composition 65

By Christina A. Neal, Robert G. McGimsey, Cynthia A. Gardner, Michelle L. Harbin, and Christopher J. Nye

8. Pyroclastic Flows of the 1992 Crater Peak Eruptions: Distribution and Origin $8 \mathbf{1}$ By Thomas P. Miller, Christina A. Neal, and Richard B. Waitt

9. Ballistic Showers During Crater Peak Eruptions of Mount Spurr Volcano, Summer 199289

By Richard B. Waitt, Larry G. Mastin, and Thomas P. Miller

10. Hybrid Wet Flows Formed by Hot Pyroclasts Interacting with Snow During the 1992

Eruptions of Crater Peak, Mount Spurr Volcano, Alaska 107 By Richard B. Waitt

11. Whole-rock Major- and Trace-element Chemistry of 1992 Ejecta from Crater Peak, Mount Spurr Volcano, Alaska 119

By Christoper J. Nye, Michelle L. Harbin, Thomas P. Miller, Samuel E. Swanson, and Christina A. Neal 
12. Use of Volcanic Glass from Ash as a Monitoring Tool: An Example from the 1992 Eruptions of Crater Peak, Mount Spurr Volcano, Alaska 129

By Samuel E. Swanson, Michelle L. Harbin, and James R. Riehle

13. Preliminary Petrology and Chemistry of Proximal Eruptive Products: 1992 Eruptions of Crater Peak, Mount Spurr Volcano, Alaska 139

By Michelle L. Harbin, Samuel E. Swanson, Christoper J. Nye, and Thomas P. Miller

14. Seismicity and Forecasting of the 1992 Eruptions of Crater Peak Vent, Mount Spurr Volcano, Alaska: An Overview 149

By John A. Power, Arthur D. Jolly, Robert A. Page, and Stephen R. McNutt

15. Preliminary Analyses of Volcanic Tremor Associated with 1992 Eruptions of Crater Peak, Mount Spurr Volcano, Alaska 161

By Stephen R. McNutt, Guy C. Tytgat, and John A. Power

16. Lightning Associated with the August 18, 1992, Eruption of Crater Peak Vent, Mount Spurr Volcano, Alaska 179

By John F. Paskievitch, Thomas L. Murray, Richard P. Hoblitt, and

Christina A. Neal

17. Lahars from the 1992 Eruptions of Crater Peak, Mount Spurr Volcano, Alaska 183

By David F. Meyer and Dennis C. Trabant

18. June 29, 1993, Outburst Flood from Kidazgeni Glacier, Mount Spurr Volcano, Alaska 199

By Christopher J. Nye, William R. Hammond, Guy C. Tytgat, and

Joseph M. Dorava

19. Effects of the 1992 Crater Peak Eruptions on Airports and Aviation Operations in the United States and Canada 205

By Thomas J. Casadevall and M. Dennis Krohn

List of Contributors 221

Appendix Time Conversion Chart 223 


\title{
The 1992 Eruptions of Crater Peak Vent, Mount Spurr Volcano, Alaska: Chronology and Summary
}

\author{
By John C. Eichelberger, Terry E.C. Keith, Thomas P. Miller, and Christopher J. Nye
}

\section{CONTENTS}

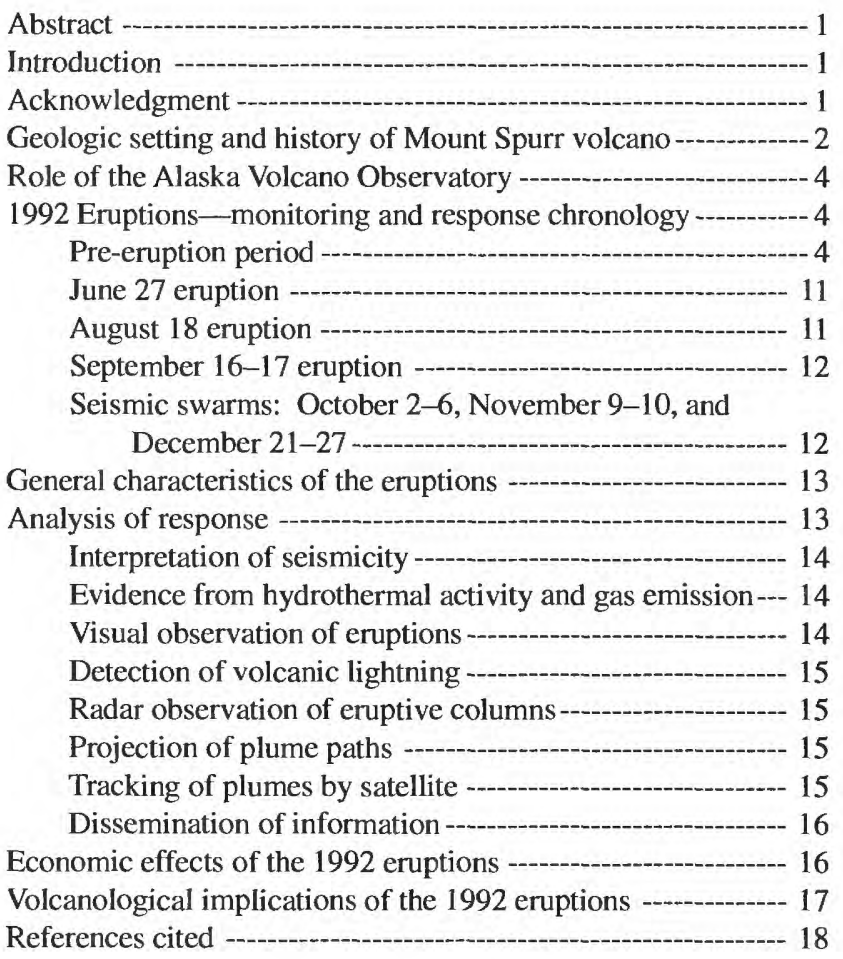

\begin{abstract}
Following 39 years of inactivity, Crater Peak vent on the south flank of Mount Spurr volcano burst into eruption at 7:04 a.m. Alaska daylight time (ADT) on June 27, 1992. This and subsequent eruptions on August 18 and September 16-17 were subplinian, had a volcano explosivity index (VEI) of 3 , and lasted about 4 hours. The June, August, and September eruptions released 44,52 , and 56 million $\mathrm{m}^{3}(12,14$, and 15 million $\mathrm{m}^{3}$ dense rock equivalent or DRE) of andesitic (57 weight percent $\mathrm{SiO}_{2}$ ) tephra, respectively and drove tephra columns 14,000 to $15,000 \mathrm{~m}$ above sea level. The August eruption had the most far-reaching
\end{abstract}

Manuscript approved for publication May 19, 1995. effects-it deposited $3 \mathrm{~mm}$ of ash on Anchorage, $125 \mathrm{~km}$ east of the volcano. Proximal pyroclastic flows accompanied the August and September eruptions. In all eruptions, lahars and debris flows descended Crater Peak's south flank, and some reached the Chakachatna River.

Real-time seismic monitoring tracked the 10month crescendo of precursory earthquakes and allowed timely warning of the increasing unrest to State and Federal government officials, the military, air carriers, and local citizens. This monitoring was augmented with other types of observations and provided the basis for accurate eruption advisories that minimized economic losses. In particular, because of an efficient ashcloud warning system in Alaska and new awareness of the problem of ash clouds within the aviation community, no jets were damaged. Unavoidable losses of $\$ 5$ to 8 million were sustained from the August ashfall on Anchorage and the Matanuska-Susitna Valley, both of which make up the State of Alaska's center of population and economic activity. Additional but unevaluated costs were incurred from flight delays in large North American airports to the south and east as ash clouds of the August and September eruptions passed overhead.

\section{INTRODUCTION}

The Crater Peak vent of Mount Spurr volcano, located $125 \mathrm{~km}$ west of Anchorage (figs. 1,2) and last active in 1953 (Juehle and Coulter, 1955; Wilcox, 1959), erupted three times in 1992 following 10 months of heightened seismicity. The first eruption occurred on June 27, 1992, and was followed by similar events on August 18 and September 16-17, 1992. This paper provides an overview of these eruptions and the Alaska Volcano Observatory's response to them.

\section{ACKNOWLEDGMENT}

This work was supported by the U.S. Geological Survey Volcano Hazards and Geothermal Studies Program and by the State of Alaska. 


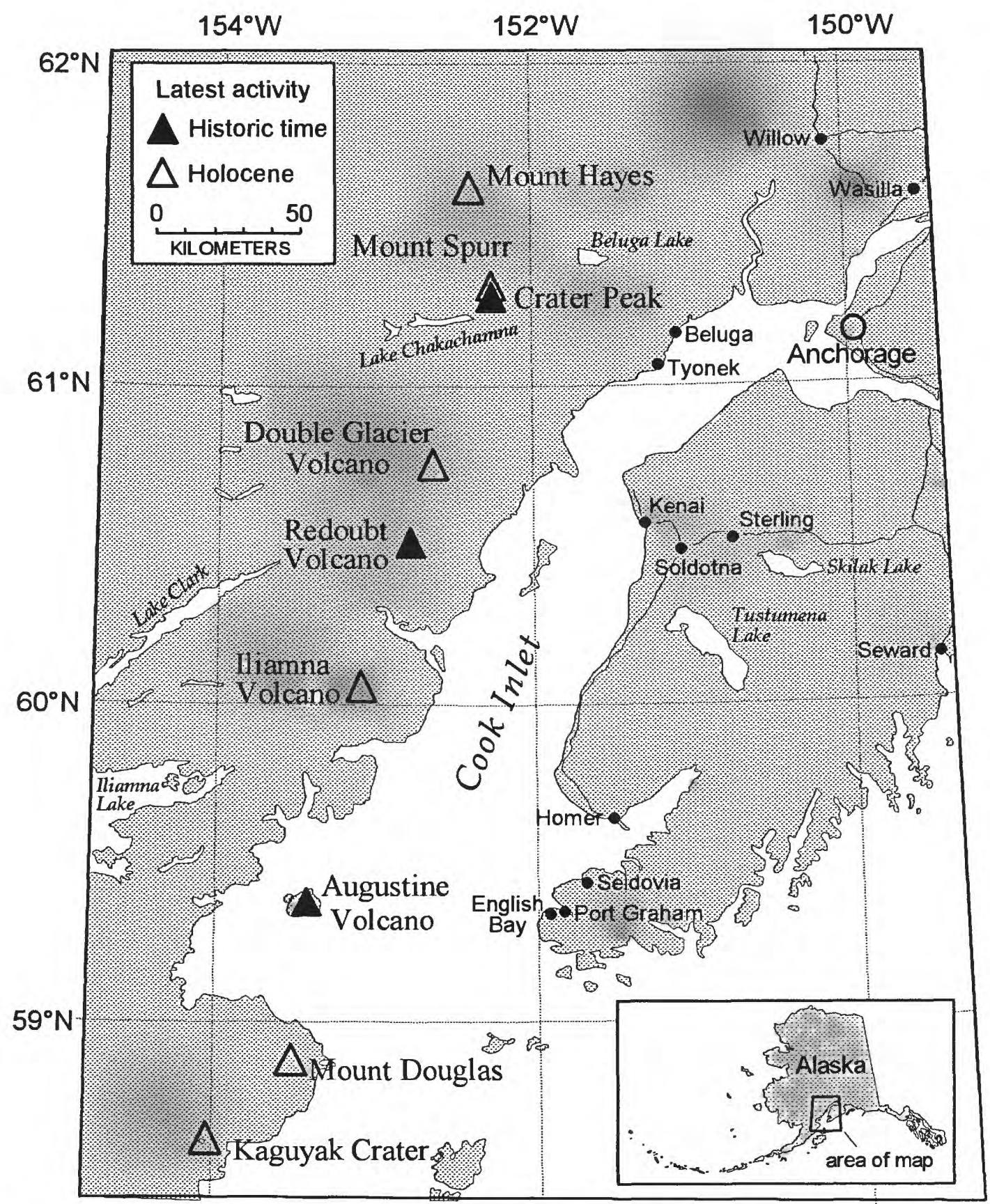

Figure 1. Index map showing volcanoes and population centers of the Cook Inlet region, Alaska.

\section{GEOLOGIC SETTING AND HISTORY OF MOUNT SPURR VOLCANO}

Mount Spurr sits $100 \mathrm{~km}$ above the WadatiBenioff zone and $500 \mathrm{~km}$ inboard of the Aleutian Trench (Jacob and others, 1977) on a basement of mainly intrusive rocks (Nye and Turner, 1990). Its large stratovolcano edifice, built of two-pyroxene andesite (5860 weight percent $\mathrm{SiO}_{2}$ ), began to form before 255,000 yr ago (Nye and Turner, 1990). Pyroclastic rocks dominate the lower part of the volcano, and lava flows dominate the upper part. Within the past $58,000 \mathrm{yr}$ but before Holocene time, the volcano collapsed southward in a manner similar to Bezymianny Volcano in Kamchatka, Russia (Gorshkov, 1959). The debris avalanche generated at Mount Spurr had a minimum runout of $25 \mathrm{~km}$ by $6 \mathrm{~km}$ and left the volcano with a horseshoe-shaped caldera rim. Collapse was followed immediately by eruption of more silicic (60-63 weight percent $\mathrm{SiO}_{2}$ ) andesitic ash-flow tuffs. A large dome complex, which now forms Mount Spurr's 3,374-m summit, grew in the center of the caldera probably no later than 5,000 $\mathrm{yr}$ ago (Riehle, 1985). The complex consists of two-pyroxene silicic andesite, chemi- 

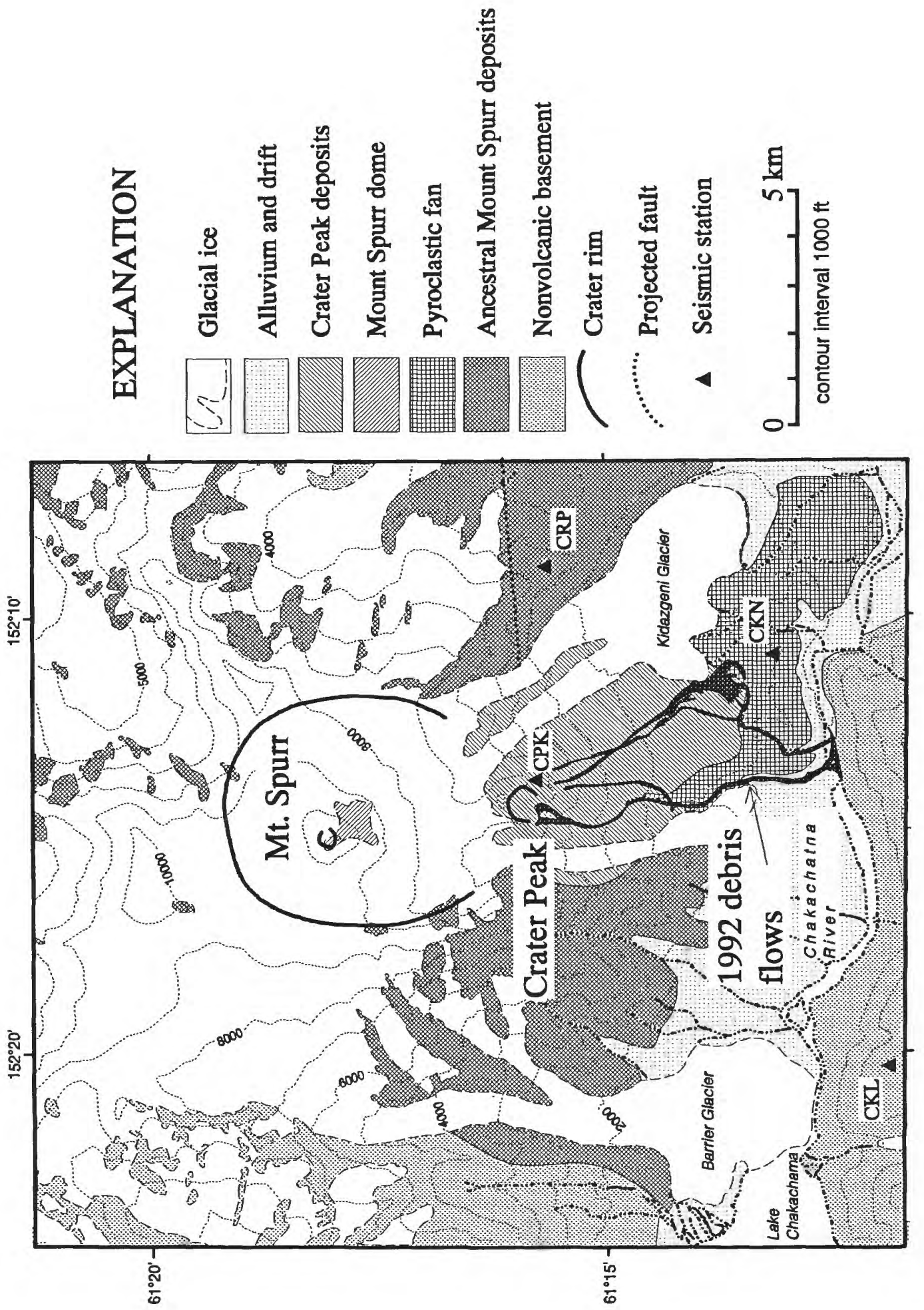

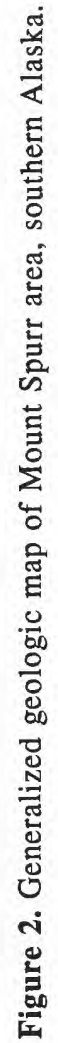


cally similar to the ash-flow tuffs (Nye and Turner, 1990). A basaltic-andesite satellitic cone developed at the same time in the caldera breach. The present Crater Peak represents a second period of satellite cone-building at the same location; it reaches an elevation of 2,309 m, $3.5 \mathrm{~km}$ south of Mount Spurr's summit. Crater Peak consists of lavas and pyroclastic flows of mafic andesite (53-57 weight percent $\mathrm{SiO}_{2}$; Nye and Turner, 1990). The 40 tephra units correlated to this vent range in age from 5,000 yr to present (Riehle, 1985). Eruption products that are apparent mixtures of Crater Peak and summit dome complex magmas indicate that the two systems were partly coeval (Nye and Turner, 1990).

Prior to 1992, the only witnessed eruption of Mount Spurr occurred on July 9, 1953. This eruption also issued from the Crater Peak vent and consisted of two main explosive pulses, followed by steam and minor ash emission. The eruption cloud rose to over $20,000 \mathrm{~m}$ above sea level and deposited 3 to $6 \mathrm{~mm}$ of andesitic (55 weight percent $\mathrm{SiO}_{2}$ ) ash on Anchorage (Juehle and Coulter, 1955; Wilcox, 1959). A debris flow dammed the Chakachatna River downslope from Crater Peak, and the dam created an 8-km-long lake. The dam was overtopped and breached within a week.

\section{ROLE OF THE ALASKA VOLCANO OBSERVATORY}

The Alaska Volcano Observatory (AVO) was established in 1988, following the 1986 eruption of Augustine Volcano; the observatory conducted its first full eruption response with the Redoubt Volcano episode of 1989-90 (Miller and Chouet, 1994). AVO is a cooperative program of the U.S. Geological Survey (USGS), University of Alaska Fairbanks Geophysical Institute (UAFGI), and Alaska Division of Geological and Geophysical Surveys (ADGGS). AVO is supported by both the Department of Interior through the USGS Volcano Hazards and Geothermal Studies Program and by the State of Alaska. AVO's primary mission is to communicate timely warnings of unrest and potential eruption of Alaska's volcanoes and to investigate the fundamental processes of hazardous volcanism, with a view toward improved eruption warnings and hazard assessments.

Since World War II, Anchorage has become the population and economic center of Alaska; over half the population of the State is currently concentrated in the Anchorage area. Three of the Cook Inlet volcanoes-Augustine Volcano, Redoubt Volcano, and Mount Spurr-are frequently active. Within the past decade, their eruptions have produced ash clouds that were hazardous to aircraft as well as to the general populace. Accordingly, the Cook Inlet region presents the greatest array of volcano hazards in Alaska and is the focus of AVO's efforts.

AVO distributes updates (fig. 3) each Friday to summarize the weekly status of the monitored Cook Inlet volcanoes and any reported activity of unmonitored volcanoes on the Alaska Peninsula and Aleutian Islands. During periods of volcanic unrest and eruption crises, additional updates are issued when significant changes in activity should be made known to the public (Brantley, 1990). Updates were issued frequently to a prioritized list of well over 100 recipients during the Crater Peak eruptions. AVO at Fairbanks faxes to the local Federal Aviation Administration (FAA), the local National Weather Service (NWS), Alaska Department of Emergency Services (ADES), local military bases, Governor's and State offices, television and radio stations, and airlines. AVO at Anchorage faxes to the local FAA, the local NWS, local military bases, USGS offices, other federal agencies, television and radio stations, news wire services, and airlines. Updates are also distributed by electronic mail to the volcano information networks.

A level of concern color code was established during the Redoubt Volcano eruptions to quickly and simply convey AVO's evaluation of eruption potential and eruption severity (Brantley, 1990; Miller and Chouet, 1994). This code was modified slightly for use with the Crater Peak eruptions (fig. 4). When a volcanic crisis begins, telephone calls are made to Federal, State, and local agencies with critical public safety responsibilities to give the level of concern color code as the update is being prepared. A calldown procedure, likewise established for the Redoubt Volcano eruptions (Brantley, 1990; Miller and Chouet, 1994), was used for the Crater Peak eruptions. Responsibility for calls are shared between AVO at Anchorage and AVO at Fairbanks, so all concerned agencies are contacted within minutes.

\section{ERUPTIONS-MONITORING AND RESPONSE CHRONOLOGY}

\section{PRE-ERUPTION PERIOD}

Early indication of unrest at Mount Spurr was a conspicuous swarm of volcano-tectonic (VT) earthquakes during the last half of August 1991 (table 1; Power and others, this volume). Unlike swarms that had occurred in 1982 and 1989, this one was directly under Crater Peak within a volume that had been aseismic for at least a decade (Jolly and others, 1994), and it was followed by caldera-wide seismicity. By February of 1992, seismic activity had increased to such a level that discussions of Mount Spurr's unrest were included in AVO's weekly updates. Through April 
ALASKA VOLCANO OBSERVATORY

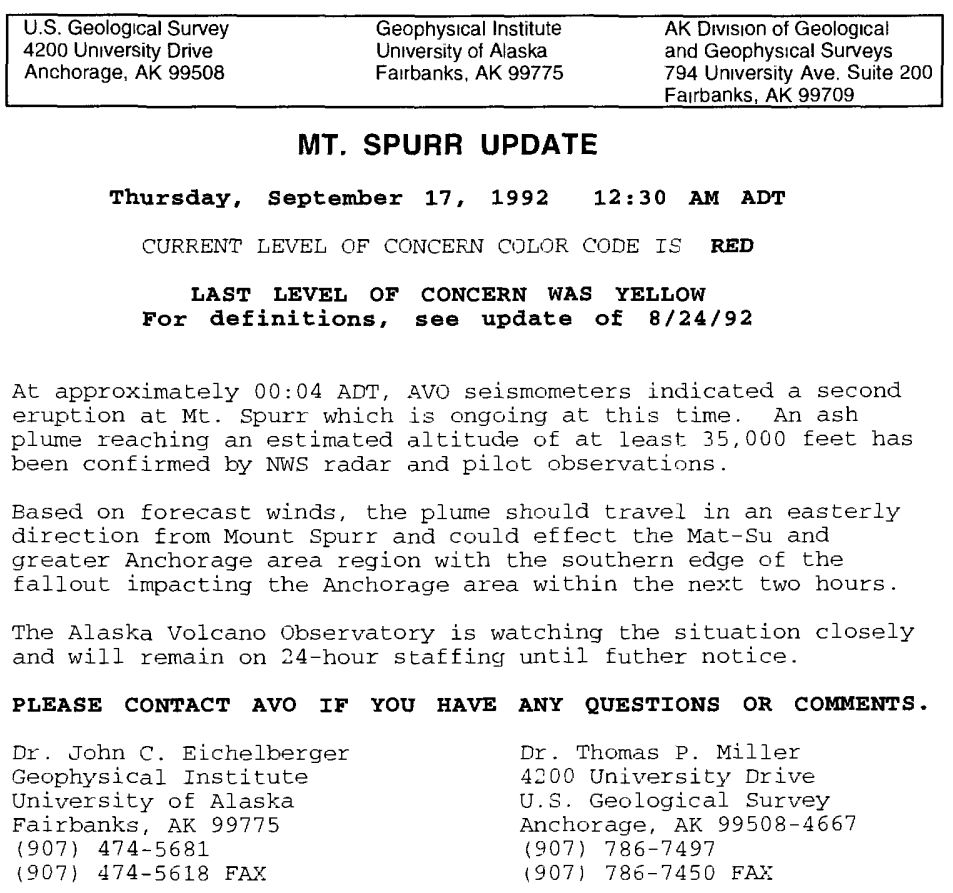

Figure 3. Example of update issued by Alaska Volcano Observatory during the eruption of Mount Spurr volcano on September 17, 1992.

\section{LEVEL OF CONCERN COLOR CODE}

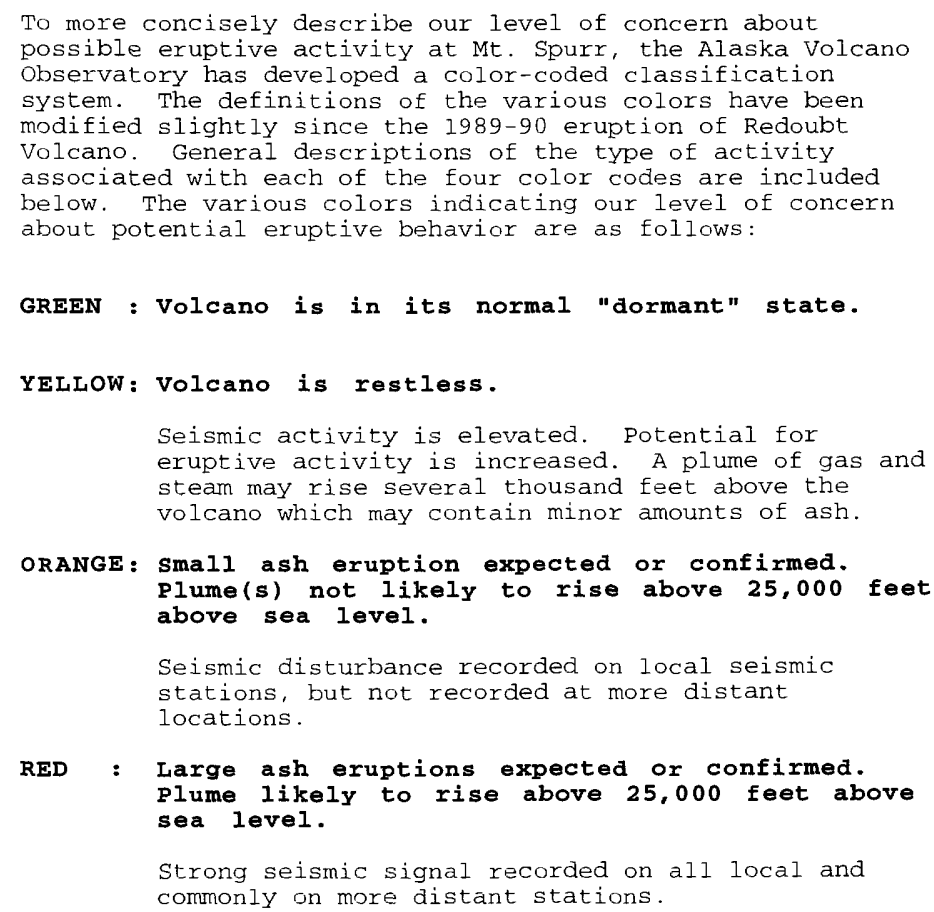

Figure 4. Alaska Volcano Observatory's level of concern color code, as used for the 1992 eruptions of Crater Peak, Mount Spurr, Alaska. This code was distributed to government agencies, the media, airlines, and the public with the announcement of level Yellow for Mount Spurr on June 26, the day prior to the first eruption. 
Table 1. Chronology of major events and Alaska Volcano Observatory notifications pertaining to the 1992 eruptions of Crater Peak vent, Mount Spurr, Alaska.

[Compiled by C.A. Neal, T. Mattox, I. Ellersieck, and T. Keith; see also Power and others and McNutt and others, this volume; Universal Time (UT) = Alaska daylight time (ADT) +8 hours. Alaska standard time (AST) +9 hours; ${ }^{*}=$ next day in UT; altitudes are above sea level; PIREP, pilot report. Beginning and end of each eruption are in bold type.]

\begin{tabular}{|c|c|c|c|c|c|}
\hline \multirow[b]{2}{*}{ DATE } & \multicolumn{2}{|c|}{ TIME } & \multirow[b]{2}{*}{ EVENT } & \multirow{2}{*}{$\begin{array}{l}\text { COLOR } \\
\text { CODE }\end{array}$} & \multirow{2}{*}{$\begin{array}{c}\text { EVENT DESCRIPTION OR } \\
\text { NOTIFICATION SUMMARY ISSUED }\end{array}$} \\
\hline & Local & Universal & & & \\
\hline $8 / 15-30 / 91$ & - & - & Seismicity & - & $\begin{array}{l}\text { Conspicuous swarm of shallow volcano-tectonic eartl quakes } \\
\text { beneath Crater Peak accompanied by increased seismicity in } \\
\text { a previously aseismic zone between } 10 \text { and } 40 \mathrm{~km} \text { depth. }\end{array}$ \\
\hline $8 / 30 / 91$ & $\cdots$ & - & Update & - & $\begin{array}{l}\text { First announcement of seismic swarm of past two weeks at } \\
\text { Mount Spurr; similar to swarms in } 1982 \text { and } 1989 ; \text { no further } \\
\text { notifications of increased seismicity through end of year. }\end{array}$ \\
\hline $2 / 7 / 92$ & - & - & Update & - & Increased seismicity beneath Mount Sparr volcano. \\
\hline $3 / 13 / 92$ & - & - & Update & - & $\begin{array}{l}\text { Began weekly reporting of increased seismicity at Mcunt } \\
\text { Spurr; noted seismicity had been above background since } \\
\text { mid-August 1991. }\end{array}$ \\
\hline $6 / 5 / 94$ & - & - & Seismicity & - - & Highest number of earthquakes per day (28) recorded to date. \\
\hline $6 / 6 / 92$ & - & - & Seismicity & - & First small tremor bursts detected beneath Crater Peak. \\
\hline $6 / 8 / 92$ & - & - & Update & - & $\begin{array}{l}\text { Discussion of increased seismicity at Mount Spurr volcano } \\
\text { localized beneath Crater Peak vent; highest seismicity in } 10 \\
\text { years; possibility of a coming eruption. }\end{array}$ \\
\hline \multirow[t]{4}{*}{$6 / 26 / 92$} & 10:30 a.m. & $18: 30$ & Update & - & $\begin{array}{l}\text { Increasing number and duration, as long as } 10 \text { minutes of } \\
\text { tremor bursts beneath Crater Peak; two tremor bursts of } 154 \\
\text { and } 142 \text { minutes, respectively, on June } 24 \text { and } 25 \text {. }\end{array}$ \\
\hline & 12:04 p.m. & 20:04 & Seismicity & - & Continuous tremor began. \\
\hline & 3:00 p.m. & 23:00 & Seismicity & - & $\begin{array}{l}\text { Decision made to announce level of concern color ccrle } \\
\text { Yellow. }\end{array}$ \\
\hline & 4:30 p.m. & $00: 30^{*}$ & Update & Yellow & $\begin{array}{l}\text { Announcement of color code Yellow. Continued increase in } \\
\text { seismicity, appearance of continuous tremor, crate- lake } \\
\text { disappeared. }\end{array}$ \\
\hline \multirow[t]{13}{*}{$6 / 27 / 92$} & 3:00 a.m. & 11:00 & Seismicity & Yellow & $\begin{array}{l}\text { Vigorous swarm of volcano-tectonic earthquakes beg?n, and it } \\
\text { included some long-period earthquakes. }\end{array}$ \\
\hline & 7:04 a.m. & 15:04 & Eruption & Yellow & $\begin{array}{l}\text { Eruption tremor began; poor weather precluded visual } \\
\text { observations. }\end{array}$ \\
\hline & 7:16 a.m. & $15: 16$ & Calldown & Orange & Color code Orange announced by calldown. \\
\hline & 7:16 a.m. & $15: 16$ & PIREP & Orange & Eruption column rose to $5,200 \mathrm{~m}$. \\
\hline & 7:40 a.m. & $15: 40$ & PIREP & Orange & Plume rose to $5,600 \mathrm{~m}$ \\
\hline & 8:00 a.m. & $16: 00$ & Update & Orange & $\begin{array}{l}\text { Color code Orange announced by the update. Increased } \\
\text { eruption column height; potential for ashfall north and } \\
\text { northwest of Mount Spurr. }\end{array}$ \\
\hline & $8: 10$ a.m. & $16: 10$ & PIREP & Orange & Plume rose to $8,530 \mathrm{~m}$. \\
\hline & 8:22 a.m. & $16: 22$ & PIREP & Orange & $\begin{array}{l}\text { Plume rose to more than } 8,500 \mathrm{~m} \text {; strong sulfur smell } 25 \mathrm{~km} \\
\text { south of Mount Spurr. }\end{array}$ \\
\hline & 8:50 a.m. & $16: 50$ & Eruption & Orange & Seismic station CPK on crater rim destroyed. \\
\hline & 9:10 a.m. & $17: 10$ & Calldown & Red & Color code Red announced. \\
\hline & 9:10 a.m. & $17: 10$ & PIREP & Red & Plume height rose to more than $9,000 \mathrm{~m}$. \\
\hline & 9:15 a.m. & $17: 15$ & Update & Red & $\begin{array}{l}\text { Announcement of color code Red. Plume height rose to } 9,100 \mathrm{~m} \\
\text { (from PIREPS.) }\end{array}$ \\
\hline & $\begin{array}{l}9: 35- \\
10: 25 \text { a.m. }\end{array}$ & $\begin{array}{l}17: 35- \\
18: 25\end{array}$ & Seismicity & Red & Tremor amplitude peaked. \\
\hline
\end{tabular}


Table 1. Chronology of major events and Alaska Volcano Observatory notifications pertaining to the 1992 eruptions of Crater Peak vent, Mount Spurr, Alaska-Continued.

\begin{tabular}{|c|c|c|c|c|c|}
\hline \multirow[b]{2}{*}{ DATE } & \multicolumn{2}{|c|}{ TIME } & \multirow[b]{2}{*}{ EVENT } & \multirow{2}{*}{$\begin{array}{l}\text { COLOR } \\
\text { CODE }\end{array}$} & \multirow{2}{*}{$\begin{array}{c}\text { EVENT DESCRIPTION OR } \\
\text { NOTIFICATION SUMMARY ISSUED }\end{array}$} \\
\hline & Local & Universal & & & \\
\hline & 10:23 a.m. & $18: 23$ & Eruption & Red & $\begin{array}{l}\text { Plume height reached maximum of } 14,500 \mathrm{~m} \text {, as determined } \\
\text { from NWS radar. }\end{array}$ \\
\hline & 11:07 a.m. & 19:07 & Eruption & Red & $\begin{array}{l}\text { Eruption tremor ended; } 24 \text { hours of long-period ev?nts } \\
\text { followed }\end{array}$ \\
\hline & 9:00 p.m. & $05: 00^{*}$ & Update & Red & $\begin{array}{l}\text { Based on morning eruption, as well as character and elevated } \\
\text { level of continued seismicity, color code remained at Red. }\end{array}$ \\
\hline $6 / 28 / 92$ & 9:00 a.m. & $17: 00$ & Update & Yellow & $\begin{array}{l}\text { Announcement of return to color code Yellow. Seism city less } \\
\text { than previous day but still elevated. }\end{array}$ \\
\hline $6 / 29 / 92$ & 1:00 p.m. & $21: 00$ & Update & Yellow & Seismicity elevated but it steadily declined. \\
\hline $6 / 30 / 92$ & 3:30 p.m. & 23:30 & Update & Yellow & Seismicity elevated but it steadily declined. \\
\hline $7 / 1 / 92$ & 4:00 p.m. & $00: 00^{*}$ & Update & Yellow & $\begin{array}{l}\text { Seismicity elevated but it steadily declined. Ash cloud reported } \\
\text { over Yakutat, Juneau, and Sitka on } 6 / 30 / 92 \text {. }\end{array}$ \\
\hline $7 / 3 / 92$ & 3:30 p.m. & $23: 30$ & Update & Yellow & $\begin{array}{l}\text { Seismicity elevated but it steadily declined. Two-page summary } \\
\text { of eruption issued. }\end{array}$ \\
\hline $7 / 7 / 92$ & 4:00 p.m. & $00: 00^{*}$ & Update & Yellow & Continued high level of microearthquakes. \\
\hline $7 / 8 / 92$ & 3:00 p.m. & 23:00 & Update & Green & $\begin{array}{l}\text { Announcement of downgrade to color code Green. } \\
\text { Microseismicity returned to lowest level of the past few } \\
\text { months. }\end{array}$ \\
\hline $7 / 10-8 / 14 / 92$ & -- & -- & Updates & Green & $\begin{array}{l}\text { Return to weekly update schedule. Continued low-levil } \\
\text { seismicity and steam plumes. }\end{array}$ \\
\hline \multirow[t]{14}{*}{$8 / 18 / 92$} & 3:37 p.m. & 23:37 & Seismicity & Green & $\begin{array}{l}\text { Weak tremor and long-period events detected on provimal } \\
\text { Mount Spurr seismic stations (post-eruption analysi:). }\end{array}$ \\
\hline & 3:41 p.m. & 23:41 & Seismicity & Green & $\begin{array}{l}\text { Start of 12-minute period of tremor indicated small premonitory } \\
\text { eruption (post-eruption analysis). }\end{array}$ \\
\hline & 3:48 p.m. & $23: 48$ & PIREP & Green & Ash cloud rose 300 to $600 \mathrm{~m}$ above Crater Peak. \\
\hline & 4:25 p.m. & $00: 25^{*}$ & PIREP & Green & Additional PIREPs confirmed ash plume. \\
\hline & 4:25 p.m. & $00: 25 *$ & Calldown & Yellow & Announcement of color code Yellow; still no strong seismicity. \\
\hline & 4:42 p.m. & $00: 42 *$ & Eruption & Yellow & $\begin{array}{l}\text { Strong tremor began; NWS radar saw no evidence of } \\
\text { eruption. }\end{array}$ \\
\hline & 4:47 p.m. & $00: 47^{*}$ & Calldown & Orange & Announcement of color code Orange. \\
\hline & 4:55 p.m. & $00: 55^{*}$ & Eruption & Orange & $\begin{array}{l}\text { Plume reached maximum height of } 13,700 \mathrm{~m} \text {, as determined } \\
\text { from NWS C-band radar. }\end{array}$ \\
\hline & 4:58 p.m. & $00: 58^{*}$ & Calldown & Red & Announcement of color code Red. \\
\hline & 4:58 p.m. & $00: 58^{*}$ & Update & Red & $\begin{array}{l}\text { Announcement of color code Red; PIREPS indicated flume } \\
\text { rose to } 10,700 \mathrm{~m} \text {; warning issued that winds were toward the } \\
\text { east and that ash could begin falling on Anchorage within } \\
\text { several hours. }\end{array}$ \\
\hline & 8:10 p.m. & $04: 10^{*}$ & Eruption & Red & Tremor ended. \\
\hline & $8: 20$ p.m. & $04: 20^{*}$ & Eruption & Red & Ash began falling in Anchorage, lasted about 4 hours. \\
\hline & $8: 30$ p.m. & $04: 30^{*}$ & PIREP & Red & Ash-free steam rose to about $5,000 \mathrm{~m}$ above Crater Peak vent. \\
\hline & 9:30 p.m. & $05: 30^{*}$ & Update & Orange & $\begin{array}{l}\text { Announcement of color code Orange based on decreasing } \\
\text { seismicity. }\end{array}$ \\
\hline \multirow[t]{3}{*}{$8 / 19 / 92$} & 5:15 a.m. & $13: 15$ & Update & Orange & $\begin{array}{l}\text { Decreasing but still elevated seismicity. Ash fell on the } \\
\text { northern Kenai Peninsula, Hope, and Whittier. Ash began } \\
\text { falling about 1:45 a.m. ADT at Valdez and Cordova. }\end{array}$ \\
\hline & 8:30 a.m. & $16: 30$ & Update & Yellow & $\begin{array}{l}\text { Color code downgraded to Yellow. Update included three- } \\
\text { page summary of the eruption. }\end{array}$ \\
\hline & 11:45 a.m. & $19: 45$ & PIREP & Yellow & Steam plume and minor amounts of ash emitted from rent. \\
\hline
\end{tabular}


Table 1. Chronology of major events and Alaska Volcano Observatory notifications pertaining to the 1992 eruptions of Crater Peak vent, Mount Spurr, Alaska-Continued.

\begin{tabular}{|c|c|c|c|c|c|}
\hline \multirow[b]{2}{*}{ DATE } & \multicolumn{2}{|c|}{ TIME } & \multirow[b]{2}{*}{ EVENT } & \multirow{2}{*}{$\begin{array}{l}\text { COLOR } \\
\text { CODE }\end{array}$} & \multirow{2}{*}{$\begin{array}{c}\text { EVENT DESCRIPTION OR } \\
\text { NOTIFICATION SUMMARY ISSUED }\end{array}$} \\
\hline & Local & Universal & & & \\
\hline & 5:00 p.m. & $01: 00^{*}$ & Update & Yellow & $\begin{array}{l}\text { Decreasing seismicity; steam plumes and minor amourts of ash } \\
\text { rose above Crater Peak. Update dispelled rumors of a } \\
\text { second eruption that day. }\end{array}$ \\
\hline $8 / 20-9 / 3 / 92$ & -- & $-\cdot$ & Updates & Yellow & $\begin{array}{l}\text { Issued every several days as necessary to dispel rumo"s of } \\
\text { eruptions and report investigations at Mount Spurr; color } \\
\text { code remained at Yellow; seismicity gradually declined but } \\
\text { remained above normal background levels. }\end{array}$ \\
\hline $9 / 4 / 92$ & 3:30 p.m. & $23: 30$ & Update & Yellow & $\begin{array}{l}\text { Increased long-period seismicity at depths of } 20 \text { to } 40 \mathrm{~km} \\
\text { beneath Mount Spurr suggested that magma was again being } \\
\text { replenished within the volcano. Update warned of fnssible } \\
\text { eruption within days or weeks; color code continued at } \\
\text { Yellow. }\end{array}$ \\
\hline $9 / 11 / 92$ & 2:00 p.m. & 23:00 & Update & Yellow & $\begin{array}{l}\text { Weekly update reported continued high level of seismicity; no } \\
\text { additional seismicity in } 20 \text { - to } 40-\mathrm{km} \text { depth range, but } \\
\text { eruption within days to weeks possible. }\end{array}$ \\
\hline \multirow[t]{7}{*}{$9 / 16 / 92$} & 7:30 p.m. & $3: 30^{*}$ & Seismicity & Yellow & $\begin{array}{l}\text { Weak tremor began and was accompanied by an increase in } \\
\text { deep earthquakes. }\end{array}$ \\
\hline & 10:25 p.m. & $6: 25^{*}$ & Seismicity & Yellow & Tremor amplitude increased. \\
\hline & 10:33 p.m. & $6: 33^{*}$ & Calldown & Red & Announcement of color code Red. \\
\hline & 10:36 p.m. & $6: 36^{*}$ & Eruption & Red & Tremor signified an 11-minute preliminary eruptive burst. \\
\hline & 10:37 p.m. & $6: 37^{*}$ & PIREP & Red & Ash column rose to $4,600 \mathrm{~m}$ \\
\hline & 10:45 p.m. & $6: 45^{*}$ & Update & Red & $\begin{array}{l}\text { Announcement of color code Red: eruption began at 10:36 p.m. } \\
\text { ADT and NWS wind data showed that the ash cloud would } \\
\text { move easterly with fallout expected over the Mataruska- } \\
\text { Susitna Valley region and perhaps as far south as } \\
\text { Anchorage. }\end{array}$ \\
\hline & $11: 11$ p.m. & $7: 11 *$ & PIREP & Red & Glow observed over Crater Peak. \\
\hline \multirow[t]{9}{*}{ 9/17/92 } & 12:03 a.m. & 8:03 & Eruption & Red & Seismicity indicated start of main eruption. \\
\hline & 12:08 a.m. & $8: 08$ & Eruption & Red & Telemetry lost from seismic station CPK on Crater Peak rim. \\
\hline & 12:30 a.m. & $8: 30$ & Update & Red & $\begin{array}{l}\text { Plume rose to } 10,700 \mathrm{~m} \text {, reported by PIREPS and NWS radar. } \\
\text { Warning issued that southern edge of plume could produce } \\
\text { ashfall on Anchorage. }\end{array}$ \\
\hline & 12:48 a.m. & $8: 48$ & Eruption & Red & Plume rose to $12,200 \mathrm{~m}$, as determined from NWS radar. \\
\hline & 12:50 a.m. & $8: 50$ & Eruption & Red & $\begin{array}{l}\text { Beginning of intense incandescence, as recorded on the slow- } \\
\text { scan television camera at Kasilof and on the video camera } \\
\text { at AVO in Anchorage. }\end{array}$ \\
\hline & 2:21 a.m. & $10: 21$ & Eruption & Red & $\begin{array}{l}\text { Maximum plume height of } 13,900 \mathrm{~m} \text { measured from NWS } \\
\text { radar. }\end{array}$ \\
\hline & 3:39 a.m. & 11:39 & Eruption & Red & Tremor ended. \\
\hline & 5:45 a.m. & $13: 45$ & Update & Red & $\begin{array}{l}\text { Eruption ended and seismicity declined although tremor } \\
\text { continued; NWS radar showed no plume at Crater Peak; } \\
\text { ashfall affected the Matanuska-Susitna Valley and stayed } \\
\text { north of Anchorage. }\end{array}$ \\
\hline & 4:00 p.m. & $00: 00^{*}$ & Update & Orange & $\begin{array}{l}\text { Color code downgraded to Orange due to decreased s sismicity, } \\
\text { low-level tremor continued. }\end{array}$ \\
\hline $9 / 18 / 92$ & 3:00 p.m. & 23:00 & Update & Orange & $\begin{array}{l}\text { Summary of eruption issued; color code remained at Orange } \\
\text { because of low-level tremor. }\end{array}$ \\
\hline $9 / 19 / 92$ & 4:00 p.m. & $00: 00^{*}$ & Update & Orange & $\begin{array}{l}\text { Steam plumes rose } 3,000 \text { to } 6,000 \mathrm{~m} \text { above Crater Pea': } \\
\text { seismicity continued but declined. }\end{array}$ \\
\hline $9 / 20 / 92$ & 4:00 p.m. & $00: 00^{*}$ & Update & Orange & $\begin{array}{l}\text { Elevated seismicity indicated the possibility of a small eruption } \\
\text { with little warning. Therefore, color code remained at } \\
\text { Orange. }\end{array}$ \\
\hline
\end{tabular}


Table 1. Chronology of major events and Alaska Volcano Observatory notifications pertaining to the 1992 eruptions of Crater Peak vent, Mount Spurr, Alaska-Continued.

\begin{tabular}{|c|c|c|c|c|c|}
\hline \multirow[b]{2}{*}{ DATE } & \multicolumn{2}{|c|}{ TIME } & \multirow[b]{2}{*}{ EVENT } & \multirow{2}{*}{$\begin{array}{l}\text { COLOR } \\
\text { CODE }\end{array}$} & \multirow{2}{*}{$\begin{array}{c}\text { EVENT DESCRIPTION OR } \\
\text { NOTIFICATION SUMMARY ISSUED }\end{array}$} \\
\hline & Local & Universal & & & \\
\hline $9 / 21 / 92$ & 4:00 p.m. & $00: 00^{*}$ & Update & Orange & $\begin{array}{l}\text { Elevated seismicity indicated the possibility of a small eruption } \\
\text { with little warning. Therefore, color code remained at } \\
\text { Orange. }\end{array}$ \\
\hline $9 / 22 / 92$ & 4:00 p.m. & $00: 00^{*}$ & Update & Orange & $\begin{array}{l}\text { Elevated seismicity indicated the possibility of a small eruption } \\
\text { with little warning. Therefore, color code remained at } \\
\text { Orange. }\end{array}$ \\
\hline 9/23/92 & 4:00 p.m. & $00: 00^{*}$ & Update & Orange & $\begin{array}{l}\text { Elevated seismicity indicated the possibility of a small eruption } \\
\text { with little warning. Therefore, color code remained at } \\
\text { Orange. }\end{array}$ \\
\hline $9 / 24 / 92$ & 4:00 p.m. & $00: 00^{*}$ & Update & Yellow & $\begin{array}{l}\text { Announcement of downgrade to color code Yellow. Tnemor } \\
\text { amplitude decreased and time between tremor episodes } \\
\text { increased. }\end{array}$ \\
\hline $9 / 25 / 92$ & 4:00 p.m. & $00: 00^{*}$ & Update & Yellow & Continued low-level seismicity. \\
\hline $9 / 28 / 92$ & 4:00 p.m. & $00: 00^{*}$ & Update & Yellow & Continued low-level seismicity. \\
\hline $9 / 29 / 92$ & 4:00 p.m. & $00: 00^{*}$ & Update & Yellow & Continued low-level seismicity. \\
\hline $9 / 30 / 92$ & 4:00 p.m. & $00: 00^{*}$ & Update & Yellow & Continued low-level seismicity. \\
\hline \multirow[t]{3}{*}{$10 / 1 / 92$} & 4:00 p.m. & $00: 00^{*}$ & Update & Yellow & Continued low-level seismicity. \\
\hline & 7:00 p.m. & $03: 00^{*}$ & Seismicity & Yellow & Continuous volcanic tremor began. \\
\hline & 11:00 p.m. & $07: 00^{*}$ & Update & Yellow & $\begin{array}{l}\text { Weak, continuous volcanic tremor resumed under Crater Peak; } \\
\text { increased } \mathrm{SO}_{2} \text { emission; heightened possibility of eruption } \\
\text { during the next several days. }\end{array}$ \\
\hline \multirow[t]{3}{*}{$10 / 2 / 92$} & 6:17 p.m. & $02: 17^{*}$ & Calldown & Red & Announcement of color code Red based on intense seismicity. \\
\hline & 6:30 p.m. & $02: 30^{*}$ & Update & Red & $\begin{array}{l}\text { Announcement of color code Red: intense seismic tremor at } \\
\text { Crater Peak; tremor amplitude comparable to levels } \\
\text { preceding the June } 27 \text { and September } 17 \text { eruptions; large } \\
\text { eruption seemed likely within } 24 \text { to } 48 \text { hrs. }\end{array}$ \\
\hline & 6:30 p.m. & $02: 30^{*}$ & Seismicity & Red & Tremor abruptly ended. \\
\hline $10 / 3 / 92$ & 4:00 p.m. & $00: 00^{*}$ & Update & Red & $\begin{array}{l}\text { Irregular tremor signified unrest of the volcano. Erupticn could } \\
\text { occur with little or no warning; color code remained at Red. }\end{array}$ \\
\hline \multirow[t]{2}{*}{$10 / 4 / 92$} & 9:00 a.m. & $17: 00$ & Update & Red & $\begin{array}{l}\text { Continued volcanic unrest indicated by banded tremor vith } \\
\text { tremor bursts that lasted } 1 \text { to } 2 \text { hours. }\end{array}$ \\
\hline & 5:00 p.m. & $01: 00^{*}$ & Update & Yellow & $\begin{array}{l}\text { Announcement of downgrade to color code Yellow. More } \\
\text { quiet time between tremor periods; banded tremor, which } \\
\text { often precedes eruption, continued; volcano still con sidered } \\
\text { restless. }\end{array}$ \\
\hline $10 / 5 / 92$ & 4:00 p.m. & $00: 00^{*}$ & Update & Yellow & $\begin{array}{l}\text { Continued banded tremor and an 18-hour period of sustained } \\
\text { tremor. }\end{array}$ \\
\hline $10 / 6 / 92$ & 4:00 p.m. & $00: 00^{*}$ & Update & Yellow & Intermittent tremor persisted. \\
\hline $10 / 7-11 / 6 / 92$ & - & -- & Updates & Yellow & $\begin{array}{l}\text { Daily weekday reports of continued irregular levels of } \\
\text { seismicity and occasional gas emission, as well as other } \\
\text { observations of the volcano. Caution issued that an eruption } \\
\text { could occur with little warning. }\end{array}$ \\
\hline $11 / 2 / 92$ & 2:00 a.m. & $11: 00$ & Seismicity & Yellow & Rate of shallow volcano-tectonic earthquakes increased. \\
\hline \multirow[t]{3}{*}{$11 / 9 / 92$} & $12: 00 \mathrm{~m}$. & $21: 00$ & Update & Orange & $\begin{array}{l}\text { Announcement of upgrade to color code Orange based on } \\
\text { shallow seismic swarm; eruption could occur withou } \\
\text { additional warning. }\end{array}$ \\
\hline & 4:00 p.m. & $01: 00^{*}$ & Update & Orange & Increased shallow seismicity. \\
\hline & 9:00 p.m. & $06: 00^{*}$ & Update & Orange & $\begin{array}{l}\text { Number of seismic events was } 1.5 / \mathrm{min} \text { for } 3.5 \mathrm{hrs} \text {; this was the } \\
\text { most energetic seismic swarm of } 1992 \text { eruptive pericd. }\end{array}$ \\
\hline
\end{tabular}


Table 1. Chronology of major events and Alaska Volcano Observatory notifications pertaining to the 1992 eruptions of Crater Peak vent, Mount Spurr, Alaska-Continued.

\begin{tabular}{|c|c|c|c|c|c|}
\hline \multirow[b]{2}{*}{ DATE } & \multicolumn{2}{|c|}{ TIME } & \multirow[b]{2}{*}{ EVENT } & \multirow{2}{*}{$\begin{array}{l}\text { COLOR } \\
\text { CODE }\end{array}$} & \multirow{2}{*}{$\begin{array}{c}\text { EVENT DESCRIPTION OR } \\
\text { NOTIFICATION SUMMARY ISSUED }\end{array}$} \\
\hline & Local & Universal & & & \\
\hline & 10:07 p.m. & $07: 07^{*}$ & Update & Red & $\begin{array}{l}\text { Announcement of upgrade to color code Red. Significant } \\
\text { increase in seismicity on all stations; large eruption seemed } \\
\text { likely within } 24 \text { to } 48 \mathrm{hrs} \text {. }\end{array}$ \\
\hline $11 / 10 / 92$ & 3:00 p.m. & $00: 00^{*}$ & Update & Orange & $\begin{array}{l}\text { Color code downgraded to Orange. Seismicity decreased } \\
\text { significantly since the buildup of } 11 / 9 / 92 \text {. }\end{array}$ \\
\hline $11 / 11 / 92$ & 3:00 p.m. & $00: 00^{*}$ & Update & Orange & $\begin{array}{l}\text { Decreased seismicity from the swarm of November } 9 \\
\text { continued unrest could result in eruption without adcitional } \\
\text { warning. }\end{array}$ \\
\hline $11 / 12 / 92$ & 3:00 p.m. & $00: 00^{*}$ & Update & Yellow & $\begin{array}{l}\text { Color code downgraded to Yellow based on } 2 \text { days of relative } \\
\text { seismic quiescence; however, volcanic unrest continued. }\end{array}$ \\
\hline $\begin{array}{l}11 / 13- \\
12 / 18 / 92\end{array}$ & -- & -- & Updates & Yellow & $\begin{array}{l}\text { Daily weekday reports of continued irregular levels of } \\
\text { seismicity and occasional gas emission, as well as other } \\
\text { observations of the volcano, still indicated that an eruption } \\
\text { could occur with little warning. }\end{array}$ \\
\hline $12 / 21 / 92$ & 3:00 p.m. & $00: 00^{*}$ & Update & Yellow & $\begin{array}{l}\text { Color code would remain at Yellow until early January } \\
\text { because: (1) continued high level of seismicity, and (2) } \\
\text { eruptions and seismic crises since June eruption occurred at } \\
55-, 30-\text {, and 53-day intervals; and by early January, } 60 \text { days } \\
\text { had passed since the seismic swarms on November } 9-10 \text {. }\end{array}$ \\
\hline $12 / 24 / 92$ & $12: 00 \mathrm{~m}$ & $21: 00$ & Update & Yellow & $\begin{array}{l}\text { Swarm of small earthquakes occurred at depth of } 8 \text { to } 12 \mathrm{~km} \\
\text { beneath Crater Peak during past } 5 \text { days; continued unrest } \\
\text { indicated that the volcano was still unstable and erurtion } \\
\text { could occur with little warning. }\end{array}$ \\
\hline $12 / 28 / 92$ & 3:00 p.m. & $00: 00^{*}$ & Update & Yellow & $\begin{array}{l}\text { Swarm of small earthquakes of December } 20 \text { continued } \\
\text { through December } 26 \text {, followed by increased shallow } 2- \\
\text { hour periods of tremor-like events beneath Crater P } 1 \text { ak on } \\
\text { December } 27 \text {; seismicity then decreased; volcano st } \because 1 \\
\text { considered unstable. }\end{array}$ \\
\hline $12 / 31 / 92$ & $12: 00 \mathrm{~m}$ & $21: 00$ & Update & Yellow & $\begin{array}{l}\text { Continued low-level seismicity including two earthquakes } \\
\text { beneath Crater Peak and two low-amplitude tremor episodes } \\
\text { during the previous } 24 \text { hrs. Decision made for color code to } \\
\text { stay at Yellow. }\end{array}$ \\
\hline $1 / 4-2 / 26 / 93$ & -- & -- & Updates & Yellow & $\begin{array}{l}\text { Return to weekly Friday reporting of low-level seismicity, } \\
\text { steam plumes, and other observations. }\end{array}$ \\
\hline $3 / 5 / 93$ & 2:00 p.m. & $23: 00$ & Update & Green & $\begin{array}{l}\text { Color code downgraded to Green. Seismicity continued at a } \\
\text { low level for a time period longer than that between the } 27 \\
\text { June and } 18 \text { August } 1992 \text { eruptions (see } 12 / 21 / 92 \text { ); p sssibility } \\
\text { of steam and ash explosions still existed. }\end{array}$ \\
\hline $\begin{array}{l}3 / 12 / 93- \\
1 / 14 / 94\end{array}$ & $\cdots$ & -- & Updates & Green & $\begin{array}{l}\text { Mention of Mount Spurr seismicity and other observations in } \\
\text { weekly updates. }\end{array}$ \\
\hline $1 / 21 / 94$ & -- & - & Update & Green & $\begin{array}{l}\text { Announcement that level of seismicity at Mount Spurr had } \\
\text { returned to background levels and that specific mention of } \\
\text { Mount Spurr in weekly updates would be discontinued. }\end{array}$ \\
\hline
\end{tabular}

of 1992, however, updates stated that the increased seismicity was not considered precursory to eruption. The heightened seismicity continued, punctuated with stronger pulses, including a prominent pulse beneath Crater Peak in May. In an internal memorandum dated June 3, 1992, AVO scientists interpreted the seismicity as the result of increasing magmatic pressure at depth, which caused intrusion into conduits below Crater Peak and the summit dome complex and minor movement of caldera faults. The memo urged increased monitoring, as well as advising government agencies and the aviation industry to review plans for coping with an eruption. Both of these recommendations were implemented.

The number of daily locatable VT earthquakes reached 28 on June 5 and then declined to about 3 to 6 events per day. Volcanic tremor began on June 6 , and an overflight on June 8 revealed upwelling in the crater lake, which had turned in color from green to gray. AVO released a special update describing the situation and stating that there would be an increase in overflights and in sensitivity of the 24-r our alarm 
system at the AVO Seismology Laboratory in Fairbanks, along with an added evening shift for AVO personnel. As many as 24 shallow tremor bursts per day, each burst lasting 1 to 10 minutes, were recorded at stations within $10 \mathrm{~km}$ of Crater Peak from June 6 to 26 (McNutt and others, this volume). A field party spent 6 hours in the crater on June 11, measured a lake temperature of $50^{\circ} \mathrm{C}$ and $\mathrm{pH}$ of 2.5 , and collected water samples for chemical analysis (Keith and others, this volume). The party observed small geysersnever before seen in the crater-at the base of the north crater wall. Geysering did not coincide with seismic tremor events.

On June 17, AVO informed ADES of the evolving situation at Mount Spurr. On June 19, AVO sent briefing materials to the Governor, noting the "well above normal" activity and continuing episodes of tremor. The Anchorage Daily News published a front-page article on June 21 that described how Mount Spurr was being monitored and what the public might expect from an eruption.

\section{JUNE 27 ERUPTION}

Seismic behavior changed ominously on June 24 when a tremor episode lasted 154 minutes, followed 12 hours later by a similar episode that lasted 142 minutes. Eight additional tremor bursts occurred within the next 8 hours. The weekly update of 10:30 a.m. Alaska daylight time (ADT) on June 26 reported "well above normal" seismic activity but still cautioned that an eruption might not be imminent in view of an absence of long-period (LP) earthquakes. At about the same time, aerial observations of the crater revealed that the lake had almost completely drained and that several large rocks had impacted the resulting mud flat. At 12:04 p.m. ADT, tremor that was continuous and stronger than earlier bursts began. AVO formally issued a warning of level of concern color code Yellow at 4:30 p.m. ADT and went on 24-hour duty. At 3:00 a.m. ADT on June 27, a swarm of VT earthquakes struck at 0 - to 2-km depths beneath Crater Peak; their rate soon increased to about one every $2 \mathrm{~min}$ utes. Three LP events accompanied this swarm. Tremor amplitude abruptly doubled at 7:04 a.m. ADT. This increase in amplitude was later interpreted to represent the onset of eruption, although weather clouds prevented visual verification. At 7:16 a.m. ADT, AVO began an emergency calldown announcing level of concern color code Orange. About the same time, telemetry was lost from the seismic station $400 \mathrm{~m}$ from the vent and an Alaska Airlines pilot reported that an eruption plume had risen $5,000 \mathrm{~m}$ above the cloud cover. AVO announced color code Red at 9:10 a.m. ADT. Tremor amplitude gradually increased, peaking between 9:35 a.m. and 10:25 a.m. ADT and registering on stations more than $100 \mathrm{~km}$ away. Pilots estimated the plume at mid-morning as high as $9,000 \mathrm{~m}$ and the NWS measured a maximum plume height of $14,500 \mathrm{~m}$ with C-band radar (Alaska Volcano Observatory, 1993; Rose and others, this volume). The tephra cloud moved northward and ash begar falling on Denali National Park at 10:30 a.m. ADT. Debris flows swept southward down narrow drainages and entered the Chakachatna River in three places. Most debris followed the course of the 1953 lahar. At about 11:30 a.m. ADT, seismicity decreased abruptly and the eruption was over. Weather and steam obscured Crater Peak and the eruption plume track from aerial observation on the afternoon of June 27, but paths of the debris flows were visible on the lower flanks of the volcano (Meyer and Trabant, this volume).

At 9:00 a.m. ADT on June 28, the level of concern was downgraded to Yellow. Aerial observation revealed a black northward-broadening swath of tephra on snow fields and glaciers. Ash thickress was about 1 to $2 \mathrm{~mm}$ at Denali National Park and Manley Hot Springs, 260 and $420 \mathrm{~km}$ north of Crater Peak, respectively (Neal and others, this volume). This region is sparsely populated and there were no other reports of tephra there. The ash cloud continued northward to the Beaufort Sea, then it turned southeast into Canada and the coterminous United States, where it became indistinguishable from weather clouds about July 2 .

The level of concern color code was don'ngraded to Green on July 8. This was done partly on the basis of greatly reduced seismicity and $\mathrm{SO}_{2}$ emission, but also on the basis of analogy to the single-eruption pattern of 1953. The downgrading to color code Green proved to be premature.

\section{AUGUST 18 ERUPTION}

Following the June eruption, seismicity remained low through the first half of August. Only one shallow and two deep earthquakes were recorded between August 12 and 17. Because the closest operatic nal seismic station at that time was $5 \mathrm{~km}$ from the vent, several attempts were made to reestablish a seismic station on the crater rim. These were unsuccessful because of poor weather conditions. At 3:37 p.m. ADT on August 18, a 16-minute episode of weak tremor and several LP events began, but these rather obscure events were not identified until post-eruption analysis of the data. At 3:48 p.m. ADT, a pilot reported an ash-rich plume. With confirmation of this plume at 4:25 p.m., AVO began a calldown announcing level of concern color code Yellow. The main eruption be- 
gan at 4:42 p.m. ADT, when strong tremor was recorded by all Mount Spurr seismic stations. AVO began a calldown announcing color code Orange at 4:47 p.m. ADT, but repeated the calldown process $11 \mathrm{~min}$ utes later to raise the color code to Red. By 4:58 p.m. ADT, a subplinian column had risen through low clouds to a height of $11,000 \mathrm{~m}$, and it ultimately reached nearly $14,000 \mathrm{~m}$. From an aircraft only $2.5 \mathrm{~km}$ away, AVO staff observed and videotaped a dark roiling cloud that was periodically surrounded by lenticular shock waves. Large bombs were thrown $800 \mathrm{~m}$ above the vent. Small-volume pyroclastic flows of breadcrusted blocks descended the east and southeast flanks of Crater Peak; these flows formed coarse, clast-supported lobate deposits with steep-fronted margins. Other flows mixed with snow and ice high on the cone and became lahars. A late fusillade of mostly lithic ballistic projectiles, some as large as $1 \mathrm{~m}$, were hurled as far as $10 \mathrm{~km}$ southeastward (Waitt and others, this volume). More than 170 lightning strikes were detected by the AVO lightning detection system (LDS) during the second half of the eruption (Paskievitch and others, this volume). The eruption ended at 8:10 p.m. ADT.

Upper-level winds moved the eruption plume eastsoutheast directly over Anchorage, where it deposited as much as $3 \mathrm{~mm}$ of sand-sized ash (Neal and others, this volume). A satellite image 44 minutes after the onset of eruption shows the plume extending $80 \mathrm{~km}$ east from the volcano over an area of $2,000 \mathrm{~km}^{2}$. Three hours after onset of eruption, the leading edge of the plume was $300 \mathrm{~km}$ southeast of Mount Spurr, and its area had grown to $21,000 \mathrm{~km}^{2}$.

Ashfall forced the closing of Anchorage International Airport for 20 hours (N.W. Gibson, Anchorage International Airport, written commun., 1993). Air quality alerts were issued in Anchorage during the fallout period and also on the following day, as vehicle traffic stirred up ash again (R.B. Stewart, Office of Emergency Management, Municipality of Anchorage, written commun., 1993). Reworked windblown ash continued to reduce air quality until the first snow of autumn, and then it reappeared during the summer of 1993.

\section{SEPTEMBER 16-17 ERUPTION}

Following the August eruption, deep seismicity gradually increased, and by mid-September it had returned to levels comparable to mid-June. AVO teams visiting the crater on September 7 and 16 noted nothing unusual. At about 7:30 p.m. ADT on September 16 , however, discrete seismic events and weak tremor were detected by the newly reinstalled crater rim sta- tion. Tremor amplitude increased at 10:25 p.m. ADT, and at 10:33 p.m. ADT, AVO declared concern color code Red and began the emergency calldowr. An eruption began at 10:36 p.m. ADT that lasted 11 minutes. Incandescence was recorded on the video camera at AVO-Anchorage and on the telemetered slow'-scan television camera at Kasilof, $120 \mathrm{~km}$ southeast of Crater Peak just south of Kenai on the Kenai Peninsula. Weak tremor through the next hour foreshadowed the main phase of eruption, which began at 12:03 a.m. ADT on September 17. Intermittent bright incendescence could be seen from Anchorage.

The September 17 eruption lasted 3.6 hours. Pyroclastic flows swept down the south-southeast and southeast flanks of Crater Peak and mixed with snow and ice to become lahars. These flows were similar in appearance to pyroclastic flows, but they were cool and water saturated hours after emplacement. Tephra fallout on the Kidazgeni Glacier generated a debris flow that temporarily dammed the Chakachatna River. Once again, a narrow ballistic field extended at least $10 \mathrm{~km}$ from the vent along the south margin of the tephra plume. The eruption closed with a strong swarm of about $50 \mathrm{VT}$ shocks between 5 and $10 \mathrm{~km}$ in depth, which may reflect readjustment of the conduit after magma withdrawal.

The plume moved eastward, dusted the north edge of Anchorage and deposited about $1.5 \mathrm{~mm}$ of ash in Palmer, Wasilla, and nearby communities in the Matanuska-Susitna Valley north of Anchorage. Very light ashfall was reported in the town of Glenallen, $350 \mathrm{~km}$ east of Crater Peak.

\section{SEISMIC SWARMS: OCTOBER $2-6$, NOVEMBER 9-10, AND DECEMBER 21-27}

The level of seismicity remained elevated, and several seismic crises caused concern at AVO. Tremor between 7:00 p.m. ADT on October 1 and 6:30 p.m. ADT on October 2, followed by quasiperiotic tremor over the next 72 hours, prompted AVO to announce concern color code Red twice during that roriod, but no eruption ensued.

At 10:07 p.m. Alaska standard time (AST) on November 9, AVO again announced concern color code Red an hour into an intense seismic swarm that lasted 3.5 hours and contained 170 detected earthquakes. These earthquakes had mixed frequency contents, occurred within a very restricted volume $1.2 \mathrm{~km}$ beneath the vent, and had magnitudes as large as 1.7. Again, seismicity receded without eruption. Because the duration of this swarm was similar to each of the three eruptions and its seismic energy release was the largest of the 1992 eruptive period, the swarn may be 
viewed as a "failed" eruption, in which magma was rapidly emplaced at shallow depth (Power and others, this volume).

A final flurry of earthquakes beneath Crater Peak on December 21 through 26 was followed by a few hours of shallow tremor-like activity on December 27. This time, AVO's advisories remained at concern color code Yellow.

At the beginning of 1993, Mount Spurr returned to a low level of seismic activity: 1 to 10 small earthquakes per day at depths of 0 to $40 \mathrm{~km}$ and rare periods of possible weak tremor. This background seismic "noise" fluctuated daily and seasonally (G. Tytgat and others, unpub. data). Some shallow seismic events were correlated with observed landslides, rockfalls, glacial melt runouts, and even airplanes flying over the volcano. Some seismicity may be attributed to posteruptive readjustments of the magmatic and hydrothermal systems, and some remains unexplained. On March 5, 1993, after a time period greater than the seismic quiescence between the June 27 and August 18, 1992, eruptions had passed uneventfully, AVO lowered the level of concern color code to Green.

Vigorous white steam plumes caused false reports of eruption several times during 1993. However, volcanic gas $\left(\mathrm{SO}_{2}\right.$ and $\left.\mathrm{CO}_{2}\right)$ emissions remained at or below the limit of detectability (less than 1,000 tonnes per day $\mathrm{CO}_{2}$, less than about 4 tonnes/day $\mathrm{SO}_{2 ;}$ Doukas and Gerlach, this volume). New concern arose on June 29, 1993, when tremor-like seismicity appeared on records from several of the Crater Peak seismic stations. A field party was fortuitously present near Crater Peak and observed the source to be an outburst flood from Kidazgeni Glacier on the southeast slope of Mount Spurr (Nye and others, this volume).

During and following the 1992 eruptions, field investigations were carried out to map and sample the eruption products. Work in the vent area of the crater was precluded through the summer of 1993 for safety reasons. This was a lesson drawn from the sudden explosions at Galeras Volcano, Columbia, and Guagua Pichincha Volcano, Ecuador, in early 1993, that resulted in the deaths of eight volcanologists, and the September 1992 eruption of Crater Peak, which followed a period of seismic quiescence and occurred just hours after an AVO team had left the vent.

\section{GENERAL CHARACTERISTICS OF THE ERUPTIONS}

The June, August, and September 1992 eruptions produced 44,52 , and 56 million $\mathrm{m}^{3}$ of tephra $(12$, 14 , and 15 million $\mathrm{m}^{3}$ dense rock equivalent or DRE), respectively. In each case, juvenile tephra clasts ranged from proximal breadcrusted bombs to distal ash in a narrowly defined band of fallout extending downwind (Gardner and others, 1993; Neal and others, this volume). The vent migrated about $50 \mathrm{~m}$ westward from June to August to September, and so in September it was nestled against the west-northwest crater wall. Near-field ejecta from each eruption were, therefore, directed progressively more strongly to the east-southeast. Otherwise, vent geometry changed remarkably little. Distribution of pyroclastic flow deposits, ballistic showers, and lahars shows that all flanks of a volcanic cone are hazardous during subplinian activity (Miller and others, this volume; Waitt, this volume).

The eruptions were strongly magmatis in character. The dominant juvenile component of 1992 ejecta is dense to scoriaceous dark gray andesite (57 weight percent $\mathrm{SiO}_{2}$ bulk composition) with a more silicic (60-62 weight percent $\mathrm{SiO}_{2}$ ) microlite-rich matrix of brown glass (Harbin and others, this volume; Nye and others, this volume; Swanson and others, this volume). A subordinate volume of bulk-chemically identical andesite is more crystal-rich and contains clear matrix glass of rhyolitic composition (73-75 weight percent $\mathrm{SiO}_{2}$ ). Trace amounts of rhyolite pumice with sparse plagioclase and quartz phenocrysts were also erupted. Pyroclastic flows of August and September contained large partially melted and greatly inflated felsic metamorphic xenoliths (Miller and others, this volume). The estimated total volume of nagma for the three Crater Peak eruptions of 41 million $\mathrm{m}^{3}$ DRE is markedly smaller than the estimated 200 million $\mathrm{m}^{3}$ DRE (Gardner and others, 1994) released in some 20 significant eruptive events during the 1989-90 Redoubt activity.

\section{ANALYSIS OF RESPONSE}

AVO's response plan went into effect as soon as unrest was recognized at Mount Spurr in August of 1991, and it continued through post-eruftive readjustment to inactive status. For alerting a community to an imminent volcanic danger, Mount Spur" provided a favorable situation. Its Holocene deposits had been mapped and some 40 tephra layers from its 5,000year-old Crater Peak vent had been identified (Riehle, 1985; Nye and Turner, 1990); these deposits place it among the more prolific volcanoes in the eastern Aleutian Arc. Moreover, it had erupted during historical time (Juehle and Coulter, 1955; Wilcox, 1959). In retrospect, the singularity of the 1953 eruption proved misleading for what was to come, but it did provide a useful example of Mount Spurr's behavior. Because of the relatively well documented record of activity, 
Mount Spurr had already been instrumented and monitored for over a decade when it reawakened. This lengthy period of monitored quiescence allowed the August 1991 seismicity to be accurately interpreted as anomalous. Mount Spurr's reawakening was gradual, and thus it permitted plans to be made and warnings to be given in a timely fashion. It was not so fast that AVO was caught off guard, nor so slow that the warnings of a future eruption could be dismissed. Care must be taken when turning observations of increasing seismicity into an appropriate warning, because not all cases of increasing seismicity, even if caused by rising magma, lead to eruption. Often, magma can solidify in the conduit without venting (Newhall and Dzurisin, 1988), as may have occurred during the seismic swarms of May, October, November, and December of 1992 (table 1). In retrospect, informing a community about the possibility of an eruption a month in advance, and issuing a serious warning a day in advance, is a useful time frame. Eruption warnings of October and November that were not fulfilled were considered by the public to be proper caution rather than mistaken judgment, coming as they did late in the episode.

Although seismic monitoring was the primary tool in AVO's response, geologic insight was necessary both for informed warnings of what was to come and for the original decision to monitor the seismic activity of Mount Spurr. A broad host of observations and techniques was used to evaluate the volcano's condition.

\section{INTERPRETATION OF SEISMICITY}

Following the establishment of AVO, seismic stations were added to the existing Mount Spurr network, making a total of 10 stations within $15 \mathrm{~km}$ of the summit (McNutt and others, this volume; Power and others, this volume). Seismicity that began in August 1991 eventually defined an active conduit without, unlike Redoubt Volcano, a hint of a volumetrically large storage zone. That elevated seismicity occurred throughout the volcanic massif indicates that stresses induced by magma intrusion and perhaps even magmatic vapor affected the entire Mount Spurr system. Helicorders, continuous digital data, event-triggered data, real-time seismic amplitude measurements (RSAM; Endo and Murray, 1991) and seismic spectral amplitude measurements (SSAM) were all used for analysis of the seismic information (McNutt and others, this volume).

Three types of shallow seismicity indicative of magma movement were identified: (1) tremor bursts that lasted 1 to 10 minutes, (2) continuous tremor lasting 2 hours to several days, and (3) eruption tremor (McNutt and others, this volume). Fourteen hours of continu- ous tremor and 4 hours of shallow VT earthquakes preceded the June eruption. However, this se ismic pattern that made forecast of the June eruption possible was not repeated in subsequent events. Only 3 hours of increased seismicity preceded the September eruption; accordingly, the warning from AVO vas issued just minutes ahead of the onset of eruptive activity and an hour and a half before the main pulse. Unfortunately, no detectable seismic activity foreshadowed the August eruption. Had it been possible to replace the near-vent seismic station destroyed during the June eruption, shallow precursory tremor bursts might have been recorded. However, the absence of the near-vent station does not explain the lack of locatable VT earthquakes before that eruption. Presumably, the strongest precursory signals were generated at the outset of the eruptive episode because rising magma and gases were reopening a cold, plugged conduit.

\section{EVIDENCE FROM HYDROTHERIMAL ACTIVITY AND GAS EMISSION}

The sense of urgency engendered by May and June seismicity was heightened by observations of the small crater lake that had existed since the 1952 eruption. Days prior to the first eruption, lake water changed from blue-green to gray, became turbid with areas of upwelling, and finally evaporated or drained (Keith and others, this volume). A single pair of measurements, one during dormancy and the other in June, revealed a two-orders-of-magnitude increase in $\mathrm{SO}_{4} / \mathrm{Cl}$ in the lake.

The increase in $\mathrm{SO}_{4} / \mathrm{Cl}$ may relate to the failure of airborne $\mathrm{SO}_{2}$ emission measurements to detect the rise of magma (Doukas and Gerlach, this volume). Airborne measurements were begun when anomalous seismicity was first detected. Not until the June eruption did the flux of $\mathrm{SO}_{2}$ from the vent increase significantly, and $\mathrm{SO}_{2}$ concentrations returned to low values 2 days later. $\mathrm{SO}_{2}$ flux was also low prior to and following the August and September eruptions. Yet, the National Aeronautical and Space Admiristration's (NASA) Total Ozone Mapping Spectrometer (TOMS) indicated $200 \pm 60,230 \pm 70$, and $400 \pm 120 \mathrm{kt}$ of $\mathrm{SO}_{2}$ emitted during the June, August, and September eruptions, respectively. It is likely that $\mathrm{SO}_{2}$ released during pre-eruptive intrusion was being scrubbod and the resulting $\mathrm{H}_{2} \mathrm{~S}$ and sulfate dissolved in the hydrothermal system. Doukas and Gerlach (this vo'ume) and Bluth and others (this volume) conclude from independent techniques that a significant amount of $\mathrm{H}_{2} \mathrm{~S}$ was emitted during the 1992 eruptions. Airborne $\mathrm{CO}_{2}$ measurements made following the September eruption did detect substantial magmatic outgassing, which suggests that monitoring of this less water-soluble gas might have provided a more diagnostic tool than monitoring of $\mathrm{SO}_{2}$ (Doukas and Gerlach, this volume). 


\section{VISUAL OBSERVATION OF ERUPTIONS}

Visual observations, when they can be obtained, are the most direct means of assessing eruptive activity. AVO's remote, slow-scan, continuously recording television camera at Kasilof on the Kenai Peninsula was turned to view Crater Peak, $120 \mathrm{~km}$ away, on May 6, 1992; it provided real-time views for AVO staff in both Anchorage and Fairbanks. In addition, a video camera was set up on the roof of AVO in Anchorage and wired into the operations room. Both cameras recorded the incandescence at the crater rim during the September 16-17 eruption (Neal and others, this volume). When weather permitted, the information from these cameras was critical in responding to false eruption alarms.

Especially helpful to AVO were the pilot reports (PIREPS) of visual observations passed on by FAA and NWS. For example, although seismicity indicated that the June eruption was imminent, the ash cloud was reported by a PIREP before seismic verification could be made and while clouds prevented groundbased visual observations of the volcano. A PIREP revealed the August eruption, because there was no precursory seismicity. PIREPs also provided a valuable record of eruption column height as a function of time.

\section{DETECTION OF VOLCANIC LIGHTNING}

Once volcanic activity has been detected seismically or visually, the most important task is to establish whether ash is being emitted. This can be difficult, given weather and light conditions in Alaska. AVO has established a lightning detection system (LDS) for the Cook Inlet region; this system is based on observations that lightning is commonly associated with vigorous, ash-laden eruptive columns at volcanoes throughout the world (Hoblitt, 1994; Paskievitch and others, this volume). Detected lightning might therefore indicate significant ash emission. During the Crater Peak eruptions, this technique proved only partially successful. A ring of lightning $10 \mathrm{~km}$ in diameter, centered $5 \mathrm{~km}$ east of the vent, was detected during the August eruption, but LDS did not detect lightning during the June and September eruptions. That lightning accompanied the June and September eruptions is indicated by interruptions in signals from seismic stations (Davis and McNutt, 1993).

\section{RADAR OBSERVATION OF ERUPTIVE COLUMNS}

One technique for detection of eruptive columns is C-band radar. An experiment conducted in cooperation with NWS by Rose and others (this volume) at Kenai provided a first test with excellert results. Radar imaged the Crater Peak eruption columns regardless of weather, and it also allowed est mates of column height and mass flux to be made. A limitation of radar observation is that only coarser particles are reflective, and so neither the top of the eruptive column, nor the cloud tens of minutes after cessation of eruption, can be seen.

\section{PROJECTION OF PLUME PATHS}

During the 1980 eruptions of Mount St. Helens, graphic plots of wind direction and velocity at several altitudes, used with permission of NWS, proved useful in determining the path of eruption plumes (Miller and others, 1981). Their usefulness was demonstrated again at Mount Spurr, particularly in calculating the time for the eruption cloud of Aucust 18 to reach Anchorage. In addition, it was immediately obvious that the June 27 eruption cloud would drift north toward sparsely populated areas and would not affect Anchorage. Winds for the September 18 eruption were flowing northeastward from the vent. A warning of possible ashfall was given to Anchorage, alth ough the model correctly showed the ash-laden winds passing just north of the city. The model correctly predicted that ash would fall mainly on the Matanuska-Susitna Valley. Also important in tracking ash were calls from citizens informing AVO of ashfall locations and thicknesses.

\section{TRACKING OF PLUMES BY SATELLITE}

The hazards of volcanic ash emitted during eruptions extend well beyond local communities. For the first several days, a cloud from an explosive eruption is dangerous to high-flying jets (Casadevall, 1992; Casadevall and Krohn, this volume). During the Mount Spurr eruptions, advanced very high resolution radiometry (AVHRR) data were processed usirg a new high-resolution picture transmission (HRPT) information processing system (HIPS) at NWS for real-time tracking of volcanic clouds (Schneider and others, this volume). The August and September eruption clouds were followed for more than 80 hours and thousands of kilometers (Schneider and others, this volume). Further development of this technique may male it possible to determine particle-size distribution and particle density in volcanic clouds, so the severity of hazard they pose can be more quantitatively evaluated.

TOMS satellite images were likewise use to track the eruption clouds for as many as 7 days after formation (Bluth and others, this volume). Sulfur diox- 
ide content of clouds from the August and September eruptions increased during their first 2 days, probably by atmospheric oxidation of $\mathrm{H}_{2} \mathrm{~S}$. At least half the $400 \pm 120 \mathrm{kt}$ of $\mathrm{SO}_{2}$ emitted by the three eruptions reached the lower stratosphere.

\section{DISSEMINATION OF INFORMATION}

AVO's use of updates, level of concern color code, calldown lists, and direct personal communications worked effectively to notify civil authorities and the general public of expected eruptions and resulting hazards from Mount Spurr. Intensive media coverage, based on interviews with AVO personnel by both local and national radio and television and the local newspaper, added to AVO's outreach.

AVO's color code is central to rapid communication of the level of hazard to concerned constituencies, particularly the aviation industry. As indicated in figure 4 , increasing levels of concern convey both increasing likelihood of eruption and increasing potential or actual size of eruption. No simple one-dimensional scale can adequately describe an impending or ongoing event. Yet, simplicity of communication is essential during an emergency. In practice, use of the code is tempered by awareness of the consequences that communication of the concern will cause. During the 1992 Crater Peak eruptions, color was used primarily to indicate likelihood of eruption. Red meant that an eruption was imminent or ongoing; Red was used because all events were major ones with eruptive columns that reached flight levels and produced regional tephra falls.

Two occasions show the kinds of decisions that must be made in applying the code and that include factors beyond the simple criteria in the code. The volcano's behavior arguably fell within the condition "restless" beginning in August of 1991. However, uncertainty as to the significance of the early seismicity, and knowledge that premature use of warning colors would entail unnecessary fueling and routing costs for the airlines, led to deferral of use of color code Yellow. A more literally based interpretation of the code was used on August 18, 1992, when AVO downgraded the concern level from Red to Orange at the end of the eruption, but 3 hours before ash stopped falling on Anchorage. The color code was not meant to address conditions away from the volcano, so the downgrading probably did not seem an adequate portrayal of the situation to citizens of Anchorage who were just beginning to be affected by the eruption. Never- theless, the AVO decision was appropriate to signal to the airlines and others that voluminous ash production at the vent had ceased and the end of ashfall in Anchorage could be predicted.

\section{ECONOMIC EFFECTS OF THF 1992 ERUPTIONS}

Economic losses from the Crater Peak eruptions were mainly effects of ashfall at Anchorage International Airport and associated disruption of air traffic from the August 18 eruption. Significant losses also included cleanup costs for the Municipality of Anchorage, adjacent military bases, and towns in the Matanuska-Susitna Valley. The cost of cleanup from the August 18, 1992, ashfall for Anchorage International Airport, Merrill Field, and Elmendorf Air Force Base, including cleaning buildings, runways, and aircraft on the ground, was at least $\$ 683,000$ (Anchorage International Airport, unpub. report, 15?3). Revenue lost from the closure of Anchorage International Airport for 20 hours is estimated at $\$ 276,000$ (Casadevall and Krohn, this volume). The Municipality of Anchorage reported nearly $\$ 2$ million in da mage, office closures, and cleanup costs from the August eruption (Municipality of Anchorage, unpub. report, 1993). In addition, there were numerous, small-scale losses incurred by businesses and citizens from the initial ashfall and reworked volcanic ash that affected equipment such as vehicle engines, building air-circulation systems, and computers in banks, b'isinesses, and local military installations. Economic impacts of ashfall on the upper Kenai Peninsula, Cordova, and the Matanuska-Susitna Valley have not been evaluated. AVO received calls from these areas following all three eruptions reporting school closures, poor rcad conditions, and health concerns. No loss of life resulted directly from the eruptions. Two heart attacks, one fatal, from shoveling ashfall were reported in Anchrage.

In contrast to the estimate of $\$ 160$ million in losses from the 1989-90 Redoubt eruptions (Tuck and Huskey, 1992), total losses from Crater Paak eruptions are informally estimated to be from $\$ 5$ to 8 million. This large difference arises from at least two causes. First, there were more eruptive pilses and greater eruptive volume in the Redoubt episode. Second, Redoubt losses were dominated by damage sustained by five jets (Casadevall, 1994). Damage to one of these aircraft nearly resulted in a catastrophe. The Crater Peak eruptions carried the same potential for disaster. However, increased awareness of the ash-cloud 
hazard within the aviation community and emplacement of an effective warning system by AVO, in concert with other agencies, resulted in minimal economic loss to air carriers.

\section{VOLCANOLOGICAL IMPLICATIONS OF THE 1992 ERUPTIONS}

The 1992 eruptions of the Crater Peak vent of Mount Spurr provide interesting insights into eastern Aleutian volcanism as well as andesitic volcanism in general. Some salient points are described below:

1. Less silicic magma composition does not necessarily mean less explosive eruptions. Silicic volcanism is often equated with explosive eruptions, and it is tempting to think of more mafic eruptions as more likely to produce lava flows. The Crater Peak eruptions were distinctly more mafic than those of either Redoubt or Augustine. Yet, these eruptions were entirely explosive, whereas a significant proportion of recent Redoubt and Augustine activity has been effusive. A rationale often applied to the case of effusive mafic eruptions is that in more fluid magma gas bubbles escape more readily and thus preclude significant buildup of pressure. However, a fluid magma can also ascend more rapidly than a viscous one. Rapid ascension of magma would prevent release of vapor from magma in the subsurface prior to eruption (Jaupart and Allegre, 1991) and could explain the explosiveness of the Crater Peak eruptions (Eichelberger, 1995).

2. Each of the three eruptions was remarkably similar in style and volume (Gardner and others, 1993; Neal and others, this volume). Quiet periods between events were of similar duration. The simplest interpretation is that the erupted magma was stored in the same way prior to each eruption. Storage at the same depth would lead to the same initial volatile conditions. One might envisage a conduit that gradually filled to the same volume prior to each event, emptied in each event, and was not physically altered during each event. In such a view, cessation of the complete eruptive episode represents decline in source region overpressure (Tait and others, 1989), and cessation of an individual eruption represents exhaustion of conduit-stored magma. Storage in a conduit extending to the base of the seismogenic zone at $40 \mathrm{~km}$ (Power and others, this volume) would require a conduit radius of $10 \mathrm{~m}$.

3. Like Redoubt, there is evident heterogeneity in melt composition in the system (Nye and others, this volume; Swanson and others, 1994), but unlike
Redoubt, there is little heterogeneity in bulk composition (Nye and others, this volume; Nye and others, 1994). This phase heterogeneity and bulk homogeneity probably represents the existence of magmatic domains that had similar origins but different pressure/ temperature histories, and that have not irteracted chemically with the mid- to upper-crust (despite the presence of abundant melted felsic xenoliths), nor lingered and fractionated there. Again unlike Redo'bt, melt heterogeneity increases with time through the episode (Harbin and others, this volume). Perhaps this difference relates to the clearly different styles of magma storage beneath the two volcanoes, but that relation is not clear.

4. Despite the similarities of eruptivo events within the 1992 episode, the character of associated seismicity varied greatly (Power and others, this volume; McNutt and others, this volume). There was seismicity preceding and following eruption, seismic quiescence preceding and following eruption, and seismicity without eruption. Because much of the seismicity defines a near-vertical line from the active vent to $40 \mathrm{~km}$ in depth, there seems little doubt that the seismicity is associated with flow of magma. It must be concluded, however, that Mount Spurr's magma can also move aseismically, and that significant shallow seismically detected movement of magma can occur without eruption. There is a mirror symmetry to the pattern, that is seismicity occurred without eruption at the beginning and end of the episode and aseismic eruption occurred in the middle. This pattern is perhaps consistent with thermal waxing and waning of the shallow system. When the system was hottest, less seis mogenic brittle fracturing or interaction between magma and hydrothermal fluids occurred. This symmet "y, however, is not complete in terms of distribution and type of seismicity, and much early seismicity occurred far from plausible sites of intrusion. The pattern is complex. Apparently, multiple processes associcted with the rise of magma generated the seismicity.

5. Although the most recent prior eruption was a good guide to the style of the 1992 events, its singularity was not. Past activity should be interpreted cautiously, especially when the data set is limited.

Interpretation of available data for the Mount Spurr volcanic system suggests the rapid migration of relatively fluid, volatile-rich magma through a narrow, deeply rooted conduit. Useful lessons have been drawn in terms of eruption prediction. For example, the importance of even weak tremor in presag ing eruption and the variability of the relation between seismicity and impending eruption. However, much re- 
mains to be learned about underlying processes. The origin of seismicity accompanying magma flow is not clearly understood, nor are the mechanisms by which new magma reopens an existing conduit. Whereas petrologic inferences can be drawn about equilibrium conditions of magma storage, the chemical and physical changes that accompany magma rise and produce the large variations in eruptive behavior are poorly known. A hope for the future is that geophysical and geologic insights from active systems such as those gained from the Crater Peak eruptions will provide the basis for a better understanding of magma's ascent to the surface. Such understanding could lead to better predictive capability - that is, to predict whether magma will merely intrude or will erupt, and to predict whether eruptions are likely to be explosive or effusive.

\section{REFERENCES CITED}

Alaska Volcano Observatory, 1993, Spurr erupts: Eos, Transactions American Geophysical Union, v. 74, no. 19, p. 217, 221-222.

Brantley, S.R., ed., 1990, The eruption of Redoubt Volcano, Alaska, December 14, 1989 - August 31, 1990: U.S. Geological Survey Circular 1061, 33 p.

Casadevall, T.J., 1992, Volcanic hazards and aircraft safety: FAA Aviation Safety Journal, v. 2, no. 3, p. 9-17.

Casadevall, T.J., 1994, The 1989-1990 eruption of Redoubt Volcano, Alaska: Impacts of aircraft operations: Journal of Volcanology and Geothermal Research, v. 62, p. 299-314

Davis, C. and McNutt, S.R., 1993, Lightning associated with the 1992 eruptions of Mt. Spurr volcano, Alaska [abs.]. Eos, Transactions American Geophysical Union, v. 74, no. 43., p. 649.

Eichelberger, J.C., 1995, Silicic volcanism: Ascent of viscous magmas from crustal reservoirs, Annual Reviews of Earth and Planetary Science, v. 23, p. 41-63.

Endo, E.T., and Murray, T.L., 1991, Real-time seismic amplitude measurement (RSAM): a volcano monitoring and prediction tool: Bulletin of Volcanology, v. 53, p. 533-545.

Gardner, C.A., Neal, C.A., and McGimsey, R.G., 1993, Volatile zonation in the Crater Peak magma: evidence from 1992 tephra-fall deposits [abs.]: Eos, Transactions American Geophysical Union, v. 74, no. 43., p. 621.

Gardner, C.A., Neal, C.A., Waitt, R.B., and Janda, R.J., 1994, Proximal pyroclastic deposits from the 1989-1990 eruption of Redoubt Volcano, Alaska-Stratigraphy, distribution, and physical characteristics: Journal of Volcanology and Geothermal Research, v. 62, p. 213-250.

Gorshkov, G.S., 1959, Gigantic eruption of Bezymianny Volcano: Bulletin of Volcanology, v. 20, p. 77-112.

Hoblitt, R.P., 1994, A lightning detection experiment at Redoubt
Volcano: Journal of Volcanology and Geothermal Research, v. 62 , p. 497-515.

Jacob, K.H., Nakamura, K., and Davies, J.N., 1977, Trench-volcano gap along the Alaska-Aleutian arc: Facts and speculations on the role of terrigenous sediments, in Talwani, M, and Pitman, W.C., eds., Island arcs, deep sea t"enches, and back-arc basins: American Geophysical Union Ewing Volume, Washington, D.C., p. 243-258.

Jaupart, C., and Allegre, C.J., 1991, Gas content, eruption rate, and instabilities of eruption regime in silicic volcanoes: Earth and Planetary Science Letters, v. 102, p. 413-429.

Jolly, A.D., Page, R.A., and Power, J.A., 1994, Seismic'ty and stress in the vicinity of Mount Spurr volcano, south central Alaska: Journal of Geophysical Research, v. 99, p. 15,305-15,318.

Juehle, W., and Coulter, H., 1955, The Mt. Spurr eruption, July 9, 1953: Eos, Transactions of the American Geophysical Union, v. 36, p. 199-202.

Miller, C.D., Mullineaux, D.R., Crandell, D.R., 1981, Hazards assessments at Mount St. Helens, in Lipman, P.W'., and Mullineaux, D.R., eds., The 1980 eruptions of Mour ' St. Helens, Washington: U.S. Geological Survey Professional Paper 1250, p. 789-802.

Miller, T.P., and Chouet, B.A, 1994, An introduction and chronology to the 1989-90 eruption of Redoubt Volcano, Alaska: Journal of Volcanology and Geothermal Research, v. 62. p. 1-10.

Newhall, C.G., and Dzurisin, D., 1988, Historical urrest at large calderas of the world, volume 1: U.S. Geological Survey Bulletin 1855, $598 \mathrm{p}$.

Nye, C.J., Swanson, S.E., Miller, T.P., and Avery, V.F., 1994, Geochemistry of the 1989-1990 eruption of Re toubt Volcano: Part I. Whole-rock major and trace-elemer' chemistry: Journal of Volcanology and Geothermal Resea"ch, v. 62, p. 429-452.

Nye, C.J., and Turner, D.L., 1990, Petrology, geoch smistry, and age of the Spurr volcanic complex, eastern Aleutian arc: Bulletin of Volcanology, v. 52, p. 205-226.

Riehle, J.R., 1985, A reconnaissance of the major Holocene tephra deposits in the upper Cook Inlet region, Alaska: Journal of Volcanology and Geothermal Research, v. 26, p. 37-74.

Swanson, S.E., Nye, C.J., Miller, T.P., and Avery, V.F., 1994, Geochemistry of the 1989-1990 eruption of Redoubt Volcano: Part II. Evidence from mineral and glass chemistry: Journal of Volcanology and Geothermal Research, v. 62, p. 453-468.

Tait, S, Jaupart, C., and Verniolle, S., 1989, Pressure, gas content, and eruption periodicity of a shallow crystallizing magma chamber: Earth Planetary Science Letters, v. 92, p. 107-123.

Tuck, B.H., and Huskey, L., 1992, The economic consequences of the 1989-1990 Mt. Redoubt eruptions: Institcte of Social and Economic Research, University of Alaska. Anchorage, $42 \mathrm{p}$.

Wilcox, R., 1959, Some effects of recent volcanic ash falls with especial reference to Alaska: U.S. Geological Sirvey Bulletin $1028-N$, p. $409-476$. 


\title{
Real-Time C-Band Radar Observations of 1992 Eruption Clouds from Crater Peak, Mount Spurr Volcano, Alaska
}

\author{
By William I. Rose, Alexander B. Kostinski, and Lee Kelley
}

\section{CONTENTS}

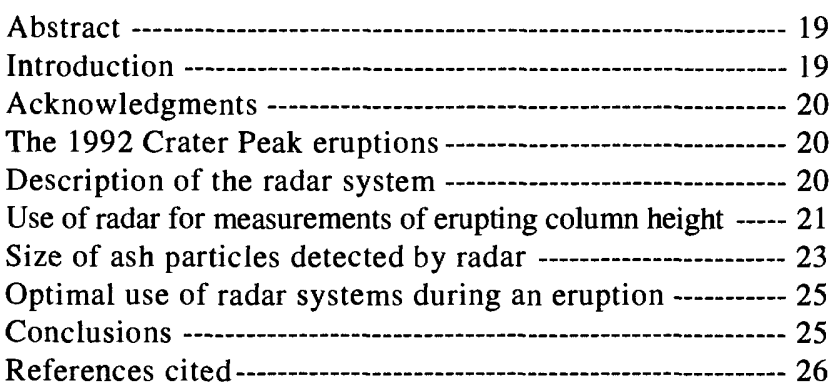

\begin{abstract}
Repeated aircraft hazards in Alaska related to volcanic clouds have resulted in the use of a mobile C-band radar devoted to volcanic-cloud monitoring. The radar is located at Kenai, in range of several volcanoes in the Cook Inlet area. Three significant eruptions from the Crater Peak vent of Mount Spurr volcano (about $80 \mathrm{~km}$ from Kenai) in 1992 provided the first tests of the radar. The system constructs maps of the eruption columns and the drifting ash clouds for short periods (as long as 30 minutes) after eruption. The radar gives direct information about active eruptions in any weather conditions and allows estimates of the altitude of the column, which are useful for three-dimensional trajectory models of ash-cloud transport. It also allows an estimate of the eruption rate based on the ash-column height. However, such estimates may be lower than the true values because the very top of the eruption column, which may not contain coarse ash, may not be detected by the radar.

We conclude that the radar detects mainly ash particles, sized from about 1 millimeter to a few centimeters on the basis of three sources-the brief duration of the reflected radar signal, data from independent ground observations on the mass and size of particles which fell out of the reflected cloud, and the intensity of the reflected signal. The most intense reflections come from ash clouds with particles that range from 2 to $20 \mathrm{~mm}$ in diameter and with a total particle mass concentration of less than .01 to $1 \mathrm{~g} / \mathrm{m}^{3}$.
\end{abstract}

The data are useful for constructing models of ash columns and deposition of coarse tephra. Radars are not useful for long-term volcanic cloud tracking because the large ash particles, that provide for strong radar signals fall out soon after an eruption. The radar does not detect smaller $(<1-100 \mu \mathrm{m}$ in diameter $)$ ash particles in drifting volcanic clouds that can persist in the atmosphere for several days or more.

\section{INTRODUCTION}

Since 1986, three volcanoes (Augustine, Redoubt, and Mount Spurr) have erupted in the Cook Inlet area of Alaska (fig. 1). Each of the eruptions ras had a considerable impact on commercial aviation in southcentral Alaska, particularly in Anchorage. Consequently, the National Weather Service (NWS) has significantly improved its capability of measuring and tracking ash clouds, in order to advise the aviation community about how to avoid ash clouds, which can be hazardous to jet aircraft. This report summarizes and inte-prets radar observations of ash clouds, made in real time during the 1992 Crater Peak eruptions, by a leased WR1002 EEC meteorological C-band radar operated at Kenai, Alaska, opposite the volcanoes (fig. 1).

The radar was installed just prior to the 1992 activity. Three eruptions of the Crater Peak of Mount Spurr volcano in 1992 provided a first, robrst test of the radar. The results provide data that are useful for real-time ash-cloud tracking and for forecast'ng cloud movement. Communication between the $\mathrm{NW}^{r} \mathrm{~S}$ office, the U.S. Geological Survey (USGS), and th: Federal Aviation Administration (FAA) at Anchorage provides for the exchange of data and for timely and effective dissemination of eruption information to the public.

The data collected are also of volcanological interest. The usefulness of weather radar systems at active volcanoes was demonstrated at Mount $\mathbf{s}+$. Helens (Harris and others 1981; Harris and Rose, 1983). The heights of ash columns, which were measur $\mathrm{d}$ during the eruptions, were used to calculate the eruntion rate of ash. The radar system also mapped the extent of the most reflective parts of the ash cloud as it moved across Washington State. 


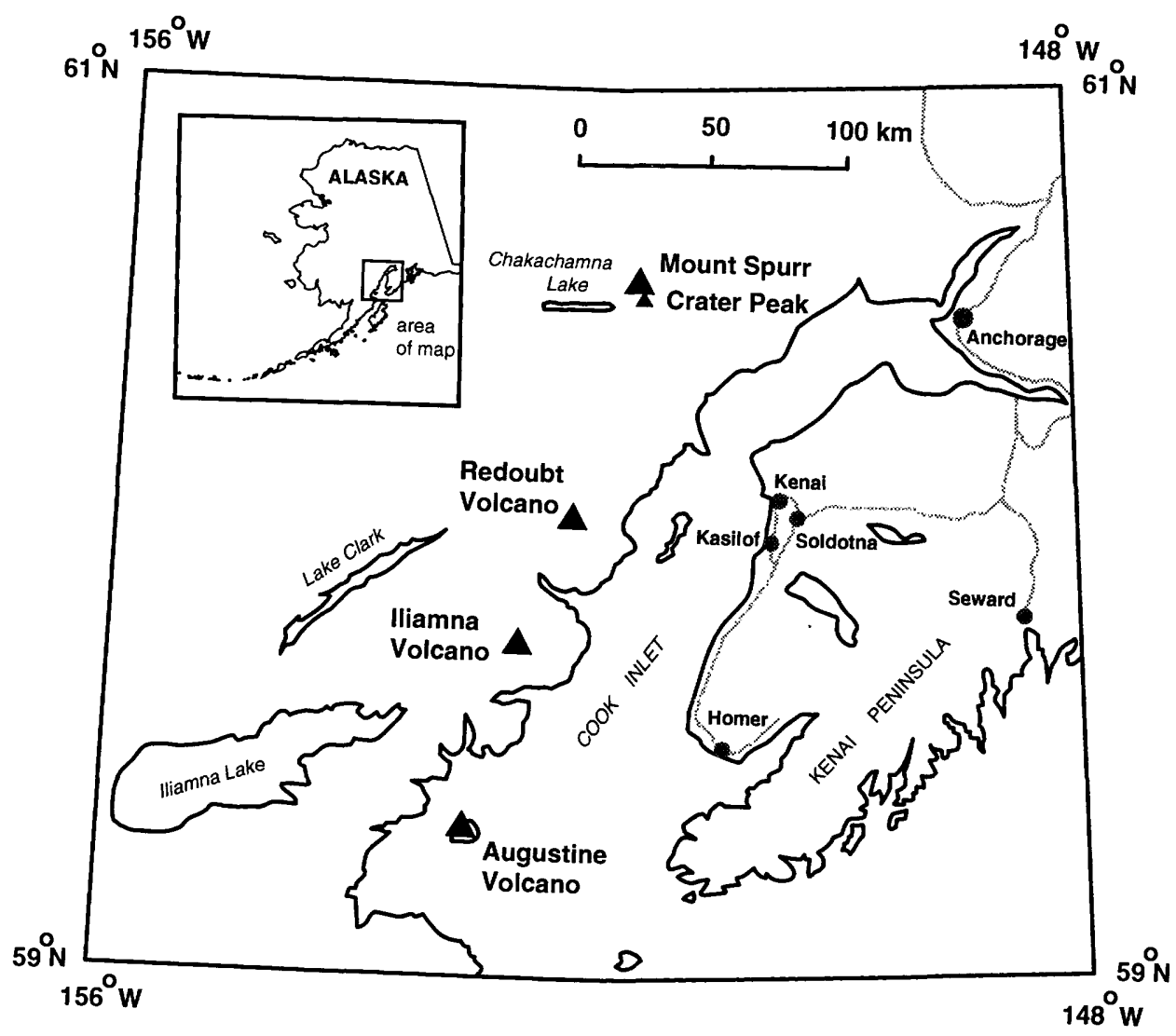

Figure 1. Index map of Cook Inlet area. The solid triangles represent volcanoes. Modified from Brantley (1990).

\section{ACKNOWLEDGMENTS}

Funding for this project came from a grant from the Cooperative Program for Operational Meteorology Education and Training (COMET), a cooperative agreement between the National Weather Service and the University Corporation for Atmospheric Research, from NASA through grant NAG5-1838, and from NSF through grants ATM-9191075 and ATM 9116075. We thank people from the NWS staff in Anchorage, including Gary Hufford, Craig Bauer, Joel Curtis, and Ray Moore. Steve McNutt and Game McGimsey were helpful in providing data from the Alaska Volcano Observatory. Dave Harris, Steve McNutt, Jim Evans, Game McGimsey, Tina Neal, Rick Holasek, and Dennis Krohn provided helpful reviews.

\section{THE 1992 CRATER PEAK ERUPTIONS}

A summary of data on the three Crater Peak eruptions of 1992 is given in table 1 . The events were similar in many respects. They each lasted 3 to 4 hours and were marked by andesitic ash eruptions, which produced roughly similar volumes of new ash (Neal and others, this volume). Each eruption resulted in narrow fallout blankets, which stretched for many kilometers from the volcano, and clouds that were much larger than those produced by the 1986 eruptions of Augustine Volcano (Holasek and Rose, 1991) and the 1989-90 eruptions at Redoubt Volcano (Schneider and Rose, 1994).

\section{DESCRIPTION OF THE RADAR SYSTEM}

The Kenai radar is remotely operated ty meteorologists stationed in the NWS forecast office in Anchorage, who communicate with the radar via modem. The main data displays are the range-height indicator (RHI), and the plan-position indicator (PPI). The RHI display is a vertical cross section of a reflecting cloud with a range and height scale (fig. 2). The PPI display is a horizontal cross section of the volcanic ash cloud on a scaled map background of Cook Inlet (fig. 2 ). The characteristics of the radar used are given in table 2. The radar's operation and performance were described in more detail by Serafin (1990). 
Table 1. Data on 1992 Crater Peak eruptions, Mount Spurr volcano, Alaska.

[ADT, Alaska daylight time; AVO, Alaska Volcano Observatory; NWS, National Weather Service; *, data unavailable; Sources of AVO data were Steve McNutt, Game McGimsey, Christina Neal, and Thomas Miller (oral commun., 1993). Anchorage International Airport closed at 6:10 p.m. ADT on 8/18/92]

\begin{tabular}{|c|c|c|c|}
\hline & $6 / 27 / 92$ & 8/18/92 & 9/17/92 \\
\hline \multicolumn{4}{|c|}{ Avo Observations } \\
\hline Eruption start, ADT - & 07:04 a.m. & 4:42 p.m. & 12:03 a.m. \\
\hline Eruption end, ADT & 11:07 a.m. & 8:10 p.m. & 3:39 a.m. \\
\hline Volume of ash $\left(\times 10^{6} \mathrm{~m}^{3}\right)$ & 12 & 14 & 15 \\
\hline \multicolumn{4}{|c|}{ NWS Radar Observations } \\
\hline Eruption start, ADT & * & * & 12:10 a.m. \\
\hline Eruption end, ADT - & * & 6:13 p.m. & 3:08 a.m. \\
\hline Minimum volume of ash $\left(\times 10^{6} \mathrm{~m}^{3}\right)$ & * & * & 16 \\
\hline Maximum column height, $\mathrm{km}$ & 14.5 & 13.7 & 13.9 \\
\hline Time of maximum height, ADT & 10:23 a.m. & 4:55 p.m. & 2:21 a.m. \\
\hline \multicolumn{4}{|c|}{ Anchorage International Airport Information } \\
\hline Service from airport & open & closed & open \\
\hline Aircraft rerouted - & yes & yes & yes \\
\hline
\end{tabular}

Table 2. Specifications of WR 100-22 EEC meteorological C-band radar used at Kenai, Alaska.

\begin{tabular}{|c|c|}
\hline Parameter & Specification for the Kenai Radar \\
\hline Primary power & 115 volts, 60 cycle, single phase \\
\hline Wavelength & $5 \mathrm{~cm}$ \\
\hline Peak power - & $250 \mathrm{KW}$ \\
\hline Pulse length & 2 microseconds \\
\hline Pulse repetition frequency & 256 Hertz \\
\hline Magnatron type & $7156 \mathrm{~A}$ \\
\hline Radio frequency - & 5500 to 5600 Megahertz \\
\hline Antenna beam width & 1.6 degrees \\
\hline Receiver minimum detectable signal -..-- & $-106 \mathrm{dBm}$ (minimum) \\
\hline Receiver IF - -...-. & 30 Megahertz \\
\hline IF bandwidth & $\log 2$ Megahertz \\
\hline Receiver dynamic range & $78 \mathrm{~dB}$ minimum \\
\hline
\end{tabular}

The reflectivity of the volcanic clouds is measured by comparing them to a standard equivalent reflectivity expressed in $\mathrm{dBZ}$, which stands for decibels relative to a rain target with a reflectivity factor of 1 $\mathrm{mm}^{6} / \mathrm{m}^{3}$, for example, $\mathrm{dBZ}=10 \log _{10}\left(\mathrm{Z} / 1 \mathrm{~mm}^{6} / \mathrm{m}^{3}\right)$; this allows inclusion of the natural range of meteorological precipitation clouds, within values of about 1 to more than 50 (Rinehart, 1991; Sauvageot, 1992). By choosing a range of $\mathrm{dBZ}$ values, contours of equal reflectivity are displayed on both the RHI and PPI images. Particle size and concentration may then be estimated from the measured reflectivities.

\section{USE OF RADAR FOR MEASUREMENTS OF ERUPTING COLUMN HEIGHT}

When operated in the RHI (range-height indicator) mode and pointed directly toward the volcano (azi- muth of 328 in the case of Spurr), the radar can detect the top of the erupting column (fig. 3). Repeated measurements during the 3-hour eruption of September 16-17, 1992, give a record of the dynamics of the eruption of Crater Peak. The height measurements can be converted to eruption rates by the inversion of the Morton Equation (Morton and others, 1056; Wilson and others, 1978). Ignoring the effects of entrained atmospheric water vapor, we can then calculate the final height of a buoyant plume, given a constant eruption rate, to give an estimate of intensity of eruption with time (fig. 3). In simplified form, the Morton equation is $\mathbf{H}=236.6 \mathrm{Q}^{1 / 4}$. $\mathrm{H}$ is the height of the erupting column in meters, and $Q$ is the eruption rate in kilograms/sec. The constant, 236.6, includes an empirical constant in the correct dimensional form.

This measure of intensity compares well with the raw seismic signal measured during eruption, based 

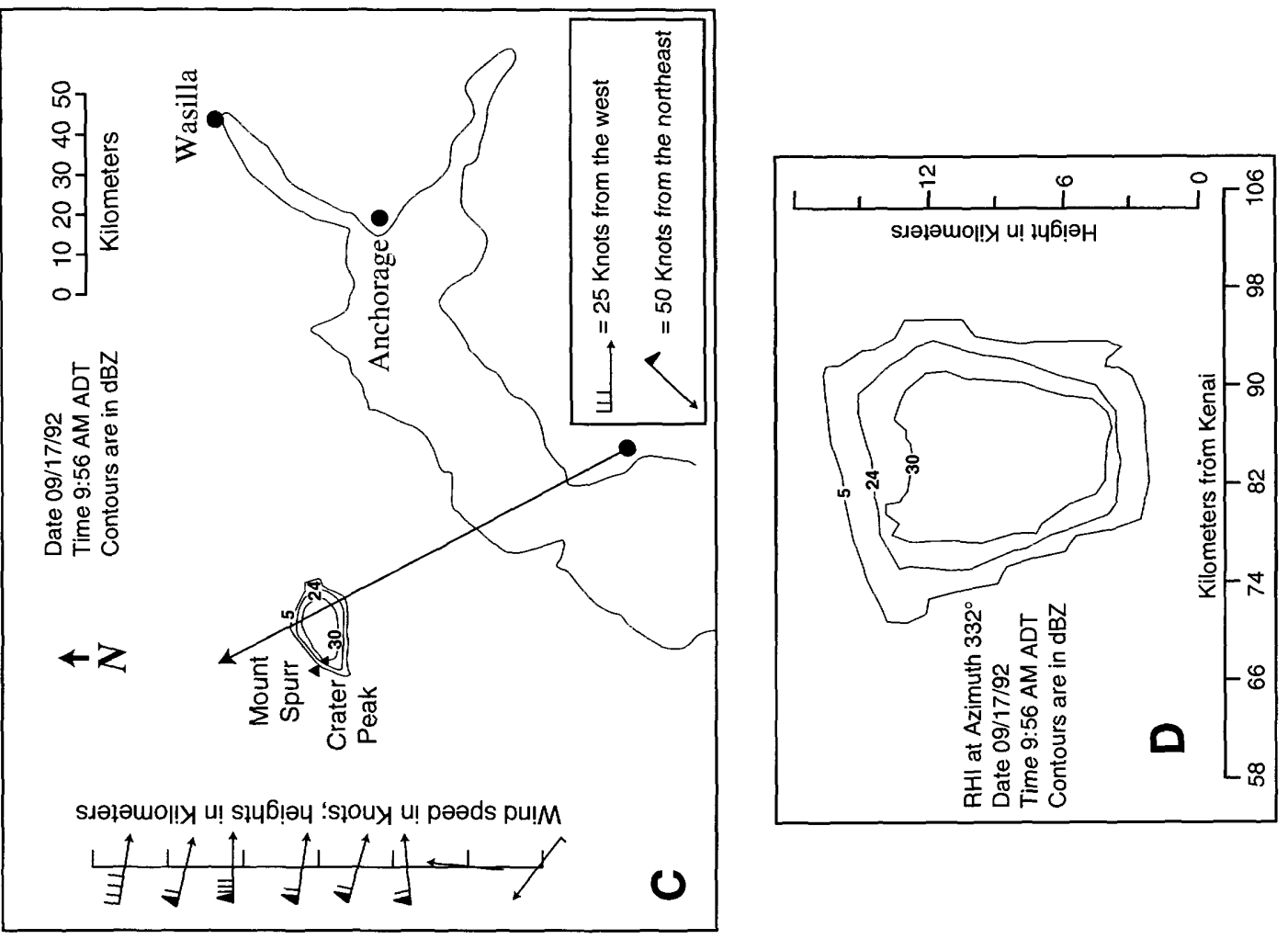

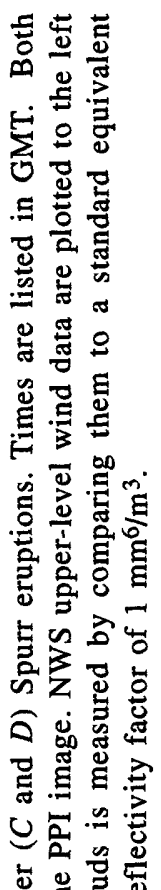

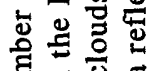

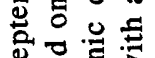

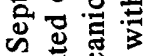

뭉음융

-

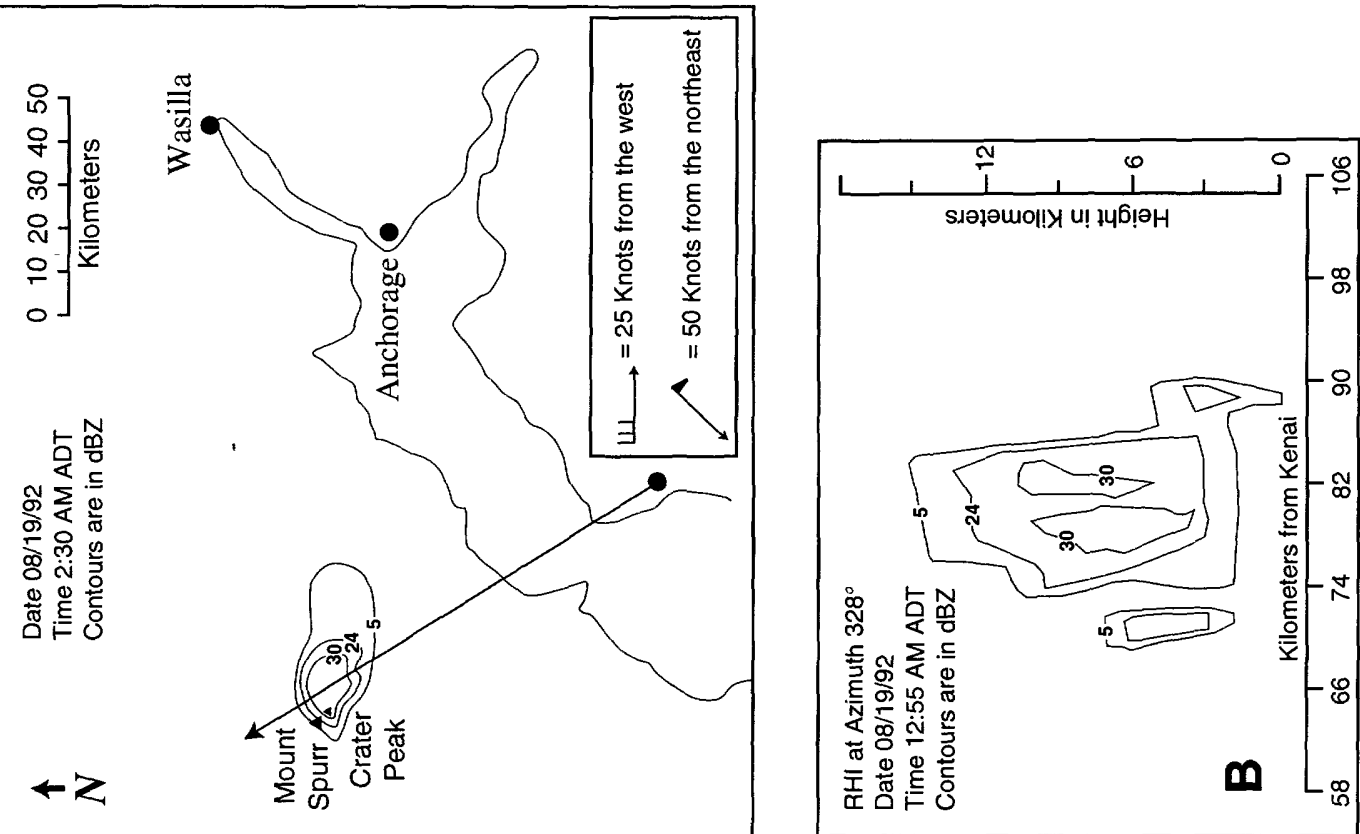

들 荡

纪

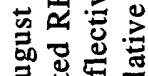

造密

ฐす원

舟完兽

岁逑

要

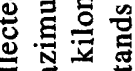

응

氜完

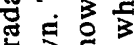

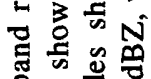

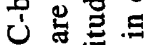

총 鸪

है

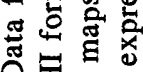

ค氠空

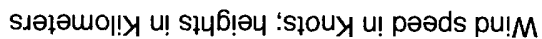

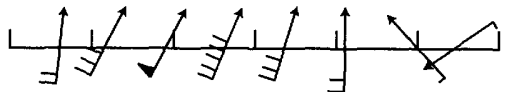

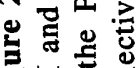

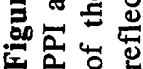




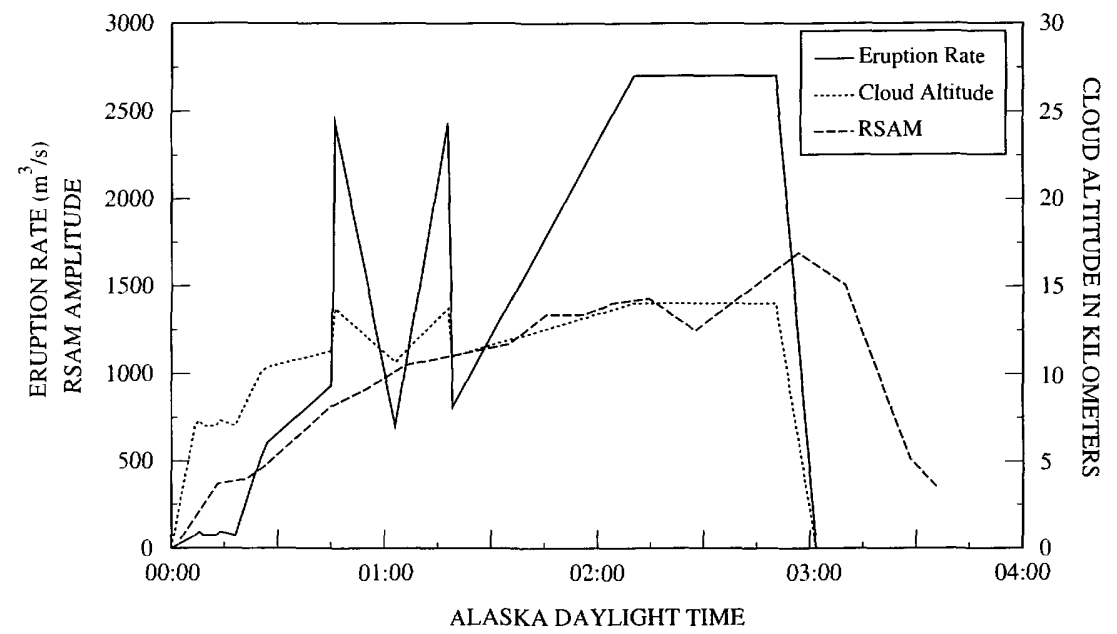

Figure 3. Plots of eruption cloud maximum height versus time for the September 17, 1992, Spurr eruption as measured by C-band radar from Kenai. RHI recordings, with azimuths of $328^{\circ}-332^{\circ}$ (toward Crater Peak from Kenai), were used. A beam width correction was applied. Eruption rate versus time for the eruption is also plotted, derived from the radar height data and application of the Morton equation. RSAM seismic results from AVO (S. McNutt, oral commun., 1993), which are also measures of eruption intensity, are plotted for comparison. RSAM is a 1-minute average of seismic amplitudes from station BGL, $10 \mathrm{~km}$ from Crater Peak vent of Mount Spurr.

on real-time seismic amplitude measurement (RSAM) (Murray and Endo, 1992; fig. 3). The apparent eruption rate, estimated by the Morton equation and radar, can be integrated over the duration to get an estimate of the volume of ash emitted. The result is about $16 \times 10^{6} \mathrm{~m}^{3}$, which is almost the same as the amount estimated from ash fallout $\left(15 \times 10^{6} \mathrm{~m}^{3}\right)$. However, the radar could underestimate the column height because larger particles do not rise as high as smaller, less reflective ones (Carey and Sparks, 1986).

In summary, the radar offers a method of measuring the height of the eruption column, which is important for trajectory models of ash cloud movements. The systematic measurement of heights of the column is a way to monitor the eruption intensity and also gives a minimum estimate of mass of ash erupted.

\section{SIZE OF ASH PARTICLES DETECTED BY RADAR}

The intensity of radar reflections is described by the Probert-Jones equation (Probert-Jones, 1962), which can be expressed in simplified form as $P_{r}=R_{c}$ $\mathrm{K}^{2} \mathrm{Z} / \mathbf{R}^{2} . \mathbf{P}_{\mathrm{r}}$ is the radar echo power received, and $\mathbf{R}_{\mathrm{c}}$ is a radar constant containing the wavelength relations specific to the radar (peak power, antenna gain, beam width, and pulse length). $R$ is the range of the target. $\mathrm{K}^{2}$ is a refractive index factor, and $\mathrm{Z}$ is the target reflectivity factor, which is proportional to the product of the number density of reflecting particles and their radii, raised to the sixth power. Because the radar echoes are so strongly dependent on the size of the particles ( $\mathrm{r}^{6}$ in the small dipole or Rayleigh approximation), the return signal detected by the radar is dominated by larger ash particles suspended in the cloud.

We observed that the radar system detected ash clouds only near the volcano and within about one half hour or less of actual eruption. The drifting cloud remains highly reflective to radar for a distance of only about 15 to $25 \mathrm{~km}$ from the volcanc (fig. 2), which at the rate of winds measured, represents a transport time of about 15 to 30 minutes. We used data from figure 4 (Lapple, 1974) to estimate the size of ash particles that would fall to the ground in less than one half hour from heights of $14.2 \mathrm{~km}(47,000 \mathrm{feet})$ or less-time and height constrained by the Crater Peak radar observations. On the basis of these estimates, spherical particles with diameters of 1,000 microns $(1 \mathrm{~mm})$ or more would have terminal velocities $(600$ $\mathrm{cm} / \mathrm{sec}$ ) that would cause them to fall out within a half hour from $14.2 \mathrm{~km}$. Because of the particles' extremely size-sensitive reflectivities and the rapid disappearance of the clouds from the radar, we think that the radar reflections we measured were caused by particles with diameters of 1,000 microns $(1 \mathrm{~mm})$ or larger. 


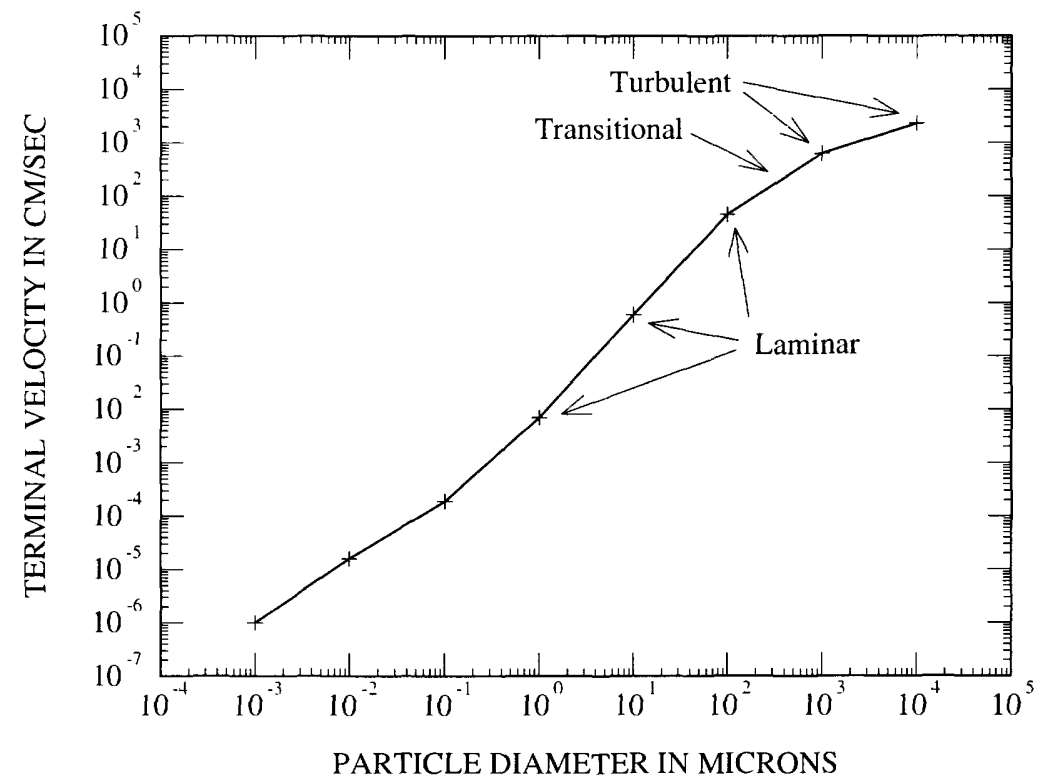

Figure 4. Terminal gravitational settling velocities of various size spheres with a density of $2.0 \mathrm{~g} / \mathrm{cm}^{3}$ in dry atmosphere at $25^{\circ} \mathrm{C}$ and 1 atm (Lapple, 1974).

A cross section of the cloud that was about 7 $\mathrm{km}$ downwind from the crater is shown in figure 3, and this cloud section shows very strong reflections $(30 \mathrm{dBZ})$. A radar reflection is caused by the summation of all of the particles multiplied by their individual reflectivities. Consequently, a large number of small particles can have a reflectivity equal to a small number of large ones. Therefore, other data are necessary to determine the characteristics of the cloud.

In this case, we have excellent additional data: the time it takes for the radar image to disappear and the size and mass of the particles that fell out of the section imaged. These radar reflections cannot be produced from very large ash particles (greater than 3 $\mathrm{cm}$ ), because their higher terminal velocities would cause them to fall out before drifting $7 \mathrm{~km}$. On the basis of prevailing winds at appropriate altitudes (about $50-60$ knots or $80-96 \mathrm{~km} / \mathrm{hr}$ ) at the time, we estimate that the cloud $7 \mathrm{~km}$ downwind is about $5 \mathrm{~min}$ utes old. Spheres with a density of $2 \mathrm{~g} / \mathrm{cm}^{3}$, which were larger than about $3 \mathrm{~cm}$, would be completely removed from a 14-km-high cloud within 5 minutes. We should expect that ash particles, which are not spherical, will have greater atmospheric drag and, therefore, slower terminal velocities, but particles with diameters much larger than a few centimeters are not likely to be present in the cloud section shown in figure 2 .

We compared the data on radar reflectivity of volcanic ash (Harris and Rose, 1983; Rose and Kostinski, 1994) to see what combinations of particle mass and size could explain the observed intensity of radar reflection. The theoretical reflectivity results, calculated for identical, spherical particles with a volcanic ash refractive index factor $\left(\mathrm{K}^{2}\right)$ of 0.3 , which is about one-third that of liquid water (0.93), are shown in figure 5. The maximum reflection, seen in the drifting cloud $7 \mathrm{~km}$ downwind $(30 \mathrm{dBZ})$, corresponds to more than $100 \mathrm{~g} / \mathrm{m}^{3}$ of ash particles with a radius of $0.25 \mathrm{~mm}, 20 \mathrm{~g} / \mathrm{m}^{3}$ of ash particles with a radius of $0.5 \mathrm{~mm}, 0.7 \mathrm{~g} / \mathrm{m}^{3}$ of ash with a radius of $1 \mathrm{~mm}$, or less than $0.01 \mathrm{~g} / \mathrm{m}^{3}$ with a radius of $4 \mathrm{~mm}$. Because the radar reflection shown in figure 2 is thousands of meters high, a particle-mass concentration of $20 \mathrm{~g} / \mathrm{m}^{3}$ implies a fallout thickness of much more than $1.5 \mathrm{~m}$. Consequently, the mass concentrations of $20 \mathrm{~g} / \mathrm{m}^{3}$ or higher are impossible because the observed fallout data are inconsistent with them.

The isopach maps of fallout on September 17, 1992, show that the thickness $7 \mathrm{~km}$ down the dispersal axis is about $10 \mathrm{~cm}$, and the grain size is mainly between 1 and $30 \mathrm{~mm}$ (R.G. McGimsey, oral commun., 1993). This data, along with our observation that the radar signal disappeared after 30 minutes, implies that most of the particles which reflected the radar signal were 2 to $20 \mathrm{~mm}$ in diameter and the particle concentrations of the reflecting cloud ranged from less than 0.01 to about $1 \mathrm{~g} / \mathrm{m}^{3}$ (shown by the shaded area of fig. 5). In comparison, Harris and Rose (1983) estimated that the particle-mass concentratic ns for the Mount St. Helens eruption clouds of May 18, 1980, and March 19, 1982, were $3 \mathrm{~g} / \mathrm{m}^{3}$ and $0.2 \mathrm{~g} / \mathrm{m}^{3}$ respectively, similar to the Crater Peak estimates. 


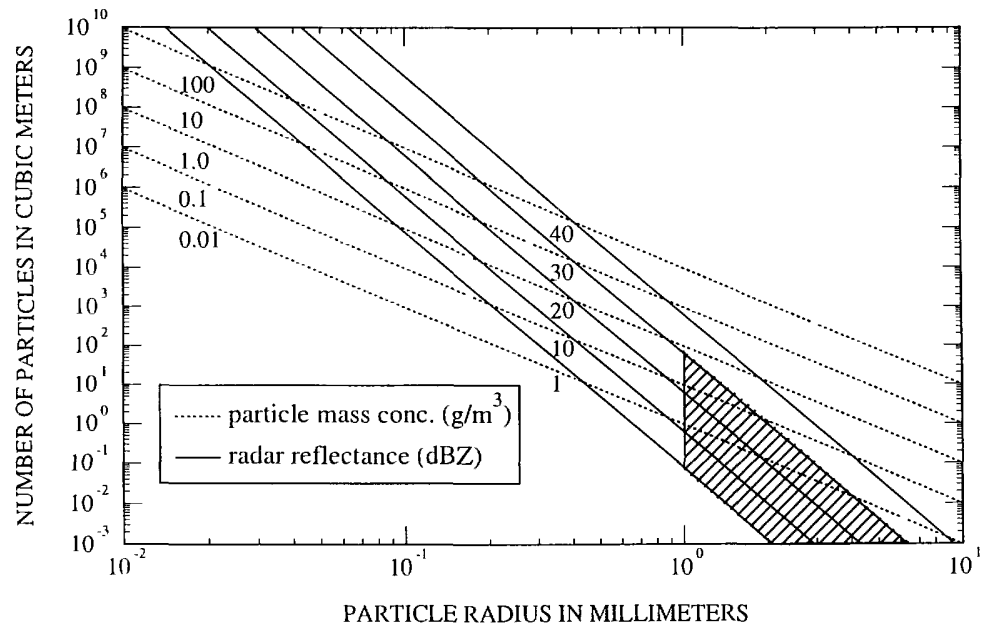

Figure 5. Relation between radar reflection returned (measured in decibels relative to a rain target or $\mathrm{dBZ}$ ), the total mass of ash particles per unit volume (measured in grams per cubic meter), the number of particles per cubic meter, and the radius of the particles in $\mathrm{mm}$. This figure is based on idealized assumptions: single size for particles, perfect spherical shape of all particles, and a refractive index factor which is about one-third of that for water droplets. Cross-hatched portion probably most closely approximates conditions in the 1992 eruption clouds from Crater Peak of Mount Spurr, which were detected by the $\mathrm{C}$-band radar. This approximation is based on the duration of radar reflection and observed size of fallout.

\section{OPTIMAL USE OF RADAR SYSTEMS DURING AN ERUPTION}

Aircraft traveling at high speeds must get timely warning of ash clouds. During eruptions, radar measurements of ash can be directly communicated from the NWS to the Anchorage Air Route Traffic Control Center (ARTCC) so that aircraft in immediate danger can be diverted and decisions on possible airspace closures can be made.

Because the returns of the radar signal come mainly from large $(1-30 \mathrm{~mm})$ ash particles, the radar measurements can only be made during and immediately following actual eruptions. At the beginning of the eruption, the radar in the RHI mode makes initial detection and height measurements.

During the September 16-17, 1992, eruption of Crater Peak vent, the radar was able to verify the Alaska Volcano Observatory's (AVO) seismic indications of activity at Crater Peak within a few minutes. The eruption began at 10:36 a.m. ADT on September 16, and the initial activity lasted 16 minutes. At 12:03 a.m. ADT on September 17, AVO called NWS alerting them that an eruption was likely in progress. At 12:10 a.m. $\mathrm{ADT}$, the Kenai radar verified a volcanic ash cloud above Mount Spurr. Later that morning, at just after 3:00 a.m. ADT, AVO called NWS with a notification that the eruption had ended. During the call from AVO, the volcano was scanned, and the ash cloud observed by the radar was detached from the volcanc. Within 20 minutes, the radar could detect no ash clond.

Radar detection is valuable in many ways. Radar-based detection is especially important during conditions of poor visibility, when other types of observations are difficult. Radar height measurements of the ash cloud are inputs to the production of a threedimensional ash dispersion tracking model, which the NWS is implementing to forecast volcanic cloud positions. In cooperation with AVO, the NWS works with the Alaska Division of Emergency Services to identify those areas of the state that will most likely be affected by ash fallout.

A new generation WSR-88D radar system was installed in 1994 at Kenai, Alaska. The WSP-88D is a modern $S$ band $(1=10-11 \mathrm{~cm})$, doppler radar, which could provide some advantages for volcanic cloud mapping, including information on radial velocities in and around the ash cloud.

\section{CONCLUSIONS}

The 5-cm radar operated from Kenai was successfully used to map ash clouds from Crater Peak about $80 \mathrm{~km}$ away. The radar signal is dominated by 
ash particles larger than about 1,000 microns in diameter. We were able to use ground measurements of the sizes and masses of fallout particles that fell from the ash cloud as well as the dynamics of fallout constrained by the duration of the radar reflection to tell us that the largest radar reflections were mainly caused by ash particles that were between 2 and $20 \mathrm{~mm}$ in diameter.

Radar can also be used to measure the height of the ash cloud, but it may underestimate the height because it does not respond to smaller ash particles, which rise higher. C-band radar does not detect distal parts of the ash cloud, which have an atmospheric residence time longer than 30 minutes, because the larger more reflective ash particles drop out.

The Kenai radar is the first type of remote sensor to actually view ash clouds. Its all weather capability fills the data gaps of satellite data as well as other observational methods and the real-time use of a radar provides an excellent way to corroborate the seismic indications of actual eruptions. Radar provides vital, immediate warning and information to the aviation community.

The radar system offers, for the first time, the opportunity of mapping internal structure of dense proximal ash plumes during eruptions. This capability can supply data to volcanologists who are interested in modeling eruption columns (Wilson and others 1978; Carey and Sparks, 1986; Bursik and others, 1992). Because of the radar's sensitivity to larger particles, such a system would be particularly valuable in testing models for the fallout of larger particles, such as the one developed by Bursik and others (1992).

\section{REFERENCES CITED}

Brantley, S.R., 1990, The eruption of Redoubt Volcano, Alaska, December 14, 1989-August 31: U.S. Geological Survey Circular 1061, 33 p.

Bursik, M.I., Sparks, R.S.J., Gilbert, J.S., and Carey, S.N., 1992, Sedimentation of tephra by volcanic plumes: 1 . Theory and its comparison with a study of the Fogo A plinian deposit, Sao Miguel (Azores): Bulletin of Volcanology v. 54, p. 329-344.

Carey, S.N., and Sparks, R.S.J., 1986, Quantitative models of the fallout and dispersal of tephra from volcsnic eruption columns: Bulletin of Volcanology, v. 48, p. 1C9-125.

Harris, D.M., Rose, W.I., Roe, R., and Thompson, M.R., 1981, Radar observations of ash eruptions, in Lipman, P.W., and Mullineaux, D.R., eds., The 1987 Eruptions of Mount St. Helens, Washington: U.S. Geological Survey, Professional Paper 1250, p. 323- 33.

Harris, D.M., and Rose, W.I., 1983, Estimating particle sizes, concentrations, and total mass of ash in volcanic clouds using weather radar: Journal of Geophysical Research, v. 88 , p. $10968-10983$.

Holasek, R.E., and Rose, W.I., 1991, Anatomy of 1986 Augustine eruption clouds as recorded by multi-spectral image processing of digital AVHRR weather satellite data: Bulletin of Volcanology, v. 53, p. 42?-435.

Lapple, C.E., 1974, Characteristics of Particles and Particle Dispersoids, in Perkins, H.C., Air Pollution, New York, McGraw-Hill, p. 224-225.

Morton, B.R., Taylor, G., and Turner, J.S., 1956 . Turbulent gravitational convection from maintained and instantaneous sources: Proceedings of Royal Society (London) Ser A, v. 234, p. 1-23.

Murray, T.L., and Endo, E.T., 1992, A real-time seismic amplitude measurement system (RSAM): United States Geological Survey Bulletin 1966, p. 5-10.

Probert-Jones, J.R., 1962, The radar equation in meteorology: Quarterly Journal, Royal Meteorologiral Society, v. 88 , p. $485-495$.

Rinehart, R.E., 1991, Radar for Meteorologists, University of North Dakota, Grand Forks.

Rose, W.I., and Kostinski, A.B., 1994, Radar remote sensing of volcanic clouds, in Casadevall, T., ed., Proceedings of the First International Symposium on Volcanic Ash and Safety: U.S. Geological Survey Bulletin 2047, p. 391-396.

Sauvageot, H., 1992, Radar Meteorology, Artecr House.

Schneider, D., and Rose, W.I., 1994, Observations of the 1989-90 Redoubt Volcano eruption clouds us ing AVHRR satellite imagery, in Casadevall, T., ed., Proceedings of the First International Symposium on Volcanic Ash and Aviation Safety: U.S. Geological Survey Bulletin 2047, p. 405-418.

Serafin, R.J., 1990, Meteorological Radar, in Skolnik, M., Radar Handbook, 2d ed.: New York, McGraw-Hill, p. 23.1-23.33.

Wilson, L., Sparks, R.S.J., Huang, T.C., and Wa+kins, N.D., 1978, The control of volcanic column heights by eruption energetics and dynamics: Journal of Geophysical Research, v. 83, p. 1829-1836. 


\title{
Tracking of 1992 Eruption Clouds from Crater Peak Vent of Mount Spurr Volcano, Alaska, Using AVHRR
}

\author{
By David J. Schneider, William I. Rose, and Lee Kelley
}

\section{CONTENTS}

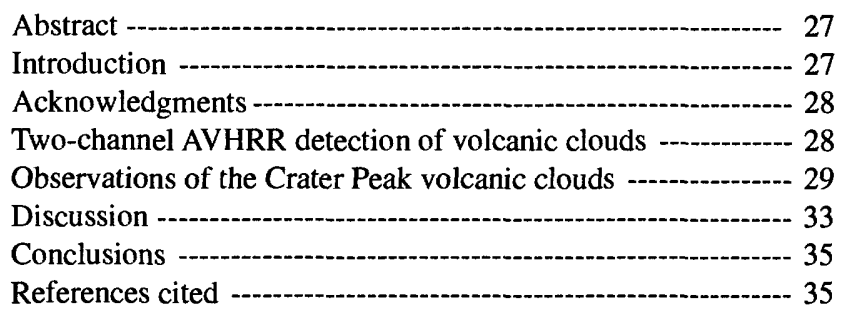

\begin{abstract}
The 1992 Crater Peak vent eruptions of Mount Spurr provided a robust test of the new High Resolution Picture Transmission (HRPT) Information Processing System (HIPS), which was installed in Anchorage for real-time tracking of volcanic clouds. One principle objective of the tracking system is to avoid aviation hazards. The system receives Advanced Very High Resolution Radiometer (AVHRR) images from polar-orbiting satellites and processes them using a two-channel technique. The resulting processed imagery reflects the extensive real-time capability now available. The frequency of data collection (about once every few hours) allows for an understanding of the patterns of change in spectral response that occur during the evolution of a volcanic cloud. Volcanic clouds imaged during and shortly after eruption are optically thick and can contain abundant water droplets and (or) ice, and these characteristics cause their spectral signal to closely resemble a meteorological cloud. As the volcanic cloud disperses, the spectral properties of the cloud change, first at the edge and then throughout. These changes produce a volcanic cloud signal that can be distinguished by using a brightness temperature difference determined from thermal bands 4 and 5 of the AVHRR. The usefulness of this technique of tracking clouds for long distances was investigated using archived data. Two clouds were tracked for more than 80 hours and thousands of kilometers, during which the band 4 minus 5 brightness tempera-
\end{abstract}

ture signal decayed. These clouds traveled southward over the continental United States and posed a potential hazard to aircraft. To alleviate this potential hazard, the measurable brightness temperature difference signal needs to be correlated with ash concentation and particle size to determine when drifting volcanic clouds are a threat to aircraft.

\section{INTRODUCTION}

Since 1986, three volcanoes (Augustine Volcano, Redoubt Volcano, and Mount Spurr) have erup+ed in the Cook Inlet area of Alaska. Each of these eruptions has had a significant impact on commercial aviation at Anchorage. The National Weather Service has greatly improved its capability to measure and track ash clouds in order to better advise the aviation community about the location of hazardous ash clouds. Two significant improvements, which were made following the Redoubt activity in 1989-90, were the installation of a High Resolution Picture Transmission (HRPT) Information Processing System (HIPS) workstation for rapid digital-image processing of Advanced Very High Resolution Radiometer (AVHRR) data from polar-orbiting weather satellites, and the leasing of a meteorological $\mathrm{C}$-band radar. Weather satellite data have been used by many investigators to observe ash clouds (Hanstrum and Watson, 1983; Matson, 1984; Sawada, 1987; Prata, 1989; Holasek and Rose, 1991; Schneider and Rose, 1994) but until now, real-time analysis of processed images has been difficult.

The AVHRR data complement the radar observations because the radar can map clouds near the volcano, within minutes of eruption (Rose and others, this volume), while the AVHRR can track the clouds for up to several days. Three eruptions of the Crater Peak vent of Mount Spurr provided a real-time test of the equipment's ability to detect and man significant ash clouds. The results obtained with the new HIPS workstation equipment, and the results obtained on the long-range tracking of the cloud over North America using archived AVHRR data are described herein. 


\section{ACKNOWLEDGMENTS}

Funding for this research came from the cooperative program for operational meteorology education and training (COMET): a cooperative agreement between the National Weather Service and the University Corporation for Atmospheric Research, and from NASA grants NAG5-1838 and NAG5-1873. We thank Gary Hufford, Craig Bauer, Joel Curtis, and Ray Moore from the NWS office in Anchorage, all of whom contributed their ideas and energy to this project; George Stephens from NOAA/NESDIS in Washington D.C., who provided the archived data; Dennis Krohn, Rick Holasek, and Libby Titus, who reviewed the manuscript; and Robert Landsparger, who provided computer support.

\section{TWO-CHANNEL AVHRR DETECTION OF VOLCANIC CLOUDS}

AVHRR satellite data are received from the NOAA 11 and 12 polar-orbiting satellites at the National Weather Service Forecast Offices in Anchorage, Alaska, through the HIPS system and is linked to meteorologist workstations in forecast offices of the Alaska Region Operations Network. Full passes (4.4-km resolution) over active volcanoes are available as soon as 10 minutes after pass completion, with subsectors (1.1$\mathrm{km}$ resolution) available within 40 minutes. All five spectral bands, from visible to thermal infrared, are received (band 1: 0.58-0.68 $\mu \mathrm{m}$; band 2: 0.73-1.10 $\mu \mathrm{m}$; band 3: 3.55-3.93 $\mu \mathrm{m}$; band $4: 10.3-11.3 \mu \mathrm{m}$; and band 5: $11.5-12.5 \mu \mathrm{m})$. Satellite coverage extends from the western edge of the Kamchatka Peninsula to east of British Columbia; this coverage encompasses four major air routes near the volcanoes of Alaska and Kamchatka. Because of orbital irregularities and the movement of volcanic clouds, coverage frequency is variable and gaps as long as 8 hours can occur.

We used band 4 minus band 5 brightness temperature difference images to detect volcanic clouds, and to distinguish them from meteorological clouds. Thermal data from bands 4 and 5 were converted from raw sensor counts to radiance, using the technique of Lauritson and others (1988). A slight nonlinearity in bands 4 and 5 was corrected using a quadratic function of radiance. The radiance values were converted into brightness temperature values, using the inverse Planck function, and band 4 minus 5 brightness temperature images were created. Volcanic clouds are known to have negative band 4 minus 5 brightness temperature differences (Prata, 1989; Schneider and Rose, 1994), whereas meteorological clouds generally have positive brightness temperature differences (Yamanouchi and others, 1987). For volcanic clouds, the magnitude of the negative brightness temperature difference depends on many characteristics. These characteristics include the optical thickness of the cloud; amounts of water, volcanic ash, and sulfuric acid in the cloud; mean size and size distribution of particles in the cloud; and temperature contrast botween the cloud and the underlying surface (meteorological clouds, land, or water) (Prata, 1989; Wen and Rose, 1994).

The volcanic cloud signal detected by the brightness temperature difference method has well-defined edges, which allow us to define the area of the cloud. Cross sections through volcanic clouds show a clearly defined edge at a brightness temperature difference value of $-0.5^{\circ} \mathrm{C}$ (fig. 1). The ability to detect cloud edges is important in reducing aircraft hazards, because it is a snapshot of cloud position that can be quickly reported. It also serves as a periodic check on the trajectory models for the ash cloud.

Table 1. List of AVHRR images used for this study showing date and time of satellite coverage, hours sine start of eruption, and satellite used.

\begin{tabular}{|c|c|c|}
\hline Time (UT) & $\begin{array}{c}\text { Hours since start of } \\
\text { eruption }\end{array}$ & Sat lllite \\
\hline \multicolumn{3}{|c|}{ August 19, 1992} \\
\hline $01: 26$ & 1.5 & NOA A-11 \\
\hline $03: 38$ & 3.6 & NOA A-11 \\
\hline $05: 10$ & 5.2 & NOA A-12 \\
\hline $13: 38$ & 13.6 & NOA A-11 \\
\hline $17: 20$ & 17.3 & NOA A-12 \\
\hline $18: 57$ & 18.9 & NOA A-I 2 \\
\hline $23: 30$ & 23.1 & NOA A-I1 \\
\hline \multicolumn{3}{|c|}{ August 20, 1992} \\
\hline $13: 23$ & 37.4 & NOAA-11 \\
\hline $23: 15$ & 47.3 & NOAA-11 \\
\hline \multicolumn{3}{|c|}{ August 21, 1992} \\
\hline 23:00 & 71.0 & NOAA-11 \\
\hline \multicolumn{3}{|c|}{ August 22, 1992} \\
\hline $11: 21$ & 83.4 & NOAA-11 \\
\hline \multicolumn{3}{|c|}{ September 17, 1992} \\
\hline $12: 40$ & 3.7 & NOAA-11 \\
\hline 17:00 & 8.0 & NOAA-11 \\
\hline $22: 44$ & 13.7 & NOAA-11 \\
\hline \multicolumn{3}{|c|}{ September 18, 1992} \\
\hline $11: 00$ & 26.0 & NOAA-11 \\
\hline $20: 45$ & 35.7 & NOAA-11 \\
\hline \multicolumn{3}{|c|}{ September 19, 1992} \\
\hline $09: 00$ & 49.0 & NOAA-11 \\
\hline $18: 53$ & 57.9 & NOAA-11 \\
\hline \multicolumn{3}{|c|}{ September 20, 1992} \\
\hline $07: 00$ & 70.0 & NOAA-11 \\
\hline $17: 04$ & 80.1 & NOAA-11 \\
\hline
\end{tabular}




\section{OBSERVATIONS OF THE CRATER PEAK VOLCANIC CLOUDS}

Eleven images of the volcanic cloud resulting from the August 18, 1992, eruption of Crater Peak and nine images of the volcanic cloud from the September 16-17, 1992, eruption were analyzed for this study (table 1). The evolution of the volcanic cloud signal can be seen in figure 2 , a series of images col- lected by the HIPS system of the August 18 volcanic cloud. The earliest image, collected about 90 minutes after the start of the eruption (fig. $2 A$ ), shows a cold, circular volcanic cloud in band 4 and high thermal contrast between the volcanic cloud and the lower, warmer meteorological clouds. The band 4 minus band 5 brightness temperature difference algorithm does not work well on this image (fig. $2 B$ ). The second image in this series was collected 2 hours later and shows a
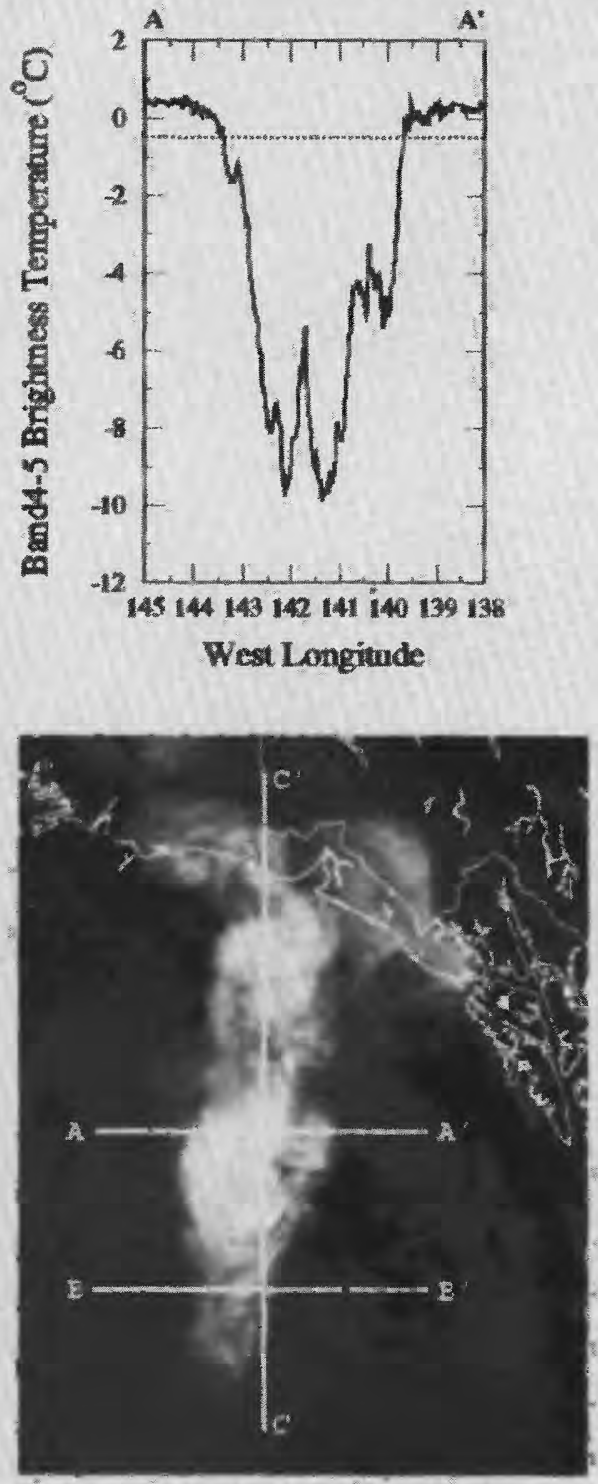

AVHRR Band 4-5
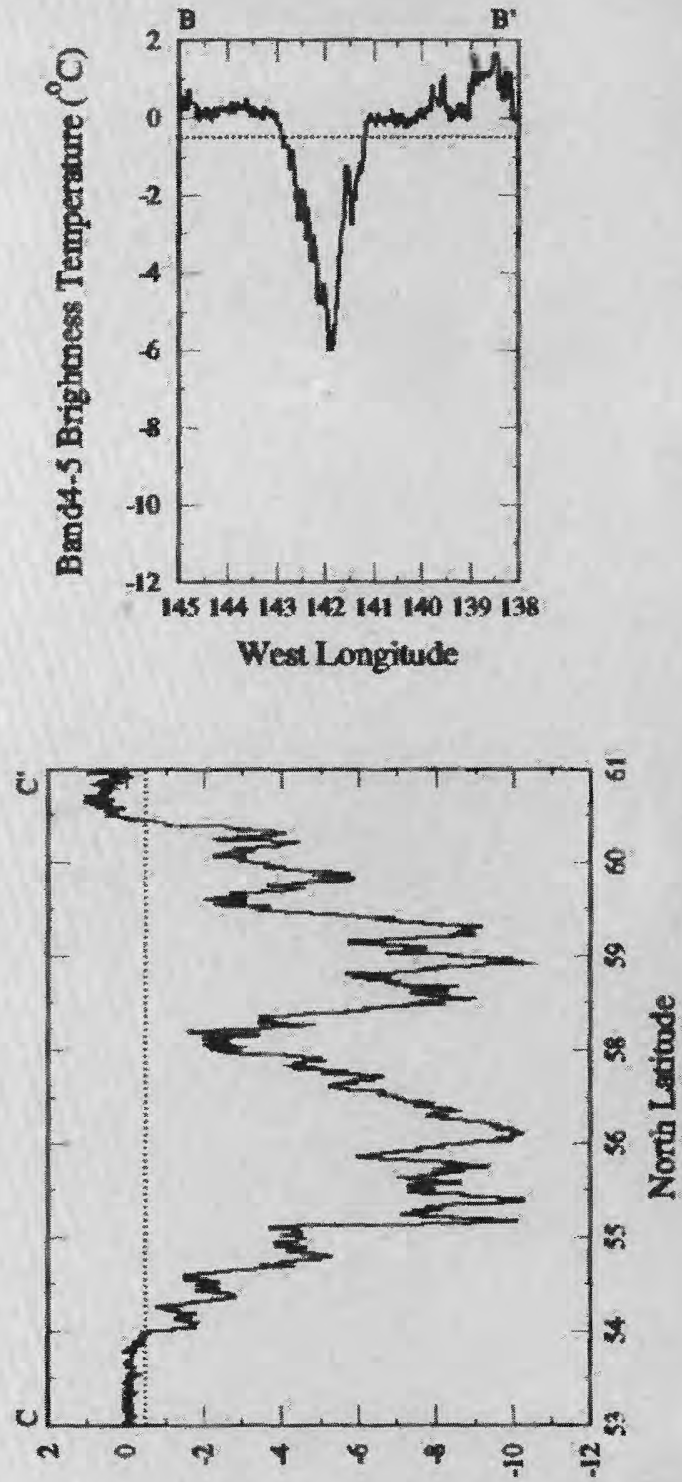

Band4-5 Brightness Temperature ( $\left.{ }^{\circ} \mathrm{C}\right)$

Figure 1. Cross sections through a band 4 minus band 5 image that compare brightness temperature difference of a volcanic cloud to those of meteorological clouds. Interior volcanic cloud shown has negative band 4 minus band 5 brightness temperature differences as large as $-14^{\circ} \mathrm{C}$, whereas meteorological clouds, land, and open water generally have brightness temperature differences greater than zero. Dotted line at $-0.5^{\circ} \mathrm{C}$ shown for reference. 

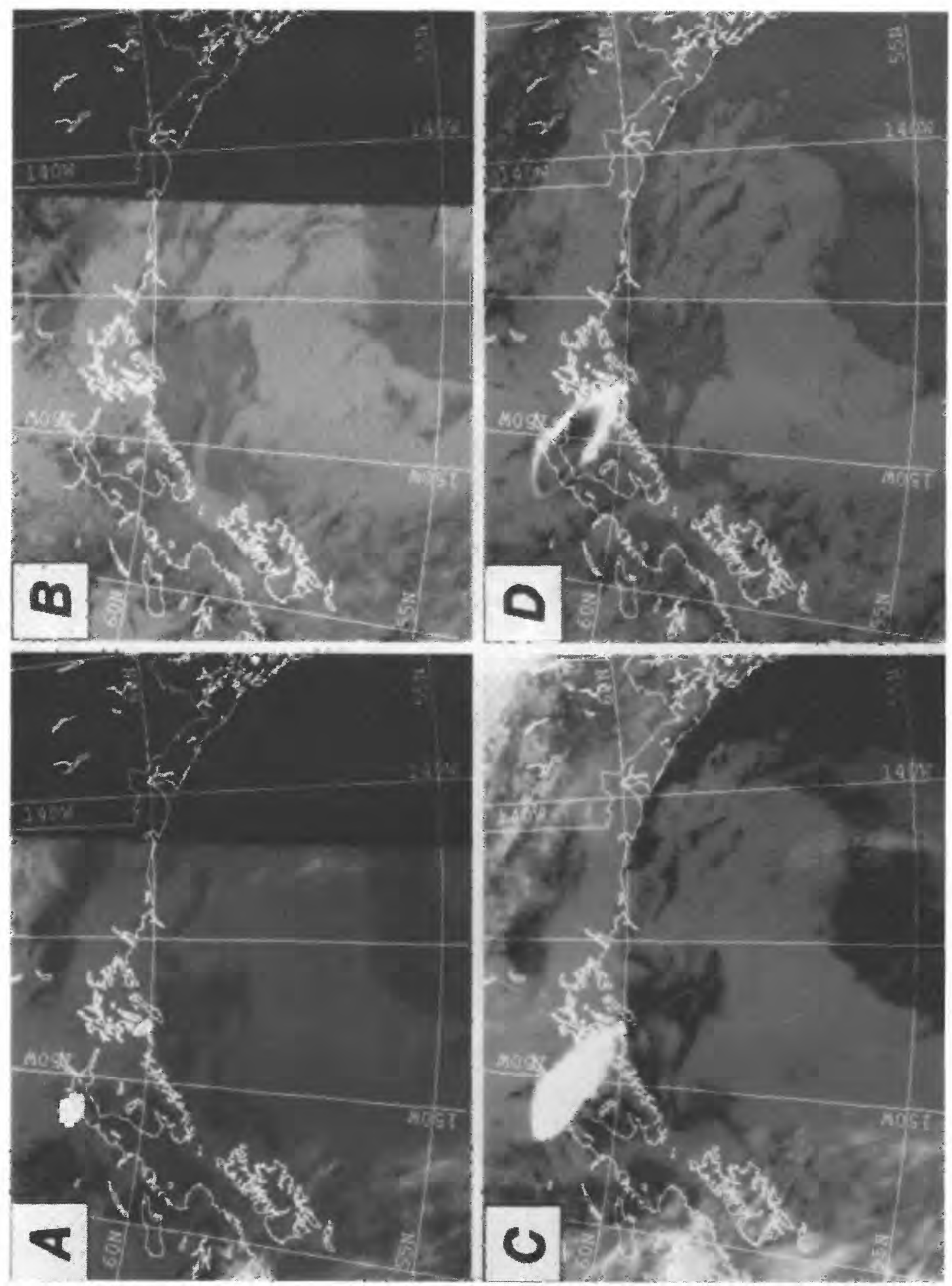

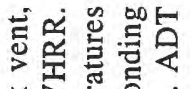

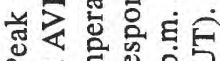

记 的的管

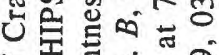

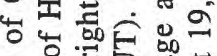
든 응유 익를 记 웜의

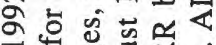
-

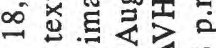
岛证 品的可记

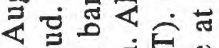
등 는 뭉요

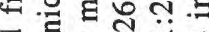

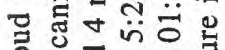
응 항 응

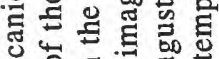

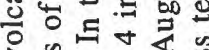

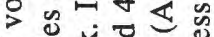
论式总比 ह 웅 定要

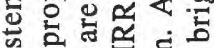

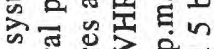

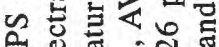
完总导 气 छ 出范焉品 可哭

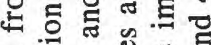

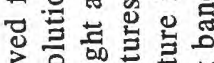

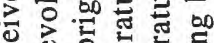

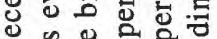

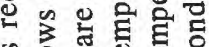
过

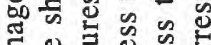

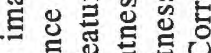
政 声导可 4 的宫它.

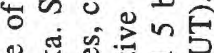
造䓵宁 娄节品骂 ज्षे व के

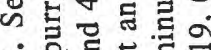
त

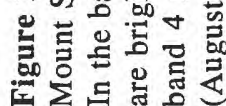



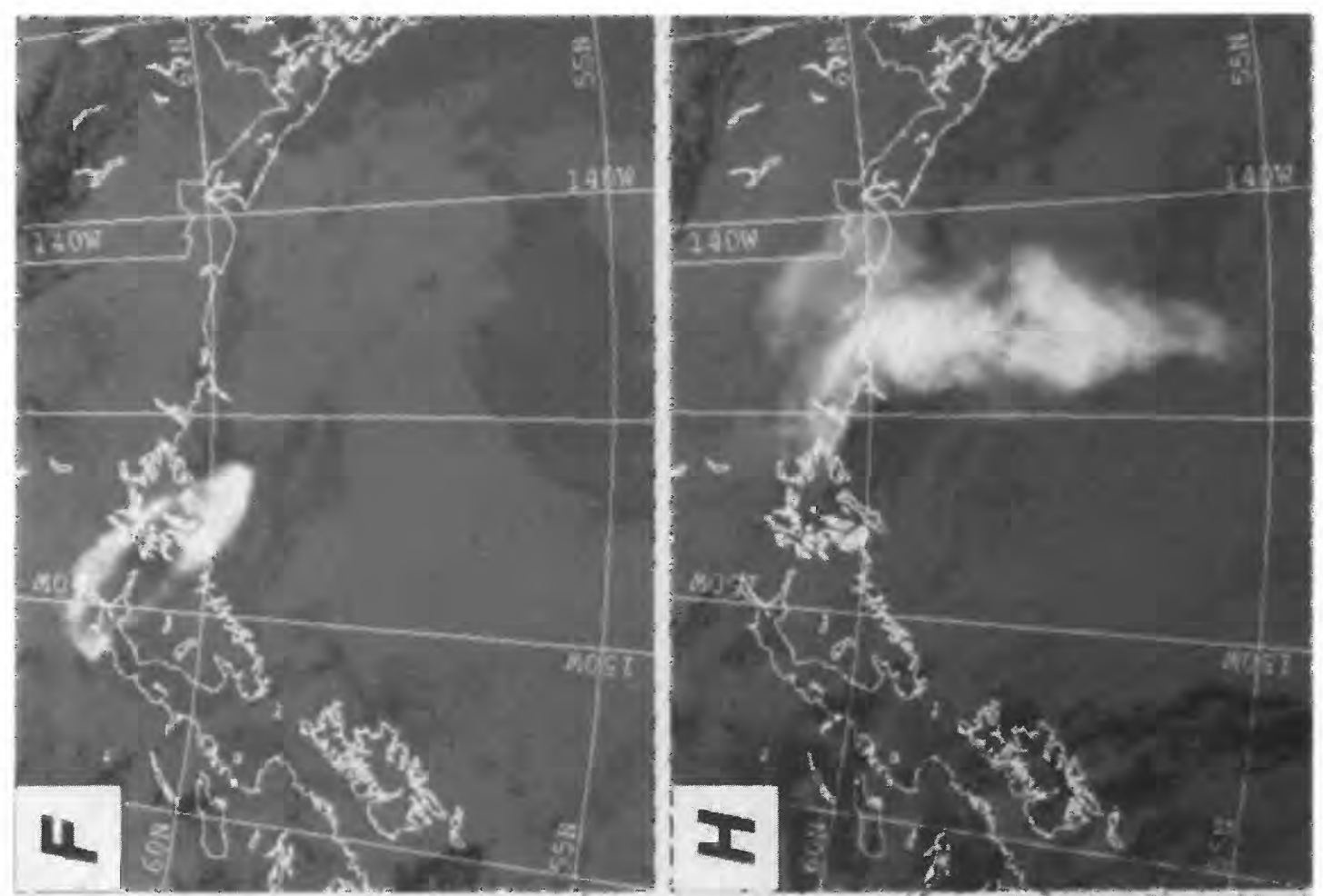

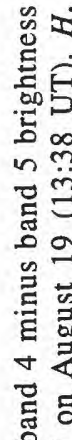

它官

島

홈

品

$\mathcal{O}$ in

过的葋

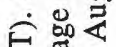

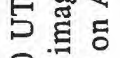

아

$\ddot{8}$ 它是

จำ घ

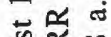

产兄

焉的
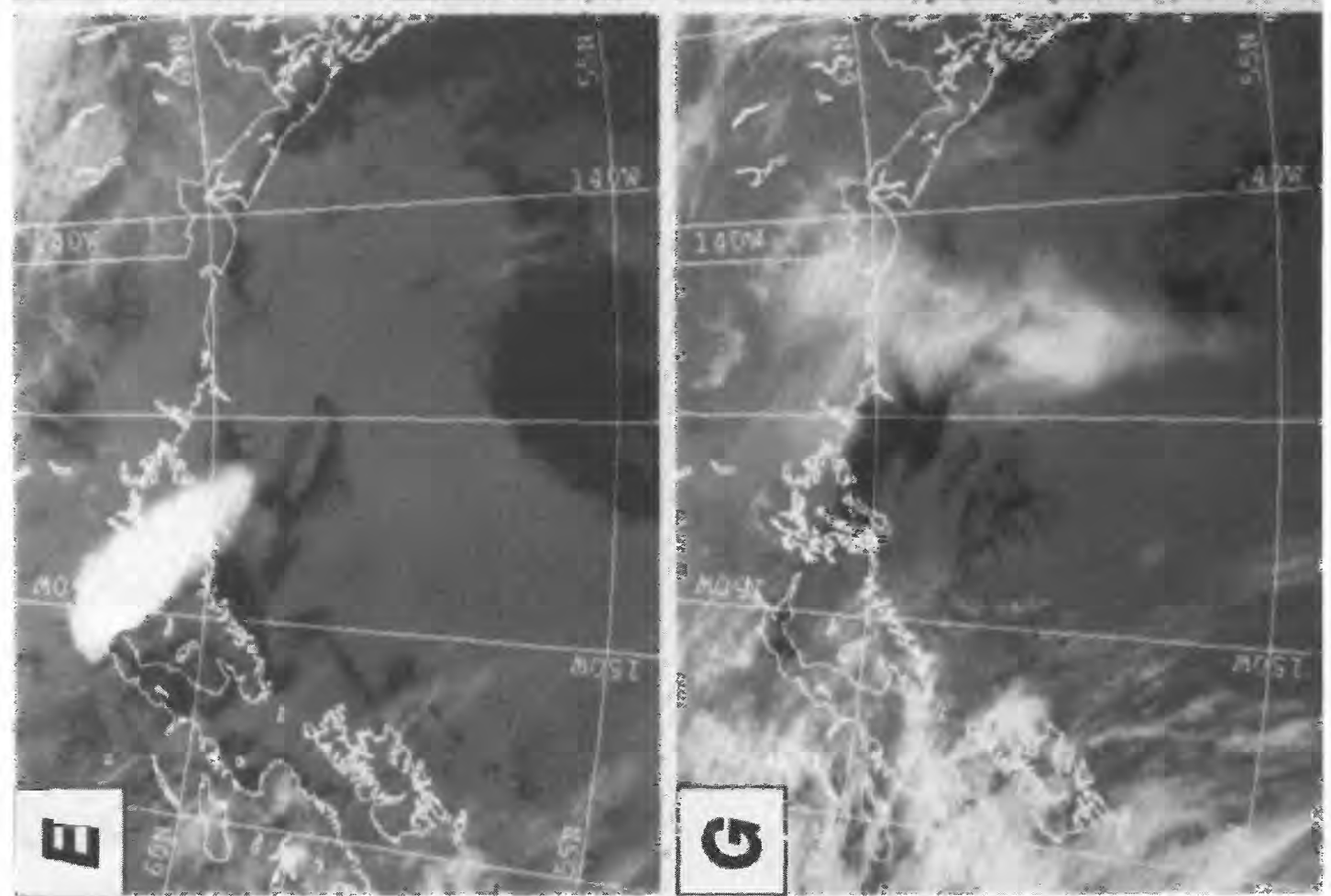

它范

安官节

它宁

두으 를

융

ส

品

马ू

$\checkmark$ 运要

동

0 元。

동

क

<०

의

एं है

品 뮴

ह.

U.

글

논

昫总它

诖 


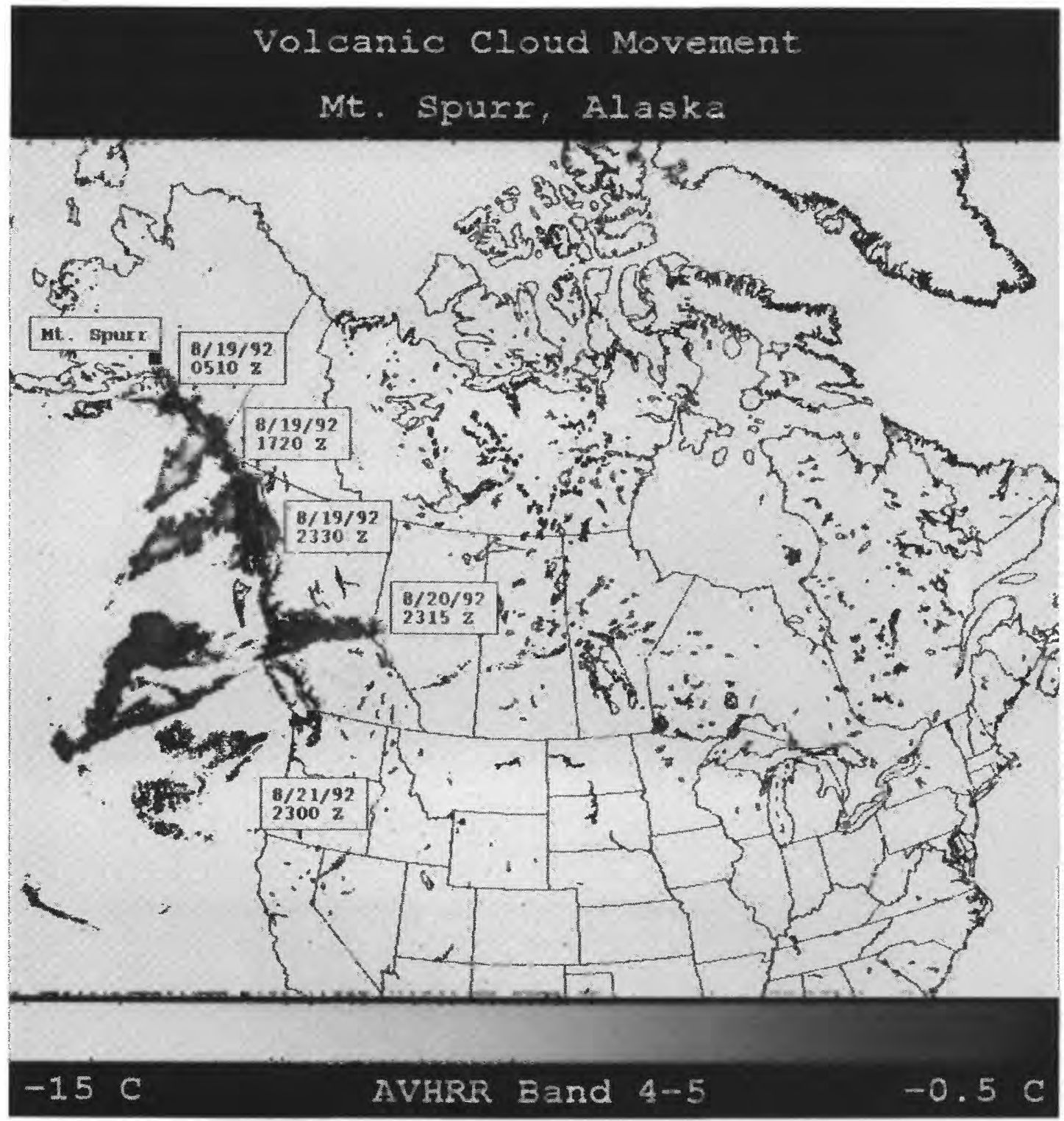

Figure 3. Composite of five band 4 minus band 5 images, showing the long-distance transport of the August 18, 1992, volcanic cloud from the Crater Peak vent of Mount Spurr, Alaska. This cloud was detected in 11 images, but for clarity, only five images are shown. Alaska daylight time equals $\mathrm{Z}$ (same as UT) - 8 hours.

larger cloud in the band 4 image (fig. $2 C$ ) and a fringing response from the band 4 minus band 5 process (fig. $2 D$ ). The third image (fig. $2 E$ ) was collected 90 minutes later. By this time the eruption had ended, and the fringe of negative band 4 minus band 5 values had grown and encircled the entire volcanic cloud (fig. $2 F$ ). The fourth image was collected 8 hours later. The volcanic cloud is difficult to distinguish from the meteorological clouds in the band 4 image (fig. $2 G$ ), but it is easily distinguished on the band 4 minus 5 image (fig. $2 \mathrm{H}$ ) in which the entire cloud shows negative brightness temperature difference values.
The utility of the band 4 minus band 5 operation to track clouds for days following an eruption was tested using two archived AVHRR data sets. A composite of five images of the August volcanic cloud is shown in figure 3 , and a composite of nine images of the September volcanic cloud is shown in figure 4 . In these images, only the pixels with negative band 4 minus band 5 brightness temperature values are shown. Because many factors affect the magnitude of the negative brightness temperature difference, the regions of the cloud with the greatest temperature difference do not necessarily have the highest concentration of particles. 


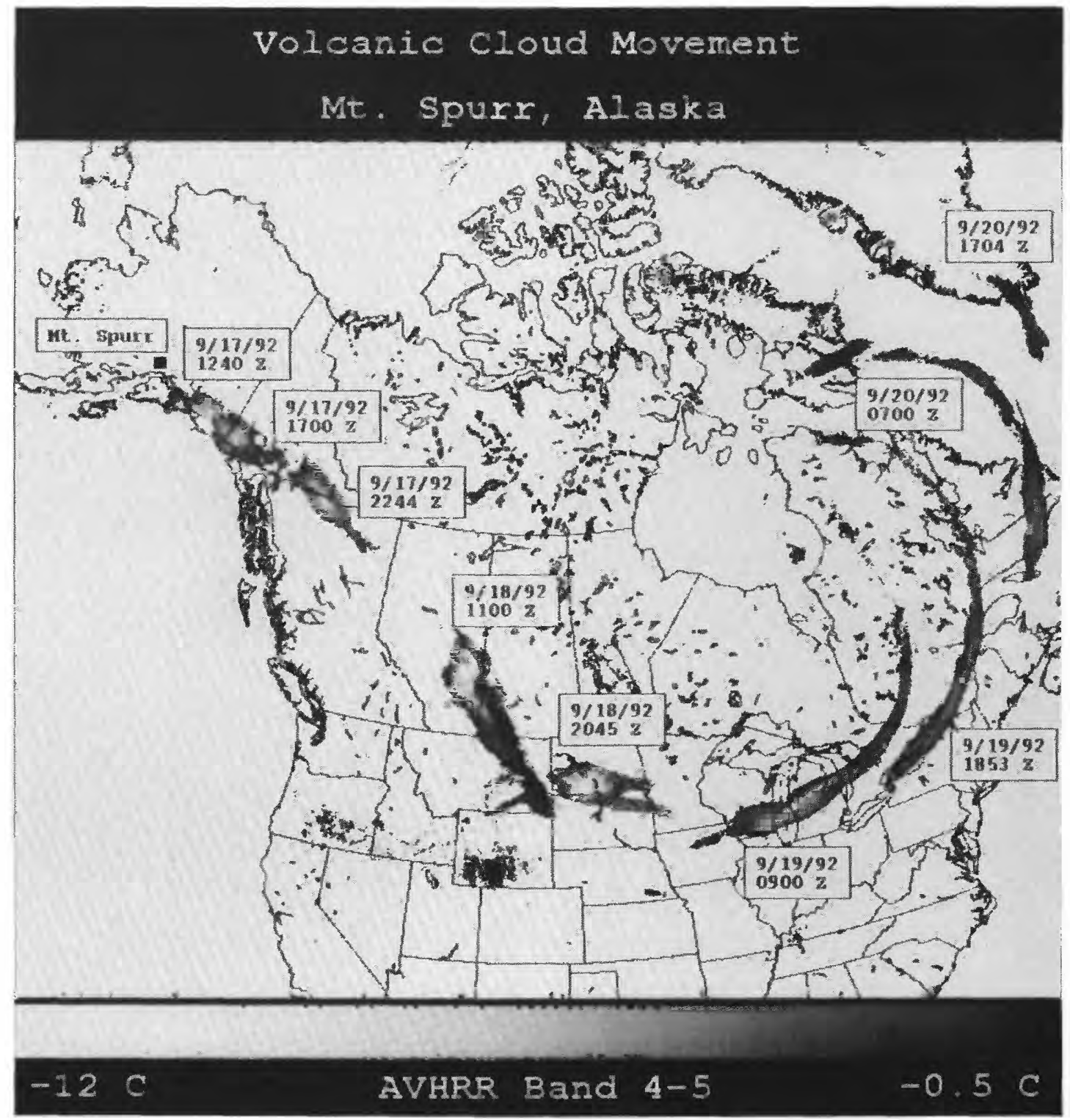

Figure 4. Composite of nine band 4 minus band 5 images, showing the long-distance transport of the September 16-17, 1992, volcanic cloud from the Crater Peak vent of Mount Spurr, Alaska. Alaska daylight time equals $\mathrm{Z}$ (same as UT) - 8 hours.

The detected area of the August cloud increased during the first 47 hours at a rate of $13,000 \mathrm{~km}^{2} / \mathrm{hr}$ and reached a maximum area of about $600,000 \mathrm{~km}^{2}$. The detected area of the September cloud increased at an average rate of $12,000 \mathrm{~km}^{2} / \mathrm{hr}$ during the first 26 hours and reached a maximum area of 310,000 $\mathrm{km}^{2}$ (fig. $5 A$ ). The leading edge of the August cloud moved about $3,000 \mathrm{~km}$ in 83 hours for an average velocity of $36 \mathrm{~km} / \mathrm{hr}$, and the leading edge of the September cloud moved about $4,400 \mathrm{~km}$ in 36 hours for an average velocity of $120 \mathrm{~km} / \mathrm{hr}$ (fig. $5 B$ ). For both clouds, the magnitude of the negative band 4 minus band 5 brightness temperature difference first increased and then decreased during the cloud evolution (fig. $5 \mathrm{C}$ ).

\section{DISCUSSION}

The sequence of images of the Crater Peak volcanic clouds defined the evolution of the spectral properties of volcanic clouds better than any previous observations. Volcanic cloud optical thickness is a critical parameter in distinguishing volcanic clouds. Opaque volcanic clouds (optical thickness $=\infty$ ) have positive band 4 minus band 5 brightness temperature values, and transparent volcanic clouds have negative band 4 minus band 5 brightness temperature values (Prata, 1989). The transition from the opaque stage to the transparent stage is seen in images of the August 18, 1992, cloud (fig. 2). 

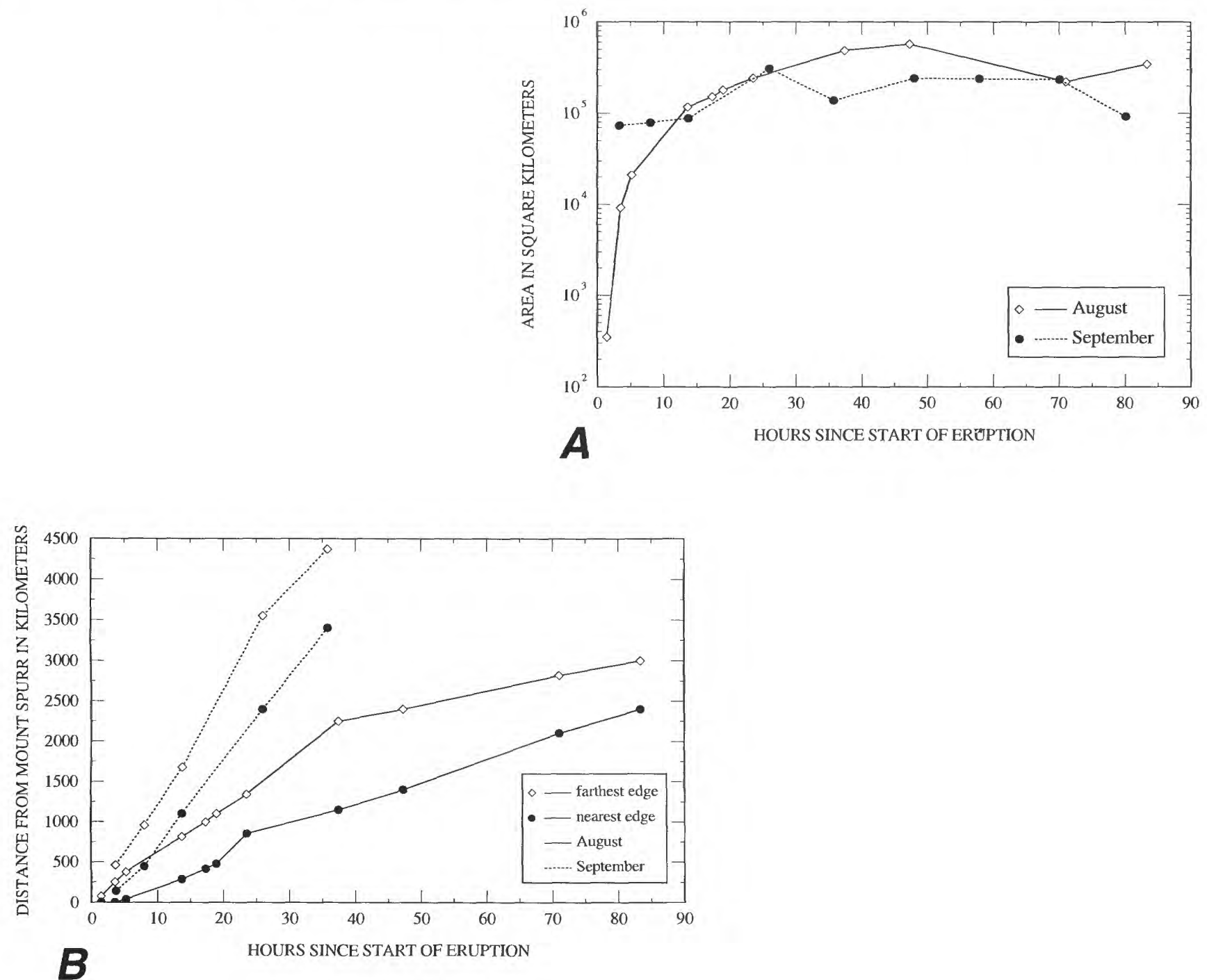

$B$

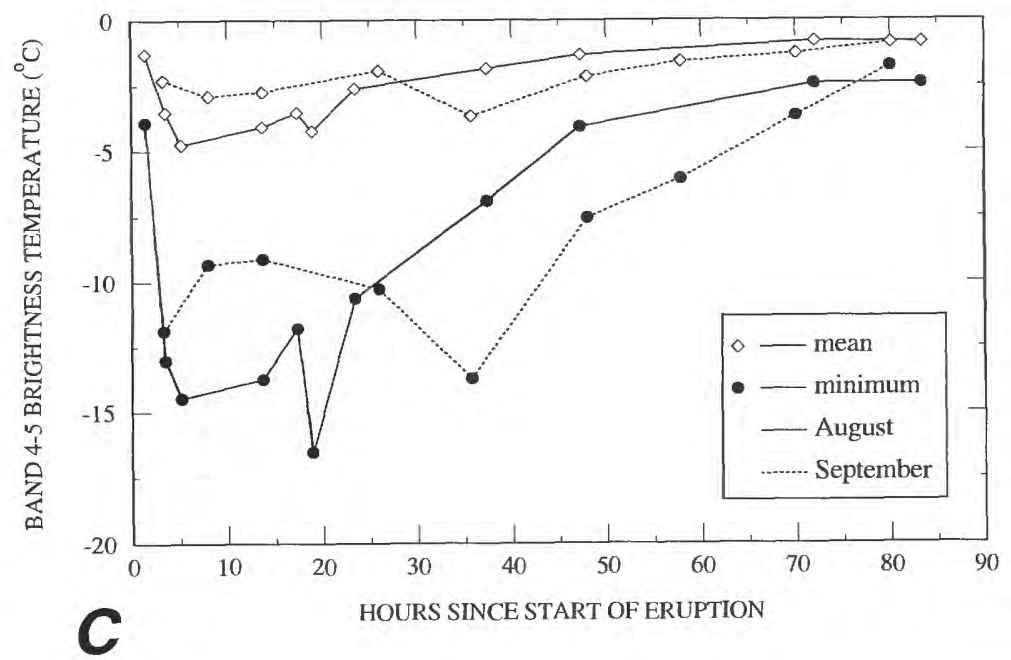

Figure 5. Changes, which occurred during transport, in the August 18 and September 16-17 volcanic clouds from the 1992 eruptions of Crater Peak vent, Mount Spurr, Alaska. A, Volcanic cloud area. B, Distance cloud was transported from the volcano. $C$, Brightness temperature differences calculated from bands 4 and 5 of AVHRR. Mean temperature of entire cloud and minimum value of each cloud are shown. See text for definition of AVHRR. 
Initially, the volcanic cloud is infused with water vapor from entrainment of moist lower tropospheric air. The formation of water droplets and ice crystals produce an opaque cloud (fig. $2 A$ ), which is spectrally similar to meteorological clouds in the band 4 minus 5 image (fig. $2 B$ ). As the cloud ages, it disperses along its perimeter to produce a transparent fringe. The transparent portion of the cloud has negative band $4 \mathrm{mi}-$ nus band 5 brightness temperature values, which are depicted as bright white regions, while the opaque core has positive values, which are depicted as dark gray regions (fig. $2 D$ ). The fringe of negative values grows and the core of positive values shrinks as dispersion proceeds (fig. $2 F$ ). This continues until the entire cloud is transparent and has negative band 4 minus band 5 values (fig. $2 H$ ). As the opaque area of the cloud decreases, the magnitude of the brightness temperature difference increases and then decreases as the cloud becomes more transparent over time (fig. $5 C$ ).

Because the band 4 minus band 5 algorithm only discriminates transparent volcanic clouds, the magnitude of the brightness temperature difference and the area of the detected cloud are influenced by the temperature of the surface underlying the volcanic cloud. The detected area of the volcanic cloud becomes discontinuous, and the magnitude of the brightness temperature difference decreases when it overlies cold meteorological clouds (see fig. 3, 8/21/92 at 23:00 UT). However, the magnitude of the temperature difference increases when a cloud overlies a warm land surface (see fig. 4, 9/18/92 at 20:45 UT). The brightness temperature difference continues to decrease until the particle concentrations are so low that the cloud is undetectable by this technique. Because several factors affect the discrimination of volcanic clouds, the minimum detectable particle concentration cannot be directly related to brightness temperature difference values.

The signal detected with the band 4 minus band 5 brightness temperature difference needs to be linked to aircraft hazard, possibly through a radiative transfer model, which can quantify the brightness temperature difference values and estimate particle size and burden (Wen and Rose, 1994). Validation of radiative transfer models could be accomplished by direct sampling of a cloud throughout its evolution.

\section{CONCLUSIONS}

AVHRR data were successfully analyzed to detect and track the position of volcanic clouds during the Crater Peak eruptions of 1992, using a new capability of the National Weather Service in Anchorage. By detecting the volcanic clouds for longer periods of time, AVHRR complements the C-band radar sys- tem employed by the NWS to image the volcanic clouds near the volcano in their first 30 minutes. Analyses of archived AVHRR data show that the volcanic clouds can be detected and tracked for several days following their eruption and throughout several thousands of kilometers of transport.

An algorithm based on a brightness temperature difference from the thermal infrared bands 4 and 5 of the AVHRR was used. A detailed sequence of images from the August eruption defined the evolution of the spectral properties of volcanic clouds better than any previous observations. The brightness temperature difference signal changes as the cloud evolves. It is more enhanced in the first few hours after the cloud forms and becomes transparent, and then it slowly decays to background values over the next few days. Because the magnitude of the brightness temperature difference is also affected by the temperature of the surface beneath the volcanic cloud, regions with the greatest temperature difference do not necessarily have the highest particle concentration.

Two of the Crater Peak clouds dispersed in the direction of the continental United States, raising the issue of whether Alaskan eruptions could pose hazards to principal domestic air routes in North America. Because the volcanic clouds were readily detectable when they crossed the continental United States, realtime processing of AVHRR data could have provided information to air traffic control outside Alaska. We need to calibrate the temperature difference signal to understand when volcanic clouds may be hazardous.

\section{REFERENCES CITED}

Hanstrum, B.N., and Watson, A.S., 1983, A case study of two eruptions of Mount Galunggung and an investigation of volcanic cloud characteristics using remote sensing techniques: Australian Meteorological Magazine, v. 31, p. 171-177.

Holasek, R.E., and Rose, W.I., 1991, Anatomy of 1986 Augustine Volcano eruptions as recorded by multispectral image processing of digital AVHRR weather satellite data: Bulletin of Volcanology, v. 53, p. 420-435.

Lauritson, L., Nelson, G.J. and F.W. Porto, 1988, Data extraction and calibration of TIROS-N/NOAA radiometers, in Planet, W.G., ed., NOAA Technical Memorandum NESS 107-Rev. 1, Washington, D.C., p. 119.

Matson, M., 1984, The 1982 El Chichón volcano eruptions-A satellite perspective: Journal of Volcanology and Geothermal Research v. 23, p. 1-10.

Sawada, Y., 1987, Study on analysis of volcanic eruptions based on eruption cloud image data obtained by the Geostationary Meteorological Satellite (GMS): Technological Report of Meteorological Research Institute (Japan) 22.

Schneider, D.J., and Rose, W.I., 1994, Observations of the 198990 Redoubt volcano eruption clouds using AVHRR satellite imagery, in Casadevall, T.J., ed., Proceedings of the First 
International Symposium on Volcanic Ash and Aviation Safety: U.S. Geological Survey Bulletin 2047, p. 405-418.

Prata, A.J., 1989, Infrared radiative transfer calculations for volcanic ash clouds: Geophysical Research Letters, v. 16, p. 12931296.

Wen, S., and Rose, W.I., 1994, Retrieval of sizes and total masses of particles in volcanic clouds using AVHRR bands 4 and 5: Journal of Geophysical Research, v. 99, p. 5421-5431.

Yamanouchi, T., Suzuki, K., and Kawaguchi, S., 1987, Detection of clouds in Antarctica from infrared multispectral data of AVHRR: Journal of the Meteorological Society of Japan, v. 65 , p. 949-961. 


\title{
Explosive Emissions of Sulfur Dioxide from the 1992 Crater Peak Eruptions, Mount Spurr Volcano, Alaska
}

\author{
By Gregg J.S. Bluth, Courtney J. Scott, Ian E. Sprod, Charles C. Schnetzler, Arlin J. Krueger, \\ and Louis S. Walter
}

\section{CONTENTS}

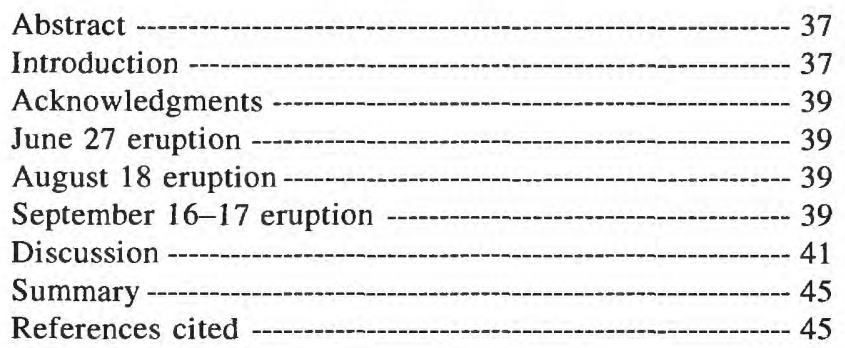

\begin{abstract}
Sulfur dioxide clouds from three explosive eruptions of Crater Peak vent of Mount Spurr during the Summer of 1992 were detected, tracked, and measured by NASA's Total Ozone Mapping Spectrometer (TOMS). From the TOMS data we calculated that the August 18 eruption produced the largest sulfur dioxide emission of the three events at $400 \pm 120$ kilotons (kt) $\mathrm{SO}_{2}$, followed by the September 16-17 and June 27 eruptions $(230 \pm 70 \mathrm{kt}$ and $200 \pm 60$, respectively). The June $\mathrm{SO}_{2}$ plume remained primarily over eastern Alaska and Canada's Yukon province, and it was observed by TOMS for 7 days. The August cloud drifted southeast along Canada's Pacific coast before being carried eastward, and after 8 days it was finally viewed passing over England. The September cloud traveled the most rapidly of the three: southeast across Canada and the northern United States, then northeast over Toronto, and finally over Greenland 5 days later. TOMS data for the August and September eruptions revealed that the two gas plumes increased in $\mathrm{SO}_{2}$ amounts over the first 2 days - well after the eruptions had ceased. The TOMS data and other available evidence suggest that significant quantities of hydrogen sulfide, in addition to sulfur dioxide, may have been explosively outgassed by these two eruptions. The maximum injection altitudes of the ash clouds, matching of $\mathrm{SO}_{2}$ cloud positions to known wind con-
\end{abstract}

ditions, and the dispersion rates of the gas clouds all suggest that at least half of the sulfur dioxide emitted by the Crater Peak eruptions reached the lower stratosphere.

\section{INTRODUCTION}

Mount Spurr, Alaska $\left(61^{\circ} 30^{\prime} \mathrm{N}, 152^{\circ} 25^{\prime} \mathrm{W}\right)$ had been inactive since 1953 but during the Summer of 1992 erupted violently three times and sent large amounts of ash and gas into the atmosphere. Because of prevailing meteorological conditions, each eruption cloud followed unique dispersal paths. The $\mathrm{SO}_{2}$ produced by these three eruptions was observed by the Total Ozone Mapping Spectrometer (TOMS), on board NASA's Nimbus-7 satellite. We used the TOMS data to analyze the eruption clouds for their $\mathrm{SO}_{2}$ contents, areal extents, and dispersion patterns.

The Nimbus-7 satellite is in a polar sun-synchronous orbit and crosses the equator every 26 degrees $(2,800 \mathrm{~km})$ of longitude at local noon, observing the whole Earth once a day (13.7 orbits per day). Scans consisting of 35 data scenes cover the 2,800-km-wide orbit swaths; each scan takes about 8 seconds to complete. The ground resolution of the TOMS ranges from $50 \mathrm{~km}$ at nadir to approximately $200 \mathrm{~km}$ at the orbit edges (average resolution is $66 \mathrm{~km}$ ). The TOMS instrument has provided global $\mathrm{SO}_{2}$ and ozone data since late 1978 by measuring the ultraviolet albedo, which is the ratio of backscattered Earth radiance to incoming solar irradiance (Krueger, 1983). The amount of $\mathrm{SO}_{2}$ is calculated on the basis of characteristic attenuation of the ultraviolet signal. The TOMS instrument gives no direct indications of $\mathrm{SO}_{2}$ cloud altitude; altitude can be derived by comparison of cloud movement to known or modeled wind velocity and directions (see Schoeberl and others, 1993).

Sulfur dioxide concentrations are calculated in milli-atmosphere centimeters (matm-cm), which express the column thickness of the gas at standard temperature and pressure (STP). The tonnage of $\mathrm{SO}_{2}$ over 

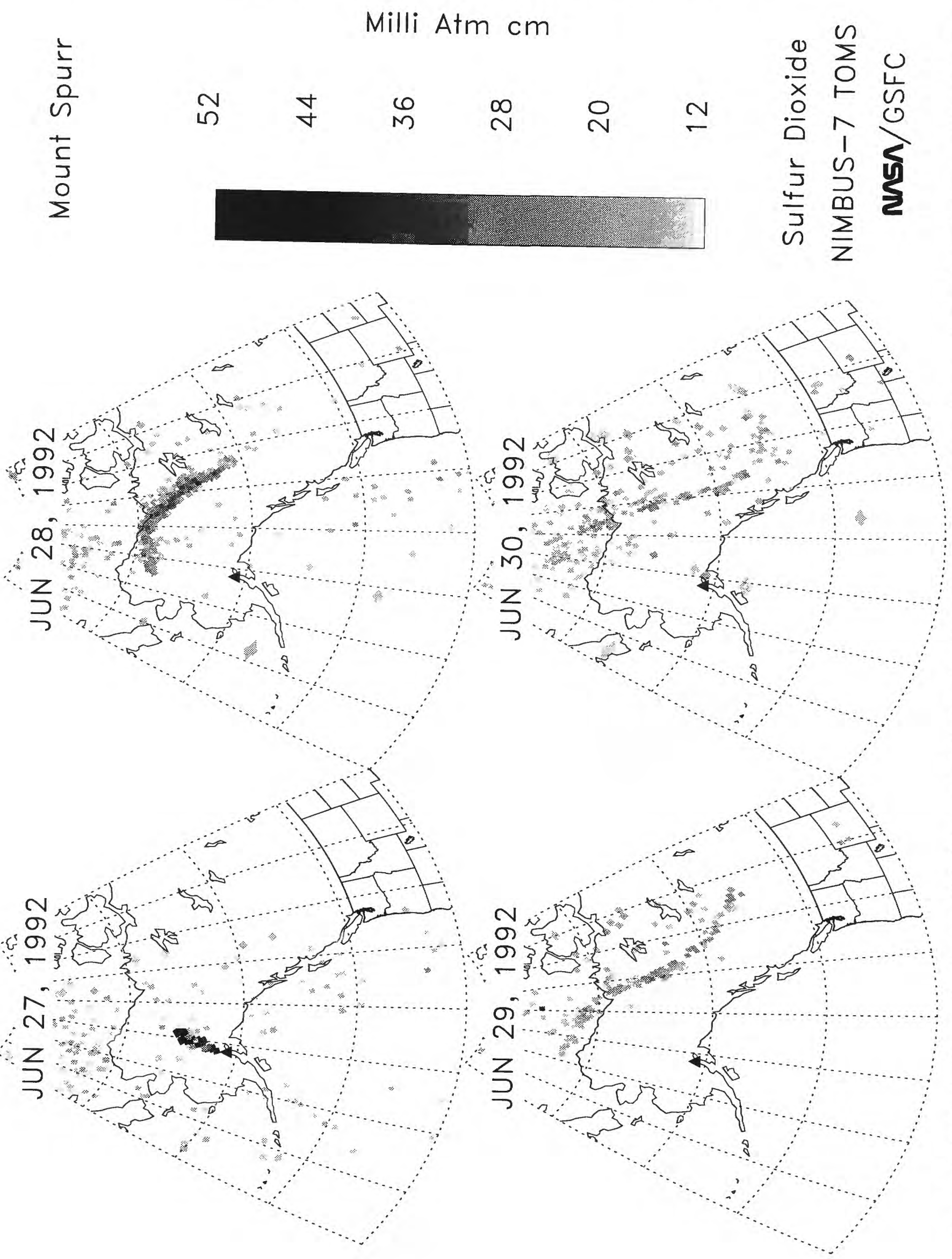

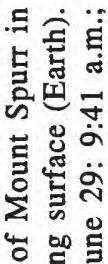

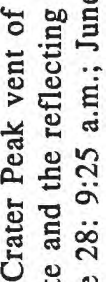
出莺志

䄕 总实 .

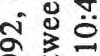
要究 กิ 穿要

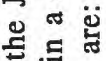

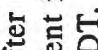
क 仓 ㄷ․등 寸 总嵒. ㄴㅇ용 녕 战壳 올 岳

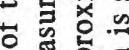
总造完. 芯

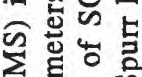
을 㤩号 若芯

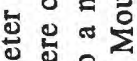
옴웅 연융혀 品 की 을 융.드리 州它 은

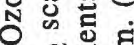
స్ㅇํㅇ 웅열 ¿ 苛

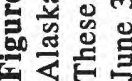


a given region is then obtained by multiplying the column amounts by their ground surface areas. Empirical corrections are used to offset the linear effects that variations in ozone and surface reflectance can impart on the $\mathrm{SO}_{2}$ calculations. Eruption cloud tonnages are estimated from measurements of the $\mathrm{SO}_{2}$ cloud compared to background measurements. Background data are taken adjacent to the $\mathrm{SO}_{2}$ cloud to minimize latitudinal (such as, solar zenith angle and climatological variations) differences, and they are also taken in identical scan positions to avoid scan bias (such as, changes in instrument resolution from nadir to scan-edge positions).

The typical TOMS detection limit of a fresh, tightly constrained eruption cloud is roughly 5 to 10 kilotons $(\mathrm{kt}) \mathrm{SO}_{2}$. Older, more dispersed clouds are difficult to discern because of low signal-to-noise ratios. Uncertainties arising from background variations and theoretical limitations of the $\mathrm{SO}_{2}$ algorithm combine to give a typical total error of approximately 30 percent in cloud tonnage, as calculated by Krueger and others (1990). The location of Mount Spurr in the northern latitudes makes TOMS data collected there more difficult to analyze owing to high solar zenith angles (the longer path lengths increase background noise), but it is also advantageous in that more observations are possible because of orbit overlap.

\section{ACKNOWLEDGMENTS}

This work was supported by funding from NASA Headquarters Solid Earth Program. Scott Doiron and Elizabeth Duncan provided technical and scientific support to the TOMS $\mathrm{SO}_{2}$ research. This paper was improved by the helpful reviews of Terry Gerlach and Bill Rose.

\section{JUNE 27 ERUPTION}

This first violent eruption of Mount Spurr began at 7:04 a.m. Alaskan daylight time (ADT $=$ UT 8 hours), and it lasted over 4 hours (Power and others, 1992). A composite image of TOMS observations is shown in figure 1. The first TOMS overpass occurred 10:49 a.m. ADT, and it caught the $\mathrm{SO}_{2}$ emission in progress. A second view of the erupting cloud was obtained in the subsequent, overlapping orbit, at approximately 12:23 p.m. ADT. The gas cloud was observed initially drifting northward and its movement was consistent with a $10-\mathrm{km}$ altitude, as determined from wind data from the National Meteorological Center (NMC). By the next day the cloud was elongated and had begun to drift to the east and southeast. By
June 29 the cloud became further elongated; it stretched from Point Barrow, Alaska, to Edmonton, Alberta, in Canada. However, on June 30 the cloud unexpectedly ceased its southeastward drift, and it rotated about $10^{\circ}$ clockwise from its position on the previous day. The $\mathrm{SO}_{2}$ cloud became more difficult to discern from background, but observations over the next 3 days indicated that the cloud continued its slow clockwise rotation. From NMC data, the shearing action on the 29 and 30 and subsequent cloud motions of the cloud suggested that the upper portion of the $\mathrm{SO}_{2}$ cloud had reached altitudes of around $12 \mathrm{~km}$. The last recognizable view of the cloud was obtained July 3 when it was oriented along $140^{\circ} \mathrm{W}$ longitude and stretched from Dawson in the Yukon province to the Gulf of Alaska.

\section{AUGUST 18 ERUPTION}

The Crater Peak vent of Mount Spurr erupted again at $4: 42$ p.m. ADT on August 18 for approximately 3.5 hours (McGimsey and Dorava, 1992). The $\mathrm{SO}_{2}$ cloud emitted from this eruption drifted southeast, and it was observed by the TOMS instrument at 10:51 a.m. ADT on August 19 as a discrete mass over the Gulf of Alaska (fig. 2). By the next day the cloud had begun to spread and show evidence of shearing on both southern and northeastern fronts. On the August 21 TOMS image, the $\mathrm{SO}_{2}$ cloud consisted of a main portion located off the coast of Oregon, and an elongated section that extended over $3,000 \mathrm{~km}$ to the east over Lake Winnipeg, Canada. The western edge of the cloud could not be delineated because of TOMS data losses during that particular overpass (for comparison with the extent of the ash component of the cloud on this day, see Schneider and others, this volume). By August 22, the elongated eastern section had separated from the main cloud mass, and it was barely detectable near Hudson Bay. NMC data suggest that this part of the cloud had been sheared away by winds at an approximately $14-\mathrm{km}$ altitude. The main cloud was located over Oregon and showed an eastward drift that indicated an altitude of about $12 \mathrm{~km}$. On subsequent days this main cloud mass elongated and followed a tortuous route along the jet stream northeast over Hudson Bay, south of Greenland, then across the Atlantic. The last remnant of the cloud visible to TOMS was observed over England on August 26.

\section{SEPTEMBER 16-17 ERUPTION}

At 12:03 a.m. ADT (September 17), the third major eruption of Mount Spurr began, and it also lasted for approximately 3.5 hours (Alaska Volcano Obser- 

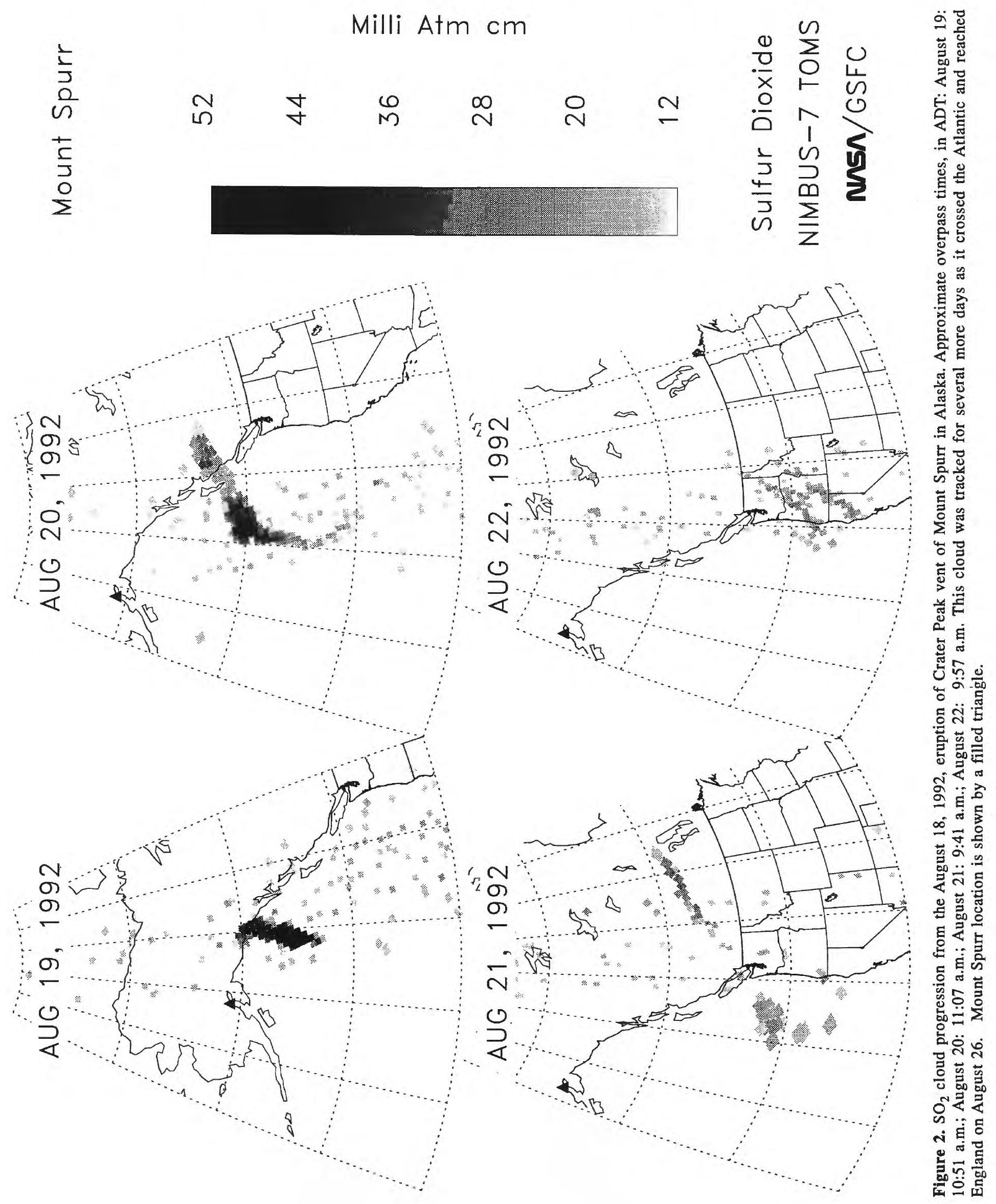
vatory, 1993). The $\mathrm{SO}_{2}$ cloud drifted eastward into Canada, then southward over the United States at a remarkable rate; it reached North Dakota (nearly 3,700 $\mathrm{km}$ away) approximately 34 hours after the eruption began (fig. 3). The cloud remained fairly compact during this time, and its behavior was consistent with NMC wind patterns over a range from 12 to $16 \mathrm{~km}$. NMC data located the $\mathrm{SO}_{2}$ cloud on a high-pressure ridge during the first 2 days after the eruption. However, by the following day the cloud was drawn into a region of high vertical shear, the steep wind gradient between high- and low-pressure systems over the Great Lakes area on the 19th. Accordingly, in the September 19 image the cloud changed drastically; it formed a 2,000-km-long arc from Detroit to northern Quebec. The extent of shearing observed was consistent with the $\mathrm{SO}_{2}$ cloud extending from 12 to $16 \mathrm{~km}$ in altitude. The following day's image showed the shearing had abated, but the cloud continued its northeasterly drift over the Labrador Sea. The last day the $\mathrm{SO}_{2}$ cloud could be discerned was on September 21 as a small mass off the east coast of Greenland.

\section{DISCUSSION}

Relations of cloud tonnage and area as a function of time can be useful in monitoring the physical and chemical processes that affect an erupted $\mathrm{SO}_{2}$ cloud. The amount of TOMS-observed $\mathrm{SO}_{2}$ generally decreases because of both chemical conversion of $\mathrm{SO}_{2}$ to $\mathrm{H}_{2} \mathrm{SO}_{4}$ and physical dissipation of $\mathrm{SO}_{2}$ at cloud margins to below the TOMS detection limits. The (chemical) decay rate of $\mathrm{SO}_{2}$ gas can ideally be described by an exponential decay function, with an e/2 or e-folding time. For large eruption clouds emplaced in the stratosphere, in which chemical processes dominate physical effects, the TOMS measurements can be used to derive an e-folding time for the cloud (for example, approximately 35 days for the 1991 Mount Pinatubo $\mathrm{SO}_{2}$ cloud; Bluth and others, 1992). However, the dispersion rate of $\mathrm{SO}_{2}$ is altitude dependent; it is typically more persistent if emplaced in the relatively drier, less turbulent, and less reactive stratosphere rather than in the troposphere. Sulfur dioxide dispersion is also dependent on cloud size and shape; the larger the surface area to mass ratio, the greater the effects of dissipation and chemical reaction at cloud boundaries.

Because TOMS observes volcanic $\mathrm{SO}_{2}$ clouds for only a short period of their total lifetimes in the atmosphere, the clouds' dispersion rates within this time can be approximated by a linear daily decrease. Empirically, $\mathrm{SO}_{2}$ clouds emplaced in the stratosphere generally decrease in mass by about 10 percent per day
(Doiron and others, 1991; Bluth and others, 1992), whereas tropospheric clouds can decrease by up to 50 percent per day (Bluth and others, 1994). In contrast, cloud area typically increases for the first few days, reflecting expansion of the gas cloud. As dispersion processes become more prevalent, the areal extent of $\mathrm{SO}_{2}$ observable by TOMS then decreases owing to chemical conversion and physical dissipation. Rapid changes in area and (or) $\mathrm{SO}_{2}$ amount generally indicate that the clouds have undergone physical changes as a result of wind shear and other turbulence. The daily tonnages and areal extents of the $\mathrm{SO}_{2}$ clouds for the three Crater Peak eruptions are shown as a function of time in figure 4.

The eruption of June 26 was in progress when initially observed by TOMS, and the first two $\mathrm{SO}_{2}$ and area values in figure $4 A$ show that the eruption cloud was still developing. Two more observations were made on June 27 , but the second orbit missed approximately 5 to 10 areal percent of the cloud's leading edge, as reflected by the small drop in $\mathrm{SO}_{2}$ amounts determined from one orbit to the next. Both the $\mathrm{SO}_{2}$ mass and area of the June cloud decreased at fairly constant rates; these decreases, along with the NMC wind data and relatively minor amount of observed drift, suggest that the local meteorological conditions were fairly stable at that time.

Both the August and September eruption clouds showed marked variations in area as they underwent fairly drastic changes as a result of wind shear (figs. $4 B$ and $4 C$ ). But the most remarkable pattern observed for these two eruptions is in the daily $\mathrm{SO}_{2}$ tonnages. After both eruptions, measured $\mathrm{SO}_{2}$ increased from the first to second day, followed by gradual cloud dispersion. In contrast to the June eruption, both eruption clouds were observed after complete separation from the volcano-accordingly, there was no possibility that the increase could have occurred from additional outgassing after the TOMS overpass. Nor was there evidence of severe physical disturbance during this time.

We can offer several reasons why measured $\mathrm{SO}_{2}$ may have increased in the clouds. First, the data variation falls within our stated accuracy of cloud tonnage estimations $( \pm 30$ percent; however, we do not believe the pattern is an artifact of the uncertainty in TOMS data or analysis. When analyzing cloud tonnages on successive days, the relative precision of the TOMS on these daily measurements of an $\mathrm{SO}_{2}$ cloud is approximately 10 percent. Thus, the $\mathrm{SO}_{2}$ increases observed for these eruption clouds are probably well above uncertainty levels.

Second, the $\mathrm{SO}_{2}$ retrieval on the first day may have been incomplete because of interference from co-erupted ash. Data from the Advanced Very High 


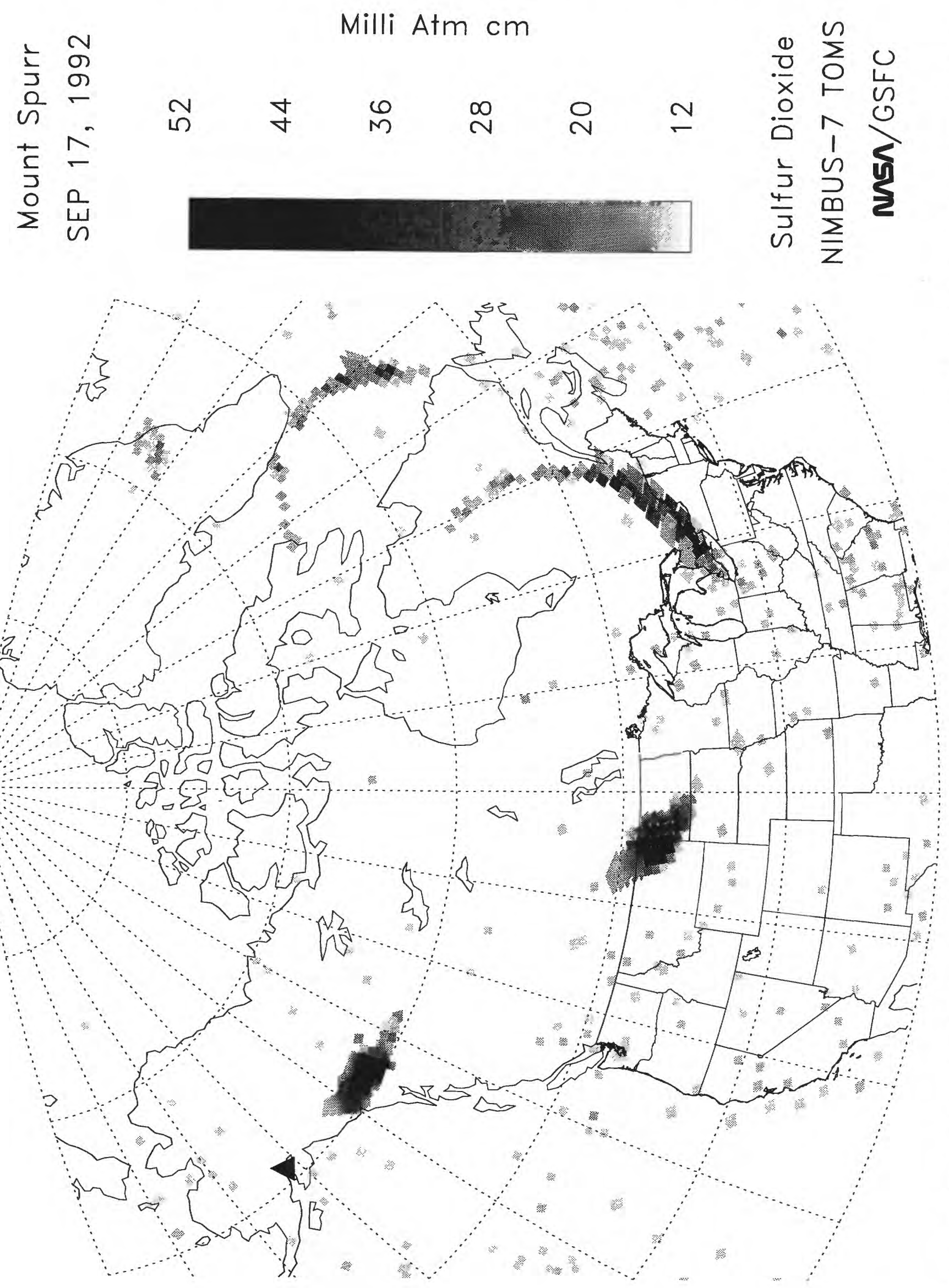

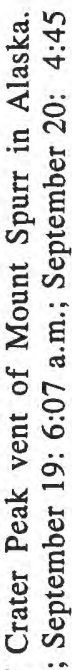

岹

돌

車

这 为

的

苾

풍응

플

ㄴㄹㄹ을

हुํㄹ

은 형

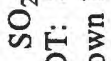

त是要

gे. .9

동ㅁㅁㅁ

ํ.

है

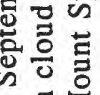

ฐ 듕

पे

:

$\Xi \ddot{\sim}$

号嵒

를 है

ن ษ

ம் 状

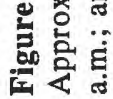




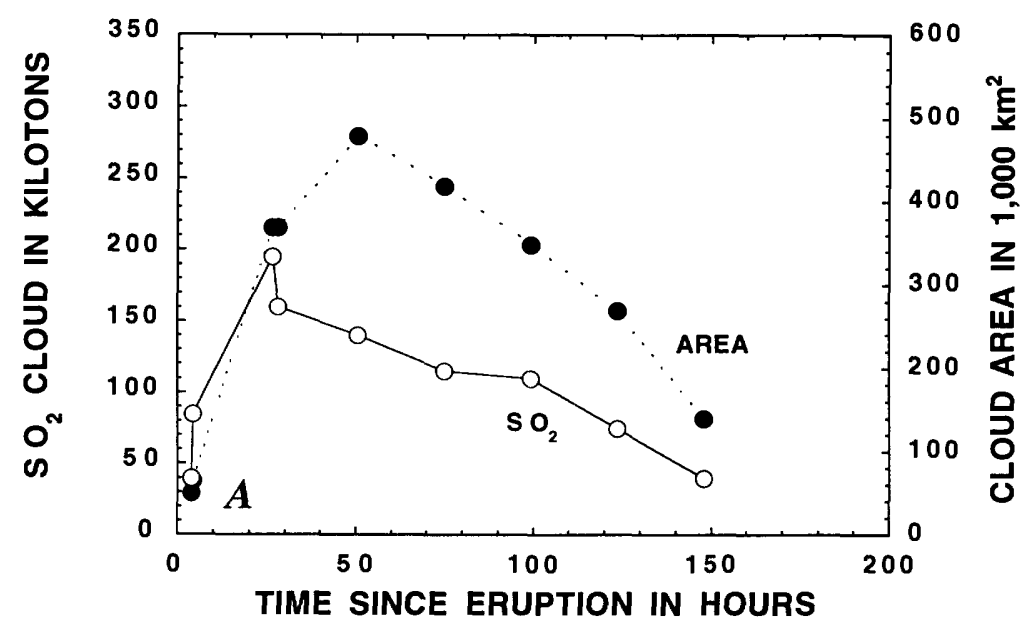

Figure 4. Comparisons of cloud sulfur dioxide mass (open circles) and area (filled circles) as a function of time after 1992 eruptions of Crater Peak vent of Mount Spurr in Alaska. A, June 27 eruption.

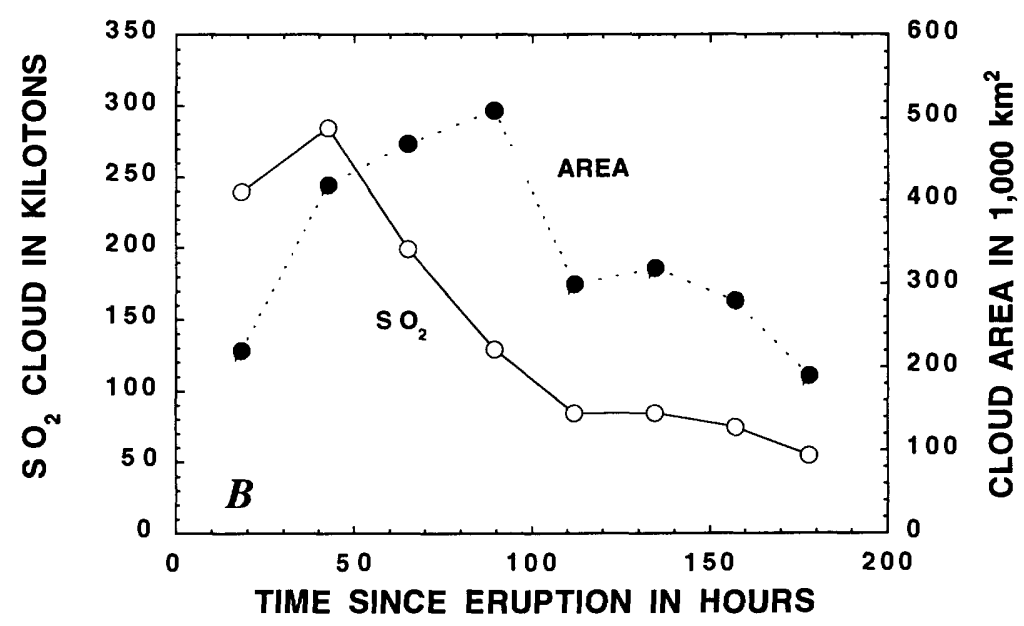

Figure 4. Continued. $B$, August 18 eruption.

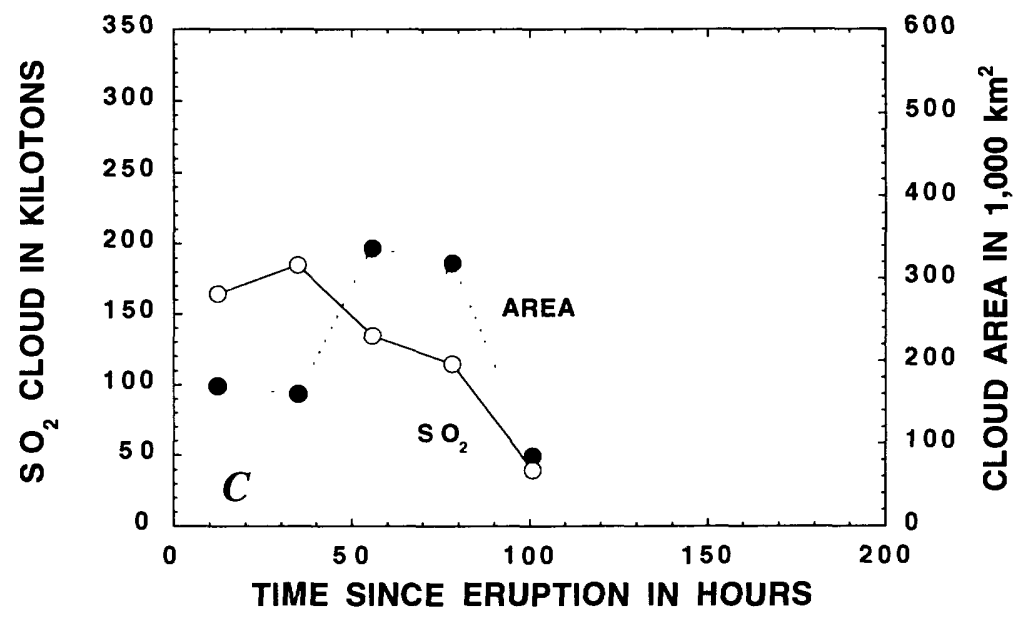

Figure 4. Continued. $C$, September 16-17 eruption. 
Resolution Radiometer (AVHRR; Schneider and others, this volume) show that the geographic positions and dimensions of the ash clouds were remarkably similar to the gas clouds. Because of the coincidence of the two, ultraviolet (UV) light scattering by the ash may have partially masked detection of $\mathrm{SO}_{2}$. However, TOMS reflectivity data (taken at two wavelengths where ozone and $\mathrm{SO}_{2}$ are nonabsorbing) showed no evidence of UV attenuation from ash particles. The fact that only the first TOMS observations were affected, 18 hours (August) and 12 hours (September) after eruption, may also provide some constraints based on the fallout rates of the tephra. For instance, the slow fallout rate of micron-sized particles in the cloud (Rose, 1993) suggests that their effect on TOMS measurements should have lasted for weeks, rather than only a single day. One of the keys to understanding the effect of ash on $\mathrm{SO}_{2}$ detection is determining the UV absorption by the variously sized particles in the cloud.

A third possibility is that significant amounts of $\mathrm{H}_{2} \mathrm{~S}$ gas were emitted, along with sulfur dioxide, from the Crater Peak eruptions. Doukas and Gerlach (this volume) report on evidence and a possible mechanism for $\mathrm{H}_{2} \mathrm{~S}$ emissions from the volcano, and Graedel (1977) calculated that $\mathrm{H}_{2} \mathrm{~S}$ in the atmosphere, derived from oxidation reactions, has a lifetime of approximately 1 day. If significant quantities of $\mathrm{H}_{2} \mathrm{~S}$ were emitted, the oxidation of this species to $\mathrm{SO}_{2}$ subsequent to the first day could explain the tonnage increases. The amount of $\mathrm{H}_{2} \mathrm{~S}$ required to produce the $\mathrm{SO}_{2}$ pattern observed in the TOMS data is roughly $75 \mathrm{kt} \mathrm{H}_{2} \mathrm{~S}$ for the August eruption (a 3:1 $\mathrm{SO}_{2}-\mathrm{H}_{2} \mathrm{~S}$ ratio), and $25 \mathrm{kt}$ $\mathrm{H}_{2} \mathrm{~S}$ for the September eruption (a $6: 1 \mathrm{SO}_{2}-\mathrm{H}_{2} \mathrm{~S}$ ratio).

This pattern of $\mathrm{SO}_{2}$ signals from an eruption cloud was observed previously in the TOMS data after the eruption of Mount St. Helens in 1980. The TOMS $\mathrm{SO}_{2}$ data for this eruption showed an increase $\mathrm{c} f$ about 10 percent from the first to the second day cf observation, then decreasing tonnage measurements on the following days (unpub. data). On May 18, only hours after the major eruption, Hobbs and others (1981) sampled the eruption cloud and reported high concentrations of $\mathrm{H}_{2} \mathrm{~S}$. However, we do not have enough data to make definitive conclusions regarding TOMS detection of $\mathrm{H}_{2} \mathrm{~S}$ gas emissions from either the Mount St. Helens or the Crater Peak eruptions.

The characteristics of the three eruptions of Mount Spurr are summarized in table 1 . The emitted $\mathrm{SO}_{2}$ is calculated from the TOMS data, assuming a linear daily loss of $\mathrm{SO}_{2}$. Data from each day were used until cloud losses through shearing were evident. A bost-fit line was determined using 7 days after the June eruption, days 2 through 4 for each of the August ard September eruptions, and projected back to the approximate end point of the eruption.

The August eruption was calculated from the TOMS data to have produced the greatest amount of $\mathrm{SO}_{2}$, at $400 \pm 120 \mathrm{kt}$. The September eruption produced $230 \pm 70 \mathrm{kt}$, and the June eruption emitted $200 \pm 60 \mathrm{kt}$ $\mathrm{SO}_{2}$. There was no apparent correlation of gas production with tephra emission that the Alaskan Volcano Observatory estimated for the June, August, and September eruptions. These estimates were 12, 14, and 15 million $\mathrm{m}^{3}$, respectively (W. Rose, oral commun., 1993).

The Mount Spurr $\mathrm{SO}_{2}$ tonnage data corresponded to a 20 to 30 percent daily loss of $\mathrm{SO}_{2}$ for each of the three eruptions; this loss suggests the clouds were injected at middle altitudes between purely stratospheric and purely tropospheric layers. At the latitudes of Alas$\mathrm{ka}$ and southern Canada, the summertime tropopause height fluctuates but is generally around $12 \mathrm{~km}$ altitude. The maximum injection altitudes of the June,

Table 1. Observations of $\mathrm{SO}_{2}$ clouds produced by the 1992 eruptions of Crater Peak vent, Mount Spurr, Alaska.

\begin{tabular}{lcccccc}
\hline & \multicolumn{9}{c}{ TOMS data } & & \\
\cline { 2 - 5 } \multicolumn{1}{c}{ Eruption } & $\begin{array}{c}\text { Days } \\
\text { observed }\end{array}$ & $\begin{array}{c}\text { Maximum } \\
\text { areal extent }\end{array}$ & $\begin{array}{c}\text { Estimated } \\
\mathrm{SO}_{2} \text { emitted }\end{array}$ & $\begin{array}{c}\mathrm{SO}_{2} \text { cloud } \\
\text { altitude }\end{array}$ & $\begin{array}{c}\text { Max ash } \\
\text { altitude }^{2}\end{array}$ & $\begin{array}{c}\text { Emitted } \\
\text { tephra }^{3}\end{array}$ \\
\hline June 27 & 7 & $480,000 \mathrm{~km}^{2}$ & $200 \pm 60 \mathrm{kt}$ & $10-12 \mathrm{~km}$ & $14.5 \mathrm{~km}$ & $12 \times 10^{6} \mathrm{~m}^{3}$ \\
August 18 & 8 & 510,000 & $400 \pm 120$ & $12-14$ & 13.7 & 14 \\
September 16-17 & 5 & 340,000 & $230 \pm 70$ & $12-16$ & 13.9 & 15 \\
\hline
\end{tabular}

${ }^{1}$ Calculated from NMC wind data and actual cloud positions from TOMS data

${ }^{2}$ Rose and others (this volume)

${ }^{3}$ Alaska Volcano Observatory (1993) 
August, and September ash clouds ranged from 13.7 to $14.5 \mathrm{~km}$ (table 1, modified from Rose and others, this volume). Each of these eruptions should therefore have reached the lower stratosphere; however, comparisons of daily wind data to actual cloud positions indicate the $\mathrm{SO}_{2}$ clouds are most accurately considered to extend several kilometers vertically. The June $\mathrm{SO}_{2}$ cloud corresponded to the lowest altitude $(10-12 \mathrm{~km})$ on the basis of its drift speed and directions, and most of this cloud probably remained in the troposphere. In contrast, most of the September cloud (ranging from $12-16 \mathrm{~km}$ by our calculations) was in the lower stratosphere. A large part of the August cloud $(12-14 \mathrm{~km})$ also appears to have reached the stratosphere. From the available data we therefore estimate that at least half of the $\mathrm{SO}_{2}$ emitted by the three Crater Peak eruptions was emplaced in the stratosphere.

\section{SUMMARY}

During the summer of 1992, Mount Spurr ended a 39-year period of quiescence and emitted large clouds of gas and ash during three separate eruptions within a 3-month period. The TOMS data suggest that the August 18 eruption was the largest of the three with $400 \pm 120 \mathrm{kt} \mathrm{SO} \mathrm{S}_{2}$ emitted, followed by the September 16-17 (230 $\pm 70 \mathrm{kt})$ and June 27 eruptions $(200 \pm 60 \mathrm{kt})$. Data for the August and September eruptions suggest that either co-emitted ash affected the TOMS measurements, or that significant quantities of $\mathrm{H}_{2} \mathrm{~S}(25-75 \mathrm{kt})$, in addition to $\mathrm{SO}_{2}$, may have been explosively outgassed by these two eruptions. However, TOMS does not measure $\mathrm{H}_{2} \mathrm{~S}$, and thus we can only, at this time, infer this possibility from $\mathrm{SO}_{2}$ data. Based on the maximum injection altitudes of the ash clouds, matching of ash and gas cloud positions to known wind conditions, and the dispersion rates of the gas clouds, the explosive eruptions of Crater Peak vent of Mount Spurr injected at least 50 percent of their $\mathrm{SO}_{2}$ into the lower stratosphere.

\section{REFERENCES CITED}

Alaska Volcano Observatory, 1993, Mt. Spurr's 1992 eru stions: Eos, Transactions of the American Geophysical Union, v. 74, p. 217-222.

Bluth, G.J.S., Casadevall, T.J., Schnetzler, C.C., Doiron, S.D., Walter, L.S., Krueger, A.J., and Badruddin, M., 1994, Evaluation of sulfur dioxide emissions from explosive volcanism: the 1982-1983 eruptions of Galunggung, Java, Indonesia: Journal of Volcanology and Geothermal P.esearch, v. 63, p. 243-256.

Bluth, G.J.S., Doiron, S.D., Schnetzler, C.C., Krueger, A.J., and Walter, L.S., 1992, Global tracking of the $\mathrm{SO}_{2}$ clouds from the June, 1991 Mount Pinatubo eruptions: Geophysical Research Letters, v. 19, p. 151-154.

Doiron, S.D., Bluth, G.J.S., Schnetzler, C.C., Krueger, A.J., and Walter, L.S., 1991, Transport of Cerro Hudson $\mathrm{SO}_{2}$ clouds: Eos, Transactions of the American Geophysica! Union, v. 72, p. 489-498.

Graedel, T.E., 1977, The homogeneous chemistry of atmospheric sulfur: Reviews of Geophysics and Space Physics, v. 15, p. $421-428$.

Hobbs, P.V., Radke, L.F., Eltgroth, M.W., and Hegg, D.A., 1981, Airborne studies of the emissions from the vol anic eruptions of Mount St. Helens: Science, v. 211, p. 816-818.

Krueger, A.J., 1983, Sighting of El Chichón sulfur dioxide clouds with the Nimbus 7 Total Ozone Mapping Spectrometer: Science, v. 220, p. 1377-1379.

Krueger, A.J., Walter, L.S., Schnetzler, C.C., and Doiron, S.D., 1990, TOMS measurement of the sulfur dioxide emitted during the 1985 Nevado del Ruiz eruptions: Journal of Volcanology and Geothermal Research, v. 41, p. 7-15.

McGimsey, R.G., and Dorava, J.M., 1992, Eruption of Mount Spurr volcano, Alaska, August 18, 1992: video footage: Eos, Transactions of the American Geophysical Union, v. 73, p. 345-346.

Power, J.A., Page, R.A., Lahr, J.C., Stephens, C.D., Crouet, B.A., McNutt, S.R., Davies, J.N., and March, G.D., 1592, Precursory seismicity and forecasting of the 1992 eruptions of Mount Spurr, Alaska: Eos, Transactions of the American Geophysical Union, v. 73, p. 342.

Rose, W.I., 1993, Comment on "another look at the ca'sulation of fallout tephra volumes" by Judy Fierstein and Manuel Nathenson: Bulletin of Volcanology, v. 55, p. 372-374.

Schoeberl, M.R., Doiron, S.D., Lait, L.R., Newman, P.A., and Krueger, A.J., 1993, A simulation of the Cerro Hudson $\mathrm{SO}_{2}$ cloud: Journal of Geophysical Research, v. 98, p. 2949-2955. 



\title{
Sulfur Dioxide Scrubbing During the 1992 Eruptions of Crater Peak, Mount Spurr Volcano, Alaska
}

\author{
By Michael P. Doukas and Terrence M. Gerlach
}

\section{CONTENTS}

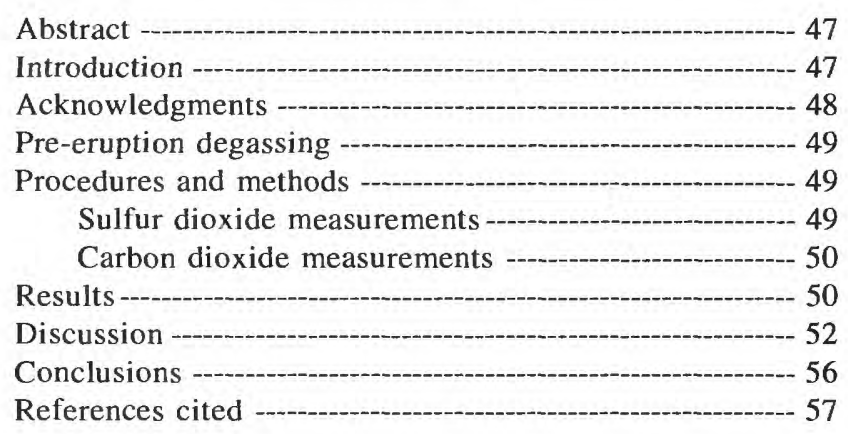

\section{ABSTRACT}

Sulfur dioxide scrubbing by liquid water masked $\mathrm{SO}_{2}$ emissions from shallow magma during the 1992 eruptions of Crater Peak and effectively prevented observation of $\mathrm{SO}_{2}$ emissions from shallow magma both before and after explosive eruptions and seismic crises. Airborne ultraviolet correlation spectrometer $(\mathrm{CO}-$ SPEC) measurements from July 22, 1991, to September 24,1992 , indicate only background to minor $(<100$ t/d) noneruptive $\mathrm{SO}_{2}$ emissions from Crater Peak, even though this period included the onset of precursory seismicity beneath Crater Peak (August 1991), the peaking in frequency of volcano-tectonic earthquakes and the initiation of volcanic tremor bursts (June 5, 1992), and three explosive eruptions that produced $\mathrm{SO}_{2}$ emissions of 200 to 400 kilotons (kt). The low, nonexplosive $\mathrm{SO}_{2}$ emissions are explained by hydrolysis of $\mathrm{SO}_{2}$ to aqueous $\mathrm{H}_{2} \mathrm{~S}$ and sulfate from interactions with liquid water: $4 \mathrm{H}_{2} \mathrm{O}(\mathrm{l})+4 \mathrm{SO}_{2}(\mathrm{aq}) \rightarrow \mathrm{H}_{2} \mathrm{~S}(\mathrm{aq})+3 \mathrm{H}^{+}(\mathrm{aq})+$ $3 \mathrm{HSO}_{4}^{-}(\mathrm{aq})$. Sulfur dioxide hydrolysis also explains the increase in the sulfate content of Crater Peak lake water prior to the first eruption, the strong $\mathrm{H}_{2} \mathrm{~S}$ odor during periods of background to low $\mathrm{SO}_{2}$ emission, the TOMS evidence for significant $\mathrm{H}_{2} \mathrm{~S}$ emissions during the explosive eruptions, and the observed decline of $\mathrm{SO}_{2}$ during periods of volcanic tremor. Abundant, local sources of melt water and a high permeability for the Mount Spurr volcanic edifice are probably the chief factors responsible for masking $\mathrm{SO}_{2}$ emissions by scrubbing, and possibly for quenching shallow intrusions that were ascending. Large $\mathrm{SO}_{2}$ emissions unencumbered by scrubbing were only possible during the three explosive eruptions when magma penetrated through liquid water zones under Crater Peak and reached the surface. Nonexplosive $\mathrm{SO}_{2}$ emissions of as much as $750 \mathrm{t} / \mathrm{d}$ were possible, however, for a brief period when dry pathways to the surface existed from September 25 until about October 10, 1992. Airborne infrared spectrometer (MIRAN) measurements of $\mathrm{CO}_{2}$ emissions indicate that in addition to the degassing of magma through dry pathways, degassing through boiling water with the loss of $\mathrm{SO}_{2}$ by scrubbing was also important during that time. The $\mathrm{CO}_{2}$ emission data indicate that magma degassing was taking place, and $\mathrm{CO}_{2} / \mathrm{SO}_{2}$ values calculated from MIRAN and COSPEC data are in the range 10 to 100 , which supports the hypothesis of $\mathrm{SO}_{2}$ loss by scrubbing. $\mathrm{Be}-$ cause of its strong preference for the vapor phase during boiling, $\mathrm{CO}_{2}$ emissions from degassing magma are less likely to be masked by the presence of water, whereas $\mathrm{SO}_{2}$ emissions may be lost totally from interactions with water; thus misleading COSPEC results are obtained. We recommend prompt and early monitoring of $\mathrm{CO}_{2}$ when Cook Inlet volcanoes become restless.

\section{INTRODUCTION}

The USGS Volcano Hazards Program supports airborne ultraviolet correlation spectrometer (COSPEC) and infrared spectrometer (MIRAN) flights to monitor sulfur dioxide and carbon dioxide gas emissions from convergent-plate volcanoes. These methods have been successfully applied to explosive eruptions at Mount St. Helens in the Cascade volcanic system (Casadevall and others, 1981, 1983; Harris and others, 1981; McGee, 1992) and at Redoubt Volcano in the Cook Inlet part of the Aleutian volcano chain (Casadevall and others, 1994). These investigations show that the emplacement and degassing of shallow magma in the crust beneath active volcanoes can be 
monitored by measuring the emission rates of $\mathrm{SO}_{2}$ and $\mathrm{CO}_{2}$ from volcanoes to the atmosphere. A common feature observed to date in the fluxes of these gas species is their tendency to decline exponentially through time after major explosive episodes. During the 1992 eruptions at Crater Peak vent on Mount Spurr volcano, however, we discovered $\mathrm{SO}_{2}$ gas fluxes that were markedly lower than those observed in past investigations. We suggest that the anomalously low $\mathrm{SO}_{2}$ degassing patterns observed at Crater Peak are related to the hydrolysis of magmatic $\mathrm{SO}_{2}$ to aqueous $\mathrm{H}_{2} \mathrm{~S}$ and sulfate by liquid water within the volcano.

Herein, we report the results and interpretation of $\mathrm{SO}_{2}$ and $\mathrm{CO}_{2}$ emission measurements obtained at Crater Peak from late 1991 through early 1993, a period that included three subplinian eruptions. (For the eruption chronology, see Eichelberger and others, this volume). Sulfur dioxide measurements were taken at Mount Spurr volcano in July of 1991 as part of the Alaska Volcano Observatory (AVO) gas-monitoring program for the volcanoes of the Cook Inlet. However, few $\mathrm{SO}_{2}$ flux measurements were made until after the third eruption on September 16-17, 1992, because of budget constraints, the surprisingly low $\mathrm{SO}_{2}$ flux observed at Crater Peak following eruptions on June 27 and August 18, 1992, and the perception that the activity would cease soon after the initial erup- tions, as it did during the 1953 eruption at Crater Peak. Shortly after the September 16-17 eruption, AVO intensified $\mathrm{SO}_{2}$ monitoring and added $\mathrm{CO}_{2}$ flux determinations in the gas-monitoring program at Mount Spurr volcano. The $\mathrm{CO}_{2}$ measurements were motivated by the working hypotheses that (1) both $\mathrm{SO}_{2}$ and $\mathrm{CO}_{2}$ were degassed noneruptively from magma and that (2) subsequent dissolution in liquid water within the volcano resulted in scrubbing of $\mathrm{SO}_{2}$ by hydrolysis reactions while $\mathrm{CO}_{2}$ remained available for emission when the liquid boiled.

\section{ACKNOWLEDGMENTS}

We are grateful for the aircraft support provided through the Office of Aircraft Services (OAS), Department of Interior, Anchorage. We are most appreciative of the pilots who skillfully and safely flew under and through the Crater Peak gas plume, often under less than ideal flying conditions. Our special thanks to Mark Iven of the Cascades Volcano Observatory who promptly checked the condition of the MIRAN instrument and shipped it to AVO after the September 16-17 eruption. We thank Terry Keith, Ken McGee, Steve McNutt, and Jeff Sutton for their reviews of a draft of this report and for suggesting several improvements.

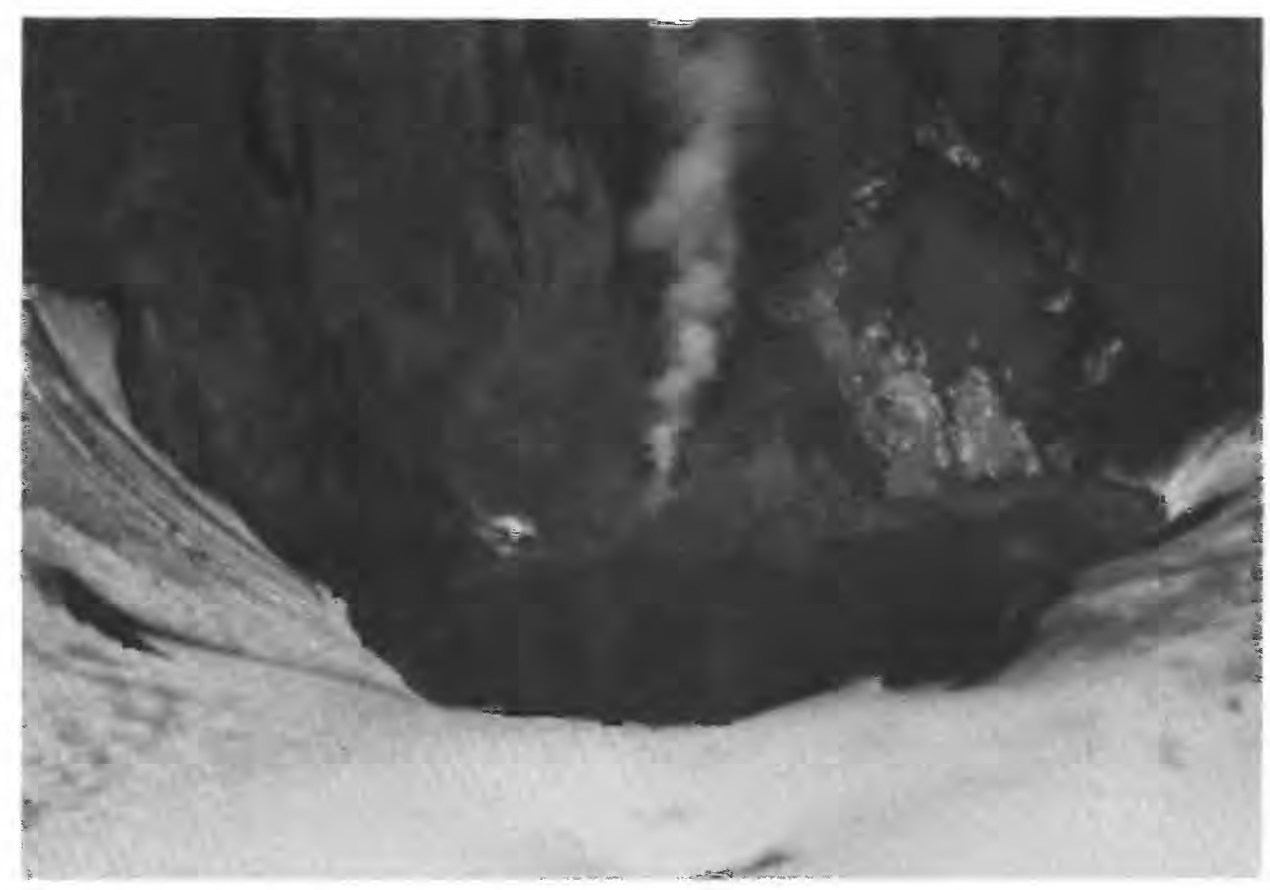

Figure 1. View of pre-eruption crater lake in summit vent of Crater Peak, Mount Spurr volcano before the June 27, 1992, eruption. Main fumarole (center) located in talus pile in northwestern quadrant of vent. Whitish upwelling located right center on lake is vapor off the lake surface, which indicates an elevated lake temperature. 


\section{PRE-ERUPTION DEGASSING}

Pre-eruption features at the Crater Peak vent on Mount Spurr included a summit crater lake occupying the 1953 explosion crater (fig. 1), a vigorous fumarole emitting through talus debris at the northwest side of the lake, and wispy fumaroles emitting steam from pyroclastic deposits on the eastern interior of the crater. The crater lake normally was blue-green in color with no apparent bubbling or surface roiling. A few weeks prior to the June 27, 1992, eruption, the lake water changed to a gray color, its temperature was measured at $49^{\circ} \mathrm{C}$, and active boiling and upwelling became apparent. Observers reported $\mathrm{H}_{2} \mathrm{~S}$ odor at the crater rim several tens of meters above the lake's surface. Analyses of crater lake samples collected on June 11, 1992, showed about a fourfold increase in sulfate content compared to lake samples collected on August 9, 1970 (Keith and others, this volume). By the day before the June 27 eruption, the lake level had dropped significantly and exposed a muddy beach and shoreline. The remaining lake and western talus cone were probably ejected during the June 27 eruption. The main vent present after the June 27 eruption included the site of the principal pre-eruption fumarole (fig. 2).

\section{PROCEDURES AND METHODS}

\section{SULFUR DIOXIDE MEASUREMENTS}

Sulfur dioxide measurements were made from a fixed-wing airplane. The COSPEC method uses solar ultraviolet light scattered by the Earth's atmosphere as an illumination source. With the instrument directed toward the sky, the COSPEC measures the difference between the amount of ultraviolet light absorbed by $\mathrm{SO}_{2}$ molecules present along the optical path through the plume and the ambient total ultraviolet light available. The COSPEC measures the amount of absorption in units of concentration pathlength $(\mathrm{ppm} \cdot \mathrm{m})$ or burden. Calibration is performed by using an internal standard with a known $\mathrm{SO}_{2}$ burden of $135 \mathrm{ppm} \cdot \mathrm{m}$. A profile of $\mathrm{SO}_{2}$ burden across the plume is measured at right angles to the plume trajectory. The product of the burden (ppm.m), the width of the plume (m), and the plume speed $(\mathrm{m} / \mathrm{s})$ gives the emission rate of $\mathrm{SO}_{2}\left(\mathrm{ppm} \cdot \mathrm{m}^{3} / \mathrm{s}\right)$, which is reported in this study in metric tons per day $\left(\mathrm{t} / \mathrm{d} ; 1\right.$ metric ton $\left.(\mathrm{t})=10^{3} \mathrm{~kg}\right)$. Reported values typically consist of four to six separate traverses averaged together and rounded to two significant figures (Casadevall and others, 1981, 1983, and 1994; McGee, 1992).

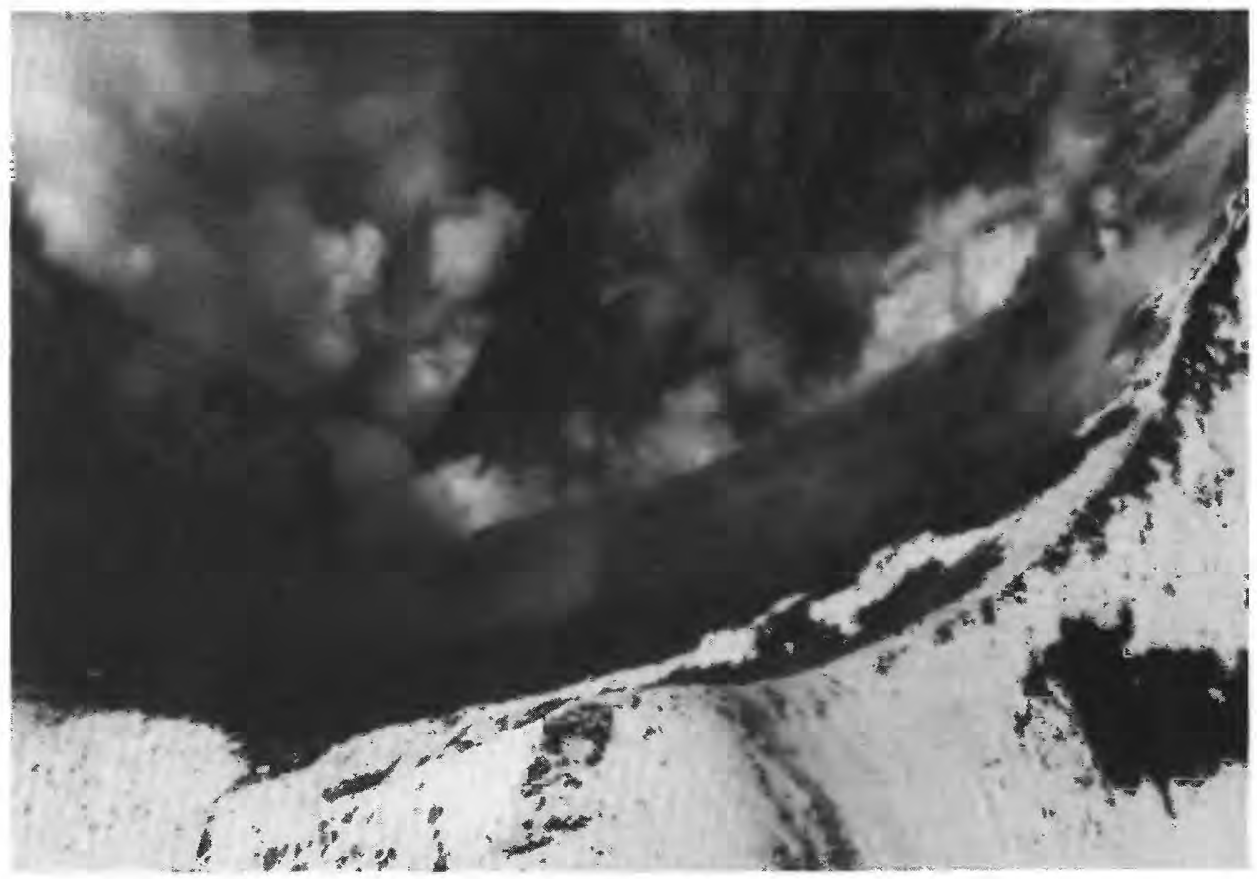

Figure 2. View of crater in Crater Peak vent, Mount Spurr volcano, Alaska, after the June 27,1992 , eruption. Dark deposit in middle ground is snow-free pyroclastic debris within crater. Dark area in background is vertical south-facing crater wall. 
Measured $\mathrm{SO}_{2}$ emission rates can vary owing to natural causes such as variation in emission rate, changes in sun angle, and amount of ultraviolet light and plume opacity due to the presence of suspended ash. Uncertainty of COSPEC measurements arises from several operational factors including operator variance (pilot, instrument manipulation, data reduction) and measurement of plume velocity (Casadevall and others, 1994).

At Crater Peak, the accurate measurement of plume velocity was usually the largest source of uncertainty. We assumed that the plume was carried along at the same speed as the ambient winds. Wind direction and speed near the vent are controlled by adjacent mountainous topography. Winds passing over the location of Crater Peak in this part of the Alaska Range can be turned, shifted, and back-eddied. Local wind directions were occasionally 180 degrees from the regional trend reported by the National Weather Service (NWS) in Anchorage, Alaska. Wind speed and direction were determined in several ways. One method relied on wind and speed determinations made twice daily at Anchorage International Airport by the National Oceanic and Atmospheric Administration (NOAA) radiosonde. One of these measurements is made at 2:00 p.m. local time, which coincides with local solar noon (highest ultraviolet levels) and the normal times of the $\mathrm{SO}_{2}$ flights. When forecast winds were light and variable, we assigned 5 knots as the operative value. Another method was to compare onboard navigational instruments or global positioning satellite (GPS) receivers with NWS forecasted winds aloft.

Aircraft speed was determined in several ways. During close orbits of the vent, geographical landmarks were identified and noted on the $\mathrm{SO}_{2}$ chart recorder paper. The chart recorder was then used as a clock to time one orbit. Using the distance from the vent as a radius, the aircraft ground speed was calculated. At other times, radar tracking from Anchorage International Airport was used to calibrate onboard instruments for reduction of aircraft airspeed to ground speed. Ideally, a moderately high emission rate is desirable (greater than $500 \mathrm{t} / \mathrm{d}$ of $\mathrm{SO}_{2}$ ) along with wind speeds of nearly 10 nautical miles per hour. During times of low $\mathrm{SO}_{2}$ flux or low wind speeds, orbits within a kilometer of the vent were required. Plume positions during these times, or when wind directions drove the plume into mountainous terrain, would not allow the aircraft to fly safely beneath the entire plume; these alternate routes resulted in minimum values being measured for $\mathrm{SO}_{2}$.

\section{CARBON DIOXIDE MEASUREMENTS}

Carbon dioxide measurements were obtained from a fixed-wing aircraft by flying directly through the plume and using the infrared spectrometer technique described by Harris and others (1981) for measuring the amount of excess $\mathrm{CO}_{2}$ in the plume relative to that in the ambient atmosphere. This method is capable of detecting excess $\mathrm{CO}_{2}$ down to 1 or $2 \mathrm{ppm}$ (by volume) and $\mathrm{CO}_{2}$ emission rates down to about $200 \mathrm{t} / \mathrm{d}$. The excess $\mathrm{CO}_{2}$ concentration profiles along a number of passes through the plume at different altitudes are combined to define the plume area and $\mathrm{CO}_{2}$ concentration in a cross section of the plume. The $\mathrm{CO}_{2}$ emission rate is calculated from the plume area, the $\mathrm{CO}_{2}$ concentration in the cross section, the density of $\mathrm{CO}_{2}$ from the altitude and temperature of the plume, and from the wind speed (Harris and others, 1981). During times of low emission and low wind speeds, orbits within a kilometer of the vent were required, which gave low $\mathrm{CO}_{2}$ emission rates because of slow instrumental response times. Thus, some $\mathrm{CO}_{2}$ emission rates reported here are minimum values.

\section{RESULTS}

The $\mathrm{SO}_{2}$ and $\mathrm{CO}_{2}$ emission rate data obtained for 1991 through 1993 are presented in table 1 . The data as a time series that includes the three 1992 eruptions of June 27, August 18, and September 16-17 are shown in figure 3; periods of low UV radiation are also shown in this figure. Data obtained after the September 16-17 eruption when COSPEC flights were more frequent and the MIRAN instrument was used for $\mathrm{CO}_{2}$ measurements are shown in figure 4 . All emission rate data are reported in metric tons/day ( $t / d)$ above the background level upwind of the volcano.

COSPEC measurements did not detect significant increases above background in $\mathrm{SO}_{2}$ emissions prior to the June 27, 1992, eruption. Some COSPEC flights made during times of increased seismicity recorded $\mathrm{SO}_{2}$ emissions slightly elevated above background levels. For example, two measurements in May and June were 88 and $21 \mathrm{t} / \mathrm{d}$, respectively, during a period of increased seismic activity. COSPEC measurements on June 29, just 2 days after the first eruption, showed $\mathrm{SO}_{2}$ emission rates of only $5 \mathrm{t} / \mathrm{d}$. Measurements on September 10, a week prior to the September 16-17 eruption, were at background levels, and measurements 4 and 6 days after the eruption were only slightly above background ( 23 and $24 \mathrm{t} / \mathrm{d}$ ). Strong $\mathrm{H}_{2} \mathrm{~S}$ odors 
Table 1. $\mathrm{SO}_{2}$ and $\mathrm{CO}_{2}$ fluxes measured at Crater Peak, Mount Spurr volcano, Alaska, 1991-1993.

[d-m-y, day-month-year; $\mathrm{t} / \mathrm{d}$, metric tons per day; sd, standard deviation; no., number of $\mathrm{SO}_{2}$ determinations; $\mathrm{BG}$, background; NM, not measured; $>$, minimum value]

\begin{tabular}{|c|c|c|c|c|c|c|c|}
\hline $\begin{array}{c}\text { Date } \\
\text { (d-m-y) }\end{array}$ & $\begin{array}{l}\mathrm{SO}_{2} \\
\text { avg } \\
\text { (t/d) }\end{array}$ & $\begin{array}{l}\mathrm{SO}_{2} \\
\text { max } \\
(\mathrm{t} / \mathrm{d})\end{array}$ & $\begin{array}{c}\mathrm{SO}_{2} \\
\text { min } \\
(\mathrm{t} / \mathrm{d})\end{array}$ & $\begin{array}{c}\mathrm{SO}_{2} \\
\mathrm{sd} \\
( \pm / d)\end{array}$ & $\begin{array}{c}\mathrm{SO}_{2} \\
\text { no. }\end{array}$ & $\begin{array}{l}\mathrm{CO}_{2} \\
(\mathrm{t} / \mathrm{d})\end{array}$ & $\begin{array}{c}\mathrm{CO}_{2} / \mathrm{SO}_{2} \\
\text { (wt) }\end{array}$ \\
\hline $22-07-91$ & BG & BG & BG & - & - & NM & - \\
\hline \multicolumn{8}{|c|}{ - Precursory seismic activity begins beneath Crater Peak, August 1991} \\
\hline $\begin{array}{l}21-08-91 \\
29-08-91 \\
03-09-91 \\
22-11-91 \\
14-05-92\end{array}$ & $\begin{array}{c}\text { BG } \\
\text { BG } \\
85 \\
\text { BG } \\
88\end{array}$ & $\begin{array}{c}\text { BG } \\
\text { BG } \\
97 \\
\text { BG } \\
96\end{array}$ & $\begin{array}{c}\text { BG } \\
\text { BG } \\
72 \\
\text { BG } \\
80\end{array}$ & $\begin{array}{l}- \\
- \\
18 \\
- \\
10\end{array}$ & $\begin{array}{l}\overline{-} \\
\overline{2} \\
\overline{2}\end{array}$ & $\begin{array}{l}\text { NM } \\
\text { NM } \\
\text { NM } \\
\text { NM } \\
\text { NM }\end{array}$ & $\begin{array}{l}- \\
- \\
- \\
-\end{array}$ \\
\hline
\end{tabular}

- Volcano-tectonic earthquakes peak, June 5, 1992

- First volcanic tremor bursts, June 6, 1992

- Eruption, June 27, 1992

$\begin{array}{lllllll}29-06-92 & 5 & 10 & 2 & 3 & 5 & \text { NM }\end{array}$

- $\quad$ Eruption, August 18, 1992

$\begin{array}{llll}10-09-92 & \text { BG } & \text { BG } & \text { BG }\end{array}$

NM

- Volcanic tremor episodes, September 12-25, 1992

- Eruption, September 16-17, 1992

$\begin{array}{llll}21-09-92 & 23 & 38 & 10 \\ 23-09-92 & 24 & 33 & 22 \\ 24-09-92 & 79 & 92 & 72 \\ 25-09-92 & 300 & 370 & 240 \\ 28-09-92 & 190 & 270 & 18 \\ 29-09-92 & 750 & 830 & 690\end{array}$

$\begin{array}{ll}10 & 12 \\ 22 & 7 \\ 72 & 11 \\ 240 & 54 \\ 180 & 25 \\ 690 & 75\end{array}$

$\begin{array}{cc}\text { NM } & - \\ \text { NM } & - \\ \text { NM } & - \\ 11,000 & 53 \\ 12,000 & 90 \\ 8,700 & 17\end{array}$

- Volcanic tremor episode, October 2-5, 1992 02-10-92 $\quad 450 \quad 450 \quad 450$ $\begin{array}{llll}03-10-92 & 220 & 320 & 110\end{array}$ $\begin{array}{llll}04-10-92 & 210 & 320 & 170\end{array}$ $\begin{array}{llll}05-10-92 & 360 & 560 & 230\end{array}$ $\begin{array}{llll}10-10-92 & 240 & 360 & 160\end{array}$

- Volcanic tremor episode, October 12, 1992

$\begin{array}{cccc}14-10-92 & 47 & 50 & 44 \\ 15-10-92 & 64 & 67 & 62 \\ 16-10-92 & >200 & - & - \\ 19-10-92 & \text { BG } & \text { BG } & \text { BG } \\ 23-10-92 & 24 & 26 & 22 \\ 29-10-92 & \text { BG } & \text { BG } & \text { BG }\end{array}$

44
62
BG
22
BG

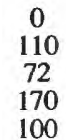

NM

3,800

3,500

NM

Earthquake swarms, November 9, 1992

$\begin{array}{llll}10-11-92 & \text { BG } & \text { BG } & \text { BG } \\ 11-11-92 & \text { BG } & \text { BG } & \text { BG } \\ 12-11-92 & \text { BG } & \text { BG } & \text { BG } \\ 13-11-92 & \text { BG } & \text { BG } & \text { BG } \\ 15-11-92 & \text { BG } & \text { BG } & \text { BG } \\ 08-12-92 & \text { BG } & \text { BG } & \text { BG } \\ 11-12-92 & \text { BG } & \text { BG } & \text { BG } \\ 15-12-92 & \text { BG } & \text { BG } & \text { BG } \\ 18-12-92 & \text { BG } & \text { BG } & \text { BG }\end{array}$

BG
BG
BG
BG
BG
BG
BG
BG
BG

2,400
NM
$>2,000$
BG
2,100
BG

74
-
-
127
-

- Swarm of small VT earthquakes, December 21-26, 1992

$\begin{array}{llll}23-12-92 & \text { BG } & \text { BG } & \text { BG } \\ 21-01-93 & \text { BG } & \text { BG } & \text { BG } \\ 18-02-93 & \text { BG } & \text { BG } & \text { BG }\end{array}$

- Seismicity at pre-August 1991 levels, April 1993 


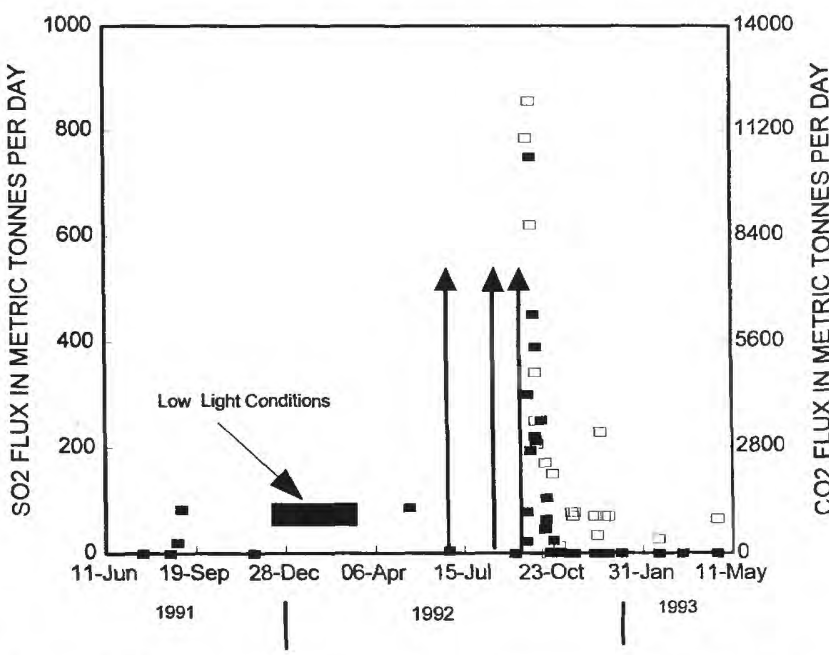

Figure 3. Sulfur dioxide and $\mathrm{CO}_{2}$ measurements at Crater Peak of Mount Spurr volcano, Alaska, from 1991 to 1993. Left vertical axis and solid squares give $\mathrm{SO}_{2}$ emission rate (in metric tons per day, or $\mathrm{t} / \mathrm{d}$ ); right vertical axis and open squares give $\mathrm{CO}_{2}$ flux (t/d). Arrows are eruptions dates (June 27, August 18, and September 16-17, 1992). Bar indicates low ultraviolet light period during winter when COSPEC measurements are not possible.

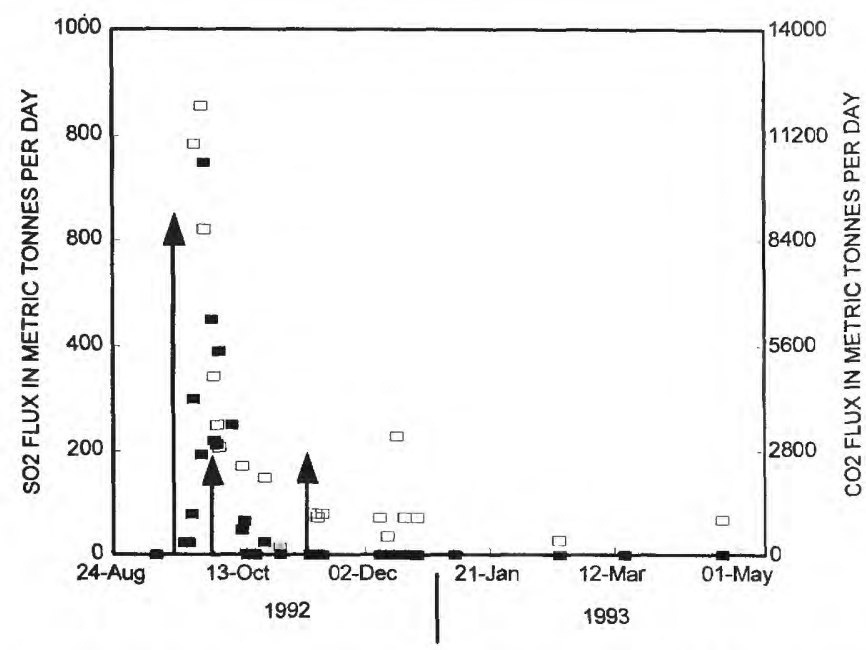

Figure 4. Sulfur dioxide (solid squares) and $\mathrm{CO}_{2}$ (open squares) emission rates after September 16-17, 1992, eruption of Crater Peak vent of Mount Spurr volcano, Alaska. Long arrow denotes September eruption; short arrows are periods of elevated seismic energy release on October 1-2 and November 9, 1992.

were frequently noted during airborne monitoring flights throughout the course of the 1992 eruptions. The periods of strongest $\mathrm{H}_{2} \mathrm{~S}$ odor correlated with times of minor to background $\mathrm{SO}_{2}$ emission rates.

On September 24, $\mathrm{SO}_{2}$ emission rates reached $79 \mathrm{t} / \mathrm{d}$. By September 25, they rose to $300 \mathrm{t} / \mathrm{d}$, just as the first $\mathrm{CO}_{2}$ measurements showed $11,000 \mathrm{t} / \mathrm{d}$. Measurements on September 28 showed $\mathrm{CO}_{2}$ at 12,000 t/d. Sulfur dioxide values peaked on September 29 at 750 $\mathrm{t} / \mathrm{d}$, coincident with a $\mathrm{CO}_{2}$ flux of $8,700 \mathrm{t} / \mathrm{d}$.

In the week following the October 2-5 tremor episode, $\mathrm{SO}_{2}$ remained above background levels, although it declined somewhat from 450 to $240 \mathrm{t} / \mathrm{d}$, as $\mathrm{CO}_{2}$ declined from 4,800 to $2,900 \mathrm{t} / \mathrm{d}$. During this period, aerosol plumes of sulfate fume derived from volcanic $\mathrm{SO}_{2}$ became visible for the first time downwind from the crater. These plumes extended beyond the water vapor condensation cloud near the vent and spread out along an inversion layer in the atmosphere (fig. 5). On October 3,4 , and $5, \mathrm{SO}_{2}$ fluxes were measured before and after the onset of volcanic tremor. After about 2 hours into each tremor episode, $\mathrm{SO}_{2}$ emission rates decreased to approximately half their pre-tremor values (fig. 6). Sulfur dioxide emission rates, but not $\mathrm{CO}_{2}$ rates, were also down sharply after the tremor episode on October 12. Measurable $\mathrm{SO}_{2}$ levels gradually declined over the next 2 weeks and returned to near background levels by the end of October 1992. Three of five $\mathrm{CO}_{2}$ measurements over the same period gave emission rates over $2,000 \mathrm{t} / \mathrm{d}$; the other two measurements showed background levels.

Both MIRAN and COSPEC surveys were made of the atmosphere around the volcano immediately after the November 9 earthquake swarms. Sulfur dioxide emission rates never rose above background levels following the crisis, but $\mathrm{CO}_{2}$ emissions rose above background to a level of about $1,000 \mathrm{t} / \mathrm{d}$ by the third day after the crisis and stayed at about this level through April 1993. Occasional later measurements showed lower $\mathrm{CO}_{2}$ levels of only a few hundred metric tons per day, which may represent the normal baseline $\mathrm{CO}_{2}$ fluxes from Crater Peak at times of inactivity.

Integrating the noneruptive $\mathrm{CO}_{2}$ emission rate data for the period September 25, 1992, to April 24, 1993 (fig. 4) gives a total $\mathrm{CO}_{2}$ emission of approximately $110 \mathrm{kt}$. A similar treatment of the COSPEC $\mathrm{SO}_{2}$ flux data results in a total $\mathrm{SO}_{2}$ emission of only about $6 \mathrm{kt}$.

\section{DISCUSSION}

COSPEC measurements (table 1) from July 22, 1991 , to September 24,1992 , indicate only background to minor $(<100 \mathrm{t} / \mathrm{d})$ noneruptive $\mathrm{SO}_{2}$ emissions from Crater Peak, although this period included (1) the onset of precursory seismicity beneath Crater Peak (August 1991), (2) the peaking in frequency of volcano-tectonic earthquakes and the initiation of volcanic tremor bursts (June 5, 1992), and (3) the three explosive eruptions (June 27, August 18, and September 16-17, 1992). 


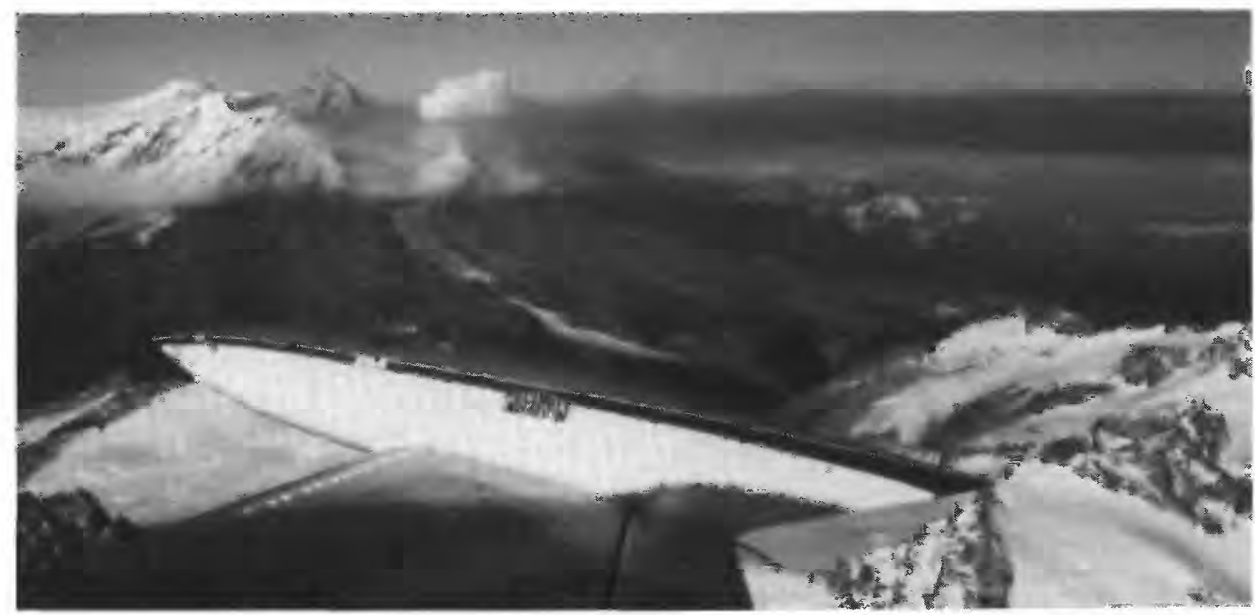

Figure 5. View of Crater Peak of Mount Spurr volcano from the south on October 2, 1992, shows condensation plume above Crater Peak vent (left center) and volcanic aerosol plume extending to the east.

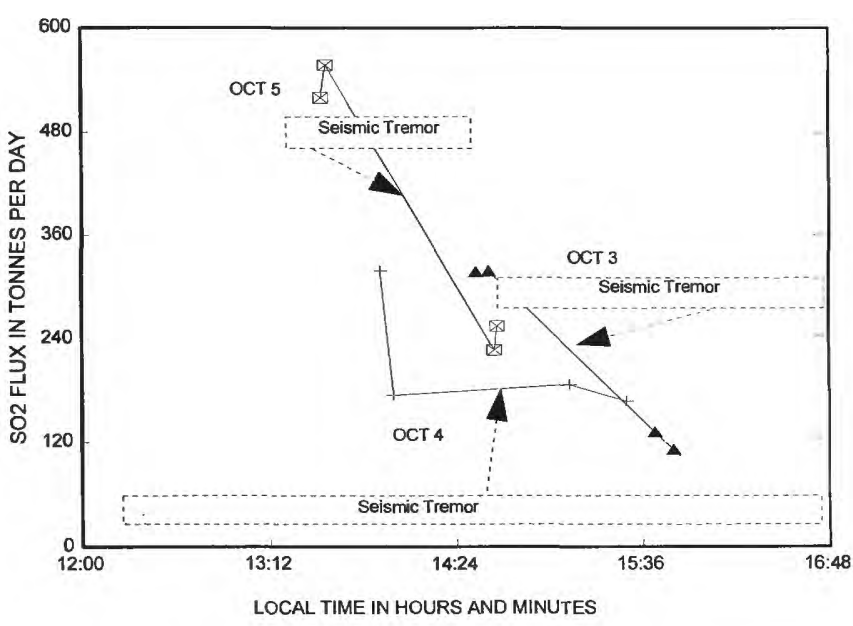

Figure 6. Relation between periods of seismic tremor and decreasing $\mathrm{SO}_{2}$ emission rates (symbols connected by solid lines) on October 3, 4, and 5, 1992. Dotted lines with arrows point to $\mathrm{SO}_{2}$ flux measured during tremor on particular days.

Total Ozone Mapping Spectrometer (TOMS) satellite measurements (Bluth and others, this volume) show large eruptive $\mathrm{SO}_{2}$ emissions by comparison for the explosive events: $200 \mathrm{kt}$ (June 27), $400 \mathrm{kt}$ (August 18 ), and $230 \mathrm{kt}$ (September 16-17). The integrated noneruptive $\mathrm{SO}_{2}$ emission of about $6 \mathrm{kt}$ is small compared to the total TOMS-based explosive $\mathrm{SO}_{2}$ emission of $830 \mathrm{kt}$. The $1989-90$ eruptions of nearby Redoubt Volcano involved similar amounts of andesitic magma and produced approximately $175 \mathrm{kt}$ of $\mathrm{SO}_{2}$ in explosive eruptive emissions, as determined by TOMS (Schnetzler and others, 1994), and approximately 800 $\mathrm{kt}$ of $\mathrm{SO}_{2}$ in noneruptive emissions, as determined by COSPEC (Casadevall and others, 1994). Total $\mathrm{SO}_{2}$ emissions are similar for both eruptions, but their eruptive and non-eruptive components are very different.

The great difference between noneruptive and eruptive $\mathrm{SO}_{2}$ degassing may reflect the role of liquid water at Crater Peak in hydrolyzing most of the noneruptively emitted $\mathrm{SO}_{2}$ gas; an abundance of water may also have played a role in effectively quenching shallow intrusions during their ascent to the surface. After obtaining an average $\mathrm{SO}_{2}$ emission rate of only $5 \mathrm{t} / \mathrm{d}$ (table 1) at Crater Peak just 2 days after the June 27 eruption, we speculated that the extremely low, noneruptive $\mathrm{SO}_{2}$ emissions resulted from the hydrolysis of $\mathrm{SO}_{2}$ to aqueous $\mathrm{H}_{2} \mathrm{~S}$ and sulfate by liquid water present in the volcano. One likely source of water is a liquid-dominated hydrothermal system postulated to exist between 1.5 and $2 \mathrm{~km}$ beneath Crater Peak (Motyka and Nye, 1993). The presence of a hydrothermal system does not, however, guarantee that $\mathrm{SO}_{2}$ emissions from shallow magma will be effectively absorbed. For example, Mount Pinatubo contained a hydrothermal system sufficiently impressive to attract exploration drilling for geothermal energy in 198889 (Delfin and others, 1992). Nevertheless, $\mathrm{SO}_{2}$ emission rates at Mount Pinatubo reached values as high as $13 \mathrm{kt} / \mathrm{d}$ in the weeks before the climactic June 15 , 1991, eruption (Daag and others, 1994). The Mount Pinatubo hydrothermal system had a low permeability-too low for geothermal-energy production (Delfin and others, 1992) - which may have inhibited its capacity to rapidly recharge water lost from boiling and to prevent (or greatly diminish) pre-eruption $\mathrm{SO}_{2}$ emissions. We suggest that, in addition to the presence of 
a hydrothermal system, important factors contributing to $\mathrm{SO}_{2}$ scrubbing at Crater Peak may have included a highly permeable volcanic edifice and large sources of liquid water from snow melt and melt from glaciers directly above and surrounding Crater Peak, thus permitting rapid and abundant recharge of water to the volcano. A $1-\mathrm{km}$-long zone of warm springs $\left(40^{\circ} \mathrm{C}\right)$ discharges from the base of the volcano about $4 \mathrm{~km}$ directly downslope from Crater Peak. Total warmwater flow from this system is estimated to be approximately $1,000 \mathrm{l} / \mathrm{min}$, and stable isotope data indicate that the meteoric recharge for the ground-water system supplying the springs is derived from local snow melt and precipitation falling at middle to upper elevations (Motyka and Nye, 1993).

The main gases, in addition to water vapor, released from shallow degassing magma of convergentplate volcanic systems are $\mathrm{CO}_{2}, \mathrm{SO}_{2}, \mathrm{H}_{2} \mathrm{~S}$, and $\mathrm{HCl}$. All these gases are soluble in liquid water that may be present in volcanic edifices. When the water boils, the dissolved gases will partition preferentially into the vapor phase. The dissolution of gases in water and their partitioning between vapor and liquid during boiling are topics beyond the scope of this report. We refer readers to a discussion of these and related topics in Henley and others (1984); much of the interpretation that follows is based on data and concepts they present. We focus entirely on liquidvapor interactions. In most cases, water-rock interactions are likely to proceed at a slow rate relative to the time scales of volcanic degassing and liquid-vapor reactions during boiling. We assume, therefore, that water-rock interactions introduce only secondary effects that can be ignored here.

Because aqueous $\mathrm{HCl}$ is a strong acid, it dissociates in water to hydrogen and chloride ions $(\mathrm{HCl}(\mathrm{aq})$ $\left.\rightarrow \mathrm{H}^{+}(\mathrm{aq})+\mathrm{Cl}^{-}(\mathrm{aq})\right)$. The concentration of $\mathrm{HCl}(\mathrm{aq})$ will therefore be negligible, and its exsolution as $\mathrm{HCl}$ gas in the vapor phase during boiling will be negligible, except for unusually acidic solutions at temperatures much greater than $250^{\circ} \mathrm{C}$. Thus, water in a volcano will dissolve $\mathrm{HCl}$ released from degassing magma, but because of its strong dissociation, $\mathrm{HCl}$ will not normally exsolve to a vapor phase when the resulting solution is boiled.

Aqueous $\mathrm{SO}_{2}$ is thermodynamically unstable in water relative to sulfate species and aqueous $\mathrm{H}_{2} \mathrm{~S}$, except at temperatures greater than $300^{\circ} \mathrm{C}$ and $\mathrm{pH}$ values less than or equal to 2. The hydrolysis of $\mathrm{SO}_{2}$ by the disproportionation reaction:

$$
\begin{gathered}
4 \mathrm{H}_{2} \mathrm{O}(\mathrm{l})+4 \mathrm{SO}_{2}(\mathrm{aq}) \rightarrow \mathrm{H}_{2} \mathrm{~S}(\mathrm{aq})+ \\
3 \mathrm{H}^{+}(\mathrm{aq})+3 \mathrm{HSO}_{4}^{-}(\mathrm{aq})
\end{gathered}
$$

proceeds strongly in the direction indicated. Consequently, the concentration of $\mathrm{SO}_{2}(\mathrm{aq})$ is very low and the contribution of $\mathrm{SO}_{2}$ to the vapor phase during boiling is negligible compared to the bulk amount of $\mathrm{SO}_{2}$ gas that may have been injected initially into the water during magma degassing.

The gases $\mathrm{CO}_{2}$ and $\mathrm{H}_{2} \mathrm{~S}$ dissolve in water as $\mathrm{CO}_{2}$ (aq) and $\mathrm{H}_{2} \mathrm{~S}(\mathrm{aq})$. Their dissociation $\left(\mathrm{H}_{2} \mathrm{O}(\mathrm{l})+\right.$ $\mathrm{CO}_{2}(\mathrm{aq})=\mathrm{H}^{+}(\mathrm{aq})+\mathrm{HCO}_{3}-(\mathrm{aq}) ; \mathrm{H}_{2} \mathrm{~S}(\mathrm{aq})=\mathrm{H}^{+}(\mathrm{aq})+$ $\mathrm{HS}^{-}(\mathrm{aq})$ ) is not appreciable in ground water and hydrothermal waters provided $\mathrm{pH}$ is below 9. Unlike $\mathrm{SO}_{2}$, they are relatively stable with respect to water, although some $\mathrm{H}_{2} \mathrm{~S}(\mathrm{aq})$ may react with dissolved $\mathrm{Fe}^{++}$ to form pyrite $\left(\mathrm{FeS}_{2}\right)$. The concentrations of $\mathrm{CO}_{2}(\mathrm{aq})$ and $\mathrm{H}_{2} \mathrm{~S}(\mathrm{aq})$ in waters that have absorbed magmatic gases are, therefore, significant compared to those for aqueous $\mathrm{HCl}$ and $\mathrm{SO}_{2}$. Carbon dioxide and $\mathrm{H}_{2} \mathrm{~S}$ are thus distributed between vapor and liquid phases during boiling. The distribution of either gas between vapor and liquid can be represented by a distribution coefficient, $B_{i}$, defined as follows:

$$
\mathbf{B}_{\mathrm{i}}=\left(\mathrm{n}_{\mathrm{i}} / \mathrm{n}_{\mathrm{H}_{2} \mathrm{O}}\right)_{\mathrm{vap}} /\left(\mathrm{n}_{\mathrm{i}} / \mathrm{n}_{\mathrm{H}_{2} \mathrm{O}}\right)_{\text {liq }}
$$

where $\left(n_{i} / n_{H_{2} O}\right)_{\text {vap }}$ is the molar ratio of the gas $i$ to $\mathrm{H}_{2} \mathrm{O}$ in the vapor, and $\left(\mathrm{n}_{\mathrm{i}} / \mathrm{n}_{\mathrm{H}_{2} \mathrm{O}}\right)_{\text {liq }}$ is the ratio of the gas to $\mathrm{H}_{2} \mathrm{O}$ in the liquid. Giggenbach (1980) derived the following regression equations, valid for $100^{\circ} \mathrm{C}$ to $340^{\circ} \mathrm{C}$, from experimental gas-solubility data for $\mathrm{CO}_{2}$ and $\mathrm{H}_{2} \mathrm{~S}$ in water:

$$
\begin{aligned}
& \log \mathrm{B}_{\mathrm{CO}_{2}}=4.7593-0.01092 \mathrm{~T} \\
& \log \mathrm{B}_{\mathrm{H}_{2} \mathrm{~S}}=4.0547-0.00981 \mathrm{~T}
\end{aligned}
$$

where $\mathrm{T}$ is in ${ }^{\circ} \mathrm{C}$. Over temperatures from $100^{\circ} \mathrm{C}$ to $340^{\circ} \mathrm{C}$, the respective values for $\mathrm{B}_{\mathrm{CO}_{2}}$ range from 4,650 to 11; those for $\mathrm{B}_{\mathrm{H}_{2} \mathrm{~S}}$ range from 1,185 to 5 . Thus, both $\mathrm{CO}_{2}$ and $\mathrm{H}_{2} \mathrm{~S}$ will move preferentially into the vapor phase during boiling, and this preference is stronger the lower the temperature of boiling.

With equations (3) and (4) and other equations provided in Henley and others (1984), it is possible to calculate the distribution of $\mathrm{CO}_{2}$ and $\mathrm{H}_{2} \mathrm{~S}$ between vapor and liquid as boiling progresses. The results depend on the temperature of boiling, the extent of boiling (that is, the fraction of the total water in the system transferred to the vapor phase as steam), the isothermal or isoenthalpic nature of the boiling process, and the open or closed character of the system. The percent of $\mathrm{CO}_{2}$ and $\mathrm{H}_{2} \mathrm{~S}$ remaining dissolved in the liq- 


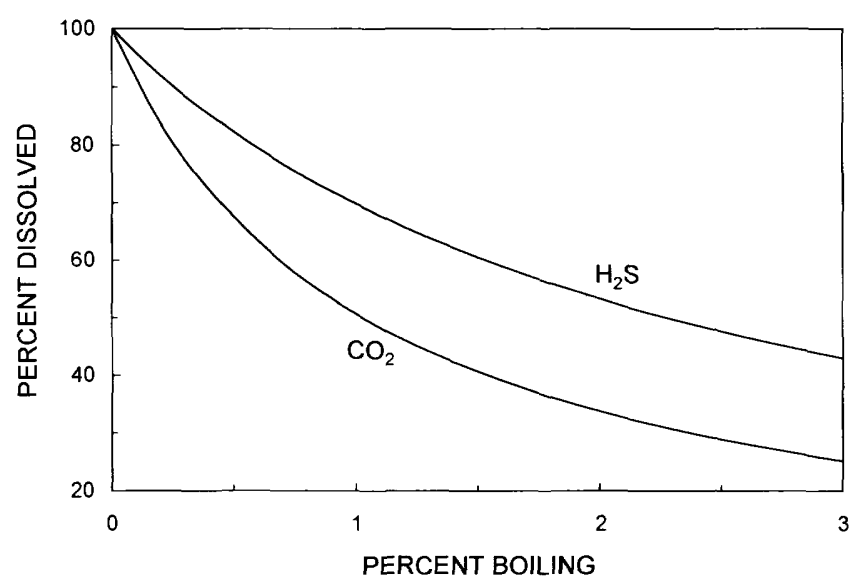

Figure 7. Percent of $\mathrm{CO}_{2}$ and $\mathrm{H}_{2} \mathrm{~S}$ dissolved in liquid water, relative to the initial amounts in solution, as a function of the percent isoenthalpic boiling for a closed system initially at $260^{\circ} \mathrm{C}$. Only 25 percent of the initial $\mathrm{CO}_{2}$ and 43 percent of the initial $\mathrm{H}_{2} \mathrm{~S}$ remain dissolved after just 3 percent boiling. The temperature after 3 percent boiling is $250^{\circ} \mathrm{C}$. The curves are based on calculations at intervals of 1 percent boiling from equations (3) and (4) in the text and other equations provided in Henley and others (1984).

uid, relative to the initial amounts in solution, as a function of the percent isoenthalpic boiling for a closed system initially at a temperature of $260^{\circ} \mathrm{C}$ are shown in figure 7. For these conditions, only 25 percent of the initial $\mathrm{CO}_{2}$ and 43 percent of the initial $\mathrm{H}_{2} \mathrm{~S}$ remain dissolved in the liquid after just 3 percent boiling. The temperature after 3 percent isoenthalpic boiling is $250^{\circ} \mathrm{C}$. The curves produced by closed-system, isothermal boiling at $260^{\circ} \mathrm{C}$ are similar but somewhat above those shown in figure 7 for the same range of percent boiling. For example, 29 percent of the initial $\mathrm{CO}_{2}$ (instead of 25 percent) remains in the liquid after 3 percent boiling. Because the values for $\mathrm{B}_{\mathrm{CO}_{2}}$ and $\mathrm{B}_{\mathrm{H}_{2} \mathrm{~S}}$ increase as the system cools, $\mathrm{CO}_{2}$ and $\mathrm{H}_{2} \mathrm{~S}$ will partition into the vapor at a faster rate from isoenthalpic boiling than from isothermal boiling. In open-system boiling, gases are removed from solution at exponential rates and cause marked changes in gas content of the liquid after only a few percent boiling. If open-system rather than closed-system conditions are assumed, less than 5 and 30 percent of the initial $\mathrm{CO}_{2}$ and $\mathrm{H}_{2} \mathrm{~S}$, respectively, remain dissolved in the liquid after just 3 percent boiling. At lower temperatures (higher $\mathbf{B}_{\mathrm{i}^{-}}$-values), less boiling is required to produce the same changes in the gas content of the liquid for both open and closed systems. In general, boiling is more effective in stripping $\mathrm{CO}_{2}$ and $\mathrm{H}_{2} \mathrm{~S}$ from aqueous solutions the lower the temperature of boiling and the more open and isoenthalpic the behavior of the system during boiling.
Our observations on $\mathrm{SO}_{2}, \mathrm{CO}_{2}$, and $\mathrm{H}_{2} \mathrm{~S}$ emissions during the 1992 eruptions of Crater Peak are consistent with the foregoing discussion of $\mathrm{SO}_{2}$ hydrolysis and the partitioning of $\mathrm{CO}_{2}$ and $\mathrm{H}_{2} \mathrm{~S}$ during boiling. We suggest that scrubbing of $\mathrm{SO}_{2}$ by liquid water in the volcano effectively masked noneruptive magmatic emissions of $\mathrm{SO}_{2}$ from the time of precursory seismic activity in August of 1991 to September 24,1992 (table 1). We particularly stress this interpretation for the COSPEC measurements from June 8 to September 25, 1992, which show $\mathrm{SO}_{2}$ emissions of background to only $88 \mathrm{t} / \mathrm{d}$ at times before, after, and between the three eruptions. At these times, $\mathrm{SO}_{2}$ emissions of at least several hundred $t / d$ vould normally be expected on the basis of past experience (Casadevall and others, 1981, 1983, 1994; McGee, 1992). In addition, the hydrolysis of $\mathrm{SO}_{2}$ accounts for the increase in the sulfate content of the Crater Peak lake water prior to the first eruption. The parsistently strong $\mathrm{H}_{2} \mathrm{~S}$ odor during this period, and during later periods when $\mathrm{SO}_{2}$ emissions were at or near background levels, is also consistent with this interpretation. In addition to direct dissolution of $\mathrm{H}_{2} \mathrm{~S}$ degassed from shallow magma, the hydrolysis of aqueous sulfur dioxide by reaction (1) converts 25 percent of the degassed $\mathrm{SO}_{2}$ into aqueous $\mathrm{H}_{2} \mathrm{~S}$. Because megmas generally emit much more $\mathrm{SO}_{2}$ than $\mathrm{H}_{2} \mathrm{~S}$, the production of $\mathrm{H}_{2} \mathrm{~S}$ by hydrolysis probably was significar tly greater than the $\mathrm{H}_{2} \mathrm{~S}$ from magmatic degassing. Aqreous $\mathrm{H}_{2} \mathrm{~S}$ derived both from direct magma degassing and from hydrolysis of degassed $\mathrm{SO}_{2}$ would be preferentially partitioned into the vapor phase and released in emissions during boiling of water. Hydrogen sulfide has a lifetime in the atmosphere of only about 1 day, because of oxidation reactions (Graedel, 1977). Thus, while it is possible that the minor $(5-88 \mathrm{t} / \mathrm{d}) \mathrm{SO}_{2}$ fluxes during the June 8 through September 25 period represent magmatic degassing of $\mathrm{SO}_{2}$ through rare dry pathways to the surface at this time, we cannot rule out the atmospheric oxidation of $\mathrm{H}_{2} \mathrm{~S}$ emissions from boiling water as the source of the detected $\mathrm{SO}_{2}$.

Large $\mathrm{SO}_{2}$ emissions were possible during the three explosive eruptions because magma ascended rapidly to the surface and could degas dirently to the atmosphere. This effectively prevented contact with liquid water and loss by scrubbing of most of the $\mathrm{SO}_{2}$ released during the eruptions. The TOMS data indicate that 15 to 25 percent of the sulfur released in the three eruptions was emitted as $\mathrm{H}_{2} \mathrm{~S}$ (Bluth and others, this volume). This suggests the possibility that $\mathrm{H}_{2} \mathrm{~S}$ emissions also occurred from the boiling of water during the explosive events. Hence some of the sulfur released in the explosive eruptions may have been degassed noneruptively as $\mathrm{SO}_{2}$ at an earlier time, converted to aqueous $\mathrm{H}_{2} \mathrm{~S}$ by hydrolysis, ard then re- 
leased during boiling from heating associated with the ascent of the erupting magma.

On September 25, about a week after the September 16-17 eruption, the system finally dried out enough to permit $\mathrm{SO}_{2}$ fluxes in excess of $100 \mathrm{t} / \mathrm{d}$ (table 1). The week of time may have been necessary to transfer the heat required to dry out a sufficient volume of the rock surrounding the shallow magma so that significant amounts of $\mathrm{SO}_{2}$ could degas and escape to the atmosphere without encountering liquid water. It is possible that some additional shallow magma was supplied during this week; this magma augmented the supply of magmatic gas and heat needed to create and maintain a dry escape route to the surface. We suggest that during this period the liquid-vapor boiling surface migrated outward from the shallow magma, because the rate at which heat was supplied for boiling outpaced the rate at which recharging water removed heat.

The $\mathrm{CO}_{2}$ emission rate data (table 1) indicate that magma was degassing, and these data support the hypothesis of $\mathrm{SO}_{2}$ loss by scrubbing. Together, the $\mathrm{CO}_{2}$ and $\mathrm{SO}_{2}$ fluxes from September 25 to about October 10 indicate that magma was degassing through boiling water as well as through a zone of dry rock. The values of $\mathrm{CO}_{2} / \mathrm{SO}_{2}$ weight ratios for magmatic gases from convergent-plate volcanic systems are less than 15 , except for gases collected from degassed domes several years after emplacement (Symonds and others, 1994). Most of the $\mathrm{CO}_{2} / \mathrm{SO}_{2}$ values at Crater Peak are in the 10 to 100 range (table 1). A higher $\mathrm{CO}_{2}$ ' $\mathrm{SO}_{2}$ ratio is expected if a significant fraction of the degassing takes place through boiling water. Magma degassing through boiling water would cause relatively minor fractionation of $\mathrm{CO}_{2}$, because of its tendency to partition preferentially into a vapor phase, compared to its effect on $\mathrm{SO}_{2}$, which is susceptible to hydrolysis. Consequently, the $\mathrm{CO}_{2} / \mathrm{SO}_{2}$ values of the gases emitted to the atmosphere will be higher than the magmatic gas values, and they will increase as the fraction of degassing through boiling water increases relative to degassing through a zone of dry rock. The high $\mathrm{CO}_{2}$ emission rates of 11 and $12 \mathrm{kt} / \mathrm{d}$ at times of relatively modest $(190$ to $300 \mathrm{t} / \mathrm{d}) \mathrm{SO}_{2}$ emissions and the high $\mathrm{CO}_{2} / \mathrm{SO}_{2}$ values of 53 to 90 on September 25 and 28 suggest that significant degassing of magma through water was also occurring in the week immediately after the September 16-17 eruption, even though $\mathrm{SO}_{2}$ fluxes were then very low $(<100 \mathrm{t} / \mathrm{d})$, presumably because of $\mathrm{SO}_{2}$ scrubbing by boiling water.

Sulfur dioxide emission rates peaked near the end of September, only about a week after the dryout zone was established. By early October, removal of heat by recharge of meteoric water apparently be- gan to outpace the supply of magmatic heat again, the dry escape route through the wet edifice began to close, and $\mathrm{SO}_{2}$ emissions started to drop. The exhaustion of gas, as well as heat, from the shallow magma probably contributed to the drop in $\mathrm{SO}_{2}$ emission rate. The coincident decline in $\mathrm{CO}_{2}$ also suggests the exhaustion of volatiles from the shallow magma.

We attribute the drop in $\mathrm{SO}_{2}$ emission rates during tremor episodes in early October (fig. 6) to the recharge of liquid water back into the dry-out zone around and above the shallow magma. As water invaded fractures within this zone, vigorous boiling ensued, presumably giving rise to tremor, and the adjacent hot rock and melt cooled sufficiently to permit the presence of an increasing amount of liquid water. As the process proceeded, $\mathrm{SO}_{2}$ was increasingly lost by scrubbing, $\mathrm{SO}_{2}$ emissions dropped, and $\mathrm{CO}_{2} / \mathrm{SO}_{2}$ and $\mathrm{H}_{2} \mathrm{~S} /$ $\mathrm{SO}_{2}$ values rose. After the tremor episode of October 12 , the system remained effectively waterlogged without a dry zone for $\mathrm{SO}_{2}$ escape. Sulfur dioxide emissions declined to background levels where they have remained.

Carbon dioxide emissions of greater than $2 \mathrm{kt} / \mathrm{d}$ suggest that episodes of boiling continued to release $\mathrm{CO}_{2}$ and $\mathrm{H}_{2} \mathrm{~S}$ after the October 12 tremor episode. Carbon dioxide emissions and strong $\mathrm{H}_{2} \mathrm{~S}$ odors were evident again 3 days after the November 9 earthquake swarms. We speculate that these swarms were related to one or more intrusions too small to penetrate through the water-saturated zone but sufficiently large to produce thermal perturbations that led to boiling and release of $\mathrm{CO}_{2}$ and $\mathrm{H}_{2} \mathrm{~S}$. Carbon dioxide fluxes of 1 to $3 \mathrm{kt} / \mathrm{d}$ continued for over 2 months. A measurement on April 24, 1993, still showed a flux of about $1 \mathrm{kt} / \mathrm{d}$ (table 1). We suspect these emission levels signify continuing restlessness because measurements on July 7 , 1994, did not detect $\mathrm{CO}_{2}$ above the background (Doukas, 1995).

\section{CONCLUSIONS}

Sulfur dioxide scrubbing by liquid water masked $\mathrm{SO}_{2}$ emissions from shallow magma during the 1992 eruptions of Crater Peak and created the urusual $\mathrm{SO}_{2}$ degassing patterns marked by the absence of exponentially declining fluxes after the three explosive eruptions. Hydrolysis reactions effectively prevented observation of $\mathrm{SO}_{2}$ emissions from shallow magma both before and after explosive eruptions and seismic crises, except for a brief period when dry degassing pathways to the surface existed from September 25 to about October 10, 1992. Measurements of $\mathrm{CO}_{2}$ emissions initiated on September 25, 1992, indicate that in addition to the degassing of magma through dry path- 
ways, degassing through boiling water with the loss of $\mathrm{SO}_{2}$ by scrubbing was also important at this time. The hydrolysis of $\mathrm{SO}_{2}$ also explains the increase in the sulfate content of Crater Peak lake water prior to the first eruption, the strong $\mathrm{H}_{2} \mathrm{~S}$ odor during periods of background to minor $\mathrm{SO}_{2}$ emissions, the TOMS evidence for significant $\mathrm{H}_{2} \mathrm{~S}$ emissions during the explosive eruptions, and the observed decline of $\mathrm{SO}_{2}$ emissions during periods of volcanic tremor. Large $\mathrm{SO}_{2}$ emissions unencumbered by scrubbing only occurred during the three explosive eruptions when magma penetrated through liquid water zones under Crater Peak and reached the surface. Abundant, local sources of melt water and a high permeability for the Mount Spurr volcanic edifice are probably the chief factors responsible for the masking of $\mathrm{SO}_{2}$ emissions by scrubbing, and possibly for quenching shallow intrusions in the process of ascending to the surface.

We strongly recommend early monitoring of $\mathrm{CO}_{2}$ when Cook Inlet volcanoes become restless. Because of its strong preference for the vapor phase during boiling, $\mathrm{CO}_{2}$ emissions from degassing magma are less likely to be masked by the presence of water, whereas $\mathrm{SO}_{2}$ emissions may be lost totally from interactions with water and thus render misleading COSPEC results. We also recommend that $\mathrm{CO}_{2}$ emission rate data sets be obtained for inactive Cook Inlet volcanoes so that baseline fluxes will be available for comparison when these volcanoes become restless.

\section{REFERENCES CITED}

Casadevall, T.J., Johnston, D.A., Harris, D.M., Rose, W.I., Jr., Malinconico, L.L., Stoiber, R.E., Bornhorst, T.J., Williams, S.N., Woodruff, L. and Thompson, J.M., 1981, $\mathrm{SO}_{2}$ emission rates at Mount St. Helens from March 29 through December, 1980, in Lipman, P.W., and Mullineaux, D.R., eds., The 1980 eruptions of Mount St. Helens, Washington: U.S. Geological Survey Professional Paper 1250, p. 193-200.

Casadevall, T. J., Rose, W. I., Gerlach, T. M., Greenland, L. P., Ewert, J., Wunderman, R., and Symonds, R., 1983, Gas emissions and the eruptions of Mount St. Helens through 1982: Science, v. 221, p. 1383-1385.

Casadevall, T.J., Doukas, M.P., Neal, C.A., McGimsey, R.G., and Gardner, C.A., 1994, Emission rates of sulfur dioxide and carbon dioxide from Redoubt Volcano, Alaska during the
1989-1990 eruptions: Journal of Volcanology and Geothermal Research, v. 62, nos. 1-4, p. 519-530.

Daag, A., Tubianosa, B., Newhall, C., Tungol, N., Javier, D., Dolan, M., de los Reyes, P.J., Arboleda, R., Martinez, M., and Regalado, M.T.M., in press, Monitoring sulfur dixxide emissions at Mount Pinatubo volcano, in Newhal: C.G., and Punonbayan, R.S., eds., Fire and Mud: Eruptions and Lahars of Mount Pinatubo, Philippines: University of Washington Press.

Delfin, F.G., Sussman, D., Ruaya, J.R., and Reyes, A.G., 1992, Hazard assessment of the Pinatubo volcanic-geothermal system: Clues prior to the June 15, 1991 eruption: Transactions, Geothermal Resources Council, v. 16, p. 519-528.

Doukas, M.P., 1995, A compilation of sulfur dioxide and carbon dioxide emission-rate data from Cook Inlet vol anoes (Redoubt, Spurr, Iliamna, Augustine), Alaska, durirg the period from 1990 to 1994: U.S. Geological Survey Open-File Report $95-55,15 \mathrm{p}$.

Giggenbach, W.F., 1980, Geothermal gas equilibria: Geochimica et Cosmochimica Acta, v. 44, p. 2021-2032.

Graedel, T.E., 1977, The homogeneous chemistry of atmospheric sulfur: Reviews of Geophysics and Space Physics, v. 15, p. $421-428$.

Harris, D.M., Sato, M., Casadevall, T.J., Rose, W.I., Jr., and Bornhorst, T.J., 1981, Emission rates of $\mathrm{CO}_{2}$ from plume measurements, in Lipman, P.W., and Mullineaux, D.R., eds., The 1980 eruptions of Mount St. Helens, Washington: U.S. Geological Survey Professional Paper 1250, p. 201-207.

Henley, R.W., Truesdell, A.H., Barton, P.B., Jr., and W itney, J.A., 1984, Fluid-mineral equilibria in hydrothermal systems, in Robertson, J.M., ed., Reviews in Economic Geology, v. 1, El Paso, Tx., Society of Economic Geologists, 267 p.

McGee, K. A., 1992, The structure, dynamics, and chemical composition of noneruptive plumes from Mount St. Helens, 198088: Journal of Volcanology and Geothermal Res :arch, v. 51, p. 269-282.

Motyka, R.J., and Nye, C.J., 1993, Fumarolic gas chemistry (1982) and thermal spring water chemistry, Crater Prak (1985), Mount Spurr, Alaska, in Solie, D.N., and Tannian, F., eds., Short notes on Alaskan geology, 1993: Alaska Division of Geological and Geophysical Surveys Professional Report 113 , p. $31-40$.

Schnetzler, C.G., Doiron, S.D., Walter, L.S., and Krueger, A.J., 1994, Satellite measurements of sulfur dioxide from Redoubt eruptions of 1989-1990: Journal of Volcanology and Geothermal Research, v. 62, nos. 1-4, p. 353-358.

Symonds, R.B., Rose, W.I., Bluth, G.J.S., and Gerlach, T.M., 1994, Volcanic-gas studies: Methods, results, applications, in Carroll, M.R., and Holloway, J.R., eds., Volatiles in Magmas: Minerological Society of America Reviews in Mineralogy, v. 30 , p. $1-66$. 



\title{
Chemistry of Crater Lake Waters Prior to the 1992 Eruptions of Crater Peak, Mount Spurr Volcano, Alaska
}

\author{
By Terry E.C. Keith, J. Michael Thompson, and Robert G. McGimsey
}

\section{CONTENTS}

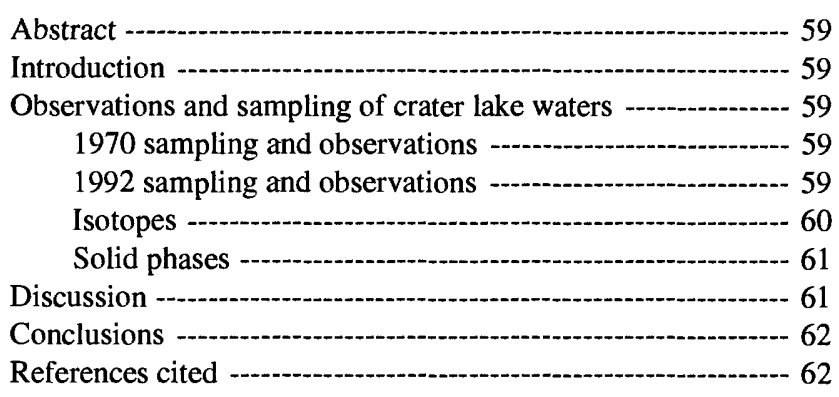

\section{ABSTRACT}

Waters sampled from the shallow lake in the Crater Peak vent of Mount Spurr volcano during June of 1992 were much higher in $\mathrm{SO}_{4}$ and lower in $\mathrm{Cl}$ than waters sampled at the same locality in August of 1970 . The major change in water composition is an effect of the degassing of shallow magma into the volcanohydrothermal system prior to the June 27, 1992, eruption. Though the timing of the chemical change is unknown, it may have been concurrent with a change in the lake observed in early June of 1992. At that time the lake changed from clear, blue-green to turbid, battleship gray. Volcanic unrest was also accompanied by upwellings and bubbling in the lake prior to its disappearance owing to evaporation and (or) draining.

\section{INTRODUCTION}

A nearly circular lake, approximately $100 \mathrm{~m}$ long, developed in the bottom of the satellitic Crater Peak vent on the south flank of Mount Spurr at an unknown time following the eruption of July 9, 1953. Air photos taken in September 1952 show ice filling the crater (Motyka and Nye, 1993) 10 months prior to its first known historical eruption. Careful study of tephras from Mount Spurr volcano show that the Crater Peak vent has erupted 35 times in the past 6,000 years, including 15 times within the past 500 years (Riehle, 1985). The lake in Crater Peak was visited and its water sampled by Bruce Reed and Marvin Lanphere during U.S. Geological Survey (USGS) mapping in the region during the Summer of 1970. Fumaroles at Crater Peak were sampled in 1982 and also visited in 1985, but in 1985 they were too diffuse to sample (Motyka and Nye, 1993). No further sampling of the lake water or fumaroles was done until 2 weeks prior to the June 27, 1992, eruption.

Thermal springs low on the west flanks of Mount Spurr volcano below Crater Peak were discovered and sampled in 1985 by Motyka and Nye (1993). Unfortunately, other priorities precluded sampling these springs during the 1991-92 period of unrest and eruption of the volcano. They were resampled on June 2-3, 1993 (R. Motyka, unpub. data, 1993).

\section{OBSERVATIONS AND SAMPLING OF CRATER LAKE WATERS}

\section{SAMPLING AND OBSERVATIONS}

Reed and Lanphere visited the Crater Perk lake on August 9, 1970, and collected two water samples for analysis (table 1). They were not equipped to measure temperature or $\mathrm{pH}$. Reed's field notes (unpub. data) state that "both samples from approximately 6 inches depth; 2.5 to $3.5 \mathrm{ft}$ from shore; water is milky gray, too hot to hold hand in; had difficulty collecting the samples because of the temperature-could hold hand in for 1-2 seconds, very hot, water is being diluted by snow meltwater..." These observations suggest temperatures in the range 55 to $65^{\circ} \mathrm{C}$.

\section{SAMPLING AND OBSERVATIONS}

Observations and photographs from fixed-wing aircraft overflights in May and the first week of June 1992 recorded the lake color as a clear blue-green, as had been observed during previous years. On the observation flight of June 8 , however, the lake was reported as being a gray color with several small areas of upwelling or bubbling, the most prominent of which 
occurred on the northeast side of the lake. During this flight, the usual scattered, wispy fumarolic activity was noted, and the most vigorous fumarole was emitting a strong steam plume from a talus pile adjacent to the lake on the west side of the crater floor.

On June 11, a descent was made into the Crater Peak vent for general observations. The lake was a murky, battleship gray color. Continued small upwellings were observed; the measured temperature of the lake water $\left(49^{\circ} \mathrm{C}\right)$ indicated that the upwellings were caused by rising noncondensible gases, rather than

Table 1. Chemical and isotopic analyses of Crater Peak (Mount Spurr) lake waters, Alaska.

\begin{tabular}{|c|c|c|}
\hline & *CP92-1 & *CP92-2 \\
\hline \multicolumn{3}{|c|}{ Conditions } \\
\hline $\mathrm{T}^{\circ} \mathrm{C}$ & $\overline{49}$ & 49 \\
\hline field pH & 2.5 & 2.5 \\
\hline lab pH & 2.48 & 2.49 \\
\hline conductance -..... & 3130 & 3120 \\
\hline \multicolumn{3}{|c|}{ Chemical species, in milligrams per liter } \\
\hline $\mathrm{SiO}_{2}$ & 263 & 312 \\
\hline Al 2 & 41.8 & 50 \\
\hline $\mathrm{Fe}$ & 33.2 & 31.6 \\
\hline Mn -................. & 2.95 & 2.94 \\
\hline As - & 0.16 & 0.26 \\
\hline $\mathrm{H} \ldots$ & 7.21 & 8.18 \\
\hline $\mathrm{Ca}$ & 184 & 187 \\
\hline $\mathrm{Mg}$ & 40.5 & 41.3 \\
\hline $\mathrm{Na}$ & 56.0 & 55.1 \\
\hline K & 3.51 & 3.69 \\
\hline $\mathrm{Li}$ & 0.034 & 0.035 \\
\hline $\mathrm{HCO}_{3}$ & 0 & 0 \\
\hline $\mathrm{SO}_{4}$ & 1450 & 1490 \\
\hline $\mathrm{Cl}$ & 53.2 & 54.5 \\
\hline F & 0.42 & 0.42 \\
\hline B & 3.36 & 3.18 \\
\hline \multicolumn{3}{|c|}{$\mathrm{SO}_{4}: \mathrm{Cl}$ ratio } \\
\hline $\mathrm{SO}_{4}: \mathrm{Cl}$ & 27.3 & 27.3 \\
\hline \multicolumn{3}{|c|}{ Isotopic hydrogen and oxygen composition } \\
\hline$* * \mathrm{dD}$ & -116 & -113.5 \\
\hline$* * \mathrm{~d}^{18} 8_{0} \ldots$ & -7.2 & -7.2 \\
\hline & $* * * 70 \mathrm{AR}-201$ & $* * * 70 \mathrm{AR}-202$ \\
\hline & (south edge) & (north edge) \\
\hline \multicolumn{3}{|c|}{ Conditions } \\
\hline $\mathrm{T}^{\circ} \mathrm{C}-(-\cdots$ & nd & nd \\
\hline field pH & nd & nd \\
\hline 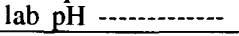 & 2.17 & 2.30 \\
\hline \multicolumn{3}{|c|}{ Chemical species, in milligrams per liter } \\
\hline Ca & 192 & 182 \\
\hline Mg & 71 & 70 \\
\hline $\mathrm{Na}-\ldots$ & 75 & 75 \\
\hline K & 7.5 & 7.3 \\
\hline $\mathrm{HCO}_{3}$ & 0 & 0 \\
\hline $\mathrm{SO}_{4}$ & 442 & 315 \\
\hline $\mathrm{Cl}$ & 1180 & 1100 \\
\hline B & 24 & 24 \\
\hline \multicolumn{3}{|c|}{$\mathrm{SO}_{4}: \mathrm{Cl}$ ratio } \\
\hline $\mathrm{SO}_{4}: \mathrm{Cl}$ & 0.4 & 0.3 \\
\hline
\end{tabular}

*analyst: J. Michael Thompson, USGS, Menlo Park, CA **analyst: L.D. White, USGS, Menlo Park, CA; values relative to SMOW

***unpublished analyses of water samples collected by Marvin Lanphere and Bruce Reed (USGS) on 8/9/70 were provided by Bruce Reed; analyst: Roberta Barnes, USGS, Menlo Park, CA; nd, not determined boiling. Geyser activity, previously unreforted, was observed in the talus pile adjacent to the north edge of the lake where the most vigorous fumarole in the Crater Peak vent had been active for at least several months. Motyka and Nye (1993) reporter the most vigorous fumarolic activity as being on the east side of the lake in 1982 and on the north side in 1985. The fairly rapid migration of active fumorolic vents suggests redirection of fumarolic channels by shallow seismic disturbances; local self-sealing of fumarolic channels by hydrothermal alteration must have occurred to some extent but probably was rot the controlling factor in this case.

On the June 11 trip, two whole-water samples were taken from the lake. One sample (CP-1) was taken adjacent to the shore and the other (CP-2) was taken about $0.5 \mathrm{~m}$ out from shore. The samples ware brought back to Anchorage approximately 4 hours following collection. Half of each sample was filtered and acidified. Chemical and isotopic analyses (tat 1 e 1 ) were made following the procedures of Thompson (1990).

The pale gray, very fine-grained filtrate was analyzed for mineral phases using X-ray diffraction. Phases identified were poorly crystalline sulfur, alunite, pyrite, and kaolinite. Following the mineral analysis, the same filtrate was chemically analyzed using semiquantitative emission spectrographic metr ods to determine minor-element concentrations (table 2).

Two weeks later, on the afternoon of June 26, geologists from the Alaska Division of Geclogical and Geophysical Surveys who were returning from fieldwork by helicopter passed by Crater Peak and observed that the shallow crater lake had "drained." Gray mud covered the crater floor, and a substantial steam cloud rose from the crater. Lake waters evaporated when heated by the rising magma in addition to lake water draining into the subsurface along fractures caused by seismic disturbances in the volcanic edifice.

\section{ISOTOPES}

Oxygen and deuterium isotopic analyses were obtained only on the 1992 lake water samples (table 1). Comparison of these data to the World Meteoric Water Line (Craig, 1961) and to data presented by Motyka and Nye (1993) for meteoric waters from Spurr and Augustine volcanoes show that the Crater Peak lake waters of June 8, 1992, fall well of " the meteoric water line (fig. 1). In a hydrothermal s:'stem, only oxygen shifts to heavier values during water-rock interaction but deuterium remains stable (Craig, 1966). Evaporation shifts both $\delta \mathrm{D}$ and $\delta^{18} \mathrm{O}$ to heavier values. Thus, isotopic values for the Crater Peak lake waters indicate that evaporation dominated any water-rock interaction. The isotope values for the Crater Peak lake waters could also be interpreted to be a 
Table 2. Semiquantitative emission spectrographic chemical analysis of minor elements in filtrate from Crater Peak (Mount Spurr, Alaska) lake waters of June 11, 1992.

[Analyst, E.A. Bailey; ppm, parts per million]

\begin{tabular}{|c|c|}
\hline \multicolumn{2}{|c|}{ element, in weight percent } \\
\hline $\mathrm{Ca}-\ldots-\cdots$ & 1. \\
\hline $\mathrm{Fe}-(-1, \ldots$ & 5. \\
\hline Mg & 1. \\
\hline $\mathrm{Na}$ & 1.5 \\
\hline P & 0.2 \\
\hline Ti & 0.7 \\
\hline \multicolumn{2}{|c|}{ element, in ppm } \\
\hline$\overline{\mathrm{Ag}}-\cdot$ & 1.5 \\
\hline As - & $<200$ \\
\hline $\mathrm{Au}$ & $<10$ \\
\hline B - - & 50 \\
\hline $\mathrm{Ba}$ & $>5,000$ \\
\hline Be - ....... & $<1$ \\
\hline $\mathrm{Bi}$ & $<10$ \\
\hline Cd - & $\sim 20$ \\
\hline Co - & 20 \\
\hline $\mathrm{Cr}$ & 70 \\
\hline $\mathrm{Cu}$ & 150 \\
\hline Ga & 30 \\
\hline Ge - & $<10$ \\
\hline 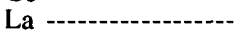 & 50 \\
\hline Mn & 300 \\
\hline Mo - & $<5$ \\
\hline Nb - & $<20$ \\
\hline $\mathrm{Ni}$ & 50 \\
\hline $\mathrm{Pb}$ & 20 \\
\hline $\mathrm{Sb}-\cdots$ & $<100$ \\
\hline Sc & 50 \\
\hline Sn - - & 20 \\
\hline $\mathrm{Sr}$ & 1000 \\
\hline Th - & $<100$ \\
\hline $\mathrm{V}$ & 200 \\
\hline W & $<20$ \\
\hline Y - - & 10 \\
\hline $\mathrm{Zn}$ & $<200$ \\
\hline $\mathrm{Zr}$ & 70 \\
\hline
\end{tabular}

result of meteoric (hydrothermal) waters mixing with magmatic waters, using the field of Sheppard and others (1969).

\section{SOLID PHASES}

Crater Peak vent andesitic rocks, in contact for years with warm, acidic lake waters of the 1970 composition (table 1) and vent fumaroles (Motyka and Nye, 1993), must have altered somewhat to common acidsulfate products such as alunite, kaolinite, pyrite, Fe oxides and hydroxides, as well as residual noncrystalline to poorly crystalline silica phases. The finegrained gray mud of the filtrate is similar in appearance and mineralogy to that in areas of characteristic acid-sulfate alteration, including mudpots of Yellowstone National Park (White and others, 1988), acid altered andesite at White Island, New Zealand (Giggenbach, 1987), and the gray muds in the Ruapehu volcano crater lake (Christenson and Wood, 1993). Upwelling disturbance of the lake waters in Crater

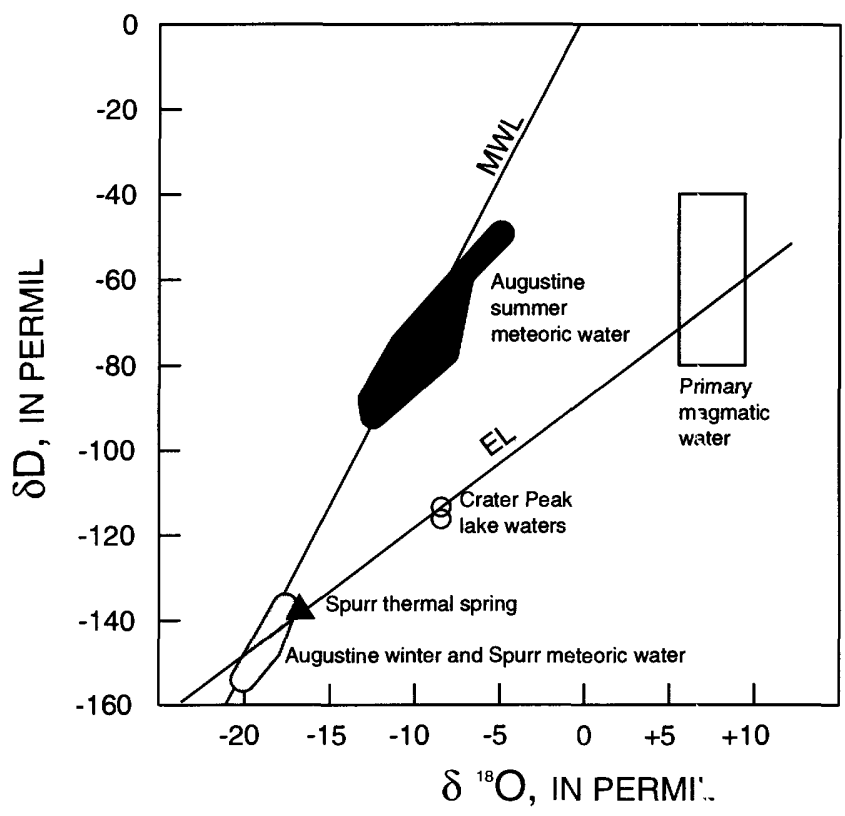

Figure 1. Plot of $\delta^{18} \mathrm{O}$ versus $\delta \mathrm{D}$ of waters from Mount Spurr and Augustine volcanoes compared to the "orld Meteoric Water Line (MWL) of Craig (1961) and an evaporation line (EL) for the Crater Peak (Mount Spurr) lake waters. Data for Augustine summer meteoric wate-s, Mount Spurr meteoric waters (including a cold stream, snowmelt), and Augustine winter meteoric waters, and the triangle representing the thermal spring on the lower soutl flank of Mount Spurr below Crater Peak from Motyka and N'ye (1993). Data for primary magmatic waters from Sheppard and others (1969). Open circles, Crater Peak thermal lake waters of June 11, 1992.

Peak suspended the fine-grained alteration products in the water. Thus the poorly crystalline filt-ate minerals (alunite, pyrite, kaolinite) identified by X-ray diffraction are residual rock alteration products, and the sulfur is from the oxidation of increased magmatic $\mathrm{H}_{2} \mathrm{~S}$ in the lake water. Although silica phases were not detected by X-ray diffraction and the amount of filtrate was too small to analyze for silica, some form of silica was probably present because the lake waters contained substantial dissolved silica.

\section{DISCUSSION}

The striking difference in chemical composition between the two sets of water samples is the high $\mathrm{SO}_{4}: \mathrm{Cl}$ ratio in samples taken in 1992 relative to those taken in 1970. The increased $\mathrm{SO}_{4}$ in water sampled in June 1992 is most likely a result of increased sulfur species degassing from rising magma in the Crater Peak vent and disproportionation of magmatic $\mathrm{SO}_{2}$ in the hydrothermal system and lake waters to form 
aqueous $\mathrm{H}_{2} \mathrm{~S}$ and sulfate, which are much more stable in water than $\mathrm{SO}_{2}$ (Giggenbach, 1987; Doukas and Gerlach, this volume). The $\mathrm{Cl}$ concentration in the crater lake water decreased in 1992 relative to 1970 . The 1992 decrease in $\mathrm{Cl}$ was apparently simultaneous with increased sulfur degassing from the magma. Generally, the concentration of dissolved $\mathrm{Cl}$ in the volcano-hydrothermal system and (or) the overlying shallow lake water would be expected to increase as a result of magma degassing into water.

The relevant question may be why $\mathrm{Cl}$ was so high in 1970 rather than why $\mathrm{Cl}$ was so low in 1992. One possibility is that the subsurface hydrothermal system was not well developed in 1970 following the 1953 eruption, and so $\mathrm{Cl}$ from degassing magma could reach the surface waters, although the large amount of precipitation in the area should have reestablished the hydrothermal system very quickly. The relatively high concentration of B in the 1970 lake waters supports the hypothesis of a well-developed hydrothermal system at that time. High $\mathrm{Mg}$ concentrations of the lake waters in both years suggest substantial water-rock interaction between the acidic lake water and the andesitic host rock of the volcanic edifice. Perhaps $\mathrm{Cl}$ was more concentrated in the August 1970 lake waters because of evaporation of thermal water (where $\mathrm{Cl}$ remained dissolved) accompanied by the precipitation of sulfate as mineral phases, thus being removed from the lake water.

The volcano-hydrothermal system within the south flank of Mount Spurr volcano and beneath the Crater Peak vent was undoubtedly disturbed by the intrusion of magma leading to the June 27, 1992, eruption. As the magma began its ascent, the water of the hydrothermal system was further heated and boiling increased; these processes released $\mathrm{H}_{2} \mathrm{O}, \mathrm{O}_{2}$, and $\mathrm{H}_{2} \mathrm{~S}$, which condensed in the lake and surface waters. Accordingly, the lake waters sampled 16 days prior to eruption in 1992, are probably a mixture of pre-existing lake, magmatic, hydrothermal, and meteoric waters as well as some component of dissolved magmatic gases including sulfur species, $\mathrm{Cl}$, and $\mathrm{F}$. The volcano-hydrothermal system has since been severely disrupted by the three 1992 eruptions and the noneruptive intrusions in late 1992 (Eichelberger and others, this volume).

The changes in character of the lake in the Crater Peak vent prior to the June 27, 1992, eruption are probably a result of major disturbances within the shallow part of the volcano. Similar changes were reported in 1985 at Ruapehu volcano, New Zealand (Scott, 1987; Christenson and Wood, 1993) during heating episodes, some of which resulted in eruption. Crater lake disturbances such as color change and upwellings are frequently associated with increased heating by rising magma.
The fact that ice occupied the Crater Peak vent during September 1952 prior to the July 1953 eruption has interesting implications for monitor:ng Mount Spurr volcano. The Crater Peak vent has a frequent eruptive pattern. Riehle (1985) has documentet 16 eruptions during the past 500 years, and this is a minimum of events because small eruptions that left no tephra records could also have occurred. Observations on the status of the ice in the crater or the development of a lake prior to the 1953 eruption are not known to exist. The development and maintenance of a warm crater lake in the vent between the 1953 and 1992 eruptions suggests that the volcano did not return to the level of inactivity that existed prior to the 1953 eruption, which was cool enough to permit ice to form in the crater. The presence or absence of ice in the crater and the characteristics and chemistry of any crater lake are important indicators of the future status of unrest. Sampling of flank thermal springs during periods of unrest and eruptions might indicate how well they are connected to the hydrothermal system near the vent.

\section{CONCLUSIONS}

The presence of a warm lake in the Crater Peak vent between its 1953 and 1992 eruptions indicates that the volcano had not returned to its pre- 1953 state of inactivity when conditions were cold enough that ice occupied the crater only 10 months prior to eruption. Variations in crater lake appearance (color and turbidity) and chemical composition, esperially the $\mathrm{SO}_{4}: \mathrm{Cl}$ ratio, can be an indicator of volcanic unrest. Such variations may signal the intrusion of ne'v magma. At Crater Peak, the lake disturbances could indicate imminent potential for magmatic or phreatic eruption. Although sampling of the lake waters in the crater may be useful, safety factors often preclude it.

\section{REFERENCES CITED}

Christenson, B.W., and Wood, C.P., 1993, Evolution of a vent-hosted hydrothermal system beneath Ruapehu Crater Lake, New Zealand: Bulletin of Volcanology, v. 55, p. 547--565.

Craig, H., 1961, Isotopic variations in meteoric waters ${ }^{\cdot}$ Science, v. 133 , p. 1702-1703.

Craig, H., 1966, Isotopic composition and origin of the Red Sea and Salton Sea geothermal brines: Science, v. 154, p. 1544 1548.

Giggenbach, W.F., 1987, Redox processes governing the chemistry of fumarolic gas discharges from White Island, N?w Zealand: Applied Geochemistry, v. 2, p. 143-161.

Motyka, R.J., and Nye, C.J., 1993, Fumarolic gas chem istry (1982) and thermal spring water chemistry, Crater Paak (1985), Mount Spurr, Alaska, in Solie, D.N., and Tannian, F., eds., Short Notes on Alaskan Geology 1993: Alaska Department 
of Natural Resources, Division of Geological and Geophysical Surveys Professional Report 113, p. 31-40.

Riehle, J.R., 1985, A reconnaissance of the major Holocene tephra deposits in the upper Cook Inlet region, Alaska: Journal of Volcanology and Geothermal Research, v. 26, p. 37-74.

Scott, B.J., 1987, Ruapehu observations and inspections, Volcano and Geothermal Observations 1985 \& 1986: New Zealand Volcanological Record No. 15, compiled by New Zealand Geological Survey, DSIR, p. 34.

Sheppard, S.M.F., Nielsen, R.L., and Taylor, H.P., Jr., 1969, Oxygen and hydrogen isotope ratios of clay minerals from porphyry copper deposits: Economic Geology, v. 64, p. 755-777.

Thompson, J.M., 1990, Chemical data from thermal and nonthermal springs in the vicinity of Mount St. Helens National Monument: U.S. Geological Survey Open-File Report 90$690 \mathrm{~A}, 16 \mathrm{p}$.

White, D.E., Hutchinson, R.A., and Keith, T.E.C., 1988. The geology and remarkable thermal activity of Norris Geyser Basin, Yellowstone National Park: U.S. Geological S $_{\text {Irvey Pro- }}$ fessional Paper 1456, 84 p. 



\title{
Tephra-Fall Deposits from the 1992 Eruptions of Crater Peak, Mount Spurr Volcano, Alaska: A Preliminary Report on Distribution, Stratigraphy, and Composition
}

\author{
By Christina A. Neal, Robert G. McGimsey, Cynthia A. Gardner, Michelle L. Harbin, and \\ Christopher J. Nye
}

\section{CONTENTS}

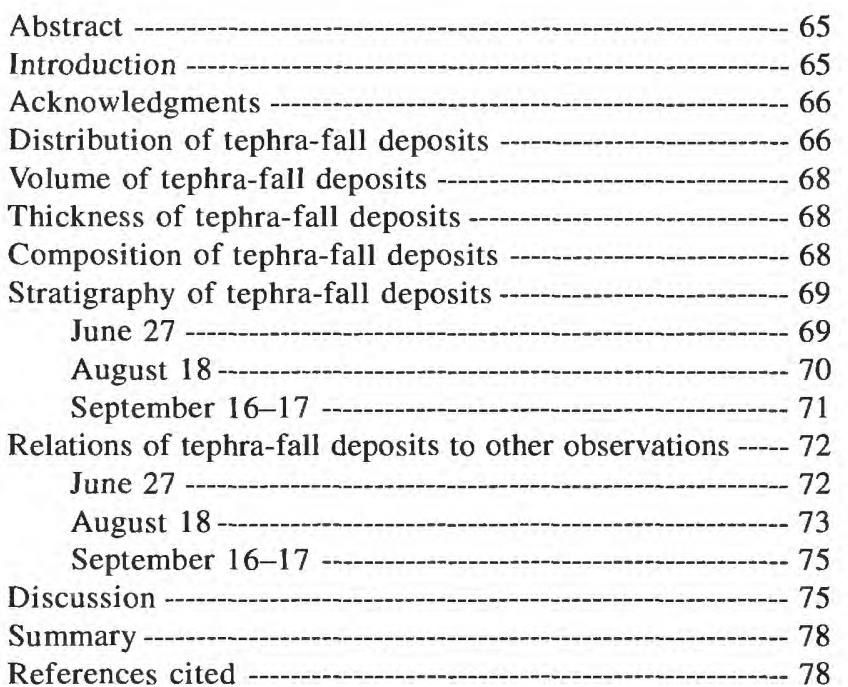

\begin{abstract}
Most ejecta from the 1992 eruptions of Crater Peak was deposited as tephra fall from eruption columns that ascended rapidly to altitudes of greater than $14 \mathrm{~km}$ above sea level. Coarse bomb- to fine ash-sized tephra fell along relatively narrow trajectories extending north, northeast, and east from the vent; these patterns reflect prevailing wind directions in upper Cook Inlet. Each brief (3.5- to 4.0-hour), small-volume (12 to $15 \times 10^{6} \mathrm{~m}^{3}$ dense rock equivalent or DRE) eruption involved two distinct juvenile andesitic tephra components that differ in color and density only; no systematic differences in glass chemistry, bulk composition, or mineralogy have been identified. The stratigraphic relations of these components in the August 18 and September 16-17 deposits suggest that the upper part of an inferred pre-eruption magma body was enriched in volatiles relative to the lower part. Clast-
\end{abstract}

size grading may reflect a progressive increase in magma discharge during the first 2 to 3 hours of tephra emission.

\section{INTRODUCTION}

After 39 years of quiescence, the Crater Peak vent on the south flank of Mount Spurr volcano reawakened with a series of three short lived but violent eruptions of andesitic tephra on June 27, August 18, and September 16-17 of 1992 (Eichelberger and others, this volume; Alaska Volcano Observatory, 1993). Each eruption lasted 3.5 to 4.0 hours and generated vulcanian to subplinian eruption columns that reached altitudes of more than $14 \mathrm{~km}$ above sea level (ASL). Carried downwind, these tephra plumes resulted in narrowly distributed fall deposits composed principally of poorly vesiculated, crystal-rich juvenile andesite that ranged in size from coarse bombs to fine ash. Plumes from the three eruptions extended north, northeast, and east away from the volcano. Two of the three 1992 events deposited significant amounts of fallout tephra onto the most heavily populated areas of south-central Alaska (fig. 1A).

Tephra-fall deposits make up the bulk of the eruptive volume for each event $\left(12,14,15 \times 10^{6} \mathrm{~m}^{3}\right.$ DRE for the three eruptions) and hence contain critical information regarding temporal changes in chemistry, eruption dynamics, and plume behavior. Each eruption also produced small pyroclastic flows and lahars, however, together these deposits make up less than 1 percent of the total bulk volume for the entire eruption series (Miller and others, this volume; D. Meyer, oral commun., 1994). This paper summarizes field characteristics and preliminary compositional analyses of proximal tephra-fall deposits, and it also proposes a model to explain observed physical and sedimentologic variations. 


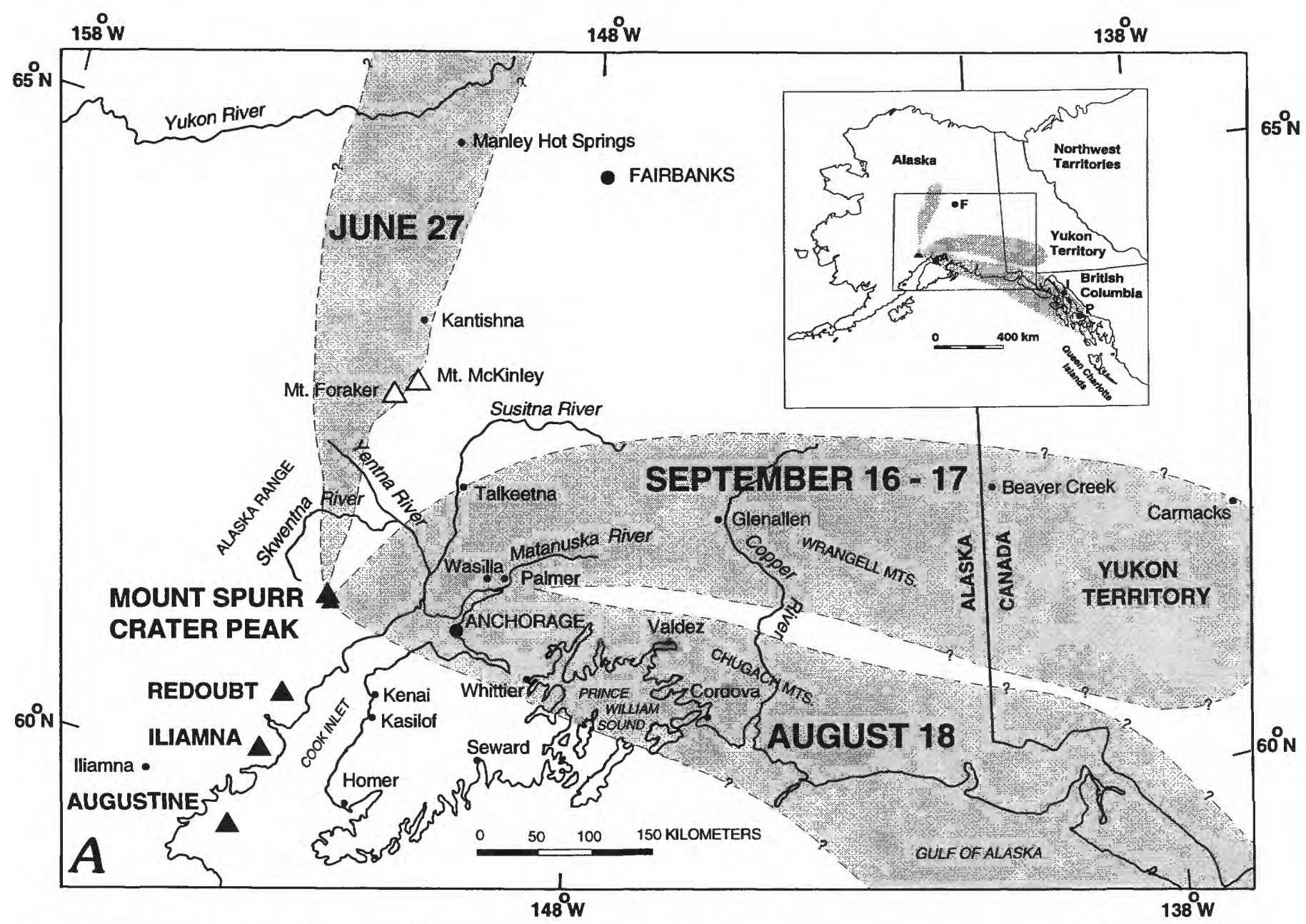

Figure 1. A, Generalized map showing extent of the three tephra-fall deposits from the 1992 eruptions of Crater Peak, Mount Spurr volcano, Alaska. Shaded areas denote approximate limits of tephra-fall inferred from ground and aerial surveys within 250 $\mathrm{km}$ of the vent as well as phone contact with distant communities within several days of the eruptions. Due to very sparse population and poor road access, the actual downwind extent of each deposit is unknown.

\section{ACKNOWLEDGMENTS}

The 1992 Mount Spurr eruption response was a team effort and we thank the entire AVO staff and many AVO affiliates for their contributions to this study. Tom Miller and Jim Begét shared observations of the June 27 deposits. Terry Keith, Deb McGimsey, and Judith Radwany assisted in sampling. Marvin Couchman is gratefully acknowledged for his measurements of clast densities. Lee Kelley of the National Weather Service (NWS) provided information on radar observations. We would also like to thank members of the public, other U.S. government agencies, Transport Canada, and the Canadian Geological Survey for sharing important observations of the eruption plume and tephra fall. Kathy Lemke and Ann Vanderpool assisted with computer graphics. Reviews by Steve Self, Richard Waitt, and Steve Carey significantly improved the content and presentation of this paper.

\section{DISTRIBUTION OF TEPHRA-FALL DEPOSITS}

Prevailing winds in upper Cook Inlet (fig. 1B) blow from the southeast, southwest, and northwest; the dominant wind direction is from the south to southwest. Consequently, tephra erupted from any Cook Inlet volcano is likely to be carried over populated areas and into the busy air traffic corridor of south-central Alaska; this phenomenon underscores the need for timely eruption notification and tracking of tephra plumes. As part of eruption-response procedures at the Alaska Volcano Observatory (AVO), hypothetical plume trajectory plots provided by the NWS were generated at AVO (Brantley, 1990, fig. 32). Based on twice-daily atmospheric soundings of wind velocity at various altitudes, these maps are used to forecast probable dispersal patterns of tephra plumes and resultant fallout 


\section{ANCHORAGE WINDS ALOFT}

\section{WINTER / SPRING SUMMER / FALL}
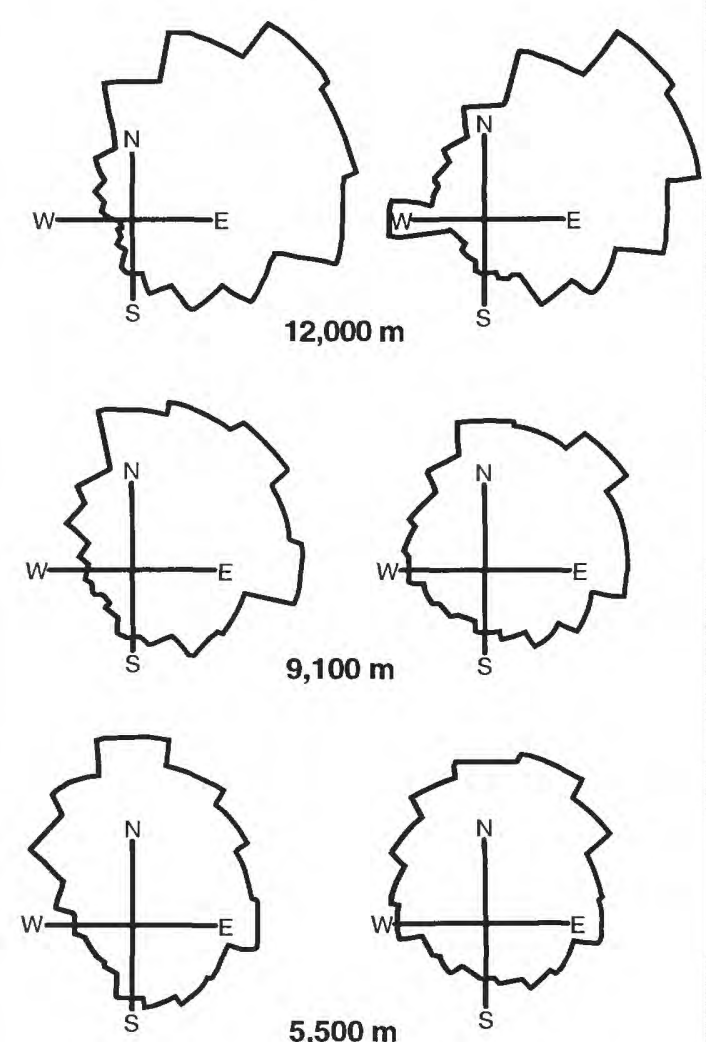

$5,500 \mathrm{~m}$
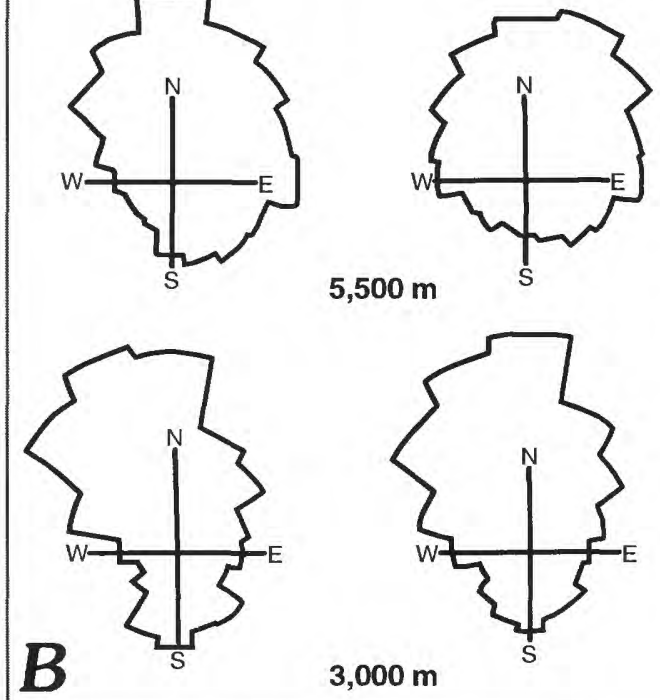

Figure 1. Continued. $B$, Compass rose diagrams indicate percent of time that winds blow toward a given direction over Anchorage (adapted from Till and others, 1993, and based on data from the National Climatic Data Center, Asheville, North Carolina for the period 1948 to 1972 ).

(Murray and others, 1994). All three tephra plumes produced during the 1992 eruptions at Crater Peak followed trajectories in good agreement with these plots.
The June 27 eruption occurred during a period of strong southerly winds and heavy overcast. As determined by $\mathrm{C}$-band (5.4- $\mathrm{cm}$-wavelength) radar operated by NWS, the vertical eruption column reached a maximum altitude of $14.5 \mathrm{~km}$ ASL by 10:23 a.m. Alaska Daylight Time (ADT), approximately 3.3 hours into the eruption (Rose and others, this volume). The tephra plume traveled north from Crater Peak (fig. $1 A)$ over the relatively unpopulated Yentna and Skwentna River basins, the Alaska Range near Mount Foraker, and the settlement of Kantishna. The most distal report of ash fall was received from Manley Hot Springs, $140 \mathrm{~km}$ west of Fairbanks and $420 \mathrm{~km}$ north of Crater Peak. To the north of this community, there are few settlements.

During the August 18 eruption, winds were westerly and the axis of the main tephra fall extended east from Crater Peak, across Cook Inlet and over the Anchorage basin where 1 to $3 \mathrm{~mm}$ of primarily coarse ash was deposited. The plume continued southeastward over Prince William Sound, the eastern Chugach Mountains, and the Gulf of Alaska (fig. 1A). Petersburg, Alaska, 1,200 km southeast of Crater Peak (fig. $1 A$, inset) reported a light dusting of fine ash on August 19. Farther south, in the Queen Charlotte Islands and along coastal British Columbia, Canadian Flight Service Station personnel noted only the passage of a hazy layer overhead. In distribution, this fallout pattern is similar to that of the 1953 Crater Peak eruption; tephra accumulation in Anchorage, however, was greater in 1953 (3-6 mm; Wilcox, 1959). The maximum radar-discernible plume height during the August 18,1992 , eruption was $13.7 \mathrm{~km}$ ASL at 4:55 p.m. ADT (Rose and others, this volume), only 14 minutes after the onset of the main phase of the eruption. Pilot estimates of the top of the visible plume suggested actual heights may have been in excess of $18 \mathrm{~km}$.

The September 16-17 eruption occurred during southwesterly winds and the plume traveled northeast over the communities of Wasilla and Palmer in the Matanuska-Susitna valley, parts of the Talkeetna Mountains, the Copper River Basin, and east into the Yukon Territory of Canada (fig. 1A). The farthest reported ash fall was in Carmacks, Yukon Territory, $860 \mathrm{~km}$ from Crater Peak. Light and variable low-level winds on September 16 and 17 accounted for numerous reports of very light dustings of ash as far south as Anchorage. Maximum radar-discernible plume height was $13.9 \mathrm{~km}$ ASL by 2:21 a.m. ADT, September 17 (Rose and others, this volume), more than 2 hours after the eruption began. Because the eruption occurred at night, there were few pilot reports of column height to corroborate this estimate. 


\section{VOLUME OF TEPHRA-FALL DEPOSITS}

Helicopter-supported mapping and road access to large areas affected by the August 18 and September 16-17 eruptions allowed for rapid measurement of tephra-fall deposit thicknesses within south-central Alaska. Most data and samples were gathered within several days to 1 week of the eruption. With the exception of some wetting and compaction owing to rainfall or incorporation of water from melting snow and ice substrate, no significant reworking of the deposits was evident during collection of most samples. For each of the three tephra-fall deposits, we collected between 5 and 50 measured area samples (typically 20 $x 20 \mathrm{~cm}$ ) along and across the deposit axis as far as $190 \mathrm{~km}$ from Crater Peak. Based on mass per unit area data (Scott and McGimsey, 1994; Fierstein and Nathenson, 1992), the DRE volumes (using $2,600 \mathrm{~kg} / \mathrm{m}^{3}$ ) calculated for each event are $12 \times 10^{6} \mathrm{~m}^{3}, 14 \times 10^{6} \mathrm{~m}^{3}$, and $15 \times 10^{6} \mathrm{~m}^{3}$ for the June 27, August 18, and September 16-17 eruptions, respectively. Bulk volumes calculated using the same method and a density of 700 $\mathrm{kg} / \mathrm{m}^{3}$ are $44 \times 10^{6} \mathrm{~m}^{3}, 52 \times 10^{6} \mathrm{~m}^{3}$, and $56 \times 10^{6} \mathrm{~m}^{3}$.

\section{THICKNESS OF TEPHRA-FALL DEPOSITS}

Stable wind conditions during each brief eruption contributed to fairly uniform changes in thickness and grain size with increasing distance from the vent. Proximal tephra-fall deposits for each eruption range similarly in thickness from about $1 \mathrm{~m}$ at the base of Crater Peak (approximately $1 \mathrm{~km}$ from vent) to 10 $\mathrm{cm}$ at a $10-\mathrm{km}$ distance (fig. 2). At a distance of 100 $\mathrm{km}$, the total ash fall is only a few millimeters thick. Over the same distance, modal grain size varies roughly from cobble gravel near the vent to coarse sand at $100 \mathrm{~km}$. Additional grain-size analyses are in progress to further characterize the deposits.

\section{COMPOSITION OF TEPHRA-FALL DEPOSITS}

Most tephra from each eruption consists of juvenile andesite fragments of two distinct colors, tan and gray. For the August 18 and September 16-17 tephra sequences, lower and upper stratigraphic units (layers A and B, respectively) reflect a distinct change in the proportion of the two colors (table 1). Overall, the deposits are volumetrically dominated by tan to light-brown, slightly pumiceous, angular, equant to pyramidal fragments of crystal-rich andesite. Many clasts were fractured during ejection or deposition and have one or more flat or slightly concave faces. Lapilli
(1-3 cm) commonly show gradational color variations from tan exteriors to dark-brown interiors. Inclusions of vesiculated basement clasts; dense gray, aphyric volcanic lithics; and rounded, sugar-textured, plagioclase-pyroxene crystal clots are common and are similar to inclusions found in the breadcrusted bombs of the pyroclastic-flow deposits (Miller and others, this volume; Nye and others, this volume; Harbin and others, this volume). Second in abundance are light- to medium-gray, microvesicular, crystal-rich andesite clasts that predominate in the upper part of the August 18 and September 16-17 tephra sections. These clasts are smaller in grain size and denser (table 2) than accompanying tan clasts, but they contain similar lithic, crystal-clot, and exotic pumiceous inclusions. They are angular to subrounded and generally equant in shape.

Accidental clasts make up a small volume of the tephra-fall deposits. These clasts consist of pre-1992 Crater Peak volcanic rocks recognized on the basis of alteration, fragments of coarse-grained metamorphic and possibly plutonic basement, crystal clots, and vesiculated clasts of basement rock (table 1; Harbin and others, this volume; Miller and others, this volume). A representative proximal sample of each tephra-fall unit was selected, and between 900 and 3,400 clasts were sorted and counted for each sample; percentages listed below and in table 1 represent the proportion of counted clasts. Fragments were classified on the basis of gross visual characteristics. Although these counts represent only a limited view of each deposit, we noted no field evidence of gross spatial changes in deposit character, and hence consider these percentages to be good first-order representations of each unit.

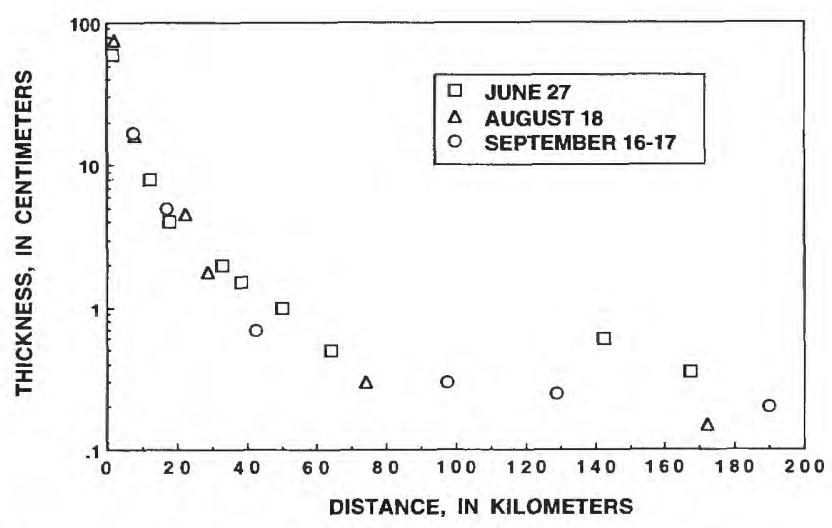

Figure 2. Thickness of tephra-fall deposits from the 1992 eruptions of Crater Peak, Mount Spurr volcano, Alaska, measured downwind along an approximate axis of each plume. The two most distant points for June 27 tephra were measured in the late summer of 1993 and are considered anomalously thick owing to percolation of the fine sand-sized tephra across a recrystallized snow layer. 
Table 1. Percentage of clast types for tephra-fall deposits from the 1992 eruptions of Crater Peak, Mount Spurr volcano, Alaska.

[Populations determined by hand picking from size fraction larger than -1.75 phi (approximately $3 \mathrm{~mm}$ ). Similar calculations based on weight or volume of each clast type produce nearly identical results. See text for description of each clast type.]

\begin{tabular}{|c|c|c|c|c|c|}
\hline & Tan andesite & Gray andesite & $\begin{array}{l}\text { Pre-1992 } \\
\text { volcanics }\end{array}$ & $\begin{array}{l}\text { Metamorphic } \\
\text { and plutonic }\end{array}$ & Total clasts \\
\hline June 27 -..... & 78 & 14 & 7 & 1 & 1761 \\
\hline August 18 layer $A$ & 70 & 23 & 6 & 1 & 3355 \\
\hline August 18 layer $\mathrm{B}$ & 6 & 91 & 3 & 0 & 1067 \\
\hline September 16-17 layer A-- & 79 & 15 & 5 & 1 & 2630 \\
\hline September 16-17 layer B---- & 26 & 64 & 10 & 0 & 918 \\
\hline
\end{tabular}

Table 2. Densities, (in $\mathrm{g} / \mathrm{cm}^{3}$ ) for selected juvenile tephra clasts from the 1992 eruptions of Crater Peak, Mount Spurr volcano, Alaska.

[Note the similarity in component densities for August and September. Overall, June clasts of both types are 10 to 15 percent denser than clasts from the other two eruptions. Densities were measured by M. Couchman following techniques described in Hoblitt and Harmon (1993).]

\begin{tabular}{|c|c|c|c|c|c|c|c|c|c|}
\hline June tan & June gray & $\begin{array}{c}\text { August } \\
\text { layer A } \\
\text { tan }\end{array}$ & $\begin{array}{c}\text { August } \\
\text { layer A } \\
\text { gray }\end{array}$ & $\begin{array}{c}\text { August } \\
\text { layer } B \\
\text { tan }\end{array}$ & $\begin{array}{c}\text { August } \\
\text { layer B } \\
\text { gray }\end{array}$ & $\begin{array}{c}\text { September } \\
\text { layer } A \\
\text { tan }\end{array}$ & $\begin{array}{c}\text { September } \\
\text { layer A } \\
\text { gray }\end{array}$ & $\begin{array}{c}\text { September } \\
\text { layer B } \\
\text { tan }\end{array}$ & $\begin{array}{c}\text { September } \\
\text { layer B } \\
\text { gray }\end{array}$ \\
\hline 1.98 & 2.21 & 1.59 & 1.98 & 1.65 & 1.98 & 1.61 & 1.85 & 1.54 & 1.83 \\
\hline 1.56 & 2.08 & 1.52 & 2.07 & 1.57 & 1.98 & 1.60 & 1.75 & 1.65 & 1.93 \\
\hline 1.76 & 1.91 & 1.93 & 1.86 & 1.32 & 1.85 & 1.37 & 1.89 & 1.53 & 1.92 \\
\hline 1.86 & 1.98 & 1.47 & 2.47 & 1.69 & 2.14 & 1.69 & 2.02 & 1.80 & 2.70 \\
\hline 1.78 & 2.14 & 1.67 & 2.07 & 1.55 & 1.80 & 1.86 & 1.87 & 1.73 & 1.99 \\
\hline 1.92 & 2.38 & 1.69 & 1.87 & 1.48 & 2.04 & 1.76 & 1.59 & 1.14 & 2.09 \\
\hline 1.66 & 2.03 & 1.34 & 1.89 & 1.48 & 2.46 & 1.16 & 1.73 & 1.64 & 2.05 \\
\hline 1.44 & 1.93 & 1.40 & 1.88 & 1.55 & 2.02 & 1.53 & 1.47 & & \\
\hline 1.93 & 2.72 & 1.87 & 2.07 & 1.53 & 1.93 & 1.71 & 2.41 & & \\
\hline 1.82 & 2.04 & 1.43 & 1.96 & 1.29 & 1.81 & 1.62 & 2.38 & & \\
\hline 1.86 & 2.69 & 1.41 & 2.36 & 1.62 & 1.95 & 1.88 & 2.61 & & \\
\hline 1.58 & 2.76 & 1.48 & 1.97 & 1.58 & 2.56 & 0.98 & 2.71 & & \\
\hline 1.58 & 2.45 & 1.57 & 2.48 & 1.47 & 1.81 & 1.59 & 2.25 & & \\
\hline 1.91 & 2.67 & 1.51 & 2.09 & 1.43 & 2.03 & 1.76 & 1.85 & & \\
\hline 1.87 & 2.10 & 1.70 & 2.02 & 1.43 & 1.96 & 1.33 & 1.79 & & \\
\hline 2.01 & & 1.67 & 1.97 & 1.41 & 1.89 & 1.62 & & & \\
\hline 1.91 & & 1.62 & 2.33 & 1.31 & 2.10 & 1.41 & & & \\
\hline 1.79 & & 1.38 & 1.88 & 1.61 & 1.90 & 1.33 & & & \\
\hline 1.43 & & 1.45 & 1.94 & 1.55 & 2.01 & 1.25 & & & \\
\hline 1.49 & & 1.38 & 1.86 & 1.55 & 2.01 & 1.51 & & & \\
\hline \multicolumn{10}{|c|}{ Average densities } \\
\hline 1.76 & 2.27 & 1.55 & 2.05 & 1.50 & 2.01 & 1.53 & 2.01 & 1.58 & 2.07 \\
\hline
\end{tabular}

\section{STRATIGRAPHY OF TEPHRA-FALL DEPOSITS}

\section{JUNE 27}

The June 27 tephra-fall deposit is light gray to tan in color, moderately well sorted, and shows weak reverse grading. Angular clasts of tan to light-brown, poorly vesicular, porphyritic juvenile andesite are the dominant component ( 78 percent; table 1), followed by a smaller population ( 14 percent) of light-gray, denser, and more finely crystalline andesite fragments. The color and textural variation between the two components is subtle and quite difficult to discern in clasts smaller than about $5 \mathrm{~mm}$ across. Pre-1992 volcanic clasts, some altered to a brick-red color, represent 7 percent of the deposit. Nonvolcanic fragments are a minor component ( 1 percent). Dry-bulk densities of five samples with median grain sizes of 0.5 to 4.0 $\mathrm{mm}$ range from 1.07 to $1.32 \mathrm{~g} / \mathrm{cm}^{3}$. The tan and gray juvenile clasts from the most proximal sample have average densities of 1.76 and $2.27 \mathrm{~g} / \mathrm{cm}^{3}$, respectively (table 2).

Less than 1 percent of the June 27 tephra consists of subangular to subrounded clasts of light-tan, light-gray or white, sugar-textured, and pumiceous (density less than $1.0 \mathrm{~g} / \mathrm{cm}^{3}$ ) mixtures of feldspar, quartz, scattered mafic minerals and silica-rich glass, here referred to as "silicic pumice" (Nye and others, this volume). These exotics represent entrained basement rock (Miller and others, this volume; Harbin and others, this volume). They are found predominantly on the surface of the June 27 (and subsequent) tephra-fall sequences, which probably reflects their low density and longer residence time in the tephra plume. 


\section{AUGUST 18}

The main August 18 tephra-fall sequence (fig. 3 ) consists of a weakly developed, fine-grained basal unit (Layer A'), a moderately well sorted, light-gray to tan, reversely graded unit (layer A) that represents from 60 to 75 percent of the total thickness of any given section, and an upper, well sorted, dark gray, ungraded unit (layer B). Layers A and B are discernible in proximal sections and in thin (less than $2 \mathrm{~mm}$ thick) distal tephra deposits as much as $170 \mathrm{~km}$ east of Crater Peak.

At three localities 6 to $14 \mathrm{~km}$ downwind from Crater Peak, a discontinuous, thin (less than 1-2 mm) dark-gray, medium-grained sand horizon is present beneath layer $A$. This layer ( $\left.A^{\prime}\right)$ was too thin to sample and was not observed with confidence at all August 18 tephra sections.

Approximately 70 percent of fragments within layer A consists of juvenile, tan, slightly pumiceous, phenocryst-rich clasts. Twenty-three percent of layer A consists of smaller juvenile fragments of andesite that are light to medium gray, microvesicular to dense, and contain sparse lithic inclusions. Clasts that contain both tan and gray components are rare, and in these clasts the boundaries between the tan and gray components are sharp and easily recognized on the basis of color and vesicularity. In addition to the tan and gray clasts, there is a small (approximately 6 percent) population of altered volcanic rock fragments and a small number of white, dense metamorphic clasts. No silicic pumice has been recognized in layer $\mathrm{A}$ samples. Dry-bulk densities of five samples range from 0.96 to $1.09 \mathrm{~g} / \mathrm{cm}^{3}$ for layer A. The tan and gray juvenile clasts from layer $A$ have average densities of 1.55 and $2.05 \mathrm{~g} / \mathrm{cm}^{3}$, respectively (table 2 ).

Most fragments (91 percent) within layer B consist of juvenile, microvesicular to dense, light to medium gray andesite that are similar to the gray fragments of layer A. Tan clasts similar to the dominant component of layer A make up only 6 percent of layer B. Three percent of layer B consists of pre-1992 volcanic clasts and there are only rare fragments of dense, white metamorphic rock. Scattered on the surface of layer B are subangular to subrounded clasts of lighttan to white silicic pumice fragments. Layer B is finer grained at a given distance from the vent than layer $\mathrm{A}$, and it has a dry-bulk density of 1.13 to $1.34 \mathrm{~g} / \mathrm{cm}^{3}$, which is approximately 30 percent higher than that of layer A. Average tan and gray clast densities are 1.50 and $2.01 \mathrm{~g} / \mathrm{cm}^{3}$, respectively (table 2 ).

In addition to the continuous tephra sequence described above, a prominent ballistic impact zone occurs along the southern margin of the proximal August 18 tephra fall. Extending as much as $10 \mathrm{~km}$ from the vent (Waitt and others, this volume), this shower of juvenile and accidental blocks as large as $1 \mathrm{~m}$ across occurred primarily late in the eruption, following the main phase of tephra emission (Miller and others, this volume; Waitt and others, this volume).

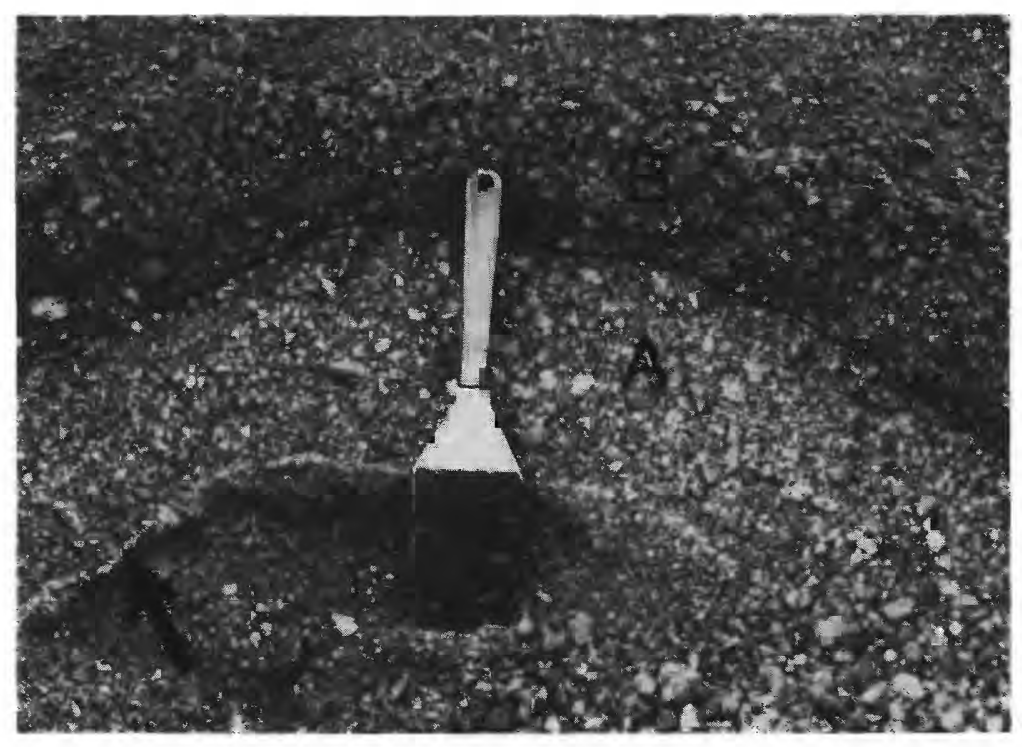

Figure 3. A 16-cm-thick tephra-fall deposit from the August 18, 1992, eruption, located approximately $6.4 \mathrm{~km}$ east of Crater Peak, Mount Spurr volcano, Alaska. Layers A and B are labeled. Note reverse grading of layer A. Section rests on sandy tephra from a 1990 eruption of Redoubt Volcano (light horizon; see arrow). Spatula is $23 \mathrm{~cm}$ long. 


\section{SEPTEMBER 16-17}

The September 16-17 fallout deposit contains three layers (layers $\mathrm{A}^{\prime}, \mathrm{A}$, and B) similar to those for the August 18 tephra, however the color change that marks the layer A-B transition is not as visually distinct (fig. 4).

At one locality $6.5 \mathrm{~km}$ from the vent, a coarse sand unit (layer A') was noted beneath the main sequence. A sample of this unit consists of coarse sandsized, crystal-rich, dense to slightly pumiceous fragments. Both tan and gray colors are represented, estimated visually to be about 60 and 30 percent, respectively. A significant (approximately 10 percent) number of particles are strongly oxidized brick red to purple in color, phenocryst-rich volcanic rock fragments or white to gray crystalline, possibly plutonic or metamorphic fragments.

Layer A makes up the lower 70 to 80 percent of the tephrafall, is moderately well sorted, reversely graded, and composed of 79 percent very light tan, slightly pumiceous, phenocryst-rich clasts similar to those in the August 18 tephra. Some of these clasts show a slight yellow tint and are among the most pumiceous of Crater Peak juvenile andesite tephra; a few are highly pumiceous and probably represent the "lightgreen-gray andesite" (a slight differentiate of the juvenile andesite) of Harbin and others, (this volume).
Fifteen percent of layer A consists of smaller fragments of juvenile microvesicular to dense, light- to medium-gray andesite. Pre-1992 volcanic fragments including distinctive rounded clasts of glassy black vesicular rock make up 5 percent of layer $\mathrm{A}$. About 1 percent consists of light-colored plutonic or metamorphic clasts. Dry-bulk densities of two layer A tephra samples are 1.09 and $1.16 \mathrm{~g} / \mathrm{cm}^{3}$. The tan and gray juvenile clasts from layer $A$ have average densities of 1.53 and $2.01 \mathrm{~g} / \mathrm{cm}^{3}$, respectively (table 2).

The September 16-17 layer B is ungraded and finer grained at a given distance from the vent than layer A. Sixty-four percent of the clasts in layer B are light- to medium-gray, microvesicular to dense andesite. Twenty-six percent of layer B clasts are light tan, slightly pumiceous and phenocryst-rich. Dry-bulk densities of two samples are 1.24 and 1.32 $\mathrm{g} / \mathrm{cm}^{3}, 15$ percent greater than layer A. The lower bulk density of September 16-17 layer B compared to August 18 layer B is reflected in the higher percentage of tan clasts in the September 16-17 deposit (table 1). Average clast densities for tan and gray components of layer B are 1.58 and $2.07 \mathrm{~g} / \mathrm{cm}^{3}$, respectively. Pre-1992 volcanic fragments make up nearly 10 percent of layer B. At more distal locations (20 to $30 \mathrm{~km}$ from the vent) scattered silicic pumice fragments litter the surface of layer $B$.

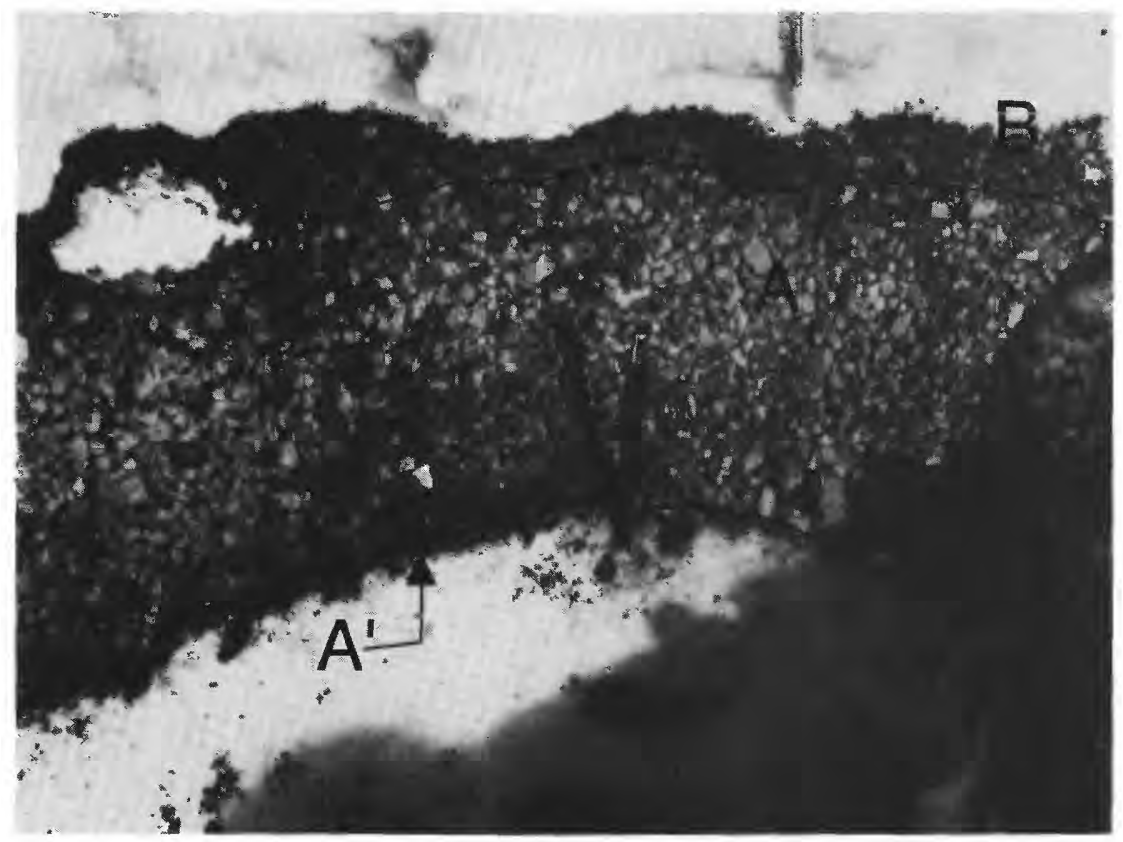

Figure 4. A 17-cm-thick tephra-fall deposit from the September 16-17, 1992, eruption, located approximately $7.2 \mathrm{~km}$ northeast of Crater Peak, Mount Spurr volcano, Alaska. Layers A', A, and B are labeled. Note reverse grading of layer A. Section rests on snow. Pencil in center of photograph is approximately 10 $\mathrm{cm}$ long. 
With increasing distance along the axis of the deposit, the color change in the September 16-17 tephra fall becomes more distinct. About $250 \mathrm{~km}$ away, at the northern edge of the deposit, the ash is very light in color, presumably reflecting dominance of the tan juvenile component (layer A?). At the southern margin, the ash is noticeably dark and probably represents the gray juvenile component (layer B?). Given measurable density differences in both dominant clast and bulk densities between layers A and B of 15 to 30 percent (table 2 ), such asymmetry could reflect within-plume sorting due to slight variations in wind direction with altitude or over the course of the eruption, similar to that documented at Mount St. Helens in 1980 (Sarna-Wojcicki and others, 1981; Waitt and others, 1981).

Ballistic emplacement of coarse breadcrusted bombs consisting principally of tan and gray juvenile components and a smaller lithic component occurred during the September 16-17 eruption. Within approximately $10 \mathrm{~km}$ of the vent, along the southern margin of the tephra-fall field, lapilli and bombs were deposited along a narrow corridor. In the snowpack, the ballistic horizon consisted of isolated bombs and lapilli in a matrix of snow and ice that extended down as much as a meter (fig. 5). This disseminated deposit was produced when hot ballistic ejecta impacted snow, differentially melting downward depending on the size of each clast. Melted entry trails were subsequently refrozen to form ice stringers. In part because of the variable settling, there was no time sequence preserved in this ballistic deposit, hence we could not evaluate any stratigraphic information. The collapsed thickness of the deposit after drying ranged from 3 to $4 \mathrm{~cm}$ between 6 and $12 \mathrm{~km}$ from the vent.

\section{RELATIONS OF TEPHRA-FALL DEPOSITS TO OTHER OBSERVATIONS}

To help interpret the proximal tephra-fall record in relation to eruptive processes, the following section summarizes aspects of the timing of tephra fall to pyroclastic flow formation, ballistic ejection of large blocks, and other observations.

\section{JUNE 27}

Cloud cover precluded direct observation of the development of the June 27 eruption column or tephra plume. Moreover, strong southerly winds carried the plume northward, $180^{\circ}$ away from the path of hotpyroclast and snow mixtures that swept down the south and southeast flanks of Crater Peak (Meyer and Trabant, this volume). Hence, there is no stratigraphic infor-

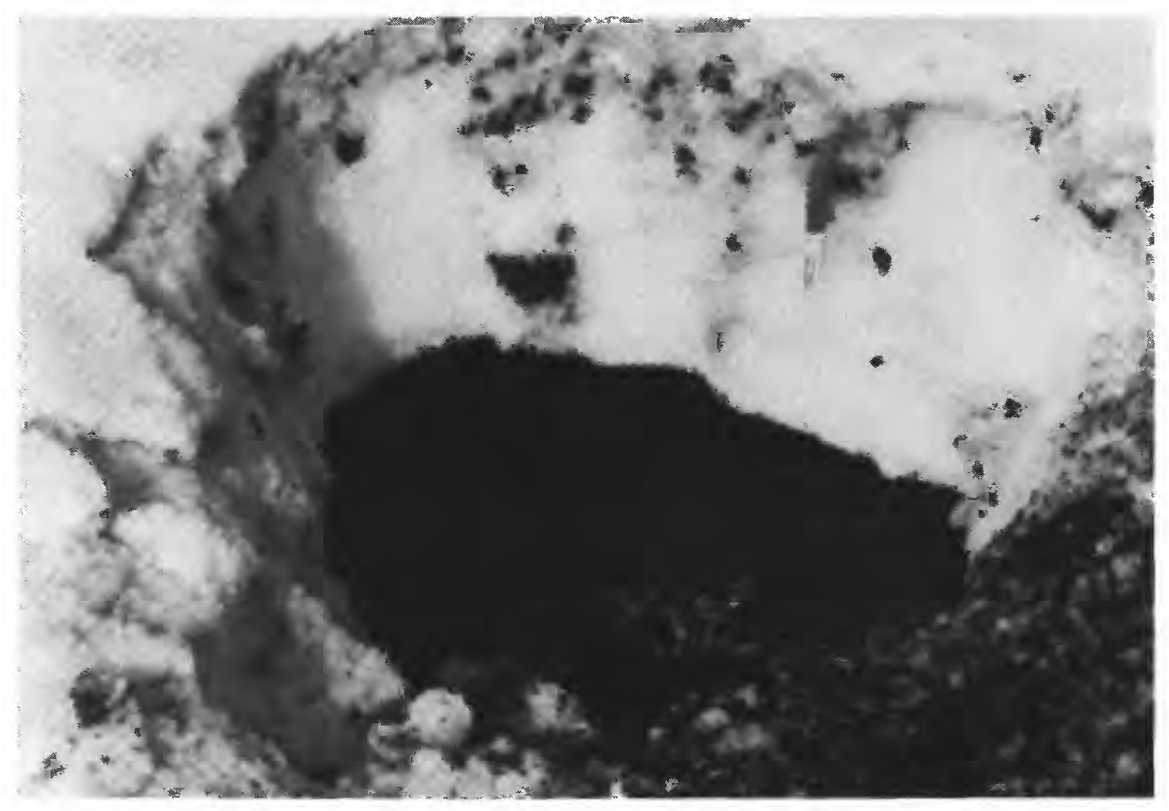

Figure 5. Ballistic tephra-fall deposit from September 16-17, 1992, eruption, located $7 \mathrm{~km}$ northeast of Crater Peak, Mount Spurr volcano, Alaska. Projectiles shown here penetrated snow upon impact and left a disseminated horizon of lapilli, bombs, snow, and ice. Dark horizon below is the August 18 tephra section. At the top is a fine ash layer that probably reflects aeolian reworking of material subsequent to the September 16-17 event. 
mation to help determine the timing of pyroclastic flow emplacement. Observations inside Crater Peak following the eruption revealed meter-sized bombs littering the surface of a greater than 10-meter-thick deposit of finer grained pyroclastic material interpreted by Miller and others (this volume) as surge deposits. Similarly, numerous coarse juvenile and lithic bombs and associated impact craters dotted the landscape north and east of Crater Peak. Thus, ejection of large bombs, perhaps caused by intermittent phreatomagmatic explosions in the upper part of the conduit, occurred at the end of the June 27 eruption.

Radar images of the June 27 eruption plume are of insufficient quality and pilot reports are too few to establish a good record of the development of the column. However, the maximum radar-discernible column height was recorded 3.3 hours into the eruption (Rose and others, this volume). This is remarkably consistent with RSAM (real-time seismic amplitude measurements; a crude measure of eruption intensity; Murray and Endo, 1989) values, which increased gradually, peaked nearly 3.5 hours into the eruption, and then decreased abruptly during the final hour (fig. 6; McNutt and others, this volume).

\section{AUGUST 18}

The opening phase of the August 18 eruption coincided with 12 minutes of tremor recorded on one Spurr seismic station between 3:41 p.m. and 3:52 p.m. ADT (station CRP; McNutt and others, this volume). This event produced a minor tephra plume that, according to pilot reports, had reached approximately $2.5 \mathrm{~km}$ above the vent ( $4.5 \mathrm{~km} \mathrm{ASL})$ by $4: 20$ p.m. ADT. A thin (less than $1 \mathrm{~mm}$ ), medium sand deposit from this event (layer $\mathrm{A}^{\prime}$ ) was identified at three localities 4 to $16 \mathrm{~km}$ east of the vent. The deposit was

Figure 6. Schematic relation in time between RSAM, maximum eruption column height, tephra production and tephrafall stratigraphy for the 1992 eruptions of Crater Peak, Mount Spurr volcano, Alaska. Curves are RSAM changes at station BGL, located $7.5 \mathrm{~km}$ west of Crater Peak; dashed where values represent instrument saturation and RSAM is unreliable. Vertical axis is digital counts. Stars denote time of maximum column height determined from C-Band radar (Rose and others, this volume). Below each curve is a schematic section of tephra-fall deposit indicating approximate proportion of tan and gray components, changes in grain size and, for August 18 and September 16-17 deposits, position of the layer A-layer B break (long dashes). For September 16-17, sandy layer A' from the opening phase of the eruptions is also shown. not sampled, and the amount of juvenile material vented during this opening phase of eruption is not known.

The main phase of the August 18 eruption occurred from 4:42 p.m. to 8:10 p.m. ADT. Parts of this event were photographed by Paul Palmer on a commercial flight from Anchorage to Iliamna and also by

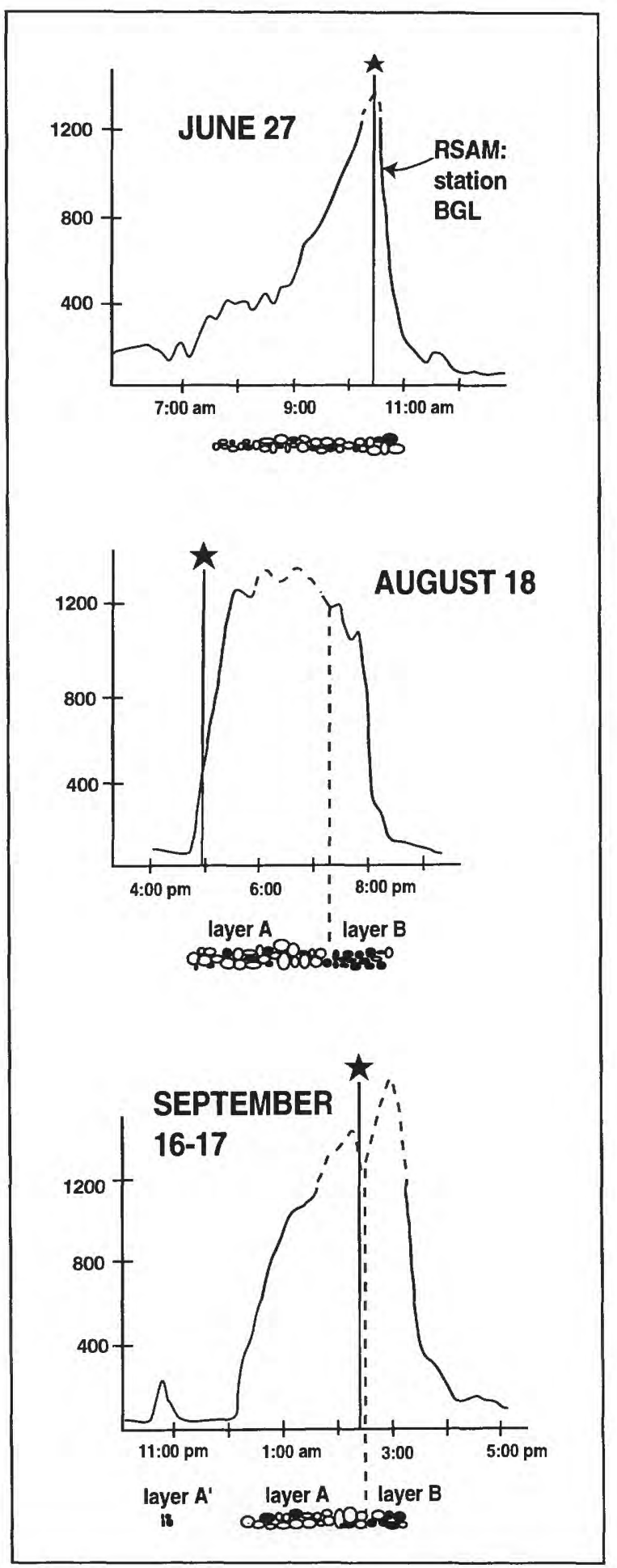


an airborne AVO crew who reached the mountain at about 5:50 p.m. ADT (McGimsey and Dorava, 1994). According to the Palmer photographs, pyroclastic flows, indicated by a light-tan elutriation cloud adjacent to the main eruption column, had already descended the southeast flank by approximately 4:55 p.m. ADT (fig. 7; P. Palmer, oral commun., 1993; Miller and others, this volume). Scaling of photographs indicates an altitude of between 10.5 and $11.5 \mathrm{~km} \mathrm{ASL}$ for the top of the main eruption plume, consistent with pilot estimates of at least $10 \mathrm{~km} \mathrm{ASL}$.

Seismicity indicates that vigorous emission of tephra continued until approximately 8:11 p.m. ADT (McNutt and others, this volume). Intermittent production of pyroclastic flows may have continued throughout the eruption, however the final pyroclastic flows did not extend as far down the flank of Crater Peak. In photographs and from a brief field inspection, these late flows were also darker in color and contained a higher percentage of gray juvenile bombs. Ballistic emplacement of dense bombs, indicated by impact craters on the surface of primary pyroclasticflow and tephra deposits east of Crater Peak, occurred during the final phase of the eruption (Miller and others, this volume; Waitt and others, this volume).

No complete exposures of the tephra sequence inside Crater Peak were accessible following the $\mathrm{Au}-$ gust 18 eruption. However, we were able to briefly examine the upper part of the section on the southwest rim of a basin bounded by a tephra rampart (see fig. 1 of Miller and others, this volume). The uppermost unit was a fine, stratified, brown mud approximately 2 to $6 \mathrm{~cm}$ thick. This mud overlay an approximately $15-\mathrm{cm}$-thick sequence of stratified, poorly sorted, brown to black, sandy debris that included a large percentage of oxidized fragments. The lowermost unit was a gravel-boulder horizon, more than several meters thick. It showed strong upward coarsening and many of its angular clasts were highly oxidized. Among the coarsest blocks at the top of this horizon were dense, prismatically jointed, dark-brown juvenile andesite, as much as $50 \mathrm{~cm}$ across, and abundant dense, light-colored, aphyric to porphyritic, volcanic bombs as much as $2 \mathrm{~m}$ across. This coarse ejecta within the crater is probably correlative with the ballistic field on the southeast flank of Crater Peak (Waitt and others, this volume) and represents a series of closely spaced phreatomagmatic explosions that increased in intensity with time at the very end of the eruption. The sand to siltsized material capping the entire sequence suggests that low-level phreatic (?) emission of fine material continued after emplacement of ballistics. This may explain the intermittent, low-frequency seismicity in the 24 hours following the eruption, as well as a pilot report of a low (a few hundred meters above Crater Peak) ash and steam column visible above Crater Peak on the morning of August 19.

The radar record of the August 18 eruption is only partially complete, but the maximum recorded height of a radar-discernible plume occurred $13 \mathrm{~min}$ utes into the main phase of the eruption (Rose and others, this volume). RSAM amplitude at station BGL reached maximum levels rapidly, and it stayed elevated throughout most of the eruption (fig. 6). Although the record is hampered by saturation problems, RSAM values apparently began to decrease by about 7:50 p.m. $\mathrm{ADT}$, approximately 3 hours into the 3.5 -hour eruption (McNutt and others, this volume).

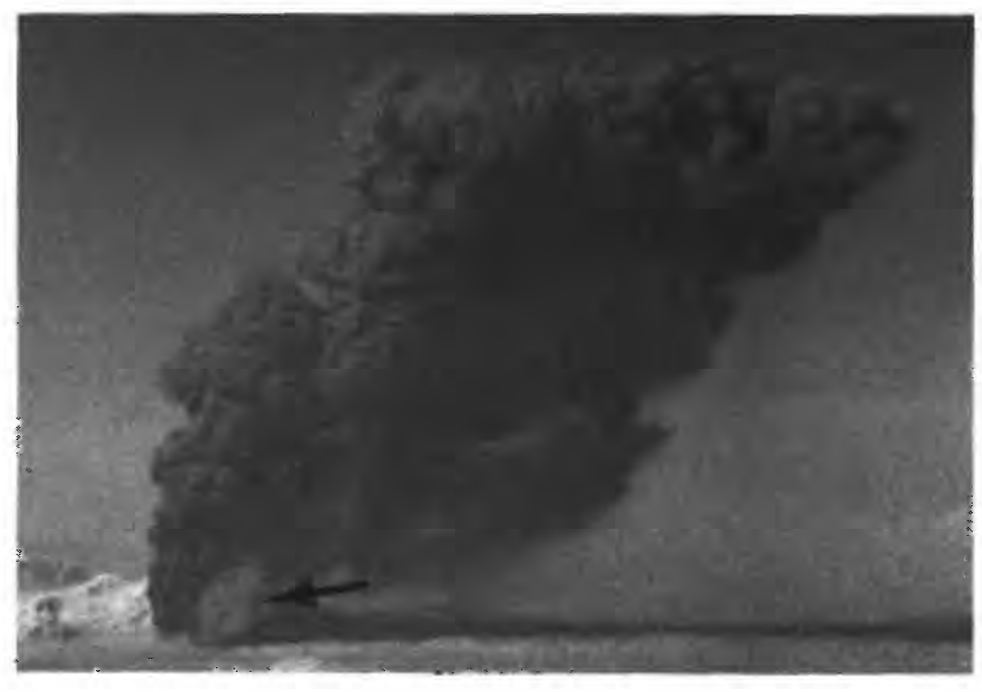

Figure 7. Photograph of the August 18 eruption column and spreading tephra cloud through the window of a commercial flight en route to Iliamna from Anchorage. View direction is approximately north-northwest. The summit of Mount Spurr is just visible to the left of the base of the eruption column. Crater Peak is hidden below a cloud layer, the top of which is about 8,500 feet $(2,590 \mathrm{~m})$ ASL. Small, lighter-colored cloud (arrow) is elutriated ash from pyroclastic flows. Time of photograph is approximately 4:55 p.m. ADT, 13 minutes after the onset of the main phase of the eruption. The top of the eruption cloud has reached an altitude of about $11 \mathrm{~km} \mathrm{ASL}$. Photograph by Paul Palmer. Used with permission. 


\section{SEPTEMBER 16-17}

The September 16-17 eruption occurred at night under clear skies. The main phase of the eruption was preceded by an 11-minute burst of seismicity and explosive tephra emission that started at 8:36 p.m. ADT. This eruption was vigorous enough to produce bright flashes on the AVO slow-scan TV camera located at Kasilof, $120 \mathrm{~km}$ southeast of Mount Spurr volcano (fig. 1A). In contrast to August 18, this opening phase was detected on $\mathrm{C}$-band radar, hence the tephra column must have extended at least $2 \mathrm{~km}$ above Crater Peak (Lee Kelley, NWS, oral commun., 1993). Tephra fall from the first phase was difficult to identify, but at one locality the deposit consisted of a few millimeters of coarse ash and lapilli of both juvenile and accidental material.

The main phase of eruption began just after midnight. Intermittent bursts of incandescence near the base of the eruption column were visible from Anchorage and recorded by the slow-scan camera. Of note is that many of the elongated light flashes captured on film deviate from vertical by several tens of degrees. Miller and others (this volume) relate this directed ejection of incandescent material to the formation of coarse pyroclastic flows on the east flank of Crater Peak. The ballistic field on the southern edge of the September 16-17 tephra deposit may have also formed during episodes of this directed eruption column. Hunters camped $18 \mathrm{~km}$ southeast of Crater Peak described incandescent bursts related to projectile impacts into debris on the glaciers east of the cone during the first hours of the eruption; their observations suggest that ballistic ejection occurred over an extended period. Bomb craters on the surfaces of primary pyroclastic-flow and lahar deposits on the glacier east of Crater Peak indicate that ballistic blocks and bombs of appreciable size also fell after generation of pyroclastic flows on September 16-17. There were no bomb craters noted in the lahar deposits that descended the south flank of Crater Peak during the September 16-17 eruption. This observation is consistent with projectiles directed predominantly eastward from the vent, as indicated on the slow-scan images.

Intracrater deposits from the September 16-17 eruption are exposed in a series of scalloped headwalls cut into terraces that ring the inner vent. On the south margin of the crater, approximately the upper meter consists of oxidized, bedded sandy surge deposits capped by fine silt, which was water saturated upon examination a few weeks after the eruption. These sandy surges thicken toward the east sector of the crater where they overlie a massive, poorly sorted very coarse sand to boulder-gravel deposit, the base of which was not exposed.
The C-band radar record of the September 1617 event is the best of the series and documents a fluctuating tephra column, which finally reacl ad a sustained maximum height of $13.9 \mathrm{~km}$ about 2.3 hours into the eruption (Rose and others, this volume). RSAM values at station BGL increased gradually, remained at high levels between about 1:30 a.m. and 3:00 a.m. ADT and decreased abruptly by 3:10 a.m. ADT, about 3 hours into the eruption (fig 6.; McNutt ard others, this volume).

\section{DISCUSSION}

The presence of tan and gray andesite components in all three eruptions is a primary characteristic of the 1992 Crater Peak tephra. Although petrographically quite similar, the two components differ in density: the tan component is consistently 22 to 24 percent less dense than the gray component (table 2). And, whereas the entire tephra sequence is mixed to some degree for all three eruptions, for August 18 and September 16-17, the tan (less dense) component dominates the lower 60 to 80 percent of the deposits (layer A) and the gray component (more dense) dominates the capping unit (layer B). One explanation of this density stratification is pre-eruption zonation in volatile content. Tan-colored clasts of layer A represent the first material erupted from the upror, volatile enriched part of the magma body; gray-colored clasts represent fragments of melt stored slightly deeper and depleted, relatively, in volatiles. The imperfect separation of components (mixing of tan and gray within layers $A$ and $B$ ) may reflect nonunifc $m$ withdrawal of magma from the conduit (Blake and Ivey, 1986).

If the layer A-B divisions within the A ugust 18 and September 16-17 deposits reflect a change in magmatic volatile content, a coincident and measurable change in the behavior of the eruption column might be expected. To test this, we superimposed a schematic representation of the fallout record or plots of RSAM, the only independent instrumental measure of eruption intensity available for the entire erupt: on series (fig. 6). To construct figure 6, seismicity, pilot reports, radar data, the few eyewitness observations, and slow-scan video were used to roughly constrain the period of tephra production. Note that we have assumed by the superposition of the RSAM record over the schematic tephra-fall section that there is an instantaneous relation between seismicity and tephra accumulation; in reality, there must be some delay.

For the June 27 eruption, there is no break in tephra-fall stratigraphy where the proportions of tan to gray components change. Hence, based solely on field observations and the samples in hand, we can- 
not simply relate the RSAM curve to the proportion of clast type. For the August 18 eruption, radar data (Rose and others, this volume) and pilot reports allow fairly accurate limits to be placed on the timing of tephra production. In figure 6, the layer A-B transition was placed approximately 65 to 70 percent through the eruption on the basis of field measurements of relative thicknesses. Projecting this break onto the RSAM curve suggests that the later stage of tephra production (dominated by the gray component of layer B) was associated in time with a period of declining RSAM. This association could be explained by tapping of a deeper, more degassed part of the magma body, which resulted in lower eruption column vigor. Unfortunately, radar data are lacking for the later stages of the eruption and we cannot independently evaluate column height. For the September 16-17 eruption, the layer A-B transition occurs during a period of instrument saturation, hence it is difficult to assess the relation of stratigraphy to RSAM data for station BGL. To summarize, only data for the August 18 eruption suggest a possible correlation between eruption intensity and clast type erupted.

Another prominent characteristic of the August 18 and September 16-17 layer A deposits, and to a lesser extent the June 27 deposits, is reverse grading. Reverse grading in tephra-fall deposits can reflect a decrease in the angle of pyroclast ejection, changes in wind velocity, or increasing magma discharge over the course of an eruption. For both the August 18 and September 16-17 eruptions, photography and slowscan TV images do not support any progressive changes in the inclination of the eruption column. Furthermore, the narrow fallout patterns indicate that local winds were steady in speed and direction over the course of all three events. Thus, we propose that the reverse grading in the June 27 and lower August 18 and September 16-17 deposits is a result of an increase in magma discharge at the vent.

To test this, we compared the stratigraphic position of maximum clast size within the resulting deposits and the times of maximum plume heights and RSAM peaks (fig. 6). For June 27, there is a good correlation among all three parameters. For August 18 layer A, maximum grain size is approximately coincident with the RSAM peak (although saturation makes this uncertain). More importantly, the amplitude of volcanic tremor recorded at more distant stations reached a maximum about halfway through the August 18 eruption (S. McNutt, written commun., 1993). Similarly, the maximum clast size is present very near the middle of the deposit. Maximum plume height on August 18, however, occurred only minutes after the onset of the eruption. For September 16-17 layer A, maximum clast size and maximum plume height are approximately congruent. While the RSAM data for September 16-17 are difficult to interpret, the strongest tremor occurred during the middle of the eruption (S. McNutt, written commun., 1993). Thus, grain size maximums for all three eruptions occur at stratigraphic positions that approximately mirror the times of maximum seismicity (as measured by a combination of RSAM and tremor amplitude). The large offset in time of maximum plume height for the August 18 eruption and the maximum clast size in the resulting tephra-fall deposit remains an enigma and may be an artifact of poor radar sampling (Rose and others, this volume). A more careful analysis of changes in grain size and clast characteristics with stratigraphic height for all three deposits is needed to determine the exact mechanism behind the development of reverse grading.

In other stratigraphic studies of tephra-fall deposits, color and clast-size changes are asscciated with small but measurable chemical or mineralogic variations, interpreted to reflect pre-eruption $\mathrm{cr}$-mical zonation in the magma chamber (Bursik and others, 1992; Criswell, 1987; Carey and Sigurdsson, 1987). Wholerock major- and trace-element analyses of individual tan and gray clasts for Crater Peak, however, show no significant differences between the two clast types either within or through the eruption series.

Major- and trace-element chemical data for tephra normalized to average 1992 andesite blocks retrieved from pyroclastic-flow deposits are shown in figure 8. Tan tephra are nearly identical to the andesite with the possible exception of low $\mathrm{Cs}$ and $\mathrm{Rb}$ concentrations in two samples. But even the e are less than 25 percent different from the andesite values $(0.1$ $\mathrm{ppm} \mathrm{Cs}$ and $3 \mathrm{ppm} \mathrm{Rb}$ ), and they are nearly within two standard deviations of the andesite mean. Over half of the gray tephra samples analyzed to date have concentrations of all elements similar to the andesite blocks. However, some gray tephra samples are more heterogeneous. These samples are highly enriched in $\mathrm{Cs}$ (as much as 3.7 times the andesite mean) and also enriched in $\mathrm{Sc}, \mathrm{Cr}$, and $\mathrm{Ni}$. The paired enrichment in alkalies and compatible transition metals suggests contamination by metamorphic country-rock represented by partially melted xenoliths found in the 1992 pyroclastic-flow deposits (see Nye and others, this volume). However, simple xenolith contamination is not controlling the high Cs in these samples (fig. 9). Those samples with very high $\mathrm{Cs}$ do not have the low $\mathrm{CaO}$ or high Th that xenolith-contaminated samples world have.

Processes controlling the chemistry of the gray tephra samples are not clearly known but may include accumulation of mafic phenocrysts, vapor-phase transport of some metals, or incorporation of lighly fractionated material from the margin of a sub-Crater Peak 
magma chamber. This final possibility is supported to some extent by the recovery of rare, light gray, moderately siliceous pumice lapilli from the June 27 eruption, which are similar to the divergent tephra samples in $\mathrm{Cs}, \mathrm{Ca}, \mathrm{Th}, \mathrm{U}$ and, to a lesser extent, $\mathrm{Cr}$ and $\mathrm{Ni}$ (Nye and others, this volume).

Finally, the gray tephra samples that are chemically unlike the andesite have compositions governed by chemical heterogeneities on a very small scale (about $10 \mathrm{~g}$ of material). Only when small sample amounts were analyzed were heterogeneities found, and the magnitude of those heterogeneities varied between splits. When larger samples (greater than $50 \mathrm{~g}$ ) were processed, the tephra analyses were generally closer to that of the andesite. In summary, bott tan and gray tephra are chemically similar or identical to the 1992 andesite and to each other. Differences that can be found are slight and related to contamination by poorly understood components on a very localized scale.

\section{TAN TEPHRA}

\section{GRAY TEPHRA}

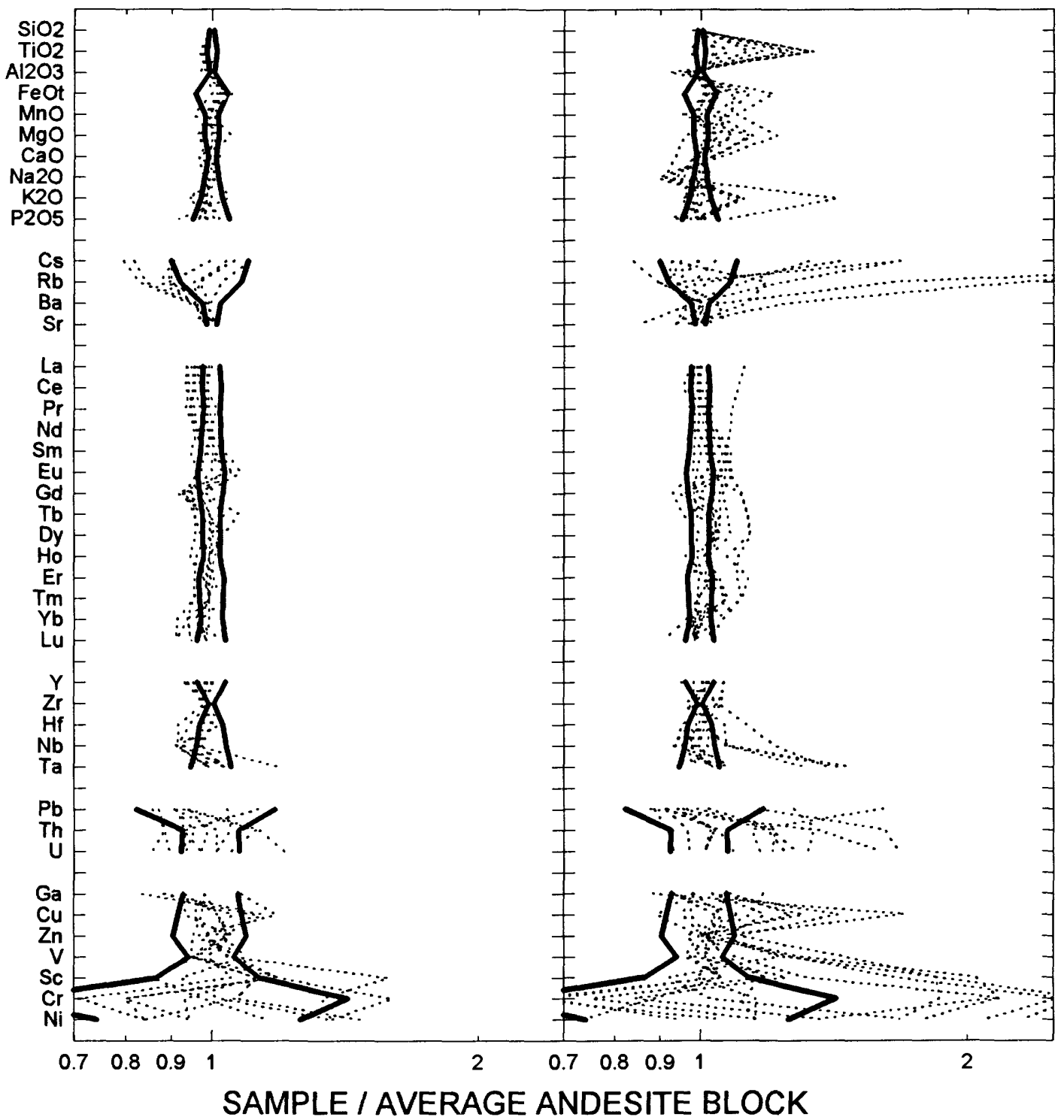

Figure 8. Whole-rock major- and trace-element compositions of selected tan and gray tephra lapilli from the 1992 eruptions of Crater Peak, Mount Spurr volcano, Alaska. FeO $_{t}=$ FeO total. Dark lines represent one standard variation about the mean of 18 juvenile andesite blocks from all phases of each eruption (see Nye and others, this volume). 

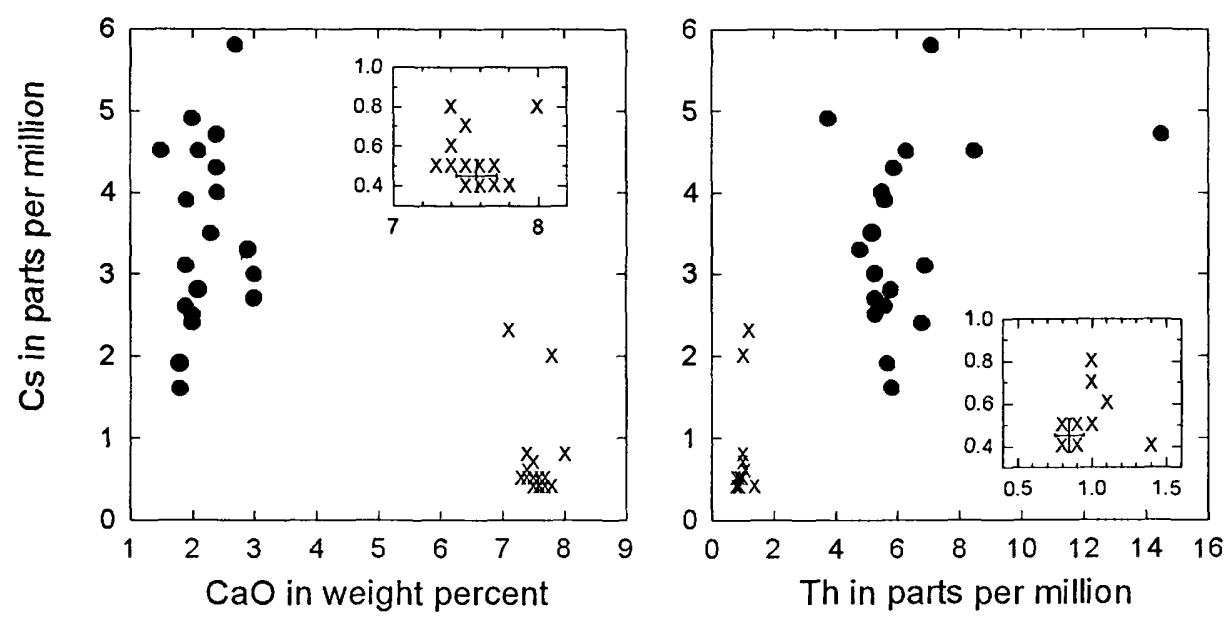

Figure 9. Variations of $\mathrm{CaO}$ and $\mathrm{Th}$ with $\mathrm{Cs}$. Filled circles, analyses of partially melted aluminous metamorphic xenoliths ejected during the 1992 eruptions of Crater Peak, Mount Spurr volcano, Alaska (see Nye and others, this volume); X, tan and gray tephra analyses of fig. 8; and + , average analysis of the 1992 juvenile andesite blocks (+ spans one standard deviation about the mean of 18 samples). Note that the majority of tephra are similar to the andesite and that those dissimilar from the andesite do not form mixing arrays with the xenoliths.

\section{SUMMARY}

Three vulcanian to subplinian eruptions of Crater Peak at Mount Spurr volcano during 1992 produced tephra-fall deposits that extend north, northeast, and east of the volcano. The eruptions were similar in magnitude, style, and duration and produced, respectively, 44, 52, and $56 \times 10^{6} \mathrm{~m}^{3}$ of bulk tephra $\left(12,14\right.$, and $\left.15 \times 10^{6} \mathrm{~m}^{3} \mathrm{DRE}\right)$ in 3.5 to 4.0 hours of vigorous eruption. Measured thicknesses ranged from about $1 \mathrm{~m}$ at the base of the vent to less than $1 \mathrm{~mm}$ at a distance of $200 \mathrm{~km}$ from Crater Peak.

Fallout tephra from the 1992 eruptions of Crater Peak consists predominantly of two texturally distinct but chemically similar juvenile andesitic components. Density data suggest that prior to each eruption, a physically zoned magma body existed beneath Crater Peak. The zonation is best explained by upward migration of volatiles and formation of a gascharged upper part of the chamber. The presence of both components in all three eruptions suggests that such zonation can develop rapidly (that is, within 4 to 6 weeks, the time intervals between eruptions). Alternatively, each eruption may have tapped only a part of an initially zoned chamber emplaced prior to the first eruption on June 27. Minor settling of mafic phenocrysts, contamination of juvenile andesite by remelted country rock, incorporation of a highly fractionated derivative of the juvenile andesite, and vapor-phase transport of some elements may account for observed small geochemical variations of individual tephra clasts.
Future analytical work on the Crater Peak tephra-fall deposits will focus on clarifying the extent and nature of small-scale geochemical heterogeneities; quantifying vesicularity, phenocryst, and groundmass textures to address the root cause of the systematic density differences (Gardner and others, 1993); and examining clast grading and density characteristics in more detail to reconstruct changes in eruption-column energetics through each event.

\section{REFERENCES CITED}

Alaska Volcano Observatory, 1993, Mt. Spurr's 1922 eruptions: Eos, Transactions of the American Geophysial Union, v. 74 , no. 19 , p. 217-222.

Blake, S.R., and Ivey, G.N., 1986, Magma mixing and the dynamics of withdrawal from stratified reservoirs: Journal of Volcanology and Geothermal Research, v. 27, p. 153-178.

Brantley, S.R., ed., 1990, The eruption of Redoubt Volcano, Alaska, December 14, 1989 - August 31, 1990: U.S. Geological Survey Circular 1061, $33 \mathrm{p}$.

Bursik, M.I., Sparks, R.S.J., Gilbert, J.S., and Carey, S.N., 1992, Sedimentation of tephra by volcanic plumes: I. Theory and its comparison with a study of Fogo A pliniar deposit, Sao Miguel (Azores): Bulletin of Volcanology, v. 54, p. 329-344.

Carey, S., and Sigurdsson, H., 1987, Temporal varitions in column height and magma discharge rate during the 79 A.D. eruption of Vesuvius: Geological Society of America Bulletin, v. 99, p. 303-314.

Criswell, C.W., 1987, Chronology and pyroclastic stratigraphy of the May 18, 1980 eruption of Mount St. Helens, Washing- 
ton: Journal of Geophysical Research, v. 92, p. 10,237 10,266 .

Fierstein, J., and Nathenson, M., 1992, Another look at the calculation of fallout tephra volumes: Bulletin of Volcanology, v. 54, p. 156-167.

Gardner, C.A., Neal, C.A., and McGimsey, R.G., 1993, Volatile zonation in the Crater Peak magma: Evidence from the 1992 tephra-fall deposits [abs.]: Eos, Transactions of the American Geophysical Union, v. 74., no. 43, p. 621.

Hoblitt, R.P., and Harmon, R.S., 1993, Bimodal density distribution of cryptodome dacite from the 1980 eruption of Mount St. Helens, Washington: Bulletin of Volcanology, v. 55, no. 6, p. 421-437.

McGimsey, R.G., and Dorava, J., 1994, Video of the August 18, 1992, eruption of Crater Peak vent on Spurr volcano, Alaska: U.S. Geological Survey Open-File Report 94-614.

Murray, T.L., Bauer, C.I., and Paskievitch, J.F., 1994, Using a personal computer to obtain predicted plume trajectories during the 1989-90 eruption of Redoubt Volcano, Alaska: Casadevall, T.J., ed., in U.S. Geological Survey Bulletin 2047, p. 253-256.

Murray, T.L., and Endo, E.T., 1989, A real-time seismic amplitude measurement system (RSAM): U.S. Geological Survey Open-File Report 89-684, 21 p.

Sarna-Wojcicki, A.M., Shipley, S., Waitt, R.B., Jr., Dz risin, D., and Wood, S.H., 1981, Aerial distribution, thickness, mass, volume, and grain size of air-fall ash from the six n'yjor eruptions of 1980: U.S. Geological Survey Professional Paper 1250 , p. $577-600$.

Scott, W.E., and McGimsey, R.G., 1994, Character, mas : distribution, and origin of tephra-fall deposits of the 198?-90 eruption of Redoubt Volcano, south-central Alaska: Journal of Volcanology and Geothermal Research, v. 62, p. 251-272.

Till, A.B., Yount, M.E., Riehle, J.R., 1993, Redoubt Volcano, Cook Inlet, Alaska: A hazard assessment based on eruptive activity since 1968: U.S. Geological Survey Bulletin 1966, 19 p.

Waitt, R.B., Jr., Hansen, V.L., Sarna-Wojcicki, A.M., and Wood, S.H., 1981, Proximal air-fall deposits of eruptions between May 24 and August 7, 1980 - stratigraphy and field sedimentology: U.S. Geological Survey Professional Paper 1250, p. 617-628.

Wilcox, R.E., 1959, Some effects of recent volcanic ash falls with special reference to Alaska: U.S. Geological Survey Bulletin 1028 , p. $409-476$. 



\title{
Pyroclastic Flows of the 1992 Crater Peak Eruptions: Distribution and Origin
}

\author{
By Thomas P. Miller, Christina A. Neal, and Richard B. Waitt
}

\section{CONTENTS}

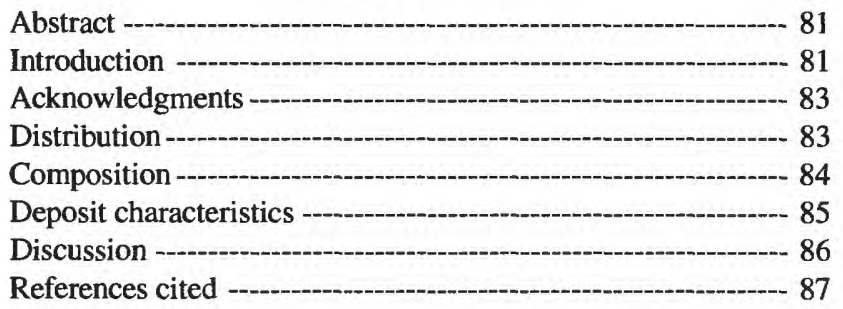

\section{ABSTRACT}

Two of the three 1992 eruption events at Crater Peak generated pyroclastic flows on the flanks of the cone. The pyroclastic-flow deposits are very coarse, generally fines poor, poorly sorted, and clast supported; 60 to 80 percent of the clasts are dense to slightly vesiculated cobble to boulder-sized blocks of juvenile andesite. Accessory and accidental clasts are chiefly fragments of lava but include some spectacularly vesiculated metasedimentary rocks (buchites). The pyroclastic flows traveled a maximum distance of about $3.2 \mathrm{~km}$ and had a combined bulk volume of about $400,000 \mathrm{~m}^{3}$, or less than 0.5 percent of the bulk volume of the entire eruption. They were avalanches of hot debris that produced sluggish, poorly inflated denseclast flows. The flows may have been generated at least in part by directed ballistic ejection of debris rather than by "boilover" through a low point on the crater rim. The lack of correlation between the distribution of pyroclastic flows and the low part of the crater rim has important implications for hazard analysis of vulcanian and subplinian eruptions elsewhere because it reminds us that all flanks of a volcano can be at risk from pyroclastic flows.

\section{INTRODUCTION}

Crater Peak, a 2,309-m-high satellite cone on the south flank of the Mount Spurr volcanic center 125 $\mathrm{km}$ west of Anchorage erupted on June 27, August 18, and the night of September 16-17, 1992 (see Eichelberger and others, this volume) after 39 years of quiescence. The three eruptions were similar in that they each produced vulcanian to subplinian eruption columns as high as $18 \mathrm{~km}$ above sea level, formed extensive bomb fields, lasted 3 to 4 hours, erupted pyroclastic material only, had ejecta bulk volumes of 44 to $56 \times 10^{6} \mathrm{~m}^{3}$ each (see Eichelberger and others, this volume), and were of andesitic composition. The July 9, 1953, eruption, the only other historic Crater Peak eruption, had similar characteristics, according to the fragmentary accounts available (Juhle and Coulter, 1955).

Crater Peak is capped by a circular summit crater $300 \mathrm{~m}$ deep and $800 \mathrm{~m}$ in diameter (fig. 1); rim elevation ranges from $1,980 \mathrm{~m}(6,500 \mathrm{ft})$ at the low point on the south-southwest to $2,309 \mathrm{~m}(7,575 \mathrm{ft})$ on the northeast. Before the initial June 27 event, the crater contained a considerable thickness of ice, snow, and an 800-square-meter lake. Most of the ice and snow was melted or removed during the 1992 eruptions, particularly the one on June 27: the lake disappeared a few days before the June 27 eruption. A terrace of $15 \mathrm{~m}$ or more of massive, locally well bedded surge deposits capped by 1 to $2 \mathrm{~m}$ of fine ash formed in the southern third of the crater during the June 27 eruption; 1 - to 2-m lithic blocks were scattered across the surface of this terrace. Later eruptions modified this feature into two tephra-covered terraces that now occupy the southern two-thirds of the crater.

The crater walls changed little during the 1992 eruptions other than steepening of the north wall. The eruptive vent, estimated by aerial observations to be less than $30 \mathrm{~m}$ across at the surface, is in the northwest and deepest part of the crater about $70 \mathrm{~m}$ below the surface of the lower terrace.

Small-volume, dense-clast pyroclastic flows moved down the outer south and east flanks of Crater Peak cone during the August 18 and September 16-17 eruptions (fig. 1). During the June 27 event, either pyroclastic flows were not generated or were turned quickly into "snowflows" or "mixed" flows (see Waitt, this volume). The total volume of the pyroclastic-flow deposits is estimated at $0.4 \times 10^{6} \mathrm{~m}^{3}$, or less than 0.05 percent of the approximately $150 \times 10^{6} \mathrm{~m}^{3}$ bulk volume of the 1992 eruption products (see Eichelberger and others, this volume). 


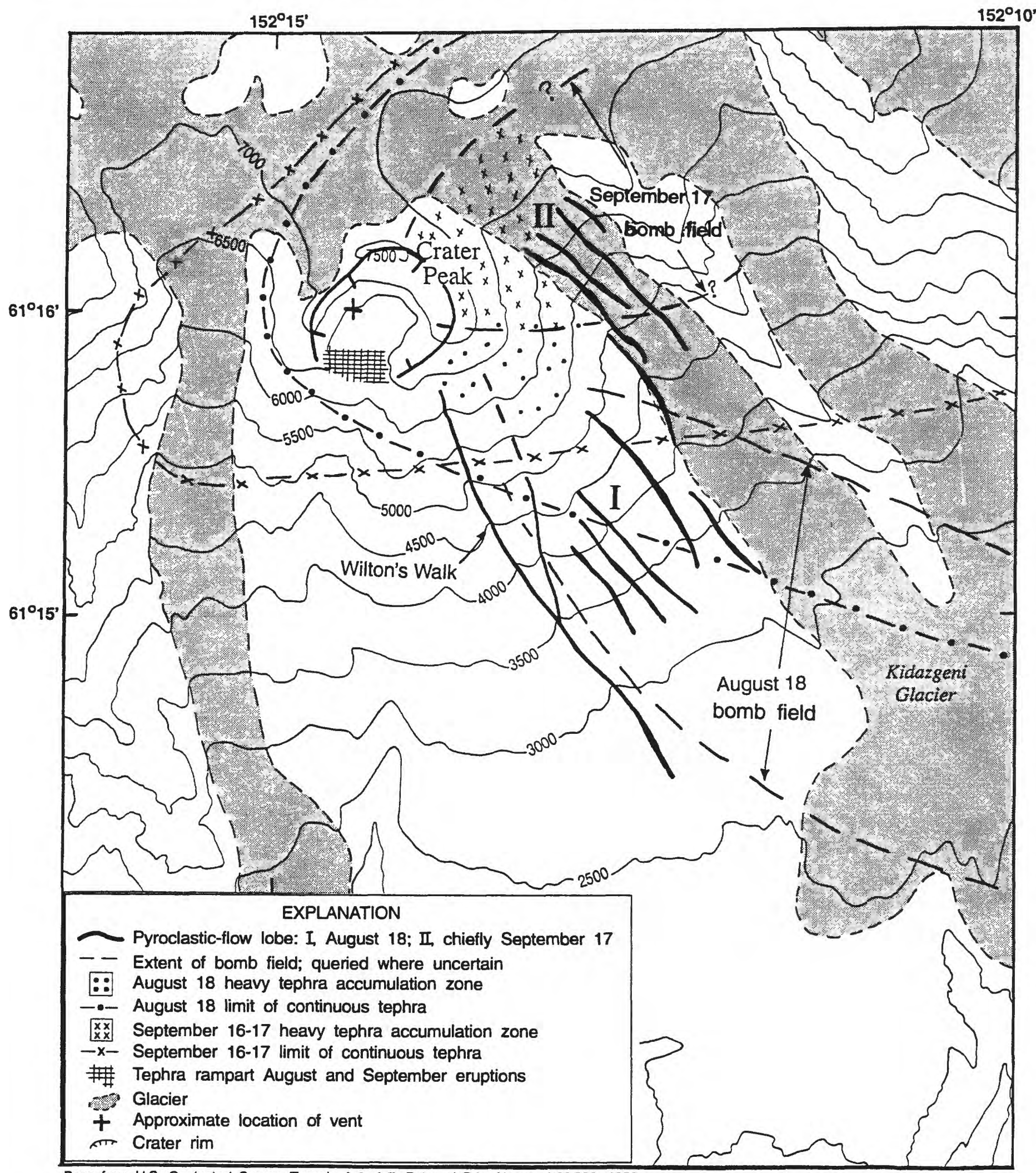

Base from U.S. Geological Survey, Tyonek, A-6, A-7, B-6 and B-7, Alaska, 1:63,360, 1958

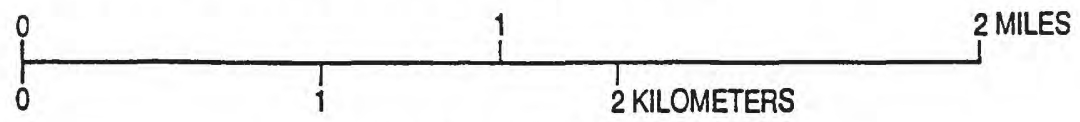


Similar pyroclastic flows, often called scoria flows, have been reported from historic eruptions at Ngauruhoe volcano in New Zealand (Nairn and Self, 1978) and at Manam volcano in the western Bismarck arc near Papua, New Guinea (McKee, 1981). Such flows are commonly thought to have formed by column collapse or by boilover of a low eruption column (Cas and Wright, 1987) and flowage through low points on crater rims. The limited distribution of the Crater Peak pyroclastic flows and the lack of any association with low points on the crater rim suggest that other mechanisms were responsible for their formation. This possibility is important for assessing hazards from similar eruptions elsewhere. Because pyroclastic flows were not observed during daylight hours, the processes that formed them must be inferred.

\section{ACKNOWLEDGMENTS}

We are indebted to Game McGimsey and Cynthia Gardner for assistance in the field during and after the eruptions. Reviews by Ric Hoblitt and Wes Hildreth greatly improved the manuscript.

\section{DISTRIBUTION}

Crater Peak is bounded on the north, west, and east by glaciers (fig. 1). The August 18 pyroclastic flows moved down the steep $\left(31^{\circ}\right.$ to $\left.7^{\circ}\right)$ south and southeast flanks of Crater Peak to elevations of 820 to $1,000 \mathrm{~m}(2,700$ to $3,300 \mathrm{ft})$ at distances of as much as $3.2 \mathrm{~km}$ from the crater rim. The flows were channeled into gullies, where they formed elongate lobes of debris (fig. 1) with steep-sided margins and flow fronts 0.5 to $1.5 \mathrm{~m}$ high. The westernmost flows of the August 18 eruption were channeled into a welldeveloped, intermittent stream drainage (informally known as Wilton's Walk; figs. 1 and 2) on top of thin snowflows of the June 27 eruption. The easternmost pyroclastic flows followed swales and low gullies lined with brush and other low vegetation. None of the pyroclastic flows descended to tree line.

Most of this report is based on study of the August 18 pyroclastic-flow deposits, which are the most accessible-although lahars from the September 16-17 eruption overlapped many of the August pyroclasticflow deposits in Wilton's Walk gully. The September 16-17 pyroclastic flows moved down the east-north-

Figure 1. Crater Peak area of Mount Spurr volcano, Alas$\mathrm{ka}$, showing distribution of pyroclastic-flow deposits and tephra accumulation zones from the August 18 and September 16-17, 1992, eruptions and the August 18 bomb field. Bomb field from September 16-17 eruption not completely mapped because of inaccessibility. east flank onto a high ice field (fig. 1), causing much melting of the ice and were soon transformed into lahars; access to these pyroclastic-flow deposits is difficult and hazardous.

The pyroclastic-flow deposits of the August 18 and September 16-17 eruptions have a close spatial association with large bomb fields (figs. 1 and 3 ) that covered areas of 7 and $2 \mathrm{~km}^{2}$, respectively. Field relations show that for the August eruption, most of the bombs were ejected after the pyroclastic flows were emplaced (see Waitt and others, this volume).

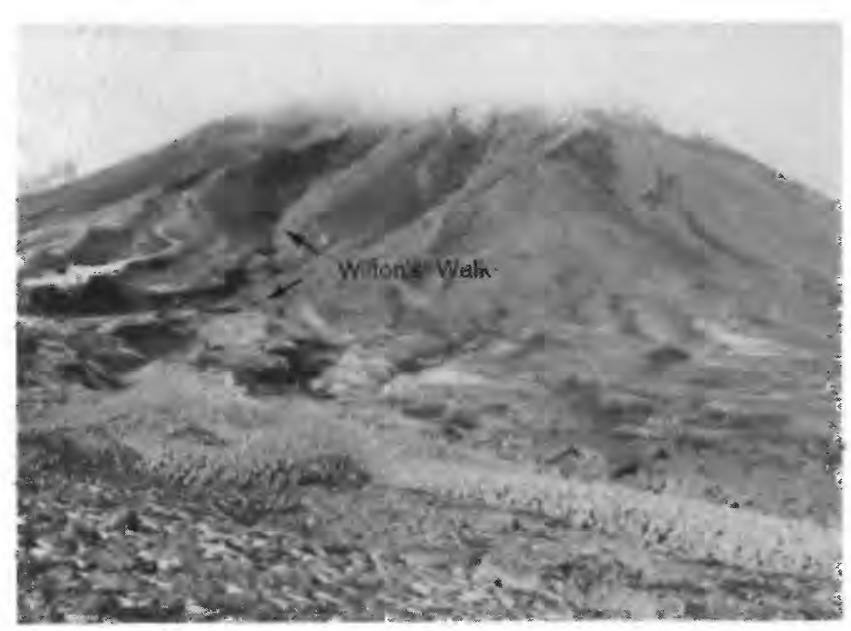

Figure 2. View of south flank of Crater Peak cone (summit obscured by clouds) with pyroclastic-flow deposit in foreground. Prominent drainage, locally known as Wilton's Walk, was the site of numerous pyroclastic flows during August 18 eruption and lahars during the September 1617,1992 , eruption.

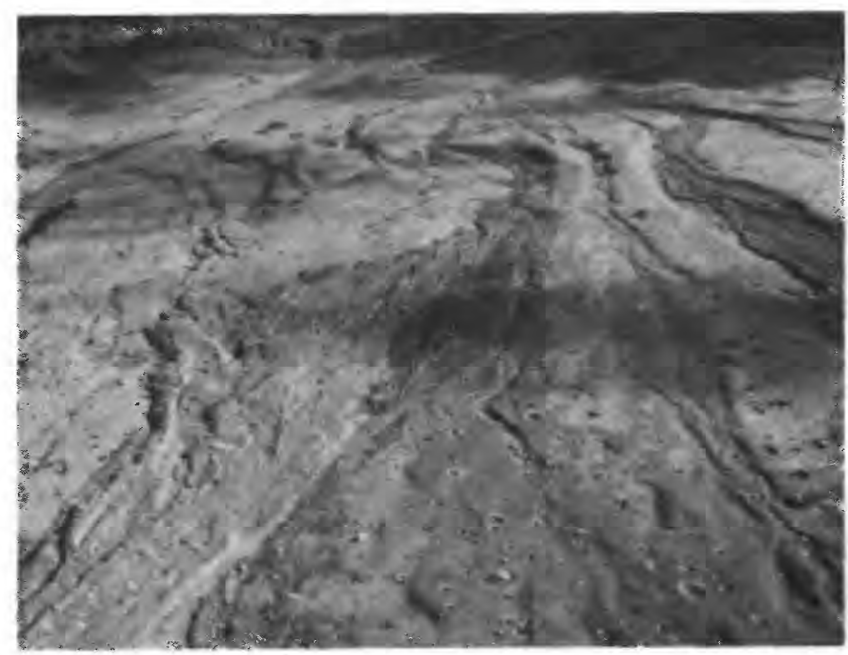

Figure 3. View toward southeast of bomb field developed on top of the August 18 pyroclastic-flow deposits, southeast flank of Crater Peak, Mount Spurr volcano, Alaska. Craters in foreground are 3 to $5 \mathrm{~m}$ in diameter. 


\section{COMPOSITION}

The pyroclastic-flow deposits are very coarse, clast supported, and generally fines poor (fig. 4). Most clasts (60 to 80 percent) consist of dense to slightly vesiculated (15 to 20 percent vesicles), dark gray to brownish-black compositionally homogeneous, porphyritic juvenile andesite (56 to 57 percent $\mathrm{SiO}_{2}$, table 1; see Nye and others, this volume); this material forms blocks as large as $1 \mathrm{~m}$ in diameter. The andesite contains about 20 percent phenocrysts consisting of plagioclase, clinopyroxene, orthopyroxene, iron oxides, and sparse hornblende in a microlite-rich groundmass of brown andesitic glass. A second and comparatively minor type of juvenile clast is a light gray-green andesite scoria that is compositionally similar to the dark andesite in spite of containing a clear rhyolite glass in the groundmass (see Nye and others, this volume).

Lithic clasts, mostly accessory but including a few accidental ones, are the second most abundant clast type (20 to 40 percent) and are typically quite large (as much as $2 \mathrm{~m}$ in diameter). The accessory clasts are chiefly unaltered andesite and basalt that were probably picked up from the conduit and the crater walls; accidental clasts were obtained from lava flows exposed on the flanks of Crater Peak. Some clasts of indurated pre-1992 pyroclastic material are also present. Accessory and accidental lithic contents of several pyroclastic-flow deposits from August 18 increase from west to east across the southeast flank of the cone.

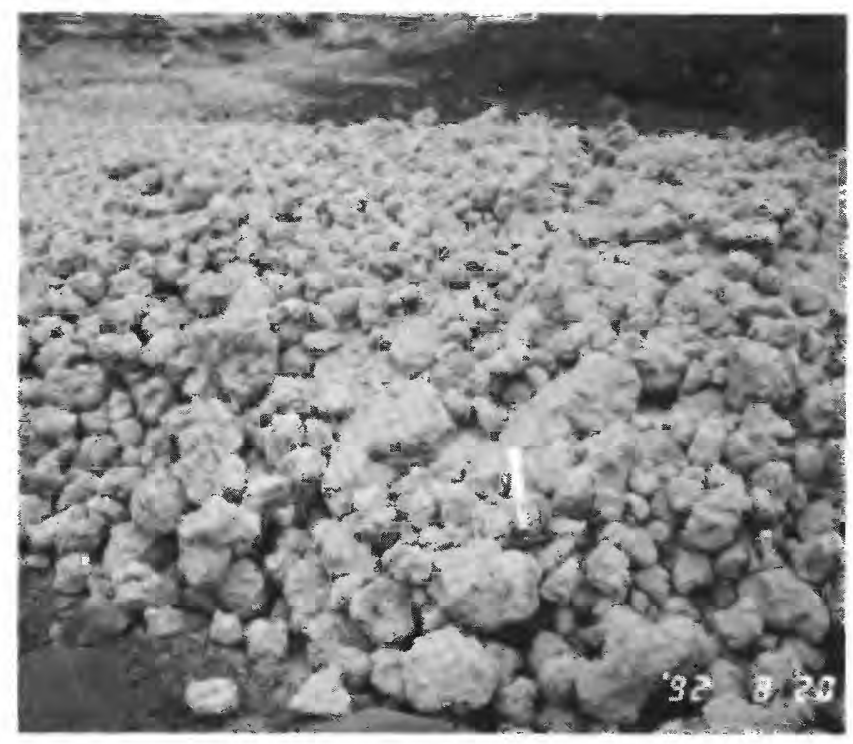

Figure 4. Dense clast, fines-poor August 18 pyroclasticflow deposits in Wilton's Walk. Photo taken August 20, 1992, 2 days after eruption of Crater Peak vent, Mount Spurr volcano, Alaska.
Table 1. Chemical analyses of juvenile andesite clasts in August 18 and September 16-17 pyroclastic flows (see Nye and others, this volume).

Table 1. Chemical analyses of juvenile andesite clasts in August 18 and September 16-17 pyroclastic flows (see Nye and others, this volume).

\begin{tabular}{|c|c|c|}
\hline & August 18 & September 17 \\
\hline $\mathrm{SiO}_{2}$ & 56.5 & 55.75 \\
\hline $\mathrm{Al}_{2} \mathrm{O}_{3}$ & 19.2 & 18.7 \\
\hline $\mathrm{FeO}$ & 6.9 & 7.0 \\
\hline $\mathrm{MgO}$ & 3.6 & 3.7 \\
\hline $\mathrm{CaO}$ & 7.6 & 7.5 \\
\hline $\mathrm{Na}_{2} \mathrm{O}$ & 4.1 & 4.0 \\
\hline $\mathrm{K}_{2} \mathrm{O}$ & .9 & 9 \\
\hline $\mathrm{TiO}_{2}$ & .67 & .68 \\
\hline $\mathrm{P}_{2} \mathrm{O}_{5}$ & .29 & .28 \\
\hline $\mathrm{MnO}$ & .15 & .15 \\
\hline Total & 99.9 & 98.6 \\
\hline $\begin{array}{r}\text { Number of } \\
\text { analyses }\end{array}$ & 3 & 4 \\
\hline
\end{tabular}

Particularly exotic metamorphic xenoliths make up less than 0.05 percent of the clasts in the flows, but they are important for determining the type (and depth) of wallrock enclosing the crustal magma chamber in which the andesitic magma may have resided immediately before eruption. These xenoliths consist of highly expanded pumice-like material that forms smooth rounded clasts as much as $60 \mathrm{~cm}$ in diameter. This partly glassy material is composed of plagioclase+orthopyroxene \pm sillimanite \pm biotite \pm cordierite \pm spinel \pm garnet \pm quartz and has $\mathrm{SiO}_{2}$ contents of about 65 percent (see Harbin and others, this volume). The clasts have a well-developed compositional banding and range from slightly to highly vesiculated. Similar material at Ngauruhoe, New Zealand, was described as "quartzofeldspathic gneisses" or "buchites" that have been "frothed" (Steiner, 1958; Nairn and Self, 1978; Graham and others, 1988).

A less abundant but equally exotic component is a white, fine-grained, sugary-textured rock composed of plagioclase+quartz+glass. This material is friable but occurs in blocks as large as $60 \mathrm{~cm}$ and it makes up less than 5 percent of the exotic lithics. Rounded pieces of this material as large as $15 \mathrm{~cm}$ across have been found in juvenile andesite blocks. Contacts between the two materials are sharp suggesting only minor interaction between the "white-rock" and the andesitic magma. This relation was observed in tephra fragments as well (see Neal and others, this volume; Harbin and others, this volume).

A few clasts of dense white garnetiferous calcsilicate skarn as much as $20 \mathrm{~cm}$ in diameter were found in the eastern pyroclastic-flow deposits of August 18. The garnets form large $(1.5 \mathrm{~cm})$ euhedral amber-colored porphyroblasts in a dense mosaic of wollastonite and plagioclase. 
Metasedimentary rocks of these compositions have not been recognized within many tens of kilometers of the volcano. Although the basement surrounding the Mount Spurr volcanic center consists chiefly of Mesozoic plutonic rocks (Magoon and others, 1976) of the Alaska-Aleutian Range batholith, few plutonic rocks have been found in the 1992 ejecta. The almost total domination of vesiculated metamorphic rocks compared to other basement rocks suggests that they form the wallrock for a crustal magma reservoir that fed the 1992 Crater Peak eruptions. The lack of plutonic xenoliths indicates that the magma reservoir could be deeper than any upper-crustal granitic pluton.

\section{DEPOSIT CHARACTERISTICS}

At least some of the August 18 pyroclastic flows formed early in the eruption on the basis of observations made during an hour-long aerial overflight that began about 20 minutes into the eruption on August 18 (McGimsey and Dorava, 1992). A thin but persistent cloud layer surrounded the volcano at about the $2,400 \mathrm{~m}$ ( 7,800 foot) level. Brief glimpses through breaks in the cloud indicated that pyroclastic flows had come down the south and east flanks of the cone to an estimated elevation of $1,000 \mathrm{~m}$. In addition to a vigorously convecting gray-black eruption column that rose to an altitude of $18 \mathrm{~km}$, a lower $(3.5$ to $4.5 \mathrm{~km}$ ) lighter colored cloud was visible along the south and southeast edge of the column and probably represented fine material elutriated from the pyroclastic flows. Blocks larger than $2 \mathrm{~m}$ were observed falling out at the perimeter of the column $300 \mathrm{~m}$ above the vent. These blocks probably contributed to the large postpyroclastic-flow bomb field southeast of the cone.

Emplacement of the September 16-17 pyroclastic flows may have taken longer. Inspection of videotape from slow-scan TV records of the night-time eruption of September 16-17, taken from a camera located $120 \mathrm{~km}$ south of Crater Peak, shows that inclined incandescent fountaining (and probably pyroclastic flow generation) took place sporadically throughout the 4-hour eruption.

Field characteristics indicate that the dense-clast pyroclastic flows of August 18 (and probably those of September 16-17) began as hot avalanches that were poorly inflated and slow moving. Minor sand-blasting of brush took place adjacent to the flows, but brush within $10 \mathrm{~m}$ of the termini of the flows showed no damage. The andesite blocks that constitute most of the pyroclastic flow deposits have a characteristic orbicular shape with irregular cauliflower-like exteriors and slightly breadcrusted surfaces; they fracture along poorly developed polygonal joints. These features suggest that extensively degassed juvenile andesitic magma was ejected explosively as hot plastic fragments, which were incandescent upon ejection (according to eyewitness reports and slow-scan video views of the September $16-17$ eruption) but were too viscous to attain appreciable degrees of rounding during flight.

The pyroclastic flows of both August 18 and September 16-17 were emplaced as hot juvenile clasts and sparse silt to sand-size matrix material were still hot to the touch when first examined about 40 hours after emplacement. Pyroclastic flows were hot enough (about $300^{\circ} \mathrm{C}$ ) to char vegetation in contact with the andesite clasts. Vegetation adjacent to the flows was not charred, indicating low temperatures in the air around the descending flows. For several weeks after the August 18 eruption, a linear axial zone of weak fumarolic activity was present in the 2-m-thick center channel of the pyroclastic-flow deposits in Wilton's Walk near their distal end.

The flows were not fluidized, and gas played little if any role in their transport. Most flows probably moved so slowly that little or no air ingestion took place. Absolute flow rates are unknown; however, at a point $2.4 \mathrm{~km}$ from the crater rim and 0.8 $\mathrm{km}$ from the terminus of the flow in Wilton's Walk, a pyroclastic flow overrode a 4-m-high vertical bank and left a thin overbank lag deposit of juvenile andesite clasts. The pyroclastic flow at this point is estimated to have been traveling at about $22 \mathrm{~km} / \mathrm{hr}$ on the basis of the relation $\mathrm{v}^{2}=\mathrm{gh}$ where $\mathrm{h}$ is the height of bank, $\mathrm{v}$ is the velocity, and $\mathrm{g}$ is the acceleration owing to gravity (see Cas and Wright, 1987, p. 179 for a discussion).

Well-developed levees and surface ridges along the margins of the pyroclastic flow indicate that the denser main body of the flow had sufficient yield strength and momentum to push earlier deposited material aside. As the flows came to rest, clasts were dumped and formed steep lobate flow fronts 1 to 1.5 $\mathrm{m}$ high (figs. 4 and 5).

Fallback of pyroclastic material on interfluvial areas high on the cone deposited a veneer of chiefly juvenile debris lying at the angle of repose. The steep dip favored formation of numerous small secondary pyroclastic flows for several days after the August 18 eruption, and so most of these were soon stripped away.

Pyroclastic flows channeled into valleys and other topographic depressions attained a maximum thickness of 1 to $3 \mathrm{~m}$. The thickest flows formed in Wilton's Walk, the widest gully on the southeast flank of Crater Peak. Most of these pyroclastic flows were later covered by September 16-17 lahars that descended to an elevation of about $975 \mathrm{~m}(3,200 \mathrm{ft})$. Considerable erosion in this drainage by lahars and associated flooding during the June 27 event cut deep channels from $975 \mathrm{~m}(3,200 \mathrm{ft})$ down to the $790 \mathrm{~m}(2,600 \mathrm{ft})$ level prior to deposition of the August 18 pyroclastic flows. 


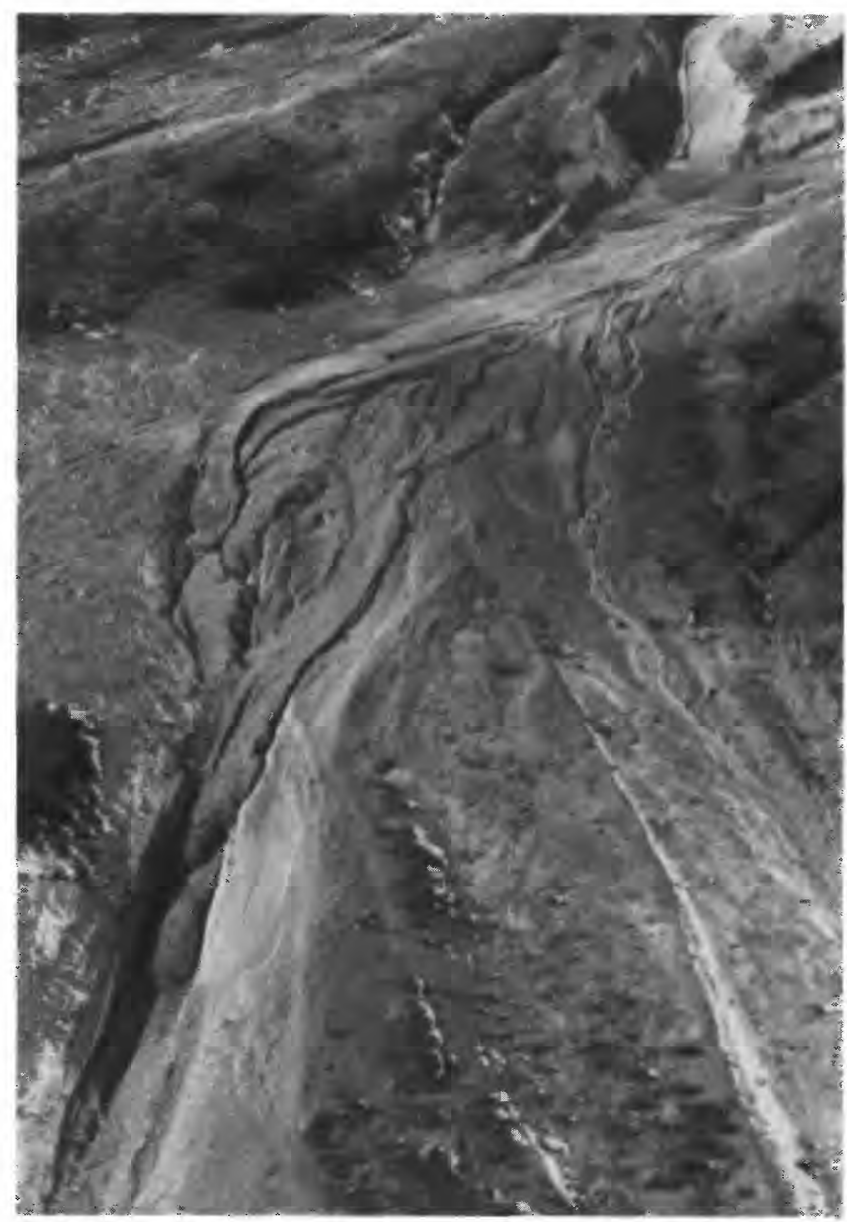

Figure 5. View to northwest of terminus of overlapping August 18 pyroclastic-flow deposits in Wilton's Walk. These deposits were produced from eruption of Crater Peak vent, Mount Spurr volcano, Alaska. Width of pyroclastic-flow deposit at terminus is about $15 \mathrm{~m}$.

\section{DISCUSSION}

The pyroclastic flows at Crater Peak were probably emplaced episodically during each eruptive episode. The distribution of the small-volume pyroclastic-flow deposits indicates that they did not result from boilover through low points on the crater rim or through column collapse because apparently no pyroclastic flows traveled through the low point of the Crater Peak rim during any of the three eruptions. Indeed, the pyroclastic-flow deposits of August 18 and September 16-17 are downslope from some of the highest parts of the crater rim $(2,200$ to $2,290 \mathrm{~m}$; fig. 1) on its eastern sector.

Some of the pyroclastic flows, particularly from the September 16-17 eruption, could have originated from asymmetrical collapse of an eruption column, because they were entirely contained within the te- phra-fall area of that eruption (fig. 1). The short (about $3 \mathrm{~km}$ ) runout distances of the pyroclastic flows suggests that the debris forming the pyroclastic flows did not rise high in the eruption column. Prevailing winds would seem unlikely to have a strong influence on the collapse pattern of such coarse material.

The zones of accumulation for the August and September pyroclastic flows are each spatially associated with large ballistic bomb fields (fig. 1). This association suggests that ballistic ejection from a confined and inclined vent may have been a factor in their formation. Numerous modest explosions from an inclined or shielded vent may have repeatedly reamed the conduit of high-viscosity andesitic magma that was already extensively degassed and that occupied the uppermost part of the conduit. Some of these explosions may have resulted from clasts too large to be expelled accumulating in the vent until it became temporarily choked. The resulting increase in pressure caused the expulsion of a mass of coarse debris. These slugs of stiff, brittle, and fragmenting magma were expelled to altitudes generally high enough (probably $<1 \mathrm{~km}$ ) to clear the northeast and east crater walls (about $310 \mathrm{~m}$ ) before falling back to form heavy, nearvent tephra deposited near the angle of repose on steep slopes. This material was quickly mobilized into coarse avalanche-like pyroclastic flows that moved downslope and into gullies that lead out of the fall-out zone.

The difference in distribution of the August and September bomb fields may reflect a change in the location and inclination of the active vent. Aerial observations indicate that the active vent shifted between eruptions from the north-central part of the crater in June to a location against and slightly beneath the overhanging northwest crater rim by September. The steep north and west walls of the vent area and a resistant east-west buttress immediately south of the vent would block ballistic material going in those directions and favor ejection to the east, as was apparently noticed on the remote slow-scan TV on September 16-17.

The lack of pyroclastic flows associated with the June 27 eruption may reflect ballistic material from this eruption being deposited in the proximal area around the cone on a high, relatively flat, undulating ice field rather than on a steep-sided cone surface. The thick pre-eruption crater fill may also have inhibited the early generation of pyroclastic flows by ballistic fountaining, whereas during the later eruptions an "open vent" situation prevailed.

The lack of correspondence between the distribution of pyroclastic flows and the low part of the crater rim and the possibility of ballistic emplacement of pyroclastic flows has important implications for hazard analyses of volcanoes prone to vulcanian or 
subplinian eruptions. Certainly drainages downslope of low points on crater rims would always be areas susceptible to be filled with pyroclastic flows that utilize the breach during a boilover. But the distribution of pyroclastic flows at Crater Peak is a reminder that such flows can be generated by directed ejection and inclined column collapse. Thus hazards may exist on any flank of the volcano, even without major vertical column collapse. This possibility needs to be considered in hazard analysis.

\section{REFERENCES CITED}

Cas, R.A.F., and Wright, J.V., 1987, Volcanic successions: Modern and ancient: Allen and Unwin, London, $528 \mathrm{p}$.

Graham, I.J., Grapes, R.H., and Kifle, K., 1988, Buchitic metagreywacke xenoliths from Mount Ngauruhoe, Taupo Volcanic Zone, New Zealand: Journal of Volcanology and Geothermal Research, v. 35, p. 205-216.
Juhle, W., and Coulter, 1955, The Mount Spurr eruption, July 9 , 1953: Abstracts, Eos, Transactions of American Geophysical Union, v. 36, p. 199.

Magoon, L.B., Adkison, W.L., and Egbert, R.M., 1976, Map showing geology, wildcat wells, Tertiary plant fossils localities, K-Ar age dates, and petroleum operations, Cook Inlet, Alaska: U.S. Geological Survey Miscellaneous Investigation Series, Map I-1019 (3 sheets).

McGimsey, R.G., and Dorava, J.M., 1992, Eruption of Mount Spurr Volcano, Alaska, August 18, 1992: Video Footage: Abstracts, Eos, Transactions of the American Geophysical Union, v. 73, p. 345-346.

McKee, C.O., 1981, Geomorphology, geology, and petrology of Manam volcano, in Johnson, R.W., ed., Cooke-Ravian Volume of Volcanological Papers, Geological Survey of Papua New Guinea, Memoir 10, p. 23-38.

Nairn, I.A., and Self, S., 1978, Explosive eruptions and pyroclastic avalanches from Ngauruhoe in February 1975: Journal of Volcanology and Geothermal Research, v. 3, p.39-60.

Steiner, A., 1958, Petrogenetic implications of the 1954 Ngauruhoe lava and its xenoliths: New Zealand Journal of Geology and Geophysics, v. 1, p. 325-363. 



\title{
Ballistic Showers During Crater Peak Eruptions of Mount Spurr Volcano, Summer 1992
}

\author{
By Richard B. Waitt, Larry G. Mastin, and Thomas P. Miller
}

\section{CONTENTS}

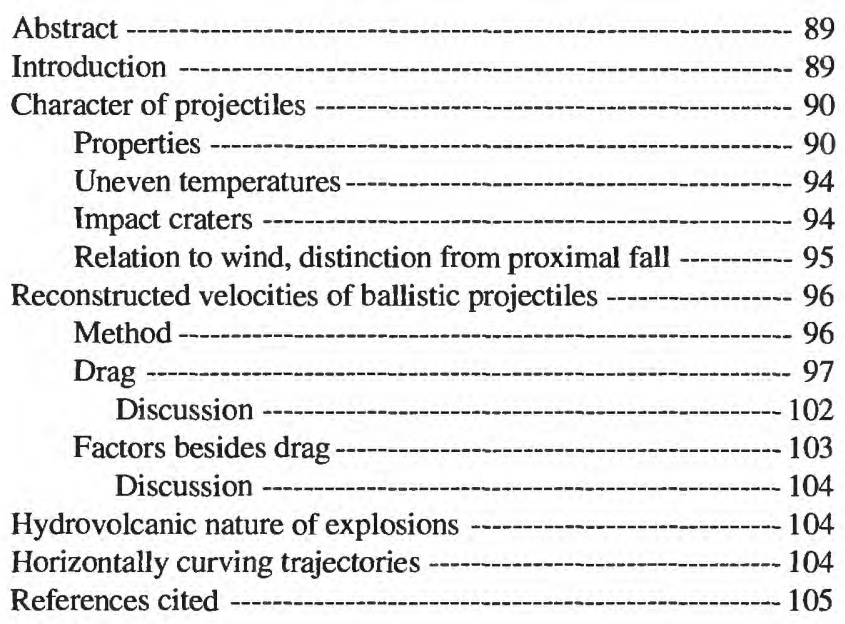

\begin{abstract}
Crater Peak vent at Mount Spurr volcano in Alaska ejected large ballistic blocks and bombs southeast from the vent near the end of the August 18, 1992, subplinian eruption. This eruption produced the most extensive bombfield of the 1992 eruptions. Lithic and juvenile andesite ballistic projectiles range in diameter from less than $10 \mathrm{~cm}$ to $2 \mathrm{~m}$, and they range in density from 1.20 to $2.75 \mathrm{~g} / \mathrm{cm}^{3}$. Lithic ballistic clasts are angular and blocky while cauliflower bombs are common among juvenile clasts, both typical of hydromagmatic explosions. As the eruption waned, ground water from the cone may have poured into the vent along with ejecta fallback and talus to fuel hydromagmatic explosions.

We estimate initial velocity needed to eject blocks to the observed 2 to $4 \mathrm{~km}$ and more from the vent by iteratively calculating the points of hypothetical trajectories. Drag influences the range of the blocks but is poorly constrained for irregularly shaped volcanic ballistics because it varies enormously with various combinations of shape, orientation, roughness, and velocity. For ballistics of $25 \mathrm{~cm}$ and larger that landed within $3.5 \mathrm{~km}$ of the vent, drag coefficients vary between 0.06 and 1.5 for spheres and cubes, and they
\end{abstract}

yield calculated vent velocities of 155 to $840 \mathrm{~m} / \mathrm{s}$; smaller and more distal clasts yield values improbably as much as several times higher. Ballistics larger than $10 \mathrm{~cm}$ apparently traveled much of their trajectories in a range of very high Reynolds numbers, between $4 \times 10^{5}$ and $1 \times 10^{7}$, where drag on smooth spheres is as low as 0.06 . In contrast to previous studies on volcanic ballistics, we infer that with low drag coefficients relatively small ballistic clasts can achieve fairly long range even with moderate ejection velocities.

Many impact craters along the southeast azimuth from the vent are aligned not directly southeastward but more nearly south. This southward deviation is typically $20^{\circ}$ to $40^{\circ}$, the maximum deviation $67^{\circ}-$ despite westerly wind that tended to shift trajectories east. A pitched baseball curves in the direction of applied spin (Magnus effect). Thus many projectiles apparently had strong angular velocity about near-vertical axes. The deviant projectiles at Crater Peak apparently acquired clockwise spin (when viewed from above) while being ejected from the vent.

\section{INTRODUCTION}

Crater Peak vent at Mount Spurr volcano ejected large ballistic blocks and bombs during all three eruptions of 1992. Ballistics flew north during the June 27 eruption, east-southeast during the August 18 eruption, and east during the September 16-17 eruption. The bombfield of the August eruption, which is scattered over an area of at least 12 square kilometers and extends more than $8 \mathrm{~km}$ east-southeast of the vent (figs. 1, 2, 3), is the most extensive and accessible bombfield of the 1992 eruptions.

Between the June 27 and August 18 eruptions, the vent shifted to the northwesternmost part of the crater, tight against and even slightly beneath the steep northwest (southeast-facing) crater wall (fig. 2). This position promoted ejection of debris preferentially southeastward. Thus pyroclastic flows of the August eruption were launched over the southeast crater rim rather than flowing south through a deep, wide breach in the crater rim (fig. 2) (Miller and others, this volume; Waitt, this volume). 


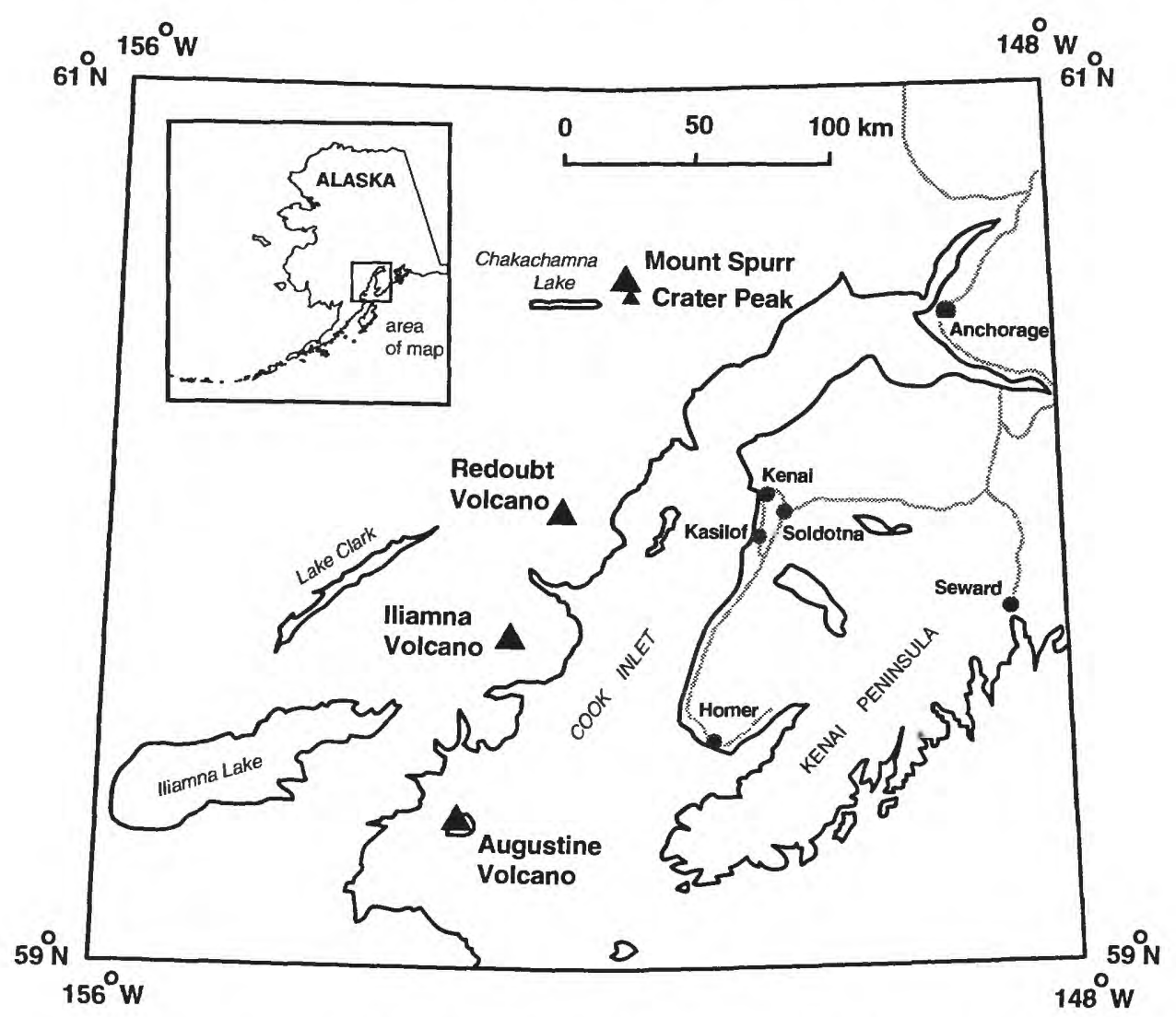

Figure 1. Index map of Cook Inlet area, Alaska, showing location of Mount Spurr volcano.

On the southeast flank of Crater Peak cone the August 18 bombfield comprises thousands of craters, bombs, and bomb fragments. Visible on 1:30,000-scale aerial photographs, the largest ( $>2 \mathrm{~m}$ diameter) and most concentrated craters extend up to altitude 1,375 $\mathrm{m}(4,500 \mathrm{ft})$ at range $1.8 \mathrm{~km}$ southeast of the vent. Above that level the slope consists of rock and is too steep for bombs to make impact craters. The abundantly cratered part of the field extends down to altitude $835 \mathrm{~m}(2,740 \mathrm{ft})$ at range $3.4 \mathrm{~km}$ from the vent. The density of large (2-5 m diameter) bomb craters is five per 100 square meters, estimated from aerial photographs. The actual number of bombs and craters including those below the resolution of the photographs (less than $2 \mathrm{~m}$ diameter) is at least an order of magnitude larger.

From field and aerial-photograph observations at several adjacent sites at range about $3.3 \mathrm{~km}$, nearly as many large impact craters ( $>1 \mathrm{~m}$ diameter) per unit area are apparent on pyroclastic-flow deposits of the August eruption as just beyond flow margins. At range $8 \mathrm{~km}$ where the ballistics overlapped the field of continuous subplinian fall, the ballistics formed small craterlets in the much finer grained fall deposit. Therefore most of the ballistics came near the end of the eruption after pyroclastic-flow and fall deposits were emplaced. Yet near range $3.3 \mathrm{~km}$ a pyroclastic-flow margin overlapped two impact craters, and so some of the ballistics clearly fell before the most extensive pyroclastic flows had occurred.

\section{CHARACTER OF PROJECTILES}

\section{PROPERTIES}

Ballistic projectiles range in diameter from about $2 \mathrm{~m}$ to $8 \mathrm{~cm}$ or less. Those larger than $30 \mathrm{~cm}$ are lithic. About half the projectiles smaller than $15 \mathrm{~cm}$ are fresh juvenile andesite, like that composing pyroclastic-flow deposits of the eruption (Miller and others, this volume); half are lithic cognate andesite and accidental basaltic andesite. The measured densities of 56 projectiles collected at sites 2.9 to $8 \mathrm{~km}$ from the vent show a wide range of 1.20 to $2.75 \mathrm{~g} / \mathrm{cm} 3$ (fig. 4). If

Figure 2. Distribution of August 18, 1992, eruption products, including field of bomb craters. 
a dense-rock equivalent density $\left(\rho_{\mathrm{d}}\right)$ of $2.6 \mathrm{~g} / \mathrm{cm}^{3}$ (Hall, 1987 , table 9) is used for andesite, these clast densities $\left(\rho_{c}\right)$ can be converted into vesicularity percent $(\mathrm{V}(\%))$ by the relation $\mathrm{V}(\%)=100\left(\rho_{d}-\rho_{c}\right) / \rho_{d}$ (Houghton and Wilson, 1989). The median vesicularity for eight density classes ranges from 0 to 50 percent (fig. 4).

The shapes and densities of gravel-sized clasts reveal something of their history (Houghton and Smith,
1993). Most Crater Peak ballistic clasts are angular and blocky. All clasts denser than $1.9 \mathrm{~g} / \mathrm{cm} 3$ are but slightly vesiculated, have angular edges and blocky shapes (fig. 5), and are very hard under the hammerclearly lithic. Most juvenile clasts are less dense than $1.8 \mathrm{~g} / \mathrm{cm}^{3}$, have microcauliflower surface texture on unbroken faces, are conspicuously vesiculated, and are completely unaltered. Many juvenile clasts have bro-

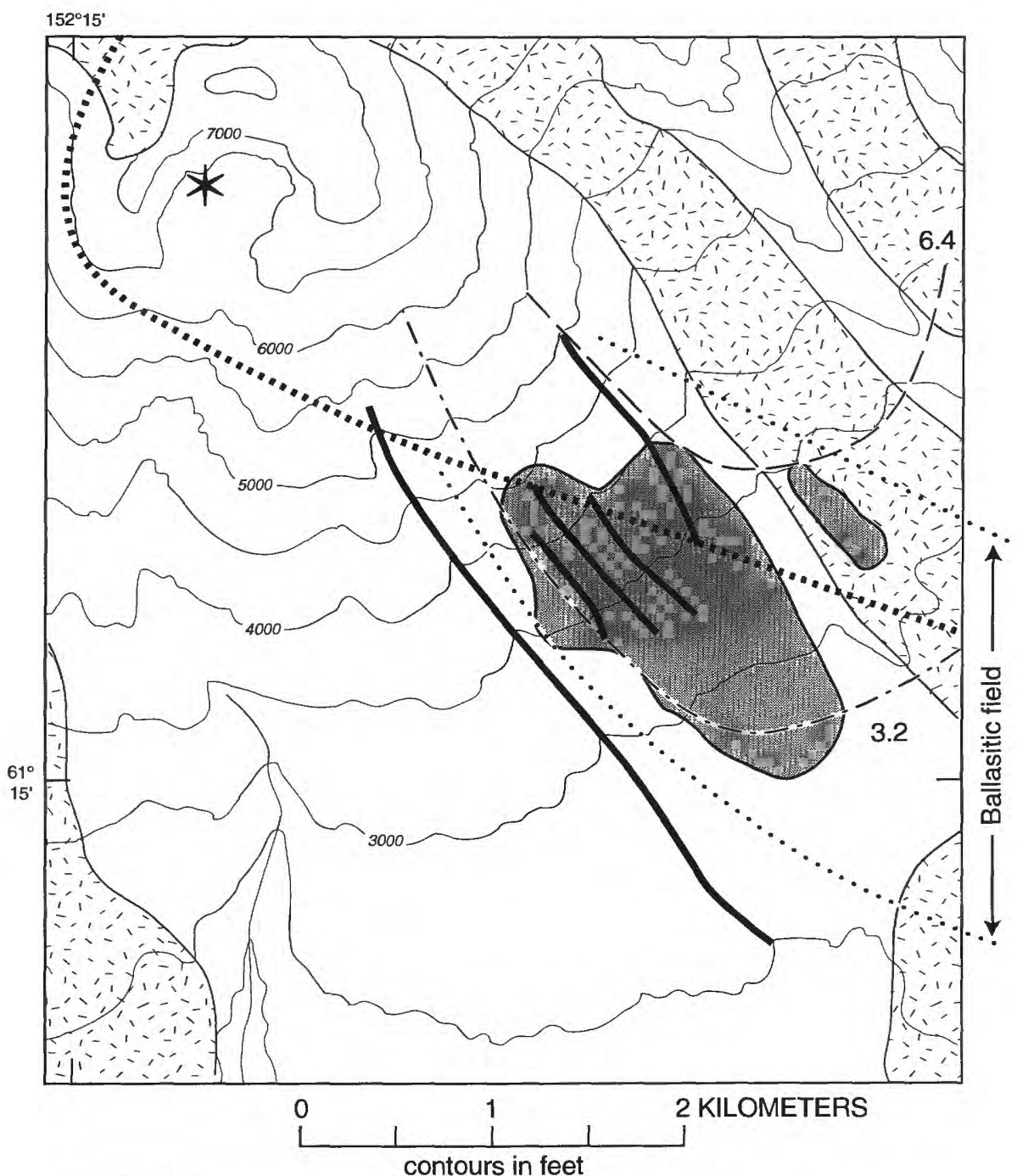

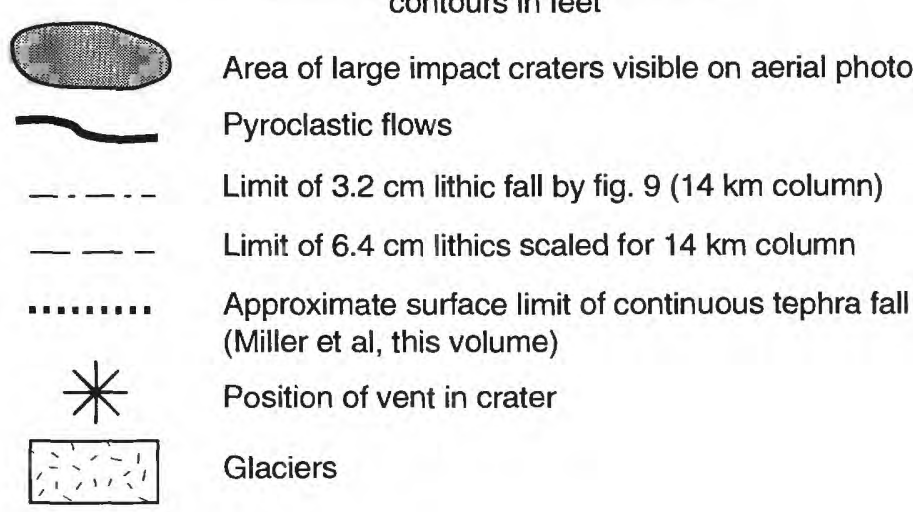




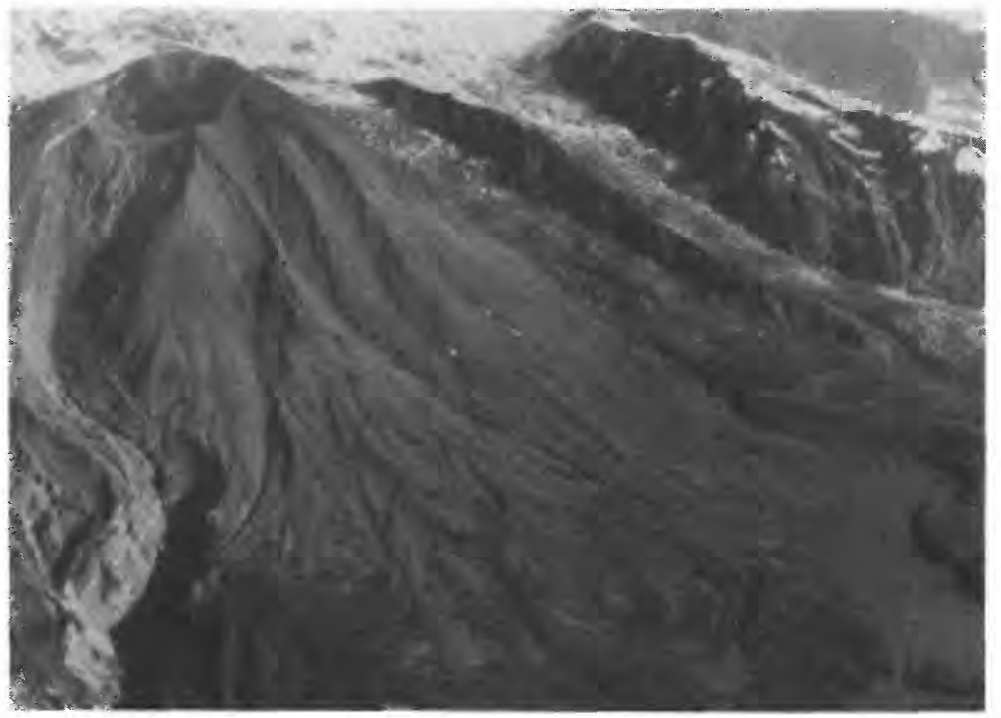

Figure 3. View north of Crater Peak on south flank of Mount Spurr volcano, Alaska. Right (south) margin of field of ballistics thrown by August 18, 1992, eruption approximately shown by dashed line. Field probably extends north beneath area covered by fall and flows of September 1992 eruption. Photograph taken July 27, 1993.

Figure 4. Density distribution of ballistic clasts of August eruption from sites 2.9 to $8.0 \mathrm{~km}$ from vent. Calculated vesicularity is also shown (at tops of columns), calculated from an assumed dense-rock-equivalent density of $2.6 \mathrm{~g} / \mathrm{cm}^{3}$. Negative vesicularities result from some basaltic-andesite accidental lithic clasts being denser than the assumed $2.6 \mathrm{~g} / \mathrm{cm}^{3}$; the area above the line drawn through the two right-hand columns hypothetically distinguishes them.

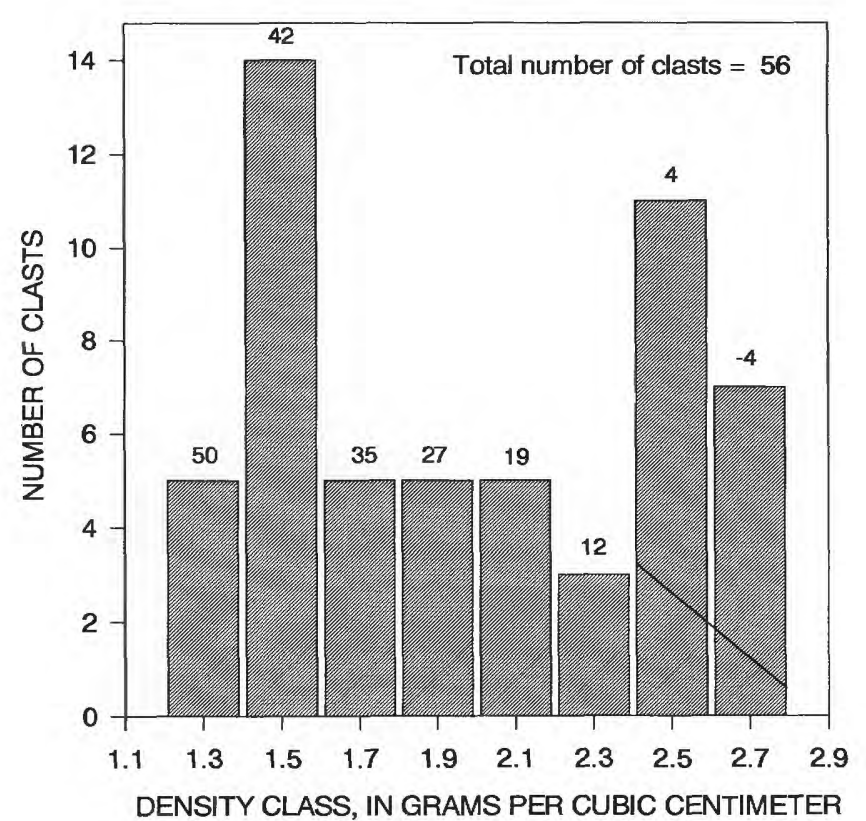

Figure 5. Shapes of small ballistic clasts from the August 18, 1992, eruption of Crater Peak vent, Mount Spurr volcano, Alas$\mathrm{ka}$. At center of juvenile group is a small cauliflower bomb, a scarcely vesicular juvenile lithic. The three in lower left are fragments of cauliflower bombs. Bar scale divisions are $5 \mathrm{~cm}$. 
ken faces (fig. 5) and show a more vesicular interior and a poorly vesicular exterior. Some juvenile lithic clasts have a more vesicular interior and a scarcely vesicular "lithic" surface. The wide range in density does not vary with throw distance (fig. 6): lithic and juvenile andesite apparently were ejected and traveled together.

Cauliflower-shaped bombs are common among the juvenile clasts (fig. 7). Where best formed, the distinctive texture is nearly identical to bombs photographed from clearly hydromagmatic deposits at Surtsey in Iceland, West Eifel maars in Germany, and Ukinrek maars in Alaska (Lorenz, 1974; Lorenz and Büchel, 1980; Self and others, 1980; Lorenz and Zimanowski, 1984). At Crater Peak, bombs 10 to $15 \mathrm{~cm}$ in diameter that were embedded in turf 3 to $4 \mathrm{~km}$ downrange

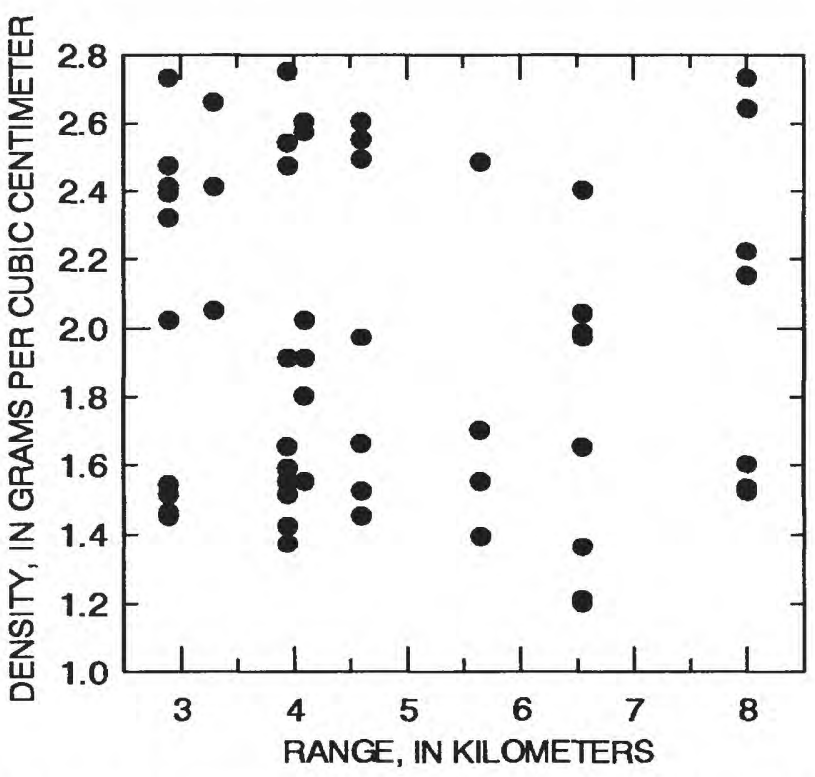

Figure 6. Density of ballistic clasts of August 18, 1992, eruption of Crater Peak vent, Mount Spurr volcano, Alaska, plotted against range of throw. are cauliflowered on top and bottom alike. Because their bottoms were not notably flattened nor their fine texture destroyed, they must have cooled enough to be no longer plastic and deformable upon impactthough they remained hot enough to scorch vegetation beneath them. Many juvenile clasts 2 to $5 \mathrm{~cm}$ in diameter are fragments of cauliflower bombs. Typically a third to a half of such a clast is gray to light brownish gray (10YR 6/1 to $6 / 2$ ) and has a microcauliflower texture, while the clearly broken faces bounded by sharp angles on other parts of the clast are dark gray to very dark gray (5YR 4/1 to $3 / 1$ ). In most such clasts, vesicularity notably decreases from 50 to 30 percent at broken (formerly interior) faces to 15 to 5 percent within $5 \mathrm{~mm}$ of the microcauliflowered surficial face.

The size of largest projectiles decreases sharply with throw distances (range) southeast from the vent (fig. 8). Three axes-the maximum, intermediate, and minimum diameters-were measured for many clasts, but because most of the projectiles are subequant to equant, only the intermediate axis is recorded for most of them. The outer limit of large projectiles is fairly sharp: those 40 to $200 \mathrm{~cm}$ in intermediate diameter stop at horizontal range $3.2 \mathrm{~km}$, those 20 to $40 \mathrm{~cm}$ in diameter stop at $3.6 \mathrm{~km}$, and those 10 to $\mathrm{cm}$ in diameter stop at $3.8 \mathrm{~km}$. Projectiles 1 to $10 \mathrm{~cm}$ in diameter lie throughout the range 2.5 to $8 \mathrm{~km}$. The plot can be interpreted in several ways. First, the steep decrease in large clasts and the long range of small ones may reflect a steeply logarithmic decay of a single population. But second, an outer limit of one population of large $(>15 \mathrm{~cm})$ clasts may exist whereas a $\mathrm{sec}-$ ond population of $1-$ to $10-\mathrm{cm}$ clasts extends out to at least $8 \mathrm{~km}$.
Figure 7. Cauliflower bombs thrown by August 18,1992 , eruption of Crater Peak vent, Mount Spurr volcano, Alaska. One on left is $12 \mathrm{~cm}$ across, that on right $9 \mathrm{~cm}$.

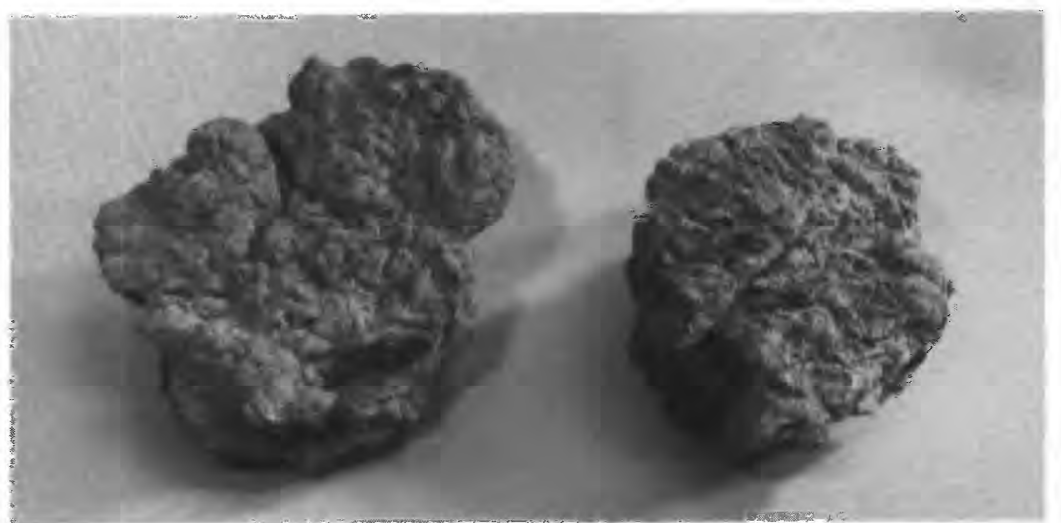




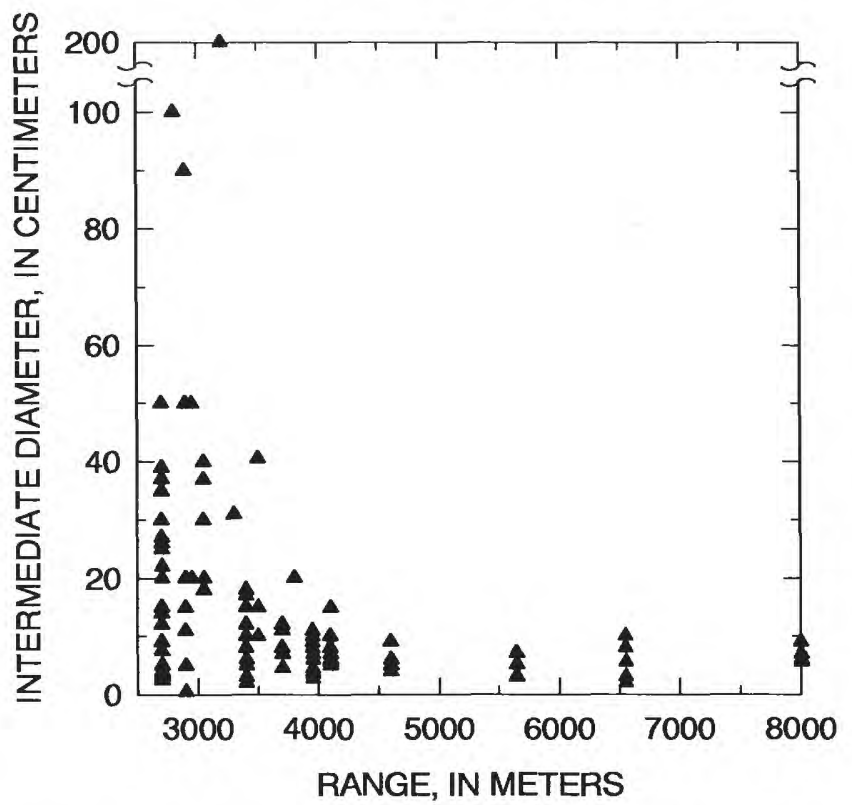

Figure 8. Intermediate projectile diameter plotted as a function of range of throw. Projectiles from August 18, 1992, eruption of Crater Peak vent, Mount Spurr volcano, Alaska.

\section{UNEVEN TEMPERATURES}

Many projectiles, both lithic and juvenile, landed in a mat of ground-hugging tundra plants such as caribou moss and scrub blueberry during growth season. Many of the vesicular, clearly juvenile clasts larger than about $10 \mathrm{~cm}$ that landed within $4 \mathrm{~km}$ of the vent notably scorched the vegetation on which they came to rest-as did juvenile clasts that tumbled off pyroclastic flows and descended into vegetated areas (Miller and others, this volume; Waitt, this volume). Yet beneath lithic ballistic clasts 5 to $50 \mathrm{~cm}$ in diameter, identical vegetation was pulverized but scarcely if at all scorched. Among the clasts of the ballistic shower(s), the juvenile ones clearly were much hotter than the lithic ones.

This pattern indicates that the juvenile and lithic clasts did not reach thermal equilibrium before ejection or during flight. The lithic clasts must not have resided at the vent long enough to acquire as high a temperature as the juvenile clasts before explosion(s) ejected them both.

Figure 9. Impact craters of blocks thrown ballistically by 1992 eruptions of Crater Peak vent, Mount Spurr volcano, Alaska. A, shattered largish block of August 18, 1992, bomb field; a third of the original clast is the angular block outside crater. $B$, Shattered block of September 17, 1992, that impacted pyroclastic-flow deposit emplaced earlier in same eruption.

\section{IMPACT CRATERS}

The largest impact craters range from 3.5 to 5.5 $\mathrm{m}$ in diameter and are as deep as $1.5 \mathrm{~m}$. The "target" material is fairly loose, coarse, lithic pyroclastic debris of the 1953 and prehistoric eruptions of Crater Peak, mantled by a thin loam soil and tundra turf (fig. 9). Whereas the largest craters contained bombs as large as $50 \mathrm{~cm}$, most projectile blocks larger than about $35 \mathrm{~cm}$ split or shattered upon impact, and parts of them lie outside the crater. When reconstructed, the largest clasts, which lie in and about the largest craters, measure 0.5 to $2 \mathrm{~m}$ in intermediate diameter. Craters larger than $3 \mathrm{~m}$ in diameter have 2 to 4 rays of ejected material radiating as much as $5 \mathrm{~m}$ downrange from the crater rim through $90^{\circ}$ to $160^{\circ}$ arcs. Clasts as small as $8 \mathrm{~cm}$ made impact craters as much as three times their diameter.
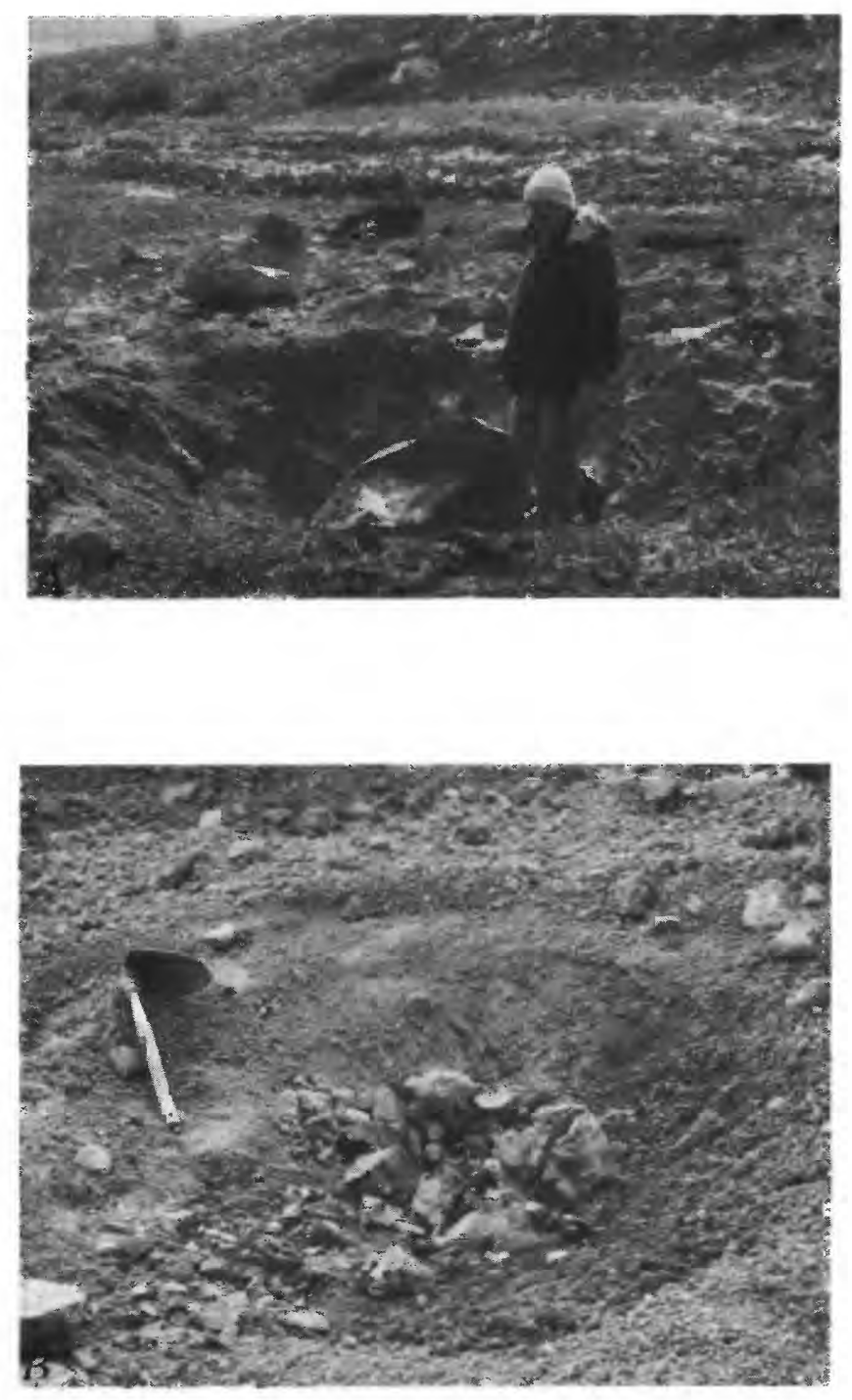


\section{RELATION TO WIND, DISTINCTION FROM PROXIMAL FALL}

The south limit of fall from the convective vulcanian column (Neal and others, this volume) is uncertain in the area within $10 \mathrm{~km}$ of the vent. The south limit of continuous fall is near the apparent north limit of the ballistic field. But within a few kilometers of vent, clasts that fell from the column can be difficult to distinguish from small clasts that moved on ballistic trajectories. During the Mount St. Helens eruptions of 1980, fall from eruption columns occurred through low-level winds oblique to the high-level winds driving the plume. Along the upwind lateral margin in proximal areas, the fall deposit was typically discontinuous-pumiceous clasts of sizes between medium pebbles and small cobbles and denser lithic clasts of small- to medium-pebble size (Waitt and others, 1981, figs. 269-273). At Crater Peak (Mount Spurr) on August 18, 1992, low-level winds were east-northeastward, oblique to the upper-level winds carrying the plume east and east-southeast (table 1).

Within the ballistic field 2 to $3.5 \mathrm{~km}$ from the vent lie clasts of all sizes from $2 \mathrm{~m}$ to $1 \mathrm{~cm}$ (fig. 8). The large $(>40 \mathrm{~cm}$ in diameter) clasts, none of them low-density pumice, are unarguably ballistics, as probably are lithic clasts down to $15 \mathrm{~cm}$ or smaller. Yet there is no distinguishable minimum-size limit of bal- listics detectable in the field. Did the $1-$ to $10-\mathrm{cm}$ clasts depicted on figure 8 arrive as ballistics or as fall? The discontinuous clasts smaller than $8 \mathrm{~cm}$ appear similar to the proximal falls at Mount St. Helens along the upwind lateral margins. Yet at Crater Peak, lithic clasts as small as $8 \mathrm{~cm}$ formed impact craters as far as $8 \mathrm{~km}$ from the vent in the much finer fall deposits there. Because the larger clasts have higher terminal velocities, they could not have traveled with the finer fall materials without landing first, not last. Therefore the larger clasts that formed small impact craterlets clearly were ejected later, and thus appear to have been ballistic projectiles. Without additional highly specific field data, distinction between the coarser ballistics and the finer fall is somewhat arbitrary.

Sparks (1986) modeled eruption columns whose diameters typically increase upward as a funnel shape, and Carey and Sparks (1986) analyzed fall from such columns (fig. 10). The highest reach of the Crater Peak eruption column of August 18, 1992, was $14 \mathrm{~km}$ (Rose and others, this volume). For a column $14 \mathrm{~km}$ high and a downrange wind velocity of $10 \mathrm{~m} / \mathrm{s}$, Carey and Sparks's (1986, fig. 14c) model predicts the outer limit of fall of 3.2-cm lithic clasts near the outer edge of the large August 18 impact craters; an extrapolated limit for $6.4-\mathrm{cm}$ clasts lies farther ventward of the main ballistic field (fig. 2). Thus by the plume model of Carey and Sparks (1986), lithic clasts only as large

Table 1. Wind data for August 18, 1992, eruption in vicinity of Mount Spurr volcano, Alaska.

[A. Projected winds beginning 7:00 p.m. August 18, 1992]

\begin{tabular}{cccc}
\hline $\begin{array}{c}\text { Altitude } \\
\text { (ft) }\end{array}$ & $\begin{array}{c}\text { Azimuth toward } \\
\text { (degree) }\end{array}$ & Wind velocity $(\mathbf{m} / \mathbf{s})$ & $\begin{array}{c}\text { Wind toward azimuth } 135 \\
(\mathbf{m} / \mathbf{s})\end{array}$ \\
\hline 5,000 & 17 & 4.8 & -2.3 \\
10,000 & 71 & 5.2 & 2.7 \\
18,000 & 72 & 11.1 & 5.0 \\
23,000 & 96 & 11.1 & 8.7 \\
30,000 & 104 & 14.7 & 12.7 \\
\hline
\end{tabular}

Source: National Weather Service

[B. Balloon sounding above Anchorage at 4:00 p.m. August 18, 1992]

\begin{tabular}{cccc}
\hline $\begin{array}{c}\text { Altitude } \\
\text { (ft) }\end{array}$ & $\begin{array}{c}\text { Azimuth toward } \\
\text { (degree) }\end{array}$ & Wind velocity $(\mathbf{m} / \mathbf{s})$ & $\begin{array}{c}\text { Wind toward azimuth 135 } \\
(\mathbf{m} / \mathbf{s})\end{array}$ \\
\hline 6,000 & 350 & 6.2 & -3.5 \\
8,000 & 30 & 5.1 & -1.3 \\
12,000 & 50 & 7.2 & 0.6 \\
16,000 & 70 & 9.3 & 3.9 \\
20,000 & 85 & 10.8 & 6.9 \\
25,000 & 115 & 15.9 & 15.0 \\
30,000 & 130 & 22.1 & 22.0 \\
\hline
\end{tabular}

Source: National Weather Service 
as 3 to $6 \mathrm{~cm}$ should have fallen as tephra within the area of the August 18, 1992, Crater Peak ballistic field. Were column height somewhat higher or winds higher than reported, somewhat larger clasts could have fallen in the shaded area shown in figure 2. By stretching the envelope of uncertainty, one can imagine lithic clasts as large as $8 \mathrm{~cm}$ being possibly related to airfall near the southeast part of the shaded area, but it doesn't help to explain larger clasts, which therefore must be ballistics.

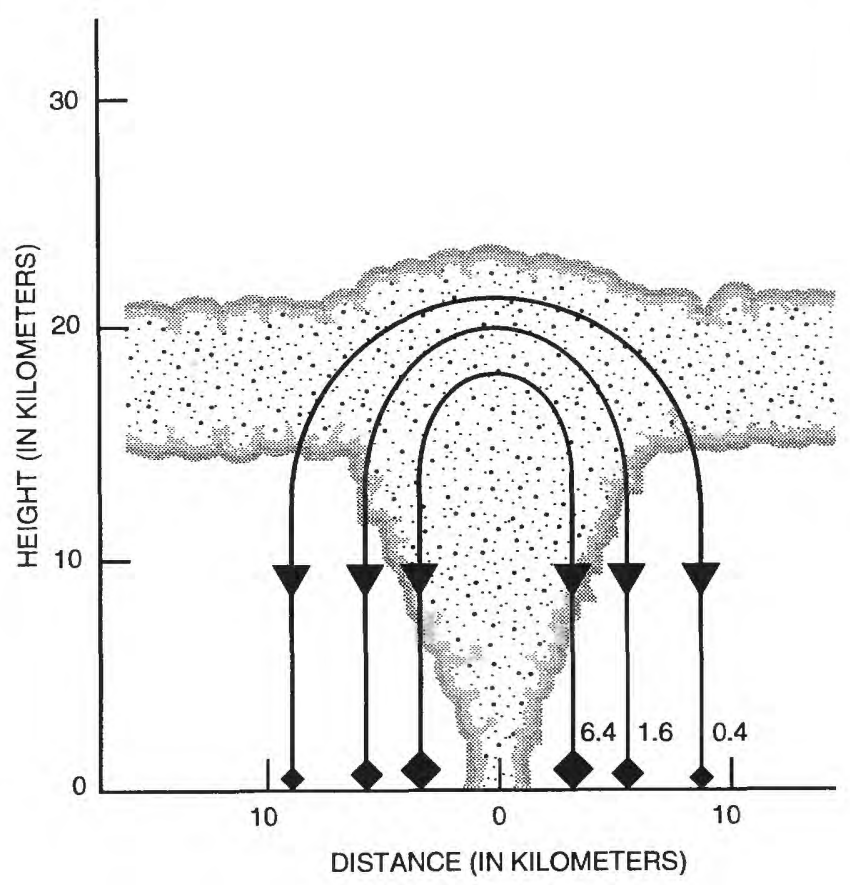

Figure 10. Fall of lithic (density $=2.5 \mathrm{~g} / \mathrm{cm}^{3}$ ) clasts from modeled column roughly 1.5 times the height of the maximum reported for the August 18, 1992, eruption of Crater Peak, Mount Spurr volcano, Alaska eruption (illustration from Carey and Sparks, 1986, fig. 6). Scale is true (no vertical exaggeration). Upward flare of model, about $23^{\circ}$ from the vertical, is about that shown by Crater Peak eruption photographs of August 18,1992 . Symbols show theoretical outer limit of lithic clasts $6.4,1.6$, and $0.4 \mathrm{~cm}$ in diameter. Outer limit of $6.4-\mathrm{cm}$ lithic clasts is $3.3 \mathrm{~km}$ from plume axis, the limit of $1.6-\mathrm{cm}$ clasts $5.5 \mathrm{~km}$. The modeled column is much higher than the Crater Peak column, thus the distance of lateral fall from plume axis is maximum-limiting case.

\section{RECONSTRUCTED VELOCITIES OF BALLISTIC PROJECTILES}

Some elements of the trajectory of a ballistic projectile can be inferred from its impact point, including minimum ejection velocity. From minimum velocity of an ejected block, vent pressure required to expel the block can be calculated within very broad limits and with considerable uncertainties.

\section{METHOD}

Wilson (1972) reconstructed volcanic-ballistic trajectories utilizing data on drag forces on cylindershaped projectiles. To reach a given distance from the vent, a small projectile (say $10 \mathrm{~cm}$ ) requires a far higher launch velocity than does a large $(1 \mathrm{~m})$ one, because for a small particle the ratio of surface area to mass is much higher, thus drag per unit mass much higher.

The velocity required to eject blocks to the distances observed at Crater Peak is estimated by computing ballistic trajectories for blocks of known properties using an algorithm outlined in Wilson (1972). Components of velocity (v) in the horizontal ( $x$ ) and vertical $(\mathrm{z})$ directions are given by:

$$
\begin{aligned}
& v_{x}=v \cos \theta \\
& v_{z}=v \sin \theta
\end{aligned}
$$

where $\theta$ is trajectory angle measured from the horizontal. At any given point along a particle's trajectory, the rates of change of $\mathrm{v}_{\mathrm{x}}$ and $\mathrm{v}_{\mathrm{z}}$ are given by:

$$
\begin{gathered}
\frac{d v_{x}}{d t}=\frac{-v_{x} \rho_{a} v A C_{d}}{2 m} \\
\frac{d v_{z}}{d t}=\frac{-v_{z} \rho_{a} v A C_{d}}{2 m}-g
\end{gathered}
$$

where $\rho_{\mathrm{a}}$ is air density, A is cross-sectional area of the block, $C_{d}$ is drag coefficient on the block, $m$ is the block's mass, $\mathrm{g}$ is gravitational acceleration, and $t$ is time. These equations are identical to equations 3 and 4 in Wilson (1972), though variables have been rearranged and different symbols are used to designate them. The variables $\mathrm{A}$ and $\mathrm{m}$ depend on the shape and size of the block, assumed in this case to be spherical (that is, $A=\pi r^{2}$ and $m=(4 / 3) \pi r^{3} \rho_{r}$ ), with block radius $(r)$ equal to the intermediate measured block semidiameter, and rock density $\left(\rho_{\mathrm{r}}\right)$ equal to 2.5 $\mathrm{g} / \mathrm{cm}^{3}$. Air density $\left(\rho_{\mathrm{a}}\right)$ varies with height and was recalculated at each point in the trajectory using the following equation, which is a best-fit curve through published altitude-density data (Ahrens, 1991, p. 546):

$$
\begin{array}{r}
\rho_{a}=.0012232-1.1389 \times 10^{-7}\left(z_{0}+z\right) \\
+3.3036 \times 10^{-12}\left(z_{0}+z\right)^{2}
\end{array}
$$


where $\mathrm{z}$ in this case is the vertical position above the vent, and $z_{0}$ is the altitude of the vent above sea level (air densities in $\mathrm{g} / \mathrm{cm}^{3}$, altitude in meters).

Equations 2 above were integrated throughout the trajectory using a fourth-order Runge-Kutta method, as were those of Wilson (1972). This algorithm was made more versatile by incorporating corrections for tailwind velocity $(w)$ downrange from the crater, and an altitude difference $(\xi)$ between the launch and landing sites $(\xi$ is $<0$ for sites that are lower than launch site, like all calculated herein). The correction for altitude difference was included by simply calculating the trajectory until the vertical position $(\mathrm{z})$ of the block reached its landing elevation $\left(z_{f}\right)$, which generally differs from launch altitude $(\mathrm{z}=0)$. The wind correction was made by substituting $\left(\mathrm{v}_{\mathrm{x}}-\mathrm{w}\right)$ for $\mathrm{v}_{\mathrm{x}}$ in equation $2 \mathrm{a}$, and $\sqrt{v_{z}^{2}+\left(v_{x}-w\right)^{2}}$ for $\mathrm{v}$ in equations $2 \mathrm{a}$ and $2 \mathrm{~b}$.

\section{DRAG}

Drag coefficient $C_{d}$ influences the final range of the blocks enormously but is poorly constrained for use with volcanic ballistics, for the experimental data show that drag on a projectile varies greatly with its shape, orientation, and roughness. Experimental results (for example, Hoerner, 1965) indicate that $C_{d}$ for variously shaped objects traveling through fluids varies with two dimensionless numbers that indicate flow regime: Reynolds number ( $\mathrm{Re}$ ) and Mach number (M). Reynolds number relates the relative importance of viscous versus inertial forces in the fluid by the relation (for external flow) $R e=v d \rho / \eta$, where $v$ is particle velocity, $d$ is particle diameter, $\rho$ is fluid density, and $\eta$ is fluid viscosity ("fluid" here being air). The range of particle sizes and calculated velocities give Reynolds numbers ( $R e)$ greater than or equal to $4 \times 10^{5}$. Drag coefficient $C_{d}$ for smooth spheres is 0.06 at $\operatorname{Re}$ of $4 \times 10^{5}$ and rises gradually to 0.2 at Re greater than about $1 \times 10^{7}$ (fig. 11) (Hoerner, 1965, figs. 3-10, 3-11; Achenbach, 1972, fig. 4).

Most authors analyzing volcanic ballistics have used high drag coefficients. In experiments on falling pyroclasts, Walker and others (1971) showed that for terminal velocities of small particles falling at low velocities (hence low Reynolds numbers), the relatively high drag coefficients for cylinders were more appropriate than the lower coefficients for spheres. Thus Wilson (1972) and Fagents and Wilson (1993) assumed that $C_{d}$ measured for cylinders applied to irregularly shaped blocks. For such objects several other authors have also assumed rather high values of $C_{d}$, usually around 1.0 and no lower than 0.7 (Minakami, 1942; Fudali and Melson, 1972; Steinberg and Lorenz, 1983; Self and others, 1980; Wilson, 1980; Mastin, 1991).

Mach number $(\mathrm{M} \equiv \mathrm{v} / \mathrm{c})$ gives the speed of the object (v) relative to the fluid's sonic velocity (c). For air under ambient conditions, the sonic velocity is about $350 \mathrm{~m} / \mathrm{s}$. As long as objects are traveling at speeds less than about 70 percent of the sonic velocity (that is, less than about $250 \mathrm{~m} / \mathrm{s}$ ), $C_{d}$ varies with Reynolds number only. But at Mach numbers above about 0.7 , the production of sound waves (and shock waves when $M \geq 1$ ) dissipates energy. Drag coefficients rise dramatically for Mach numbers in the range 0.7 to 1.5 and stabilize for Mach numbers above 1.5 (fig. 12).

To calculate ballistic trajectories for the irregularly shaped blocks at Crater Peak, we assumed drag coefficients for spheres (which have low drag) and

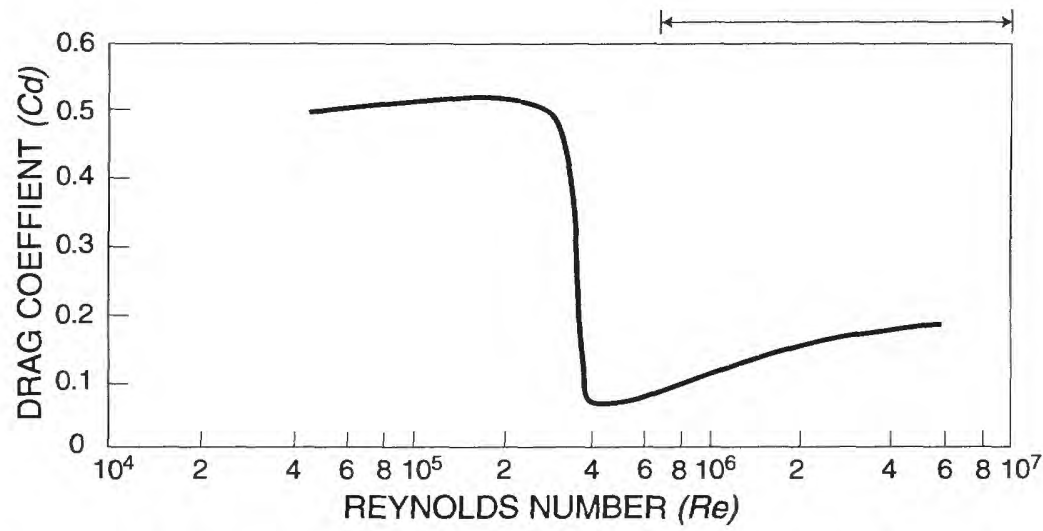

Figure 11. Low drag coefficients for smooth spheres at very high Reynolds numbers (from Achenbach, 1972, fig. 4). Bar with arrowheads shows range of Reynolds numbers calculated from initial velocities computed for ballistic clasts from the 1992 eruptions of Crater Peak, Mount Spurr volcano, Alaska. 


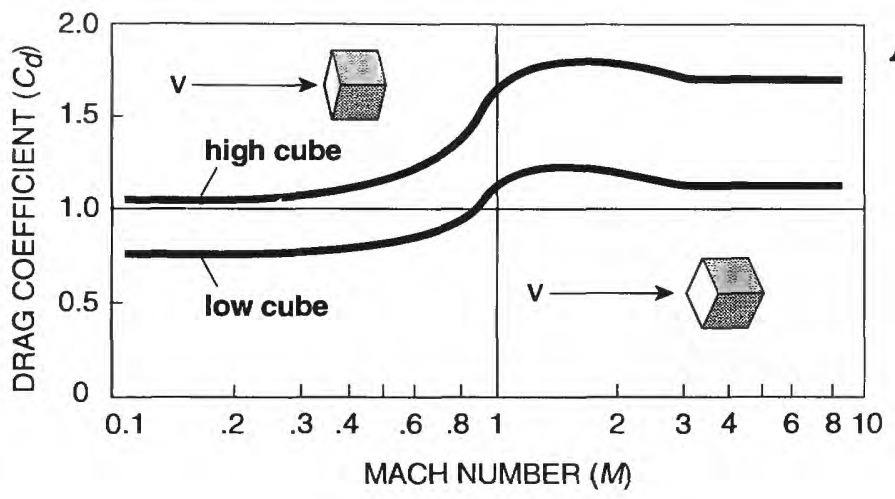

A

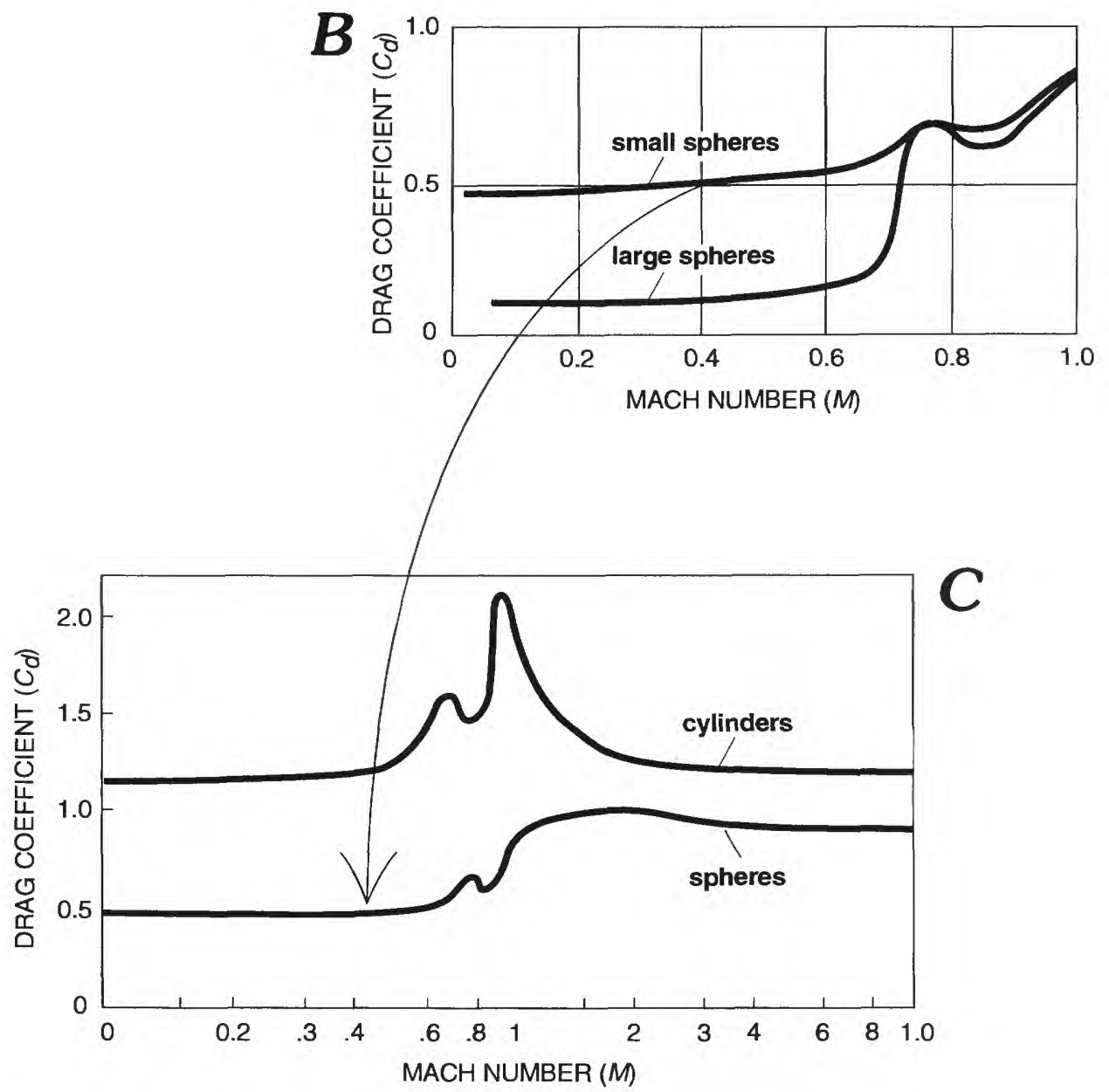

Figure 12. Drag coefficients for $(A)$ cubes at transonic velocities, $(B)$ spheres at velocities approaching sonic, and $(C)$ cylinders (top curve) and spheres (lower curve) at transonic velocities. Top curve in $(A)$ represents drag coefficients for cubes oriented with one face perpendicular to the direction of motion. Bottom curve represents drag for cubes oriented with the vertex between three faces at the leading edge of the cube. Top curve in $(B)$ represents drag coefficients for small spheres at Reynolds numbers below the critical transition $\left(\operatorname{Re}=\sim 2 \times 10^{5}\right.$ ), whereas the lower curve represents drag coefficients for large spheres at Reynolds numbers above the critical transition. The ballistic model calculates Reynolds number at each point in the trajectory and uses the drag appropriate at the calculated Reynolds and Mach numbers (for all blocks analyzed in this study, the appropriate drag coefficient is represented by the large-sphere curve). Calculations for supersonic velocities used drag coefficients for spheres illustrated in (C). Modified from Hoerner (1965). 
for cubes (with high drag) (table 2). At each point in the trajectory the Mach number (taken from fig. 12) was used for the next calculation. Results from this program using some typical input parameters are shown in figure 13 for a launch angle of $45^{\circ}$.

We back-calculate initial velocities for the largest one or two projectiles from each small sampled area. Altitude of impact site $\left(\mathrm{Z}_{\text {final }}\right.$ or $\left.\mathrm{Z}_{\mathrm{f}}\right)$ was measured in the field by altimeter and plotted on a topographic map, from which range $\left(x_{f}\right)$ was read. We assume a lithic particle density of $2.5 \mathrm{~g} / \mathrm{cm}^{3}$ and launch angles between $30^{\circ}$ and $35^{\circ}$ - the most efficient launch angles calculated by the program under the conditions of range less than $4 \mathrm{~km}$ and with impact altitude far below launch altitude. We assume downrange windspeed of $0 \mathrm{~m} / \mathrm{s}$; calculations with the highest permissible windspeed $(10 \mathrm{~m} / \mathrm{s})$ do not substantially affect results.

Our results for ballistic clasts thrown by Crater Peak are shown by table 3 , calculated using values of $C_{d}$ measured for spheres and cubes. At the very high Reynolds numbers $\left(\operatorname{Re}>4 \times 10^{5}\right)$ typical for Mount Spurr ballistics, $C_{d}$ for smooth spheres can be as low as 0.06 (fig. 11) but for very rough objects may be much higher.

For comparison to the Mount Spurr data is a synopsis of ballistics thrown by other eruptions, calculated with a constant high drag coefficient $\left(C_{d}=1\right)$ used by investigators of those eruptions. At drag coefficient $\mathrm{C}_{\mathrm{d}}=1$ (table 3 , col. 8), our calculated initial velocities at Ukinrek maars and Inyo Craters-where ballistic clasts are fairly large and maximum range only about $700 \mathrm{~m}$-are near the values 85 to $100 \mathrm{~m} / \mathrm{s}$ reported by Self and others (1980) and Mastin (1991) respectively. The calculated initial velocities for the large ballistics at moderate to long distance at Asama in 1938, Arenal in 1968, and Ngauruhoe in 1975, (195$322 \mathrm{~m} / \mathrm{s}$ ) are also well below sonic velocities, more so than originally reported (Minakami, 1942; Fudali and Melson, 1972; Nairn, 1976).

If we use a constant $\mathrm{C}_{\mathrm{d}}=1$ at Crater Peak (Mount Spurr), subsonic velocities are given only by the largest $(2 \mathrm{~m})$ clast thrown to moderate range, whose calculated $v_{i}$ is $183 \mathrm{~m} / \mathrm{s}$ (table 3 , col. 8). The only other

Table 2. Drag coefficients for three-dimensional shapes.

\begin{tabular}{|c|c|c|}
\hline Shape & Laminar flow & Turbulent flow \\
\hline Sphere & 0.47 & 0.10 \\
\hline \multicolumn{3}{|l|}{$\begin{array}{l}\text { Ellipsoidal body with } \\
\text { circular cross section }\end{array}$} \\
\hline $2: 1$ & 0.27 & 0.06 \\
\hline $4: 1$ & 0.20 & 0.06 \\
\hline $8: 1 \longrightarrow<$ & 0.25 & 0.13 \\
\hline Disk & \multicolumn{2}{|c|}{1.17} \\
\hline Cube & \multicolumn{2}{|c|}{1.05} \\
\hline & \multicolumn{2}{|c|}{0.80} \\
\hline $60^{\circ}$ cone & \multicolumn{2}{|c|}{0.49} \\
\hline \multicolumn{3}{|l|}{ Solid hemisphere: } \\
\hline Convex surface to flow & \multicolumn{2}{|c|}{0.38} \\
\hline Flat face to flow & \multicolumn{2}{|c|}{1.17} \\
\hline
\end{tabular}

Adapted from Mironer (1979, table 8.2) 


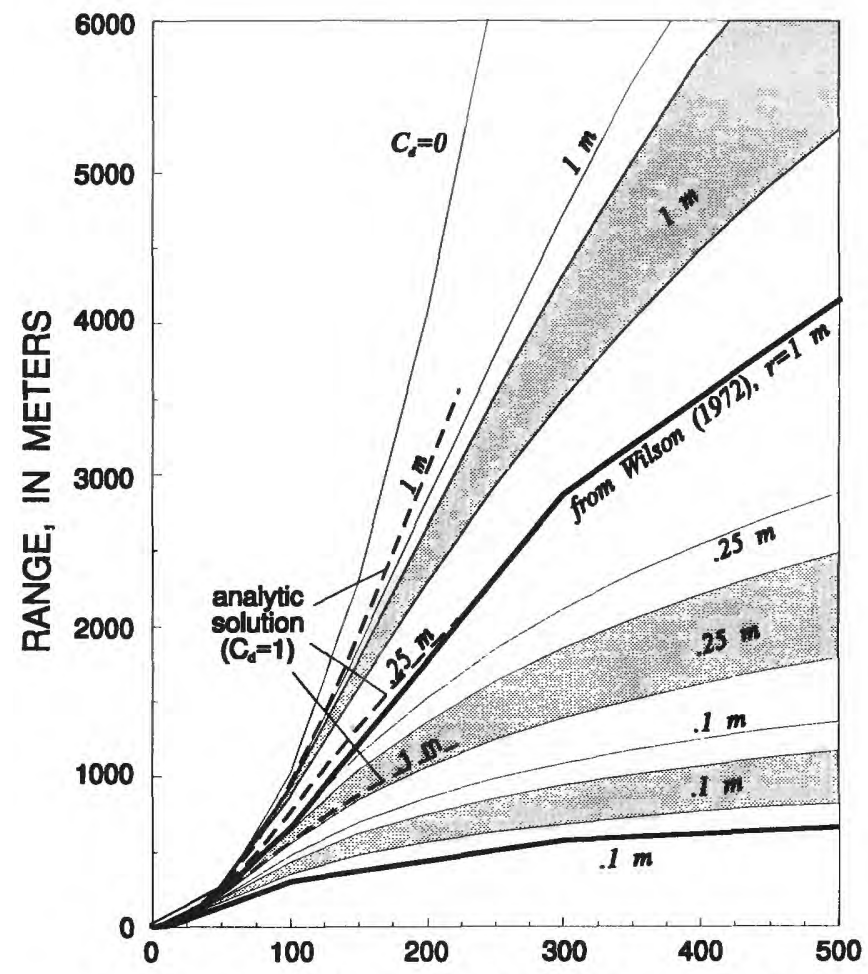

INITIAL VELOCITY, IN METERS PER SECOND clasts yielding subsonic (barely) initial velocities are $50 \mathrm{~cm}$ or more in diameter. Ballistics 37 to $39 \mathrm{~cm}$ in diameter even in the nearest part of the sampled range $(2.7 \mathrm{~km})$ yield much higher supersonic velocities $(>400$ $\mathrm{m} / \mathrm{s}$ ). Calculated velocities above $700 \mathrm{~m} / \mathrm{s}$ (Mach number $\approx 2$ ) for projectiles of smaller size and (or) those thrown to greater range seem unreasonably high.

If now these clasts are calculated using a variable drag coefficient as low as $\mathrm{C}_{\mathrm{d}}=0.06$ - the values for smooth spheres when Re exceeds $4 \times 10^{5}$ (fig. 11) ballistic clasts with diameters as small as $15 \mathrm{~cm}$ have

Figure 13. Initial velocity of blocks ejected plotted as a function of range assuming wind velocity $w=0 \mathrm{~m} / \mathrm{s}$, impact altitude below vent altitude $\xi=0 \mathrm{~m}$, density of projectiles $\rho=2.5 \mathrm{~g} / \mathrm{cm}^{3}$, and the initial trajectory angle is $45^{\circ}$ from horizontal. Shaded regions represent results using drag coefficients for cubes, thin solid lines represent results using drag coefficients for spheres. Heavy solid lines are values from Wilson (1972) based on drag coefficients for cylinders. Dashed lines show values from the approximate analytical solution of Minakami (1942) (see also Self and others, 1980; Mastin, 1991) that assumes a constant drag coefficient $\mathrm{C}_{\mathrm{d}}=1$.

Table 3. Ballistics of August 1992 eruption of Crater Peak, Alaska.

[Vent altitude, 1,952 m. $\mathrm{C}_{\mathrm{d}}$, drag coefficient; Re, Reynolds number; M, Mach number]

\begin{tabular}{|c|c|c|c|c|c|c|c|c|c|}
\hline \multirow[b]{3}{*}{$\begin{array}{c}\text { Station No. } \\
\quad 1993\end{array}$} & \multirow[b]{3}{*}{$\begin{array}{c}\text { Range } \\
(\mathrm{m})\end{array}$} & \multirow[b]{3}{*}{$\underset{(\mathrm{m})}{\text { Altitude }}$} & \multirow[b]{3}{*}{$\begin{array}{c}\begin{array}{c}\text { Altitude } \\
\text { difference } \\
(\mathbf{m})\end{array} \\
\end{array}$} & \multirow[b]{3}{*}{$\begin{array}{c}\text { Azimuth } \\
\text { (degree) }\end{array}$} & \multirow[b]{3}{*}{$\begin{array}{c}\text { Diameter } \\
\text { (cm) }\end{array}$} & \multicolumn{4}{|c|}{ INITIAL VELOCITY } \\
\hline & & & & & & \multirow[b]{2}{*}{$\begin{array}{c}\text { Vacuum } \\
\mathbf{C}_{\mathbf{d}}=\mathbf{0} \\
(\mathrm{m} / \mathrm{s})\end{array}$} & \multirow[b]{2}{*}{$\begin{array}{c}\text { Fixed Cd } \\
\mathbf{C}_{\mathbf{d}=1} \\
(\mathrm{~m} / \mathrm{s}) \\
\end{array}$} & \multicolumn{2}{|c|}{$C_{d}$ variable with $R e$ and $M$} \\
\hline & & & & & & & & Sphere $(\mathrm{m} / \mathrm{s})$ & Cube $(\mathrm{m} / \mathrm{s})$ \\
\hline .01 & 2700 & 976 & -976 & 140 & 37 & 140 & 432 & 156 & 342 \\
\hline .02 & 2700 & 976 & -976 & 140 & 39 & 140 & 398 & 156 & 319 \\
\hline .02 & 2700 & 976 & -976 & 140 & 25 & 140 & 1025 & 165 & 761 \\
\hline .03 & 2700 & 968 & -984 & 140 & 9 & 140 & Infinite & 194 & Infinite \\
\hline .04 & 2900 & 961 & -991 & 133 & 50 & 145 & 331 & 160 & 277 \\
\hline .05 & 2950 & 930 & -1022 & 133 & 50 & 146 & 340 & 162 & 283 \\
\hline .06 & 2950 & 930 & -1022 & 133 & 20 & 146 & 3400 & 184 & 2411 \\
\hline .08 & 3200 & 891 & -1061 & 132 & 200 & 154 & 183 & 157 & 175 \\
\hline .09 & 3400 & 857 & -1095 & 133 & 17 & 159 & Infinite & 219 & Infinite \\
\hline .10 & 3400 & 851 & -1101 & 134 & 18 & 159 & Infinite & 216 & Infinite \\
\hline .11 & 3300 & 866 & -1086 & 134 & 31 & 156 & 914 & 188 & 839 \\
\hline .12 & 3500 & 836 & -1116 & 137 & 40.5 & 162 & 672 & 189 & 534 \\
\hline .12 & 3500 & 836 & -1116 & 137 & 15 & 162 & Infinite & 245 & Infinite \\
\hline .13 & 3700 & 817 & -1135 & 138 & 11 & 167 & Infinite & 604 & Infinite \\
\hline .14 & 3800 & 787 & -1165 & 139 & 20 & 169 & Infinite & 248 & Infinite \\
\hline .15 & 4100 & 790 & -1162 & 140 & 15 & 177 & Infinite & 582 & Infinite \\
\hline .19 & 3950 & 747 & -1205 & 137 & 11 & 172 & Infinite & 936 & Infinite \\
\hline .20 & 6550 & 628 & -1324 & 134 & 10 & 231 & Infinite & Infinite & Infinite \\
\hline .24 & 8000 & 686 & -1266 & 121 & 9 & 262 & Infinite & Infinite & Infinite \\
\hline Asama 1938 & 3500 & & -1100 & & 100 & & 266 & (Minakami, & \\
\hline Ngauruhoe & 2800 & & -980 & & 80 & & 237 & (Nairn, 1976 & \\
\hline Arenal & 5000 & & -500 & & 200 & & 291 & (Fudali and & on, 1972) \\
\hline Ukinrek & 700 & & 0 & & 200 & & 87 & (Self and oth & 1980) \\
\hline Inyo & 700 & & 40 & & 40 & & 108 & (Mastin, 199 & \\
\hline
\end{tabular}


subsonic velocities (table 3, col. 9). The larger projectiles (intermediate diameters between 200 and 17 $\mathrm{cm}$ ) thrown downrange 2.7 to $3.5 \mathrm{~km}$ give reconstructed initial velocities between 156 and $248 \mathrm{~m} / \mathrm{s}$. For smooth spheres the variable $C_{d}$ of table 3 , column 9 is low throughout most or all of a clast's range, except where required initial velocity exceeds Mach number 0.7 , which triggers the use of higher drag coefficients taken from figure 12. Under the drag assumptions for smooth spheres, implied vent velocities for the particles of $18 \mathrm{~cm}$ and larger thrown from Crater Peak during its August eruption were between 160 and $250 \mathrm{~m} / \mathrm{s}$.

Figure 14 illustrates the highly variable drag for a sphere initially shot at $400 \mathrm{~m} / \mathrm{s}$. During the initial part of its flight, drag coefficient is about 0.85 and falls to 0.65 in the first one-sixth of its flight. Then as Mach number drops below 0.7, drag falls off rapidly to 0.2 . From there it drops even lower as veloc- ity reaches a minimum at the top of the trajectory, and then rises back to about 0.2 as velocity increases on the downward leg of the trajectory.

Volcanic particles are not spheres and many have angular faces. Wind-tunnel drag data are readily available (Hoerner, 1965) for cubes. If we test the Crater Peak ballistics with these drag coefficients for cubes, all but the largest block would have required initial velocities above $400 \mathrm{~m} / \mathrm{s}$. Many of those exceed even maximum theoretical velocities for eruptions under nearly all reasonable initial pressure conditions (about $2000 \mathrm{~m} / \mathrm{s}$, Mastin, 1995). Of the many apparently ballistic projectiles smaller than $18 \mathrm{~cm}$ in diameter that landed downrange 2.7 to $8.0 \mathrm{~km}$ from the vent (fig. 8), implied initial velocities are 500, 1000, 2000 $\mathrm{m} / \mathrm{s}$ and higher. The more the calculated values for initial velocity exceed $400 \mathrm{~m} / \mathrm{s}$, the less believable they are.

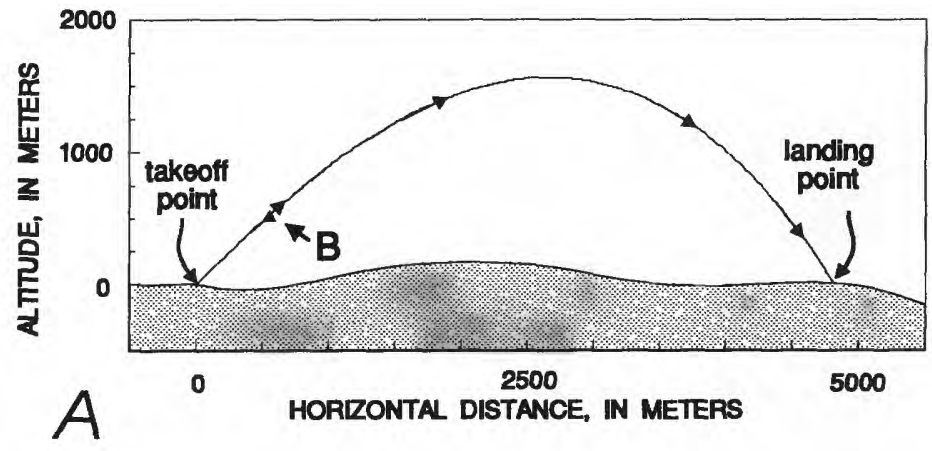

Figure 14. Successively, sharply lower drag coefficients of typical ballistic block thrown from Crater Peak whose velocity is initially supersonic. $A$, Block's vertical trajectory during flight. $B$, Change in drag coefficient during flight.

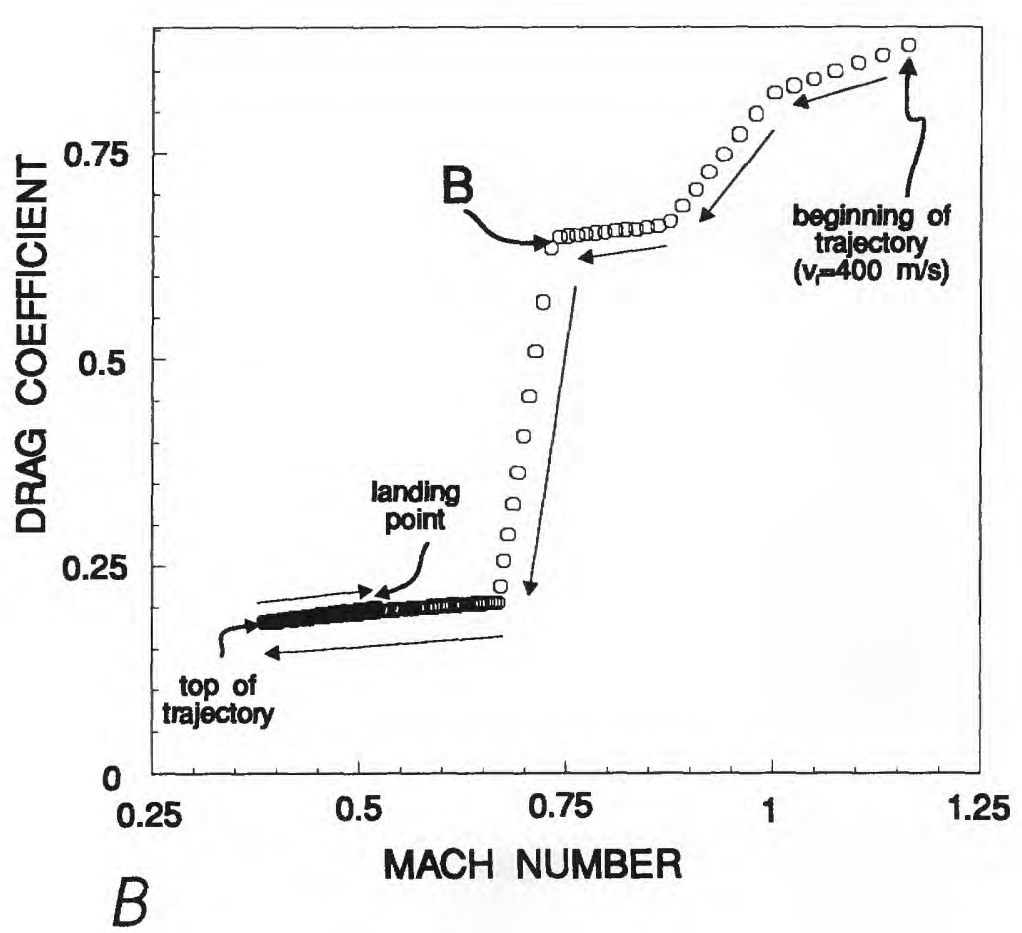




\section{DISCUSSION}

Most or all students of volcanic ballistics have followed Walker and others (1971) in assuming high drag coefficients (as for cylinders) in calculating trajectories of volcanic ballistics, and no other experiments have appeared to test that analysis. But calculations using such high drag give impossibly high initial velocities for the smaller of the Crater Peak clasts that are clearly ballistics.

Drag data on cubes compiled by Hoerner (1965) also entails fairly high drag coefficients (fig. 12A). High drag in the computations yields the high initial velocities for a clast even of moderate size (say, 20$40 \mathrm{~cm}$ ) to be thrown to moderate range (say, 2.5 to $3.5 \mathrm{~km}$ ). These results are then compounded where Mach numbers exceed 0.6 , above which drag further increases significantly (fig. $12 B, C$ ).

Velocities of 100 to $250 \mathrm{~m} / \mathrm{s}$ of clasts 0.1 to 1.0 $\mathrm{m}$ in diameter generate Reynolds numbers between about $7 \times 10^{6}$ and $1 \times 10^{7}$. This is the range of very high Reynolds numbers explored by Achenbach (1972) for smooth spheres, whose drag coefficients he measured to be very low-below 0.2 , even as low as 0.06 (fig. 11). Terminal velocities exceeding $40 \mathrm{~m} / \mathrm{s}$ of ballistics larger than $5 \mathrm{~cm}$ in diameter keep them from "mov- ing leftward" on figure 11 below Reynolds numbers smaller than $5 \times 10^{6}$ and into a range of much higher drag coefficients, even toward the end of their flight. If the flight of a particle occurs mostly or entirely within this envelope of low drag, 10- to 40-cm particles thrown even to range 4 to $8 \mathrm{~km}$ would require initial velocities far below sonic velocity (table 3 , col. 9). We sense that the much lower drag coefficients permitted by wind-tunnel data on spheres where Reynolds numbers are greater than $4 \times 10^{6}$ is the key to unlock the enigma of far-traveled small ballistics.

While drag coefficients for very rough volcanic particles generally exceed those for smooth spheres, there may be compensating effects. For instance, slight roughening of a smooth sphere increases turbulence in the boundary layer and causes the wake to be much smaller (fig. 15); thus drag is reduced. Photographs illustrating this principle are shown in many textbooks on fluid mechanics (Rouse, 1946, plate 16; Mironer, 1979, fig. 8.19; White, 1979, fig. 7.14). A golf ball "roughened" by inverse topography ("dimples") travels farther than a smooth one (Jorgensen, 1993, p. 62-64).

The surfaces of volcanic ballistics may be irregular in shape, but few resemble the least aerodynamic geometric solid (cube) tested in wind tunnels
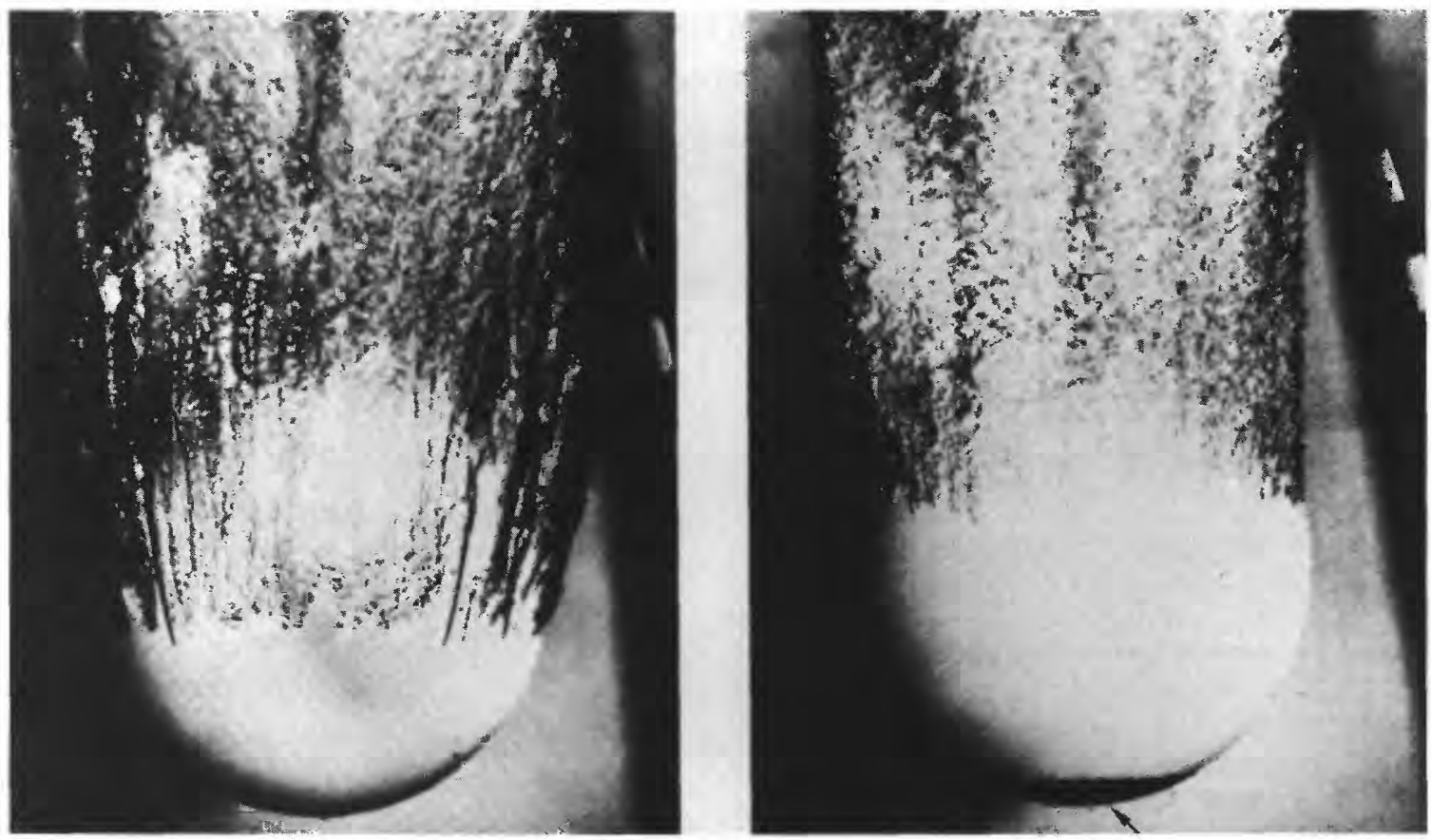

Figure 15. Bowling ball in two experiments generating similar Reynolds numbers. The roughened surface of ball on right (sandpaper patch at base [arrow] causes "premature" boundary-layer turbulence and consequent decrease in area of wake in lee of sphere, compared with that of smooth ball. The smaller wake decreases the relative vacuum behind the object that exerts a small backward force on it, and hence decreases total drag. From Waugh and Stubstab (1973, fig. 15.6). 
(table 2). Until actual volcanic ballistics are tested in wind tunnels, one can only infer that drag coefficient will be somewhere between about 0.06 and 1.5 at substantially subsonic velocities. If the lower end of this enormous range proves at all close to reality, the evidently "impossible" great range achieved by some smallish ballistic particles will be partly explained.

\section{FACTORS BESIDES DRAG}

Other factors besides a cannonlike ejection into a continuous air-drag environment must influence the great distance traveled by many of the smaller blocks. These other factors could include: (1) much higher tailwinds than assumed in the model, (2) convective lift during flight, (3) large blocks traveling mostly intact but then disaggregating before landing, (4) smaller blocks drawn behind larger blocks or ejected as aggregates with other blocks and thus collectively subject to less drag than imposed on blocks separately, and (5) shock waves and other forward air movement attending ejection of blocks, which reduce air drag during the first part of the trajectory. These five factors are examined below.

Using a range of hypothetical tailwind velocities, we calculate initial ejection velocities for the 40.5$\mathrm{cm}$ block thrown $3.5 \mathrm{~km}$ from the vent (table 4). Even with a low drag coefficient appropriate for smooth spheres and the lowest appropriate for cubes, tailwind velocities exceeding $35 \mathrm{~m} / \mathrm{s}$ are required throughout the trajectory to bring ejection velocities within the less than $400 \mathrm{~m} / \mathrm{s}$ range of velocities previously observed. With the higher drag coefficients for cubes, required tailwind velocities would be about $60 \mathrm{~m} / \mathrm{s}$. Such hypothetical wind speeds are 5 to 30 times those shown by the NOAA data for August 18, 1992, (table 1).

Table 4. Hypothetical effect of tailwind in carrying blocks to greater distance.

[Example of a 40.5 -cm-diameter block thrown to range $3,500 \mathrm{~m}$ and landing $1,116 \mathrm{~m}$ below vent altitude]

\begin{tabular}{cc}
\hline $\begin{array}{c}\text { Wind Velocity } \\
(\mathbf{m} / \mathbf{s})\end{array}$ & $\begin{array}{c}\text { Initial Velocity } \\
(\mathbf{m} / \mathbf{s})\end{array}$ \\
\hline 0 & 1200 \\
10 & 770 \\
20 & 575 \\
40 & 330 \\
60 & 210 \\
80 & 160 \\
\hline
\end{tabular}

Convective lift cannot explain the distance traveled by the larger blocks. The terminal velocity of blocks $40 \mathrm{~cm}$ in diameter is 100 to $300 \mathrm{~m} / \mathrm{s}$ in air (depending on drag coefficient chosen) as calculated from a standard equation (Mironer, 1979, p. 277). Only updrafts a large fraction of terminal velocity would greatly lengthen a block's trajectory. Convective updrafts of tens of meters per second or more occur in sustained plinian eruptive columns (Woods, 1988), but it is unlikely that transient bursts such as at Crater Peak could sustain such drafts. Yet clasts smaller than $5 \mathrm{~cm}$ diameter, whose terminal velocities are less than $50 \mathrm{~m} / \mathrm{s}$, could be somewhat affected by small updrafts. Perhaps this factor, operating during the subplinian phase of the first 3 hours of the eruption (I 'eal and others, this volume) especially in an upward-funneling column as analyzed by Sparks (1986) and by Carey and Sparks (1986), could explain the many lithic and juvenile clasts smaller than $5 \mathrm{~cm}$ scattered throughout the ballistic range as elements of fall. Yet because most of the ballistics apparently were ejected near the end of the eruption, some traveling as far as $8 \mathrm{~km}$ from the vent even after the subplinian fall had ended, sustained updrafts seem unimportant for mary of the small ballistic clasts.

If larger blocks somehow disaggregated in flight just before landing, the ballistic blocks should lie in clusters of broken fragments of like lithology'. Such a clustering was nowhere decipherable, excef ${ }^{+}$purely hypothetically if applied to juvenile clasts scattered throughout the impact area. The many fragments of cauliflower bombs seemed randomly and widely dispersed, as though they were shattered upon explosion at the vent, not near the end of their flightpath. Some juvenile clasts are completely rimmed with cuenched margins (figs. 5, 6) and clearly did not fragment in the air or on impact. In-flight fragmentaticn therefore does not help explain the large distances traveled by many of the blocks.

Numerous images of explosive "cockstail plumes" captured on movie film, video, and photograns (for examples, Williams and McBirney, 1979, p. 251; G. Rosenquist in Voight, 1981, p. 75-76) show each fingerlike projection to be led by a large block in whose wake trails a cloud of smaller debris. At Crater Peak this could help explain many small blocks within the $3.5-\mathrm{km}$-range limit of large blocks. Yet the smaller blocks extend much farther (fig. 8), and they are about as plentiful just beyond the limit of large tlocks as just inside that limit. Thus smaller fragments drawn behind large ones cannot be important in the outer half of the August ballistic field.

Forward air movement attending the whole complex process of ejection has been suggestet to aid the flight of ballistics (Wilson, 1980), a concept supported by visual observation of shock waves accom- 
panying explosive eruptions (Nairn and Self, 1978; Ishihara, 1985). Fagents and Wilson (1993) included this effect in their ballistic analysis by considering that the blocks were ejected within an envelope of air whose velocity (initially the same as that of the blocks) decayed exponentially with time.

\section{DISCUSSION}

Convective uplift helps explain many small apparent ballistics lying generally outside the continuous-airfall field as clasts that dropped from a funnelshaped eruption column as shown by Carey and Sparks (1986, figs. 3, 13). Several researchers think that gas streaming from the vent could account for small particles thrown to the same or even greater range as large particles (Lorenz, 1970; Self and others, 1980; Mastin, 1991). Fagents and Wilson (1993) offer a numerical modification of Wilson (1972) that takes into account a gas-expansion phase 25 to $150 \mathrm{~m}$ outward from the vent, which reduces but does not eliminate the unreasonably high initial velocities that calculations for smaller particles yield. Further analysis of a gas-expansion phase during the Crater Peak ballistic explosions and of drag coefficients is in progress (L.G. Mastin and R.B. Waitt, unpub. data).

\section{HYDROVOLCANIC NATURE OF EXPLOSIONS}

Violent explosions caused by rapid intermixing of molten material and water have been analyzed in industrial and volcanic settings (Colgate and Sigurgeirsson, 1973; Peckover and others, 1973; Wohletz, 1983; Wohletz and McQueen, 1984). Swift interaction of magma with external water could help explain the transiently high pressure generated at apparently shallow depths near the end of the August eruption of Crater Peak. The August eruption lasted about 4 hours. As magmatic vent pressure waned, ground water from the cone may have poured into the vent along with ejecta fallback and talus from the overhanging northwest crater wall. Mixing of hot rock and water in the vent, contained beneath collapsing crater walls and slumping talus, could fuel hydroexplosions. Most of the ballistic blocks from Crater Peak are angular, blocky lithic clasts and cauliflower bombs (mostly fragmented cauliflower bombs). Vesicularity among juvenile clasts is only low to moderate (generally $<50$ percent), and the range in vesicularity is high. These characteristics resemble hydromagmatic deposits elsewhere and contrast with strombolian deposits having higher vesicularity and fluidal external shapes (Lorenz and Büchel, 1980; Self and others, 1980; Lorenz and Zimanowski, 1984; Houghton and Hackett, 1984;
Houghton and Schmincke, 1989; Houghton and Nairn, 1991). Thus the explosions late in the August eruption appear to have been propelled by hydromagmatic processes rather than by vesiculation of magma.

Eruptions of some stratovolcanoes have evolved from magmatic to hydromagmatic as an eruption wanes. As the Vesuvian A.D. 79 magmatic eruption dwindled, interaction of magma with external water produced the final surge beds (Sheridan and others, 1981; Sigurdsson and others, 1985). Increased interaction with water also occurred near the end of many other Vesuvian eruptions from Pleistocene to recent (Sheridan and others, 1981; Rosi and Santacroce, 1983; Rosi and others, 1993; Bertagini and others, 1991).

\section{HORIZONTALLY CURVIN'G TRAJECTORIES}

Many ballistic projectiles at Crater Peak are embedded in the downrange side of the impact crater, or they shattered and the fragments spread downrange from the crater, which indicate the projectiles arrived at distinct angles to the vertical. Most impact craters are elongate and have an asymmetric ejecta rim. The largest craters have ejecta rays radiating on one side. Both phenomena register the azimuth of the block's impact.

In the accessible right-marginal part of the August 1992 ballistic field investigated, some impacts point directly away from the Crater Peak vent on an azimuth of $135^{\circ}$, yet most of them along this general azimuth point more southward than in a straight line from the vent (fig. 16). A typical southward deviation is $20^{\circ}$ to $40^{\circ}$ south, the maximum $67^{\circ}$. In this downrange right side of the ballistic field. the deviation is systematically southward; no trajectory has the opposite displacement from a straight line. The southward tendency at the end of the ballistic trajectories was despite the ambient wind toward the east-southeast (toward about azimuth $115^{\circ}$ ), which tended to straighten out (that is, shift eastward) any scuth-curving trajectories. The angular deviation from a straight-line trajectory seems to be largely independent of a projectile's diameter.

A pitched baseball or softball will always curve in the direction of a sharply applied spin. This phenomenon, known as the "Magnus effect," has been variously analyzed by Briggs (1959) and Adair (1990), among others. The systematic map-view pattern at Crater Peak-of which we have found no other example in the literature on volcanic ballistics-suggests that many of these clasts had a notable angular velocity about strongly vertical axes. The deviant clasts that curved systematically rightward (viewed from above), if caused by spinning, would have spun clockwise. 
In several movies and videos showing typical low-energy strombolian-type explosions, the clasts do not spin much, certainly less than $1 \mathrm{rev} / \mathrm{s}$. If spinning is the cause of deviations in the horizontal component of trajectory of the Crater Peak ballistics, it must be a phenomenon induced by high-energy ejection.

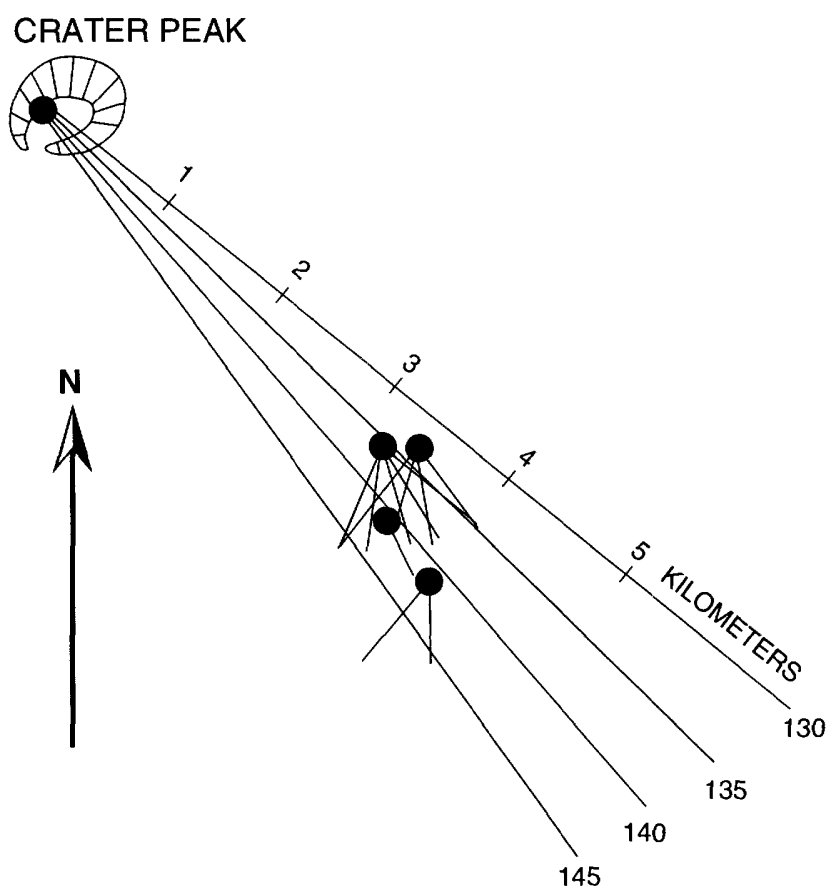

Figure 16. Azimuths of projectiles arriving at right margin bomb field of August 18, 1992, eruption of Crater Peak vent, Mount Spurr volcano, Alaska.

\section{REFERENCES CITED}

Achenbach, E., 1972, Experiments on the flow past spheres at very high Reynolds numbers: Journal of Fluid Mechanics, v. 54, p. 565-575.

Adair, R.K., 1990, The physics of baseball: New York, Harper Row, $110 \mathrm{p}$.

Ahrens, C.D., 1991, Meteorology Today, 4th ed.: St. Paul, Minn, West Publishing Co., 577 p.

Bertagini, A., Landi, P., Santacroce, R., and Sbrana, A., 1991, The 1906 eruption of Vesuvius-from magmatic to phreatomagmatic activity through the flashing of a shallow depth hydrothermal system: Bulletin of Volcanology, v. 53, p. 517532.

Briggs, L.J., 1959, Effect of spin and speed on the lateral deflection (curve) of a baseball; and the Magnus effect for smooth spheres: American Journal of Physics, v. 27, p. 589-596.

Carey, S., and Sparks, R.J.S., 1986, Quantitative models of the fallout and dispersal of tephra from volcanic eruption columns:
Bulletin of Volcanology, v. 48, p. 109-125.

Colgate, S.A., and Sigurgeirsson, T., 1973, Dynamic mixing of water and lava: Nature, v. 244, p. 552-555.

Fagents, S.A., and Wilson, L., 1993, Explosive volcanic eruptionsVII. The ranges of pyroclasts ejected in transient volcanic explosions: Geophysical Journal International, v. 113, 359370.

Fudali, R.F., and Melson, W.G., 1972, Ejecta velocities, magma chamber pressure and kinetic energy associated wit' 1 the 1968 eruption of Arenal volcano: Bulletin Volcanologiaue, v. 35 (2), p. 383-401.

Hall, A., 1987, Igneous petrology: New York, John Wile.' \& Sons, $573 \mathrm{p}$.

Hoerner, S.F., 1965, Fluid Dynamic Drag: Vancouver, Wcsh., (published by author), $450 \mathrm{p}$.

Houghton, B.F., and Hackett, W.R., 1984, Strombolian and phreatomagmatic deposits of Ohakune Craters, Ruapehu, New Zealand-a complex interaction between external water and rising basaltic magma: Journal of Volcanology and Geothermal Research, v. 21, p. 207-231.

Houghton, B.F., and Nairn, I.A., 1991, The 1976-1982 strombolian and phreatomagmatic eruptions of White Is/ 'nd, New Zealand-eruptive and depositional mechanisms at a 'wet' volcano: Bulletin of Volcanology, v. 54, p. 25-49.

Houghton, B.F., and Schmincke, H.-U., 1989, Rothenberg scoria cone, East Eifel-a complex Strombolian and phreatomagmatic volcano: Bulletin of Volcanology, v. 52, p. 28-48.

Houghton, B.F., and Smith, R.T., 1993, Recycling of magm atic clasts during explosive eruptions-estimating the true juvenile content of phreatomagmatic volcanic deposits; Bulletin of Volcanology, v. 55, p. 414-420.

Houghton, B.F., and Wilson, C.J.N., 1989, A vesicularity index for pyroclastic deposits: Bulletin of Volcanology, v. 51, p. 451462.

Ishihara K., 1985, Dynamical analysis of volcanic explosion: Journal of Geodynamics, v. 3, p. 327-349.

Jorgensen, T.P., 1993, The physics of golf: New York, American Institute of Physics, and Oxford University Press, $155 \mathrm{p}$.

Lorenz, V., 1970, Some aspects of the eruption mechanism of the Big Hole Maar, central Oregon: Geological Society of America Bulletin, v. 81, p. 1823-1830.

Lorenz, V., 1974, Studies of the Surtsey tephra deposits: Surtsey Research Progress Report, v. 7, p. 72-79.

Lorenz, V., and Büchel, G., 1980, Zur Vulkanologie der Młaare und Schlackenkegl der Westeifel: Mitt. Pollichia, v. 68 , p. 29 100.

Lorenz, V., and Zimanowski, B., 1984, Fragmentation of alkalibasalt magmas and wall-rocks by explosive volcanism: Annal of Science, University of Clermont-Ferrand [France], v. 74 , p. $15-25$.

Mastin, L.G., 1991, The roles of magma and groundwater in the phreatic eruptions at Inyo Craters, Long Valley cal tera, California: Bulletin of Volcanology, v. 53, p. 579-596

Mastin. L.G., 1995, Thermodynamics of gas and steam-blast eruptions: Bulletin of Volcanology, v. 57, p. 85-98.

Minakami, T., 1942, On the distribution of volcanic ejecta, Part I, the distributions of volcanic bombs ejected by the recent explosions of Asama: Bulletin of the Earthquake Research Institute, Tokyo, v. 20, p. 65-91.

Mironer, A., 1979, Engineering fluid mechanics: New York, McGraw-Hill, 592 p. 
Nairn, I.A., 1976, Atmospheric shock waves and condensation clouds from Ngauruhoe explosive eruptions: Nature, v. 259, p. 190-192.

Nairn, I.A., and Self, S., 1978, Explosive eruptions and pyroclastic avalanches from Ngauruhoe in February 1975: Journal of Volcanology and Geothermal Research, v. 3, p. 39-60.

Peckover, R.S., Buchanan, D.J., and Ashby, D.E.T.F., 1973, Fuelcoolant interactions in submarine vulcanism: Nature, v. 245, p. 307-308.

Rosi, M., and Santacroce, R., 1983, The A.D. 472 "Pollena" eruption-volcanological and petrological data for this poorlyknown plinian-type event at Vesuvius: Journal of Volcanology and Geothermal Research, v. 17, p. 249-271.

Rosi, M., Principe, C., and Vecci, R., 1993, The 1631 Vesuvius eruption-a reconstruction based on historical and stratigraphical data: Journal of Volcanology and Geothermal Research, v. 58 p. 151-201.

Rouse, H., 1946, Elementary mechanics of fluids: New York, John Wiley (republished 1978 by Dover Publications, New York), $376 \mathrm{p}$.

Self, S., Kienle, J., and Huot, J.-P., 1980, Ukinrek Marrs, Alaska, II-deposits and formation of the 1977 craters: Journal of Volcanology and Geothermal Research, v. 7, p. 39-65.

Sheridan, M.F., Barberi, F., Rosi, M., and Santacroce, R., 1981, A model for plinian eruptions of Vesuvius: Nature, v. 289, p. 282-285.

Sigurdsson, H., Carey, S., Cornell, W., and Pescatore, T., 1985, The eruption of Vesuvius in A.D. 79: National Geographic Research, v. 1, p. 332-387.

Sparks, R.J.S., 1986, The dimensions and dynamics of volcanic eruption columns: Bulletin of Volcanology, v. 48, p. 3-15.

Steinberg, G.S., and Lorenz, V., 1983, External ballistic of volcanic explosions: Bulletin of Volcanology, v. 46, p. 333-348.

Voight, B., 1981, Time scale for the first moments of the May 18 eruption, in Lipman, P.W. and Mullineaux, D.R., The 1980 eruptions of Mount St. Helens, Washington: U.S. Geological Survey Professional Paper 1250, p. 69-86.

Waitt, R.B., Hansen, V.L., Sarna-Wojcicki, A.M., and Wood, S.H., 1981, Proximal air-fall deposits of eruptions latween May 24 and August 7,1980 — stratigraphy and field sedimentology, in Lipman, P.W., and Mullineaux, eds., Tre 1980 eruptions of Mount St. Helens, Washington: U.S. Geological Survey Professional Paper 1250, p. 617-628.

Walker, G.P.L., Wilson, L., and Bowell, E.L.G., 1971, Explosive volcanic eruptions-I, The rate of fall of pyriclasts: Geophysical Journal of the Royal Astronomical So ziety, v. 22, p. 377-383.

Waugh, J.G., and Stubstad, G.W., 1973, Hydroballis'ic modeling: San Diego, U.S. Naval Undersea Center (now Naval Command, Control, and Ocean Surveillance Center), 348 p.

White, F.M., 1979, Fluid mechanics: New York, McGraw Hill, $701 \mathrm{p}$.

Williams, H., and McBirney, A.R., 1979, Volcanology: San Francisco, Freeman, Cooper \& Co., 397 p

Wilson, L., 1972, Explosive volcanic eruptions-II, th? atmospheric trajectories of pyroclasts: Geophysical Journa' of the Royal Astronomical Society (London), v. 30, p. 381-392.

Wilson, L., 1980, Relationships between pressure, vo' 1 tile content, and ejecta velocity in three types of volcanic explosion: Journal of Volcanology and Geothermal Research.v. 8, p. 297313.

Wohletz, K.H., 1983, Mechanisms of hydrovolcanic pyroclast formation-grain-size, scanning electron micros?opy, and experimental studies: Journal of Volcanology ant Geothermal Research, v. 17, p. 31-63.

Wohletz, K.H., and McQueen, R.G., 1984, Volcanic ard stratospheric dustlike particles produced by experimental water-melt interactions: Geology, v. 12, p. 591-594.

Woods, A.W., 1988, The fluid dynamics and thermodyn'mics of eruption columns: Bulletin of Volcanology, v. 50, p. 169-193. 


\title{
Hybrid Wet Flows Formed by Hot Pyroclasts Interacting with Snow During the 1992 Eruptions of Crater Peak, Mount Spurr Volcano, Alaska
}

\author{
By Richard B. Waitt
}

\section{CONTENTS}

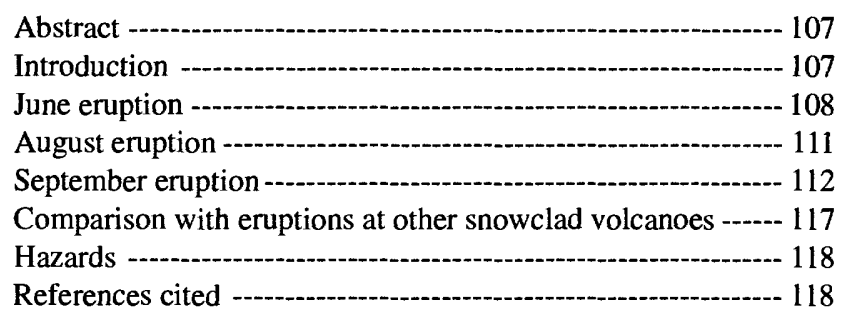

\begin{abstract}
During each of the three 1992 eruptions of Crater Peak at Mount Spurr volcano in Alaska, hot pyroclasts interacted with snowpack to form mixed snowpyroclast flows. Some flows were mostly of snow that melted slightly to be mobile but still cold; others were mostly of pyroclasts whose snow component melted entirely to make the flows more mobile and cooler than ordinary pyroclastic flows. Some pyroclastic flows were large enough to substantially melt and erode glacier ice to generate a lahar that greatly enlarged a moraine breach. The largest wet flows coalesced, swept down and off the volcano flanks, and transformed into lahars. On the volcano flanks were a wide range of hybrid flows between conventional pyroclastic flows and conventional lahars. The hybrid flows of mixed debris from Crater Peak resemble some formed by swift pyroclast-snow interactions at Mount St. Helens, Washington, during explosive events between 1980 and 1991; at Nevado del Ruiz, Colombia, in 1985; at Augustine Volcano, Alaska, in 1976 and 1986; and at Redoubt Volcano, Alaska, in 1989-90. Wet pyroclastic flows are hazardous insofar as their reduced internal friction projects destructive flows down valleys beyond the reach of dry pyroclastic currents. The trajectory of pyroclasts launched over the crater rim by a partly obstructed, inclined vent produced flows on the southeast and east flanks in addition to those along a southward route through the low point of the crater rim.
\end{abstract}

\section{INTRODUCTION}

Crater Peak at Mount Spurr volcano, Alaska (fig. 1), erupted three times in 1992: June 27, August 18, and September 16-17. These eruptions, each lasting 3 to 4 hours, were the first activity since a single eruption on 9 July 1953 (Juhle and Coulter, 1955). During each of the 1992 eruptions, hot pyroclasts turbulently interacted with snowpack to form mixed snowpyroclast flows.

Pyroclastic flows and surges on the one hand, and lahars on the other, are commonly treated as distinct phenomena. Hybrid flows lie somewhere in between. This report describes the deposits and the erosion of glaciers by hybrid pyroclast-snow flows on the flanks of Crater Peak, gives photographic documentation, qualitatively discusses pyroclast-srow interaction processes, and analyzes flow-initiation mechanisms. Of the 1992 Crater Peak eruptions, chronology and overview are addressed by Eichelberger and others (this volume), pyroclastic flows by Miller and others (this volume), tephra deposits by Neal and others (this volume), and sizable lahars on the lower volcano flanks by Meyer and Trabant (this volume).

The behavior of a hybrid mixed flow depends partly on the proportion of components. Two end members of mixed flows are: (1) mostly snow that only partly melts but including a minor pyroclastic component; and (2) mostly pyroclasts but including a minor proportion of snow that entirely melts. The pyroclast component can vary between lithic and pumiceous end members. A pyroclastic flow that incorporates only a small proportion of snow will behave more or less as a conventional hot and dry pyroclastic flow but be somewhat cooler. A small pyroclastic flow that triggers a huge snow avalanche will behave more or less as a snow avalanche-albeit a wet one lacause of some melting. Intermediate pyroclast-snow mixtures form a wide variety of fluid flows ranging from wet pyroclastic flows, to slushflows, to debris flows, to floods. 


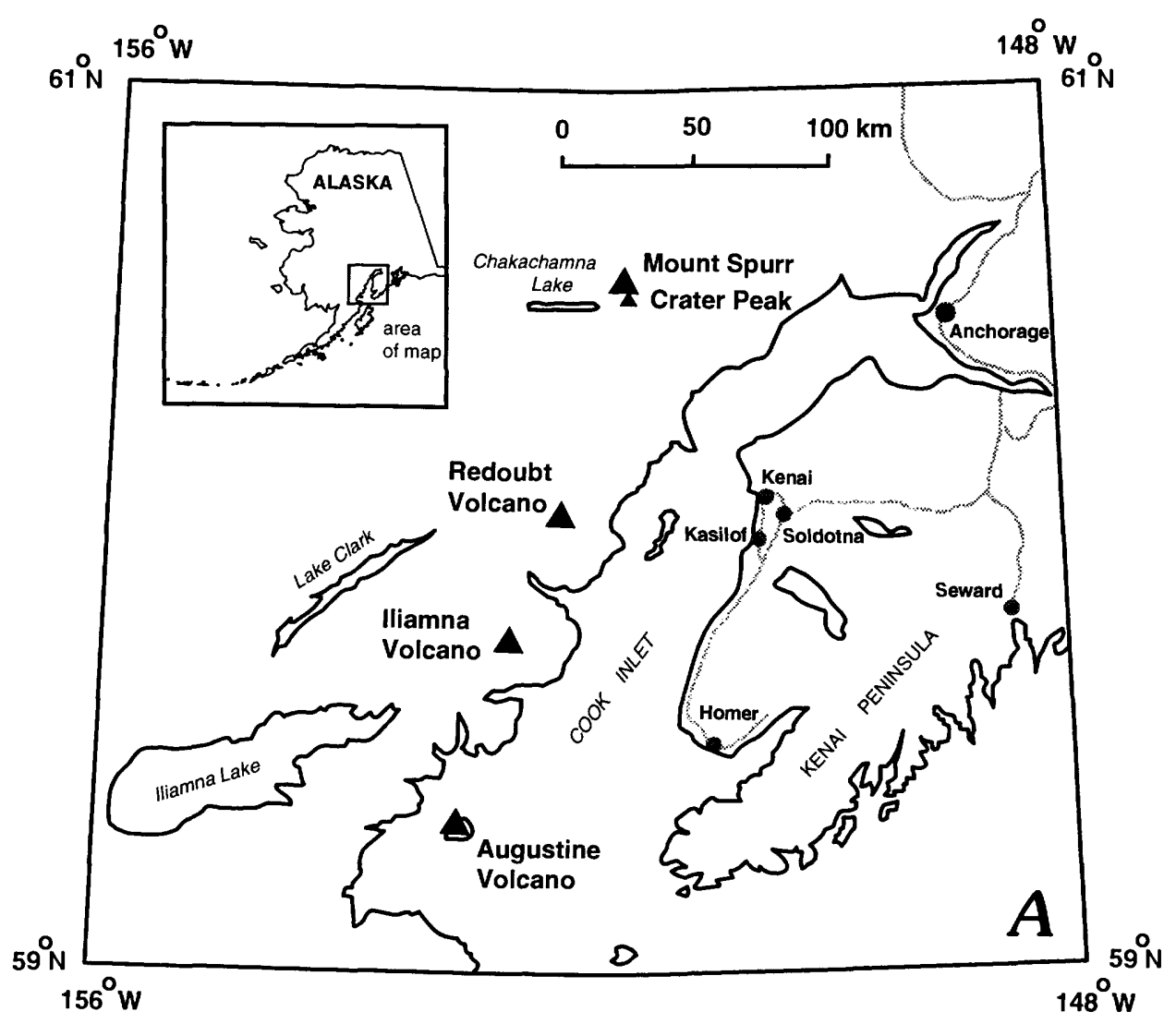

Figure 1. Index maps of ( $A$, above) Cook Inlet area and ( $B$, below left) Mount Spurr and Crater Peak area, Alaska (stipple pattern, glacier).

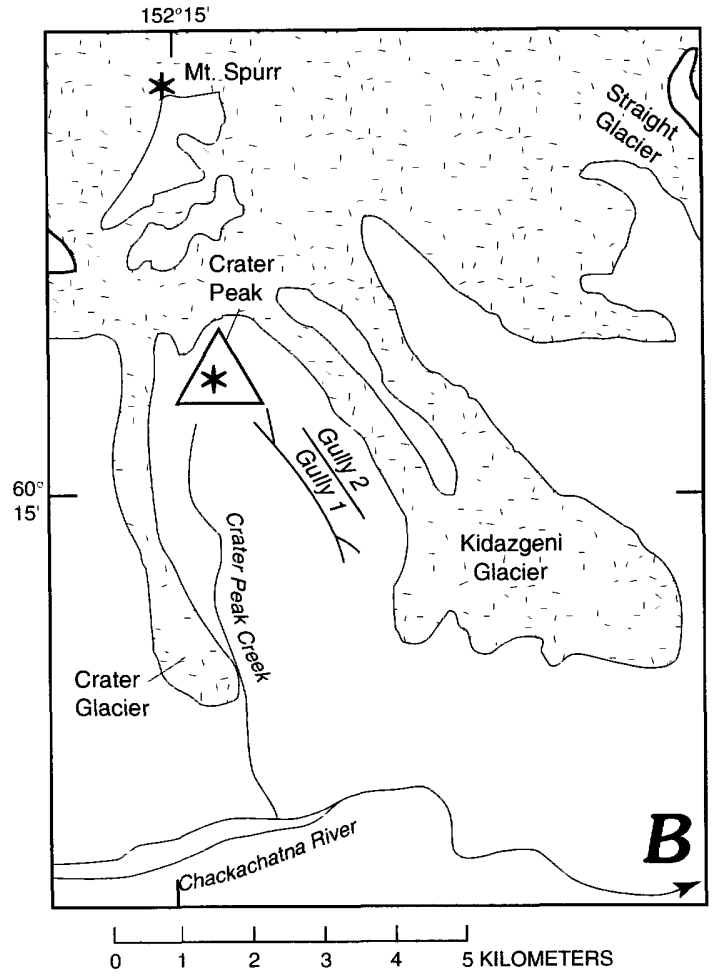

\section{JUNE ERUPTION}

Before the June 27 eruption, snowpack discontinuously clad Crater Peak from the crater rim $(2,135-$ $1,950 \mathrm{~m}$ ) down to $1,370 \mathrm{~m}$, thickest in gullies. Hot pyroclastic debris mixed with this snow during the June eruption to form mixed snow, ice, and rock avalanches that flowed south down creeks betw'een Kidazgeni and Crater Peak Glaciers. These flow's entered the Chakachatna River $6 \mathrm{~km}$ from the crater in two places. Most of the debris flowed down Crater Peak Creek drainage, the course followed by a lahar that briefly dammed the river during the 1953 eruption.

The largest flow exited the south-facing crater breach and followed a sinuous deep gully to Crater Glacier and Crater Peak Creek (fig. 2A,B) (I Teyer and Trabant, this volume). Gully 1 , which descends the south-southeast flank of Crater Peak, does not head at the south-facing breach in the crater rim $(1,950 \mathrm{~m})$. A snowy debris flow of volume of $1 \times 10^{5} \mathrm{~m}^{3}$ or less descended gully 1 , broadly overflowed its sides (fig. 3 ), and fingered out; the flow in the main channel continued down below altitude $740 \mathrm{~m}$. At a sharp bend 

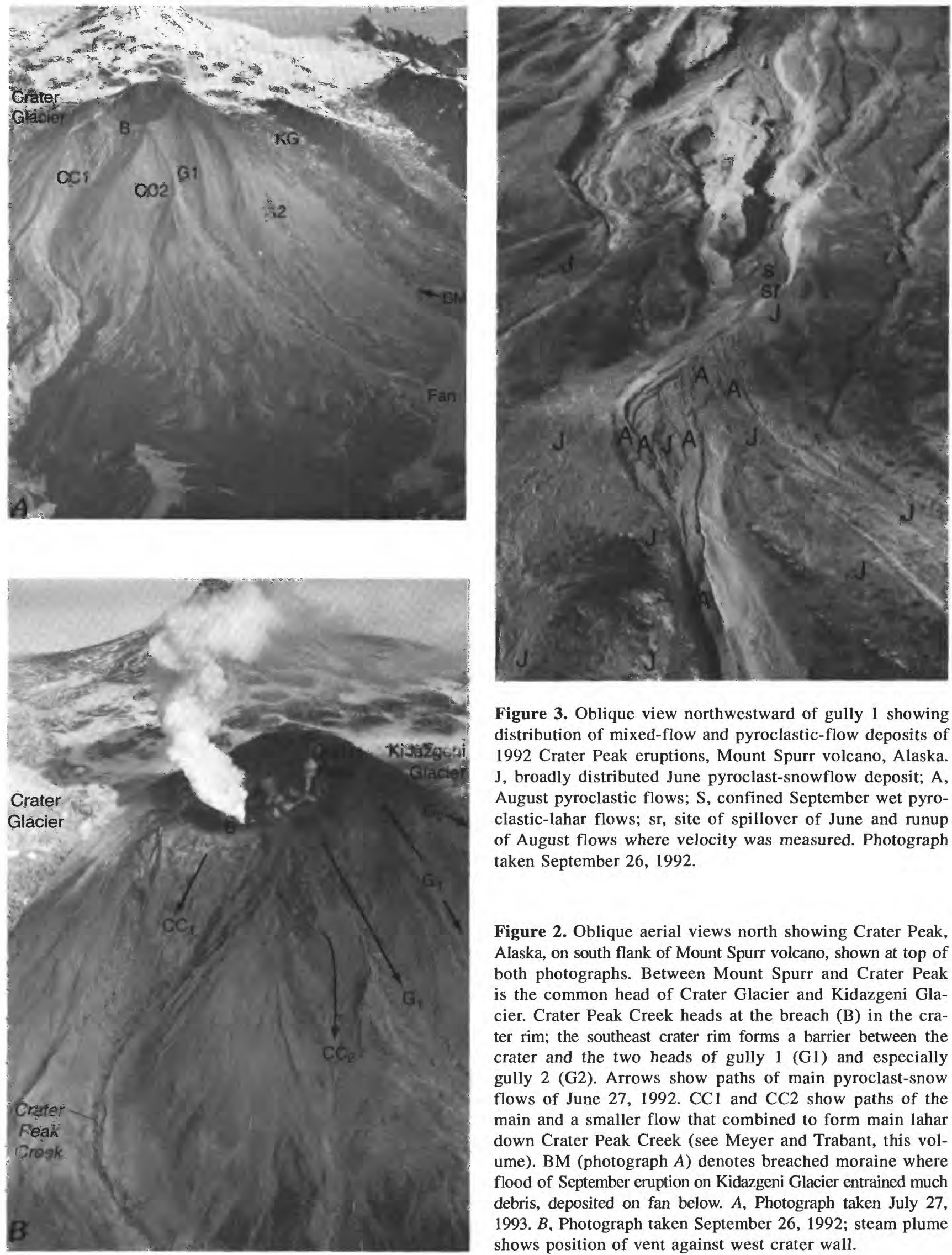

Figure 3. Oblique view northwestward of gully 1 showing distribution of mixed-flow and pyroclastic-flow deposits of 1992 Crater Peak eruptions, Mount Spurr volcano, Alaska. J, broadly distributed June pyroclast-snowflow deposit; A, August pyroclastic flows; S, confined September wet pyroclastic-lahar flows; sr, site of spillover of June and runup of August flows where velocity was measured. Photograph taken September 26, 1992.

Figure 2. Oblique aerial views north showing Crater Peak, Alaska, on south flank of Mount Spurr volcano, shown at top of both photographs. Between Mount Spurr and Crater Peak is the common head of Crater Glacier and Kidazgeni Glacier. Crater Peak Creek heads at the breach (B) in the crater rim; the southeast crater rim forms a barrier between the crater and the two heads of gully 1 (G1) and especially gully 2 (G2). Arrows show paths of main pyroclast-snow flows of June 27, 1992. CC1 and CC2 show paths of the main and a smaller flow that combined to form main lahar down Crater Peak Creek (see Meyer and Trabant, this volume). BM (photograph $A$ ) denotes breached moraine where flood of September eruption on Kidazgeni Glacier entrained much debris, deposited on fan below. A, Photograph taken July 27 , 1993. B, Photograph taken September 26, 1992; steam plume shows position of vent against west crater wall. 
in the creek at about altitude $790 \mathrm{~m}$, the flow ran as high as $8 \mathrm{~m}$ up a steep wall nearly transverse to flow. The equation $\mathrm{v}=(2 \mathrm{gh})^{1 / 2}(\mathrm{v}$, velocity; g, gravitational acceleration; $h$, runup height) relating kinetic energy converted to potential energy at a runup gives a velocity of $13 \mathrm{~m} / \mathrm{s}$ or $47 \mathrm{~km} / \mathrm{hr}$.

At summer's end, the flow deposit was a loose, unsorted diamict with a sandy matrix that carried lithic clasts (no pumice) as large as $0.5 \mathrm{~m}$. The deposit had an intricately rough surface texture in places including small ( $<20 \mathrm{~cm}$ deep) kettles (fig. 4) and an outer margin only 10 to $30 \mathrm{~cm}$ high. Scrub willow abraded by the flow was unscorched and uncharred, and by late summer perennials such as fireweed had sprouted up through the deposit where it was thinner than 30 $\mathrm{cm}-$-both of which suggest that this flow had not been hot. A high proportion of internal voids formed during summer by melting of a substantial snow component caused the deposit to suddenly deflate when jarred underfoot. The deflatable character and the rough, kettled surface of this deposit was like that of mixed lithic pyroclast-snow flows emplaced during several eruptions at Mount St. Helens between 1981 and 1986 (Waitt and MacLeod, 1987). After a winter season of compaction beneath snow, a spring season of wetting, and a summer season of episodic high winds, the deposit had become fully deflated and its surface smoother. The deposit shows no evidence of having been channeled by free surface water during emplacement, except along the gully axis where a wetter phase carved a broad channel (fig. 5) and transformed into a small debris flow downchannel (Meyer and Trabant, this volume).

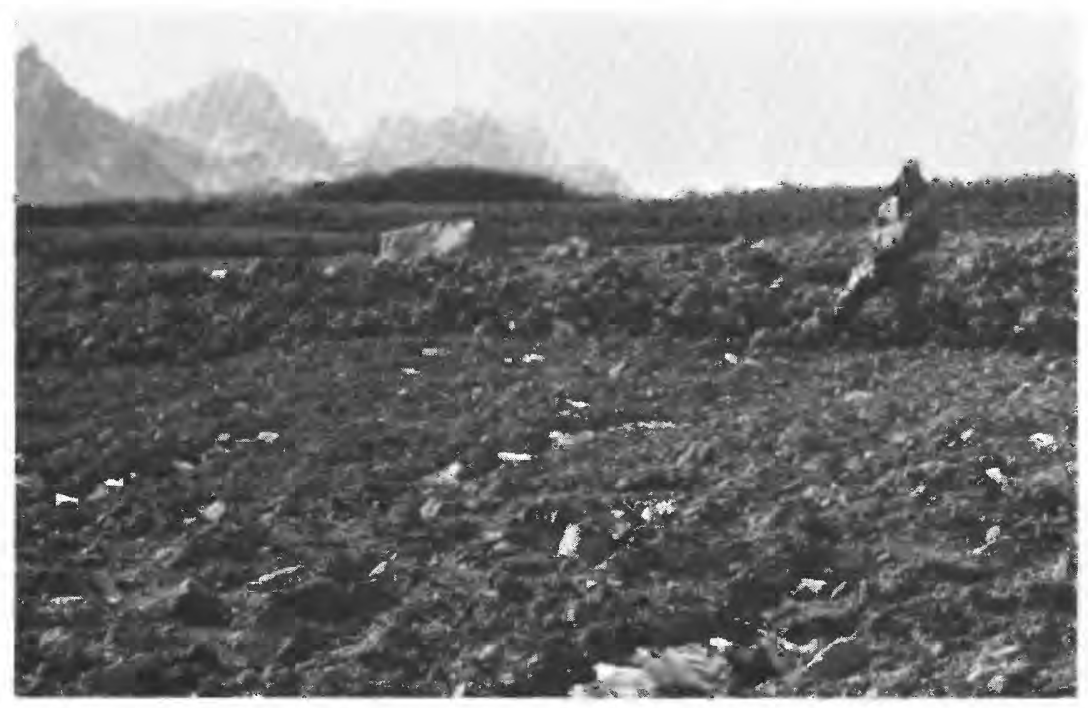

Figure 4. View in gully 1 at altitude 770 $m$ of unsorted mixed-flow deposit from June 27, 1992, eruption of Crater Peak, Mount Spurr volcano, Alaska. Mixed-flow deposit in foreground is deflated by melting of its former snow constituent. It is overlapped by August pyroclastic-flow deposit (just behind person). Photograph taken September 26, 1992.

Figure 5. View northwest in gully 1 on Crater Peak, Mount Spurr volcano, Alaska, showing channel (C) cut through snowflow deposits $(J)$ of June eruption by trailing watery phase of same flow, then partly filled by pumiceous pyroclastic flow of August eruption (A). Photograph taken July 27, 1993.

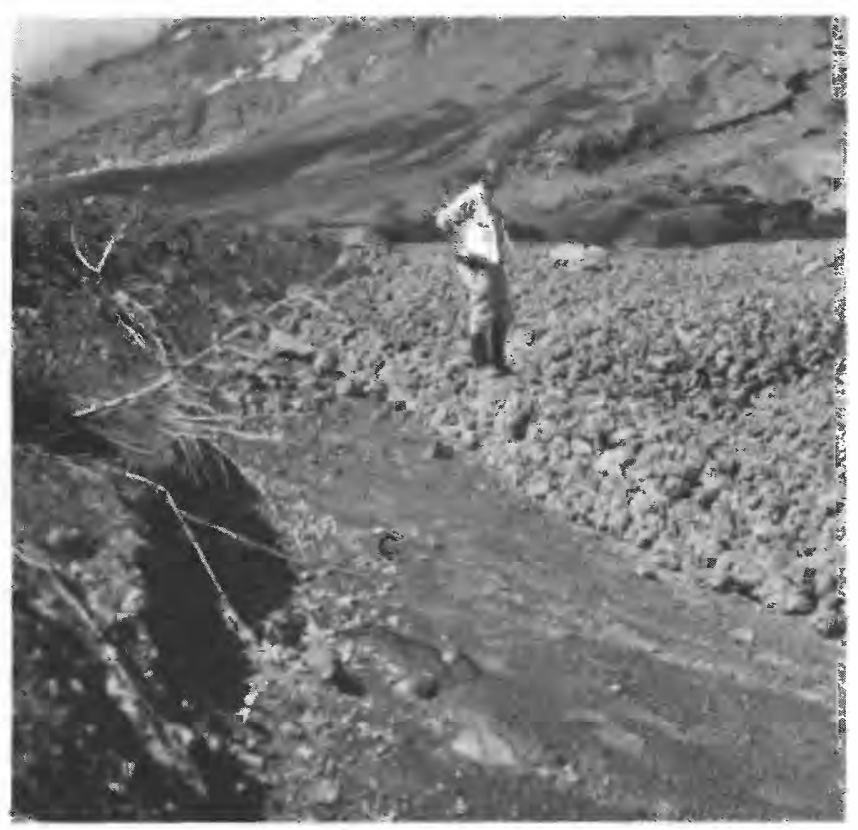


The trajectory of the Crater Peak eruption debris not only southward through the low point on the crater rim but also broadly over the higher south-southeast rim was influenced by the position of the vent against the northwest crater wall (fig. $2 A, B$ ). This vent position directed explosions southeastward; thus voluminous hot fragmental material lofted over the crater rim and onto the outer flank of the cone where it swiftly and turbulently mixed with snowpack. The ejected debris was mainly lithic, apparently derived from the vent walls and crater wall. Southeastward ejection occurred despite wind that carried the eruption's tephra plume north (Neal and others, this volume).

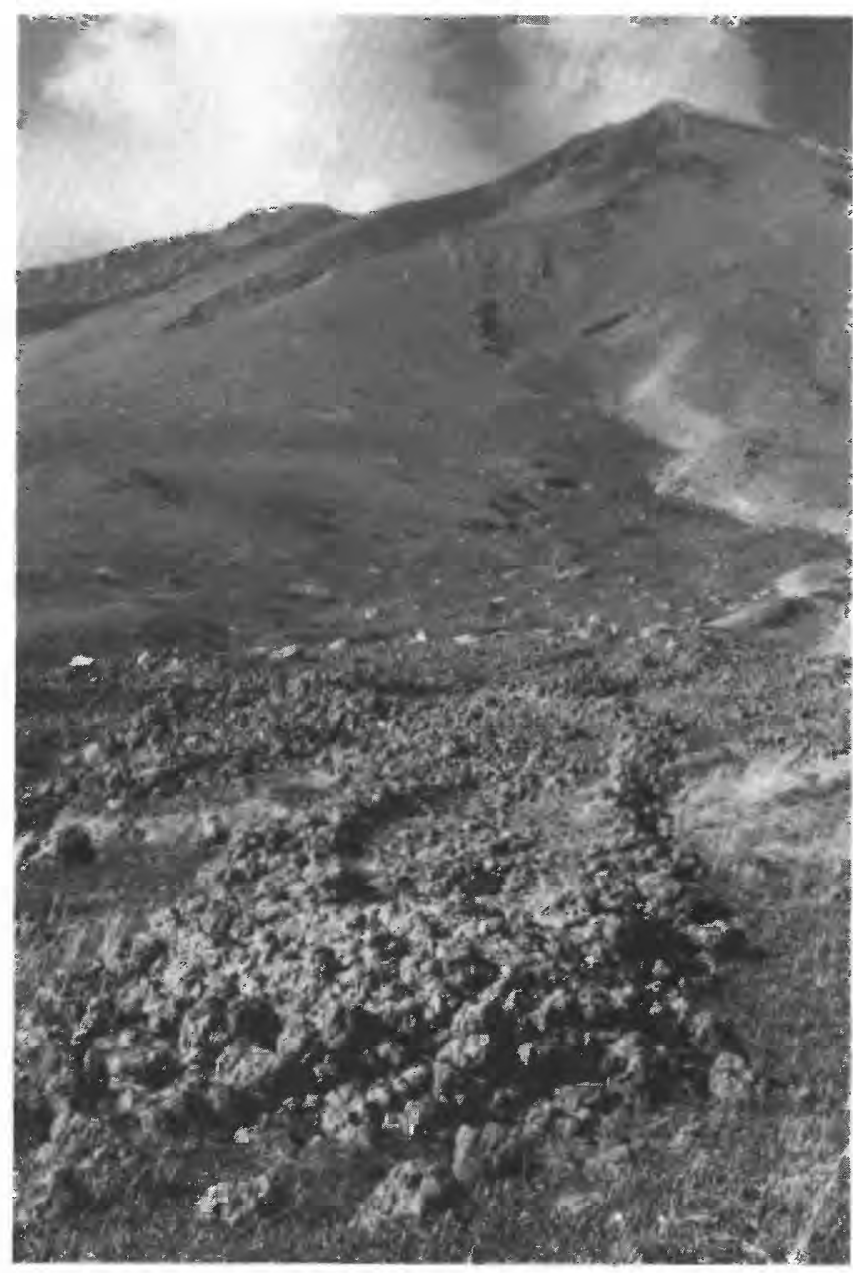

Figure 6. Steep, lobate deposits of hot pyroclastic flows that descended gully 2 during August 1992 eruption of Crater Peak, Mount Spurr volcano, Alaska. Concentrated pumice blocks are at flow margin, beneath which vegetation is charred. Width of lobe in foreground is about $3 \mathrm{~m}$.

\section{AUGUST ERUPTION}

The August 18 eruption sent small-volume pyroclastic flows of breadcrusted dark andesite pumice down the east and southeast flanks of Crater Peak (Miller and others, this volume). The deposits at the surface are coarse, clast supported, and fines poor. In gully 1, levees of angular pumice mark the extents of successive flow lobes. They rode up $7 \mathrm{~m}$ on a steep nearly transverse side $\left(\mathrm{v}=(2 \mathrm{gh})^{1 / 2}=12 \mathrm{~m} / \mathrm{s}\right.$ or 43 $\mathrm{km} / \mathrm{hr}$ ), and they overflowed the gully sides in a few places but far less than did the June mixed flow (fig. 5). Steep-fronted deposits of the flow terminate in the main channel at about altitude $745 \mathrm{~m}$ (fig. 3), well upvalley of the June mixed-flow terminus.

Several pumiceous pyroclastic flows swept the east-southeast flank of Crater Peak, down to 885-m altitude in gully 2 , where they left typical steep, finespoor, lobate margins 1 to $2 \mathrm{~m}$ high (fig. 6). The deposits remained hot for days, and blocks at the edges of these flows charred vegetation beneath them.

One of these pyroclastic flows in gully 2 mixed with snow high on the cone to form a flow much more mobile but compositionally identical (pumiceous) to one that descended the west side of the gully down to altitude $780 \mathrm{~m}$ (fig. 7). In contrast to typical pyroclastic-flow deposits upslope, this deposit has gently sloping margins only 20 to $50 \mathrm{~cm}$ high. The flow did not char vegetation that it had abraded; pumiceous blocks at the flow edge did not scorch underlying tundra plants. Small boulders jammed up behind large ones (fig. 8) much more than in the steep-margined flowsevidence of a crude sorting process that trapped coarse clasts and evidence that flow continued after depositing jams. A water phase must have caused the higher mobility. Traced upgully to altitude $885 \mathrm{~m}$, this mobile-flow deposit merges with a steep-fronted typical pyroclastic-flow lobe on the east side of gully 2. Thus the part of the flow in the deeper part of the gully detached and flowed much farther. This relation is evidence that a single pyroclastic flow divided because part of it mixed with snow in the gully axis, became wet and lost some internal friction, and thus was able to flow farther even on gentle slopes.

These flows descended gully 2 despite that the gully heads on the high southeast segment of the crater rim far from the south-facing crater breach (fig. 2). Downslope from the even higher segment of the crater rim, pyroclastic flows also mixed with snow to form a small watery lahar that flowed down the west side of Kidazgeni Glacier, through a moraine breach, and to Chakachatna valley (Meyer and Trabant, this volume). The pyroclastic debris did not spill through the southward gap in the crater rim but was explosively launched east and southeast with enough vol- 


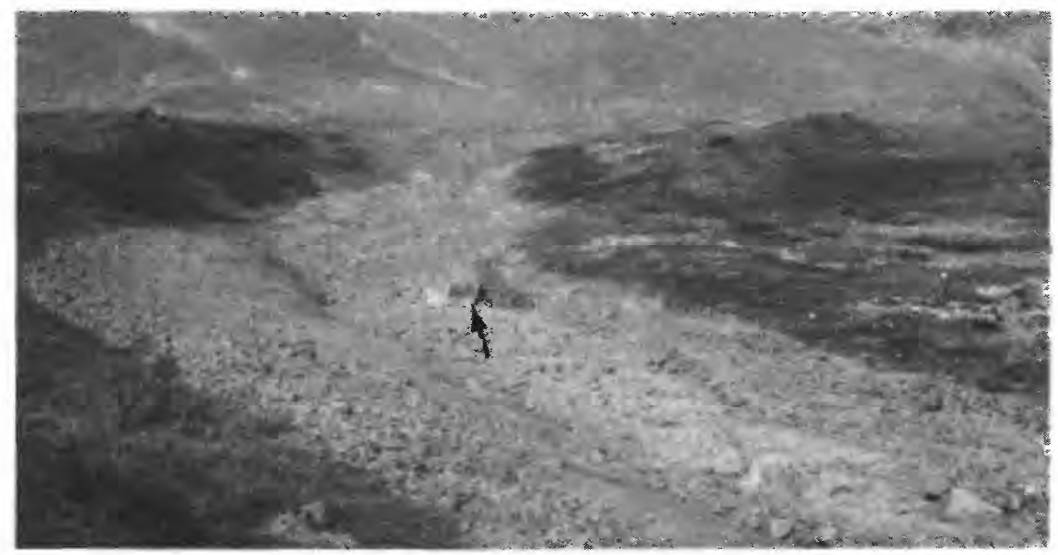

Figure 7. View upvalley of mobile-flow deposit of the August 1992 eruption of Crater Peak, Mount Spurr volcano, Alaska, that greatly outdistanced normal pyroclastic flows in gully 2. Margins are low, clasts are sorted (water winnowed), and vegetation is abraded but not charred. Person (to right) is standing in ballistic impact crater. Boulder jam shown in figure 8 marked by arrow. Compare with figure 6 .

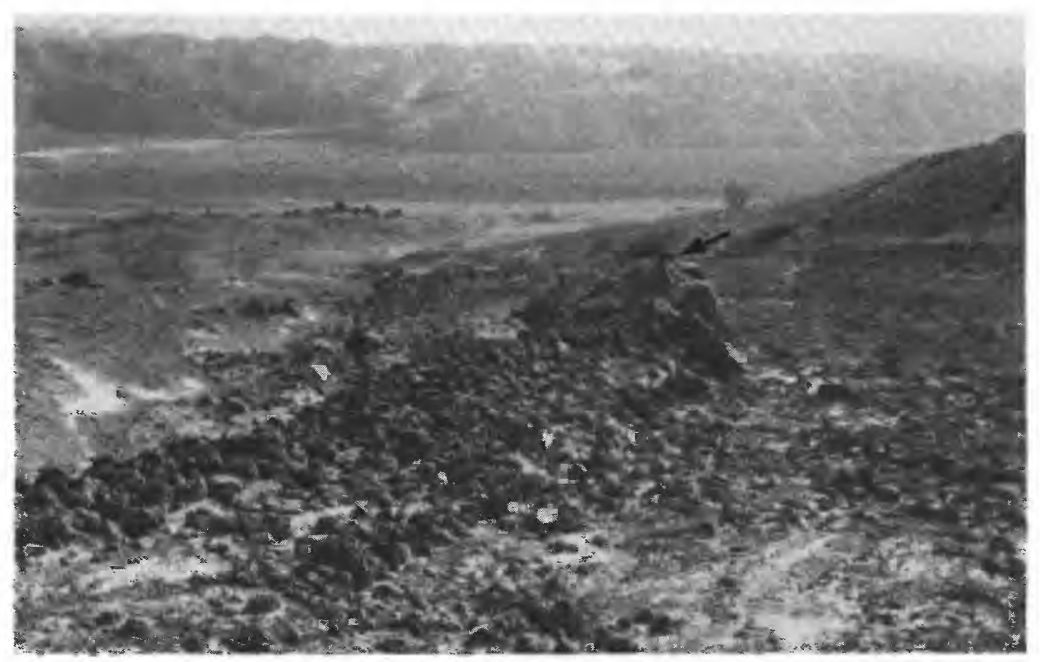

Figure 8. View downflow of jam of cobbles and small sorted boulders on upstream side of $1.5-\mathrm{m}$ boulder in August 1992 mixed-flow deposit in gully 2. Handle of shovel (center of photograph) is about $50 \mathrm{~cm}$ long. Crater Peak, Mount Spurr volcano, Alaska.

ume to erode and melt snow that lingered even in late summer. Ballistic projectiles-lithic clasts as large as $1.5 \mathrm{~m}$ and smaller juvenile projectiles-were hurled at least $4 \mathrm{~km}$ southeast of Crater Peak (fig. 7) (Waitt and others, this volume). This ballistic shower, which mostly occurred after the pyroclastic flows were emplaced on the same flank, is further evidence that the vent explosively directed debris southeast over the crater rim.

\section{SEPTEMBER ERUPTION}

The eruption during the night of September 1617 sent at least two wet pyroclastic (laharic) flows down the south-southeast and southeast flanks of Crater Peak. In gully 1 a fluid flow with gentle termini fingered out $300 \mathrm{~m}$ upgully of the August pyroclasticflow termini. A second deposit in gully 1 has a sharp steep margin 0.5 to $1.5 \mathrm{~m}$ high (fig. 9) of several 
lobes whose crosscutting patterns delineate slight differences in arrival times. That second flow apparently was far more viscous than the slightly earlier flow, and it terminated abruptly about $50 \mathrm{~m}$ upvalley of the first wet-flow terminus. The September deposits consist largely of breadcrusted to angular clasts of juvenile andesite pumice superficially resembling pyroclastic-flow deposits. Yet 12 to 15 hours after the eruption both were cool and water saturated (R.M. McGimsey, oral commun., 1992). The younger of the two has arcuate pressure ridges indicating a flow with internal strength (fig. 9). Rather than remaining loose as in typical pyroclastic flows, the matrix hardened within days as the wet clay and silt particles adhered to each other and bound the coarse clasts. Unlike the largely pumiceous August flows, only two-thirds of gravel clasts of the September wet flows are juvenile; the rest are diverse porphyritic andesite clasts of older Crater Peak rocks incorporated upgully.

Pumice-lithic pyroclastic flows also descended the east-northeast side of Crater Peak cone and turned southeast down Kidazgeni Glacier. An eyewitness situated $18 \mathrm{~km}$ to the southeast reported the heaviest incandescent flows of the night eruption on the east flank. At altitude 1,000 $\mathrm{m}$ their collective deposit is a poorly sorted pebble gravel that consists mostly of dark brownish gray andesite and lithic clasts. Many ice blocks as large as $1 \mathrm{~m}$ were entrained as the flow descended an ice fall. This deposit broadly overlies gently sloping parts of the glacier between altitudes 1,050 and $800 \mathrm{~m}$ (fig. 10B). Along the west side of the glacier from altitude 2,000 down to $1,000 \mathrm{~m}$ (gradients 500 to $150 \mathrm{~m} / \mathrm{km}$ ), meltwater stripped off this deposit along

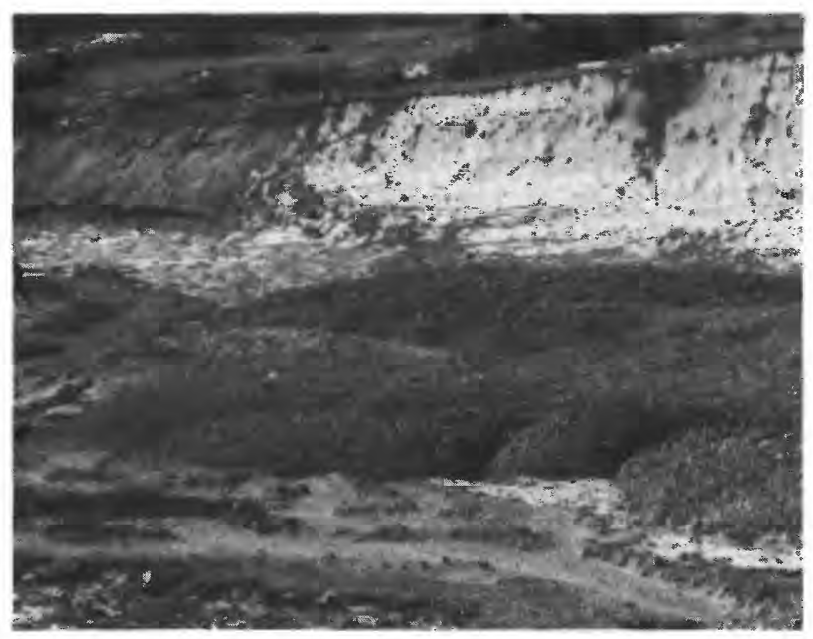

Figure 9. Terminus of lobate laharic flow of the September 1992 eruption of Crater Peak, Mount Spurr volcano, Alaska in gully 1. Note delicate pressure ridges on flow surface. Person for scale. Photograph taken September 26, 1992.

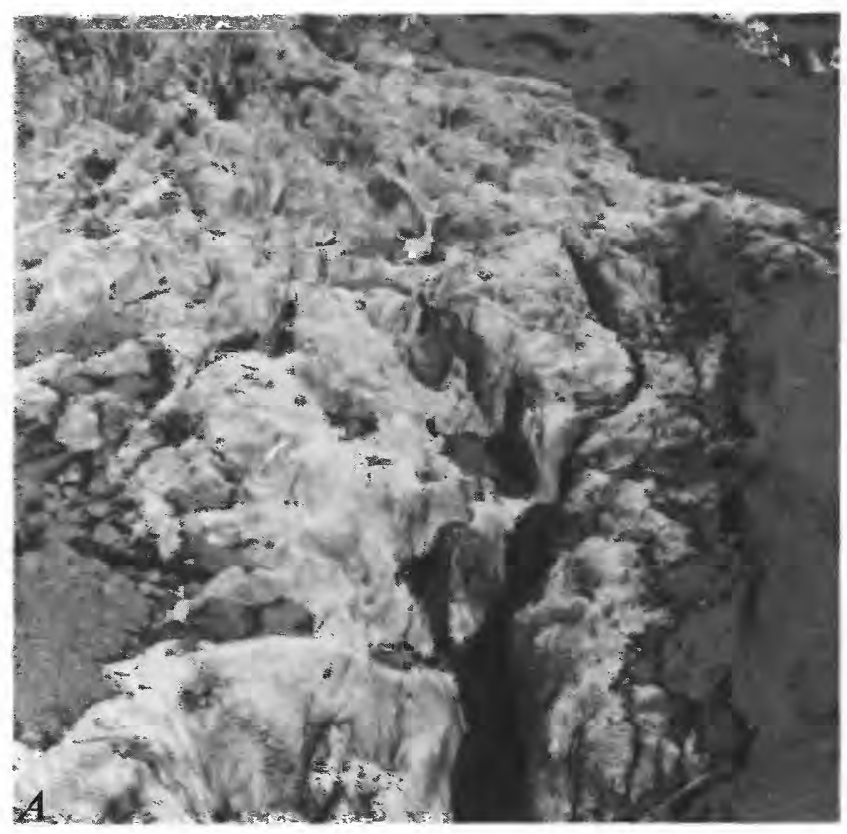

Figure 10. Low-level aerial views (photographs taken September 29,1992 ) of ice scabland produced by flood during September 1992 eruption of Crater Peak, Mount Spurr volcano, Alaska, along west side of Kidazgeni Glacier. $A$, September pyroclastic-flow deposit veneer stripped along September ice-scabland channels; width between scarps in deposit in lower part of photograph is about $5 \mathrm{~m}$.

a tract 5 to $15 \mathrm{~m}$ wide while eroding a stepped series of cataracts and plunge pools several meters wide and deep (figs. 10, 11). This essentially subfluvial topography is a small-scale scabland with $0.5-$ to $1-\mathrm{m}$ scarps along its margins, analogous to the bizarre topography of Washington's channeled scabland, two to four orders of magnitiude larger cut in basalt by gigantic floods during the Pleistocene (Bretz, 1928, 1959; Waitt, 1994). Within the ice scabland on Kidazgeni Glacier are pockets of poorly sorted diamict containing lithic boulders as large as $1.5 \mathrm{~m}$ indicative of debris flow, and moderately sorted gravel in the form of small expansion bars (also a channeled-scabland analogy) at the lower ends of some eroded ice-scabland channels, indicative of sediment-laden streamflow. The debris flow formed as meltwater mixed with the new pyroclastic-flow deposit; the streamflow ensued as the proportion of meltwater outstripped the available supply of pyroclasts. The watery phase of flow down the glacier closely followed the debris-flow phase.

From the ice-scabland tract the flows emerged onto a flatter (gradient 100 to $50 \mathrm{~m} / \mathrm{km}$ ) part of the glacier and spread out as a broad fan 50 to $75 \mathrm{~m}$ broad. Later incision of this deposit exposed more than $1.2 \mathrm{~m}$ of compact, nearly massive pebble gravel (diamict) capped by $20 \mathrm{~cm}$ of loose openwork pebble 


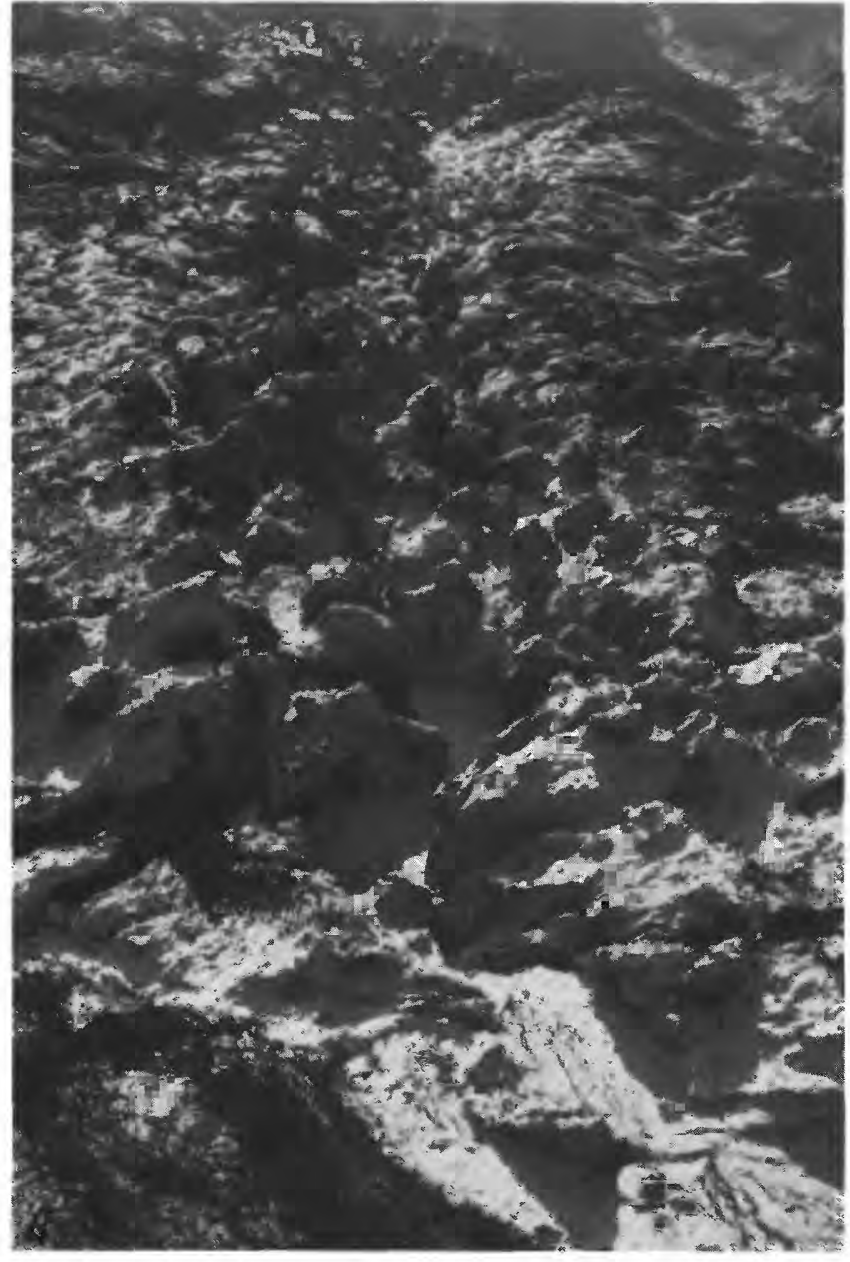

Figure 10. Continued. $B$, View directly up main ice-scabland tract; width of roughest part of tract about $8 \mathrm{~m}$.

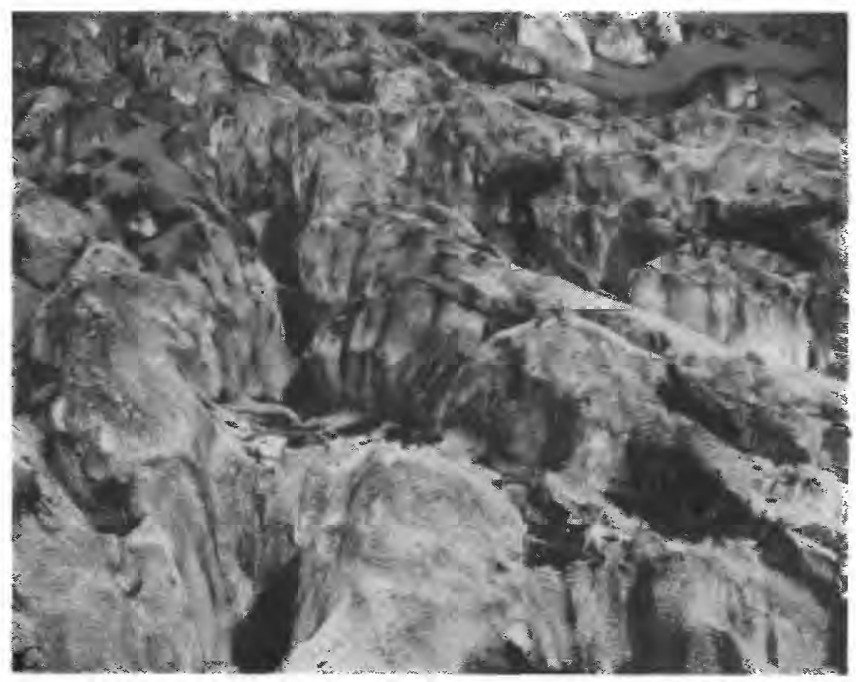

Figure 10. Continued. $C$, Erosional ice-scabland and patches of pyroclastic-flow deposit, view upglacier; height of largest scabland elements about $2.5 \mathrm{~m}$.

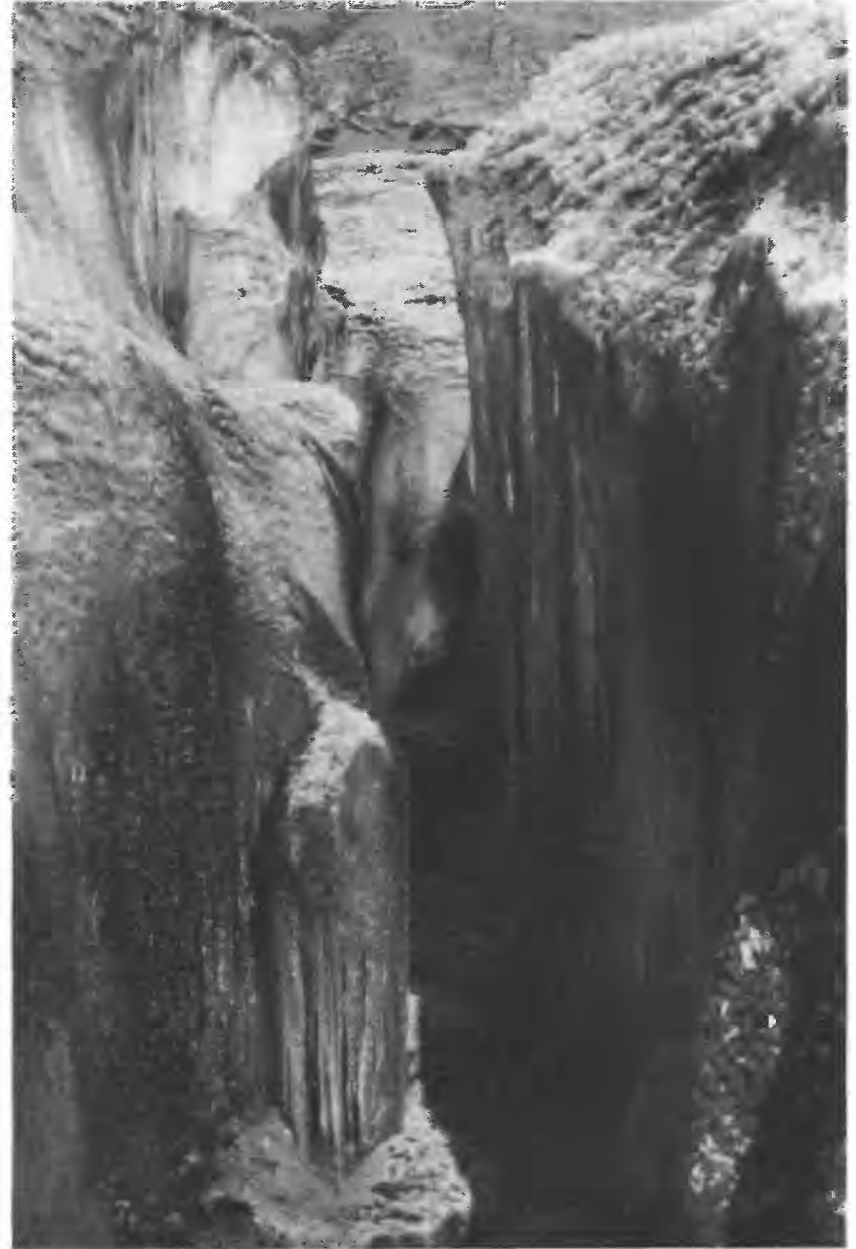

Figure 11. Close view (photograph taken September 29, 1992) upglacier of ice scabland on Kidazgeni glacier produced by flood during September 17, 1992 eruption of Crater Peak, Mount Spurr volcano, Alaska. Depth of scour shown here is about $2.5 \mathrm{~m}$.

gravel (fig. 12). This two-layer deposit bespeaks a voluminous debris flow phase followed by a voluminous watery phase.

Detailed grain-size analyses are beyond the scope of this study, but differences obvious in the field are quantified by histograms and cumulative-frequency grain-size distributions obtained by sieving representative samples (fig. 13A,B). Mass-flow deposits are poorly sorted, the water-flow deposit moderately sorted (tables 1,2). In Folk's (1980) classification the pyroclastic-flow deposit is medium-pebble gravel, the debris-flow deposit sandy small-pebble gravel (but both are diamicts), and the watery flow deposit a largepebble gravel (fig. 13C). The large deviation in clast sizes within the pyroclastic-flow deposit bespeaks its polymodal source and lack of winnowing during flow. The even poorer sorting of the debris-flow deposit probably reflects its incorporation of supraglacial de- 


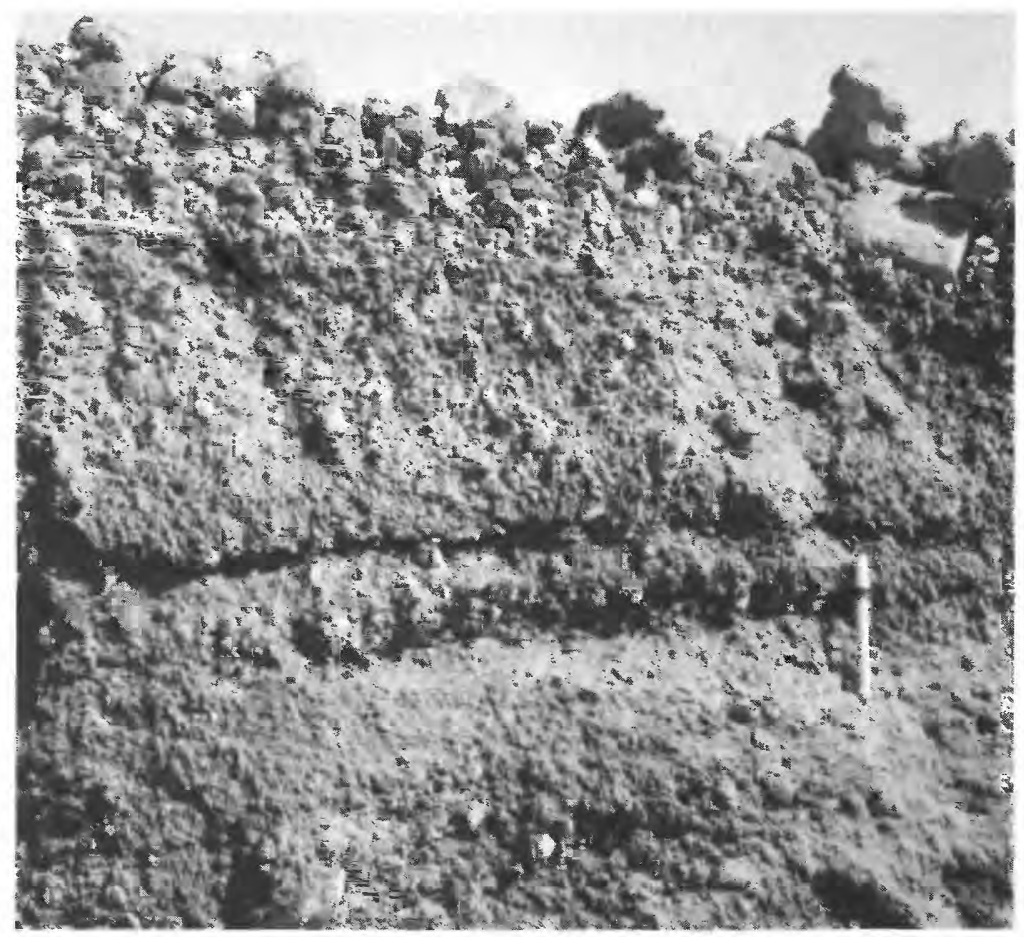

Figure 12. Section exposing September 13, 1992, flowage deposits overlying Kidazgeni Glacier, Crater Peak, Mount Spurr volcano, Alaska. Matrix-bearing debris-flow deposit with poorly developed plane bedding is overlain at pencil (arrow) by openwork pebble-cobble gravel watery-flow deposit. Pen to right is $13 \mathrm{~cm}$ long.

bris; the far lower deviation of the waterlaid deposit demonstrates a winnowing out of the fines and perhaps also the coarsest clasts.

The composite debris and watery flow descended to the glacier side and through an existing breach in the right-lateral moraine about at altitude $1,068 \mathrm{~m}$. The flow apparently greatly enlarged the erosional gash, where it incorporated much coarse sediment before spreading gravel across a fan west of the glacier at altitude 825 to 670 (fig. 14). From there a small lahar tongue descended to the Chakachatna River (Meyer and Trabant, this volume).

The September pyroclastic flows and derivative water-containing flows were concentrated on the eastnortheast through south-southeast segment of the cone rather than downslope from the south-facing crater breach. This distribution indicates that the pyroclasts were launched by directed explosions, as they were during the June and August eruptions. Over the course of the three eruptions the vent was observed to migrate progressively west, and so after the September eruption it was tight against the west-northwest crater wall (T.P. Miller, oral commun., 1992). With each eruption the migrating vent directed energetic explo- sions successively farther counterclockwise, from southsoutheastward to eastward, obliquely away from the south-facing crater-rim breach.

Table 1. Sieve analyses for three samples of flows of the September 1992 eruption of Crater Peak, Mount Spurr volcano, Alaska.

[Values are weight percent of entire sieved sample.]

\begin{tabular}{cccc}
\hline Size class in phi (ø) & Pyroclastic flow & Debris flow & Watery flow \\
\cline { 2 - 4 }-6 & 11.5 & & \\
-5 & 5.8 & 5.3 & 34.5 \\
-4 & 11.8 & 10.9 & 51.0 \\
-3 & 22.1 & 25.3 & 12.7 \\
-2 & 17.5 & 20.7 & 0.1 \\
-1 & 16.7 & 12.9 & 0.0 \\
0 & 10.9 & 8.7 & 0.0 \\
1 & 2.7 & 5.1 & 0.0 \\
2 & 0.7 & 7.3 & 0.1 \\
3 & 0.3 & 3.3 & 0.2 \\
4 & 0.1 & 0.1 & 0.3 \\
$>4$ & 0.0 & 0.4 & 1.2 \\
Total $-\cdots-.-$ & 100.0 & 100.0 & 100.0 \\
\hline
\end{tabular}


Table 2. Statistical data from sieved samples of flows of the September 1992 eruption of Crater Peak, Mount Spurr volcano, Alaska.

[Parameters of Folk, 1980]

\begin{tabular}{|c|c|c|c|}
\hline Parameter & Pyroclastic flow & Debris flow & Watery flow \\
\hline Weight percent gravel ------ & 85.4 & 75.1 & 98.3 \\
\hline Weight percent sand & 14.6 & 24.5 & 0.6 \\
\hline Weight percent mud ----- & 0 & 0.4 & 1.1 \\
\hline \multirow[t]{2}{*}{ Mean $(\varnothing)$} & -3.1 & -2.2 & -4.8 \\
\hline & medium pebble & small pebble & large pebble \\
\hline \multirow[t]{2}{*}{ Sorting $(\varnothing)$} & 1.8 & 2.1 & 0.8 \\
\hline & poor & very poor & moderate \\
\hline \multirow[t]{2}{*}{ Skewness - - } & 0.02 & 0.29 & 0.0 \\
\hline & symmetrical & fine skewed & symmetrical \\
\hline
\end{tabular}
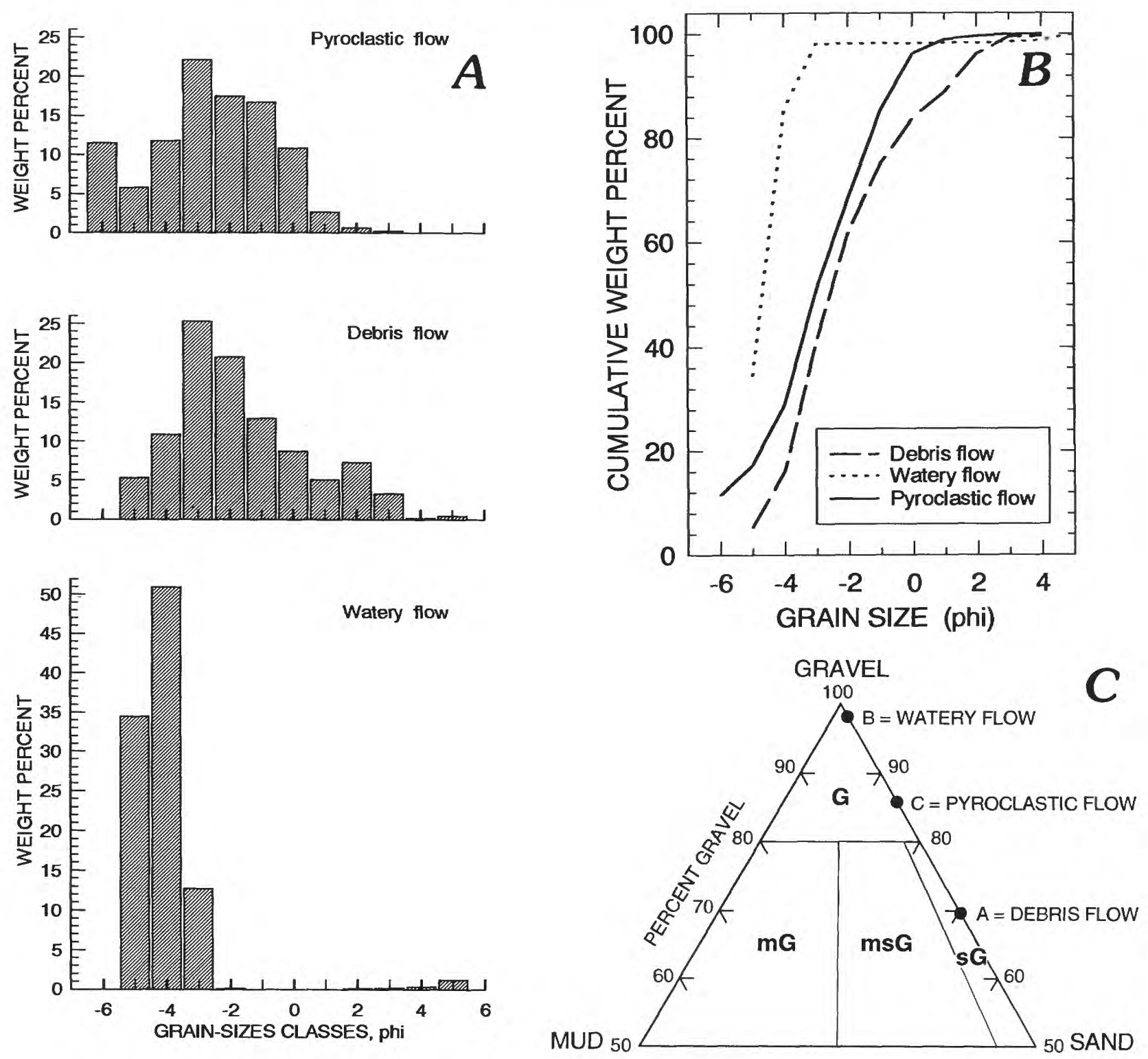

Figure 13. Grain-size character of pyroclastic-flow deposit of August 18, 1992, eruption on Kidargeni glacier and deposits derived from it by water-flow processes. Crater Peak, Mount Spurr volcano, Alaska. A, Histographs showing grain-size distribitions. $B$, Cumulative grain-size-frequency distributions. $C$, Names according to Folk's (1980) classification. Only top (gravel) portion of Folk's classification triangle shown. G, gravel; sG, sandy gravel; msG, muddy sandy gravel; mG, muddy gravel. 


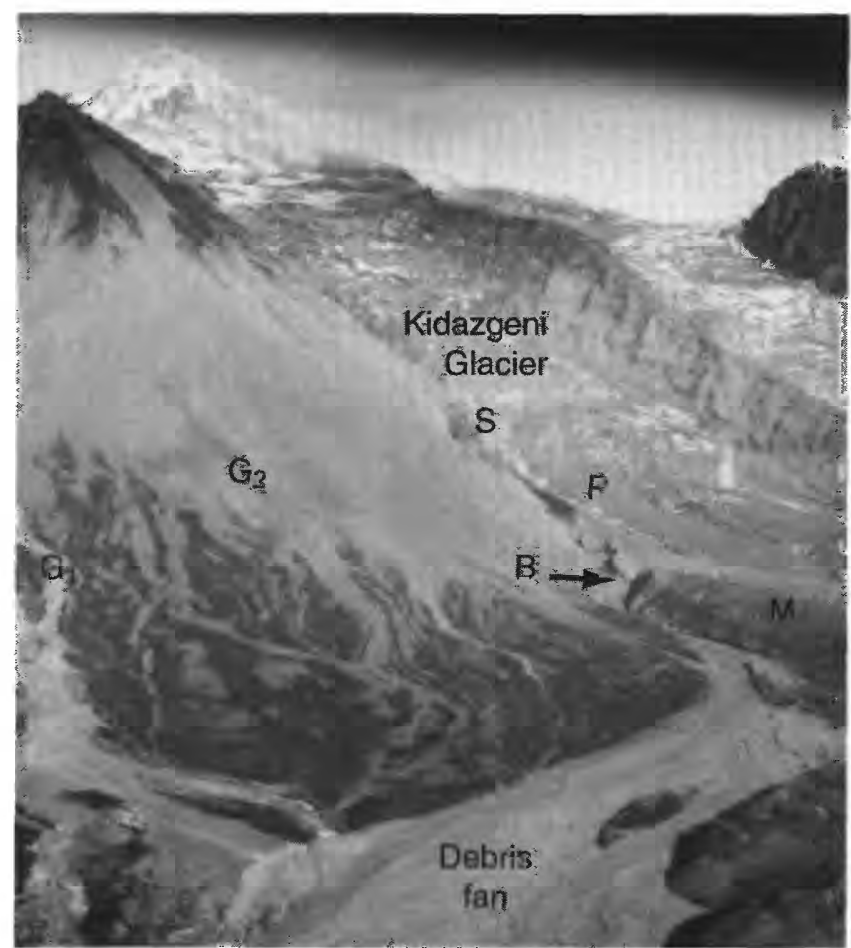

Figure 14. View north showing fan of flood debris below the right-lateral moraine of Kidazgeni Glacier and other effects of September 16-17, 1992, eruption of Crater Peak, Mount Spurr volcano, Alaska. Mount Spurr is high, snowcapped peak to upper left; Crater Peak is peak on far left. G1, gully $1 ; G 2$, gully $2 ; \mathrm{P}$, pyroclastic-flow deposit on glacier; S, water-scoured west side of glacier. B, breach enlarged by flood through lateral moraine. Debris fan resulted from distribution of material from moraine breach. At the mouth of gully 1 , the September fan cuts across small fan of June flow that descended gully 1 .

\section{COMPARISON WITH ERUPTIONS AT OTHER SNOWCLAD VOLCANOES}

The deposits of hybrid flows from Crater Peak resemble those of mixed pyroclast-snow flows during several other recent eruptions. Swift pyroclast-snow mixing occurred at the base of the huge pyroclastic surge off Mount St. Helens during the first minutes of the cataclysmic eruption of May 18, 1980. Stratigraphy shows that large laharic flows down the east and west volcano flanks trailed the pyroclastic surge and were clearly caused by it (Waitt, 1989). Between 1981 and 1991 many small to moderate explosive eruptions at Mount St. Helens caused turbulent, rapid mixing of hot pyroclasts with snowpack on the crater walls and floor to form various mixed flows (Waitt and others, 1983; Waitt and MacLeod, 1987; Mellors and others, 1988). Each mixed-flow deposit included a relatively dry marginal facies consisting largely of snow that did not melt and which froze soon after emplacement. Many pyroclast-snow mixing events also produced far more mobile slushflows along deeper and more axial parts of flowpath. Further melting transformed some of them into watery flows that deeply channeled snowpack along the lowest axial part of the flowpath.

During the eruption of Nevado del Ruiz, Colombia, in November 1985, initial pyroclastic surges dynamically mixed with snowpack, firn, and ice to form unusual, mixed ice-debris deposits (Pierson and others 1990, figs. 8, 9). Ensuing pyroclastic flows did far more turbulent mixing and melting to form lahars that flowed down surrounding valleys, where they enlarged with debris and streamwater into huge lethal flows.

At Augustine Volcano, Alaska, pyroclastic flows of two recent eruptions turbulently mixed pyroclasts with snowpack to yield watery flows. During the 1976 winter eruption, pumiceous pyroclastic flows incorporated winter snowpack to form pumiceous deposits more sorted and with more rounded clasts than adjacent pyroclastic-flow deposits (Kamata and others, 1991, fig. 9). The 1986 spring eruption produced typical pumiceous pyroclastic flows that merge downslope into small scabland erosional tracts overlain by patchy, matrix-free water-washed coarse gravel (unpub. data, 1988), evidence that pyroclastic flows swiftly melted snowpack they overrode.

During the 1989-90 eruptions of Redoubt Volcano, Alaska, repeated collapses of fragmented hot dome rock onto glacier ice formed debris flows and watery floods. The initial eruption of December 15, 1989, formed an expansive "dry" ice-diamict deposit on both the north and south volcano flanks (Waitt and others, 1994). The degree of melting was small because pyroclasts were swiftly cooled by a huge volume of readily incorporated snow and firn. But during many later dome collapses, fragmented dome rock swiftly interacted with and greatly eroded the northside Drift glacier (Trabant and others, 1993) to yield large watery floods.

At Crater Peak the wet, mixed flows were fairly small. The dry-appearing hybrid-flow deposit of June 27 closely resembles the surface texture of the "dry" phases of mixed-flow deposits at Mount St. Helens between 1982 and 1986 and also the melted ice-diamict surface at Redoubt (Waitt and others, 1994, figs. 11, 12). The small scabland eroded into Kidazgeni Glacier in September was similar to the ice-erosional forms carved in Drift glacier by the 1989-90 Redoubt eruptions (Trabant and others, 1994).

Hybrid flows are probably far more common than past reports suggest. Those from Crater Peak and the other cited eruptions were documented because of ac- 
cess by helicopter soon after eruption. Because the flows are cool or cold, snowfall quickly obscures them in winter. Because some of the flows contain much snow, much of the original volume disappears and the resulting deposit can resemble a typical pyroclasticflow or lahar deposit. The subtle evidence of wetness can be mostly lost in the geologic record, indeed easily overlooked even in recent surface deposits.

\section{HAZARDS}

Had the wet or snowy flows at Crater Peak been larger they might have dammed Chakachatna River and induced large floods, but they would not have endangered life or property in that remote setting. Yet these small hybrid flows illustrate a hazard common to snowclad volcanoes. When hot pyroclasts turbulently mix with snow or flow over glacier ice, they swiftly generate wet flows that can soon travel beyond the limits of dry, hot pyroclastic flows. Thus their damaging effects extend beyond the mountain flanks. At volcanoes in Indonesia and the Phillipines that are affected by monsoons, most lahars initiate secondarily when torrential rains act on loose, hot, unstable pyroclastic debris (Rodolfo and Arguden, 1991; Pierson and others, 1992). The type of snowflows and floods produced at Mount Spurr volcano, Mount St. Helens, Redoubt Volcano, and other snowclad volcanoes, are primary, produced as they are swiftly $d u r$ ing a pyroclastic eruption by turbulent hot flows moving over snow or ice. Large, lethal examples of such floods originated at Öræfajökull in Iceland in 1362 (Thorarinsson, 1958), at Cotopaxi in Ecuador in 1877 (Wolf, 1878), and at Nevado del Ruiz in Colombia in 1985 (Pierson and others, 1990). In a literature review, Major and Newhall (1989) compiled data on historical eruptions at snowclad volcanoes, concluding that pyroclastic flows and surges acting on ice and snow are the most important processes generating primary large lahars and floods.

\section{REFERENCES CITED}

Bretz, J H., 1928, The Channeled Scabland of eastern Washington: Geographical Review, 18, pp. 446-477.

Bretz, J H., 1959, Washington's Channeled Scabland: Washington Division of Mines and Geology, Bulletin 45, 57 p., 4 plates.

Folk, R.L., 1980, Petrology of sedimentary rocks: Austin, Tx., Hemphill Publishing Co., $184 \mathrm{p}$.

Juhle, W., and Coulter, H., 1955, The Spurr eruption, July 9, 1953 : Eos, Transactions, American Geophysical Union, v. 36, p. 199.
Kamata, H., Johnston, D.A., and Waitt, R.B., 1991, Stratigraphy, chronology, and character of the 1976 pyroclastic eruption of Augustine volcano, Alaska: Bulletin of Volcanology, v. 53 , p. 407-419.

Major, J.J., and Newhall, C,G., 1989, Snow and ice perturbation during historical volcanic eruptions and the formation of lahars and floods: Bulletin of Volcanology, v. 52, p. 1-27.

Mellors, R.A., Waitt, R.B., and Swanson, D.A., 1988, Generation of pyroclastic flows and surges by hot-rock avalanches from dome of Mount St. Helens volcano, USA: Bulletin of Volcanology, v. 50, p. 14-25.

Pierson, T.C., Janda, R.J., Thouret, J.-C., and Borrero, C.A., 1990, Perturbation and melting of snow and ice by the 13 November 1985 eruption of Nevado del Ruiz, Colombia, and consequent mobilization, flow and deposition of lahars: Journal of Volcanology and Geothermal Research, v. 41, p. 17-66.

Pierson, T.C., Janda, R.J., Umbal, J.V., and Daag, A.S., 1992, Immediate and long-term hazards from lahars and excess sedimentation in rivers draining Mt. Pinatubo, Philippines: U.S. Geological Survey Water-Resources Investigations Report 92-4039, 35 p.

Rodolfo, K.S., and Arguden, T., 1991, Rain-induced generation and sediment-delivery systems at Mayon volcano, Philippines, in Sedimentation in volcanic settings: Society for Sedimentary Geology (SEPM) Special Publication 45, p. 71-87.

Thorarinsson, S., 1958, The Örafajökull eruption of 1362: Acta Naturalia Islandica, v. 2, no. 2, 102 p.

Trabant, D.C, Waitt, R.B., and Major, J.J., 1994, Disruption of Drift glacier and origin of floods during the 1989-90 eruptions of Redoubt Volcano, Alaska: Journal of Volcanology and Geothermal Research, v. 62, p. 369-386.

Waitt, R.B., 1989, Swift snowmelt and floods (lahars) caused by great pyroclastic surge at Mount St. Helens, Washington, 18 May 1980: Bulletin of Volcanology, v. 52, p. 138-157.

Waitt, R.B., with contributions from J.E. O'Connor and Gerardo Benito, 1994, Scores of gigantic, successively smaller Lake Missoula floods through Channeled Scabland and Columbia valley [guide for fieldtrip \#2, GSA 1994 Annual Meeting]: in Swanson, D.A., and Haugerud, R.A., eds., Geologic field trips in the Pacific Northwest: Department of Geological Sciences, University (Geological Society of America, 1994 Annual Meeting), v. 1, Chapter 1K, 88 p.

Waitt, R.B., Pierson, T.C., MacLeod, N.S., Janda, R.J., Voight, B., and Holcomb, R.T., 1983, Eruption-triggered avalanche, flood, and lahar at Mount St. Helens-effects of winter snowpack: Science, v. 221, p. 1394-1397.

Waitt, R.B., and MacLeod, N.S., 1987, Minor explosive eruptions at Mount St. Helens dramatically interacting with winter snowpack in March-April 1982, in Washington Division of Geology and Earth Resources Bulletin 77, p. 355-379.

Waitt, R.B., Gardner, C.A., Pierson, T.C., Major, J.J., and Neal, C.A., 1994, Unusual ice diamicts emplaced during 15 December 1989 eruption of Redoubt Volcano, Alaska: Journal of Volcanology and Geothermal Research, v. 62, p. 409428.

Wolf, T., 1878, Geognostische Mitteilungen aus Ecuador; Der Cotopaxi und seine letzte Eruption am 26 Juni 1877: Neues Jahrbuch für Mineralogie, Geologie, und Paläontologie, p. 113167. 


\title{
Whole-rock Major- and Trace-element Chemistry of 1992 Ejecta from Crater Peak, Mount Spurr Volcano, Alaska
}

\author{
By Christopher J. Nye, Michelle L. Harbin, Thomas P. Miller, Samuel E. Swanson, and \\ Christina A. Neal
}

\section{CONTENTS}

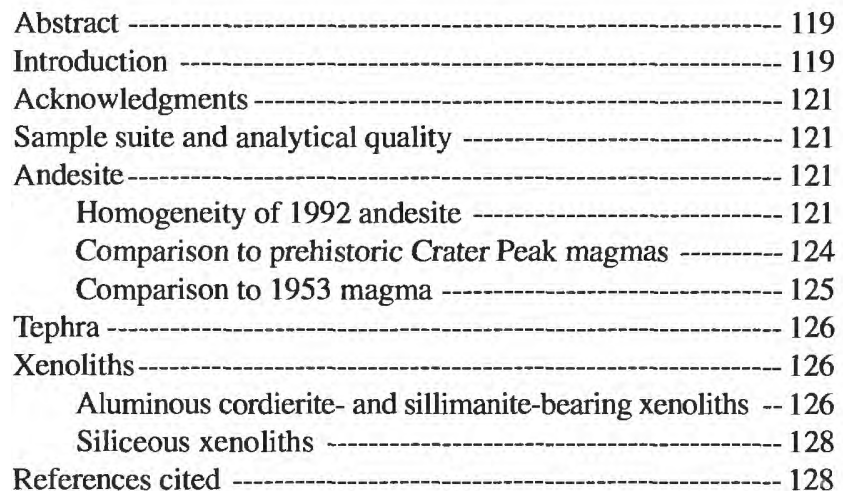

\section{ABSTRACT}

Juvenile ejecta from the three 1992 eruptions of the Crater Peak vent of Mount Spurr are calcalkaline andesite and contain about 57 percent $\mathrm{SiO}_{2}$ by weight. Samples are chemically uniform within analytical error for all but a few of the most mobile of the 43 elements whose concentrations were determined. The andesite is unlike prehistoric Crater Peak andesites of similar silica content in having high concentrations of $\mathrm{Al}_{2} \mathrm{O}_{3}, \mathrm{Na}_{2} \mathrm{O}$, and $\mathrm{Sr}$ and low concentrations of compatible transition metals. These differences suggest that the immediate parent to the 1992 andesite crystallized relatively more ferromagnesian silicate (probably clinopyroxene) and less plagioclase than previous Mount Spurr andesites, which requires either higher water pressure, greater residence depth, or both. The 1992 andesite is also unlike previous Crater Peak andesites, including that erupted in 1953, in having lower concentrations of some incompatible elements yet higher amounts of silica. These observations suggest that the magma that fed the 1992 eruptions was not derived from the same magma body that fed the 1953 eruption, but it instead is new magma that came from the source region in the deepest crust or mantle. The
1992 eruptions also ejected partially melted aluminous metamorphic xenoliths characterized by high concentrations of both incompatible and compatible trace elements despite moderate silica contents and by mineral assemblages unlike exposed country rock. Small quantities of highly siliceous xenoliths characterized by dramatic depletion of all but a few trace elements $(\mathrm{Rb}, \mathrm{Ta}, \mathrm{U})$ were also erupted.

\section{INTRODUCTION}

Mount Spurr volcano, $125 \mathrm{~km}$ west of Anchorage, is the next-to-last Holocene volcano at the northeastern end of the Aleutian arc. It is about $100 \mathrm{~km}$ above the Benioff zone and $500 \mathrm{~km}$ from the trench in a direction parallel to the movement between the Pacific and North American plates. The region surrounding Mount Spurr is underlain by a Jurassic to mid-Tertiary granitic batholith, which intrudes Paleozoic to Mesozoic limestone, basalt, and flysch of generally low metamorphic grade (Wilson and others, 1985).

Spurr volcano is composed of an ancestral Mount Spurr (fig. 1) whose construction began at least 255 ka (Nye and Turner, 1990). It is predominantly built of 58 to 60 percent $\mathrm{SiO}_{2}$ two-pyroxene andesite flows that are interbedded with a few more mafic flows. Lava flows dominate the upper part of the cone, and pyroclastic rocks dominate the lower part. The growth of the ancestral Mount Spurr was terminated by Bezymianny-type avalanche caldera formation and the production of a debris avalanche with a minimum runout of $25 \mathrm{~km}$ and a volume of a few cubic kilometers (Nye and Turner, 1990). The resultant amphitheater is $5 \mathrm{~km}$ by $6 \mathrm{~km}$, predominantly ice filled, and breached to the south. The debris avalanche is immediately overlain by partially welded ashflows more silicic (61-63 percent $\mathrm{SiO}_{2}$ ) than ancestral Mount Spurr andesites. Intrusion of this silicic magma high into the cone was presumably the cause of stratocone failure. The age of caldera formation is not precisely known. It post- 


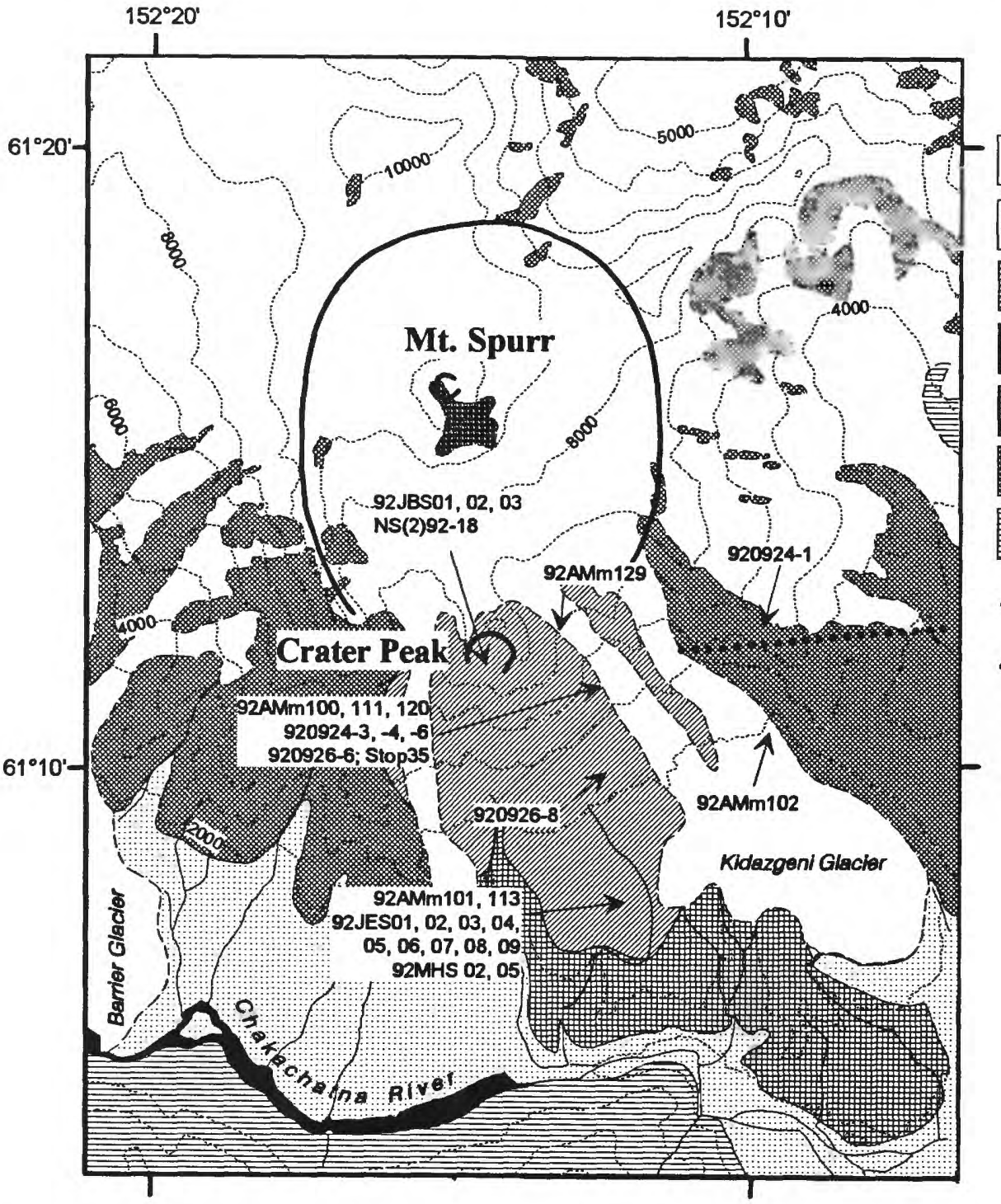

\begin{tabular}{|ll}
\hline & Glacial ice \\
& Alluvium and drift \\
Crater Peak deposits \\
Mount Spurr dome \\
Pyroclastic fan \\
Ancestral Mount Spurr deposits
\end{tabular}

Nonvolcanic basement

Crater rim

$\therefore$ Projected fault
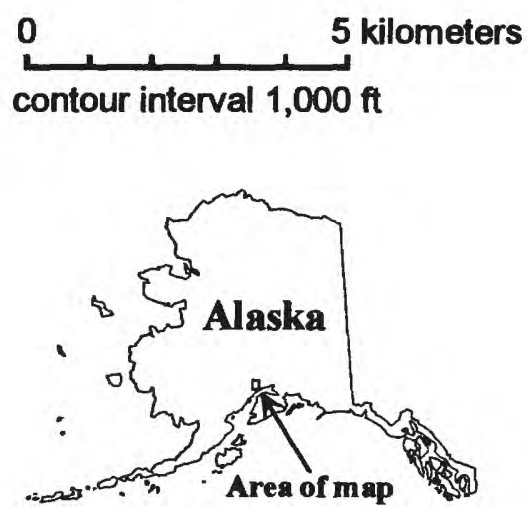

Figure 1. Geology (modified Nye and Turner, 1990) and geography of the area immediately surrounding Mount Spurr, Alaska. Locations of samples analyzed for this study are also shown.

dates the youngest cone-building andesite (youngest measured age is $59 \mathrm{ka}$; Nye and Turner, 1990 ) and predates the oldest post-caldera tephra ( $>7 \mathrm{ka}$; Riehle, 1985). The lack of a tephra blanket suggests that caldera formation occurred during a time of widespread ice cover, ergo a Pleistocene age. The lack of erosion of the debris avalanche, despite its location in major glacial valley, suggests a late Pleistocene age of caldera formation.

After caldera formation, a large dome formed in the center of the caldera (fig. 1). It forms the current summit of Mount Spurr and is ice covered except for periodically exposed patches of dome lava with scattered, diffuse boiling-point fumaroles. The few samples recovered from the dome have 61 to 63 weight percent $\mathrm{SiO}_{2}$, plagioclase, two pyroxenes, and occasional hornblende xenocrysts and have composi- tions similar to the ashflows overlying the debris avalanche (Nye and Turner, 1990). Tephra from this vent do not appear to be younger than about $5 \mathrm{ka}$ (Riehle, 1985). Crater Peak, $6 \mathrm{~km}$ south of the Mount Spurr summit (fig. 1), sits in the caldera breach and is the historically active vent. It consists of lava and pyroclastic flows with 54 to 57 percent $\mathrm{SiO}_{2}$-more mafic than cone-building andesites, which contain plagioclase, two pyroxenes, and sparse hornblende phenocrysts. Tephra from Crater Peak range in age from $5 \mathrm{ka}$ to the present (Riehle, 1985). However, the presence of block-and-ash flows produced by the eruption of magmas that are apparent mixtures of Crater Peak and Spurr summit dome magmas as well as hornblende xenocrysts derived from Crater Peak magmas in Spurr summit dome magmas, suggest that the two magmatic systems overlapped in time (Nye and Turner, 
1990). Remnants of an older cone in the position of the current Crater Peak lie just west and east of Crater Peak. These are referred to as ancestral Crater Peak here, but they were called proto-Crater Peak by Nye and Turner (1990).

The Crater Peak vent of Mount Spurr erupted on June 27, August 18, and September 16-17, 1992 (Eichelberger and others, this volume). Eruptions were 3.5 to 4 hours in duration, and they produced subplinian columns which deposited extensive tephra blankets and minor proximal pyroclastic flows and other debris flows. These eruptions produced six types of ejecta. In order of decreasing volume, they are: (1) widespread blankets of mostly juvenile andesitic tephra with a combined dense-rock-equivalent volume of about $35 \times 10^{6} \mathrm{~m}^{3}$ (Neal and others, this volume); (2) brown to dark-gray, breadcrusted andesite blocks deposited in pyroclastic flows, lahars, and ballistic bomb fields with a total volume of about one percent of that of the tephra (Miller and others, this volume; Waitt and others, this volume); (3) aluminous xenoliths composed of highly inflated, partially melted blocks of metamorphic country rock, with a total volume of about one percent of the volume of the andesite blocks (Harbin and others, this volume); (4) light gray-green andesite, which is distinguished most readily from the dark andesite by clear, rhyolitic groundmass glass rather than the brown, andesitic glass of the dark andesite; (5) volumetrically minor metamorphic xenoliths including a white glass-quartz-plagioclase rock and wollastonite-bearing skarn; and (6) accidental blocks of older Crater Peak andesite. Representative samples of most of these types of ejecta were analyzed in bulk for 10 major and 33 trace elements.

\section{ACKNOWLEDGMENTS}

We thank Diane Johnson and Charles Knaack of the GeoAnalytical Laboratory at Washington State University for their fast, courteous, and responsive attention to our analytical requests. We also thank members of the Alaska Volcano Observatory and its affiliates including Jim Beget, John Eichelberger, and Cynthia Gardner for collecting some of the samples for this study. Julie Donnelly-Nolan and John Pallister provided conscientious technical reviews that substantially improved the original manuscript.

\section{SAMPLE SUITE AND ANALYTICAL QUALITY}

The samples discussed herein include 19 juvenile andesite blocks (three from the June 27 eruption, nine from the August 18 eruption, and seven from the September 16-17 eruption). These blocks span the known emplacement modes and stages of each eruption. We also analyzed five light gray-green andesites (four from August 18 and one 1 from September 16-17); 20 aluminous xenoliths (all from August 18); and 3 white glass-quartz-plagioclase xenoliths from August 18 deposits. Sample locations for andesite blocks and xenoliths are shown in figure 1. In addition we analyzed a total of 20 proximal tephra samples consisting of two or three samples from light and dark and upper and lower tephra from each eruption. $\mathrm{Tl}$ ase are described more fully in Neal and others (this volume). Separate splits of each sample were powdered in a tungsten-carbide shatterbox for analysis by $\mathrm{X}$ ray fluorescence (XRF) and in a steel shatterbox for analysis by inductively coupled plasma mass spectrometry (ICP/MS). Crushing in tungsten-carbide avoids compatible-transition-metal contamination and crushing in steel prevents high-field-strength element contamination. Milling and analysis were done at the GeoAnalytical laboratory at Washington State University. One duplicate was chosen at random and analyzed for each batch of samples submitted. These duplicates form the basis for our reported analytical precision (table 1). Overlap of analyzed elements betw'een techniques (high-precision $\mathrm{Rb}, \mathrm{Ba}, \mathrm{Y}$, and $\mathrm{Nb}$ data vere obtained by both XRF and ICP-MS) provides another method of monitoring analytical quality.

\section{ANDESITE}

\section{HOMOGENEITY OF 1992 ANDESITE}

Two types of andesite erupted from Crater Peak in 1992: dense to scoriaceous brown to dark-gray antesite and much less abundant light gray-green andesite. The dark andesite is fairly homogeneous throughout the deposits from all three 1992 eruptions (tabler 1, 2). For most elements the percent deviation of all 1992 Spurr andesites is close to the analytical precision of the laboratory. Some of the highly incompatible elements $(\mathrm{Cs}, \mathrm{Rb}, \mathrm{U}, \mathrm{Th}$, and $\mathrm{Pb}$ ) have variations in 1992 ejecta outside analytical precision, but even for these elements the total variation among samples is small. For example, Cs variability between samples is about 9 percent, but this only represents a 0.04 ppm standard deviation of the analyses. $\mathrm{Pb}$ variability is apparently quite high (18 percent), but this reflects the inclusion in the mean of a single sample from the September 17 eruption with $9.54 \mathrm{ppm} \mathrm{Pb}$. Omission of this sample from the calculation results in a relative deviation of only 4 percent. We did not analyzed this sample in duplicate to verify its $\mathrm{Pb}$ content. Some of the compatible transition metals ( $\mathrm{Fe}$, $\mathrm{Sc}, \mathrm{Cr}$, and $\mathrm{Ni}$ ) also show variability outside analytical precision. 


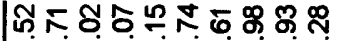
फั

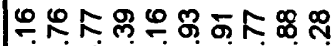
फั ठั

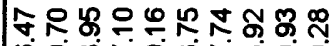

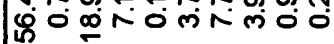

๓

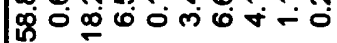

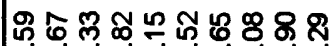
प्ष०ण0

กุ กุ ำ

Hำ a. ळ.

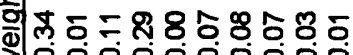
30000000000

。

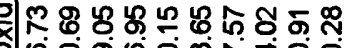

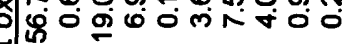
ही.

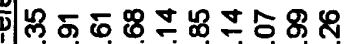

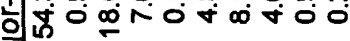
(7)

ஐ

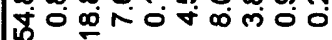

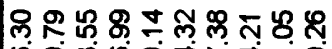

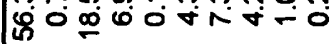

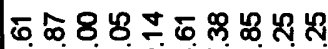

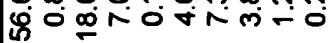

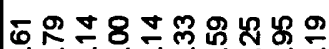

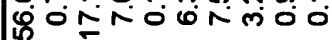

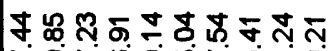

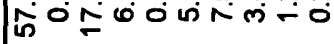

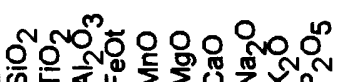

|ธ่

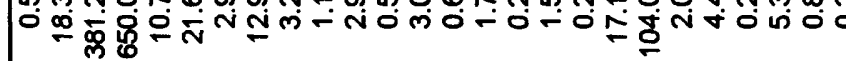

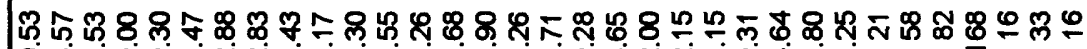

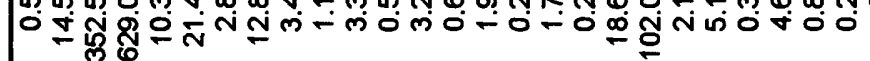

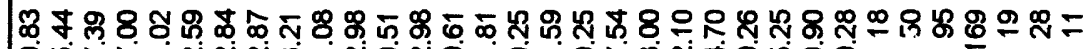

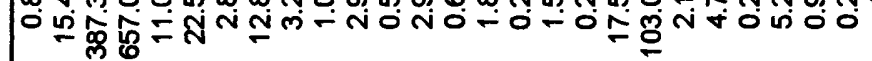

本車

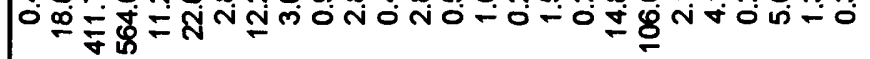

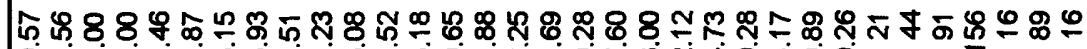

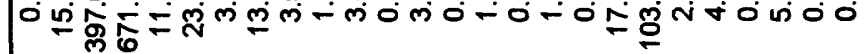

har

Oดmm 동

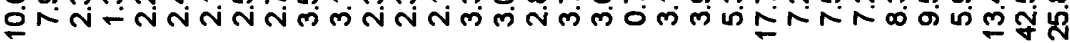

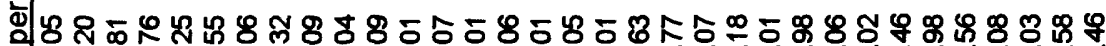

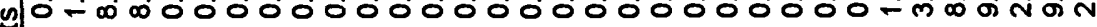
్ํㅇ

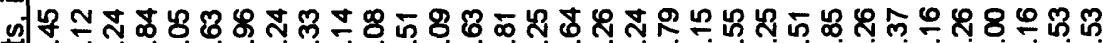

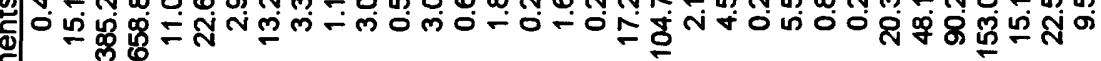
잉

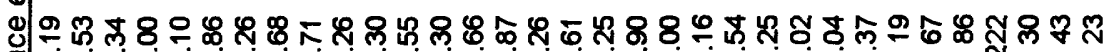

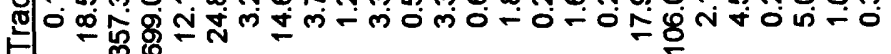

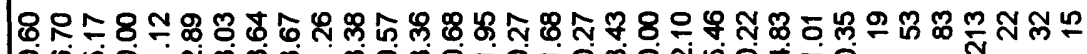

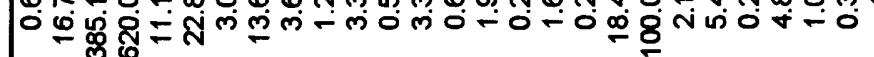

พุ\& 8 8

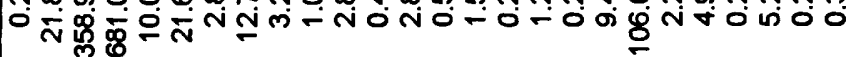

พุ๊

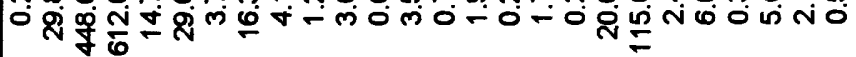

옹ㅇำ

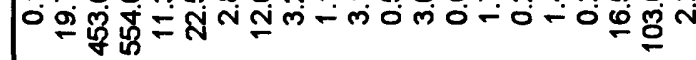

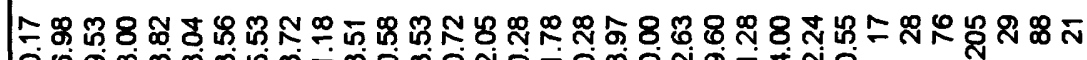
० \& gु

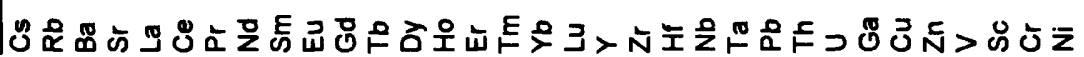




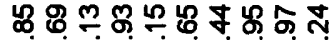

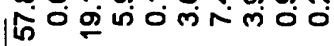

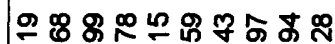

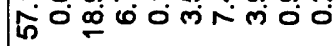

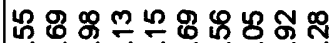

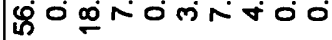

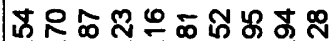
फू०

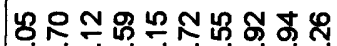

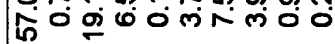

สำㄴํㅇ능

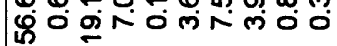

ஐ फ०

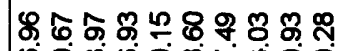
पि०00 离

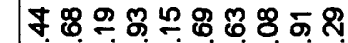

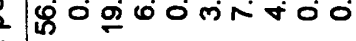
䆑 ๓ 8 ช ४ण

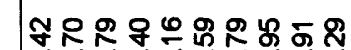

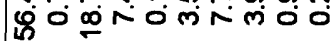

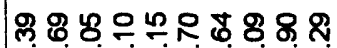

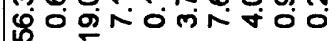

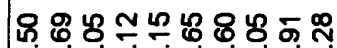

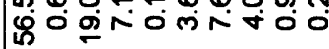

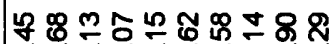

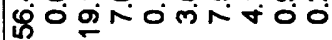

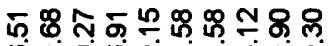

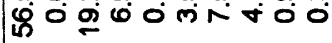

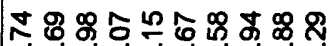

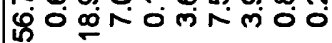

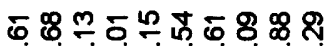

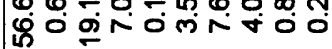

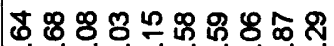
iिO

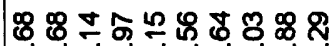

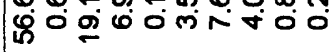

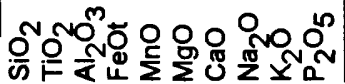

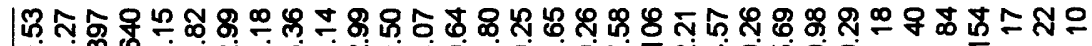

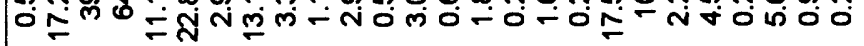

ธุด

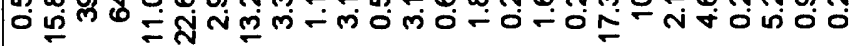

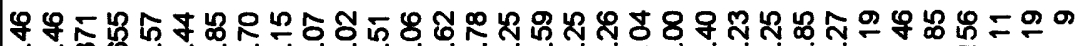

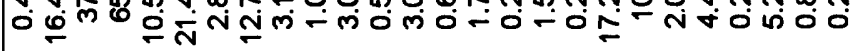

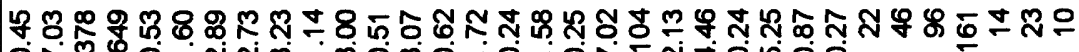

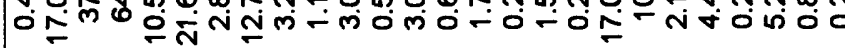

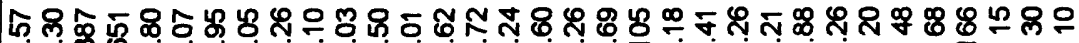
○ 以ू

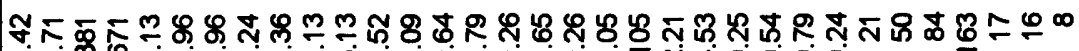

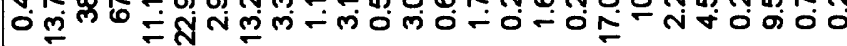

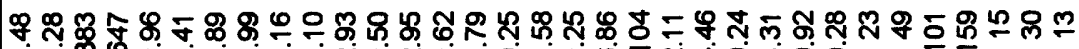

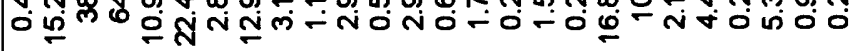

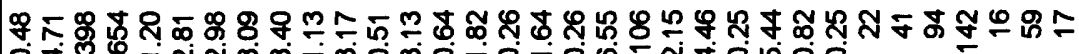

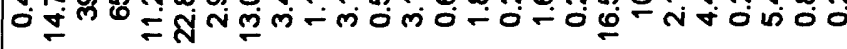

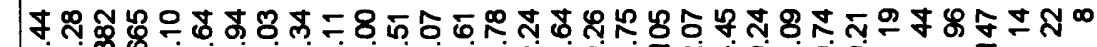
OM

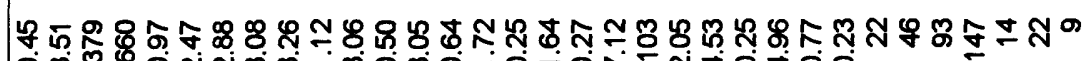
急

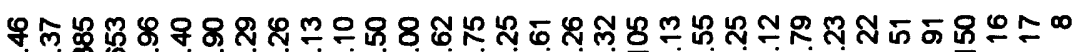

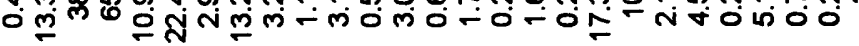

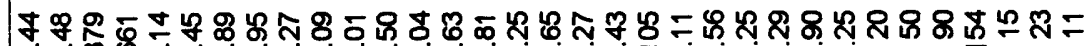
O

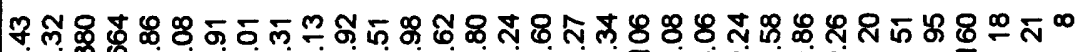

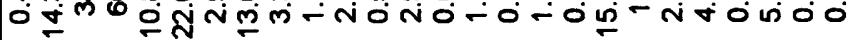

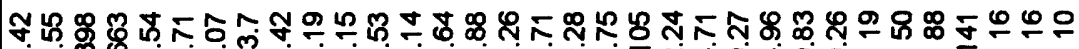

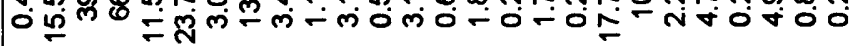

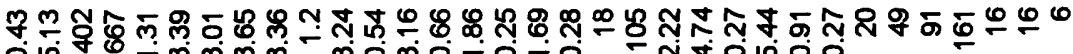

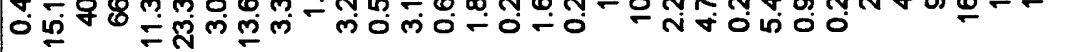

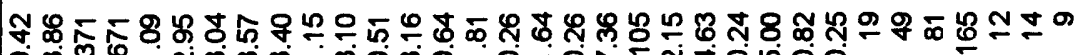

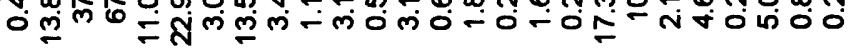

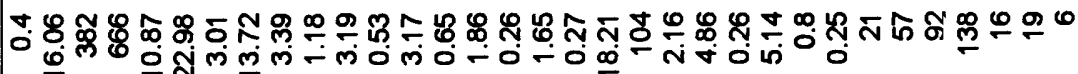
$\because \quad \frac{4}{2}$

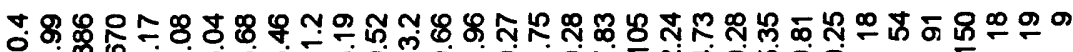
药

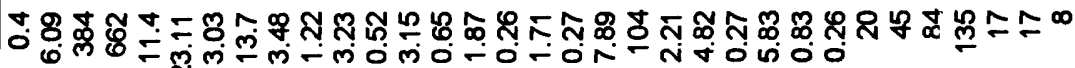

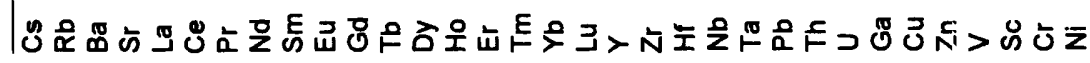


Four of the five light gray-green andesites that were analyzed are compositionally identical to the dark andesite, except for slightly higher and more variable Cs (table 1). This similarity is remarkable in view of the drastically different composition of the groundmass glass in the light gray-green andesites (rhyolite glass) versus dark andesites (andesite to dacite glass) (Harbin and others, this volume). The similar wholerock chemistry in spite of different groundmass chemistry presumably reflects, on the scale of individual blocks, more extensive crystallization of the dark andesite to produce the light gray-green andesite, perhaps at the chamber margin. The fifth sample (92AMm113c) is more evolved, and it contains 58.8 percent $\mathrm{SiO}_{2}$. This sample has no distinguishing petrographic characteristics, and it may contain a higher ratio of glass to crystals.

\section{COMPARISON TO PREHISTORIC CRATER PEAK MAGMAS}

Prehistoric Crater Peak lavas are hornblende-bearing two-pyroxene calcalkaline basaltic andesite and andesite (Nye and Turner, 1990). Besides being slightly more mafic than all but a very few ancestral conebuilding andesites, their most important distinguishing feature compared to other Mount Spurr lavas is the presence of centimeter-sized, holocrystalline, cumulus pyroxenite clots (Nye and Turner, 1990). The 1992 magma is also calcalkaline andesite, but it falls outside chemical trends of prehistoric magmas in many ways. The 1953 and prehistoric lava compositions normalized to average 1992 andesite are shown in figure 2. Data for selected samples are presented in table 1. The prehistoric andesites that are plotted have $\mathrm{SiO}_{2}$ within 1 weight percent of the 1992 andesite. Important differences between the 1992 andesite and previous andesites, at nearly constant $\mathrm{SiO}_{2}$, are higher concentrations of $\mathrm{Al}, \mathrm{Na}$, and $\mathrm{Sr}$, and lower concentrations of $\mathrm{Ti}, \mathrm{V}, \mathrm{Mg}, \mathrm{Sc}, \mathrm{Cr}$, and $\mathrm{Ni}$. These two observations suggest more protracted crystallization of the parent to the 1992 andesite at mid- to lower-crustal depths, where the increased pressure favors ferromagnesian silicate crystallization over plagioclase crystallization. $\mathrm{MgO}$ and $\mathrm{Al}_{2} \mathrm{O}_{3}$ versus $\mathrm{SiO}_{2}$ are shown in figure 3 for the entire Mount Spurr suite. These plots suggest that increased plagioclase (high $\mathrm{Al}_{2} \mathrm{O}_{3}$ ) and decreased pyroxene (low $\mathrm{MgO}$ ) components in the 1992 andesites are shared by the 1953 andesites, but not by most older magmas. Low $\mathrm{MgO}$ by itself does not uniquely demonstrate pyroxene crystallization, but pyroxene is likely to be the most abundant ferromagnesian phase. Greater-than-normal reservoir depths may be characteristic of latest Holocene Crater Peak magmatism.

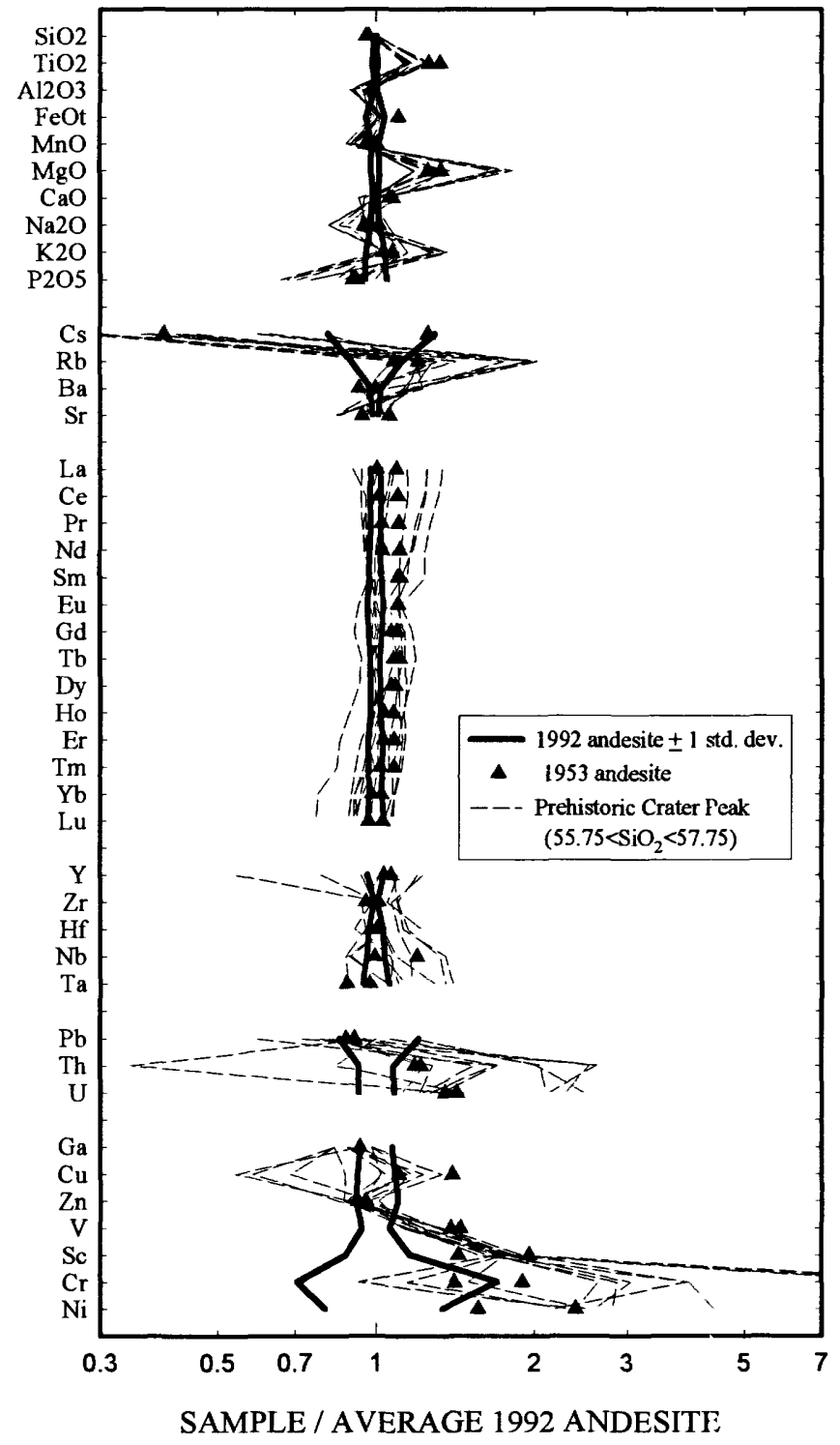

Figure 2. Mean composition of andesite erupted during 1992 from Crater Peak volcano, Mount Spurr, Alaska, cc mpared to 1953 andesite and prehistoric Crater Peak andesite. Each line is a single sample's composition divided by the mean composition of 1992 andesite blocks. Gaps separate groups of geochemically similar elements. $\mathrm{FeO}_{\mathrm{t}}$ is total iron as $\mathrm{FeO}$.

There are also major differences in the abundances and ratios of highly incompatible tra?e elements between 1992 andesite and previous andesite of similar $\mathrm{SiO}_{2}$. Specifically, 1992 andesite has Cs concentrations about two times higher than older andesite, yet slightly lower concentrations of the other alkali elements $\mathrm{K}$ and $\mathrm{Rb}$. These differences are about 20 times analytical uncertainty. Compared to most previous andesite, 1992 andesite has low concentrations of $\mathrm{Th}$ and $\mathrm{U}$, yet it has about the same $\mathrm{Pb}$ content. These differences in the relative concentrations of 
highly incompatible elements cannot be generated by fractional crystallization and must reflect some process in the source that varies for individual batches of magma. Andesite from the 1992 eruptions has a slightly lower $\mathrm{La} / \mathrm{Yb}$ ratio, and thus it is slightly less light-rare-earth-element enriched than previous andesite. Concentrations of the high-field-strength elements are comparable for some, but not all, samples of previous Crater Peak andesite.

$\mathrm{Rb}-\mathrm{SiO}_{2}$ variations in samples from the 1992 and 1953 eruptions of Crater Peak are shown in figure 4; also shown are $\mathrm{Rb}-\mathrm{SiO}_{2}$ variations from prehistoric flows from Crater Peak and the eastern and western remnants of the ancestral Crater Peak. The relative stratigraphic positions of samples are known, with the exception that the relative ages of the east and west ancestral Crater Peak sections are unknown. Three groups of samples (Crater Peak and west and east ancestral Crater Peak) are connected by lines in order of stratigraphic succession. In each case the oldest samples are the most silicic. In many cases $R b$ variations in near-neighbor mafic flows are so large that they cannot be related by fractional crystallization or mixing. $\mathrm{Rb}$ variations at 54 to 55 percent $\mathrm{SiO}_{2}$ are large enough that simple crystal sorting also cannot explain the variations. These relations suggest that relatively small volumes of chemically unrelated magma can migrate from deep within the system to feed just a few eruptions.

\section{COMPARISON TO 1953 MAGMA}

An important volcanological question is whether the 1992 andesite erupted from new magma that recently migrated to the upper crust, or whether it erunted from the remnant of the upper-crustal magma tody that fed the 1953 eruption. Analyses of two samples from proximal 1953 pumice deposits are shown in table 1 and plotted in figures 2, 3, and 4. Andesite f"om 1992 is unlike 1953 andesite in that, despite its higher $\mathrm{SiO}_{2}$, it has lower concentrations of some incompatible elements such as $\mathrm{Rb}, \mathrm{U}$, and the middle rareearth elements. These differences cannot be produced by fractional crystallization, and they suggest that the 1992 andesite indeed represents a new magma. Calculated fractional crystallization paths for $1953 \mathrm{mag}$ mas are shown in figure 4 . The crystallization calculation is from Nye and Turner (1990) and is based on detailed least-squares calculations to relate $\mathrm{SiO}_{2}$ in-
Figure 3. $\mathrm{MgO}$ and $\mathrm{Al}_{2} \mathrm{O}_{3}$ versus $\mathrm{SiO}_{2}$ (in weight percent) of Pleistocene, Holocene, and historic samples from Mount Spurr volcano, Alaska. Samples not discussed in this paper are discussed in Nye and Turner (1990). Note the high $\mathrm{Al}_{2} \mathrm{O}_{3}$ and low $\mathrm{MgO}$ of 1992 andesite compared to previous Crater Peak andesite and other Mount Spurr lavas.
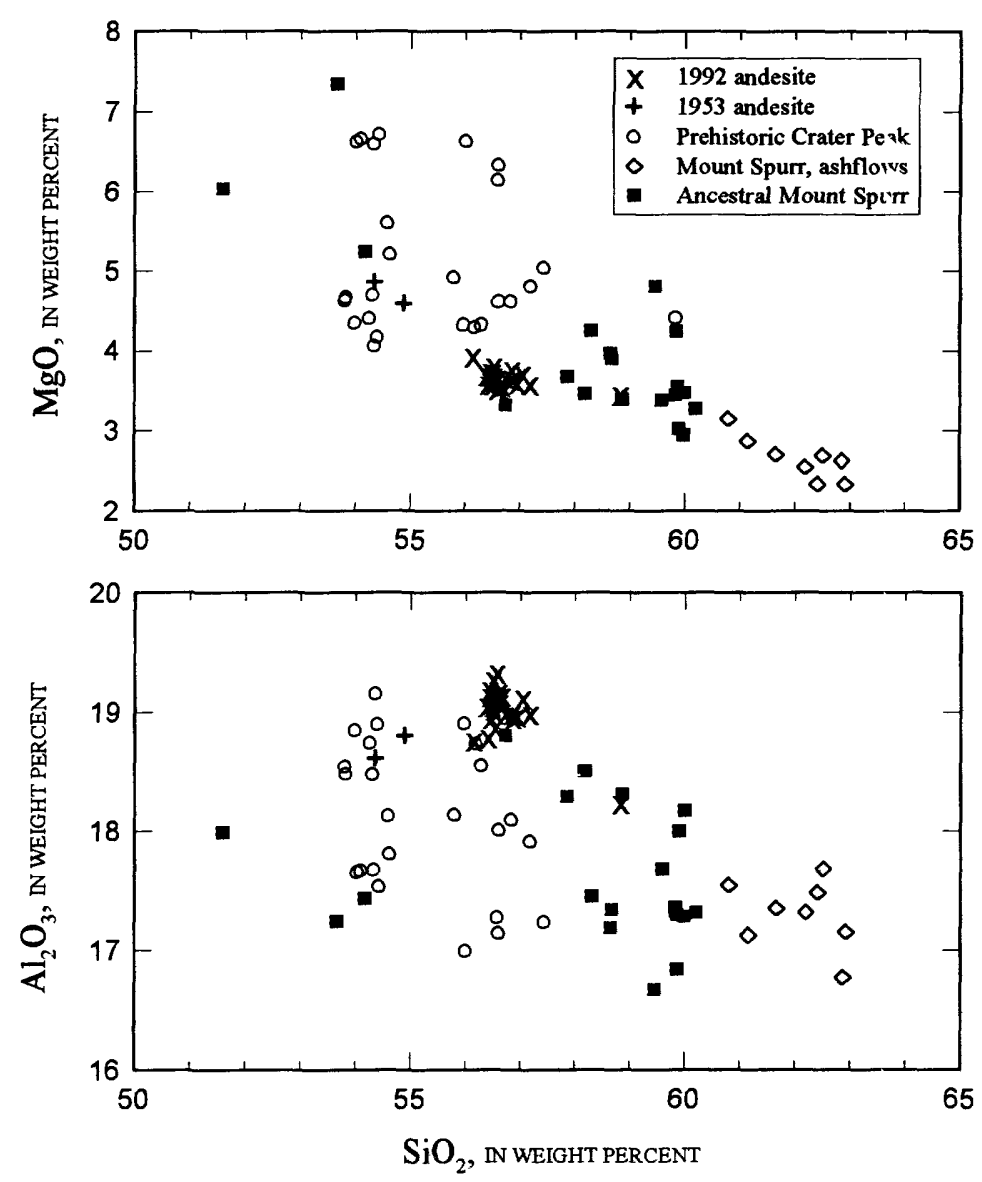


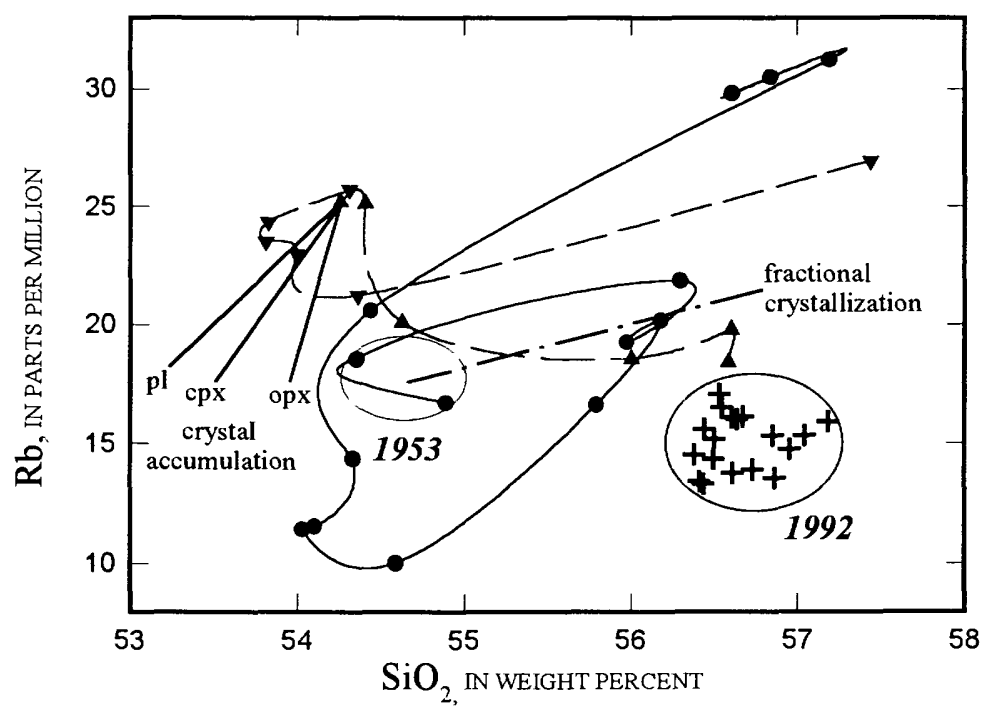

Figure 4. $\mathrm{Rb}$ (in ppm) versus $\mathrm{SiO}_{2}$ (in weight percent) for samples from the Crater Peak vent of Mount Spurr volcano, Alaska. Pre-1992 samples are discussed in Nye and Turner (1990). The plot also shows data from east (inverted triangles) and west (upright triangles) ancestral Crater Peak and the current Crater Peak (filled circles). Lines connecting symbols represent stratigraphic order, with the most siliceous end of each line being the oldest.

crease to the amount of fractionation. If the 1992 andesite was derived by simple fractional crystallization of the 1953 magma, then about 16 to 19 percent (by weight) of crystals would have to have separated and the concentrations of $\mathrm{Rb}$ should have increased to about $21 \mathrm{ppm}$, compared to the $15 \mathrm{ppm} \mathrm{Rb}$ in the 1992 andesite. The differences in $\mathrm{Rb}$ between 1953 and 1992 andesite are also unlikely to be have been produced by open-system processes such as fractionation combined with crustal assimilation, which also causes increasing $\mathrm{Rb}$ with increasing $\mathrm{SiO}_{2}$.

Andesite from 1953 is also unlike 1992 andesite in its high $\mathrm{Ti}, \mathrm{Mg}, \mathrm{Sc}, \mathrm{Cr}$, and $\mathrm{Ni}$. Some or all of this is to be expected because the 1953 andesite has lower $\mathrm{SiO}_{2}$, and it is therefore less evolved.

\section{TEPHRA}

Tephra samples were analyzed in a search for compositional diversity in 1992 ejecta and to test for compositional differences between the light-colored (less dense) and dark-colored (more dense) tephra components (Neal and others, this volume). A more extended discussion is presented by Neal and others (this volume). The main conclusions are that all the light tephra and half of the dark tephra samples are identical to 1992 andesite in their concentrations of 10 major and 33 trace elements. Those dark tephra samples that are different have anomalously high $\mathrm{Cs}, \mathrm{Rb}$, and com- patible transition metals including $\mathrm{Cr}$ and $\mathrm{Ni}$. The anomalous compositions are the products of chemical heterogeneities on the scale of a few grams of material. When large masses ( $>50$ grams) of carefully chosen lapilli were crushed together, the anomalous compositions were not found. The contaminant has $r$ t yet been identified, but it is not small fragments of the xenoliths discussed in the next section.

\section{XENOLITHS}

\section{ALUMINOUS CORDIERITE- AND SILLIMANITE-BEARING XENOLITHS}

1992 ejecta also include a minor proportion of xenoliths. These are partially fused metamorphic rocks with 60 to 70 percent $\mathrm{SiO}_{2}$, which contain glass, plagioclase, and some combination of cordierite, sillimanite, garnet, biotite, pyroxene, and spinel. Their bulk compositions fall off the trend of Mount Spurr lavas toward high $\mathrm{Ti}, \mathrm{Fe}, \mathrm{K}, \mathrm{Cs}, \mathrm{Rb}, \mathrm{Ba}, \mathrm{REE}, \mathrm{Nb}, \mathrm{Ta}$ (but not $\mathrm{Zr}$ and $\mathrm{Hf}$ ), $\mathrm{Y}, \mathrm{U}, \mathrm{Th}, \mathrm{Pb}, \mathrm{V}, \mathrm{Cr}$, and $\mathrm{Ni}$ ard low $\mathrm{Na}, \mathrm{Ca}$, and $\mathrm{Sr}$ (table 3, figure 5). The bulk-xenolith composition may not reflect the composition of the protolith because the liquid (now glass) may have moved with respect to the crystal residue. Additional work on glass separates is in progress. The high transition metal concentrations and low $\mathrm{Na}$ make it unlikely that xenoliths such as these have been routinely 


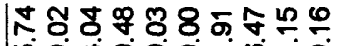
hं है

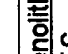
뜅우 ตั้

\$ هิ-

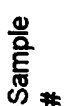

능종ํำ ڤั

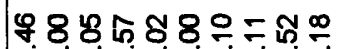

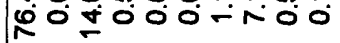

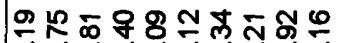

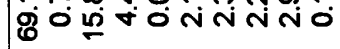
电只 80 ஸू०

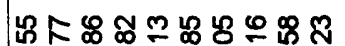

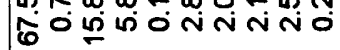

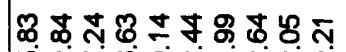

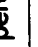

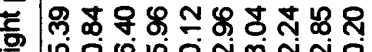

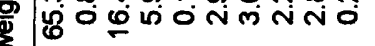
ᄃ

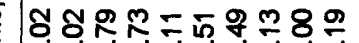
UัN

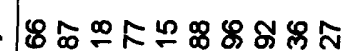
广ั0.

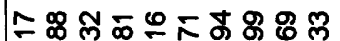
ஜํㄴำ

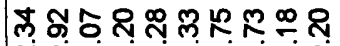

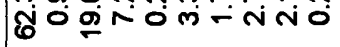

ชั

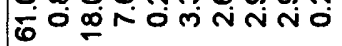

攺安 İ

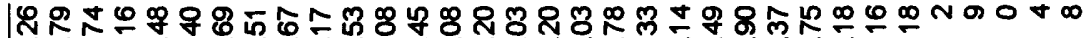
年

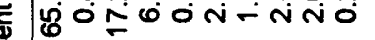

क

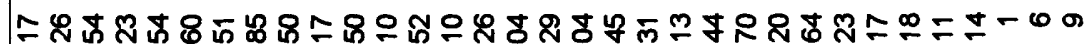

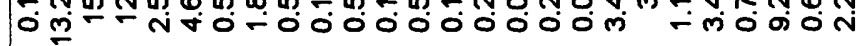

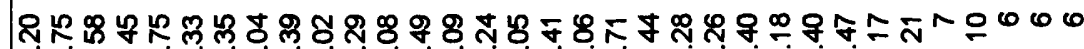

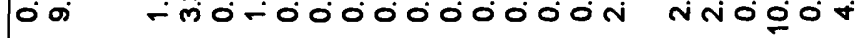

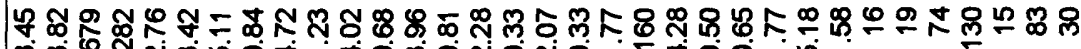
m

饮

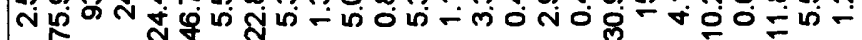

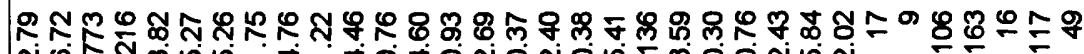
Ne

ㄷำ \&

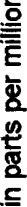
总

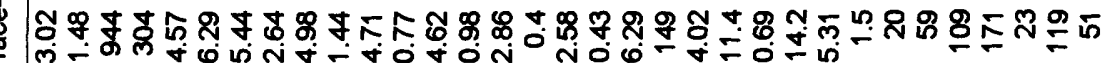
운

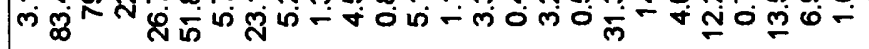

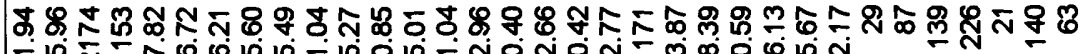
药

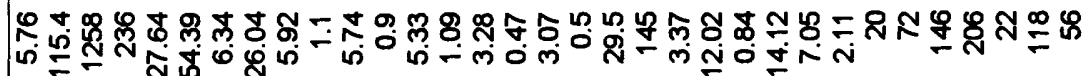

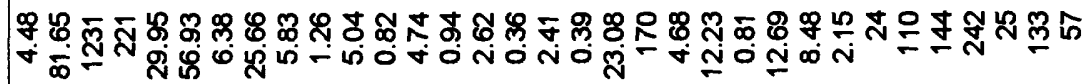

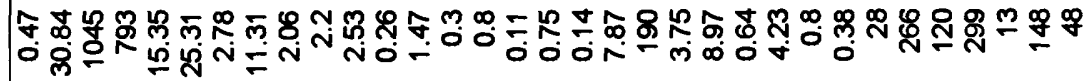

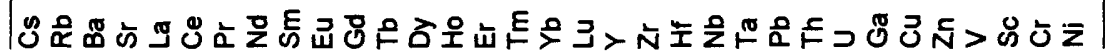


assimilated by Mount Spurr magmas. Nye and Turner (1990) appealed to a large-ion lithophile element (LILE)-rich, high-field-strength element (HFSE)- and heavy rare-earth element (HREE)-poor crustal contaminant in Spurr magmas. This component could logically be derived from small degrees of partial melting of country rock leaving such phases as garnet, spinel, zircon, and rutile in the residue. Whereas these xenoliths are not that component, their glass may be.

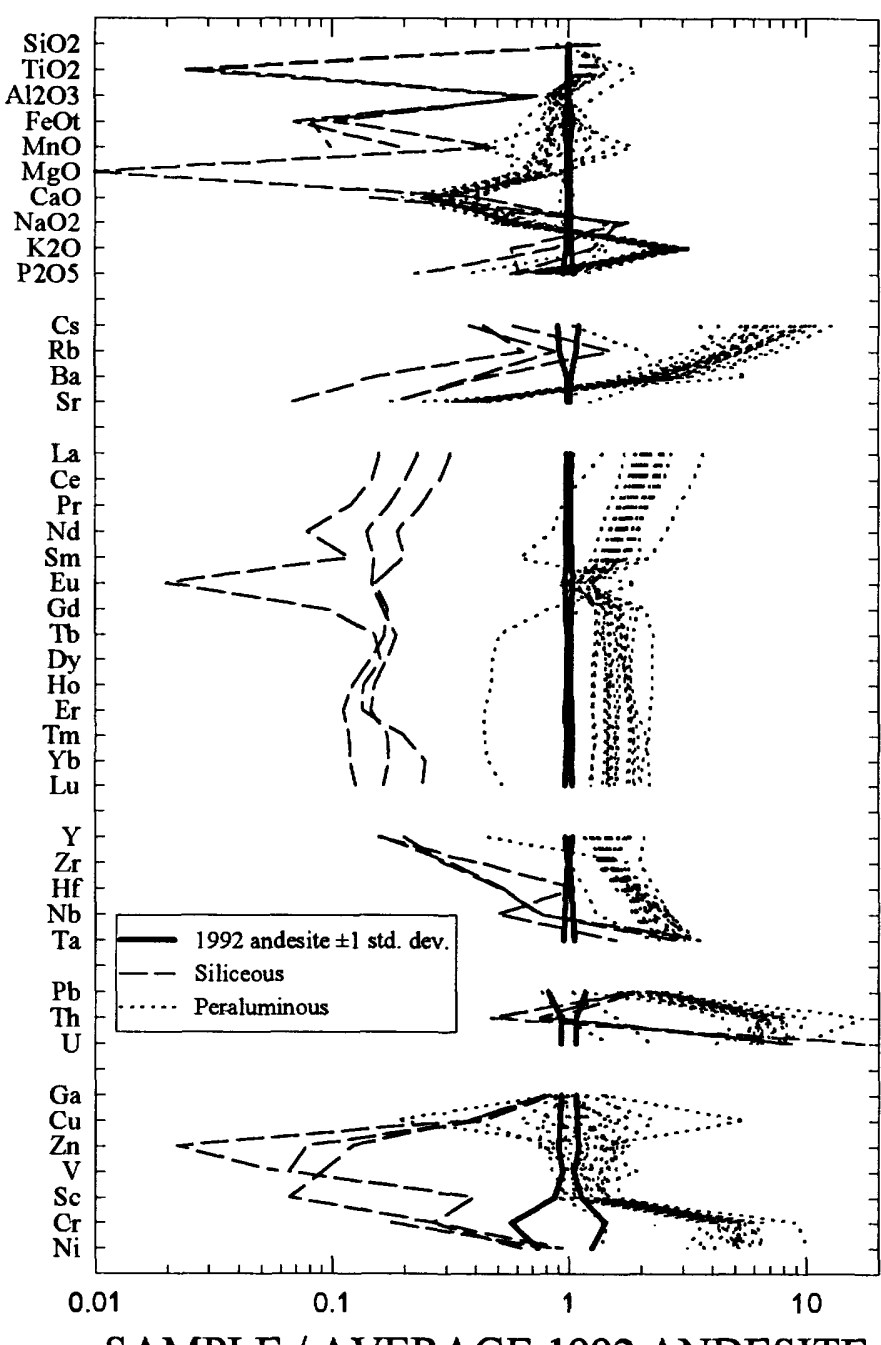

SAMPLE / AVERAGE 1992 ANDESITE

Figure 5. Compositions of aluminous and siliceous xenoliths compared to the mean composition of 1992 andesite. Each xenolith sample was normalized to the mean of all 1992 juvenile andesite blocks. $\mathrm{FeO}_{\mathrm{t}}$ is total iron as $\mathrm{FeO}$.

\section{SILICEOUS XENOLITHS}

A few siliceous, bright white, plagioclase-quartzglass xenoliths of uncertain parentage also occur. They make up a very small percentage of erupted material. They have rhyolitic $\mathrm{SiO}_{2}$ (table 3), but they are strongly depleted in all elements except $\mathrm{Na}, \mathrm{Rb}, \mathrm{Ta}, \mathrm{U}$, and $\mathrm{Ni}$ (fig. 5). Both mobile and immobile trace elements are depleted. Concentrations of $\mathrm{K}, \mathrm{Rb}, \mathrm{Ba}, \mathrm{Zr}$, and $\mathrm{Y}$ are all very low; they average around 0.8 percent, 17 ppm, $130 \mathrm{ppm}, 36 \mathrm{ppm}$, and $2 \mathrm{ppm}$, respectively. For comparison, concentrations of these elements in Novarupta rhyolites, are 3.2 percent, $63 \mathrm{ppm}, 901 \mathrm{ppm}$, $150 \mathrm{ppm}$, and $48 \mathrm{ppm}$ (Hildreth, 1983; Nye, unpublished data). The siliceous xenoliths are unlikely to represent crustal minimum melts or any kind of a hightemperature crustal distillate, particularly bec ause of their low LILE. The parents to these xenoliths may be some highly depleted protolith, such as hydrothermal veins, or they may be strongly leached rock of some other lithology. Xenoliths that are macroscopically similar to these are also found in prehistoric Crater Peak andesites.

\section{REFERENCES CITED}

Kienle J., Swanson, S.E., and Pulpan, H., 1983, Magmatism and subduction in the eastern Aleutian Arc, in Shimozuru, D., and Yokoyama, I., eds., Arc Volcanism: Physics and Tectonics: Terra Scientific Publishing Co. Tokyo, Japan. p. 191224.

Nye, C.J., and Turner, D.L., 1990, Petrology, geochemistry, and age of the Spurr volcanic complex, eastern Alettian arc: Bulletin of Volcanology, v. 52, p. 205-226.

Riehle, J.R., 1985, A reconnaissance of the major Holoce $า$ tephra deposits in the upper Cook Inlet region, Alaska: Juurnal of Volcanology and Geothermal Resources, v. 26, p. 37-74.

Wilson, F.H., Detterman, R.L., and Case, J.E., 1985, Tre Alaska Peninsula terrane: A definition: U.S. Geological Survey Open-File Report 85-450, 17 p. 


\title{
Use of Volcanic Glass from Ash as a Monitoring Tool: An Example from the 1992 Eruptions of Crater Peak, Mount Spurr Volcano, Alaska
}

\author{
By Samuel E. Swanson, Michelle L. Harbin, and James R. Riehle
}

\section{CONTENTS}

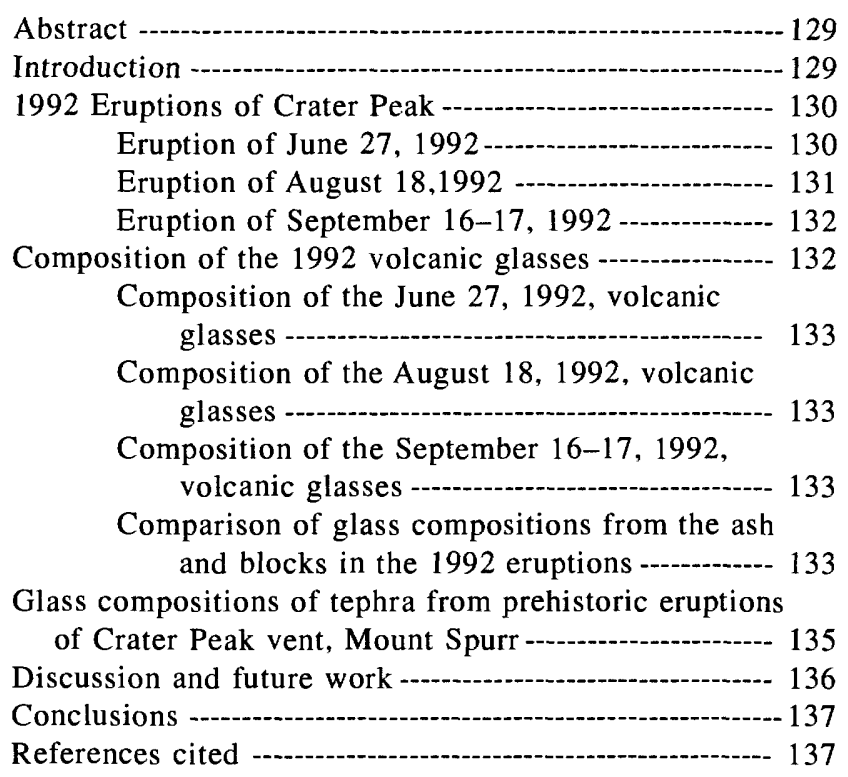

\begin{abstract}
Compositions of volcanic glass from ash ejected during the 1992 eruptions of the Crater Peak vent of Mount Spurr are dominantly andesitic $\left(\mathrm{SiO}_{2}\right.$ of 61 62 weight percent), but they include much smaller amounts of dacitic ( $\mathrm{SiO}_{2}$ of 63-69 weight percent) and rhyolitic ( $\mathrm{SiO}_{2}$ of 74-77 weight percent) glass. In each eruption (June, August, and September), glass in the ash and matrix glass in rocks from proximal deposits show similar chemical trends.

The rhyolitic glass component was first recognized in the ash from the June 27, 1992, eruption of Crater Peak. Subsequent work on proximal samples resulted in the identification of rhyolitic glasses in the matrices of juvenile volcanic blocks and in partially melted metamorphic xenoliths (buchites). Reexamination of prehistoric tephra materials from Crater Peak reveals a similar rhyolitic component; this
\end{abstract}

discovery suggests that generation of minor amounts of silica-rich melt is common at Crater Peak. Re bid analysis of volcanic glass in ash from the 1992 Crater Peak eruptions proved a useful monitor of the chsmistry of the erupting magma.

\section{INTRODUCTION}

Volcanic ash is a common component of eruptions of andesitic magmas. The ash can be hazardous, especially to aircraft and other air-filtering cultural activities (Swanson and Kienle, 1988; Casadevall, 1992). Volcanic ash is fine-grained material that enters the air during an eruption. Ash may be injected into the atmosphere directly as part of the explosive phase of the eruption or as an elutriating cloud from advancing pyroclastic flows or avalanches. Materials in the ash are typically glass (quenched melt) as vell as mineral and rock fragments. The mineral and rock fragments may be juvenile magmatic material or part of the vent fill, crater, or conduit walls that were entrained during eruption.

Petrologists have been reluctant to monitor the petrologic evolution of volcanic systems using ash because of the potential for mechanical sorting during ash transportation and deposition (Steen-McIntyre, 1977). Another problem is the heterogeneity of ash; it may contain various proportions of rock fragments, mineral grains, and volcanic glass, any of which can be accidental or comagmatic. Even so, ash can be eaily sampled and can provide samples of erupted material before proximal materials can be sampled. Volcanic ash can also reveal something about the nature of the ongoing eruption (that is, whether or not new magma is involved, Swanson and others, 1991). Bulk compositions of volcanic ash are subject to sorting or contamination, however, compositions of individual phases within the ash may provide important clues about an erupting magmatic system, especially if one can demonstrate that the phase is clearly a juvenile magmatic product. 
The glass phase (quenched melt) in the ash is a sensitive monitor of the magmatic conditions during an eruption (Swanson and others, 1991). Most, if not all, the glass in andesitic ash represents the fractionated melt after crystallization of some mineral phases. Accordingly, the composition of the melt is controlled by the mineralogy and proportion of the crystallizing phases, which, in turn, are controlled by magmatic conditions (for example, temperature, pressure, water content, and oxygen fugacity). Using the morphology of glass particles (delicate, vesicular, often shard-like), it is relatively easy to identify juvenile material in the ash. Small differences in glass compositions produced by different fractionating mineral assemblages can quickly and routinely be measured using an electron microprobe. Glass compositions from different eruptions will be different depending on the fractionation process, and there may even be changes in glass compositions during an eruption. This lesson was learned from numerous tephra studies of individual eruptions (Mount St. Helens, Scheidegger and Federman, 1982; Pinatubo, Pallister and others, 1992; 1912 Novarupta, Federman and Scheidegger, 1984, Avery, 1992; Redoubt Volcano 1989-90 eruption, Swanson and others, 1994).

Volcanic glass is generally enriched in incompatible components with respect to the bulk-rock composition (see Swanson and others, 1994). Thus it is common for andesite to have a matrix glass with a rhyolitic composition produced by crystallization of plagioclase, pyroxenes, FeTi oxides, and perhaps hornblende from the bulk magma.

If glass in volcanic ash is used to monitor magmatic systems during volcanic eruptions, then it must be established that changes in the magmatic system are clearly reflected in the glass chemistry in a timely fashion. During the 1989-90 eruptions of Redoubt Volcano, there was a change from bimodal dacite-rhyolite matrix glass early in the eruption to solely rhyolite matrix glass (Swanson and others, 1994). This change in matrix glass compositions (determined from blocks and pumice bombs) was perfectly mimicked by the glass in the volcanic ash (Swanson and others, 1991).

Questions about the nature of the erupting material and what that means in terms of eruption phenomena are some of the first questions asked during the early stages of a volcanic eruption (Sarna-Wojcicki and others, 1981). Recognition of juvenile magmatic material (typically represented by glass) in an eruption can result in an upgrading of the hazard assessment for that event (Fiske, 1984). Some workers (Sparks and others, 1977; Gourgaud and others, 1989; Pallister and others, 1992) think that magma mixing is an important triggering process in some eruptions.
Thus, the timely recognition of mixed magma during an eruption may indicate a higher hazard level than for single-magma eruptions.

Volcanic ash provides an ideal material for monitoring magmatic changes during an eruption. Glass compositions in the Redoubt ashes (measured after the eruption) reflected changes in the magmatic system. This observation prompted us to consider using volcanic ash glass compositions as a way of moritoring magmatic changes during a protracted volcanic eruption (Swanson and others, 1991). We developet techniques for rapid sample preparation and analysis of glass from volcanic ash. The eruption of Crater Peak in 1992 provided the opportunity to test our technique of monitoring an ongoing volcanic eruption usirg glass from volcanic ash.

\section{ERUPTIONS OF CRATER PFAK}

Crater Peak, a vent on the flank of Mount Spurr volcano, erupted three times during the summer and fall of 1992 (Eichelberger and others, this volume). The eruptions were from the same vent that last erupted in 1953 (Juhle and Coulter, 1955). Each of the eruptions was similar to the 1953 event: a moderate subplinian eruption that lasted for several hours and then stopped. Each of the eruptions was accombanied by a large ash cloud that was carried upward from 6 to $15 \mathrm{~km}$ and was then dispersed to the north and east by prevailing winds (Neal and others, this volume). Pyroclastic flows accompanied the eruptions in August and September, and ash was producet from these flows (Miller and others, this volume).

\section{ERUPTION OF JUNE 27, 1992}

Ash from the June 27 eruption came from an erupting column with a maximum height estimated by radar to be $14.5 \mathrm{~km}$ (Rose and others, this volume). Prevailing winds carried the ash north over Mount McKinley, just west of Fairbanks, and over the Yukon River just downstream from Fort Yukon on June 27 (Neal and others, this volume).

The ash provided the first material from the June 27 eruption for analysis. Samples of the ash were obtained from near the volcano and from distal sites (200 to $450 \mathrm{~km}$ north of Mount Spurr) in the Mount McKinley area, Lake Minchumina, and Manley Hot s prings. All of the ash samples are similar. Maximum grain size of the ash is about $0.4 \mathrm{~mm}$ within $50 \mathrm{~km}$ of the volcano and 0.11 to $0.13 \mathrm{~mm}$ in the distal samples from beyond Mount McKinley. Most of the ash is composed of dark-brown to black porphyritic volcaric rock 
fragments. The rock fragments contain micrphenocrysts set in a groundmass of brown glass with abundant microlites. Isolated phenocryst fragments are also found in the ash. Plagioclase is the most common phenocryst phase, but small amounts of augite, hypersthene, hornblende, and FeTi oxides are also present in the ash and in the volcanic rock fragments. The hornblende is pleochroic from green to brown. Colorless, microlitefree blocky or microvesicular fragments of glass are rare (much less than 1 percent).

At first, shortly after the eruption, it was not clear whether juvenile magmatic material had been erupted. However, the presence of delicate shards of colorless glass (fig. 1) that could not have survived "recycling" in this eruption confirmed the presence of at least some juvenile material in the eruptive products. Subsequent geochemical work (Nye and others, this volume) shows the eruptive products are compositionally distinct from other recent Mount Spurr lavas.

The June ash is a fine-grained version of the blocks deposited near the volcano both in terms of mineralogic composition and relative abundance. Most of the proximal lapilli and blocks deposited on June 27 consist of black, vesicular andesite, but rare (much less than 1 percent) white to light-gray compositionally banded pumice lapilli are also present (Harbin and others, this volume). The dark andesite contains phenocrysts set in a matrix of brown glass with abundant microlites, whereas the light-colored pumice lapilli contain phenocrysts in a matrix of colorless, microlitefree glass. Details of the petrography are given in Harbin and others (this volume). Nye and others (this volume) discuss the bulk geochemistry of the pumice and andesite.

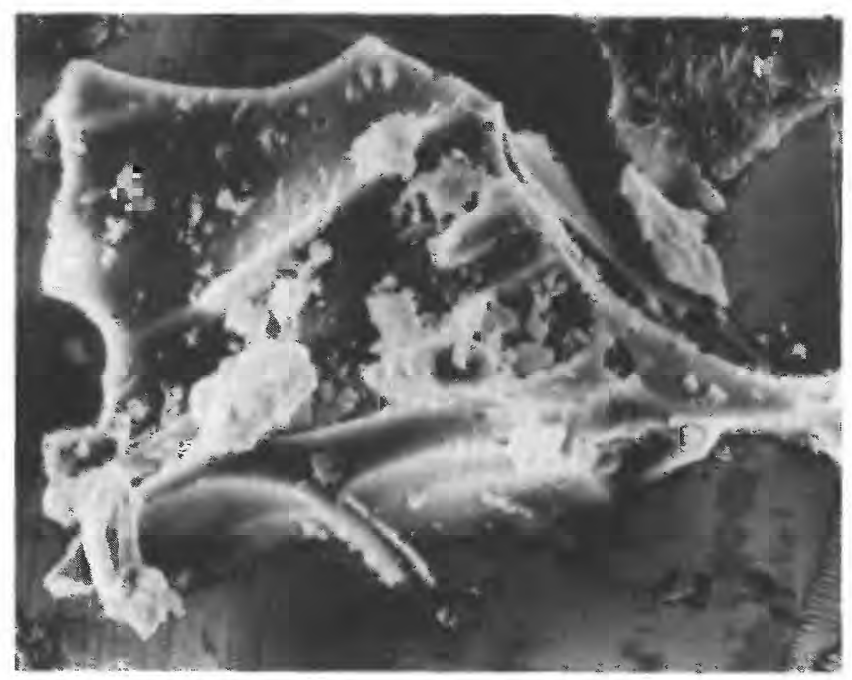

\section{ERUPTION OF AUGUST 18, 1992}

Strong explosive eruptions carried ash to altitudes of $15 \mathrm{~km}$ during the eruption of Crater Peak on August 18, 1992. Winds carried the ash east, directly over Anchorage (Neal and others, this volume) and then to the south and east over southeastern Alaska.

With the fall of ash on Anchorage, collection of ash samples was easy. One suite of samples (AVOPAT) was collected over timed intervals (about 30 to 60 minutes) as the ash fell on the patio of the Alaska Volcano Observatory at Gould Hall, $124 \mathrm{~km}$ downwind from the volcano. Most of the ash fell during a period of about 3 hours.

Initial maximum grain size of the ash at Anchorage was about $0.5 \mathrm{~mm}$ in diameter, and it decreased to about $0.3 \mathrm{~mm}$ by the end of the ash fall. The color of the ash also changed from a light yellowish-brown to a darker gray-brown by the end of the eruption. The lighter color appears to be partly the result of light-gray, fine-grained ash that coats the darker, larger fragments and partly the result of a difference in vesicularity.

The ash consists of dense, dark volcanic rock fragments with phenocrysts of plagioclase, pyroxene, hornblende, and FeTi oxides in a matrix of brown glass rich in microlites. Fragments of these same phenocrysts are also found in the ash. The amount of plagioclase crystal fragments is greatest followed by pyroxene, hornblende, and FeTi oxides. These observations are based on visual estimates. About 1 percent of the ash is composed of microvesicular or blocky fragments of colorless microlite-free glass. There is no apparent variation in the proportions of these phases within the suite of ash samples collected during the 3-hour ashfall.

The August 18 ash is virtually identical to the ash from the June eruption and the variation in the ash also mimics the variation in the bombs and blocks deposited near the volcano. Black, breadcrusted bombs of andesite and lighter vesicular greenish-gray andesite blocks are the most common component in the lahar and pyroclastic-flow deposits (Miller and others, this volume) from the August eruption. This black andesite corresponds to the dark volcanic rock fragments in the ash, but the vesicular greenish-gray andesite does not have an obvious counterpart in the ash. Details of andesite petrography are given by Harbin and others (this volume), and Nye and others (this volume) discuss the bulk composition of the andesite.

Figure 1. Secondary electron image of a rhyolitic glass shard from ash of the June 27, 1992, eruption of Crater Peak taken with an electron microprobe at the University of Alaska, Fairbanks by Michelle Harbin. White scale bar is $20 \mu \mathrm{m}$. 
Table 1. Composition of glass from volcanic ash and pumice lapilli erupted on June 27, 1992, from Crater Peak vent, Mount Spurr volcano, Alaska.

[*, total $\mathrm{Fe}$ as $\mathrm{FeO}$; number of points analyzed in parentheses below sample number]

\begin{tabular}{|c|c|c|c|c|c|c|c|c|}
\hline \multirow[b]{2}{*}{ Sample no. } & \multicolumn{2}{|c|}{ Volcanic ash } & \multicolumn{6}{|c|}{ Pumice lapilli } \\
\hline & $\begin{array}{l}\text { SS-2 } \\
\text { (13) }\end{array}$ & $\begin{array}{l}\text { SS-2 } \\
\text { (1) }\end{array}$ & $\begin{array}{c}\text { JB-4A } \\
\text { (9) }\end{array}$ & $\begin{array}{c}\text { JB4B1 } \\
\text { (6) }\end{array}$ & $\begin{array}{c}\text { JB-4B2 } \\
(21)\end{array}$ & $\begin{array}{c}\text { JB-4B2 } \\
\text { (15) }\end{array}$ & $\begin{array}{c}\text { JB-4B3 } \\
\text { (14) }\end{array}$ & $\begin{array}{c}\text { JB-4B3 } \\
\text { (19) }\end{array}$ \\
\hline glass color & brown & colorless & colorless & colorless & colorless & light brown & colorless & brown \\
\hline $\mathrm{SiO}_{2}$ & $60.51 \pm 0.93$ & 76.60 & $74.28 \pm 1.26$ & $75.66 \pm 1.37$ & $71.59 \pm 1.23$ & $67.41 \pm 1.45$ & $75.87 \pm 1.37$ & $61.00 \pm 0.80$ \\
\hline $\mathrm{TiO}_{2}$ & $.60 \pm 0.25$ & 0.37 & $0.40 \pm 0.18$ & $0.19 \pm 0.13$ & $0.33 \pm 0.13$ & $0.44 \pm 0.12$ & $0.22 \pm 0.14$ & $0.62 \pm 0.14$ \\
\hline $\mathrm{Al}_{2} \mathrm{O}_{3}$ & $17.22 \pm 1.00$ & 12.60 & $13.40 \pm 0.95$ & $12.16 \pm 0.87$ & $14.41 \pm 0.48$ & $15.06 \pm 0.55$ & $12.45 \pm 1.47$ & $16.97 \pm 0.69$ \\
\hline $\mathrm{FeO}^{*}$ & $6.46 \pm 0.89$ & 1.11 & $2.31 \pm 0.30$ & $1.24 \pm 0.11$ & $2.60 \pm 0.42$ & $4.28 \pm 0.52$ & $0.85 \pm 0.25$ & $6.23 \pm 0.71$ \\
\hline $\mathrm{MgO}$ & $2.34 \pm 0.85$ & 0.24 & $0.50 \pm 0.08$ & $0.15 \pm 0.03$ & $0.55 \pm 0.08$ & $1.04 \pm 0.16$ & $0.18 \pm 0.15$ & $2.56 \pm 0.48$ \\
\hline $\mathrm{CaO}$ & $5.45 \pm 0.61$ & 0.37 & $1.01 \pm 0.25$ & $0.66 \pm 0.12$ & $1.28 \pm 0.38$ & $3.02 \pm 0.38$ & $0.79 \pm 0.15$ & $5.85 \pm 0.31$ \\
\hline $\mathrm{Na}_{2} \mathrm{O}$ & $4.35 \pm 0.34$ & 3.54 & $2.56 \pm 0.14$ & $0.80 \pm 0.36$ & $3.27 \pm 0.31$ & $3.72 \pm 0.52$ & $0.42 \pm 0.13$ & $4.36 \pm 0.44$ \\
\hline $\mathrm{K}_{2} \mathrm{O}$ & $1.36 \pm 0.10$ & 4.99 & $4.40 \pm 0.14$ & $6.83 \pm 0.40$ & $3.99 \pm 0.30$ & $2.67 \pm 0.16$ & $7.06 \pm 0.33$ & $1.43 \pm 0.45$ \\
\hline $\mathrm{Cl}$ & $0.21 \pm 0.04$ & 0.17 & $0.02 \pm 0.01$ & $0.04 \pm 0.02$ & $0.03 \pm 0.03$ & $0.15 \pm 0.04$ & $0.11 \pm 0.03$ & $0.21 \pm 0.03$ \\
\hline total & 98.50 & 99.98 & 98.88 & 98.74 & 98.05 & 97.79 & 97.97 & 98.74 \\
\hline
\end{tabular}

Buchites, partially melted blocks of metamorphic rocks, form pumiceous blocks in the proximal August deposits (Harbin and others, this volume). Highly vesicular, colorless, microlite-free glass is present in all of the buchites, and it ranges in abundance from trace to 30 percent. The glass in the buchites is identical in appearance to the small amounts of colorless glass found in the ash.

\section{ERUPTION OF SEPTEMBER 16-17, 1992}

The major phase of the September eruption of Crater Peak began just after midnight local time on September 17,1992 . A series of violent explosions again carried ash high into the air. Winds carried ash to the east, to the north of Anchorage, and eventually into the Yukon Territory of Canada.

Ash was sampled at 45 and $110 \mathrm{~km}$ downwind from Crater Peak. The ash that fell $45 \mathrm{~km}$ downwind from the volcano had a maximum grain size of $0.7 \mathrm{~mm}$, whereas the ash that fell $110 \mathrm{~km}$ downwind had a maximum grain size of $0.5 \mathrm{~mm}$. Petrographically, the ash from both sites is very similar. Blocky fragments of porphyritic andesite (containing fragments of phenocrysts of plagioclase, hornblende, augite, hypersthene, and FeTi oxides in a matrix of brown glass with abundant microlites) were the most common constituent of the ash. Isolated grains of the phenocryst minerals were also common as angular fragments in the ash. A few grains of quartz and cordierite were also found in this ash during microprobe analysis. Fragments of colorless, microlite-free, highly vesiculated glass with a few plagioclase microphenocrysts were noted in the finer grained (about $0.5 \mathrm{~mm}$ ) fraction of the ash.
Blocks from the September eruption show the same pattern of petrographic variation as observed in the ash. Dense, black glassy blocks of andesite contain phenocrysts in a matrix of light-brown glass with abundant microlites. Some blocks of light-gray andesite contain phenocrysts in a matrix of colorless glass rich in microlites of plagioclase, pyroxene, and FeTi oxides. Buchites, similar to those from the August deposits, were also erupted in September. Harbin and others, and Nye and others (both this volume) provide more information on the petrology and geochemistry of the andesites.

\section{COMPOSITION OF THE 1992 VOLCANIC GLASSES}

Compositions of volcanic glass from each of the Mount Spurr eruptions were determined by electron microprobe at the University of Alaska Fairbanks. Glasses from the 1992 eruptions were analyzed on a four-channel electron microprobe using an $8 \mu \mathrm{m}$ beam at $15 \mathrm{Kev}$ with a $10-\mathrm{sec}$ counting time and a 0.01 microamp sample current. Natural glasses were used as standards. The analytical routine was designed to minimize alkali loss in these relatively anhydrous glasses. Experience with this same analytical routine on the Redoubt glasses (Swanson and others, 1994) showed no significant alkali loss occurs during the analytical routine when sodium is measured (first 10 seconds of the analysis). All of the analyses were made on polished grain mounts of the ash. Multiple points were selected for analysis (one point per grain) and the microprobe was run in the automated mode. Analy- 
ses that obviously included mineral grains and glass were eliminated from the data set, as were analyses with totals outside of the range 98 to 101 weight percent oxide.

Compositions of the prehistoric tephra glasses were determined on a nine-channel microprobe at a U.S. Geological Survey laboratory. The glasses were analyzed at $15 \mathrm{keV}$, with a 10 -second counting time, 0.01 -microamp sample current, and a beam size of $10 \mu \mathrm{m}$. Natural glasses were used as standards and rhyolitic glass was analyzed repeatedly as an internal standard. Somewhat lower analytical totals (96-99 weight percent) for the prehistoric glasses are probably related to the hydration of these glasses.

\section{COMPOSITION OF THE JUNE 27, 1992, VOLCANIC GLASSES}

Both proximal and distal tephra samples were analyzed from the eruption of June 27,1992 . The distal sample (SS-2) was collected from Manley Hot Springs, approximately $450 \mathrm{~km}$ north of the Crater Peak vent on Mount Spurr. Proximal samples (JB-4A, JB-4B 1, JB-4B2, and JB-4B3) consisted of small pumice lapilli and were collected a few kilometers north of Crater Peak.

The ash and pumice lapilli both contain a heterogeneous suite of glass compositions (table 1). The common brown glass with abundant microlites is typically andesitic with an $\mathrm{SiO}_{2}$ content of about 61 weight percent (columns 1 and 8 , table 1). However, brown glass in one of the pumice lapilli (JBS-4B2) is dacitic ( $\mathrm{SiO}_{2}$ of 67.4 weight percent, column 6 , table 1 ). The colorless microlite-free glass in the ash (SS-2) is rhyolitic $\left(\mathrm{SiO}_{2}\right.$ of 76.6 weight percent, column 2 , table 1). Similar microlite-free colorless rhyolitic glass is found in the pumice lapilli (columns 3, 4, 5, 7; table 1).

\section{COMPOSITION OF THE AUGUST 18, 1992, VOLCANIC GLASSES}

Glass in the ash of August 18, 1992, is heterogeneous. Three distinct populations of glass compositions are found in the ash (table 2). The most common (more than 90 percent) component is a brown microlite-rich andesitic glass $\left(\mathrm{SiO}_{2}\right.$ of about 62 weight percent, column 1, table 2). A few percent of very light brown dacitic glass $\left(\mathrm{SiO}_{2}\right.$ of 65 weight percent, column 2, table 2) with abundant microlites are also present. A rare (less than 1 percent) colorless, microlite-free rhyolitic glass $\left(\mathrm{SiO}_{2}\right.$ of about 76 weight percent, column 3, table 2) is also found in the ash erupted in August.

\section{COMPOSITIONS OF THE SEPTEMBER 16-17, 1992, VOLCANIC GLASSES}

Ash analyzed from the eruption of September 16-17, 1992 (sample 19B, table 3) was collected 110 $\mathrm{km}$ downwind from Crater Peak. The sample is a bulk sample for the entire eruption.

Four compositionally distinct glass populations are present in the September ash (table 3). Three brown dacitic glasses $\left(\mathrm{SiO}_{2}\right.$ of about 63-69 weight percent, columns 1, 2, 3, table 3) with abundant microlites are the most common, but colorless, microlite-free rhyc' ${ }^{1}$ itic glass is also present in the suite (column 4 , table 3 ).

\section{COMPARISON OF GLASS COMPOSITIONS FROM THE ASH AND BLOCKS IN THE 19?2 ERUPTIONS}

The pattern of glass compositional variation found in the ash is generally mimicked by the variation of matrix glass compositions measured in the blocks (Harbin and others, this volume). Similar results were

Table 2. Composition of glass from volcanic ash erupted on August 18, 1992, from Crater Peak vent, Mount Spurr volcano, Alaska, collected on a patio at Alaska Volcano Observatory in Anchorage.

[*, total $\mathrm{Fe}$ as $\mathrm{FeO}$; number of points analyzed in parentheses below sample number; AVOPAT, patio at Alaska Volcano Observatory]

\begin{tabular}{|c|c|c|c|}
\hline Sample no. & $\begin{array}{c}\text { AVO-PAT } \\
(107)\end{array}$ & $\begin{array}{c}\text { AVO-PAT } \\
\text { (18) }\end{array}$ & $\begin{array}{c}\text { AVO-PAT } \\
\text { (12) }\end{array}$ \\
\hline glass color & brown & light brown & colorless \\
\hline $\mathrm{SiO}_{2}$ & $62.25 \pm 1.32$ & $65.49 \pm 0.92$ & $75.93 \pm 1.36$ \\
\hline $\mathrm{TiO}_{2}$ & $0.59 \pm 0.17$ & $0.59 \pm 0.11$ & $0.35 \pm 0.17$ \\
\hline $\mathrm{Al}_{2} \mathrm{O}_{3}$ & $16.45 \pm 1.11$ & $15.62 \pm 1.16$ & $12.55 \pm 0.45$ \\
\hline $\mathrm{FeO}^{*}$ & $5.62 \pm 0.96$ & $4.82 \pm 1.1 \mathrm{I}$ & $2.29 \pm 0.28$ \\
\hline MgO - & $2.01 \pm 0.61$ & $1.36 \pm 0.48$ & $0.46 \pm 0.05$ \\
\hline $\mathrm{CaO}$ & $5.37 \pm 0.58$ & $4.42 \pm 0.51$ & $0.91 \pm 0.10$ \\
\hline $\mathrm{Na}_{2} \mathrm{O}$ & $5.26 \pm 0.33$ & $5.32 \pm 0.40$ & $3.06 \pm 0.16$ \\
\hline $\mathrm{K}_{2} \mathrm{O}$ & $1.39 \pm 0.19$ & $1.80 \pm 0.25$ & $4.07 \pm 0.27$ \\
\hline 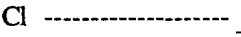 & $0.20 \pm 0.05$ & $0.23 \pm 0.07$ & $0.02 \pm 0.01$ \\
\hline Total -.-.-...... & 99.14 & 99.62 & 99.64 \\
\hline
\end{tabular}


Table 3. Composition of glass from volcanic ash erupted on September 17, 1992, from Crater Peak vent, Mount Spurr volcano, Alaska.

[*, total $\mathrm{Fe}$ as $\mathrm{FeO}$; number of points analyzed in parentheses below sample number]

\begin{tabular}{|c|c|c|c|c|}
\hline Analysis no. & $\begin{array}{c}\text { 19B } \\
\text { (159) }\end{array}$ & $\begin{array}{l}19 B \\
\text { (75) }\end{array}$ & $\begin{array}{l}\text { 19B } \\
\text { (14) }\end{array}$ & $\begin{array}{l}\text { 19B } \\
\text { (14) }\end{array}$ \\
\hline glass color & brown & light brown & light brown & colorless \\
\hline $\mathrm{SiO}_{2}$ & $63.02 \pm 1.14$ & $65.61 \pm 1.00$ & $69.16 \pm 1.41$ & $73.37 \pm 1.68$ \\
\hline $\mathrm{TiO}_{2}$ & $0.53 \pm 0.16$ & $0.52 \pm 0.16$ & $0.48 \pm 0.16$ & $0.51 \pm 0.24$ \\
\hline $\mathrm{Al}_{2} \mathrm{O}_{3}$ & $16.64 \pm 1.32$ & $15.87 \pm 0.92$ & $15.71 \pm 1.68$ & $13.28 \pm 1.02$ \\
\hline $\mathrm{FeO}^{*}$ & $5.14 \pm 1.12$ & $4.65 \pm 1.04$ & $3.06 \pm 1.40$ & $2.39 \pm 1.01$ \\
\hline MgO - & $1.87 \pm 0.71$ & $1.39 \pm 0.51$ & $0.88 \pm 0.80$ & $0.46 \pm 0.46$ \\
\hline $\mathrm{CaO}$ & $5.20 \pm 0.62$ & $4.30 \pm 0.58$ & $3.20 \pm 0.96$ & $1.54 \pm 0.66$ \\
\hline $\mathrm{Na}_{2} \mathrm{O}$ & $5.34 \pm 0.36$ & $5.38 \pm 0.36$ & $5.17 \pm 0.92$ & $3.80 \pm 0.89$ \\
\hline $\mathrm{K}_{2} \mathrm{O}$ & $1.43 \pm 0.25$ & $1.80 \pm 0.51$ & $2.45 \pm 0.40$ & $4.01 \pm 1.09$ \\
\hline $\mathrm{Cl}$ & $0.20 \pm 0.06$ & $0.21 \pm 0.06$ & $0.14 \pm 0.08$ & $0.15 \pm 0.16$ \\
\hline Total -.-.-...- & 99.37 & 99.73 & 100.25 & 99.51 \\
\hline
\end{tabular}

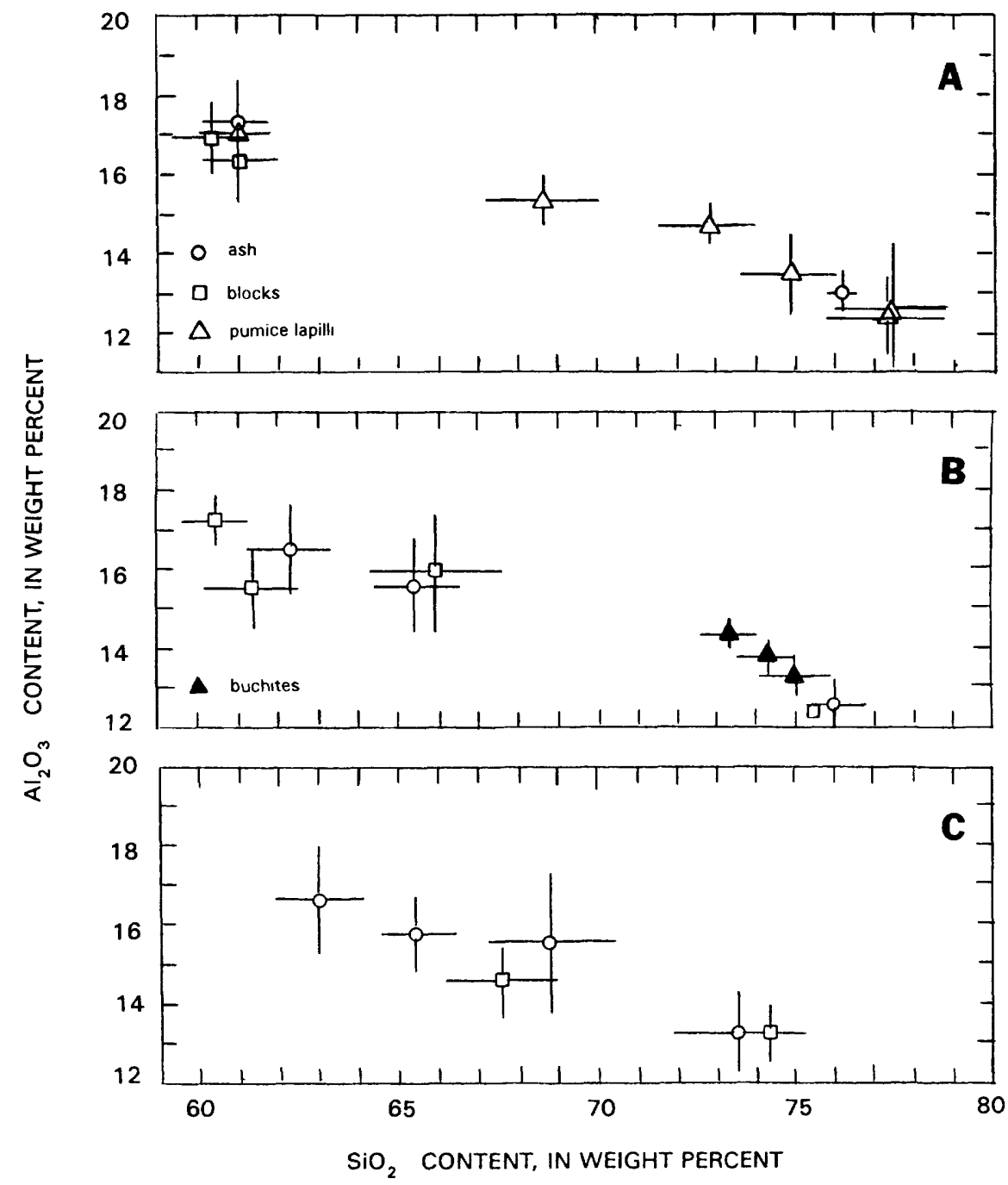

Figure 2. Glass compositions from the June 27, $1992(A), 18$ August $1992(B)$; and September 17, $1992(C)$ eruptions of Crater Peak. Bars on the points represent the one sigma standard deviations about the mean of the data. Data on blocks and buchites are from Harbin and others (this volume). Data on ash and pumice lapilli are from tables 1-3. 
found in the 1989-90 Redoubt eruption (Swanson and others, 1991) where matrix glass and glass from volcanic ash showed similar patterns of variation on the same time scale.

The June ash contains an andesitic and rhyolitic component (table 1). Comparison of these glasses to the matrix glass in blocks from the June eruption (Harbin and others, this volume) shows that the andesitic glass is derived from the dark gray to black "cauliflower" bombs noted in the proximal June deposits (Miller and others; Harbin and others, this volume). After recognition of the rhyolitic component in the June ash, a careful search was made of the June proximal deposits for possible block equivalents. A few small lapilli of light-gray pumice were found in the proximal deposits. Some of these lapilli contained bands with brown andesitic matrix glass. However, the dominant glass in the lapilli was a colorless, microlitefree rhyolite ranging from 68.6 to 76.3 weight percent $\mathrm{SiO}_{2}$ (fig. 2). The rhyolitic glass in the gray pumice lapilli is very similar to the rhyolitic glass in the ash (fig. 2).

Compositions of glass from the ash and blocks were also similar in the August eruption (fig. 2). The brown andesitic glass in the ash is represented in the blocks by the dark "cauliflower" bombs of andesite. A dacitic glass is found in the ash (table 2, column 2 ) and in a block of greenish andesite scoria (Harbin and others, this volume). The matrix glass in the andesitic scoria is very light brown and the glass contains abundant microlites. Rhyolitic glass is found in the ash (table 2, column 3), in vesicular, gray-green andesite, and in buchites in the August deposits. The graygreen andesite has colorless matrix glass without microlites and is very similar to the rhyolitic glass found in the ash (fig. 2). Glass in the buchites is also colorless and microlite-free, but is slightly lower in $\mathrm{SiO}_{2}$ than either the ash or the greenish-gray andesitic glasses (fig. 2).

Rhyolitic and dacitic glasses are found in both the ash and in the matrix of blocks produced in the
September eruption. The rhyolitic matrix glass is colorless and contains abundant microlites. Rhyolitic glass from the ash (column 4, table 3 ) is identical in composition to the rhyolitic matrix glass found in a lightgray prismatically-jointed andesite block (fig. 2). Highsilica dacitic glass (about 69 weight percent $\mathrm{SiO}_{2}$ ) is found in the September ash (table 3, column 3) and in the matrix of a black prismatic andesite block. The two high-silica dacitic glasses are very similar in composition (fig. 2). Brown, microlite-rich low-silica cacitic and high-silica andesitic glasses are found in the matrix of blocks from the September eruption (Harbin and others, this volume), and the low-silica dacitic matrix glass is similar to glass in the ash (fig. 2).

\section{GLASS COMPOSITIONS OF TEPH'A FROM PREHISTORIC ERUPTIONS OF CRATER PEAK VENT, MOUNT SPURR}

Brown andesitic glass, similar to that erupted in 1992 , is the common glass in the prehistoric tephra from Crater Peak vent of Mount Spurr (Riehle, 1985) and is easily recognized in the Quaternary deposits of south-central Alaska (Riehle, 1985; Beget and others, 1994). These are the only Cook Inlet volcanoes that have produced andesitic glass-the other Cook Inlet volcanoes produce dacitic or rhyolitic glasses (Riehle, 1985).

A volumetrically small but persistent rhyolitic glass phase is also found in the prehistoric tephra from Crater Peak (Riehle, 1985). The rhyolitic glass is colorless and microlite-free. Commonly the rhyolitic glass is vesicular. Reexamination of microprobe anclyses reveals that rhyolitic glass is present in most prehistoric Crater Peak tephra samples.

New analyses of this rhyolitic component (table 4) have been done on some prehistoric tephras to compare these rhyolitic glasses with those of the 1992 eruption. The rhyolitic glasses in the prehistor: te-

Table 4. Rhyolitic glass compositions of prehistoric basal tephras and pyroclastic-flow samples from Mount Spurr volcano, Alaska.

[*. total $\mathrm{Fe}$ as $\mathrm{FeO}$; number of points analyzed in parentheses below sample number]

\begin{tabular}{|c|c|c|c|c|}
\hline \multirow[b]{2}{*}{$\mathrm{SiO}_{2}$} & \multirow{2}{*}{$\begin{array}{l}\text { Pyroclastic flow } \\
74.58 \pm 0.75\end{array}$} & \multicolumn{3}{|c|}{ Basal tephra } \\
\hline & & $74.06 \pm 2.35$ & $74.61 \pm 1.75$ & $73.46 \pm 1.95$ \\
\hline $\mathrm{TiO}_{2}$ & $0.39 \pm 0.03$ & $0.45 \pm 0.16$ & $0.45 \pm 0.09$ & $0.46 \pm 0.07$ \\
\hline $\mathrm{Al}_{2} \mathrm{O}_{3}$ & $11.89 \pm 0.72$ & $12.57 \pm 0.44$ & $13.31 \pm 0.67$ & $12.53 \pm 1.52$ \\
\hline $\mathrm{FeO}^{*}$ & $1.45 \pm 0.14$ & $2.11 \pm 0.80$ & $1.86 \pm 0.47$ & $2.10 \pm 0.33$ \\
\hline $\mathrm{MnO}$ & $0.01 \pm 0.02$ & $0.08 \pm 0.03$ & $0.05 \pm 0.04$ & $0.06 \pm 0.03$ \\
\hline MgO & $0.13 \pm 0.06$ & $0.04 \pm 0.45$ & $0.27 \pm 0.12$ & $0.43 \pm 0.23$ \\
\hline $\mathrm{CaO}$ & $0.72 \pm 0.37$ & $1.42 \pm 0.43$ & $1.40 \pm 0.30$ & $1.48 \pm 0.66$ \\
\hline $\mathrm{Na}_{2} \mathrm{O}$ & $3.00 \pm 0.21$ & $2.97 \pm 0.36$ & $2.96 \pm 0.26$ & $2.84 \pm 0.21$ \\
\hline $\mathrm{K}_{2} \mathrm{O}$ & $4.45 \pm 0.16$ & $3.96 \pm 0.78$ & $4.01 \pm 0.17$ & $3.85 \pm 0.87$ \\
\hline Total & 96.62 & 98.02 & 98.92 & 96.94 \\
\hline
\end{tabular}


phras are very similar to those from the 1992 eruptions. All of the Crater Peak vent of Mount Spurr rhyolitic glasses are peraluminous and they show similar ranges of alkali content (fig. 3 ).

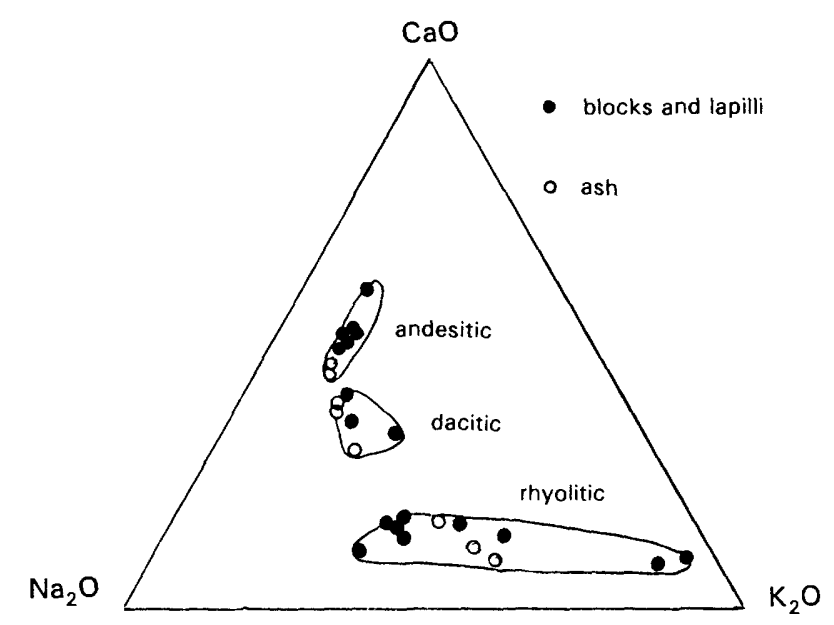

A

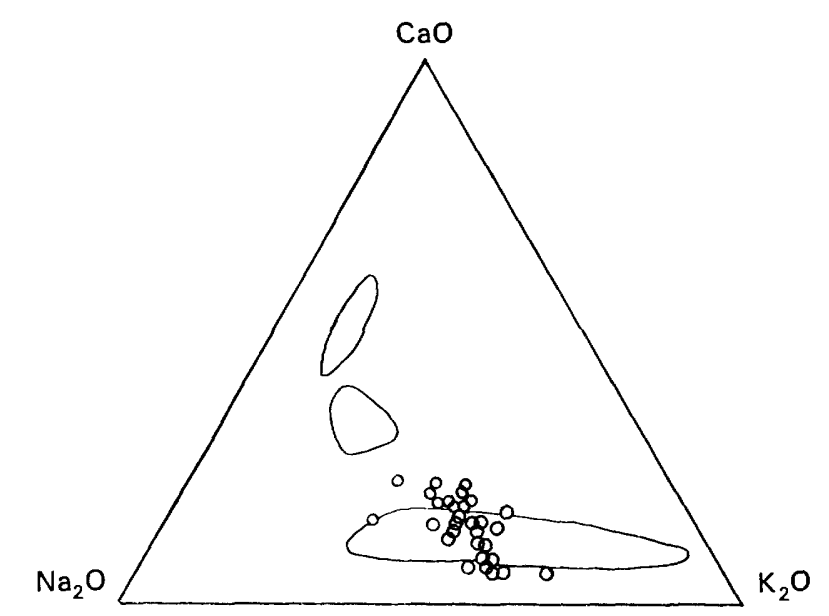

B

Figure 3. A, Compositions of the 1992 Crater Peak glasses in terms of $\mathrm{CaO}-\mathrm{Na}_{2} \mathrm{O}-\mathrm{K}_{2} \mathrm{O}$. Compositional fields outline andesitic, dacitic, and rhyolitic glasses. Data sources as in figure 2. $B$, Individual analyses (averages given in table 4) of rhyolitic glasses in prehistoric Crater Peak tephras in terms of $\mathrm{CaO}-\mathrm{Na}_{2} \mathrm{O}-\mathrm{K}_{2} \mathrm{O}$. Composition fields for the 1992 glasses are reproduced from figure $3 A$.

\section{DISCUSSION AND FUTURE WORK}

Glass compositions in the ash from the 1992 eruptions of Crater Peak provided a valuable meens of monitoring changes in the magmatic system. The glass compositions in the ash and matrix glass from l locks all show the same patterns for each of the erupt: ons.

Rhyolitic glasses similar to those in the 1992 eruption occur in prehistoric tephra from Mount Spurr and Crater Peak, indicating that the 1992 eruption was typical of other prehistoric eruptions. Rhyolitic glass occurs in ash, the matrix of blocks, and in burhites from the August 1992 eruption (fig. 2). All of these rhyolitic glasses are very similar (fig. 3), supporting an origin of the rhyolitic melt by partial melting of metamorphic basement rocks. The variable alkali contents of the rhyolitic glasses (for example, compare sodium and potassium of columns 3-8, table 1) are typical of the disequilibrium melts produced in the initial stages of melting pelitic buchites (Grapes, 1986). The occurrence of these rhyolitic glasses in prehistoric deposits suggests that similar buchites should be found in prehistoric Crater Peak deposits.

During an eruption of multiple magmas it is commonly difficult to estimate the relative proportions of each of the magmas. Glass compositions in volcanic ash provide a relatively easy technique for estimating relative proportions of magmas in an eruption. For example, table 3 shows averages of glass analyses that represent over 250 individual analyses of glass in a bulk sample of the September ash. All of the points were selected randomly in a polished grain mount. Most of the glass in the September sample is represented by low-silica dacitic compositions ( 234 out of 262 total analyses); high-silica dacitic and rhyolitic glasses each amounted to only 14 out of 262 analyses. This provides one quantitative way of determining the relative proportions of the magmatic components that erupted in September. Some caution is reeded in the application of this technique because of the potential for differential sorting of comagmatic phases in the ash clouds. The fragments of crystal-rich ardesite glass might be expected to fall closer to the volcano than the relatively crystal free shards of rhyolite glass, but this has not been apparent in the petrographic examination of proximal and distal samples. When ash can be sampled sequentially, either as it falls or from well-preserved stratigraphy within the ash layer, detailed analysis of the subsets provides useful clues to magmatic variation during an eruption. 


\section{CONCLUSIONS}

Volcanic ash provides important clues to the nature of an erupting magmatic system. The composition of glasses in the 1992 Crater Peak ashes proved that new (different from prehistoric) magma was being erupted and that a small rhyolitic component was involved in the eruption. Because the ash was dispersed great distances from the volcano, it was possible to sample the magma at safe, distal locations.

\section{REFERENCES CITED}

Avery, V.F., 1992, A petrogenetic study of the dacite from the 1912 eruption of Novarupta, Katmai National Park, Alaska: Implications for magma storage locations: M.S. thesis, University of Alaska Fairbanks, Fairbanks, Alaska, 177 p.

Beget, J.E., Stihler, S.D., and Stone, D.B., 1994, A 500-year-long record of tephra falls from Redoubt Volcano and other volcanoes in upper Cook Inlet, Alaska: Journal of Volcanology and Geothermal Research, v. 62, p. 55-67.

Casadevall, T.J., 1992, Volcanic hazards and aviation safety: Federal Aviation Administration Aviation Safety Journal, v. 2, p. 9-17.

Federman, A.N., and Scheidegger, K.F., 1984, Compositional heterogeneity of distal tephra deposits from the 1912 eruption of Novarupta, Alaska: Journal of Volcanological and Geothermal Research, v. 21, p. 233-254.

Fiske, R.S., 1984, Volcanologists, journalists, and the concerned public: A tale of two crises in the eastern Caribbean, in Explosive volcanism: Inception, evolution and hazards, Washington, D.C., National Academy Press, p. 170-176.

Gourgaud, A., Fichaut, M., and Joron, J.L., 1989, Magmatology of Mt. Pele (Martinique, F.W.I.): Magma mixing and triggering of 1902-1929 nuees ardentes, Journal of Volcanology and Geothermal Research, v. 38, p.143-169.
Grapes, R.H., 1986, Melting and thermal reconstitution of pelitic xenoliths, Wehr Volcano, East Eifel, West Germany: Jcurnal of Petrology, v. 27, p. 343-396.

Juhle, W., and Coulter, H.W., 1955, The Mt. Spurr eruption, J'ly 9 , 1953: American Geophysical Union Transactions, v. 36, p. 199-202.

Pallister, J.S., Hoblitt, R.P., and Reyes, A.G., 1992, A basalt trigger for the 1991 eruptions of Pinatubo volcano?: Nature, v. 356, p. 426-428.

Riehle, J.R., 1985, A reconnaissance of the major Holocene tophra deposits in the upper Cook Inlet region, Alaska: Jounal of Volcanology and Geothermal Research, v. 26, p. 37-74.

Sarna-Wojcicki, A.M., Waitt, R.B., Jr., Woodward, M.J., Sh:vley, S., and Rivera, J., 1981, Premagmatic ash erupted from March 27 through May 14, 1980-Extent, mass, volume, and composition, in The 1980 eruptions of Mount St. Helens Lipman, P.W., and Millineaux, D.R., eds., U.S. Geologica' Survey Professional Paper 1250, p. 569-575.

Scheidegger, K.F., and Federman, A.N., 1982, Compositional heterogeneity of tephras from the 1980 eruptions of Mount St. Helens: Journal of Geopohysical Research, v. 87, p. 1C 9 h110881.

Sparks, R.S.J., Sigurdsson, H., and Wilson, L., 1977, Magma mixing: A mechanism for triggering acid explosive eruptions: Nature, v. 267, p. 315-318.

Steen-McIntyre, V.C., 1977, A manual for tephrachronology: Idaho Springs, Colorado, $167 \mathrm{p}$.

Swanson, S.E., and Kienle, J., 1988, The 1986 eruption of Mount St. Augustine: Field test of a hazard evaluation: Jourral of Geophysical Research, v. 93, p. 4500-4520.

Swanson, S.E., Beget, J.E., and McGimsey, R.G., 1991, Compositional equivalence of tephra and groundmass glasses in the 1989-90 eruption of Mount Redoubt: Implications for eruption monitoring [abs.]: Geological Society of America Abstracts with Program, v. 23 , no. 5 , p. A396.

Swanson, S.E., Nye, C.J., Miller, T.P., and Avery, V.F., 1994, Geochemistry of the 1989-1990 eruption of Redoubt Volcano: part II. mineral and glass chemistry: Journal of Volcanology and Geothermal Research, v. 62, p. 453-468. 
$\mid$ 


\title{
Preliminary Petrology and Chemistry of Proximal Eruptive Products: 1992 Eruptions of Crater Peak, Mount Spurr Volcano, Alaska
}

\author{
By Michelle L. Harbin, Samuel E. Swanson, Christopher J. Nye, and Thomas P. Miller
}

\section{CONTENTS}

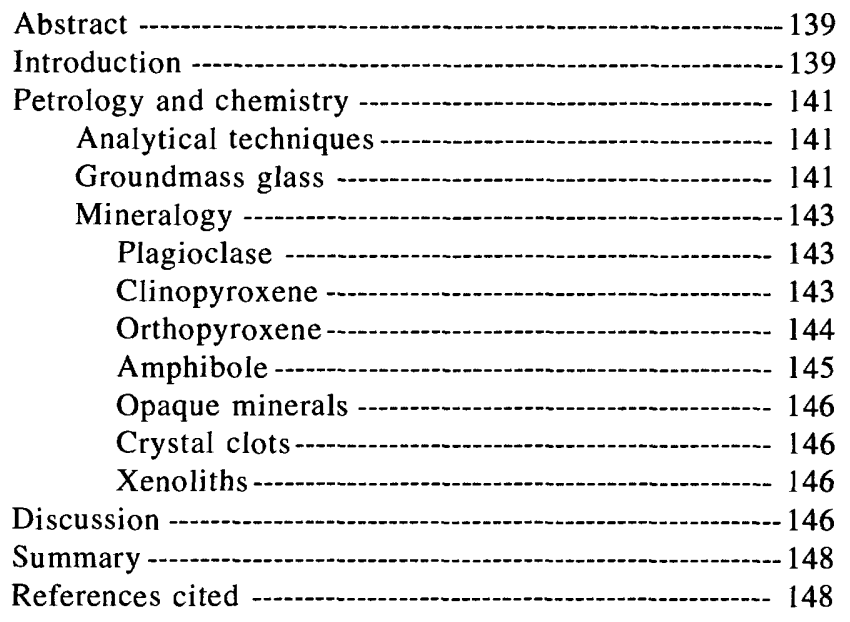

\section{ABSTRACT}

The 1992 eruptions of Crater Peak, Mount Spurr, Alaska, produced two types of andesite distinguished macroscopically by color and texture. The two andesites also have slight petrographic differences. The mineral assemblage of plagioclase, orthopyroxene, clinopyroxene, amphibole, and FeTi oxides is the same for both andesites, and compositions of the mineral phases are nearly identical. However, the color and composition of the groundmass glass differ; one type is brown and andesitic (60-62 weight percent $\mathrm{SiO}_{2}$ ) and the other type is colorless and rhyolitic (73-75 weight percent $\mathrm{SiO}_{2}$ ). Intermediate dacitic glass compositions are also present. The stability of hornblende phenocrysts also differs between the andesites. In the andesite containing brown andesitic glass, hornblende typically shows little or no reaction corona, whereas in andesite with rhyolitic groundmass glass hornblende phenocrysts have well-developed coronas. Xenoliths of partially melted metamorphic rocks were also ejected during the eruptions.

\section{INTRODUCTION}

Mount Spurr, Alaska, located approximately 125 $\mathrm{km}$ west of Anchorage, is the northernmost historically active volcanic center of the eastern Aleutian arc. Prehistoric Mount Spurr was an andesitic stratovolcano that underwent avalanche caldera formation approximately 10,000 years ago (Nye and Turner, 1990). Following subsequent ash flows, a dacite dome was emplaced in the caldera and now forms the summit of Mount Spurr. Crater Peak, a flank vent, was built in the breach of the southern caldera rim and has been the site of historic volcanism, including the eruptions in 1953 and 1992.

The 1992 eruptions were subplinian (after Fisher and Schmincke, 1984) and occurred on June 27, August 18, and September 16-17. Each eruption lasted 3.5 to 4 hours (AVO, 1993; Eichelberger and otl ars, this volume). Most of the eruptive material consisted of tephra fall (Neal and others, this volume; Swanson and others, this volume); pyroclastic flows (Miller and others, this volume), debris flows (Meyer and others, this volume), and ballistic showers (Waitt and others, this volume) were less significant. This study concentrates on juvenile blocks emplaced either as bombs or as clasts in the pyroclastic flows during all three eruptions (table 1). Originally, there was some dehate as to whether juvenile material was ejected during the June eruption. However, presence of fresh vesicular glass fragments in the distal tephra fall (Swanson and others, this volume), small pumice lapilli, and geoch omistry (Nye and others, this volume) indicate that juvenile magma was indeed erupted. Recycling of 1953 olivine-bearing material may be reflected in two olivine-bearing samples-one collected from the June deposits, and one collected from a September pyroclastic flow. The ejecta have been broadly classified into three groups, two of which are juvenile andesite on the basis of hand-sample characteristics. The first group consists of brown-black, breadcrusted, cauliflower-shaped andesite (approximately 95 percent by 


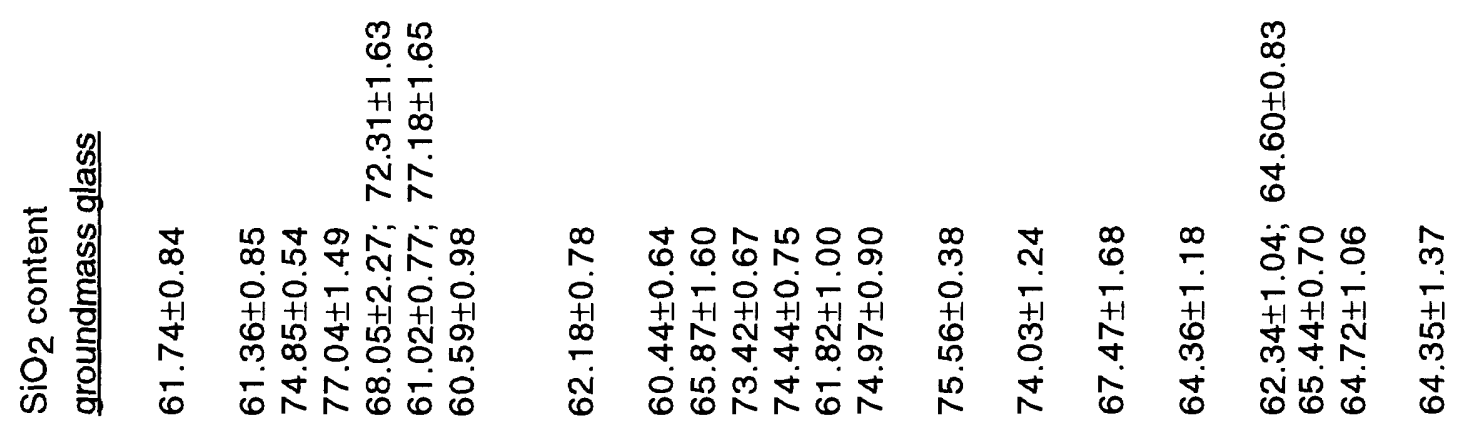

$\stackrel{\infty}{0} \overline{0}$

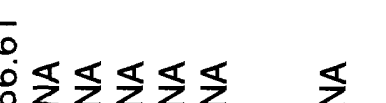

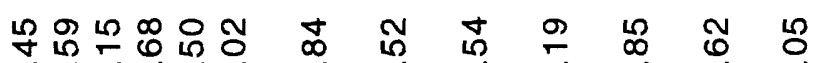
I

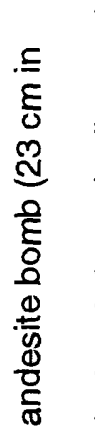

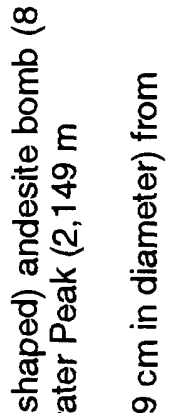

क्ष

$\frac{1}{0} \mathrm{U}$

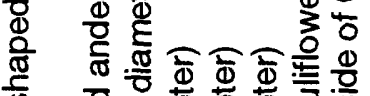

음

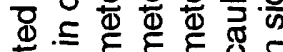

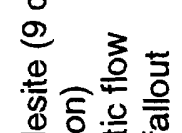

ஸ்

$\infty$

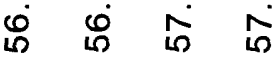

in in

\section{产}

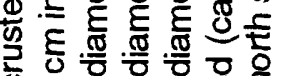

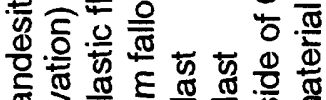

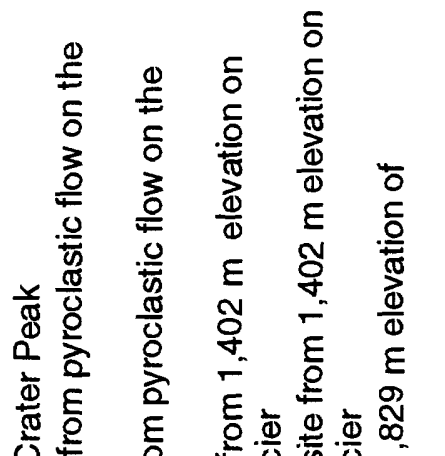

$\overline{\bar{D}}$

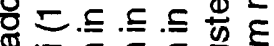

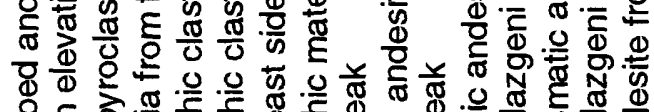

ब $\frac{2}{2} \cdot \frac{\pi}{5} \frac{0}{2}$

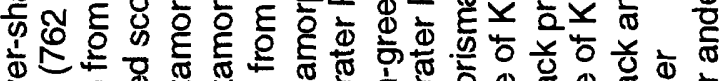

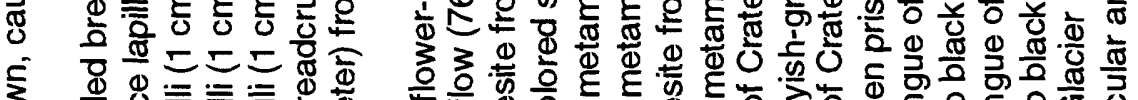

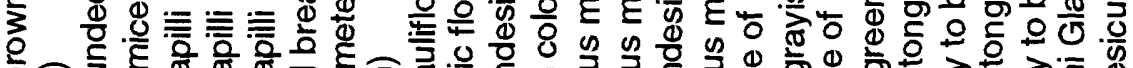

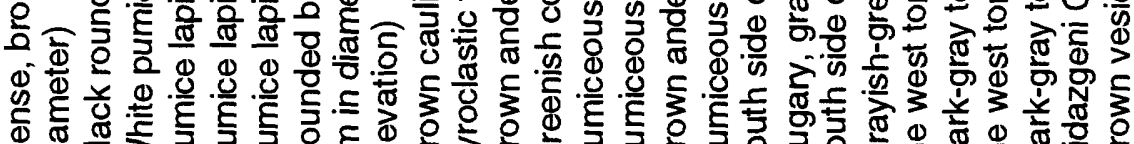

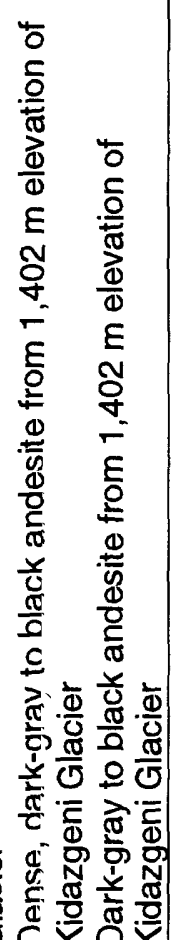

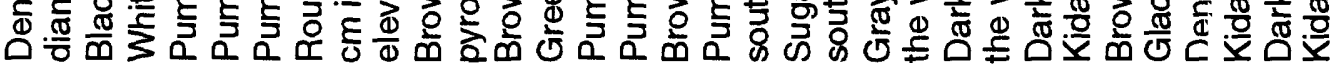

휳

ลิ ลิลลิลลิง

$\infty \quad \infty \infty \infty \infty \infty \infty$

$\infty \leqslant$

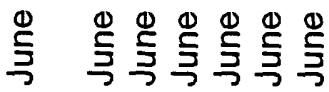

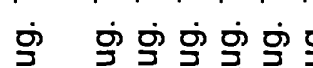

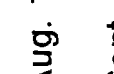

这

옐

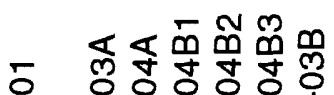

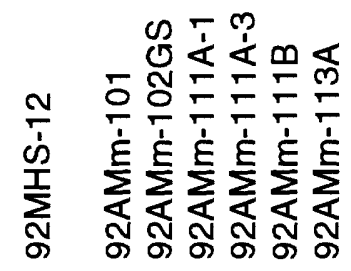

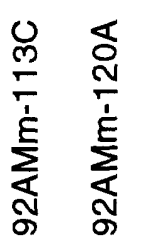



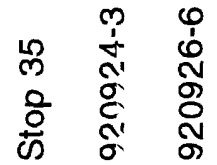


volume of pyroclastic flows). The second group consists of greenish-gray andesite (approximately I percent by volume of pyroclastic flows) erupted in August and September. The third group consists of xenoliths and old volcanic rocks (approximately 4-5 percent by volume of pyroclastic flows) (Miller and others, this volume).

\section{PETROLOGY AND CHEMISTRY}

Petrographically, the andesite of the first two groups are nearly identical. Both contain phenocrysts of plagioclase, orthopyroxene, clinopyroxene, hornblende, and FeTi oxides. One difference between the andesites is the groundmass glass. The brown andesite has a groundmass of very microlite-rich (plagioclase, pyroxene, FeTi oxides) brown glass. The greenish-gray andesite has a colorless groundmass glass with or without microlites. The other striking difference between the two andesite types is the apparent stability of hornblende phenocrysts. Hornblende in the brown andesite does not have reaction coronas, but hornblende phenocrysts in the greenish-gray andesite have welldeveloped reaction coronas.

Metamorphic xenoliths are present in small pumice lapilli from the June eruption and as large blocks in the pyroclastic flows and bomb fields of August and September. These xenolithic blocks are as much as $50 \mathrm{~cm}$ in maximum diameter and typically are highly inflated (40-60 percent vesicles). Phases represented in the xenoliths include vesicular colorless rhyolitic glass, quartz, plagioclase, pyrrhotite \pm orthopyroxene \pm cordierite \pm spinel \pm magnetite \pm ilmenite \pm sillimanite \pm biotite \pm garnet \pm apatite \pm graphite \pm corundum.

\section{ANALYTICAL TECHNIQUES}

Analyses of polished thin sections were performed on the four-channel electron microprobe at the University of Alaska, Fairbanks. Mineral analyses were done using an accelerating voltage of $15 \mathrm{Kev}$, a beam current of $10 \mathrm{nA}$, a beam diameter of $5 \mu \mathrm{m}$, and a counting time of $10 \mathrm{sec}$ per element. Well-characterized natural minerals were used as standards. Glass analyses were done at $15 \mathrm{Kev}, 10 \mathrm{nA}, 8 \mu \mathrm{m}$, and a 10 -sec counting time per element. Natural glasses were used as standards for all major elements. The scapolite standard was used as a standard for chlorine. This analytical routine was designed to minimize $\mathrm{Na}$ loss during analysis of these glasses. Analysis of Redoubt Volcano samples using this same analytical routine (Swanson and others, 1994) indicates no significant loss of $\mathrm{Na}$ during an analysis when $\mathrm{Na}$ is measured within the first 10 seconds of the analysis. Analyses that clearly included mineral grains were eliminated from the data set. Statistical tests were then perforned on the data set to develop a good total range of acceptable analyses. The microlite-rich glasses were the most contaminated, and some of the heterogeneit:" of these glasses can be attributed to the presence of the microlites.

\section{GROUNDMASS GLASS}

The brown-black andesite of the June and August eruptions contains a microlite-rich brown glass, but most samples from the September eruption and some from the August eruption contain a microliterich, lighter-brown glass. However, it is nearly impossible to macroscopically identify samples with the light-brown glass because they are similar to samples with a brown groundmass glass in August deporits, but the clasts from September are lighter in color. August and September ejecta also contain greenish-gray andesite with a colorless groundmass glass.

Color differences among the groundmass glass types identified to date correlate with differences in the composition of the glass. Compositionally, the brown microlite-rich glass from the June and August eruptions is andesitic (60-62 weight percent $\mathrm{SiO}_{2}$ ) (fig. 1 , table 2). Small pumice lapilli on the surface of the June deposits contain brown andesitic (60-62 weight percent $\mathrm{SiO}_{2}$ ) (the same as that in the large brownblack blocks) and dacitic (65-71 weight percent $\mathrm{SiO}_{2}$ ) glass and colorless glass that is dacitic (68-73 weight percent $\mathrm{SiO}_{2}$ ) and rhyolitic (75-79 weight percent $\mathrm{SiO}_{2}$ ) in composition. The boundaries between the two glarses are sharp. One sample from the August eruption has a light-brown microlite-rich glass that is dacitic (approximately 65 weight percent $\mathrm{SiO}_{2}$ ).

Brown-black andesite from the September exuption is lighter in color and contains lighter, more silicic groundmass glass relative to that of the June and August brown-black andesite. September glasses are mostly dacitic (63-68 weight percent $\mathrm{SiO}_{2}$ ) (fig. 1, table 2) but show a wide compositional range among and within samples. This change in dominant glass composition was also observed in analyses of distal tephra fall (Swanson and others, this volume).

One sample from September (Stop 35, table 1) contains all three colors of glass (brown, light brc wn, and colorless) with diffuse contacts between the three glasses; some of the brown glass has an andesitic composition similar to that of June and August samoles (table 2), and some is more similar to the light-brown glass in the sample. Both the light-brown glass and colorless glass are dacitic, but the light-brown glass 


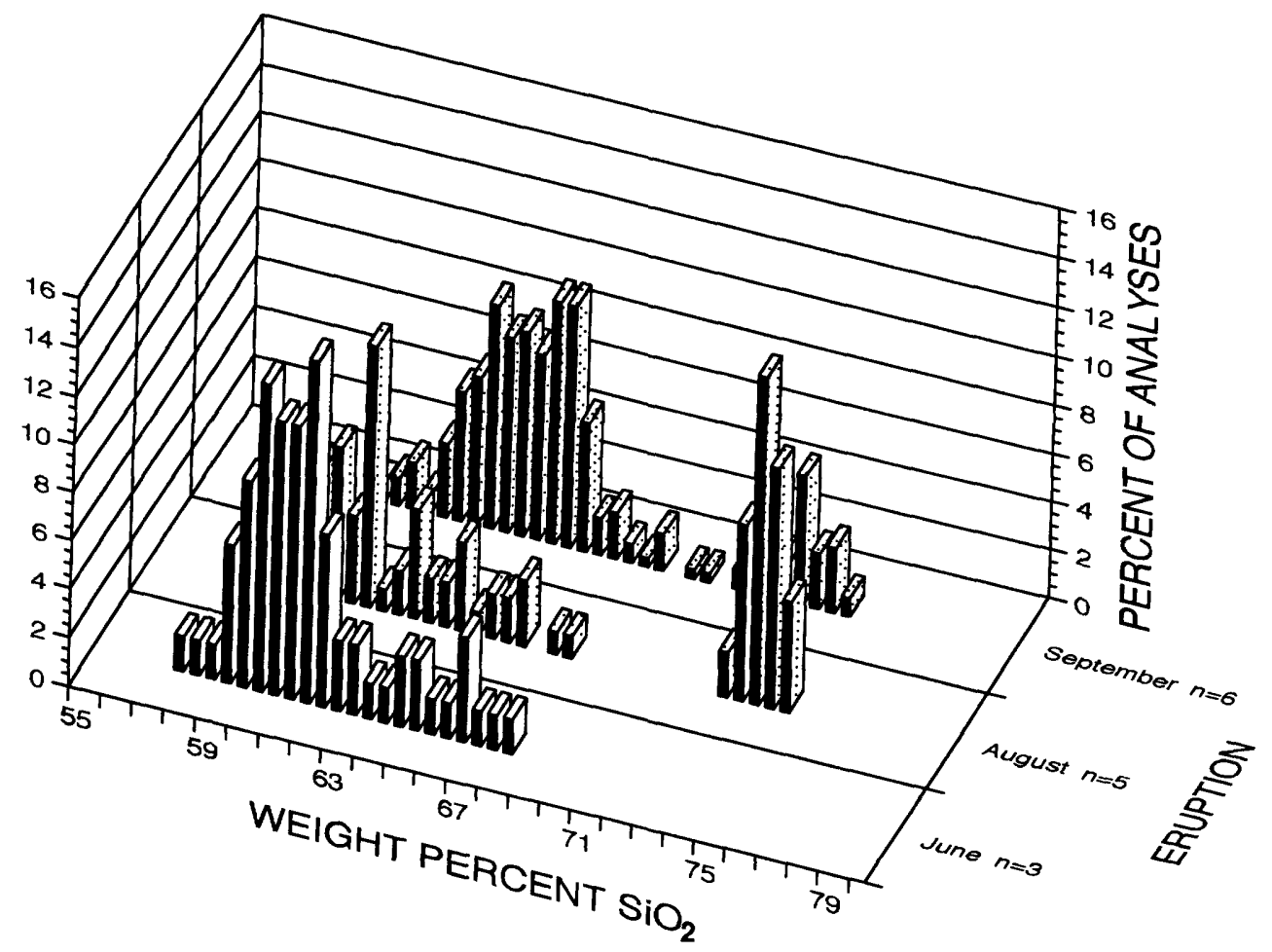

Figure 1. Histogram of groundmass glass compositions analyzed for each of three eruptions of Mount Spurr volcano, Alaska. June and August brown glasses are nearly identical, but the peak is shifted toward more silicic compositions in September. The August and September colorless glasses are also nearly identical. "Percent of Analyses" is the percentage of total analyses of a given weight percent $\mathrm{SiO}_{2}$. The total number of analyses varies for each eruption, 71 for June samples, 111 for August, and 261 for September. n, number of samples analyzed from each eruption.

Table 2. Average groundmass glass compositions for andesite from 1992 eruptions of Mount Spurr volcano, Alaska.

[*, total $\mathrm{Fe}$ as $\mathrm{Fe}_{2} \mathrm{O}_{3}$; n, number of analyses; $†$, sample from June eruption; $¥$, sample from August eruption; $\S$, sample from September e*uption]

Andesite glass

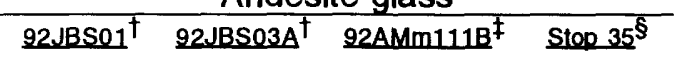

$\mathrm{SiO}_{2}$

$\mathrm{TiO}_{2}$

$\mathrm{Al}_{2} \mathrm{O}_{3}$

$\mathrm{Fe}_{2} \mathrm{O}_{3}^{*}$

$\mathrm{MgO}$

$\mathrm{CaO}$

$\mathrm{Na}_{2} \mathrm{O}$

$\mathrm{K}_{2} \mathrm{O}$

$\mathrm{Cl}$

Total

\section{$60.39 \pm 1.63$}

$0.67 \pm 0.12$

$16.24 \pm 0.60$

$6.92 \pm 0.69$

$2.14 \pm 0.43$

$5.61 \pm 0.31$

$4.38 \pm 0.17$

$0.67 \pm 0.12$

$0.12 \pm 0.04$

$97.81 \pm 1.83$

14

n

\section{$61.34 \pm 0.81$}

$0.66 \pm 0.18$

$15.95 \pm 0.71$

$7.64 \pm 0.63$

$2.33 \pm 0.67$

$5.73 \pm 0.33$

$4.91 \pm 0.25$

$0.66 \pm 0.18$

$0.21 \pm 0.04$

$99.97 \pm 0.53$
$60.98 \pm 0.89 \quad 61.65 \pm 0.80$

$0.65 \pm 0.18$

$15.44 \pm 1.11$

$7.34 \pm 0.90$

$2.80 \pm 0.94$

$5.34 \pm 0.48$

$4.54 \pm 0.29$

$0.65 \pm 0.18$

$0.16 \pm 0.04$

$98.65 \pm 0.69$

24
$61.65 \pm 0.80$
$0.50 \pm 0.07$

$16.2 \pm 0.41$

$7.03 \pm 1.20$

$2.26 \pm 0.32$

$5.09 \pm 0.35$

$4.45 \pm 0.19$

$0.50 \pm 0.07$

$0.17 \pm 0.04$

$98.90 \pm 1.36$
Dacite glass

22AMm102GS ${ }^{\ddagger}$ 22AMm129a ${ }^{\S}$ 92AMm120B

$65.24 \pm 2.04$

$0.48 \pm 0.15$

$15.76 \pm 1.53$

$5.24 \pm 1.03$

$1.21 \pm 0.70$

$4.35 \pm 0.92$

$4.75 \pm 0.37$

$1.80 \pm 0.23$

$0.21 \pm 0.04$

$99.04 \pm 0.95$

22

$\begin{array}{cc}63.27 \pm 1.36 & 67.08 \pm 1.61 \\ 0.56 \pm 0.21 & 0.60 \pm 0.18 \\ 15.86 \pm 0.93 & 14.61 \pm 1.07 \\ 6.09 \pm 0.90 & 5.34 \pm 0.82 \\ 1.75 \pm 0.46 & 0.94 \pm 0.45 \\ 4.50 \pm 0.55 & 3.67 \pm 0.64 \\ 4.50 \pm 0.26 & 4.85 \pm 0.29 \\ 1.59 \pm 0.20 & 2.14 \pm 0.31 \\ 0.18 \pm 0.04 & 0.20 \pm 0.05 \\ & \\ 98.31 \pm 1.30 & 99.42 \pm 0.51\end{array}$

38
32
Rhyolite glass ${\text { 92AMm } 113 \mathrm{C}^{\ddagger} \quad \text { 92AMm120A }}^{\mathrm{S}}$

$74.28 \pm 0.54$

$0.39 \pm 0.16$

$12.21 \pm 0.14$

$2.68 \pm 0.21$

$0.39 \pm 0.03$

$1.36 \pm 0.19$

$3.72 \pm 0.15$

$2.96 \pm 0.08$

$0.33 \pm 0.04$

$98.31 \pm 0.56$
$99.23 \pm 0.62$

$73.46 \pm 1.27$

$0.26 \pm 0.12$

$13.41 \pm 1.01$

$2.49 \pm 0.40$

$0.26 \pm 0.04$

$1.57 \pm 0.67$

$4.41 \pm 0.26$

$3.02 \pm 0.28$

$0.35 \pm 0.07$

46 
is slightly less $\mathrm{Si}$ rich. The three glasses also contain different microlite abundances. The brown glass is very rich in microlites, the light brown glass has abundant microlites, and the colorless glass is relatively free of microlites.

Blocks of greenish-gray andesite in August and September ejecta have a colorless groundmass glass that is rhyolitic (73-75 weight percent $\mathrm{SiO}_{2}$ ) and peraluminous (table 2). The sample from the August eruption contains no microlites in the groundmass glass, but the sample from the September eruption has abundant microlites.

\section{MINERALOGY}

\section{PLAGioclase}

The modal percentage of plagioclase ranges from approximately 17 to 31 percent (dense rock). It makes up 70 to 90 percent of the phenocrysts, and it typically occurs as euhedral crystals as much as $1 \mathrm{~mm}$ long with normal, reverse, oscillatory, and patchy zoning. Sieved (abundant glass inclusions) cores or zones parallel to grain boundaries are very common in phenocrysts.

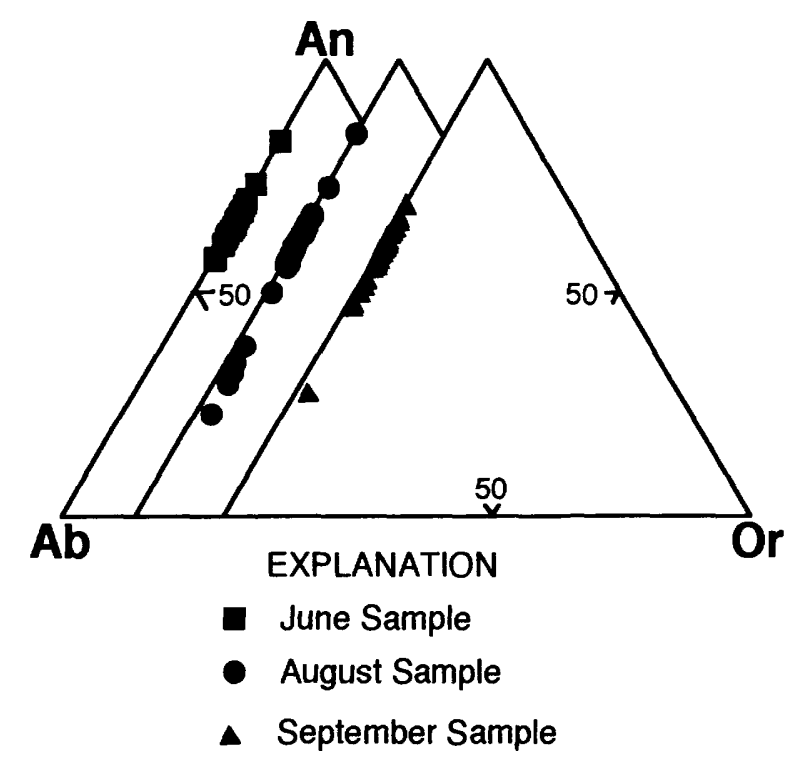

A

Figure 2. $A$, Range of plagioclase rim compositions of andesites for each of the 1992 Mount Spurr eruptions.
Rim compositions vary over the eruption seq "ence and correlate with the composition of the grouncmass glass; rhyolitic glass samples contain the more sodic compositions. In June samples, rims range from $\mathrm{An}_{82}$ to $\mathrm{An}_{56}$, in August samples, they range from $\mathrm{Ar}_{94}$ to $\mathrm{An}_{22}$, and in September samples, they range from $\mathrm{An}_{64}$ to $\mathrm{An}_{27}$ (fig. $2 A$, table 3). Samples from throughout the eruption series that contain similar groundmass glasses have similar compositional ranges. A range of $A n_{84}$ to $A n_{55}$ characterizes andesitic glass, $A r_{95}$ to $\mathrm{An}_{50}$ characterizes dacitic glass, and $A n_{75}$ to $\mathrm{An}_{22}$ characterizes rhyolitic glass (fig. $2 B$ ).

\section{CLINOPYROXENE}

Light-green, weakly pleochroic clinopyrcxene phenocrysts make up less than 1 percent of the mode (dense rock) in both andesite types. Crystals are subhedral to euhedral and less than $0.5 \mathrm{~mm}$ in length. The restricted compositional range of $\mathrm{En}_{38-48} \mathrm{Fs}_{14-19}$ $\mathrm{Wo}_{36-44}$ (rim compositions) (fig. 3, table 3 ) is naarly identical to that of prehistoric Mount Spurr clinopyroxene (Nye and Turner, 1990). There is no clear change in composition with changing groundmass glass composition nor any compositional change through the eruption series.

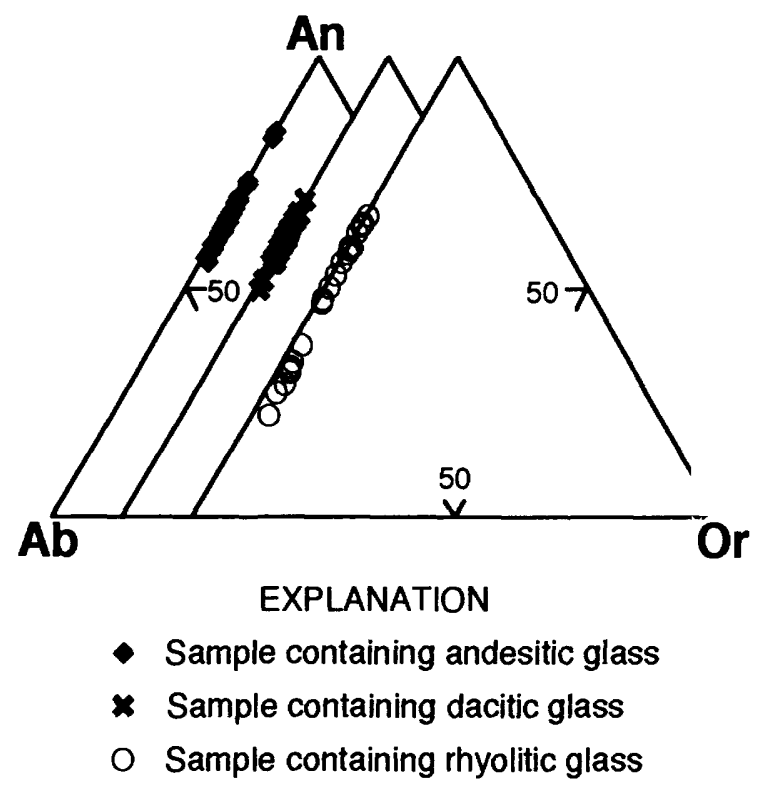

B

Figure 2. Continued. $B$, Range of plagioclase rim compositions for different groundmass glass compositions. 
Table 3. Representative analyses of plagioclase and clinopyroxene of andesites from 1992 eruptions of Mount Spurr volcano, Alaska.

[*, total $\mathrm{Fe}$ as $\mathrm{Fe}_{2} \mathrm{O}_{3}$; pyroxene recalculation scheme from Lindsley (1983) and represents rim compositions; $\mathrm{FeO}_{\text {, }}$, total measured iron as $\mathrm{FeO}$; $\mathrm{Mg}, \mathrm{Mg} /(\mathrm{Mg}+\mathrm{Fe}) \cdot 100 ; \mathrm{\dagger}$, sample from June eruption; $¥$, sample from August eruption; $\S$, sample from September eruption]

\section{Plagioclase}

\begin{tabular}{|c|c|c|c|c|c|c|}
\hline $\mathrm{SiO}_{2}$ & $\frac{92 \mathrm{JBSO1}}{49.39}$ & $\frac{92 \mathrm{AMm} 111 \mathrm{~B}^{\ddagger}}{50.34}$ & $\frac{92 \mathrm{AMm} 102 \mathrm{GS} \ddagger}{46.89}$ & $\frac{92 \mathrm{AMm} 113 \mathrm{C} \ddagger}{58.90}$ & $\frac{92 \mathrm{AMm} 129 \mathrm{a} \S}{46.84}$ & $\frac{92 \mathrm{AMm} 120 \mathrm{~A} \S}{53.88}$ \\
\hline $\mathrm{Al}_{2} \mathrm{O}_{3}$ & 32.27 & 31.29 & 33.98 & 26.04 & 33.69 & 28.52 \\
\hline $\mathrm{Fe}_{2} \mathrm{O}_{3}{ }^{*}$ & 0.52 & 0.66 & 0.50 & 0.19 & 0.29 & 0.56 \\
\hline $\begin{array}{c}\mathrm{CaO} \\
\mathrm{Na}_{2} \mathrm{O}\end{array}$ & $\begin{array}{r}14.92 \\
2.86\end{array}$ & $\begin{array}{r}13.44 \\
3.44\end{array}$ & $\begin{array}{l}16.45 \\
2.15\end{array}$ & $\begin{array}{l}7.19 \\
6.93\end{array}$ & $\begin{array}{l}16.54 \\
2.15\end{array}$ & $\begin{array}{l}10.97 \\
5.20\end{array}$ \\
\hline $\mathrm{K}_{2} \mathrm{O}$ & 0.03 & 0.01 & 0.02 & 0.34 & 0.04 & 0.08 \\
\hline Total & 99.99 & 99.18 & 99.99 & 99.60 & 99.57 & 99.21 \\
\hline $\begin{array}{l}A n \\
A b \\
O r\end{array}$ & $\begin{array}{r}74.11 \\
25.69 \\
0.20\end{array}$ & $\begin{array}{r}68.25 \\
31.64 \\
0.10\end{array}$ & $\begin{array}{c}80.76 \\
19.14 \\
0.10\end{array}$ & $\begin{array}{c}35.68 \\
62.25 \\
2.07\end{array}$ & $\begin{array}{c}80.75 \\
19.05 \\
0.20\end{array}$ & $\begin{array}{c}53.61 \\
45.99 \\
0.40\end{array}$ \\
\hline
\end{tabular}

\section{Clinopyroxene}

\begin{tabular}{|c|c|c|c|c|c|c|}
\hline & $\underline{92 J B S O 3 A}^{\dagger}$ & $\underline{92 \mathrm{CNSO}}^{\dagger}$ & ${\underline{92 A M m 111 B^{\ddagger}}}^{\ddagger}$ & 92AMm102GS & 92AMm113C & 92AMm120A \\
\hline $\mathrm{SiO}_{2}$ & 50.33 & 51.89 & 52.41 & 52.17 & 51.73 & 52.11 \\
\hline $\mathrm{TO}_{2}$ & 0.54 & 0.38 & 0.37 & 0.44 & 0.44 & 0.35 \\
\hline $\mathrm{Al}_{2} \mathrm{O}_{3}$ & 3.28 & 2.00 & 1.95 & 2.40 & 2.42 & 1.70 \\
\hline $\mathrm{Fe}_{2} \mathrm{O}_{3}$ & 2.79 & 1.63 & 1.04 & 0.55 & 1.37 & 1.51 \\
\hline $\begin{array}{c}\mathrm{FeO} \\
\mathrm{MnO} \\
\mathrm{MgO} \\
\mathrm{CaO} \\
\mathrm{Na}_{2} \mathrm{O}\end{array}$ & $\begin{array}{l}6.74 \\
0.41 \\
15.72 \\
20.03 \\
0.33\end{array}$ & $\begin{array}{c}7.40 \\
0.43 \\
16.30 \\
19.78 \\
0.26\end{array}$ & $\begin{array}{c}8.70 \\
0.28 \\
16.97 \\
18.24 \\
0.27\end{array}$ & $\begin{array}{l}8.47 \\
0.32 \\
15.72 \\
19.79 \\
0.26\end{array}$ & $\begin{array}{c}7.56 \\
0.30 \\
15.36 \\
20.66 \\
0.35\end{array}$ & $\begin{array}{c}8.23 \\
0.42 \\
16.32 \\
19.27 \\
0.26\end{array}$ \\
\hline $\begin{array}{l}\text { Total } \\
\text { FeOt }\end{array}$ & $\begin{array}{c}100.17 \\
9.25\end{array}$ & $\begin{array}{c}100.07 \\
8.87\end{array}$ & $\begin{array}{c}100.23 \\
9.64\end{array}$ & $\begin{array}{c}100.12 \\
8.96\end{array}$ & $\begin{array}{c}100.19 \\
8.79\end{array}$ & $\begin{array}{c}100.17 \\
9.59\end{array}$ \\
\hline $\begin{array}{l}\text { En } \\
\text { Fs } \\
\text { Wo } \\
\text { Mg\# }\end{array}$ & $\begin{array}{l}44.23 \\
15.25 \\
40.52 \\
74.36\end{array}$ & $\begin{array}{l}45.61 \\
14.60 \\
39.79 \\
75.75\end{array}$ & $\begin{array}{l}47.59 \\
15.62 \\
36.79 \\
75.29\end{array}$ & $\begin{array}{l}44.71 \\
14.82 \\
40.47 \\
75.11\end{array}$ & $\begin{array}{l}43.48 \\
14.45 \\
42.07 \\
75.06\end{array}$ & $\begin{array}{l}45.58 \\
15.70 \\
38.71 \\
74.38\end{array}$ \\
\hline
\end{tabular}

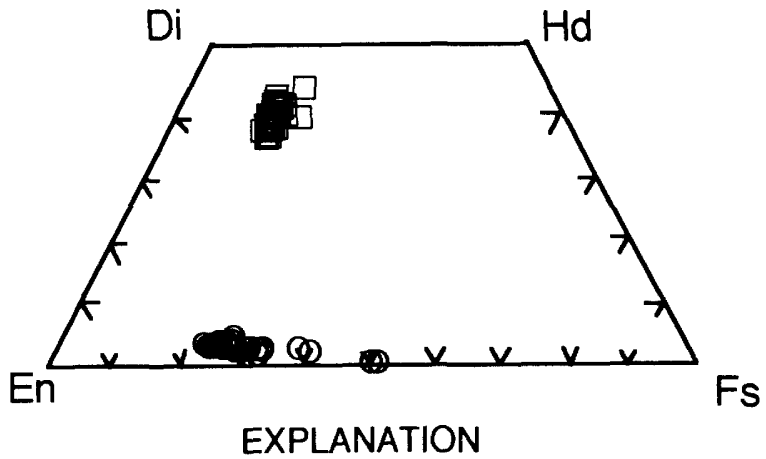

$\square$ Clinopyroxene analysis

o Orthopyroxene analysis

Figure 3. Representative range of clinopyroxene and orthopyroxene rim compositions of andesite samples from three eruptions of Mount Spurr, Alaska, in 1992. Di, diopside; Hd, hedenbergite; En, enstatite; Fs, forsterite.

\section{ORTHOPYROXENE}

Orthopyroxene phenocrysts are the mo't abundant mafic phase in all andesite samples, typically 3 to 7 percent of the mode (dense rock). Crystals are subhedral to euhedral and as much as $1.2 \mathrm{~mm}$ long, pale greenish-brown, and weakly to moderately pleochroic. Some crystals have zones (typically ccres) that are more strongly colored. The abundance of such "cored" crystals appears to increase in samples from each succeeding eruption. The wide compositional range of $\mathrm{En}_{49-74} \mathrm{Fs}_{22-51} \mathrm{Wo}_{0.3-5}$ (rim compositions) (fig. 3, table 4) is similar to that for prehistoric orthopyroxene (Nye and Turner, 1990). Unlike clinopyroxene, the orthopyroxene shows a compositional charge with groundmass glass composition. Orthopyroxene phenocrysts in andesitic and dacitic glass samples have a similar range of $\mathrm{En}_{61-74} \mathrm{Fs}_{22-37} \mathrm{Wo}_{0.9-5}$, but rhyolitic 
glass samples contain orthopyroxene with more iron -rich compositions $\left(\mathrm{En}_{49-73} \mathrm{Fs}_{24-51} \mathrm{Wo}_{0.3-5}\right)$.

\section{AMPHIBOLE}

Pargasitic amphibole phenocrysts (Hawthorne, 1981) form less than 2 percent of the mode (dense rock) in all samples. Crystals are euhedral to anhedral, less than $2 \mathrm{~mm}$ in largest dimension, and pleochroic in shades of green and brown. Coronas of plagioclase, orthopyroxene, and FeTi oxides surround amphibole in some samples and presumably record disequilibrium. Well-developed coronas are dominant in samples with a colorless rhyolitic groundmass glass, whereas samples containing brown groundmass glass typically lack evidence of disequilibrium. However, amphibole both with and without coronas are found in some samples. Compositionally, the amphibole is high in $\mathrm{Al}\left(\mathrm{Al}\left(\mathrm{IV}^{\gamma}\right)=\right.$ 1.35-2, based on 23 oxygens) and alkalies ( $\mathrm{Na}+\mathrm{K}$ in A site $=0.6-0.85$ ) (table 4$)$, similar to the range for prehistoric Mount Spurr amphibole (Nye and Turner, 1990). Pargasitic Mount Spurr amphibole falls at the end of the Aleutian amphibole trend (Kay and Kay, 1985) and is similar to other eastern Aleutian pargaritic amphibole (from Augustine Volcano (Daley, 1986) and Redoubt Volcano (Swanson and others, 1994)) (fig. 4).

Table 4. Representative analyses of orthopyroxene and hornblende of andesite from 1992 eruptions of Mount Spurr volcano, Alaska.

\section{Orthopyroxene}

\begin{tabular}{|c|c|c|c|c|c|c|}
\hline $\mathrm{SiO}_{2}$ & $\frac{92 \mathrm{JBSO} 03 \mathrm{~A}^{\dagger}}{53.21}$ & $\frac{92 \mathrm{CNSO} 3 \mathrm{~B}}{54.21}$ & $\frac{92 \mathrm{AMm} 111 \mathrm{~B}^{\ddagger}}{53.17}$ & $\frac{92 \mathrm{AMm} 102 \mathrm{GS}}{53.04}$ & $\frac{92 A M m 113 C \ddagger}{51.31}$ & $\frac{92 \mathrm{AMm} 120 \mathrm{~A}^{\S}}{52.01}$ \\
\hline $\mathrm{THO}_{2}$ & 0.19 & 0.12 & 0.16 & 0.26 & 0.19 & 0.16 \\
\hline $\mathrm{Al}_{2} \mathrm{O}_{3}$ & 1.66 & 0.96 & 1.09 & 1.90 & 1.25 & 2.53 \\
\hline $\mathrm{Fe}_{2} \mathrm{O}_{3}$ & 1.87 & 1.33 & 1.47 & 1.32 & 0.18 & 2.00 \\
\hline $\begin{array}{c}\mathrm{FeO} \\
\mathrm{MnO} \\
\mathrm{MgO} \\
\mathrm{CaO} \\
\mathrm{Na}_{2} \mathrm{O}\end{array}$ & $\begin{array}{c}13.82 \\
0.63 \\
26.58 \\
2.11 \\
0.03\end{array}$ & $\begin{array}{c}13.86 \\
0.47 \\
27.54 \\
1.49 \\
0.06\end{array}$ & $\begin{array}{c}16.62 \\
0.69 \\
25.54 \\
1.20 \\
0.00\end{array}$ & $\begin{array}{c}14.79 \\
0.52 \\
26.29 \\
1.62 \\
0.00\end{array}$ & $\begin{array}{c}25.39 \\
0.77 \\
19.24 \\
0.87 \\
0.01\end{array}$ & $\begin{array}{c}15.69 \\
0.51 \\
25.32 \\
1.49 \\
0.00\end{array}$ \\
\hline $\begin{array}{l}\text { Total } \\
\mathrm{FeO}_{\mathrm{t}}\end{array}$ & $\begin{array}{c}100.10 \\
15.50\end{array}$ & $\begin{array}{l}100.04 \\
15.06\end{array}$ & $\begin{array}{l}99.94 \\
17.94\end{array}$ & $\begin{array}{l}99.74 \\
15.98\end{array}$ & $\begin{array}{l}99.21 \\
25.55\end{array}$ & $\begin{array}{l}99.71 \\
17.49\end{array}$ \\
\hline $\begin{array}{c}\text { En } \\
\text { Fs } \\
\text { Wo } \\
\text { Mg\# }\end{array}$ & $\begin{array}{c}71.54 \\
24.38 \\
4.08 \\
74.58\end{array}$ & $\begin{array}{c}73.78 \\
23.35 \\
2.87 \\
75.96\end{array}$ & $\begin{array}{c}69.29 \\
28.37 \\
2.34 \\
70.95\end{array}$ & $\begin{array}{c}71.61 \\
25.23 \\
3.16 \\
73.95\end{array}$ & $\begin{array}{c}55.54 \\
42.65 \\
1.81 \\
56.57\end{array}$ & $\begin{array}{c}69.37 \\
27.69 \\
2.94 \\
71.47\end{array}$ \\
\hline
\end{tabular}

\section{Hornblende}

\begin{tabular}{|c|c|c|c|c|c|}
\hline & 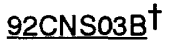 & 92AMm111B & 92AMm102GS & 92AMm113C & 92AMm120B ${ }^{\S}$ \\
\hline $\mathrm{SiO}_{2}$ & 42.84 & 42.94 & 42.87 & 42.64 & 43.36 \\
\hline $\mathrm{TiO}_{2}$ & 2.14 & 2.39 & 2.70 & 2.61 & 2.38 \\
\hline $\mathrm{Al}_{2} \mathrm{O}_{3}$ & 13.51 & 12.74 & 11.23 & 11.92 & 12.45 \\
\hline $\mathrm{FeO}_{\mathrm{t}}$ & 10.64 & 12.69 & 12.60 & 12.85 & 12.09 \\
\hline $\begin{array}{c}\mathrm{MnO} \\
\mathrm{MgO} \\
\mathrm{CaO} \\
\mathrm{Na}_{2} \mathrm{O}\end{array}$ & $\begin{array}{c}0.07 \\
15.01 \\
11.10 \\
2.36\end{array}$ & $\begin{array}{c}0.11 \\
13.34 \\
10.75 \\
2.30\end{array}$ & $\begin{array}{c}0.27 \\
14.26 \\
10.70 \\
2.45\end{array}$ & $\begin{array}{c}0.15 \\
13.53 \\
11.01 \\
2.42\end{array}$ & $\begin{array}{c}0.30 \\
13.91 \\
10.77 \\
2.28\end{array}$ \\
\hline $\mathrm{K}_{2} \mathrm{O}$ & 0.26 & 0.38 & 0.35 & 0.35 & 0.31 \\
\hline $\begin{array}{c}\stackrel{\mathrm{C}}{\mathrm{F}} \\
\mathrm{H}_{2} \mathrm{O}\end{array}$ & $\begin{array}{l}0.04 \\
0.14 \\
1.99\end{array}$ & $\begin{array}{l}0.08 \\
0.23 \\
1.90\end{array}$ & $\begin{array}{l}0.05 \\
0.37 \\
1.83\end{array}$ & $\begin{array}{l}0.06 \\
0.37 \\
1.83\end{array}$ & $\begin{array}{l}0.03 \\
0.05 \\
2.02\end{array}$ \\
\hline $\begin{array}{l}\mathrm{F}=\mathrm{O} \\
\mathrm{Cl}=\mathrm{O}\end{array}$ & $\begin{array}{l}-0.06 \\
-0.01\end{array}$ & $\begin{array}{l}-0.10 \\
-0.02\end{array}$ & $\begin{array}{l}-0.16 \\
-0.01\end{array}$ & $\begin{array}{l}-0.16 \\
-0.01\end{array}$ & $\begin{array}{l}-0.02 \\
-0.01\end{array}$ \\
\hline Total & 100.02 & 99.73 & 99.52 & 99.56 & 99.92 \\
\hline
\end{tabular}




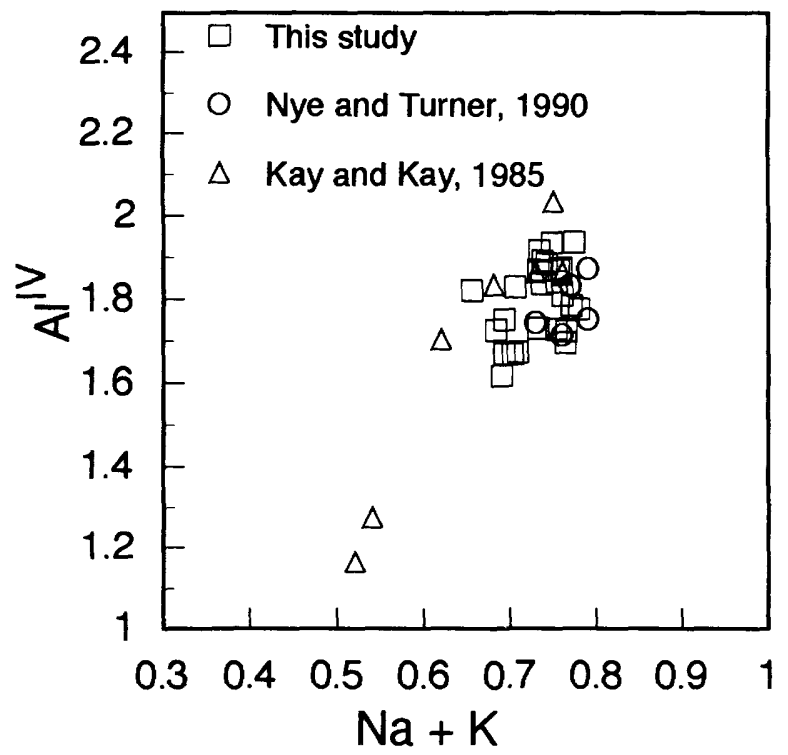

Figure 4. $\mathrm{Al}(\mathrm{IV})$ versus $\mathrm{Na}+\mathrm{K}$ for hornblende of this study and hornblende from Mount Spurr and other Aleutian volcanoes from Nye and Turner (1990) and Kay and Kay (1985).

\section{OPAQUE MINERALS}

Opaque minerals are dominantly magnetite, but include a trace amount of pyrrhotite, and they may make up as much as 5 percent of the mode (dense rock). Magnetite occurs as anhedral to subhedral crystals less than $0.2 \mathrm{~mm}$ in maximum dimension. Pyrrhotite occurs as anhedral masses as much as $0.5 \mathrm{~mm}$ in maximum dimension.

\section{CRYSTAL CLOTS}

Small $(\leq 2 \mathrm{~mm})$ crystal clots of different minerals are found in all samples (1-2 percent of the mode). The most common clots are (1) plagioclase and magnetite; (2) orthopyroxene and magnetite; (3) plagioclase, orthopyroxene, and magnetite; and (4) poikilitic hornblende and plagioclase. Clinopyroxene is also present in some clots. The pyroxene crystals are subhedral to anhedral, whereas the plagioclase is subhedral to euhedral and typically somewhat sieved.

\section{XENOLITHS}

Metamorphic inclusions are present in many samples. The inclusions are of three types: (1) plagioclase and spinel $\pm \mathrm{FeTi}$ oxides, (2) polycrystalline quartz, and (3) plagioclase, quartz, sillimanite, spinel, FeTi oxides, pyrrhotite \pm biotite \pm cordierite \pm corundum. Grains of cordierite are present in some andesites and are probably derived from xenoliths. Nye and Turner (1990) also described plagioclase-spinel clots in Mount Spurr lavas, which they inferred to be altered anorthosite. The ubiquitous nature of spinel in the large metamorphic blocks suggests that they are of metamorphic origin. Xenoliths of older volcanic material are also present in some samples.

\section{DISCUSSION}

The brown-black and greenish-gray andesites are petrographically and geochemically similar (Nye and others, this volume); they differ only in their groundmass glass compositions. Groundmass glass compositions in the brown-black andesite from the June and August eruptions are nearly identical. However, in the samples from the September eruption the dominant glass is more silicic and the compositions shif relative to those of samples from the June and August eruptions (fig. 1). This shift in the dominant mel: composition from August to September could possibly be the result of progressive crystallization. Presumably this crystallization occurred in the magma body throughout the eruption sequence. Thus, the shift in melt composition suggests the presence of a single magma body undergoing progressive crystallization and tapp $\% d$ for three eruptions. The presence of a single magma body is supported by the geochemistry of the andesite (Nye and others, this volume).

The rhyolitic groundmass glasses from the August and September eruptions also show identical compositional ranges (fig. 1). This observation suggests that the same process generated andesite with rhyolitic groundmass glass in August and September.

Differences in the groundmass glass compositions also result in differences in the range of $\mathrm{F}^{\prime}$ agioclase and orthopyroxene compositions. The brown-black andesite with both andesitic and dacitic glasses has plagioclase rim compositions from $\mathrm{An}_{84}$ to $\mathrm{An}_{56}$, whereas in the greenish-gray andesite with rhyolitic glass rim compositions are very sodic and extend to $\mathrm{An}_{22}$. The orthopyroxene in samples with andesitic and dacitic glass has rim compositions of $\mathrm{En}_{61-74}$ and in the rhyolitic glass samples, $\mathrm{En}_{49-73}$.

There are three possible mechanisms to explain the origin of the various glasses and the resulting sympathetic plagioclase and orthopyroxene compositional differences. These mechanisms are fractional crystallization, assimilation, and magma mixing. Incorporation of more felsic material either through melting of continental crust (assimilation) or magma mixing could cause changes in the melt and crystallizing phases. However, the similarity of andesite geochemistry argues for a closed system (Nye and others, this volume) during the eruption sequence. Therefore, the more 
likely explanation is fractional crystallization. Groundmass glass major-element variation diagrams (fig. 5) show predominantly linear trends between the andesitic and rhyolitic glasses, with the exception of $\mathrm{Na}_{2} \mathrm{O}$ and $\mathrm{MgO}$. $\mathrm{Na}_{2} \mathrm{O}$ vector modeling of plagioclase crystallization indicates it would be possible to drive glass compositions from the dacitic glass to rhyolitic glass through crystallization of plagioclase with compositions of approximately $\mathrm{An}_{35-45}$.
Hornblende phenocrysts, although identical in composition, are stable in the andesitic glasses and to a degree in the dacitic glasses, but they are clearly unstable in the rhyolitic glasses. There are three possible explanations for this: differences in water content of the different glasses (melts); the peraluminous nature of the rhyolitic melts; and reaction kinetics (Rutherford and Hill,1993). It is unclear which of these three mechanisms is the most likely explanation.
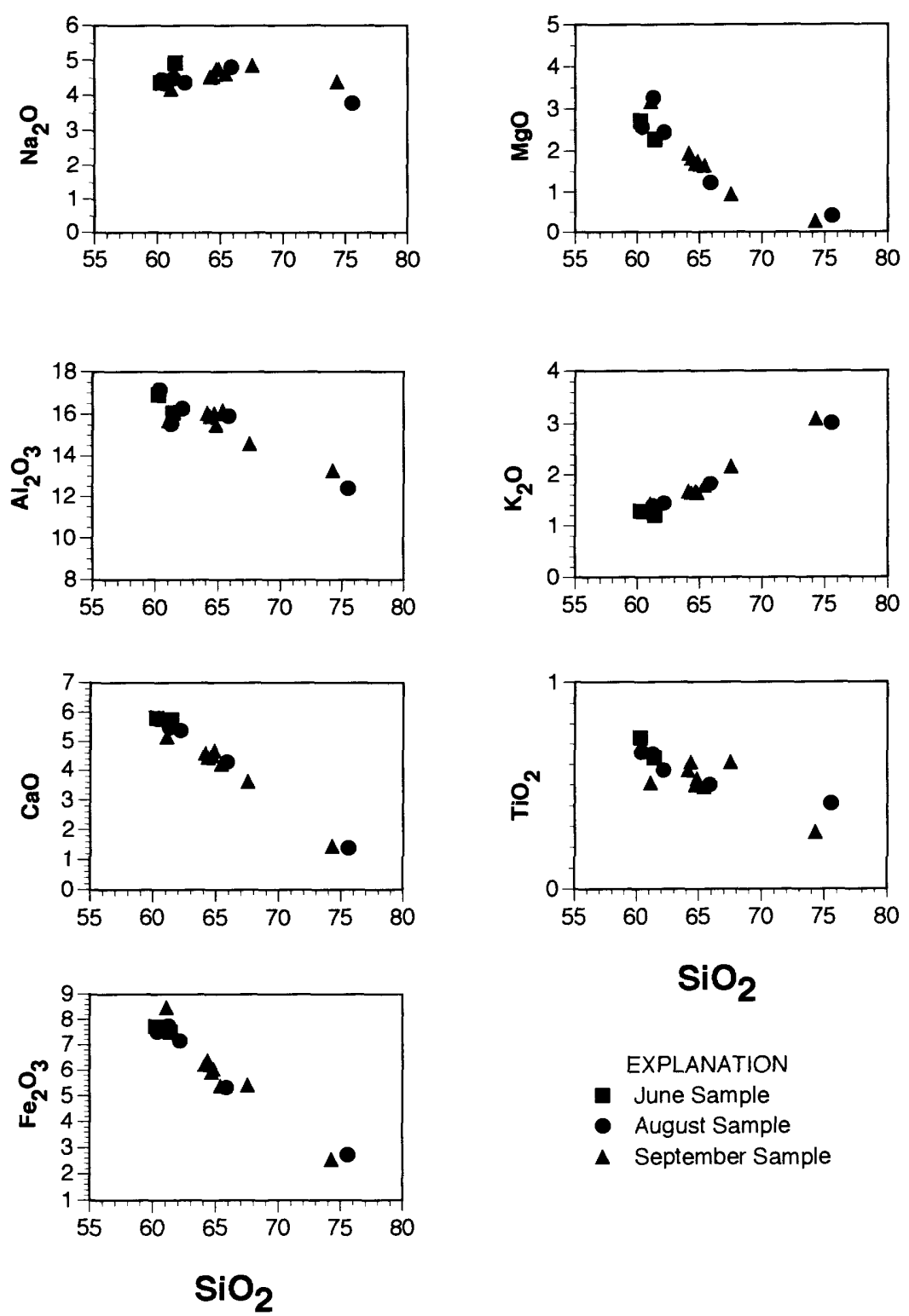

Figure 5. Average groundmass glass compositions (in weight percent) of major oxides plotted against weight percent $\mathrm{SiO}_{2}$. Glass from andesite samples collected following three eruptions of Mount Spurr, Alaska, in 1992. 


\section{SUMMARY}

The 1992 eruptions of Mount Spurr provided several types of products for examination, including two types of andesite. Derivation of the greenish-gray andesite with rhyolitic glass appears to have been accomplished through fractional crystallization of brown andesite with andesitic glass. Fractional crystallization is supported by the compositional changes observed in plagioclase and orthopyroxene. Examination of the andesite groundmass glasses suggests that a single magma body undergoing progressive crystallization was present. It seems likely that progressive crystallization took place as microphenocrysts and microlites. Work will be done on groundmass crystallinity to determine any differences.

The role of the metamorphic xenoliths in the Crater Peak magmatic system is not understood. The system was apparently closed during the eruption sequence so any affect on the magma must have occurred prior to the June eruption. Nye and Turner (1990) suggested that crustal sweats have influenced the Mount Spurr magmatic system. The presence of the xenoliths suggests that they are the origin of these crustal sweats. Future work will involve characterizing the xenoliths to determine their role.

\section{REFERENCES CITED}

Alaska Volcano Observatory, 1993, Mt. Spurr's 1992 Euptions: Eos, Transactions of the American Geophysical Union, v. 74 , no. 19, May 11, 1993, p. 217 and 221-222.

Daley, E.E., 1986, Petrology, geochemistry, and the evolution of magmas from Augustine Volcano, Alaska: M.S. the.ris, University of Alaska Fairbanks, p. 106.

Fisher, R.V., and Schmincke, H.-U., 1984, Pyroclastic rocks: New York, Springer-Verlag, p. 472.

Hawthorne, F.C., 1981, Crystal chemistry of the amphiboles, in Veblen, D.R., ed., Amphiboles and other hydrous pyribolesMineralogy. Mineralogical Society of America Re:views in Mineralogy, v. 9A, p. 1-102.

Kay, S.M., and Kay, R.W., 1985, Aleutian tholeiitic and calcalkaline magma series I: The mafic phenocrysts: Cont ibutions to Mineralogy and Petrology, v. 90 , p. 276-290.

Lindsley, D.H., 1983, Pyroxene thermometry: American Mineralogist, v. 68, p. 477-493.

Nye, C.J., and Turner, D.L., 1990, Petrology, geochemi ${ }^{\circ}$ try, and age of the Spurr volcanic complex, eastern Aleutian arc: Bulletin of Volcanology, v. 52, p. 205-226.

Rutherford, M.J., and Hill, P.M., 1993, Magma ascent retes from amphibole breakdown: An experimental study appl: $: d$ to the 1980-1986 Mount St. Helens eruption: Journal of Geophysical Research, v. 98, p. 19,667-19,685.

Swanson, S.E., Nye, C.J., and Miller, T.P., 1994, Geochemistry of the 1989-1990 eruption of Redoubt Volcano: part II. mineral and glass chemistry, in Miller, T.P., and Chouet, B.A., eds., The 1989-1990 eruptions of Redoubt Volcano, Alaska. Journal of Volcanology and Geothermal Research, v. 62, p. 453-468. 


\title{
Seismicity and Forecasting of the 1992 Eruptions of Crater Peak Vent, Mount Spurr Volcano, Alaska: An Overview
}

\author{
By John A. Power, Arthur D. Jolly, Robert A. Page, and Stephen R. McNutt
}

\section{CONTENTS}

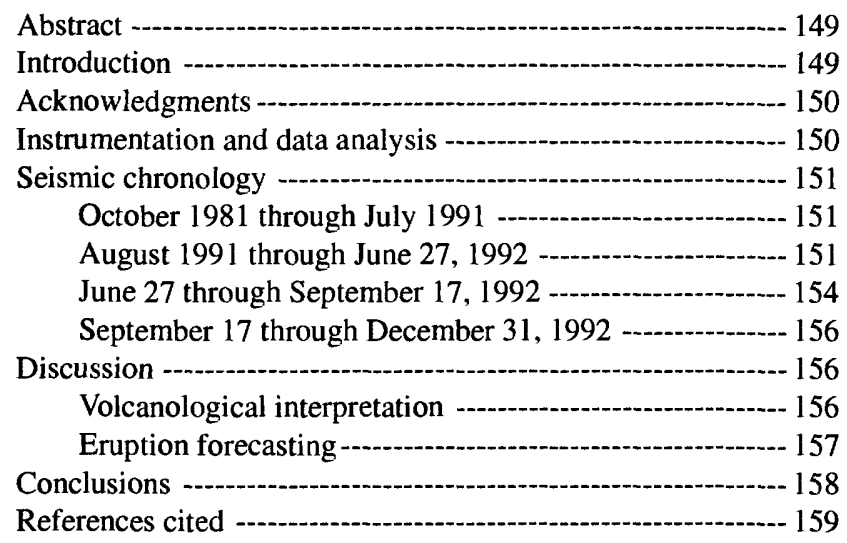

\section{ABSTRACT}

Seismicity associated with the 1992 eruptions of the Crater Peak vent of Mount Spurr was monitored by a network of 6 to 10 seismometers within $15 \mathrm{~km}$ of the mountain's summit. Precursory seismicity began in August of 1991. It was marked by a conspicuous swarm of shallow volcano-tectonic (VT) earthquakes beneath Crater Peak, the first such swarm in a decade of monitoring, and by the gradual onset of seismicity between depths of 5 and $40 \mathrm{~km}$, in a volume of rock that had been essentially aseismic for nearly a decade. The volcano erupted three times during 1992: on June 27, August 18, and September 16-17. The June eruption was preceded by about 14 hours of continuous tremor and a vigorous 4-hour swarm of shallow VT earthquakes. Following the June eruption, shallow seismicity decreased to normal background levels, and the August eruption occurred without any detectable precursory seismicity. A few hours of shallow seismicity preceded the September eruption, after which seismicity in the depth range of 5 to $40 \mathrm{~km}$ peaked. From an initial analysis of the seismic data, we suggest the 1992 eruption sequence resulted from the in- trusion of magma into the mid-crust that began in mid1991. The magma had migrated to shallower denths by early June of 1992, when the distribution of hypocenters changed and volcanic tremor began. The character of seismograms suggests the deep seismicity included a variety of source processes ranging from brittle failure of the country rock in response to injection and withdrawal of magma to the vibration of fluid-filled cracks associated with magma transport.

Close monitoring of Mount Spurr seismicity allowed the Alaska Volcano Observatory to issue public statements describing the increased activity berinning in August of 1991. Forecasts were issued frior to the June 27 and September 16-17 eruptions, and notifications were issued shortly after all three events. Two additional forecasts were issued on the basis of observed increases in seismicity that did not culminate in eruptions.

\section{INTRODUCTION}

During the summer of 1992, Crater Peak erupted three times-on June 27, August 18, and September 16-17. Each of the eruptions lasted 3.5 to 4 hours and produced large tephra plumes, which drifted downwind across large parts of Alaska (Neal and otters, this volume).

Rudimentary seismic monitoring of Mount Sourr volcano began in 1971, and since 1989 the Alaska Volcano Observatory (AVO) has operated a 6- to 10station seismic array (herein referred to as the Snurr network) centered on the volcano. The reawakening of Crater Peak was preceded by roughly 10 months of elevated earthquake activity that spanned the caldera and extended to depths of $40 \mathrm{~km}$. The seismicity associated with the eruptions constitutes a complex sequence of events including shallow volcano-tectonic (VT) earthquakes, long-period (LP) events, volcanic tremor, and periods of seismic quiescence (see "Instrumentation and Data Analysis" section for definitions). 
In this paper we describe the seismicity at Mount Spurr preceding and accompanying the 1992 eruption sequence. First we review the seismic instrumentation, data acquisition, and data analysis. We then briefly summarize the seismic data from the Mount Spurr area beginning in 1981 as well as develop a more detailed seismic chronology for the period between August of 1991 and December of 1992. This chronology is based primarily on earthquake hypocenter plots and helicorder records, and to a lesser degree on Real-time Seismic Amplitude Measurements (RSAM) (Endo and Murray, 1991) and Seismic Spectral Amplitude Measurements (SSAM) (Stephens and others, 1994). We offer an initial volcanological interpretation of the patterns of seismicity, and we conclude with a review of the role that seismic observations played in forecasting the 1992 eruptions.

\section{ACKNOWLEDGMENTS}

We thank John Paskievitch, Steve Estes, John Rogers, and John Benevento for keeping instrumentation and telemetry running reliably throughout the 1992 eruptions. Gail Davidson provided valuable ass stance with data acquisition and computer management. The success in forecasting the Crater Peak eruptions is shared with our colleagues, most notably Johr Lahr, Bernard Chouet, Scott Stihler, Christopher Stephens, Guy Tytgat, and John Davies. We thank Elliot Endo and Randy White for their reviews of the manuscript and figures.

\section{INSTRUMENTATION AND DATA ANALYSIS}

Seismic monitoring on Mount Spurr volcano has a relatively long history. Station SPU was inctalled roughly $14 \mathrm{~km}$ from the summit of Mount Spurr in August of 1971 (fig. 1). The addition of stations CRP and CGL in the fall of 1981 allowed small earthruakes near Mount Spurr to be located. Station CGL w'as not maintained between late 1985 and early 1989 , so only two stations were operating near the volcano. Following the establishment of AVO, three new stations, CKL, BGL, and NCG, were added to the seismic network in late 1989, and stations CKN and CPK were in-

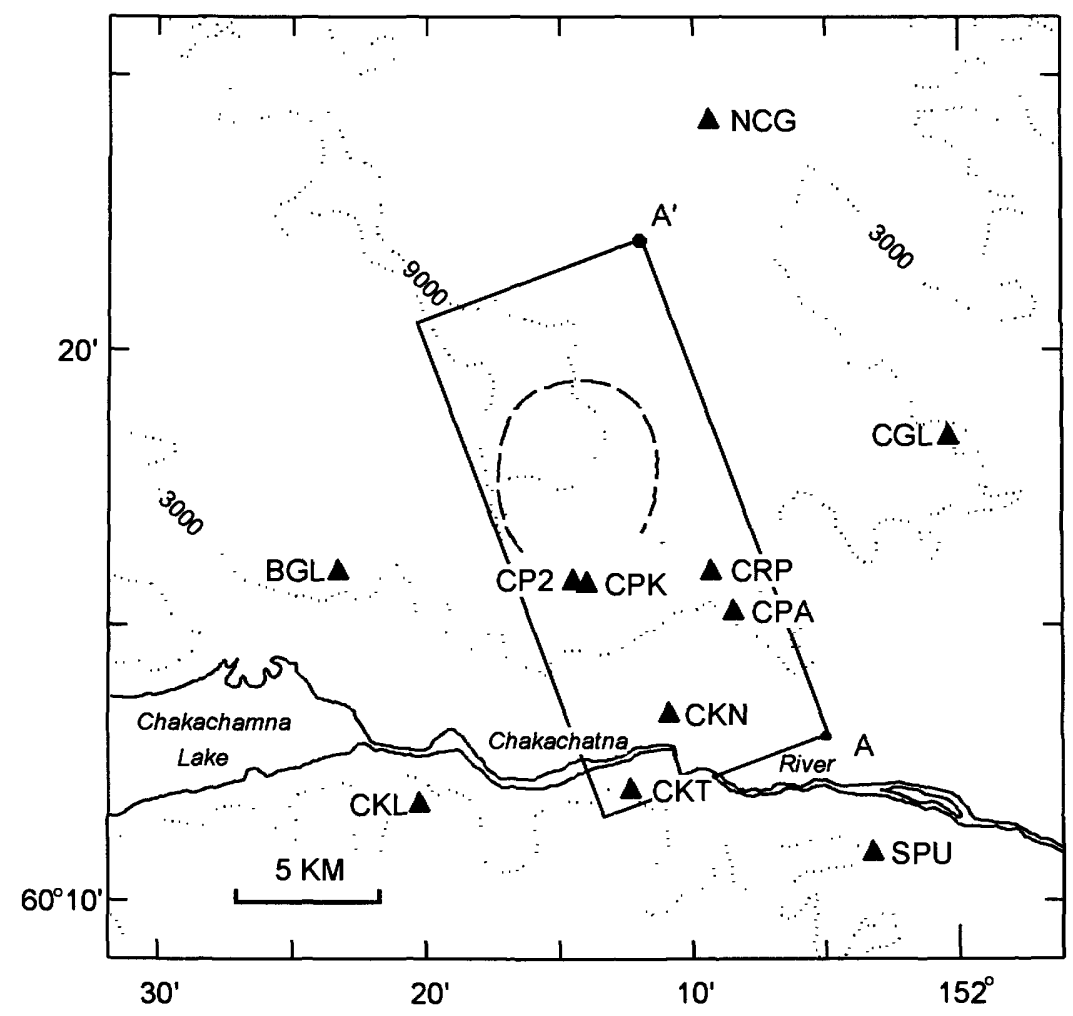

Figure 1. Seismic stations near Mount Spurr volcano, Alaska. Dotted lines represent 3,000- and 9,000- foot contours, dashed line represents approximate location of caldera rim. Box and line $A-A^{\prime}$ denote spatial extent of hypocenters shown in figure 4 , and the location of projected plane for cross sections in figure 3. 
stalled in the fall of 1991. Station CPK was destroyed during the June 27, 1992, eruption. A new instrument was installed at the same location on September 10 , and it was subsequently destroyed during the September 16-17 eruption. Station CPK was replaced by station CP2 on October 23. Stations CKT and CPA were added to the network on September 20 and October 29, respectively, which brought the total number of stations in the seismic network to ten. All stations were shortperiod single-component vertical seismometers except CPA and the original CPK, each of which had horizontal components. The original CPK also had a lowgain vertical component.

Between 1981 and 1989, data from the Spurr seismic network was recorded on 16-mm photographic film. Starting in July of 1988 these data were digitally recorded on a computer system at the AVO office in Fairbanks (AVO staff, 1990). In October of 1989, we also began recording the Spurr network on a personal computer using the program MDETECT, which digitizes and records 16 channels of event-detected data (Lee and others, 1989). This acquisition system provided the primary data set used in this study. Not all the stations from the Spurr network were recorded on the personal computer system during 1990 (fig. 2) because stations monitoring the ongoing eruptions of Redoubt Volcano were given higher priority for available channels on the system (Power and others, 1994). Beginning January 1, 1991, a complete suite of Spurr stations was established on this system and the triggering parameters were held constant through February 1993. Stations in the Spurr network were also monitored by an RSAM (Endo and Murray, 1991) and an SSAM (Stephens and others, 1994) system. March and Power (1990) described the various computer systems and their networking.

Event-detected waveforms were transferred to a microcomputer and phase arrivals were determined using the program XPICK (Robinson, 1992). Hypocenters and local magnitudes were determined using the program HYPOELLIPSE (Lahr, 1989) with a flatlayered velocity model and station corrections to account for local variations in seismic-wave velocities. The model we used was developed specifically for the Mount Spurr area by Jolly and others (1994). In this model, earthquake depths are permitted to occur as much as $3.2 \mathrm{~km}$ above sea level: the elevation of the summit of Mount Spurr. Consequently, depths are referenced to sea level; negative depths refer to height above sea level.

In describing the various waveforms and event types at Mount Spurr volcano, we use terminology and event classifications similar to that developed by Chouet and others (1994), Lahr and others, (1994), and Power and others, (1994) during the 1989-90 eruptions of Redoubt Volcano. This classification system is based on our present understanding of the physical processes associated with various seismic sources. Volcano-tectonic earthquakes refer to sources represonting purely elastic processes. Long-period events are thought to represent a more complex process in which fluids (gas and liquid phases) play an active role in the generation of seismic waves (Chouet, 1992). Volcano-tectonic and LP events represent end members of a spectrum; events combining these two characteristics are referred to as hybrid events. We do not identify hybrid events in this paper because identification of their spectral characteristics requires additional analysis, which has not yet been attempted (see I,ahr and others, 1994). The seismic events associated with the forcible ejection of gas and ash from the volcano are referred to here as explosive eruptions.

\section{SEISMIC CHRONOLOGY}

\section{OCTOBER 1981 THROUGH JULY 1991}

Mount Spurr and the surrounding area has teen seismically active since local monitoring began in 1981 . During periods between October 1981 and August 1991 when three or more stations were operating in the Snurr network, an average of 8.5 earthquakes per month greater than magnitude $\left(\mathrm{M}_{\mathrm{L}}\right) 0.0$ were located within $20 \mathrm{~km}$ of the volcano (fig. 2). Most of this activity concentrates beneath the summit at depths shallower than $3 \mathrm{~km}$. Very few shocks were located deeper than $5 \mathrm{~km}$ (fig. 3A). The largest located event in the Spurr area is a magnitude 3.3 , which occurred on November 16, 1989, at a depth of $16.5 \mathrm{~km}$ about $12 \mathrm{~km}$ northwest of the summit. Most located events range between magnitudes -0.5 and 1.5 .

A second concentration of epicenters lies on the north rim of the Mount Spurr caldera. Activity in this area occurred in two clusters; one is about $2 \mathrm{~km}$ north of the main summit cluster, and the other is roughly $3 \mathrm{~km}$ northeast of the main summit cluster (fig. $3 A$ ). The one northeast of the summit is the site of two small swarms of shallow earthquakes that occurre 1 in early 1982 and in early 1989 (fig. 4A). Hypocenters could not be calculated for the 1989 swarm, because only two stations were operating at the time. On the basis of similarities in waveforms between the two swarms, however, we surmise that the 1989 swarm occurred in the same location as the 1981 swarm. A more detailed description and analysis of the seismicity during this period is given by Jolly and others (19?4).

\section{AUGUST 1991 THROUGH JUNE 27, 1992}

The first sign of reawakening at Mount Spurr volcano was a small swarm of VT earthquakes be- 


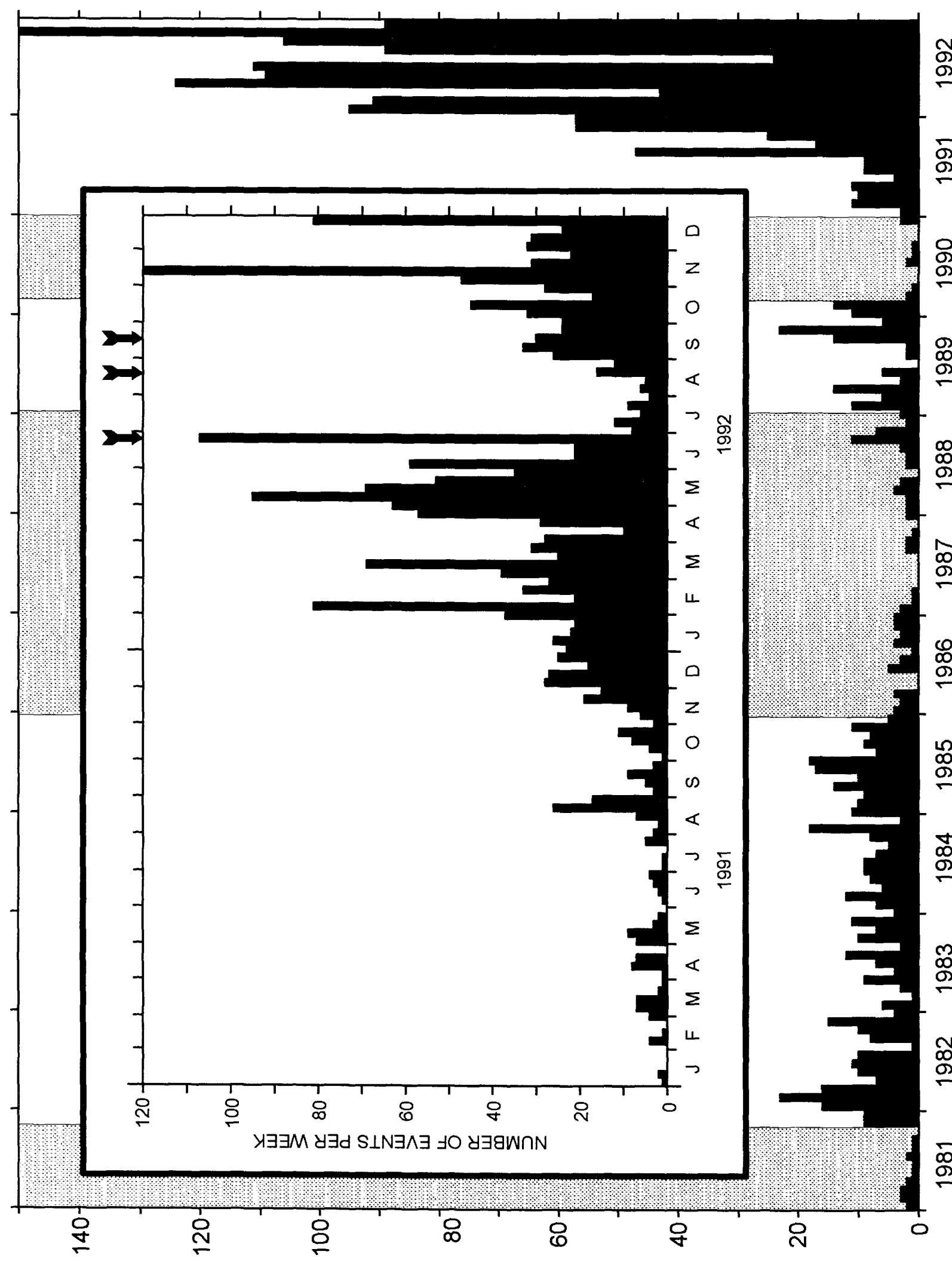

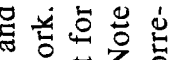

กิ O $\cong$ 过

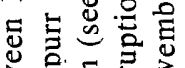

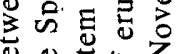

क

을 on.

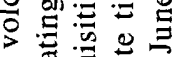

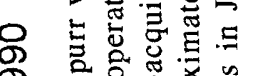
की

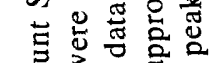
$\sum^{\circ}$

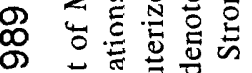

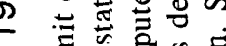

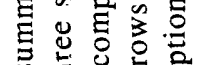

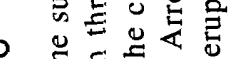

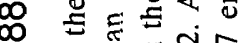
品 두웜 눈

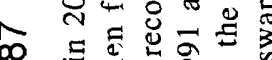
을 की कै 다늘 $\circ$ 㱐 D

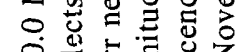

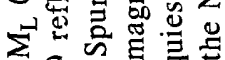
L O 远

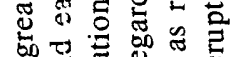
+ 然 类 के ता क्ष 흐응 응

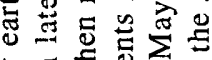

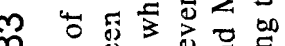

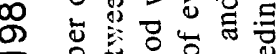

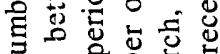
덩 $\sim$ 후 政 (

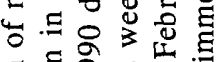
- छ $\infty$ 要売. 믄휴

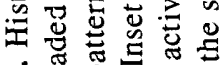

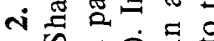
แ 실 包 

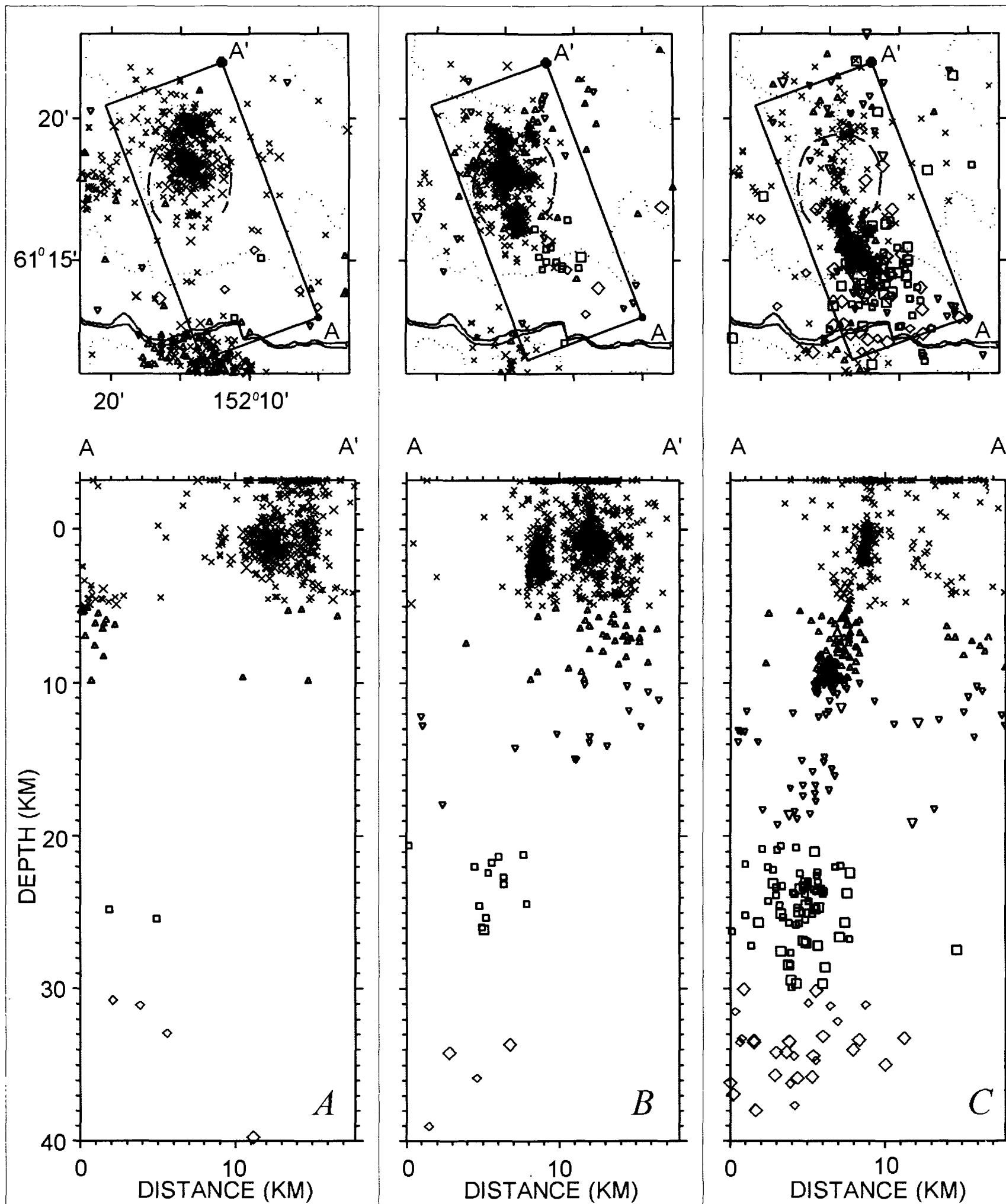

A

$A^{\prime}$

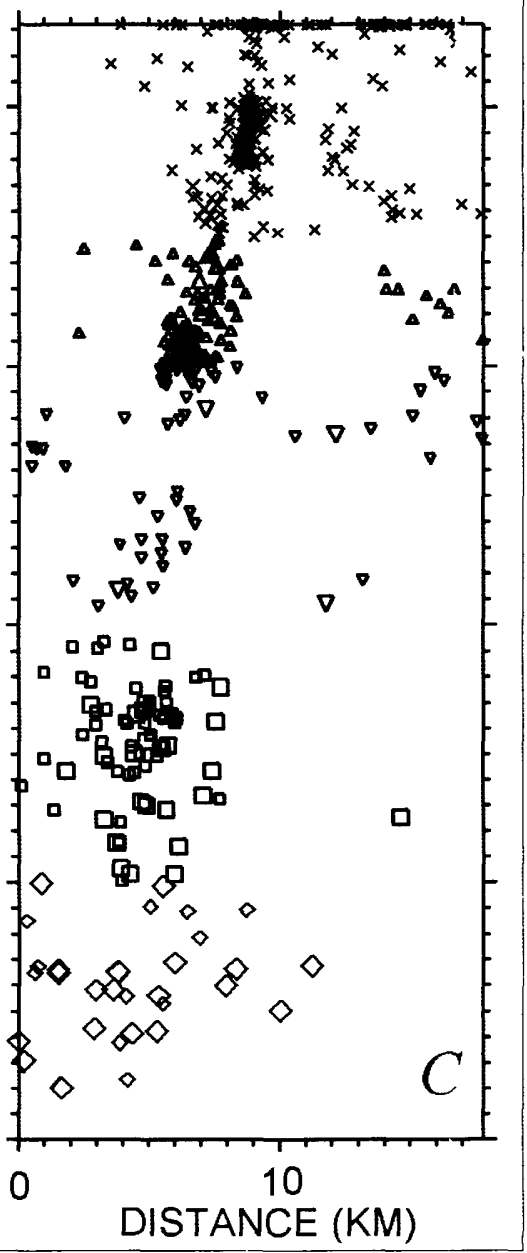

DEPTHS

$X-3.2+\triangleleft 5.0+\triangle 10.0+\square 20.0+\diamond 30.0+$

$\square-9.0+\quad \square 1.0+\quad \square 2.0+$

Figure 3. Epicenter maps and cross sections (A to A', figure 1) for three successive periods: $A$, background, October 1981 through July 1991; $B$, precursory, August 1991 through June 1992; and $C$, eruptive, July through December 31 , 1992. 
neath Crater Peak in August of 1991 (fig. 4B). Most of these shocks were less than ML 1.0 and ranged in depth from 1 to $4 \mathrm{~km}$. This swarm marked the first sustained seismic activity observed beneath Crater Peak since earthquake hypocenters could be reliably determined in 1981 (fig. 4A).

The August activity beneath Crater Peak was followed by two months of quiescence, and then by continuous elevated activity punctuated by more intense periods of seismicity in February and May (fig. 4B).

The August 1991 Crater Peak swarm initiated an increase in shallow seismic activity, which spanned the Mount Spurr caldera. Except for the Crater Peak area, this increase was mostly confined to areas that had been historically active-the summit and the north caldera rim. The number of VT earthquakes beneath the summit of Mount Spurr began to increase in October of 1991 (fig. 4B). Activity beneath the summit then increased nearly continuously until early June of 1992. Hypocenters were generally concentrated between -1.0 and $5.0 \mathrm{~km}$ in depth, although several shocks were recorded as deep as $15 \mathrm{~km}$ (fig. $3 A$ ). The largest event during this period was a $\mathrm{M}_{\mathrm{L}} 1.7$ on February 18,1992 , at a depth of $0.3 \mathrm{~km}$.

Activity beneath the north caldera rim was more discontinuous (fig. $4 B$ ). The first perceptible increase was a small group of earthquakes between 0 and 2 $\mathrm{km}$ depth in mid-December. More vigorous swarms occurred in March, April, and May of 1992. These events were concentrated near the two clusters of events from the previous decade (compare figs. $3 A$ and $3 B$ ). The distribution of depths in the north cluster is more diffuse, generally ranging from -2.0 to $6.0 \mathrm{~km}$. The largest event during this period beneath the north rim is a $M_{L} 1.6$, which occurred on May 3, 1992, at a depth of $0.3 \mathrm{~km}$.

On June 5, 1992, the number of located earthquakes at Mount Spurr volcano reached 28, the highest number recorded in any 24-hour period. These shocks ranged in depth between -1.0 and $1.0 \mathrm{~km}$ and were clustered beneath Crater Peak. Coincident with this swarm, short bursts of volcanic tremor were recorded on the stations closest to Crater Peak for the first time (McNutt and others, this volume). Following the June 5 swarm, the number of locatable events declined throughout the entire caldera, most notably beneath the summit and Crater Peak (figs. 2 and $4 B$ ).

The other noticeable change in seismicity, which occurred between August of 1991 and June 27, was the onset of activity in the depth range of 10 to 40 $\mathrm{km}$ beneath and southeast of Crater Peak (figs. $3 B$, $4 B$ ). The first of these events was located in August of 1991 , and more than 40 occurred before the June 1992 eruption. These events occurred in a volume that had been practically aseismic during the previous decade (compare fig. $3 A$ and $3 B$ ). Waveforms from events at depth display a broader range of spectral characteristics that range from high-frequency earthruakes, which appear to be volcano-tectonic to low-frequency events, which have a strong long-period character. Attenuation of the seismic waves from these deep events makes their classification difficult. Those events that we feel are volcano-tectonic generally have vell-defined phases and a dominant frequency between 3 and $4 \mathrm{~Hz}$, whereas low-frequency events lack well-defined phases, have peak frequencies of about $2 \mathrm{~Hz}$, and have extended coda. The variability in observed waveforms for two events from roughly $33 \mathrm{~km}$ depth is sl own in figure 5. A detailed spectral analysis of all of the events below $1.0 \mathrm{~km}$ has not yet been completed.

At 12:04 p.m. ADT on June 26 continucus volcanic tremor began, which was easily visible on all stations within $14 \mathrm{~km}$ of the volcano $(\mathrm{McN} \times \mathrm{tt}$ and others, this volume). At roughly 3:00 a.m. ADT on June 27 , just 4 hours before eruptive activity began, a vigorous swarm of shallow VT earthquakes began. These shocks were located between -1.0 and $1.0 \mathrm{~km}$ in depth and ranged in magnitude between -0.6 and 1.2. The magnitudes of events increased thro"gh the duration of the swarm. To date, only three LF events have been identified in this swarm. The eruption on June 27 lasted 4 hours and 3 minutes (McNutt and others, this volume). The June 27 eruption v'as followed by a short-lived shallow swarm of LP events, which lasted for about 24 hours.

\section{JUNE 27 THROUGH SEPTEMBER 17, 1992}

Following the June 27 eruption, the volcano entered a period of relative quiescence in which the shallow seismicity was comparable to or lower than the pre-August 1991 level (fig. 4B). In contrast, the deeper seismicity continued at a low, steady rate comparable to its August 1991 through June 1992 level. The area beneath the summit remained nearly aseismic throughout the remainder of 1992, and only low levels of activity occurred beneath the north caldera rim (figs. $3 C, 4 B)$.

Figure 4. Time-distance $(A, B)$ and time-depth $(C)$ plots for hypocenters within the box shown in figure 1 . A and $B$ are time distance plots along the line A-A' for pericds 1981 through 1992 and 1991 through 1992, respectively. Shaded arrow in $A$ shows approximate location of $1989 \mathrm{swarm}$. $C$, data from 1991-92. Solid arrows denote the three eruptions on June 27, August 18, and September 16-17. 

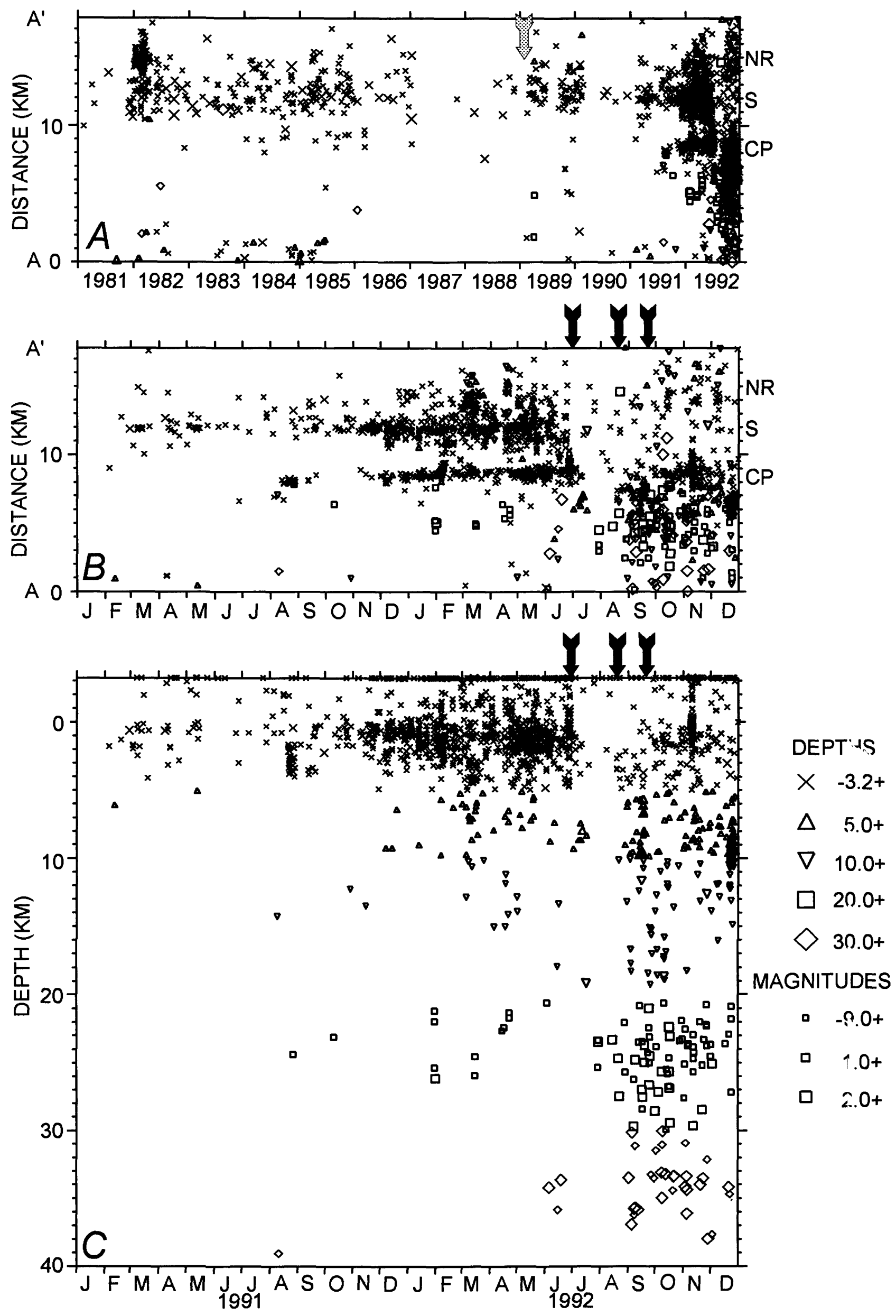


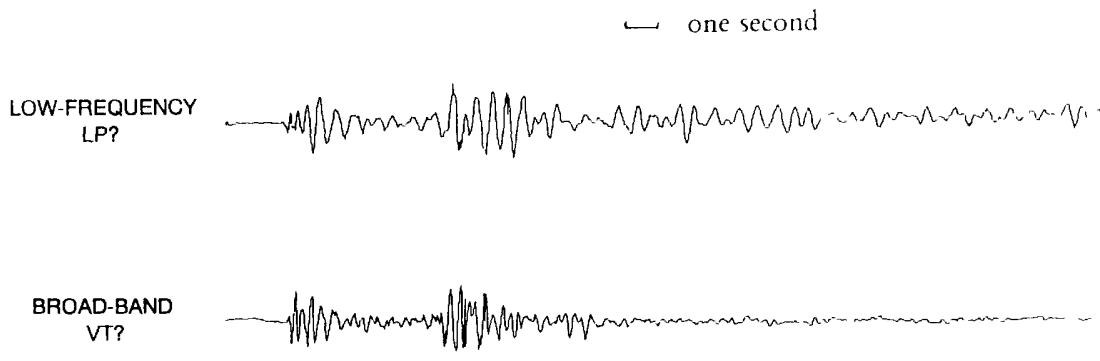

Figure 5. Comparative waveforms recorded at seismic station CGL on Mount Spurr volcano, Alaska, from two events located at a depth of approximately $33 \mathrm{~km}$. These waveforms illustrate the diversity of signals observed in events at depths greater than $10 \mathrm{~km}$. Note the monochromatic character and long duration of the low frequency event (upper trace). Such features are typical of long-period (LP) events.

The August 18 eruption occurred with no obvious seismic precursor at CRP, the closest station to the crater that was operating at the time. Eruptive activity on August 18 began with a small ash-laden plume at 3:37 p.m. ADT, which was accompanied by 16 minutes of weak tremor and several LP events. The main eruption began at 4:42 p.m. ADT and lasted about 3 hours and 28 minutes (McNutt and others, this volume).

Following the August 18 eruption, seismicity below depths of $2 \mathrm{~km}$ began to slowly increase, while that at shallower depths remained low (fig. $4 C$ ). Activity in the depth range of 2 to $10 \mathrm{~km}$ and below 20 $\mathrm{km}$ appears to have stabilized at a new, higher background level at about the time of the September eruption (fig. 4C). On September 16, shallow tremor, which was interspersed with small discrete events, began about 7:30 p.m. ADT. A small eruption, which lasted about 11 minutes, began at 10:36 p.m. ADT. Seismic activity remained elevated, and at 12:04 a.m. ADT on September 17 the main eruption began. The intense seismicity associated with this eruption lasted 3 hours and 36 minutes (McNutt and others, this volume). The waning phase of the eruption included a series of VT earthquakes between 2 and $11 \mathrm{~km}$ depth, the largest of which was a $\mathrm{M}_{\mathrm{L}} 1.9$.

\section{SEPTEMBER 17 THROUGH DECEMBER 31, 1992}

The seismicity that followed the September 16-17 eruption differed markedly from seismicity that followed the two earlier eruptions. Strong volcanic tremor occurred for roughly 9 days on stations close to the volcano. The rate of VT earthquakes between depths of 0 and $5 \mathrm{~km}$ increased and remained elevated over the next 6 weeks (figs. $4 B, 4 C$ ). The occurrence rate of shocks deeper than $10 \mathrm{~km}$ also increased following the September eruption.

Shallow volcanic tremor returned several times between October 2 and 7. Early on November 9 the rate of shallow VT earthquakes began to increase on the stations closest to the volcano. By 9:00 p.m. ADT the events were occurring at a rate of approximately 1.5 per minute. This activity continued for roughly 3.5 hours and comprised more than 170 shocks. The magnitude of the largest earthquake was 1.7. This was the most energetic swarm recorded at Mount Spurr associated with the 1992 eruption sequence.

Following the swarm on November 9 and 10, activity remained elevated at all depths. In early December the rate of events between depths of 20 and $40 \mathrm{~km}$ began to decline slowly. A swarm of small $\left(\mathrm{M}_{\mathrm{L}}\right.$ < 1.5) VT earthquakes occurred between December 21 and 26. These events originated between depths of 5 and $12 \mathrm{~km}$, and most of the events were clustered between 8 and $10 \mathrm{~km}$. Activity slowly declined through early 1993 and by late April the number of locatable earthquakes in the Mount Spurr ar:a approached a level comparable to that observed prior to August of 1991.

\section{DISCUSSION}

\section{VOLCANOLOGICAL INTERPRETATICN}

From our observations of the spatial and temporal patterns of hypocenters, waveforms of the various seismic events, and amplitude and spectral measurements, we offer some interpretations. This discussion should be viewed as preliminary, as it is based on primary observations rather than a detailed analysis of all available seismic data.

Between October 1981 and July 1991, Mount Spurr seismicity was characterized by steady-state activity beneath the summit, punctuated by two swarms under the north caldera rim. There is a marked absence of seismicity at depths greater than $5 \mathrm{k} \mathrm{n}$ during this period. Jolly and others (1994) model this aseismic zone as a volume of hot buoyant rock, heated by earlier episodes of intrusion, which deformet plastically rather than elastically. 
The first unusual activity identified prior to the 1992 eruptions was a shallow short-lived swarm of VT earthquakes beneath Crater Peak in August of 1991 (fig. $4 B$ ). This swarm was followed within several months by an increase in shallow activity throughout the caldera. A more subtle increase was also observed at depths greater than $10 \mathrm{~km}$. Its onset may have preceded slightly the August 1991 Crater Peak swarm, but there are too few deep events to draw a definitive conclusion. We propose that most of the seismicity in the 10 -month period prior to the June 27 eruption resulted from an intrusion of magma between depths of 5 and $15 \mathrm{~km}$. Thus we suggest a deep origin for the initiation of the eruption sequence. The calderawide seismicity likely resulted from a mechanical response to deformation and stresses associated with this intrusion. We suggest that the intrusion produced strain rates that were sufficient to drive rock in the aseismic volume identified by Jolly and others (1994) from plastic to brittle behavior.

That seismicity beneath the summit declined following the June 5 swarm lends support to the mechanical model for the precursory seismicity. The June 5 swarm is coincident with the onset of volcanic tremor at Crater Peak. We suggest that magma had migrated to shallower depths by this time and had activated the shallow hydrothermal system (McNutt and others, this volume). This migration concentrated stress at Crater Peak, which resulted in the decline in activity in other areas of the caldera.

Following the June eruption, seismicity entered a 7-week period of near-quiescence comparable to or less than the level of activity observed prior to August of 1991. This quiescence suggests that stress and related deformation, as well as fluid pressures within the shallow hydrothermal system, were greatly reduced following the eruption. Activity below a depth of 10 $\mathrm{km}$ did not lapse into quiescence, although the overall rate of deeper events remained relatively low and did not increase until after the August 18 eruption.

That no increase in shallow seismicity preceded the August 18 eruption and that the September 16-17 eruption was preceded by only several hours of shallow activity visible on CPK suggest that the vent and shallow conduit system were left relatively unobstructed following the June eruption.

Deeper seismicity $(>10 \mathrm{~km})$ increased markedly following the August 18 eruption and peaked shortly after the September eruption. The waveforms of these events cover a broad spectrum ranging from VT events to rather monochromatic, low-frequency signals suggestive of LP events (fig. 5). These events might reflect the recharge and migration of magma at these depths. Alternatively, these events might result from readjustments of stress in response to the removal of magma from these depths. Both these explanations are quite plausible in view of the variety of observed waveforms. However, additional analyses are required to demonstrate that the low-frequency waveforms are related to the characteristic of the source process rather than the result of attenuation of higher frequancy energy along the wave path.

The strong swarm of events on November $S$ and 10 is likely related to a shallow intrusion of magma. Preliminary analysis of these events suggests they occurred at three locations a few hundred meters apart between 0.0 and $-1.0 \mathrm{~km}$ depth (Chris Stephens, written commun.). The cluster of events in late Decembar is perhaps related to an additional deeper intrusion at 8 to $10 \mathrm{~km}$ depth.

\section{ERUPTION FORECASTING}

In this section we review the role that seismological observations played in formulating eruption forecasts and the factors that influenced our interpretations at the time. The forecasting strategy use t by AVO relied on the synthesis of data from a number of monitoring techniques, which include a variety of seismic methods (hypocenters, seismicity rate, RSAM, SSAM, and waveform characteristics), visual observations, measurements of gas emissions, and geochemical and petrologic analyses. In reviewing AVO's public statements concerning volcanic activity at Mount Spurr volcano, we use the terms forecast and eruption notification. A forecast describes statements issued prior to expected eruptive activity. Forecasts were relatively imprecise statements concerning the timing and nature of expected eruptive activity. Our use of the term forecast differs somewhat from that of Swanson and others (1985) because at Mount Spurr forecasts were formulated on the basis of observed changes in seismic measurements and observations of the volcano. We avoid the term prediction because staterrents issued for Mount Spurr contained little precise information on the timing of expected eruptive activity. Eruption notifications were purely factual staterrents that contained information about the onset time and size of eruptions. Eruption notifications described here belong in the category of factual statements in the terminology of Swanson and others (1985). The primary vehicle by which AVO disseminated forecasts and eruption notifications to other government agencies, industry, and the public was based on a color code system similar to that developed during the 198990 eruptions at Redoubt Volcano (Brantley, 1990). The color code definitions used at Redoubt were modified slightly on the afternoon of June 26 to more appropriately describe the situation and conditiors at Mount Spurr.

Both the June 27 and September 16-17 eruptions were successfully forecast. Whereas no forecast 
was issued for the August 18 eruption, seismic confirmation allowed AVO to issue an eruption notification within minutes of the onset of both the premonitory and the main eruption. Forecasts were also issued during a period of heightened tremor on October 2 and during the November 9-10 earthquake swarm, but no subsequent eruption occurred.

The 10-month period of precursory VT earthquakes makes the June 27 eruption one of the more anticipated eruptions on record. The unusual character of the August 1991 swarm was recognized as the events were occurring. This was possible because of the long-term operation of the seismic network and the availability of the associated earthquake catalog. Between August of 1991 and June of 1992, the increasing caldera-wide seismicity was discussed in weekly AVO public information releases. On June 8 in response to the escalating seismicity, AVO issued a special public advisory, which stated that the present seismic unrest could be an early forerunner of an eruption. In response to the onset of continuous tremor on June 26, AVO issued a forecast that cited potential hazards associated with an eruption of Crater Peak. The basis for this forecast was the onset of strong continuous volcanic tremor (McNutt and others, this volume) as well as observed changes in the hydrothermal regime at Crater Peak (Eichelberger and others, this volume). While this warning did discuss the increased probability of an eruption, it did not state that an eruption was likely within the next few days. Our hesitation regarding the imminence of an eruption on the evening of June 26 largely stemmed from two factors: two strong episodes of volcanic tremor had occurred earlier on June 24 and 25 (McNutt and others, this volume), and the absence of swarms of LP events. We were perhaps overly focused on the occurrence of swarms of LP events, because of our recent experiences at Redoubt Volcano (Chouet and others, 1994, Stephens and others, 1994) and Mount Pinatubo (Harlow and others, 1991), at which strong LP swarms preceded many of the eruptions. Once the swarm of VT earthquakes began at about 3:00 a.m. ADT on June 27, we had little doubt that an eruption was close at hand. In hindsight, the strength of the tremor on June 26 differed enough from earlier episodes to justify a stronger forecast.

In contrast to late June, no unusual shallow precursory activity was observed prior to the August 18 eruption, although station CPK had not yet been repaired. The eruption ended the 7-week period of shallow seismic quiescence, which followed the June event. The eruption was not expected as the level of seismicity had declined sharply after the June eruption and remained low. Additionally, the 1953 eruption at Crater Peak consisted of a single event (Juhle and Coulter, 1955). The caldera-wide volume activated seismically prior to the June eruption raised the q'estion of the volume of magma involved and the possibility of additional eruptive events. However, in view of the long duration of seismic quiescence following the June eruption, the timing of the August eruption was a surprise. Seismic monitoring did allow confirmation of a small premonitory eruption at 3:35 p.m. ADT, which was reported by a pilot. The occurrence of this small event prompted AVO to issue a public advisory of increased activity. When the main phase of the eruption began at 4:42 p.m. ADT, AVO issued an eruption notification within 2 minutes of its onset.

The September 16-17 eruption was preceded by 3 hours of identifiable shallow precursory antivity (McNutt and others, this volume). The overall level of seismicity below a depth of $3 \mathrm{~km}$ had been increasing steadily since the August 18 eruption. Following the August 18 eruption, we were particularly mindful that future eruptive events might occr with little or no precursory activity. Close monitoring of the seismicity allowed identification of the precursory tremor shortly after it began and the recognition of the small premonitory eruption at 10:36 p.m. ADT. A forecast was issued at 10:45 p.m. ADT, more than an hour before the main phase of the eruption began at 12:04 a.m. ADT on September 17, and an eruption notification was issued shortly after its onset.

The two unsuccessful forecasts issued during the 1992 eruption sequence were based on an increase in tremor amplitude on October 2, and on an increase in the rate of earthquake occurrence during the November 9-10 swarm. The tremor on October 2 was similar in character to that which immediately preceded the June 27 eruption. Average tremor amplitudes increased dramatically between October 1 and $5\left(M^{\mu} \mathrm{cNutt}\right.$ and others, this volume). The swarm on November 9-10 was the most energetic observed during the eruption sequence and is likely related to the emplacement of a shallow intrusion. At the height of this swarm, earthquakes were occurring at a rate of roughly 1.5 per minute. While neither of these seismic episodes culminated in an eruption, the forecasts were justified on the basis of the continuing increases in seismicity that were larger than those observed p-ior to the August and September eruptions. These events serve as a reminder that not all strong increases in seismicity result in eruptions. At this time, there is no seismological basis for differentiating these sequerces of events from those that resulted in eruptions.

\section{CONCLUSIONS}

Seismological observations suggest that precursory seismicity resulted from an intrusion at mid-crustal depths, perhaps 5 to $15 \mathrm{~km}$. The shallow precursory seismicity that occurred throughout the Mount Spurr 
caldera was likely a mechanical response to the intrusion. We also observed an increase in seismicity in a previously identified aseismic volume of rock, between depths of 10 and $40 \mathrm{~km}$ depth (Jolly and others, 1994). The onset of this seismicity suggests the intrusion generated sufficient strain rates to induce brittle failure in a volume that had previously deformed plastically.

The June 27 eruption was preceded by 10 months of shallow VT earthquakes, several weeks of shallow volcanic tremor, and immediately by 14 hours of tremor and a 4-hour swarm of VT earthquakes between depths of -1.0 and $1.0 \mathrm{~km}$. In contrast the August 18 eruption had no precursory activity visible on the stations operating at the time, and the September 16-17 eruption had only about 3.5 hours of shallow precursory activity. We conclude that the vent and the upper portions of the conduit were left largely unobstructed following the June eruption.

Seismicity between depths of 10 and $40 \mathrm{~km}$ exhibits a variety of waveforms ranging from VT to LP. The diversity of waveforms suggests a variety of source processes ranging from stress adjustments in the country rock caused by withdrawal or intrusion of magma, or the transport of magma. Planned analysis of individual deep events should allow us to narrow our interpretations.

\section{REFERENCES CITED}

Alaska Volcano Observatory Staff, 1990, The 1989-1990 eruption of Redoubt Volcano: Eos, Transactions of the American Geophysical Union, v. 71, p. 265-275.

Alaska Volcano Observatory, 1993, Mount Spurr's 1992 eruptions: Eos, Transactions of the American Geophysical Union, v. 74, p. 217-222.

Brantley, S. R., 1990, The eruption of Redoubt Volcano, Alaska, December 14, 1989 - August 31, 1990: U.S. Geological Survey Circular 1061, 33 p.

Chouet, B.A., 1992, A seismic source model for the source of longperiod events and harmonic tremor, in Gasparini, P., Scarpa, R., and Aki. K., eds., Volcanic Seismology: IAVDEI Proceedings in Volcanology, Berlin, Springer-Verlag.

Chouet, B.A., Page, R.A., Stephens, C.D., Lahr, J.C., and Power, J.A., 1994, Precursory swarms of long-period events at Redoubt Volcano (1989-1990) and their use as a forecasting tool: Journal Volcanology and Geothermal Research. v. 62, p. $95-136$.

Endo, E.T., and Murray, T.L., 1991, Real-time seismic ampl'tude measurement (RSAM): a volcano monitoring and prediction tool: Bulletin of Volcanology, v. 53, p. 533-545.

Harlow, D.H., Punongbuyan, P.S., Power, J.A., Newhall, C.G., Hoblitt, R.P., Lockhart, A.B., Murray, T.L., Ewert, J.E., 1991, Seismic activity and forecasting of the climactic eruption of Pinatubo Volcano, Luzon, Philippines on June 15, 1991 [abs.]: Eos, Transactions of the American Geophysical Urion, v. 72, p. 61 .

Jolly, A. D., Page, R.A., and Power, J.A., 1994, Seismicity and stress in the vicinity of Mount Spurr volcano, South Central Alaska: Journal of Geophysical Research, v. 99, p. 15305-1 ₹318.

Juhle, W., and Coulter, H., 1955, The Mount Spurr eruption, JLly 9 , 1953: Eos, Transactions of the American Geophysical Urion, v. 36, p. 199-202.

Lahr, J.C., 1989, Hypoellipse/version 2.00: A computer program for determining local earthquake hypocentral parameters, magnitude, and first motion: U.S. Geological Survey OpenFile Report 89-116, 89 p.

Lahr, J.C., Chouet, B.A., Stephens, C.D., Power, J.A., and Page, R.A., 1994, Earthquake location and error analysis procedures for a volcanic sequence: Application to 1989-1990 eruptions at Redoubt Volcano, Alaska: Journal of Volcanology and Geothermal Research. v. 62, p. 137-153.

Lee, W.H.K., ed., 1989, Toolbox for seismic data acquisition, processing, and analysis: IASPEI Software Library, Volume 1: Seismological Society of America, El Cerrito, $284 \mathrm{p}$.

March, G.D., and Power, J.A., 1990, A networked computer configuration for seismic monitoring of volcanic eruptions: U.S. Geological Survey Open-File Report 90-422, 19 p.

Power, J.A., Lahr, J.C., Page, R.A., Chouet, B.A., Stephens, C.D., Harlow, D.H., Murray, T.L., and Davies, J.N., 1994, Seismic evolution of the 1989-90 eruption sequence of Redoubt Volcano, Alaska: Journal of Volcanology and Geotherma' Research, v. 62, p. 69-94.

Robinson, M.R., 1992, XPICK user's manual V 4.2: Seismclogy Lab of the Geophysical Institute, University of Alaska, Fairbanks, $119 \mathrm{p}$.

Stephens, C.D., Chouet, B.A., Page, R.A., Lahr, J.C., and Pc 'ver, J.A., 1994, Seismological aspects of the 1989 - 1990 eruptions at Redoubt Volcano, south-central Alaska: The SrAM perspective: Journal of Volcanology and Geothermal Research, v. 62, p 153-182.

Swanson, D.A., Casadevall, T.J., Dzurisin, D., Holcomb, R.T. Newhall, C.G., Malone, S.D., and Weaver, C.S., 1985, Forecasts and predictions of eruptive activity at Mount St. Helens, USA: 1975-1984: Journal of Geodynamics, v. 3, p. 397-423. 



\title{
Preliminary Analyses of Volcanic Tremor Associated with 1992 Eruptions of Crater Peak, Mount Spurr Volcano, Alaska
}

\author{
By Stephen R. McNutt, Guy C. Tytgat, and John A. Power
}

\section{CONTENTS}

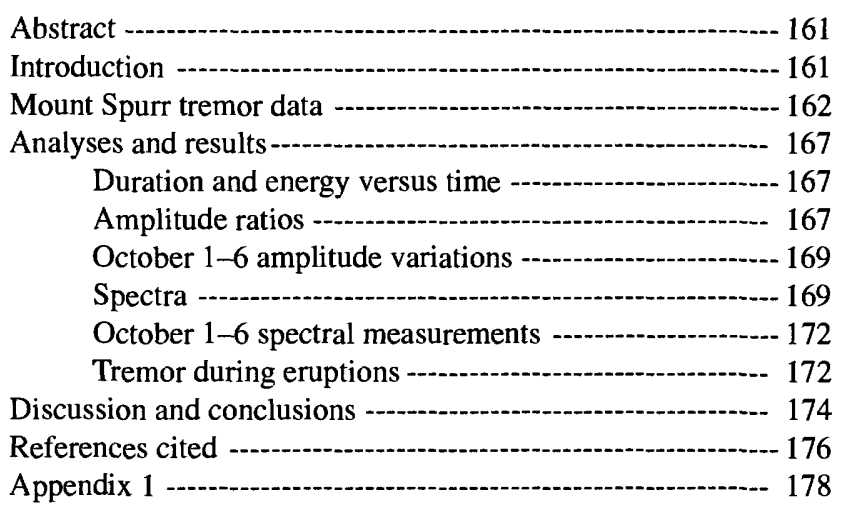

\begin{abstract}
The occurrence of volcanic tremor played an important role in monitoring and eruption forecasting at Mount Spurr by signifying changes in rates of precursory seismicity and indicating the beginnings and ends of eruptions. For example, the onset of continuous tremor provided the principal basis for changing the level of concern color code 15 hours before the first eruption on June 27, 1992. The onset of strong tremor marked the beginning of each of the three main eruptions, and it was the basis for issuing updates and notifications The declines in tremor amplitude signaled the ends of the eruptions. Tremor also provided physical insight concerning eruptive processes based on spatial and temporal variations in amplitudes and frequencies versus time. The volcano is monitored by a network of 10 seismic stations within $22 \mathrm{~km}$ of the vent, in addition to regional seismic stations at greater distances. Three types of tremor were observed at Mount Spurr in association with the 1992 eruptionstremor bursts lasting 1 to 10 minutes, continuous tremor lasting 2 hours to several days, and tremor during eruptions. Tremor bursts occurred from June 6 to 26 in higher numbers at first which then declined. The overall cumulative energy curve is concave upward, but individual segments are all concave downward; this phe-
\end{abstract}

nomenon suggests that sources of energy such as heat or water formed quickly then gradually lost energy. Tremor energy increased by one order of magnitude in the 3 days before the first eruption on June 27, 1992. Comparison of spectra from June 26 and June 27 showed that spectral peaks were shifted to lower frequencies by 18 percent; this shift suggests an increase in source length or a decrease in velocity caused perhaps by formation of bubbles. RMS amplitude ratios computed for near $(400 \mathrm{~m})$ and far $(5 \mathrm{~km})$ stations showed an increase by a factor of 2.7 at the near station from June 11 to June 25, which we model as a shoaling of the source depth. Eruption tremor was substantially stronger than any of the pre-eruption tremor, and was recorded on stations at distances of as much as $138 \mathrm{~km}$. Calculated reduced displacements ranged from 16 to $30 \mathrm{~cm}^{2}$ for the strongest eruption tremor. The duration of the strongest eruption tremor was crudely proportional to the tephra volume for the three eruptions. Future efforts will focus on modeling the source mechanisms in greater detail.

\section{INTRODUCTION}

Active volcanoes produce a great variety of seismic signals. In addition to earthquakes and various low-frequency events, volcanic tremor is often obse"ved. The typical appearance of tremor is that of an irregular sinusoid, and a key distinguishing feature is its long duration compared with earthquakes of the same amplitude. Continuous signal durations of days, weeks, and longer are common. Tremor has been recorded at 129 volcanoes worldwide (McNutt, 1992).

Volcanic tremor has received considerable attention in the literature over the past few years. Research efforts have been concentrated in four main areas: (1) sources, including shock-waves, (2) propagation effects, (3) magma flow and bubble distribution, and (4) nonlinear models. Theoretical work on tremor by Chouet (1992) focused chiefly on source effects of fluid pressurization in resonant cavities excited by a variety of mechanisms. Chouet numerically treated a rectangular crack that was excited by pressure p"lses 
acting at various locations on the surface of the crack. He considered his source model to apply to both longperiod (LP) events and to volcanic tremor, by assuming that superposition of LP events produced tremor. More recently, Chouet and others (1994) have extended this model to the LP swarms accompanying the 198990 eruptions of Redoubt Volcano, Alaska. They suggest, in the new model, flow-induced shock waves at a depth of $1.4 \mathrm{~km}$ below the vent as the source of the pressure pulses. Dawson and others (1992) modeled a small, low-velocity zone at the same depth, and they suggested the presence of a small magma body.

Gordeev (1992) studied propagation effects, using near-surface pressure fluctuations such as explosions as sources, and he modeled waveforms propagating through low-velocity layers overlying a half space. His conclusion was that the frequencies and waveforms of tremor are chiefly caused by propagation effects. Hurst (1992) performed stochastic simulations of tremor using both white noise and Poisson forcing functions to excite resonance in a simple harmonic oscillator. He also allowed the oscillator to have a random damping factor. His simulations produced synthetic signals that closely resemble observed volcanic tremor at Ruapehu in New Zealand.

Montalto and others (1992) qualitatively modeled the effects of bubble distribution on tremor and eruption energy for the 1990 eruptions of Mount Etna in Sicily. They suggest that low-amplitude tremor is caused by bubbly flow of magma, whereas high-amplitude tremor is caused by slug flow.

Ukawa (1993) made an important observation for the 1989 Ito-oki submarine eruption. He found that low-frequency $(1 \mathrm{~Hz})$ tremor within $50 \mathrm{~km}$ of the source consisted primarily of surface waves trapped in sedimentary layers. Middle-frequency tremor $(2-7 \mathrm{~Hz})$ observed at the same time at more distant stations was composed primarily of body waves, thus highlighting the importance of propagation effects. Julian (1994) studied a nonlinear model for tremor generation, using a lumped parameter model of flow through a channel that is represented by a mass-spring system, which includes damping. He argued that selfoscillations of this system can produce most of the main features observed in volcanic tremor. In summary, all this recent work suggests that a variety of source and propagation effects are present in volcanic tremor, and there is as yet no consensus about the tremor source. In fact, there are such a variety of observations and source models that there are probably several sources for tremor, not just one.

The occurrence of volcanic tremor played an important role in eruption monitoring and forecasting at Mount Spurr by signifying changes in rates of precursory seismicity and indicating the beginnings and ends of eruptions. For example, the onset of continuous tremor provided the principal basis for changing the level of concern color code 15 hours before the first eruption on June 27, 1992. The onset of strong tremor marked the beginnings of each of the three main eruptions, and it was the basis for issuing updates and notifications. The declines in tremor amplitude signaled the ends of the eruptions. Analyses of tremor helped provide insight into physical pro?esses that occurred prior to, during, and after the three eruptions of June 27, August 18, and September 16-17, 1992. Three types of volcanic tremor were recorded at Mount Spurr: (1) tremor bursts of 1 to 10 minutes duration, with irregular amplitudes, occurring from June 6 to June 26; (2) continuous tremor lasting 2 hours to several days, with uniform amplitudes, occurring June 24-27, September 17-25, October 2-20, ard November 9-10; and (3) tremor during eruptions on June 27. August 18, and September 16-17. The purpose of this paper is to show examples of all three tyoes of tremor and to present results from the preliminary analyses that have been performed as of April 1993. We also discuss possible models for tremor at Mount Spurr, compare its tremor to that at other volcanoes, and discuss the role played by tremor in eruption forecasting.

\section{MOUNT SPURR TREMOR DATA}

Mount Spurr is monitored by a network of 10 seismic stations within $22 \mathrm{~km}$ of the summit (f'g. 1). The active vent, Crater Peak, is located $400 \mathrm{~m}$ west of seismic station CPK. Eight of the stations have a $1-\mathrm{Hz}$ vertical geophone, (CPK and CPA are three-component) and data are telemetered in analog form via radio and microwave to the Alaska Volcano Observatory offices at the Geophysical Institute of the University of Alaska Fairbanks. Power and other: (this volume) describe the instrumentation and various dataacquisition systems in detail. One data-acquisitic n system used in Fairbanks digitizes the signals at a sampling rate of 120 samples per second using a Masscomp computer system. In addition to triggered event recording, this system records data continuously from about 140 stations of the Alaska regional seismic network 24 hours per day on DAT tapes (Sonnafrank and others, 1991). This computer provided the primary data set analyzed in this paper. Seismic data are also recorded on a Real-time Seismic Amplitude Measurement (RSAM) system (Endo and Murray, 1991), a Seismic Spectral Amplitude Measurement (SSAM) system (Stephens and others, 1994), and on a PC/AT computer, which runs continuously in event-detected mode (Lee, 1989). 


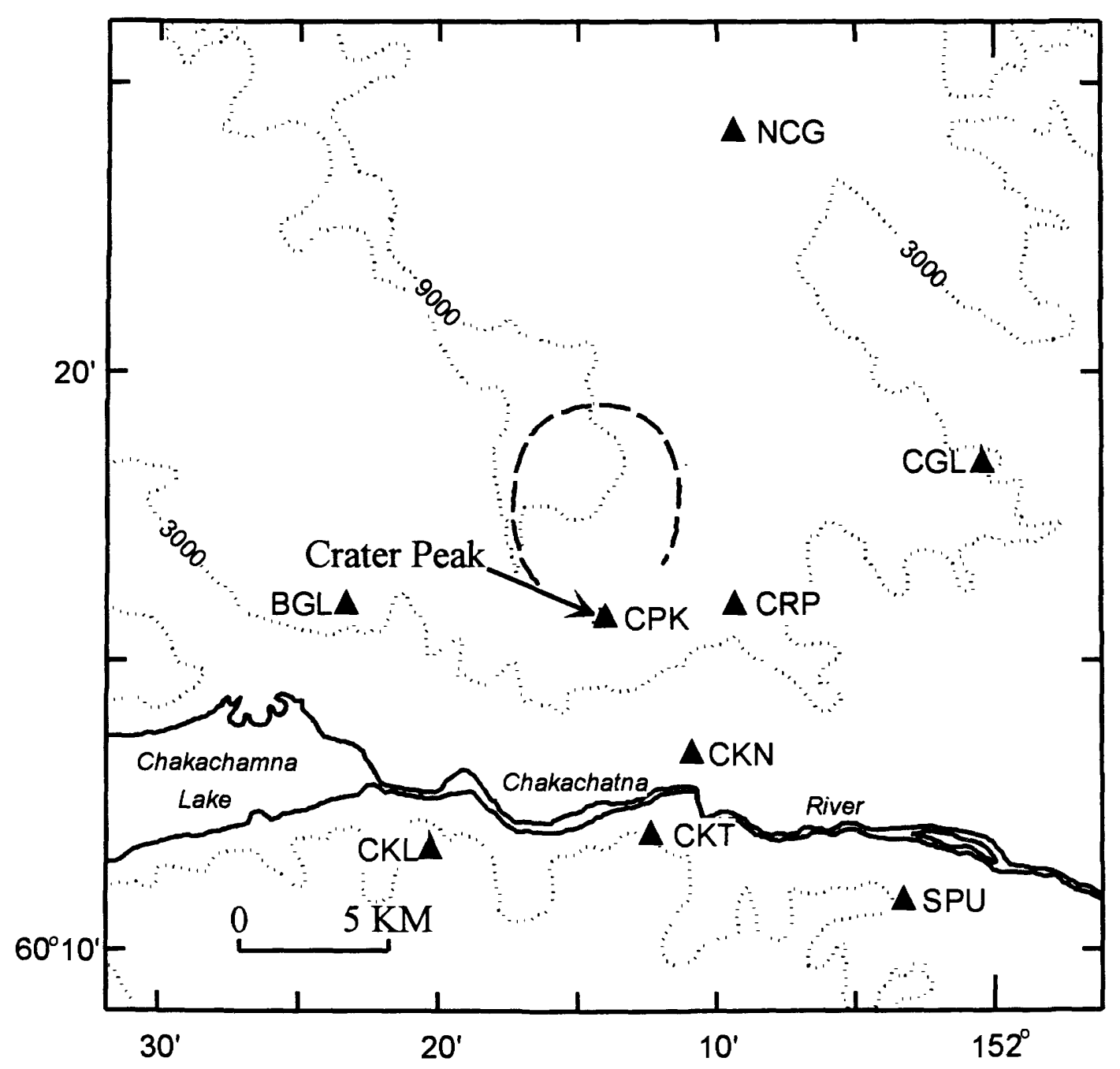

Figure 1. Seismic stations within $20 \mathrm{~km}$ of Mount Spurr volcano, southwestern Alaska. Station CPK was destroyed 46 minutes after the start of the June 27,1992 , eruption and was reinstalled in early September. Station CPK was destroyed again on September 17 and was replaced by station CP2. Station CRP became inoperative about 2 hours after the start of the August 18 eruption, and was repaired several days later. Dashed line is caldera boundary. Contours in feet.

Both RSAM and SSAM are rapid-analysis tools used routinely by the Alaska Volcano Observatory. RSAM provides plots of 1-minute averages of seismic amplitude or energy, and SSAM provides plots of spectral amplitude in predetermined narrow frequency bands. Both of these monitoring tools are useful for quantitatively determining the gross features of tremor automatically during crises when detailed manual analyses are not possible. RSAM and SSAM are especially useful digital recording techniques when signal amplitudes on helicorder drums begin to overlap or exceed the physical dynamic range of analog recording, and so reliable amplitudes cannot be easily obtained. At Mount Spurr, RSAM and SSAM were most useful during tremor episodes on June 2627 , October 1-6, and November 9-10.
Volcanic tremor first appeared at Mount Spurr on June 6, 1992, following a 9.5-month swarm of volcano-tectonic earthquakes (Power and others, this volume). The tremor appeared as irregular events 1 to 10 minutes in duration, and had relatively high amplitudes at station CPK (400 m from the vent; CPKis a co-located low-gain station) and lower amplit xdes at other stations (fig. 2). Dominant frequencies were between 3 and $6 \mathrm{~Hz}$ at station CPK, and about $2 . \mathrm{Hz}$ at other stations. We called the events tremor bursts on the basis of their similarity to events recorded at other volcanoes, such as Mammoth Mountain (Hill and others, 1990). We use the term "bursts" for tremor lasting 1 to 10 minutes and the term "episodes" for tremor lasting hours or longer. The only tremor with durations between 10 minutes and 1 hour was associated with eruptions on August 18 and September 16-17. 

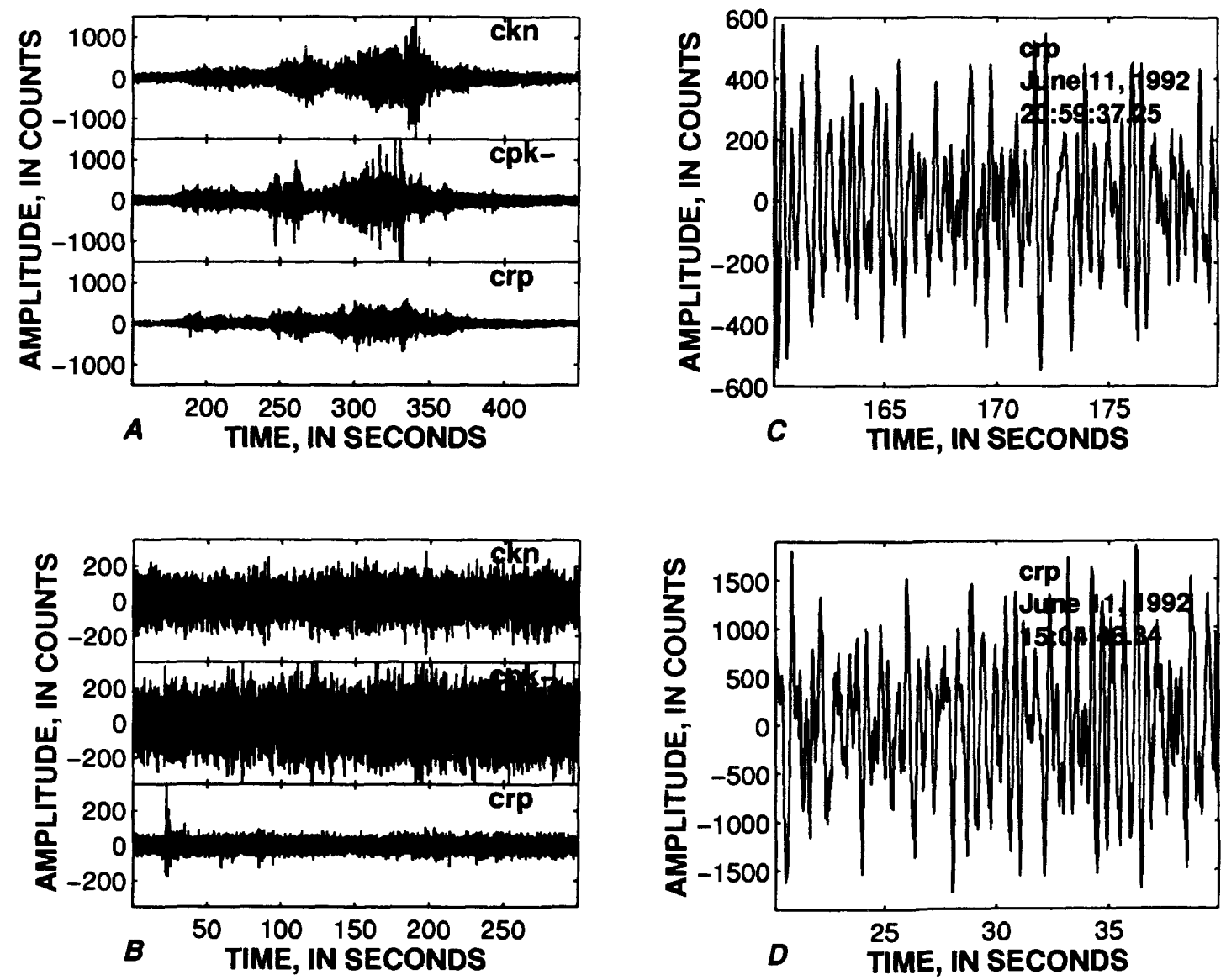

Figure 2. Seismograms of volcanic tremor from Mount Spurr volcano, Alaska. A, tremor burst from June 11,1992 , on stations CKN, CPK, and CRP, $300 \mathrm{sec}$ of data shown; $B$, tremor episode June 24-25, 1992, same 3 stations, $300 \mathrm{sec}$ of data shown; $C$, continuous tremor from June 26, 1992, station CRP, 20 sec of data shown; $D$, eruption tremor, June 27, 1992, station CRP, 20 sec of data shown.

A total of 174 tremor bursts occurred between June 6 and June 27 (Appendix 1). A peak rate of 24 tremor bursts occurred on June 11, and one burst each occurred on June 17,18 , and 21 . We measured durations in seconds for each event on seismograms from station CPK, and peak-to-peak amplitudes in $\mathrm{mm}$ on seismograms from station CRP because CPK was frequently saturated (see Appendix 1). Squaring the amplitude and multiplying by the corresponding duration of each burst gave a measure of relative energy. We then summed the durations and energies for each 6-hour period. The resulting plots of cumulative durations and energy rates were approximately constant from June 6 to June 13, then declined (became less steep) until June 21, when they increased slightly (fig. 3 ). On June 24 , a 154-minute long tremor episode occurred, followed 12 hours later by another similar episode lasting 142 minutes. Continuous tremor began at 12:03 p.m. ADT (20:03 UT) on June 26 and lasted 19 hours until the onset of the eruption on June 27 at 07:04 a.m. ADT (15:04 UT). The amplitude fluc- tuated during this time (fig. 4) and the signal res 9 mbled banded tremor (Kieffer, 1984; McKee and others, 1981). The three tremor episodes from June 24-27 represented an order of magnitude increase in energy over all the tremor bursts recorded until June 24 (fig. 3). Tremor amplitude approximately doubled on June 27, 1992, at 07:04 a.m. ADT (15:04 UT), signaling the start of the eruption. This was recognized within 2 minutes, and the level of concern color code was formally changed several minutes later.

Being able to consistently determine eruption start times, end times, and durations (table 1) precisely was problematic because of station failures. Start times were determined as the time when the amplitude on the station CRP helicorder in Fairbanks first exceeded 3 $\mathrm{mm}$ peak-to-peak $(1.5 \mathrm{~mm}$ peak to-peak for September owing to a gain change). On June 27 , this occurred about 12 seconds after the apparent start of the eruption on station CPK, which was the closest station, located on the crater rim $400 \mathrm{~m}$ from the vent. The 12 -sec delay was partly due to propagation time 

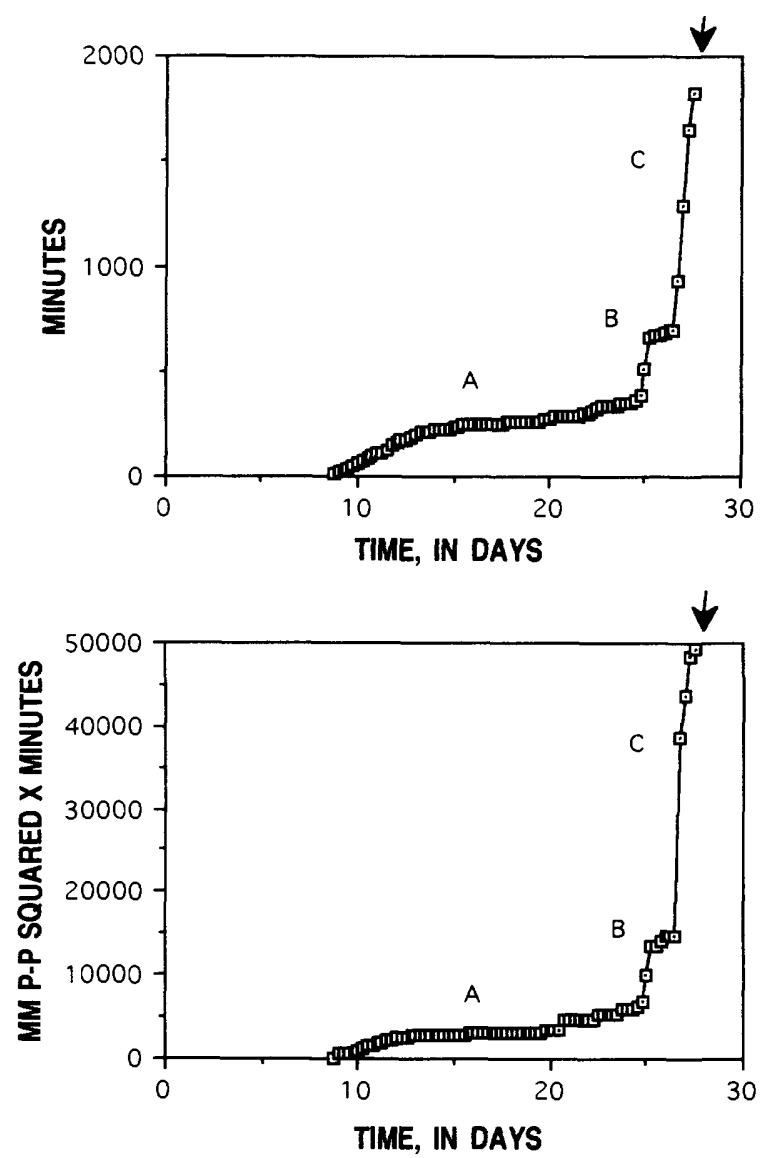

Figure 3. Mount Spurr tremor cumulative duration and energy versus time for June 1992. Data computed for 6-hour intervals. Eruption occurred on June 27 (arrows). The energy units are mm squared times minutes, and differ from standard units such as ergs by a multiplicative constant. Parts labeled $A, B$, and $C$ are discussed in text.

and partly due to attenuation at the $5-\mathrm{km}$ distance of station CRP. Unfortunately, station CPK was destroyed, so it could not be used to determine the start times for all the eruptions, so station CRP was used instead. The end times were determined when the peak-to-peak amplitude on the station BGL helicorder in Fairl anks dropped below $1 \mathrm{~mm}$ ( $2 \mathrm{~mm}$ for September). This is a fairly high threshold because of the greater distance of station BGL $(7.7 \mathrm{~km})$, so the indicated times correspond to the strong phases of activity. Station BGL was used for end times because station CRP berame inoperative after a lightning strike during the eruption on August 18. All times and durations are shown in table 1.

This first eruption lasted $4 \mathrm{hr}$ and $3 \mathrm{~min}$ (table 1). No tremor was recorded over the next 52 days until August 18, when a 12-minute burst of weak tremor including 3 entrained LP events coincided with pilot reports of a small ash plume. About 1 hour later, the main phase of the second eruption began, accompanied by strong tremor (as much as $30 \mathrm{~cm}^{2}$ recuced displacement) lasting $3 \mathrm{hr}$ and $28 \mathrm{~min}$. No tremor was recorded over the next 29 days until September 16, about 3 hours before the September 16-17 eruption. Medium-strength tremor (maximum about $5 \mathrm{~cm}^{2}$ reduced displacement) occurred for $11 \mathrm{~min}$ during the first phase of the eruption at 10:36 p.m. ADT, and strong tremor (as much as $25 \mathrm{~cm}^{2}$ reduced disflacement) occurred for $3 \mathrm{hr}$ and $36 \mathrm{~min}$ during the main phase of the eruption which began at 12:03 a.m. ADT September 17 (table 1). Unlike the aftermath of the June 27 and August 18 eruptions, continuous tremor occurred for 1 week following the September 17 eruption.

Tremor reappeared on October 2, and it occurred almost continuously with variable amplitude until October 20. The last tremor occurred during a swarm of earthquakes on November 9-10, 1992, that may have been associated with an intrusion (Stephens and others, unpub. data).

Altogether, during the 1992 activity of Mount Spurr, more than 460 hours of volcanic tremor were recorded.

Table 1. Mount Spurr volcano, Alaska, eruption start times, end times, and durations, as determined from tremor amplitudes, for 1992 eruptions.

[All times expressed in Alaskan daylight time.]

\begin{tabular}{ccccc}
\hline Date & $\begin{array}{c}\text { Start time } \\
\text { CRP>3 } \mathbf{m m}\end{array}$ & $\begin{array}{c}\text { End time } \\
\text { BGL<1mm }\end{array}$ & $\begin{array}{c}\text { Duration } \\
\text { hr:min }\end{array}$ & $\begin{array}{c}\text { Tephra volume^ } \\
\mathbf{x 1 0}^{\mathbf{3}} \mathbf{\mathbf { m } ^ { \mathbf { 3 } }}\end{array}$ \\
\hline 6/27 & $07: 04: 49$ a.m. & $11: 07: 51$ a.m. & $4: 03$ & 44 \\
$8 / 18$ & $03: 41: 06$ p.m. & $03: 52: 55$ p.m. & $0: 12$ & (visible ash plume) \\
$8 / 18$ & $04: 42: 25$ p.m. & $08: 10: 45$ p.m. & $3: 28$ & 52 \\
$9 / 16$ & $10: 36: 18$ p.m. & $10: 47: 40$ p.m. & $0: 11$ & (2-km ash plume) \\
$9 / 17$ & $12: 03: 48$ a.m. & $03: 39: 52$ a.m. & $3: 36$ & 56 \\
\hline
\end{tabular}

\footnotetext{
$\wedge$ R. McGimsey, written commun., 1993

\# measured at station CRP

* $\mathrm{BGL}<2 \mathrm{~mm}$
} 


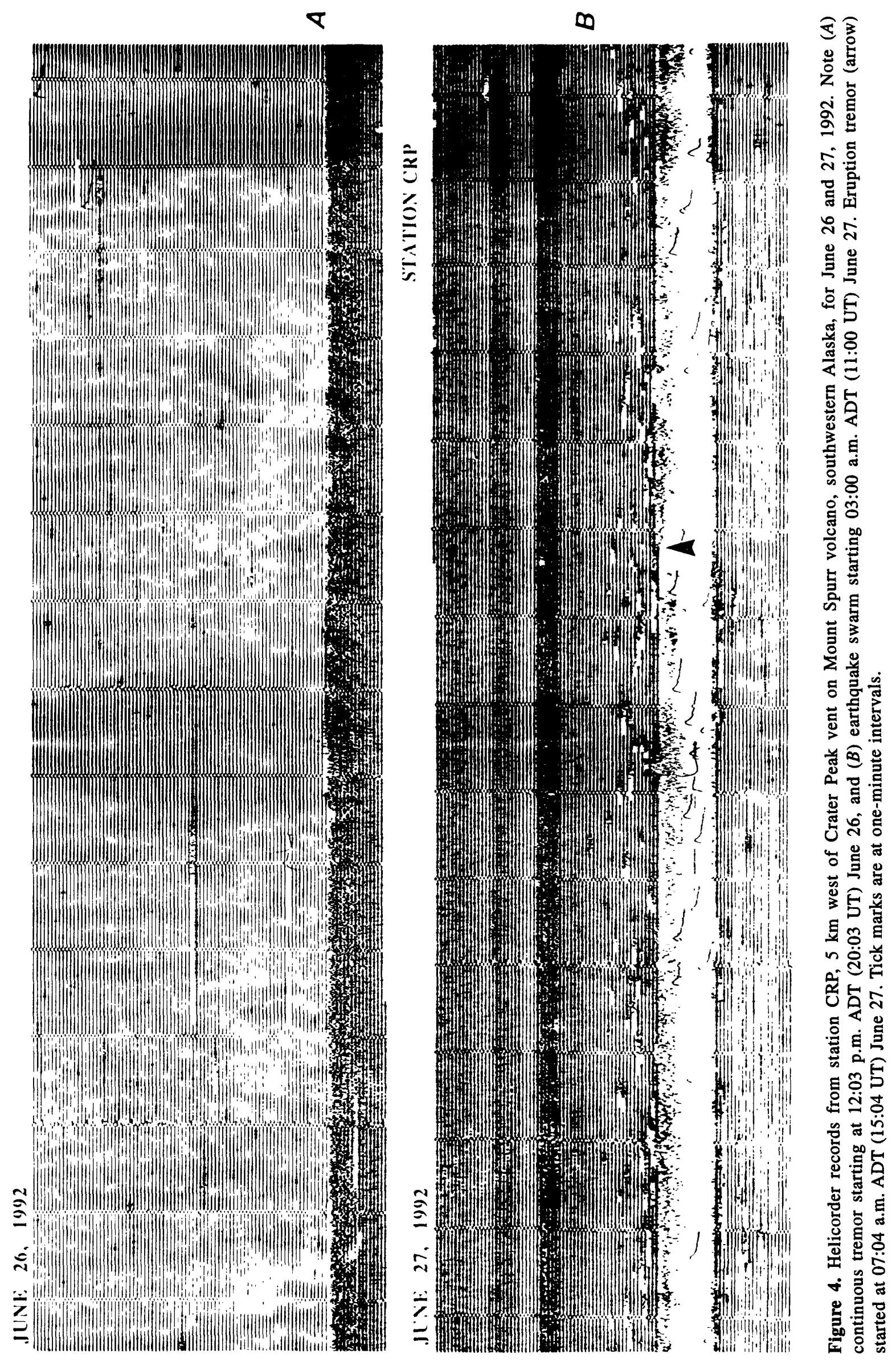




\section{ANALYSES AND RESULTS}

We studied (1) duration and energy versus time for all the tremor bursts and the first three episodes of continuous tremor during June 6-27; (2) amplitude ratios for selected tremor bursts (June 8-22) and one episode of continuous tremor on June 24-25; (3) amplitude variations for October 1-6 continuous tremor; (4) spectra for a tremor burst, the June 24-25 tremor episode, a sample of June 26 tremor, and a sample of June 27 tremor during the first eruption; (5) spectral variations for October 1-6 continuous tremor; and (6) a comparison of tremor during eruptions at Mount Spurr with tremor recorded during eruptions at other volcanoes.

\section{DURATION AND ENERGY VERSUS TIME}

Tremor bursts began on June 6,1992, and we tabulated the events and plotted the cumulative duration and cumulative energy as a function of time (fig. 3 and Appendix). We observed that the overall pattern of the plots was concave upward, but individual segments were all concave downward. For example, the cumulative-duration plot was concave downward from June 6 to June 21 (A in fig. 3) indicating that the rate of occurrence of the tremor bursts was decreasing with time. On June 11 , a field party observed that the crater lake had changed color from light blue to dark gray, and that adjacent fumaroles had increased in activity (T. Miller and R. McGimsey, oral commun., 1992). These observations and shallow earthquake locations suggested that a change had occurred in the shallow geothermal system, specifically an increase in heat caused by magma intruding to shallow levels in the crust. The concave downward part of figure 3 suggests that the source of heat moved up and stopped, and it gradually lost energy as a function of time. Alternatively, the geothermal system could have used up its supply of water or some other geochemical change could have occurred, such as partial sealing of cracks and pores. The low amplitudes of the tremor bursts (about $1 \mathrm{~cm}^{2}$ reduced displacement) were in the same range as tremor observed elsewhere in association with hydrothermal activity, lending further evidence to the hypothesis that the tremor bursts probably represented some type of boiling phenomena.

The two 2-hr long tremor episodes on June 2425 occurred during poor weather, so no direct field observations were made. However, on June 26 a field party observed that the crater lake was half empty, and lithic block impact marks were photographed on the mud of the former lake bottom (C. Nye, oral commun., 1992). The cumulative duration and cumu- lative energy plots from June 24 to June 26 ( $B$ in fig. 3 ) are also concave downward, suggesting that a heat source (magma) moved upward and stopped, loring its heat or using up the available water. The impact marks suggest that mild phreatic activity may have occurred. The last part of the tremor ( $C$ in fig. 3 ) on June 26 and 27 is also concave downward in energy, but straight in cumulative duration because the same duration of tremor occurred in each 6-hour time step once it became continuous. Inspection of the seismograms in figure 4 shows that the continuous tremor occurred in four bands. In each case the onset was relative abrupt and strong, and the tremor then gradually declined in amplitude over several hours. Each of these four bands follows the same pattern as parts $A, B$, and $C$ in figure 3 , again suggesting that the magma moved upward to a shallower level and stopped, losing heat or using up the available water. Following the 4-hr VT earthquake swarm on June 27 (fig. 4) the onset of strong tremor marked the start of the eruption, confirming that magma had indeed moved to shallow levels in the volcano.

\section{AMPLITUDE RATIOS}

Except in rare cases when the onset is abrupt (Aki and Koyanagi, 1981), volcanic tremor cannct be routinely located because no clear phases such $\mathbf{a}^{-} \mathbf{P}$ wave or S-wave arrival times are present in the $w^{2} v e-$ forms. Therefore, indirect techniques are commonly used to infer changing tremor source locations. At Mount Spurr we examined amplitude ratios between near and far stations to determine whether any significant depth changes had occurred. We used data from stations CPK, $400 \mathrm{~m}$ from the vent, and CRP, $4.8 \mathrm{~km}$ from the vent (fig. 1). The requirement of onscale seismograms for CPK and good signal-to-noise ratio for CRP restricted our search to only a few samples, yet sufficient data have been analyzed to provide reliable results.

We computed rms (root-mean-square) amplitides for CPK and CRP data for six samples (table 2) using the program SAC (Tapley and Tull, 1991). Amplitudes for a tremor burst on June 11 and the 2.5-hr episode on June $24-25$ at stations CPK and CRP are shown in figure 5 . The plots are normalized so that the amplitude on station CRP appears the same (left side, fig. 5), whereas the CPK amplitude varies. We observe that the amplitude ratio CPK/CRP for June 11 is 1.5 , and the ratio for June $24-25$ is 4 . The amplitude on the close station CPK has increased significantly compared with the amplitude at the more distant station CRP. We interpret this as evidence for a shoaling of the depth of the source. Recall that the 
Table 2. Root mean square amplitudes of Mount Spurr volcanic tremor.

\begin{tabular}{cccccc}
\hline Date & Time (ADT) & CKN rms amplitude & CPK rms amplitude & CRP rms amplitude & CPK/CRP ratio \\
\hline June 8 & $08: 20$ a.m. & 92 & 63 & 41 & 1.5 \\
June 11 & $07: 00$ a.m. & 199 & 204 & 138 & 1.5 \\
June 17 & $12: 16$ a.m. & 74 & 63 & 50 & 1.3 \\
June 22 & $08: 44$ a.m. & 119 & 141 & 58 & 2.4 \\
June 24 & $04: 24$ p.m. & 44 & 68 & 17 & 4.0 \\
\hline
\end{tabular}
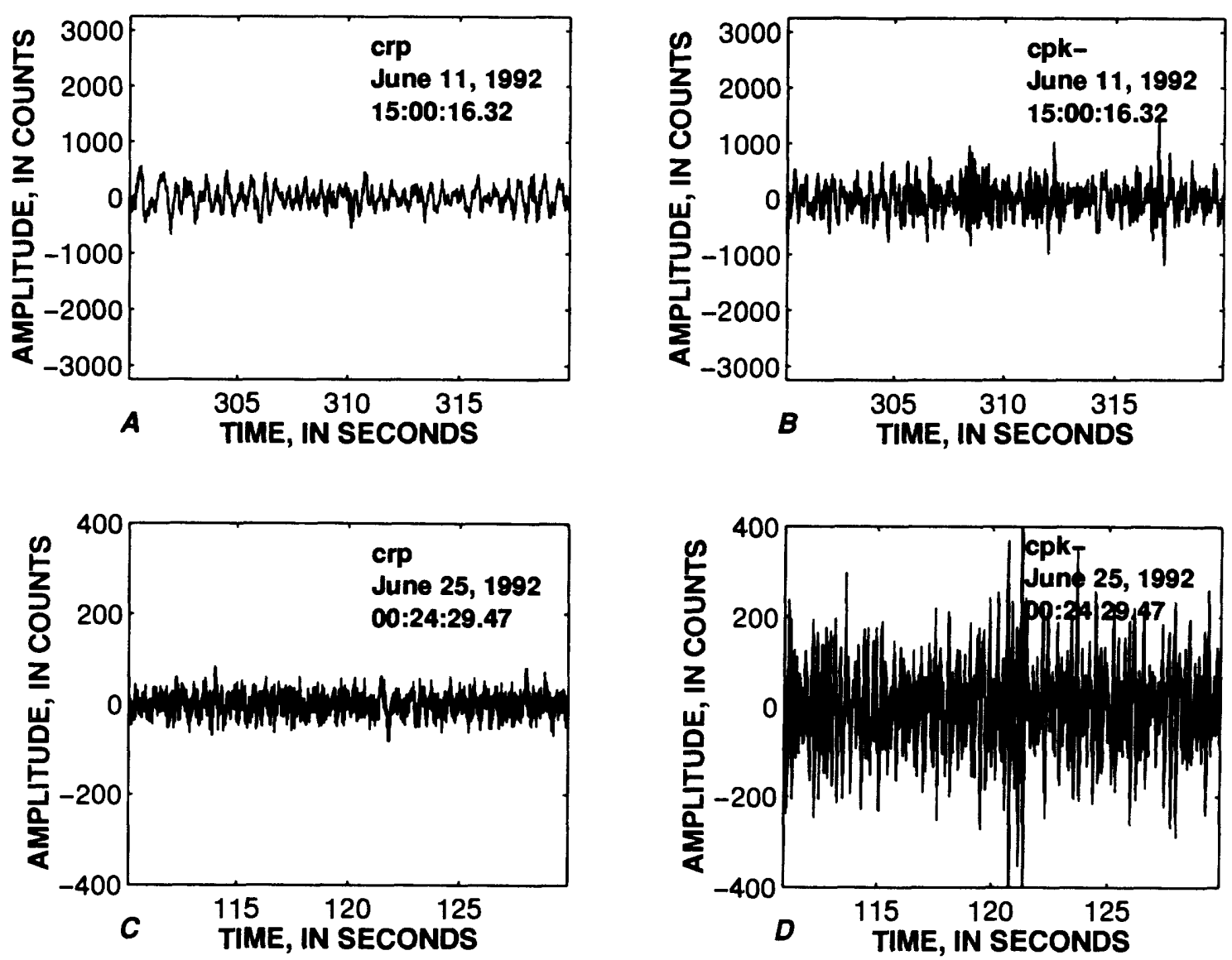

Figure 5. Amplitude ratios for two tremor samples from seismic stations on Mount Spurr volcano, Alaska. For each sample, data from stations CRP $(A$ and $C)$ and CPK $(B$ and $D)$ are shown. The plots are normalized to the CRP rms amplitude. The ratio CPK/CRP on June 11 is about 1.5 (compare $A$ and $B$ ), whereas on June 24-25 the ratio is about 4 (compare $C$ and $D$ ). This suggests that the June $24-25$ event occurred closer to station CPK, or at shallower depth since station CPK is located only $400 \mathrm{~m}$ from the vent whereas station CRP is located $5 \mathrm{~km}$ from the vent. Universal Time.

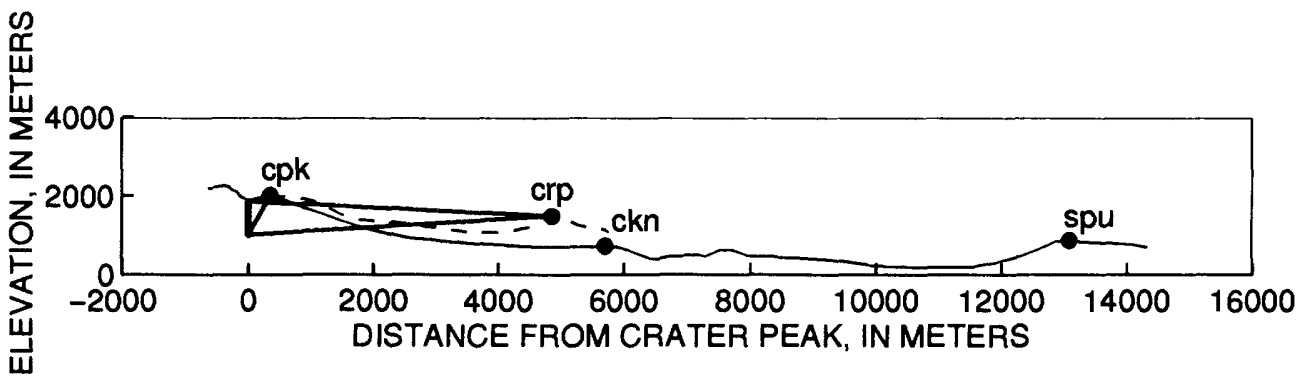

Figure 6. Schematic diagram of postulated depth distribution that explains amplitude ratios shown in figure 5. Two true-scale topographic profiles are shown. Straight line ray paths are drawn to stations CPK and CRP. The rays to station CRP are nearly the same length, whereas those to station CPK are scaled to the changing amplitude ratio. The straight rays to station CRP are unrealistic because of the topography, nevertheless, they illustrate the concept. 
crater lake was half empty, with lithic block impacts visible, when it was viewed June 26 prior to the onset of the continuous tremor (Alaska Volcano Observatory, 1993; C. Nye, oral commun., 1992). This observation suggests that mild phreatic activity may have occurred, probably during the June 24-25 tremor episodes.

If we assume a point source at the surface for the June 24-25 tremor, then we can perform a simple inversion for the depth of the tremor burst on June 11. The geometry is shown in figure 6 . The distance of the ray path to the distant station CRP $(4.8 \mathrm{~km})$ changes very little with a change in source depth, whereas the distance to the close station CPK (400 $\mathrm{m}$ ) changes significantly. We use the amplitude ratios 1.5 and 4 given above, and assume $1 / \mathrm{r}$ geometric spreading for body waves (energy decays as $1 / \mathrm{r}^{2}$, so amplitude decays as $1 / \mathrm{r}$ ). This means the distance must increase by a factor of $4 / 1.5=2.67$. We assume straightline ray paths, and use the Pythagorean theorem to solve for the depth change. This yields a depth of $920 \mathrm{~m}$ for the June 11 tremor burst. If the June 2425 source is located at a depth of $100 \mathrm{~m}$ rather than at the surface, then the depth of the tremor burst would be $934 \mathrm{~m}$. This calculation is a first-order approximation only (probably reliable to only one significant figure), and it ignores effects such as attenuation, reflections, and refractions. If the source was not deeper but was farther away in some other direction, the distances would be different than those determined above. Also, if the source is a line source or some other geometry, the calculation is more complicated, and it has not yet been attempted.

\section{OCTOBER 1-6 AMPLITUDE VARIATIONS}

Volcanic tremor continued for 1 week following the September 17 eruption and ceased on September 25. After a 1-week hiatus, tremor resumed on October 1. The tremor sequence in October showed significant temporal variations, including patterns similar to those that have preceded eruptions at Mount Spurr and elsewhere.

The RSAM plot (fig. 7) shows tremor starting on October 1 and then increasing in amplitude at a nearly exponential rate on October 2 , after which it stopped rather abruptly. This episode was similar to the RSAM plot for the days preceding the January 2, 1990, eruption of Redoubt Volcano (Brantley, 1990). On October 3 a series of 5 tremor episodes occurred, each about $1.5 \mathrm{hr}$ long. This signal resembled banded tremor (Kieffer, 1984), and it was also similar to the tremor preceding the June 27 eruption of Mount Spurr. On October 4 , tremor returned and the amplitude again increased nearly exponentially. When this tremor declined in amplitude on October 5, another series of tremor episodes occurred, each about 2 hr long, similar to those of October 3 , but followed by a gratual decline.

From October 1 through October 6 a steam pl ime was being emitted from Crater Peak to heights of 2,000 to $12,000 \mathrm{ft}$ above the volcano, and approximately steady amounts of $\mathrm{SO}_{2}$ and $\mathrm{CO}_{2}$ gas were being emitted (400 and 2,900 tons/day, respectively). Doukas and Gerlach (this volume) noted a drop in $\mathrm{SO}_{2}$ flux shortly after the onset of several tremor episodes. There was no clear correlation between plume height and tremor amplitude, and no eruption occurred.

The RSAM plots were valuable for near-real-time monitoring to quickly compare the current tremor level to that of the previous few days and to monitor the temporal patterns. Although the amplitude varied considerably, the tremor was quite stationary in its frequency characteristics and in its relative amplitides at different stations. We speculate that this tremor was caused by magma degassing at shallow depths.

The tremor observed in October demonstrated that patterns of occurrence alone, such as exponential increases in amplitude or periodic banding, are not sufficient basis for forecasting eruptions.

\section{SPECTRA}

We computed Fourier spectra for several re oresentative portions of the tremor data to search for significant spectral peaks that might help identify source properties. We selected a typical tremor burst on June 11 , and samples of tremor episodes on June 25, June 26, and during the eruption on June 27 (fig. 2). For each sample, we chose four adjacent windows, each $10 \mathrm{sec}$ long, computed Fast Fourier Transform spectra, then stacked the spectra. This adds stability because constructive interference enhances the real peaks whereas destructive interference diminishes the noise. Results are shown in figure 8. For all the samples, significant spectral amplitudes occur between 0.5 and $5 \mathrm{~Hz}$, and the highest amplitude peaks are near $2 \mathrm{~Hz}$. In detail, however, two of the spectra show something quite remarkable.

If the June 26 spectrum is horizontally compressed and superimposed on the June 27 spectrum, as stown in figure 9, we see that nearly all of the main snectral peaks coincide. The amount of compression is 18 percent. Mori and others (1989) showed a shifting in frequency of a single prominent peak at Langila Volcano in Papua New Guinea, and Kamo and others (1977) showed a series of spectral peaks from Sakurajima Volcano in Japan whose positions changed sys- 


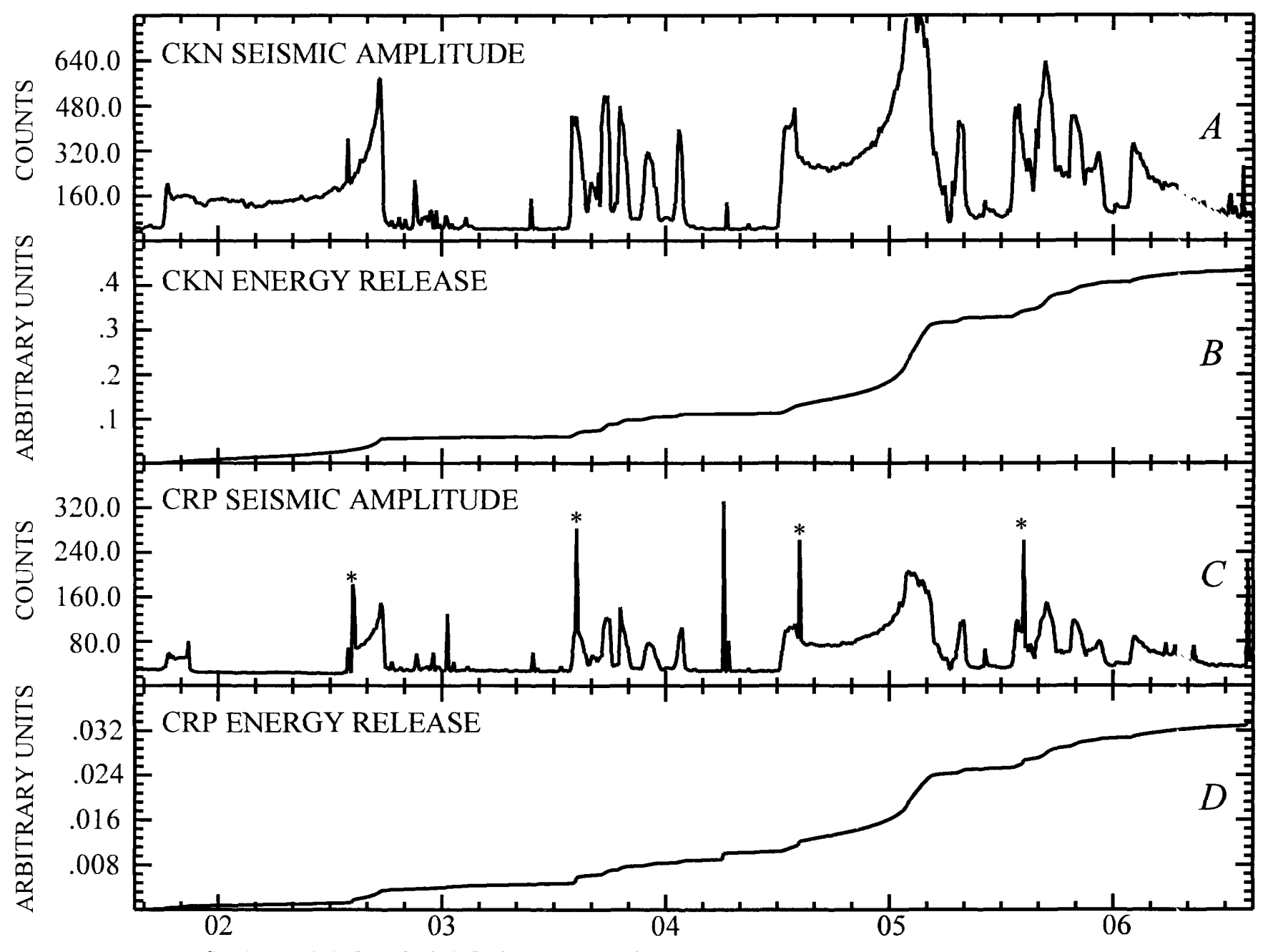

START DATE IS OCT. 01, 1992 AST

Figure 7. RSAM (Real-time Seismic Amplitude Measurement) plot for tremor data from Mount Spurr volcano, Alaska, for October 1-6, 1992. Horizontal axis is time in days; vertical axis is digital counts for $A$ and $C$, arbitrary units for $B$ and $D$. $A$, amplitude, station $C K N ; B$, cumulative energy release, station CKN; $C$, amplitude, station CRP; $D$, cumulative energy' release, station CRP. In $D$ on October 2 the signal gain-ranged for part of the time. Equally spaced spikes (asterisks) are daily calibration sequences.

tematically with time. In all three cases the shifting of peaks implies either that the length of a resonator changed by 18 to 40 percent, or that the acoustic wave speed changed, as could happen, for example, with the introduction of bubbles. The presence of even a small amount of bubbles dramatically lowers acoustic speeds of fluids (Kieffer, 1977).

The Mount Spurr data differ from these other data in several significant respects. First, the Mount Spurr eruptive conditions changed from no eruption to vigorous subplinian eruption. The Langila and Sakurajima data, on the other hand, were recorded during times of relatively constant conditions. Second, the Langila case was recorded over 2 minutes, whereas the Spurr data were recorded over 19 hours. Third, the Langila and Sakurajima seismograms appear to be very even and regular, whereas the Spurr data are far more irregular (fig. 2). On closer inspection of figure 9 , the Spurr spectra consist of a broadband triangular shaped part (apex upward) from 0.5 to $4 \mathrm{~Hz}$, with evenly-spaced sharp individual peaks superimposed. This has important implications for the source model. The broadband part suggests that a series of random pulses was acting at the source (see Hurst, 1992). These could be, for example, bubble cavitations, flow perturbations, or impacts of blocks on the side of a conduit. The evenly-spaced sharp peaks, on the other hand, suggest resonance modes of an oscillator. The single set of peaks suggests a one-dimensional oscillator, with each of the peaks representing an eigenfrequency of vibration (for example, Schick and others, 1982; Kamo and others, 1977; McNutt, 1986). 

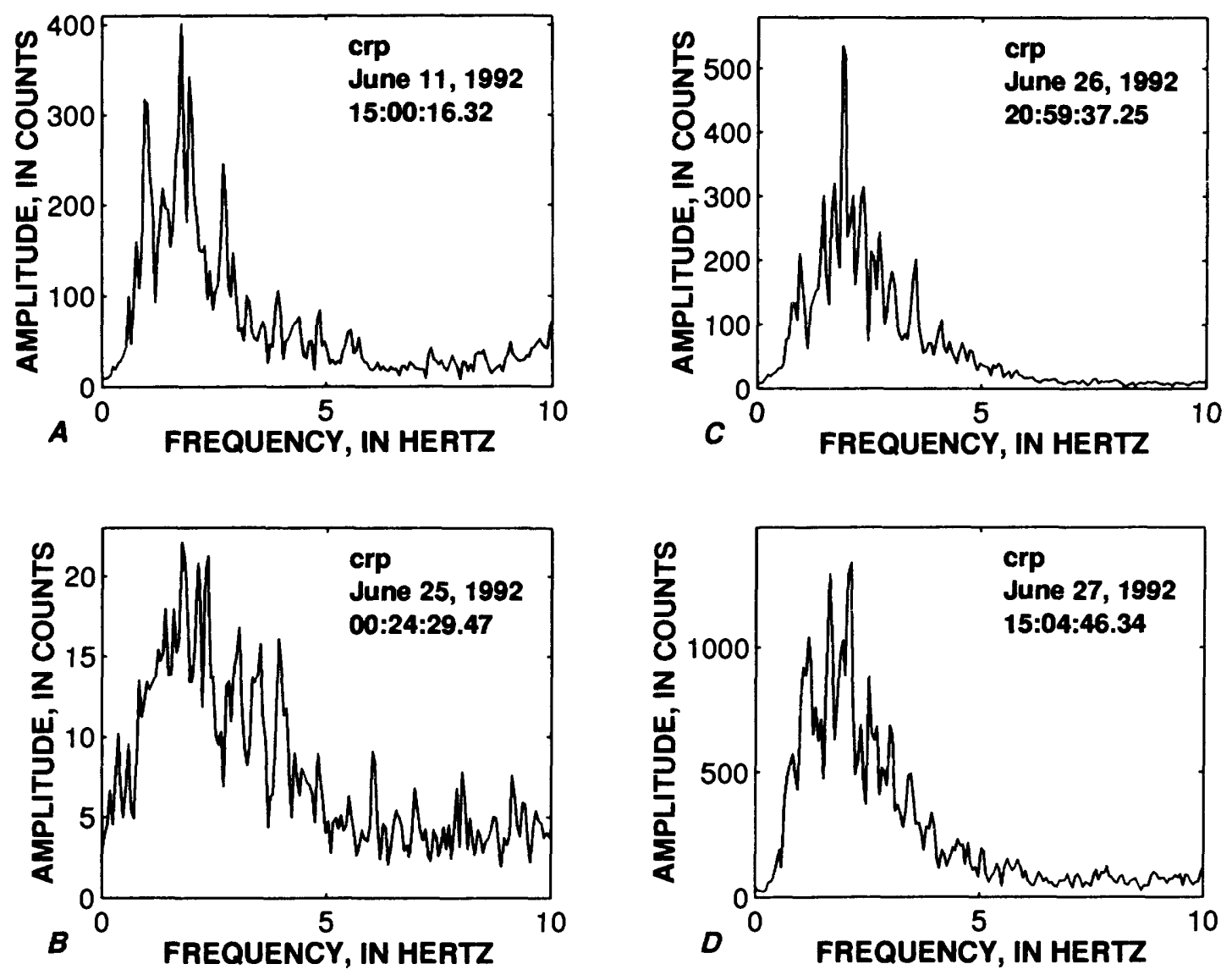

Figure 8. Fourier spectra for the time series shown in figure 2. Each spectrum is a stack of four individual spectra, each for a 10 -sec sample of data. $A$, tremor burst, June 11, 1992. $B$, tremor episode 154 minutes long, June 24-25, 1992. $C$, continuous tremor prior to the eruption, June 26, 1992. D, eruption tremor, June 27,1992 . Universal Time.

Models of this type involve a one-dimensional oscillator such as the familiar organ pipe, whose permissible frequencies of resonance are determined by the length, velocity, and boundary conditions. A pipe with two open or two closed ends has resonance modes $n \lambda / 2$ (where $\lambda$ =wavelength and $n=1,2,3, \ldots$ ). A pipe with one open end and one closed end has resonance modes $n \lambda / 4$ (where $\lambda$ =wavelength and $n=1,3,5, \ldots$ ). In each case the spectral peaks are evenly spaced, however, the spacing from the origin to the first peak is different. The interpeak and origin-to-peak spacing is the same for $n \lambda / 2$ modes, whereas the origin-to-peak distance is $\lambda / 2$ that of the interpeak distance for $n \lambda / 4$ modes. This feature provides a simple way to identify modes on a spectrum.

The data suggest that both sets of modes are present in spectra from June 26 and June 27 , before and during the eruption. The peaks on figure 9 have been numbered for identification, and we observe that alternate peaks change amplitudes systematically from before to during the eruption. Peaks $1,3,5,7$, and 9 had the same or only slightly different amplitules, whereas peaks $2,4,6,8$ and 10 became significantly larger during the eruption. The pattern is most clear for peaks $1,2,3$, and 4 . The most straightforward interpretation for this pattern is that there was a change in the boundary conditions. We suggest that the spectral peaks represent mixed modes of organ pipe vibration, that is, both open-ended and close-ended modes are present. If the boundary conditions are changed, for example by breaking an impermeable cap, changing the shape, or transmitting lava, then one $\mathrm{se}^{+}$of modes would be enhanced relative to the other. It is best to think of the boundary conditions in terms of reflection and transmission, rather than open-endet or close-ended. However, the open-ended and close-erded modes give a clear conceptual picture. We observe that the close-ended modes (that is, one open end and one closed end) became stronger during the eruption, which is what would be expected as the vent is reamed out. Although preliminary, to the best of our knowledge, this is the first observation of this type that has 
been made on volcanic tremor spectra. This is also a clear source effect. The fundamental mode for the evennumbered peaks (closed-end modes) does not appear on figure 9 because its frequency is too low to be recorded on the $1-\mathrm{Hz}$ seismometer we used.

While we have presented our preferred preliminary model, other possibilities exist. The shape of a resonator could have changed, for example from a onedimensional pipe-like structure to a two-dimensional rectangular crack (Chouet, 1992), and the systematic variation of spectral amplitudes could be caused by preferential excitation of modes in one direction over the other. It is also possible that no resonator was involved, and that the observed amplitude variation is caused by some other process (Julian, 1994). It is conceivable that the alternate peak spectral amplitude variations are due to chance alone, however, we think that it is very unlikely that random fluctuations would be so systematic.

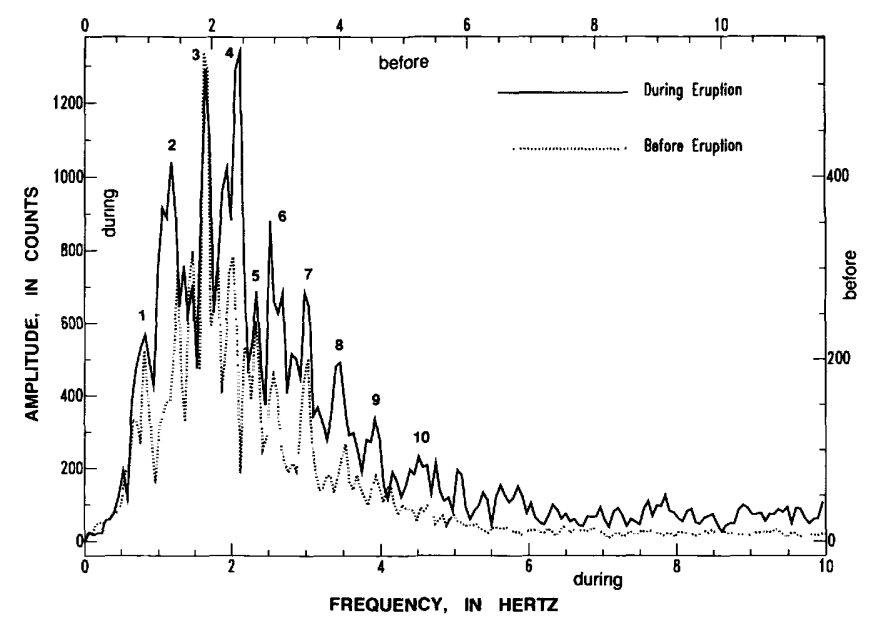

Figure 9. Spectra from figure $8 C$ and $8 D$ superimposed with the horizontal axis compressed by 18 percent for the June 26 spectrum. Left and bottom scales refer to tremor during the eruption on June 27 . Top and right scales refer to preeruption tremor on June 26. Peaks numbered for reference.

\section{OCTOBER 1-6 SPECTRAL MEASUREMENTS}

In addition to computation of spectra for selected tremor samples as discussed above, we also studied spectra using SSAM (Stephens and others, 1994). SSAM runs continuously in the background, and plots can be made at any time for stations and times of interest. SSAM plots show spectral amplitudes in predetermined bands that are several tenths of a Hertz wide. SSAM is thus a good tool to use when the spectra do not vary with time, but it lacks the resolution to identify small changes in spectral position.
The SSAM plot (fig. 10) shows data from October $2-6$, the same period as figure 7 . Here we see persistent high amplitudes in the 1.9 to $2.5 \mathrm{~Hz}$ bands, the same frequencies that are high amplitude in the spectra shown in figure 8 . We also observe that as the signal becomes stronger (fig. 7), the spectral content becomes somewhat more broadband. This may be partially caused, however, by saturation of the spectral bands for strong signals. In general, the snectral content is remarkably uniform over the period October 2-6. Based on the results of both RSAM and SSAM, we conclude that volcanic tremor with a single source occurred during October 1992. Our preliminary conclusion is that shallow-level degassing of magma was the source. It is not known whether the degassing was juvenile, hydrothermal, or a mixture of the two, although we suggest the latter was the more likely gas source (Doukas and Gerlach, th is volume).

Tremor occurred again for several hours on November 9-10 in association with a swarm of shallow earthquakes. This tremor was observed mainly on the closest station CP2 (a replacement for CPK, fig. 1) and consisted of a high signal level recorded botween discrete events of the earthquake swarm. The frejuency content of this tremor was somewhat higher than that of previous tremor $(>5 \mathrm{~Hz})$. No detailed analyses have yet been carried out on this tremor.

\section{TREMOR DURING ERUPTIONS}

Time histories for the three eruptions using RSAM data for station BGL, which operated continuously during all three eruptions, are shown in figure 11. Station BGL has a 1-sec vertical geophone, and it is located $7.7 \mathrm{~km}$ west of the Crater Peak vent (fig. 1). Because the station is fairly close to the vent, its data are partially saturated (clipped), especially for higher amplitudes above 1,200 counts. The total durations and volumes of each eruption are shown in table 1. However, the duration of the strongest eruption tremor was roughly proportional to the tephra volume of each eruption. For example, the duration of tremor greater than 800 counts on June 27 was 1 hour, on August 18 about 2.8 hours, and on September 16-17 about 2.5 hours (recall that the end of the September eruption was "contaminated" by an earthquake swarm), whereas the tephra volumes were 44,52 , and 56 million cubic meters, respectively.

The amplitude of Mount Spurr eruption tremor is compared to that from eruptions. at other volsanoes in figure 12 (modified from McNutt, 1994). Representative values from the June 27 and August 18 eruptions are shown; the maximum amplitude during the August eruption was approximately double the June 


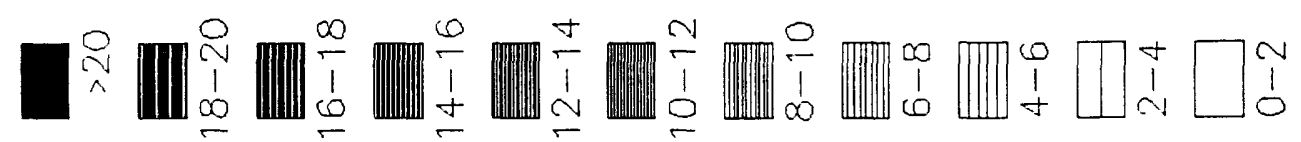

$\stackrel{0}{0}$

迅

8
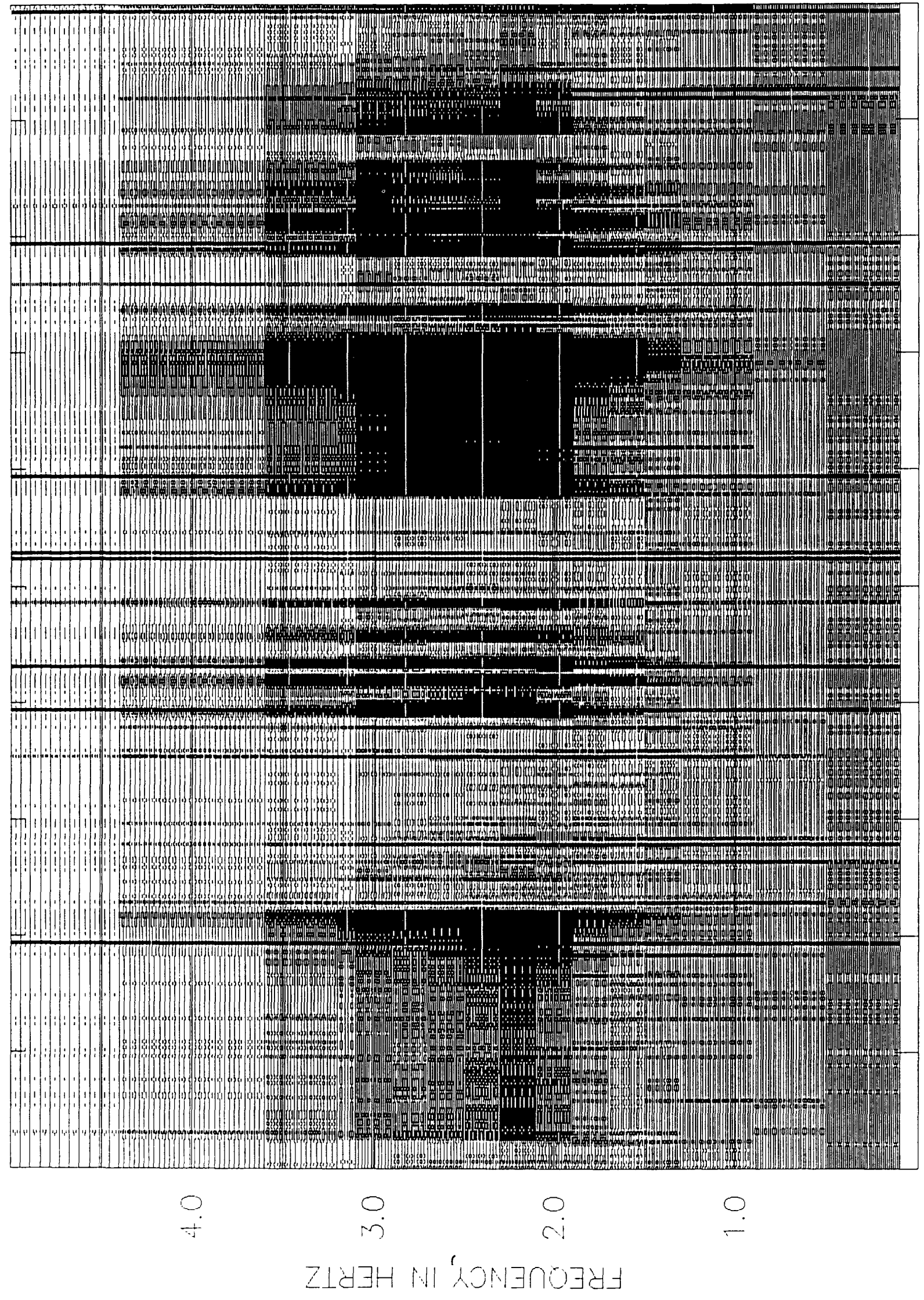

㝵 
maximum. Each datum represents the tremor amplitude normalized to reduced displacement, which corrects for distance, geometric spreading, and instrument magnification (Aki and Koyanagi, 1981; Fehler, 1983), and is plotted versus the Volcanic Explosivity Index (VEI) of Newhall and Self (1982). Each of the three main eruptions of Mount Spurr were VEI=3, as determined from tephra volumes (table 1) and ash-column heights of 9 to $15 \mathrm{~km}$. The Mount Spurr tremor amplitudes are similar to values obtained elsewhere for eruptions of similar size, although this does not imply that the exact eruption mechanisms were iden-

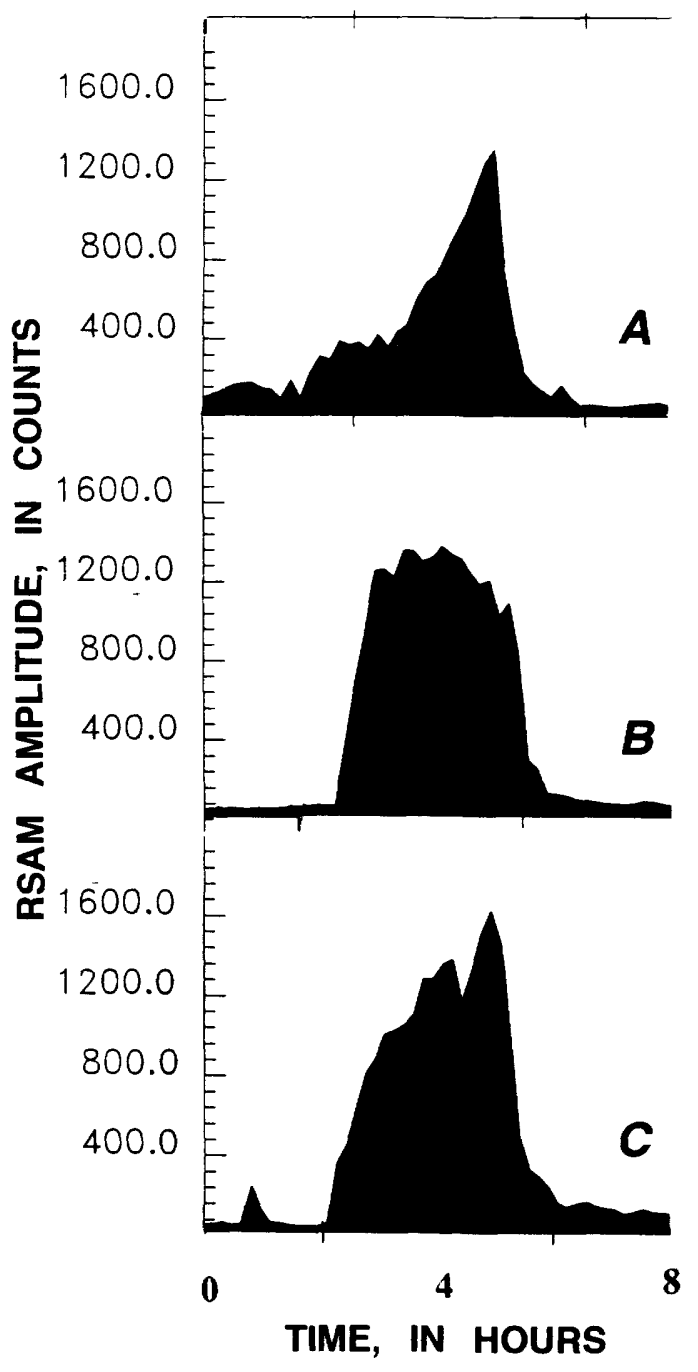

Figure 11. RSAM (Real-time Seismic Amplitude Measurement) plot for volcanic tremor amplitudes during the three 1992 eruptions of Mount Spurr in southwestern Alaska. Station BGL is located $7.7 \mathrm{~km}$ west of Crater Peak, the active vent. Vertical axis is digital counts. Partial saturation of highest amplitudes (above 1200 counts) occurred during all three eruptions. A, June 27; $B$, August $18 ; C$, September 16 17 tical. The mechanisms of the Mount Spurr eruptions are discussed by Neal and others (this volume), and they are characterized as subplinian.

The amplitude of a representative tremo- burst from June 11 is also shown in figure 12 for comparison. The VEI was set at 0 because of the less than 1 $\mathrm{km}$ steam plume and the impact block craters in the mud flat within a few tens of meters of the vert. This value also falls in the range observed at other volcanoes for eruptions of similar size and characteristics (Gil Cruz and others, 1987; Leet, 1988; McNutt, 1994).

\section{DISCUSSION AND CONCLUSIO'TS}

We used a variety of methods to study tremor at Mount Spurr, choosing specific techniques for different time periods based on station operation, signal strength, and overall data sufficiency. In this section, we synthesize the key results into a preliminary qualitative model of tremor generation.

The tremor bursts first appeared on June 6, the day after the highest daily number of volcano-tectonic (VT) earthquakes, 28 events on June 5 (Power and others, this volume), of the 9.5-month swarm up to that time. During the three weeks over which tremor bursts were observed, the seismicity remained $a^{+}$about 5 to 10 locatable VT earthquakes per day. This suggests that magma or volatiles had reached shallow' levels in the crust, and instead of building up stresses and triggering VT earthquakes, the magma or volat les interacted with ground water to produce tremor bursts. Recall that geochemical changes were observer in the crater lake shortly after the tremor bursts first ap eared. For 18 days the cumulative duration and cumulative energy plots were concave downward (fig. 3), which means that the rates of tremor occurrence and energy were declining with time. Amplitudes were small (about $1 \mathrm{~cm}^{2}$ reduced displacement) and source depth was about $1 \mathrm{~km}$. We infer that magmatic heat was interacting with the shallow geothermal system.

A significant change occurred on June 24-25 when a 2.5-hour tremor episode occurred, followed by another similar episode 12 hours later (fig. 3 and Appendix). The durations and energies of these two episodes alone exceeded those of all the earlier bursts together. The source was becoming shallower, as indicated by changing amplitude ratios (figs. 5 and 6 ) and the crater lake was partially emptied, with lithic block impact marks visible. The next significant change was the onset of continuous tremor 19 hours before the first eruption. The cumulative duration increased again by a factor of about 3 , the cumulative energy also increased by a factor of 3 (fig. 3 ), and the source remained shallow. Evenly-spaced, narrow spectral peaks suggest that a one-dimensional resonator (pipe or con- 
duit) was active at this time. We believe the conduit was filled with a mixture of water, lithic materials, magma, and magmatic fluids. The concave downward parts of the energy plot and the similar amplitude patterns on seismograms (figs. 3 and 4) suggest that heating and upward movement occurred intermittently and abruptly, rather than smoothly and steadily.

The onset of a shallow (1 to $2 \mathrm{~km}$ beneath the vent) VT earthquake swarm preceded the first eruption by 4 hours (Power and others, this volume); the onset suggests that stresses were again building up as magma made its final ascent to the surface. Tremor was constant and of low amplitude during this swarm. We speculate this means that all the fluids had been boiled off by this time. The eruption began quite abruptly and the tremor looked much the same as tremor recorded previously except that it was stronger by a factor of two. Spectra computed for tremor during the eruption showed the same peaks shifted in frequency by 18 percent. The presence of the same peaks implies that the same structure was active; namely, the conduit previously occupied mainly by water or a water-rich mixture was now occupied mainly by magma. The shifting of the spectral peaks to lower frequencies (fig. 9) suggests that either the resonator (conduit) length increased or the acoustic velocity decreased within the conduit. Either hypothesis is reasonable and we cannot yet distinguish between these possibilities. The systematic change in amplitudes of alternate spectral peaks (fig. 9) suggests that boundary conditions changed from closed (reflection) to open (transmission) at one end of the conduit from before to during the eruption. This observation is consistent with disruption of an impermeable cap at the top of the conduit during the initial stages of the eruption. Tremor during the eruptions was stronger than any previous tremor and was similar in strength (16 to 30 $\mathrm{cm}^{2}$ reduced displacement) to that recorded at other volcanoes (fig. 12).

All three eruptions were similar to each other in their durations, volumes, ash-column heights, chemistry, and other parameters (table 1, fig. 11; Alaska Volcano Observatory, 1993). Tremor during the eruptions was also similar. However, patterns of tremor occurrence before and after the eruptions varied considerably. In June, most tremor preceded the eruption; we suggest that this tremor was chiefly hydrothermal in origin. No tremor followed the June eruption. In August, only a single short tremor episode occurred about 1 hour before the eruption. We suggest that the hydrothermal system had not yet been fully re-established, or had been re-established with different geometry or boundary conditions. In September, weak tremor occurred for 3 hours before the eruption, but in contrast to June and August, tremor occurred after the eruption continuously for 1 week. Because the hydro-

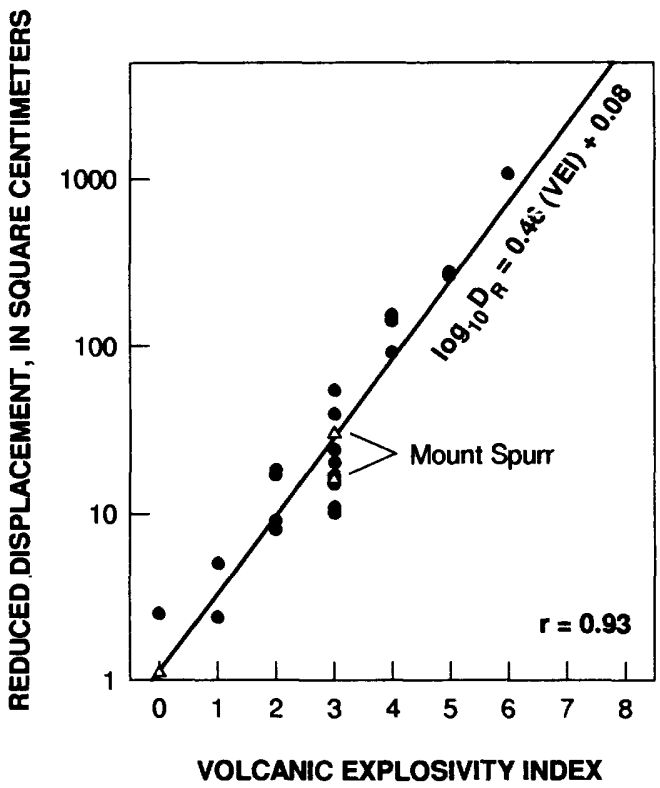

Figure 12. Volcanic tremor reduced displacement versus the Volcanic Explosivity Index (VEI) of Newhall and Self (1982). Data represent 24 eruptions at 15 different volcanoes. The plotted line is a linear regression fit to the data excluding Mount Spurr volcano in southwestern Alaska and has a correlation coefficient $r$ of 0.93. Representative values from the June 27 and August 18 eruptions of Mount Spurr, and from a tremor burst, shown as triangles. Modified from McNutt (1994).

thermal system had been seriously perturbed by the eruption, we suggest that continued degassing of unerupted shallow magma was the source of this tremor. Similar conditions and tremor occurred from October 1 to 20. The last tremor on November 9-10 may be different than most other tremor at Mount Spurr; its frequency content was higher and its amplitude distribution between stations was different. However, thorough analyses of this last tremor are not yet complete.

Several of the observations made during this preliminary work have implications for our monitcring efforts. For example, spectra are routinely computed for tremor and there are many published examples in the literature. Nevertheless, our observation of the systematic change in the amplitude of alternate peaks appears to be unique and we are not aware of any published examples. This is clearly a source effect, and it may be possible to exploit this feature in the future to improve eruption forecasting. The shifting of the spectral peaks has been observed elsewhere, but the Mount Spurr observations occurred over a longer time scale and when eruption conditions had clearly changed. Future analyses will elucidate the timing more precisely. SSAM was not useful for determining the 
shifting of the spectral peaks and the amplitude variations of alternate peaks because the frequency bins were fixed and did not coincide with the spectral peaks.

Several of our most important observations depended on data from individual seismic stations. Station CPK, which was located only 400 meters from the vent, proved to be especially valuable. This station enabled us to identify the occurrence of tremor bursts in early June when they were small enough that they were not clearly recognized on more distant stations. This station also enabled us to determine dramatic changes in the rms amplitude ratios (fig. 5), which we believe were most likely caused by a shoaling of the source. The station CPK was destroyed twice during eruptions, and its replacement was worth the cost because of the insight into physical characteristics of tremor we obtained from this key station. We suggest that every monitored volcano would benefit from having at least one station within a few hundred meters of the active vent.

Our analyses and monitoring efforts greatly benefited from having a variety of tools at our disposal, including helicorders, continuous digital data, eventtriggered data, RSAM, and SSAM. Our experience in forecasting eruptions at Mount Spurr illustrates the importance of closely monitoring volcanic tremor using a variety of techniques and methods. Future work at Mount Spurr will focus not only on more detailed analyses of the data presented here, but also on improvements in the methods for recording and analyzing tremor in general.

\section{REFERENCES CITED}

Aki, K. and Koyanagi, R.Y., 1981, Deep volcanic tremor and magma ascent mechanism under Kilauea, Hawaii: Journal of Geophysical Research, v. 86, p. 7095-7110.

Alaska Volcano Observatory, 1993, Mt. Spurr's 1992 Eruptions: Eos, Transactions of the American Geophysical Union, v. 74 , no. 19 , p. 217 and 221-222.

Brantley, S.R., 1990, The eruption of Redoubt volcano, Alaska, December 14, 1989 - August 31, 1990: U.S. Geological Survey Circular 1061, 33 p.

Chouet, B., 1992, A seismic model for the source of long-period events and harmonic tremor, in Gasparini, P., Scarpa, R., and Aki, K., eds., Volcanic Seismology, IAVCEI Proceedings in Volcanology, v. 3, Berlin, Springer-Verlag, p. 133-156.

Chouet, B.A., Page, R.A., Stephens, C.D., Lahr, J.C., and Power, J.A., 1994, Precursory swarms of long-period events at Redoubt Volcano (1989-1990), Alaska: Their origin and use as a forecasting tool: Journal of Volcanology and Geothermal Research, v. 62, p. 95-135.

Dawson, P.B., Chouet, B.A., Lahr, J.C., and Page, R.A., 1992, Spatial relationship between $L P$ earthquakes and a shallow threedimensional velocity anomaly beneath Redoubt Volcano, Alaska: Eos (American Geophysical Union Transactions) supplement, v.73, p. 343.
Endo, E.T., and Murray, T.L., 1991, Real-time Seismic Amplitude Measurement (RSAM): a volcano monitoring and prediction tool: Bulletin of Volcanology, v. 53, p. 533-545.

Fehler, M., 1983, Observations of volcanic tremor at Mount St. Helens volcano: Journal of Geophysical Research, v. 88, p. 34\%5-3484.

Gil Cruz, F., Meyer, H., Chouet, B., and Harlow, D.H., 1987, Observations of long-period events and tremor at Nerado del Ruiz volcano 1985-1986: Abstract volume, Hawaii Symposium on How Volcanoes Work, Hilo, Hawaii, p. 90.

Gordeev, E.I., 1992, Modeling of volcanic tremor wave fields: Jnumal of Volcanology and Geothermal Research, v. 51, p. 145-16?.

Hill, D.P., Ellsworth, W.L., Johnston, M.J.S., Langbein, J.O., Oppenheimer, D.H., Pitt, A.M., Reasenberg, P.A., Sorey, M.L., and McNutt, S.R., 1990, The 1989 earthquake swarm beneath Mammoth Mountain, California: An initial look at the 4 May through 30 September activity: Seismological Society of America Bulletin, v. 80, p. 325-339.

Hurst, A.W., 1992, Stochastic simulation of volcanic tremor from Ruapehu: Journal of Volcanology and Geothermal Research, v. 51 , p. $185-198$.

Julian, B.R., 1994, Volcanic tremor: Nonlinear excitation by fluid flow: Journal of Geophysical Research, v. 99, p. 11,859-11,878.

Kamo, K., Furuzawa, T., and Akamatsu, J., 1977, Some natures of volcanic microtremors at the Sakurajima volcano: Bulletin of the Volcanological Society of Japan, v. 22, p. 41-58.

Kieffer, S.W., 1977, Sound speed in liquid-gas mixtures: water-air and water-steam: Journal of Geophysical Research, v. 82, p. 2895-2904.

1984, Seismicity at Old Faithful Geyser: An isolated source of geothermal noise and possible analogue of volca nic seismicity: Journal of Volcanology and Geothermal Research, v. 22 , p. $59-95$.

Lee. W.H.K., 1989, Toolbox for seismic data acquisition, processing, and analysis: IASPEI Software Library Volume 1, Seismological Society of America, El Cerrito, Calif.

Leet, R.C., 1988, Saturated and subcooled hydrothermal boiling in groundwater flow channels as a source of harmonic tremor: Journal of Geophysical Research, v. 93, p. 4835-4\&49.

McKee, C., Wallace, D.A., Almond, R.A., and Talai, B., 1981, Fatal hydroeruption of Karkar volcano in 1979: Deve'spment of a maar-like crater, in Johnson, R.W., ed., Cooke-Ravian Volume of Volcanological Papers: Geological Survey' of Papua New Guinea, Memoir 10, p. 63-84.

McNutt, S.R., 1986, Observations and analysis of b-typ: earthquakes, explosions, and volcanic tremor at Pavlof volcano, Alaska: Bulletin of the Seismological Society of America, v. 76 , p. 153-175.

1992, Volcanic tremor: Encyclopedia of Earth System Sciences, San Diego, Calif., Academic Press, v. 4, p. 417-425. 1994, Volcanic tremor amplitude correlated with eruption explosivity and its potential use in determining ash hezards to aviation: U.S. Geological Survey Bulletin 2047, p. 377-385.

Montalto, A., Distefano, G., and Patane, G., 1992, Seismic patterns and fluid-dynamic features preceding the January 15, 1990 eruptive paroxysm on Mt. Etna (Italy): Journal of Volcanology and Geothermal Research, v. 5.1, p. 133-143.

Mori, J., Patia, H., McKee, C., Itikarai, I., Lowenstein, P., De Sa'nt Ours, P., and Talai, B., 1989, Seismicity associated with the eruptive activity at Langila volcano, Papua New Guinea: Journal of Volcanology and Geothermal Research, v. 38, p. 243-255.

Newhall, C.G., and Self, S., 1982, The volcano explosivity index 
(VEI): An estimate of explosive magnitude for historical volcanism: Journal of Geophysical Research, v. 87, p. 1231-1238.

Schick, R., Lombardo, G., and Patane, G., 1982, Volcanic tremors and shocks associated with eruptions at Etna (Sicily), September 1980: Journal of Volcanology and Geothermal Research, v. 14, p. 261-279.

Sonnafrank, G.H.C., Power, J., March, G., and Davies, J.N., 1991, Acquisition and automatic processing of seismic data at the Geophysical Institute, University of Alaska: Seismological Research Letters, v. 62, p. 23.

Stephens, C.D., Chouet, B.A., Page, R.A., Lahr, J.C., and Power,
J.A., 1994, Seismological aspects of the 1989-1990 eruptions at Redoubt Volcano, Alaska: The SSAM perspective: Journal of Volcanology and Geothermal Research, v. 62, p. 153-182.

Tapley, W.C., and Tull, J.E., 1991, SAC-Seismic Analysis CodeUsers Manual: Lawrence Livermore National Laboratory, Livermore, Calif.

Ukawa, M., 1993, Excitation mechanism of large-amplitude volcanic tremor associated with the 1989 Ito-oki submarine eruption, central Japan: Journal of Volcanology and Geotrermal Research, v. 55, p. 33-50. 
178

THE 1992 ERUPTIONS OF CRATER PEAK VENT, MOUNT SPURR, ALASKA

Appendix 1. Tremor bursts measured at seismic stations CPK and CRP between June 6 and June 26, 1992, Mount Spurr volcano, Alaska.

[All dates expressed in Universal Time; duration expressed in seconds; amplitude expressed in millimeters]

\begin{tabular}{|c|c|c|c|c|c|}
\hline $\begin{array}{l}\text { Time } \\
\text { (UT) }\end{array}$ & $\begin{array}{l}\text { CPK duration } \\
\text { (sec) }\end{array}$ & $\begin{array}{c}\text { CRP amplitude } \\
(\mathrm{mm})\end{array}$ & $\begin{array}{l}\text { Time } \\
\text { (UT) }\end{array}$ & $\begin{array}{c}\begin{array}{c}\text { CPK duration } \\
\text { (sec) }\end{array} \\
\end{array}$ & $\begin{array}{c}\text { CRP amplitude } \\
(\mathrm{mm})\end{array}$ \\
\hline \multicolumn{3}{|c|}{ June 6, 1992} & \multicolumn{3}{|c|}{ June 10, 1992-Continued } \\
\hline $15: 00$ & 190 & 5.5 & 07:19 & 90 & 2.0 \\
\hline $16: 57$ & 130 & 4.0 & $08: 28$ & 160 & 3.0 \\
\hline $18: 16$ & 80 & 5.0 & 08:41 & 160 & 2.0 \\
\hline $20: 43$ & 90 & 3.5 & $10: 54$ & 120 & 6.0 \\
\hline 22:04 & 160 & 2.5 & $11: 39$ & 110 & 5.0 \\
\hline \multicolumn{3}{|c|}{ June 7,1992} & 13:04 & 170 & 7.0 \\
\hline $01: 26$ & 190 & 1.5 & $\begin{array}{l}14: 09 \\
15 \cdot 25\end{array}$ & 150 & $\begin{array}{l}6.0 \\
1.5\end{array}$ \\
\hline $02: 28$ & 130 & 5.0 & $15: 31$ & 120 & 5.0 \\
\hline 04:58 & 220 & 3.0 & $15: 44$ & 110 & 3.0 \\
\hline $05: 47$ & 80 & 3.5 & $16: 55$ & 70 & 3.0 \\
\hline $07: 26$ & 180 & 2.5 & $17: 09$ & 150 & 3.0 \\
\hline $08: 23$ & 200 & 2.0 & $17: 20$ & 160 & 2.0 \\
\hline $09: 40$ & 170 & 2.5 & I9:38 & 110 & 1.5 \\
\hline $10: 58$ & 180 & 1.5 & $20: 43$ & 190 & 5.0 \\
\hline $11: 56$ & 180 & 1.0 & $21: 52$ & 230 & 6.0 \\
\hline $13: 38$ & 190 & 4.0 & \multicolumn{3}{|c|}{ June 11,1992} \\
\hline $14: 04$ & 100 & 1.0 & $00: 16$ & 100 & 4.0 \\
\hline $14: 47$ & 200 & 3.0 & $00: 31$ & 70 & 3.0 \\
\hline $15: 29$ & 110 & 3.5 & $00: 35$ & 140 & 2.5 \\
\hline $15: 48$ & 140 & 3.0 & $00: 45$ & 180 & 1.5 \\
\hline $16: 06$ & 110 & 2.5 & $02: 53$ & 180 & 1.5 \\
\hline $18: 24$ & 140 & 3.5 & $03: 48$ & 100 & 2.5 \\
\hline 19:01 & 170 & 2.5 & $03: 50$ & 110 & 2.5 \\
\hline $19: 35$ & 140 & 1.0 & 04:39 & 100 & 10.0 \\
\hline \multicolumn{3}{|c|}{ June 8, 1992} & $07: 05$ & 70 & 2.0 \\
\hline $06: 30$ & 320 & 3.0 & 07:29 & 150 & 3.0 \\
\hline $07: 58$ & 310 & 1.0 & $14: 26$ & 120 & 2.0 \\
\hline $6 / 8 / 92$ & & & $14: 45$ & 150 & 2.0 \\
\hline $09: 38$ & 250 & 5.5 & $15: 03$ & 230 & 5.0 \\
\hline 09:46 & 80 & 1.5 & $16: 07$ & 100 & 2.0 \\
\hline $10: 24$ & 240 & 4.0 & $17: 15$ & $>90$ & 1.5 \\
\hline $11: 00$ & 120 & 1.0 & $17: 18$ & 100 & 4.0 \\
\hline $11: 36$ & 130 & 3.5 & $18: 09$ & 120 & 4.0 \\
\hline $12: 02$ & 100 & 2.0 & $18: 33$ & 240 & 2.0 \\
\hline $12: 35$ & 90 & 3.0 & $20: 04$ & 90 & 3.5 \\
\hline $12: 52$ & 80 & 2.0 & $21: 07$ & 220 & 3.5 \\
\hline $14: 17$ & 130 & 2.0 & $21: 34$ & 90 & 2.5 \\
\hline $15: 04$ & 170 & 1.5 & $21: 36$ & 110 & 3.0 \\
\hline $15: 53$ & 160 & 1.5 & $22: 08$ & 110 & 3.5 \\
\hline $17: 13$ & 170 & 3.0 & $23: 47$ & 110 & 3.5 \\
\hline $17: 40$ & 170 & 2.0 & \multicolumn{3}{|c|}{ June 12, 1992} \\
\hline $18: 28$ & 130 & 1.5 & $01: 01$ & 230 & 1.0 \\
\hline $19: 52$ & 180 & 5.0 & $03: 17$ & 250 & 6.0 \\
\hline 21:38 & $>150$ & 5.0 & $05: 59$ & 180 & 2.0 \\
\hline \multicolumn{3}{|c|}{ June 9, 1992} & $06: 25$ & 220 & 1.5 \\
\hline $00: 58$ & 270 & 5.0 & $10: 49$ & 240 & 2.5 \\
\hline $01: 16$ & 220 & 6.0 & 11:04 & 200 & 2.5 \\
\hline $01: 26$ & $\sim 150$ & 2.0 & $11: 12$ & 80 & 2.5 \\
\hline 02:02 & 80 & 4.0 & $15: 10$ & 130 & 3.0 \\
\hline 02:37 & 100 & 3.0 & $15: 23$ & 180 & 1.0 \\
\hline $03: 22$ & 90 & 3.0 & $20: 47$ & 360 & 4.0 \\
\hline $04: 55$ & 190 & 4.0 & $21: 00$ & 220 & 4.0 \\
\hline $15: 27$ & $>120$ & 2.5 & 21:08 & 80 & 4.0 \\
\hline $15: 49$ & 160 & 1.5 & \multicolumn{3}{|c|}{ June 13, 1992} \\
\hline $16: 02$ & 180 & 2.5 & $00: 15$ & 200 & 3.0 \\
\hline $16: 33$ & 80 & 2.0 & $00: 45$ & 210 & 22. \\
\hline 18:07 & 150 & 2.0 & $09: 27$ & 190 & 2.5 \\
\hline $20: 29$ & 170 & 3.5 & $09: 30$ & 110 & 2.0 \\
\hline $22: 15$ & 140 & 3.5 & $09: 43$ & 150 & 1.5 \\
\hline \multicolumn{3}{|c|}{ June 10, 1992} & $10: 09$ & 120 & 1.0 \\
\hline $01: 01$ & 160 & 4.0 & $10: 29$ & 70 & 1.5 \\
\hline 03:04 & 190 & 2.0 & $11: 29$ & 150 & 3.0 \\
\hline 04:56 & 250 & 6.0 & $15: 03$ & 230 & 1.5 \\
\hline 05:03 & 140 & 2.0 & $18: 04$ & 120 & 3.5 \\
\hline $06: 12$ & 130 & 8.0 & $23: 10$ & 100 & 2.0 \\
\hline & & & $23: 39$ & 120 & 1.0 \\
\hline
\end{tabular}

\begin{tabular}{|c|c|c|}
\hline $\begin{array}{l}\text { Time } \\
\text { (UT) }\end{array}$ & $\begin{array}{c}\text { CPK duration } \\
\text { (sec) }\end{array}$ & $\begin{array}{c}\mathrm{CR}^{\top} \text { amplitude } \\
\text { (mm) }\end{array}$ \\
\hline \multicolumn{3}{|c|}{ June 14, 1992} \\
\hline $04: 19$ & 100 & 3.0 \\
\hline $06: 24$ & 200 & 3.0 \\
\hline 09:00 & 120 & 2.0 \\
\hline 09:39 & 110 & 1.0 \\
\hline $16: 32$ & 80 & 1.5 \\
\hline $17: 39$ & 90 & 3.5 \\
\hline \multicolumn{3}{|c|}{ June 15,1992} \\
\hline $00: 08$ & 260 & 1.5 \\
\hline 04:05 & 90 & 5.0 \\
\hline $12: 48$ & 160 & $<1.0$ \\
\hline $13: 16$ & 120 & 1.0 \\
\hline $13: 50$ & 150 & 1.5 \\
\hline 14:04 & 70 & 1.0 \\
\hline $19: 24$ & 100 & 6.0 \\
\hline \multicolumn{3}{|c|}{ June 16, 1992} \\
\hline $08: 44$ & 250 & 1.0 \\
\hline $17: 39$ & 230 & 3.0 \\
\hline $20: 50$ & 90 & 0.0 \\
\hline \multicolumn{3}{|c|}{ June 17, 1992} \\
\hline $20: 16$ & 110 & 3.5 \\
\hline \multicolumn{3}{|c|}{ June 18, 1992} \\
\hline $14: 07$ & 120 & 2.0 \\
\hline \multicolumn{3}{|c|}{ June 19, 1992} \\
\hline $04: 57$ & 370 & 5.0 \\
\hline $18: 35$ & 260 & 2.0 \\
\hline 19:08 & 110 & 4.0 \\
\hline $19: 36$ & 180 & 2.0 \\
\hline 20:02 & 360 & 3.5 \\
\hline \multicolumn{3}{|c|}{ June 20, 1992} \\
\hline $10: 54$ & 220 & $<1.0$ \\
\hline 20:59 & 550 & 12.0 \\
\hline \multicolumn{3}{|c|}{ June 21, 1992} \\
\hline $23: 05$ & 130 & 2.0 \\
\hline \multicolumn{3}{|c|}{ June 22, 1992} \\
\hline $03: 25$ & 320 & 3.5 \\
\hline 03:50 & 80 & $<1.0$ \\
\hline $05: 49$ & 110 & 3.0 \\
\hline $07: 19$ & 270 & 2.0 \\
\hline 08:35 & 130 & 2.0 \\
\hline 09:29 & 210 & 2.0 \\
\hline $09: 47$ & 100 & 2.0 \\
\hline $16: 45$ & 600 & 6.0 \\
\hline $22: 16$ & 370 & 1.5 \\
\hline $22: 47$ & 190 & 3.5 \\
\hline \multicolumn{3}{|c|}{ June 23, 1992} \\
\hline $14: 28$ & 220 & 6.5 \\
\hline 22:06 & 80 & 10.5 \\
\hline 22:09 & 210 & 5.0 \\
\hline $22: 33$ & 170 & 3.5 \\
\hline \multicolumn{3}{|c|}{ June 24, 1992} \\
\hline $06: 01$ & 260 & 5.0 \\
\hline $15: 09$ & 350 & 6.5 \\
\hline 23:34 & 9,240 & 5.0 \\
\hline \multicolumn{3}{|c|}{ June 25, 1992} \\
\hline $06: 52$ & 350 & 5.0 \\
\hline $11: 13$ & 310 & 5.5 \\
\hline 11:32 & 8,520 & 4.5 \\
\hline $15: 58$ & 240 & 7.5 \\
\hline 20:11 & 130 & 9.0 \\
\hline $23: 55$ & 360 & 7.0 \\
\hline \multicolumn{3}{|c|}{ June 26, 1992} \\
\hline $04: 51$ & 450 & 10. \\
\hline $05: 36$ & 150 & 2.0 \\
\hline $11: 16$ & 390 & 3.5 \\
\hline 20:03 & 68,460 & $\sim 10.0$ \\
\hline
\end{tabular}




\title{
Lightning Associated with the August 18, 1992, Eruptic n of Crater Peak Vent, Mount Spurr Volcano, Alaska
}

\author{
By John F. Paskievitch, Thomas L. Murray, Richard P. Hoblitt, and Christina A. Neal
}

\section{CONTENTS}

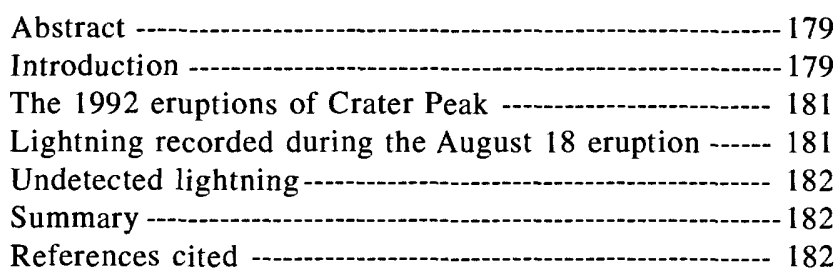

\begin{abstract}
The Alaska Volcano Observatory's lightning detection system detected and located 171 lightning strokes during the August 18, 1992, eruption of the Crater Peak vent of Mount Spurr volcano in Alaska. The strokes, predominantly intracloud, were detected during a 70-minute interval that began more than an hour into the eruption. All detected strokes were of positive polarity. The spatial distribution of the strokes in the horizontal plane defines a ring-like pattern approximately $10 \mathrm{~km}$ in diameter and displaced roughly $5 \mathrm{~km}$ to the east of Crater Peak. Although lightning was observed during the September 16-17, 1992, eruption of Crater Peak, no lightning was detected by the lightning detection system.
\end{abstract}

\section{INTRODUCTION}

Although the occurrence of lightning in volcanic eruption clouds is well documented, few attempts have been made to use lightning detection and location to monitor eruptions. Such a monitoring approach could potentially allow for the detection of an ash cloud even when meteorological conditions might prevent observations from satellites and ground-based radar. In 1990, the Alaska Volcano Observatory (AVO) experimented with a lightning detection system (LDS) used by the Bureau of Land Management (BLM) in their forest fire program. BLM's network is configured to locate typical meteorologic lightning strikes that could potentially cause forest fires. A subset of BLM's network was modified and configured to enhance the potential to detect and locate volcanogenic lightning caused by the eruptions of Redoubt Volcano, Alaska. The system successfully detected and located volcanogenic lightning during several eruptions (Hoblitt, 1994). In 1991, AVO installed its own LDS and configured it to detect lightning in the Cook Inlet area.

The typical lightning discharge, or flash, is composed of a number of strokes. The series of strokes associated with a lightning flash occur within a few tenths of a second. A lightning discharge is termad a "strike" only if it makes contact with some conductive surface such as the Earth, trees, or aircraft. Each discrete stroke of lightning generates a broadband radio signal that radiates at the speed of light in an omnidirectional pattern.

The LDS at AVO incorporates lightning stroke detectors in the Alaska cities of Palmer, Iliamna, and Homer (fig. 1). These detectors monitor a portion of the radio frequency spectrum for a lightning-induced instantaneous rise in signal amplitude. A stroke that generates a radio signal with an amplitude excee ling the detector's threshold will be recorded at each detector at a different instant in time. The time of arrival of a signal is measured and recorded to submicrosecond resolution. Using these precise times of arrival and the known locations of the detector sites, a lightning stroke's location can be determined.

A central analyzer in Anchorage calculates the locations of strokes. Communication between the analyzer and the remote detectors is via modem and phoneline (fig. 2). At regular intervals, the central analyzer automatically dials and queries each of the three remote detectors. Data is downloaded by the central analyzer and quickly correlated to determine if lightning strokes were detected. Various parameters are determined for each stroke including amplitude, polarity, and location.

There are two primary modes of recording LDS data: in a $\log$ file, and in the video information system (VIS). Processed and raw data (including systemstatus reports) are automatically transferred to and 


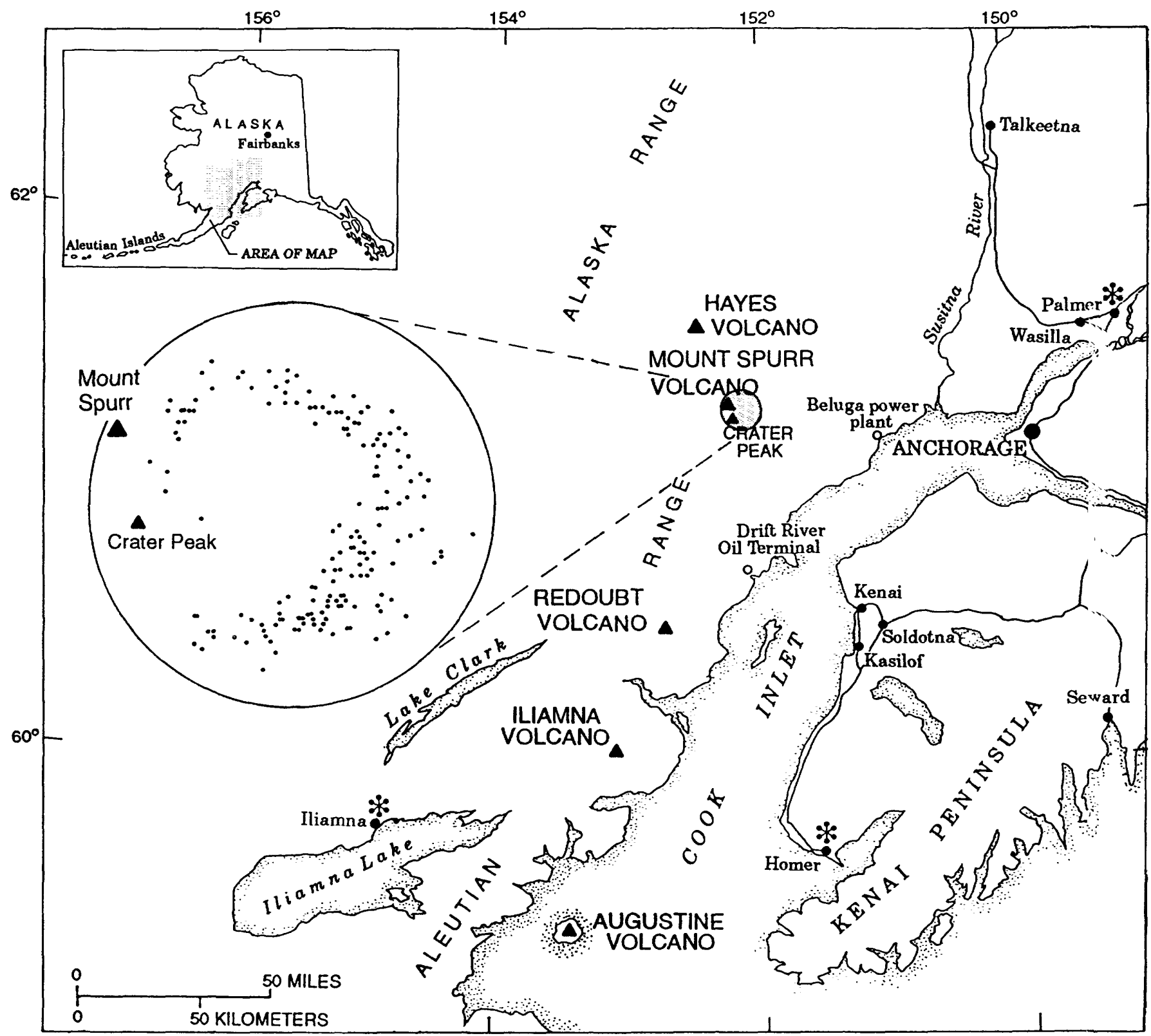

Figure 1. Cook Inlet area and locations of the active volcanoes. Asterisks show locations of LDS receivers. Enlarget view (inset) of area surrounding Mount Spurr shows 171 lightning strokes.

Figure 2. Data storage and communication links for Alaska VoIcano Observatory's (AVO) lightning detection system. The central analyzer queries (via modem and phone line) each remote receiver at user-defined intervals. Incoming data are stored in the central analyzer and the computer named "Sparky." Data can be manipulated and viewed graphically through the video information system (VIS) and the AVO main computer.

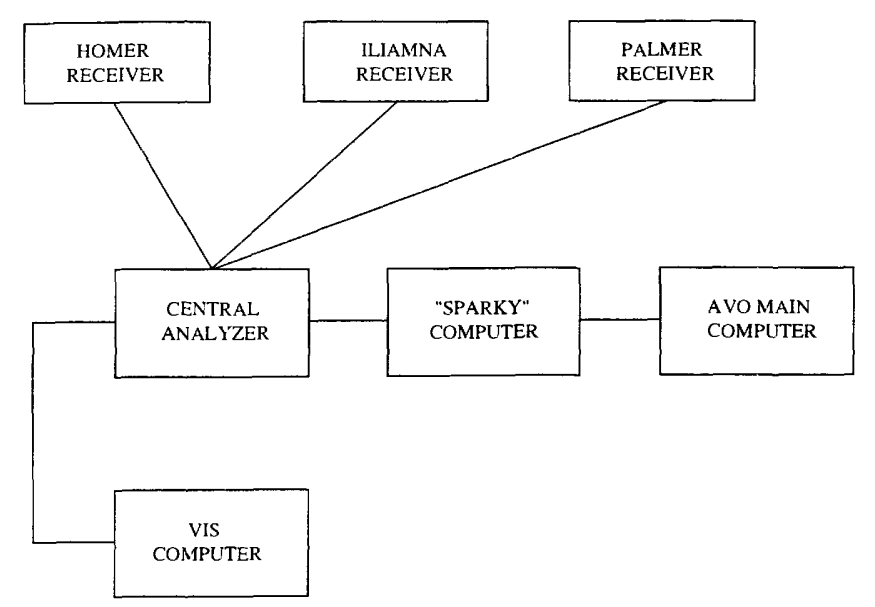


stored in a $\log$ file on an associated computer. This file essentially contains the entire central analyzer output. The VIS data are initially stored in a buffer in the central analyzer. Before lightning data are sent to the VIS, a stroke must meet the criteria of being regionally comparable to, and occurring within $5 \mathrm{~min}$ utes of a preceding stroke. These criteria are designed to ensure the reliability of data. The VIS provides a graphic display of stroke locations and allows access to various quantitative stroke parameters.

\section{THE 1992 ERUPTIONS OF CRATER PEAK}

Mount Spurr volcano is located $125 \mathrm{~km}$ west of Anchorage at the northeastern end of the Aleutian arc (fig. 1). Following 10 months of elevated seismicity, the volcano erupted explosively on June 27, August 18, and September 16-17, 1992. The site of the three eruptions was Crater Peak, a satellite cone at 2,300 m elevation on the southern margin of the caldera and $3.2 \mathrm{~km}$ south of Mount Spurr's summit cone (Nye and Turner, 1990).

The three eruptions of Crater Peak were similar in character. The eruptions were explosive with sudden and impulsive onsets to each main phase. Duration of the main phase of each eruption were 3.5 to 4 hours, material ejected largely consisted of andesitic tephra, dense-rock equivalent erupted volumes for each of the eruptions were similar (Neal and others, this volume), and maximum radar-discernible column heights were approximately 13 to $15 \mathrm{~km}$ above sea level (Rose and others, this volume).

\section{LIGHTNING RECORDED DURING THE AUGUST 18 ERUPTION}

Although lightning was visually observed during the August and September eruptions, the LDS recorded lightning only during the August 18 eruption. The main phase of the August 18 eruption began at 4:42 p.m. Alaska daylight time (ADT). The LDS was unable to establish communication with the detector at Iliamna and therefore was not fully operational prior to 6:30 p.m. ADT. This prevented direct comparison of the onset of the eruption with the onset of lightning. Although the LDS first detected and located lightning at 6:30 p.m. ADT, it is known that lightning did occur before this time. First, an independent LDS operated by the BLM and designed to detect only ground strokes, or strikes, recorded 14 strikes associated with the eruption between 5:43 p.m. ADT and 7:51 p.m. ADT (Keith Pollock, BLM, oral commun., 1992). Sec- ondly, the two operational detectors at Homer and Palmer recognized common events believed to be lightning strokes associated with the eruption as early as 5:30 p.m. ADT. Third, airborne observers at the volcano saw lightning at 5:45 p.m. ADT (G. McGirsey, USGS, oral commun., 1992).

Once communication to all three detectors was established, the LDS recorded 171 strokes during a 70-minute interval. The horizontal spatial pattern of recorded stroke locations forms a crude circle roughly $10 \mathrm{~km}$ in diameter (fig. 1). There is a concentration of strokes on the eastern side of the circle. The center of the circle of strokes is displaced approximately $5 \mathrm{~km}$ in a direction $110^{\circ}$ (true north) from the eruptive vent. This displacement is consistent with the migration of the eruption cloud resulting from the westerly winds during the eruption (Neal and others, this volume).

At the time of lightning detection, the eruption column had extended to its maximum altitude of about $14 \mathrm{~km}$ on the basis of C-band radar estimates (Pose and others, this volume), or $18 \mathrm{~km}$ (unpublished pilot reports). Satellite imagery near this time depicts an elongate plume extending to the east. The National Weather Service's C-band radar provides a cross-sectional view of the plume (not the eruption column) displaced to the east of the vent. The image shows zones that are defined by regions of like particle size (Rose and others, this volume).

The spatial pattern made by the stroke locations is very uniform, which suggests that it is not a random function. Stroke occurrence and location are most likely controlled by concentrations of particle-size fractions or particle densities within the plume that in turn control charge densities and polarities.

Analyses of stroke signals suggest that more than 70 percent of the strokes were intracloud, and the remaining 30 percent were ground strokes, or strikes. However, caution must be exercised when considering the distinction between these intracloud and cloudto-ground strokes. The LDS determines stroke type with a model that is based on typical meteorolngic lightning. The time between peak stroke signal and the first polarity change is measured. If this time interval is less than 10 microseconds, the stroke is classified as intracloud. If the time interval exceeds 10 microseconds, a ground stroke is indicated. However, volcanogenic lightning might behave quite differently than meteorologic lightning in this regard. For instance, the conductive ionized channel that precedes volcanogenic lightning could perhaps be a slower path than that for meteorologic lightning (Rodney Bent, Atmospheric Research Systems, Inc., oral commun., 1992). If this were the case, some volcanogenic intracloud strokes could be misclassified as ground strokes. 
Stroke amplitudes, calculated by AVO's central analyzer, for the 50 detected ground strokes ranged from $15 \mathrm{kA}$ to $40 \mathrm{kA}$ with an average amplitude of $22 \mathrm{kA}$. These values fall within the range of ground strokes observed in local area thunderstorms but approach neither the low nor high values that describe this observed range ( $3.5 \mathrm{kA}$ to $350 \mathrm{kA}$ ). The LDS is unable to calculate amplitudes for intracloud strokes.

\section{UNDETECTED LIGHTNING}

Lightning was neither detected nor observed during the June eruption. Although the occurrence of lightning was observed during the September eruption, none was detected by the LDS even though the system appeared to be operational. Indeed, the system probably did not detect all of the lightning that occurred during the August 18 eruption, even when the system was fully operational. There are several possibilities for this. The simplest explanation is that the signal from intracloud lightning has a lower amplitude than cloud-to-ground lightning. Data from the August 18 eruption indicate that intracloud lightning predominates. Possibly the typical signal levels from these strokes fall below the detection threshold of the LDS. The subset of strokes recorded for the August 18 eruption may have produced greater signal strengths and were therefore the only ones detected.

Considering the similarities between the three eruptions, it is puzzling that strokes were detected for only the August eruption. Perhaps subtle factors are involved in an eruption that would raise the stroke amplitudes or affect other stroke characteristics that would allow for detection. Also, atmospheric and meteorologic conditions at the time of an eruption may influence volcanogenic lightning characteristics.

\section{SUMMARY}

An LDS was installed at AVO to further explore the potential to determine the occurrence of volcanic ash clouds through the detection of associated lightning. Such a monitoring approach would allow for the detection of an ash cloud even when meteorologeic conditions might prevent observation from satellites and ground-based radar. During one of the three 1992 Crater Peak eruptions, it was demonstrated that the system could function as anticipated. The LDS was able to detect and locate at least a subset of the lightning associated with the August 18 eruption. The circular pattern of the stroke locations give an indication of both size and movement of the ash cloud.

Although lightning was observed during the September eruption, none was detected by the LIS. The LDS did not record all of the lightning associated with the August eruption. A plausible explanation for this is that the relatively low-amplitude intracloud lightning that was predominant during these eruptions did not, with the exception of the 171 lightning strokes recorded during the August eruption, generate strong enough signals to be detected at all three detector locations. Installing a fourth detector closer to the monitored volcanoes may enhance the ability to detect volcanogenic lightning during future eruptions of Cook Inlet volcanoes.

\section{REFERENCES CITED}

Hoblitt, R.P., 1994, An experiment to detect and locate lightning associated with eruptions of Redoubt Volcano: Journal of Volcanology and Geothermal Research, v. 62 , nos. $1-4$, p. 499-517.

Nye, C.G. and Turner, D.L., 1990, Petrology, geochem ‘ 4 try and age of the Spurr volcanic complex, Eastern Aleutian arc: Bulletin of Volcanology, v. 52, p. 205-226. 


\title{
Lahars from the 1992 Eruptions of Crater Peak, Mount Spurr Volcano, Alaska
}

\author{
By David F. Meyer and Dennis C. Trabant
}

\section{CONTENTS}

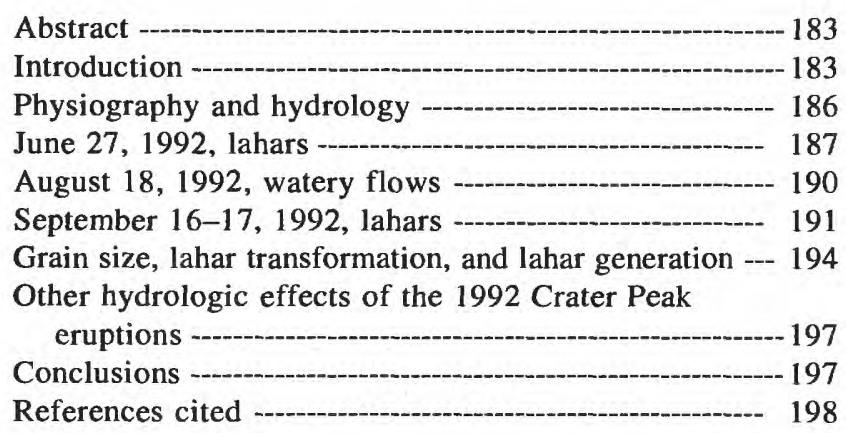

\begin{abstract}
Lahars, which are flows of volcanic sediment and water, are commonly the most immediate hydrologic hazard resulting from volcanic eruptions. Lahars often change character as they flow downstream, and a single flow can behave as a debris flow at one time and place and as streamflow at another time and place. Crater Peak, a vent on the flank of Mount Spurr volcano, erupted on June 27, August 18, and September 16-17, 1992. Lahars generated during these eruptions illustrate the effects of clay content on lahar behavior, processes of flow transition, and thresholds of glacier slope and surface roughness, below which lahars are not generated.

On June 27, snow, ice, and rock avalanches were triggered by the eruption and flowed down several steep gullies on the south flank of Crater Peak. These flows became debris flows and entered the Chakachatna River in three places. During the August 18 eruption, at least four pulses of hot pyroclastic flow covered a small area on the middle part of Kidazgeni Glacier and flowed down three gullies on the south flank of Crater Peak, but no lahars resulted and no flows entered the Chakachatna River. On September 16-17, pyroclastic flows covered and traversed a larger area on Kidazgeni Glacier and eroded snow and ice along steep, crevassed icefalls then coalesced near the toe of the glacier to form a debris flow that deposited most of its sedi-
\end{abstract}

ment along a more gently sloping reach. The debris flow then eroded more material as it descended a narrow gully, and the resulting deposit at the mouth of that gully dammed the Chakachatna River.

Comparison of the behavior of the 1992 Crater Peak lahars with lahars that resulted from the 1980 eruption of Mount St. Helens, Washington, indicates that if less than 1 percent clay-size material is present in the flow, coarse-grained material is deposited on relatively steep slopes, and debris flows do not extend as far downstream as do debris flows with larger proportions of clay-size material.

\section{INTRODUCTION}

Lahars often present the most serious of all volcanic risks in populated areas. The hazard these flows of sediment and water represent depends on their character. Lahars can range from Newtonian, sedimentladen streamflow to non-Newtonian debris flow and can change as they move downstream. The character of the flows depends on initiating mechanisms, nature of the material incorporated in the flow, water content, and changing channel and valley geometries. Although numerous lahars have been documented, especially since the devastating eruptions of Mount St. Helens, Washington, and Nevado del Ruiz, Columbia (see Janda and others, 1981; Pierson and others, 1990; Scott, 1988; 1989), documentation of the range of factors that produce lahars remains incomplete.

Lahars were produced during two of the three 1992 eruptions of Crater Peak, a vent on Mount Spurr volcano. During the June 27 eruption, avalanches of snow and volcaniclastic debris flowed down Crater Peak creek (informal name) and Wilton's Walk gully (informal name; fig. 1) and evolved into debris flows. During the September 16-17 eruption, pyroclastic flows eroded and incorporated snow and glacier ice on Kidazgeni Glacier, and they transformed into debris flows that eventually dammed the Chakachatna River at the mouth of Bench gully (informal name; fig. 1). During the August 18 eruption, pyroclastic flows extended down the gullies on the upper flanks of Crater 
Peak and onto Kidazgeni Glacier and produced small meltwater flows that did not evolve into debris flows.

In both eruptions in which debris flows were generated (June 27 and September 16-17), the volume and character of the flows changed as older volcaniclastic material was entrained and as sediment was deposited along the flow path. Most of the sediment was deposited near the base of the volcano, and the lahars did not extend far downstream.

Lahars generated during the July 9, 1953, eruption of Crater Peak (Juhle and Coulter, 1955) affected the same drainages that were affected during the 1992 eruptions and were about the same size. They flowed down Crater Peak creek, across an area known informally as "the Bench," and down Bench gully and an unnamed stream draining from Kidazgeni Glacier, 2 $\mathrm{km}$ downstream from Bench gully (figs. 1 and 2). The Crater Peak creek lahar deposited debris that formed a fan in the channel of the Chakachatna River that dammed the river and formed a lake. The lake still existed in 1995, although it was not as large. Smaller fans were deposited at the mouths of Bench gully and the unnamed stream $2 \mathrm{~km}$ farther downstream. Apparently, considerable tephra was deposited on Kidazgeni and Straight Glaciers, but little, if any, tephra was deposited on Crater or Barrier Glaciers. The summit crater of Crater Peak was filled with snow and ice prior to the 1953 eruption. The snow and ice were completely removed by the 1953 eruption.

Currently no structures or people are at risk from flows down the south flank of Mount Spurr. However, hydroelectric and hydrothermal development and extensive coal mining have been or are being considered in the region. The significant hazard presented by lahars from Mount Spurr is integral to land-use planning for areas surrounding the volcano.

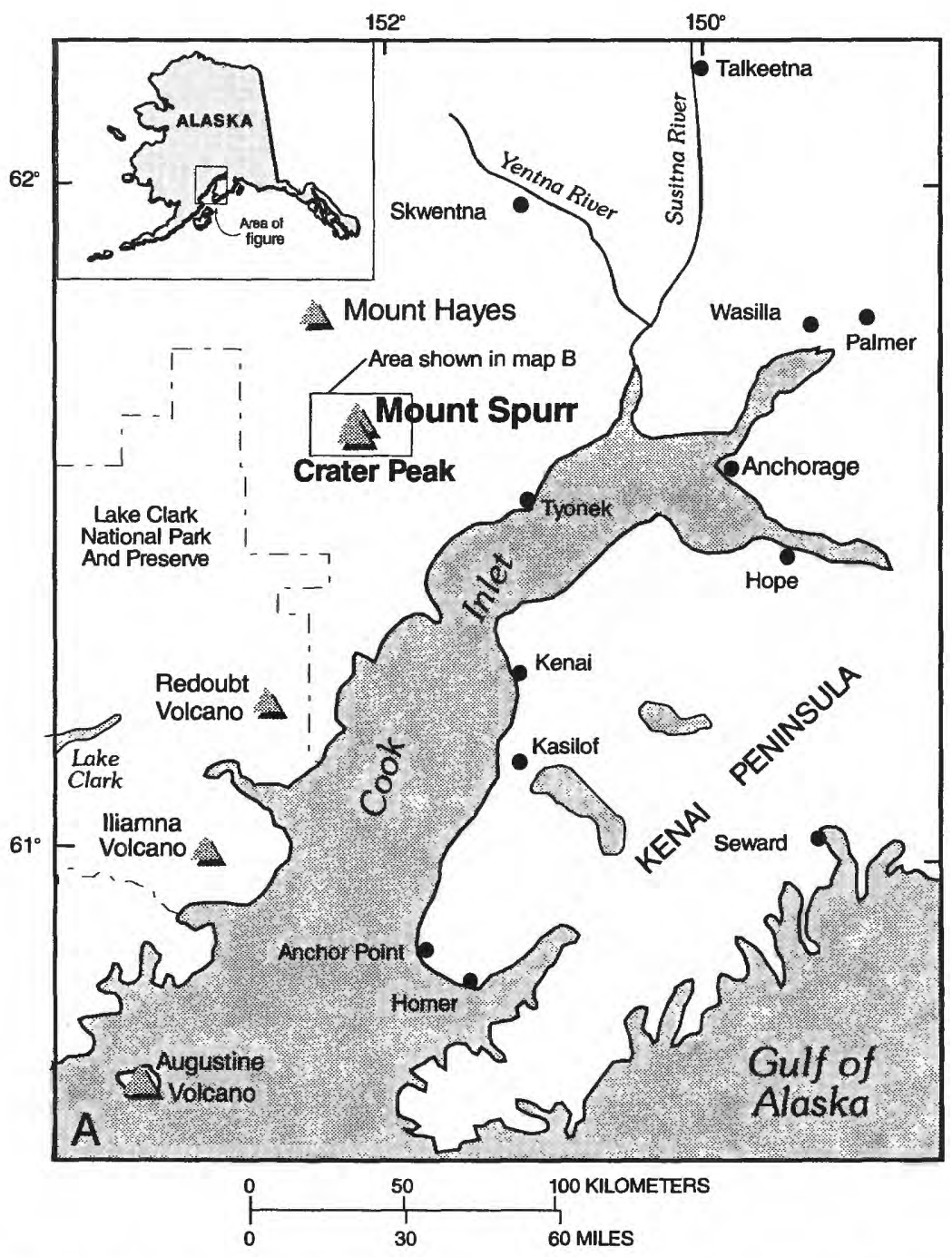

Figure 1. $A$, Location of Mount Spurr volcano and its active vent, Crater Peak, in southwestern Alaska. 

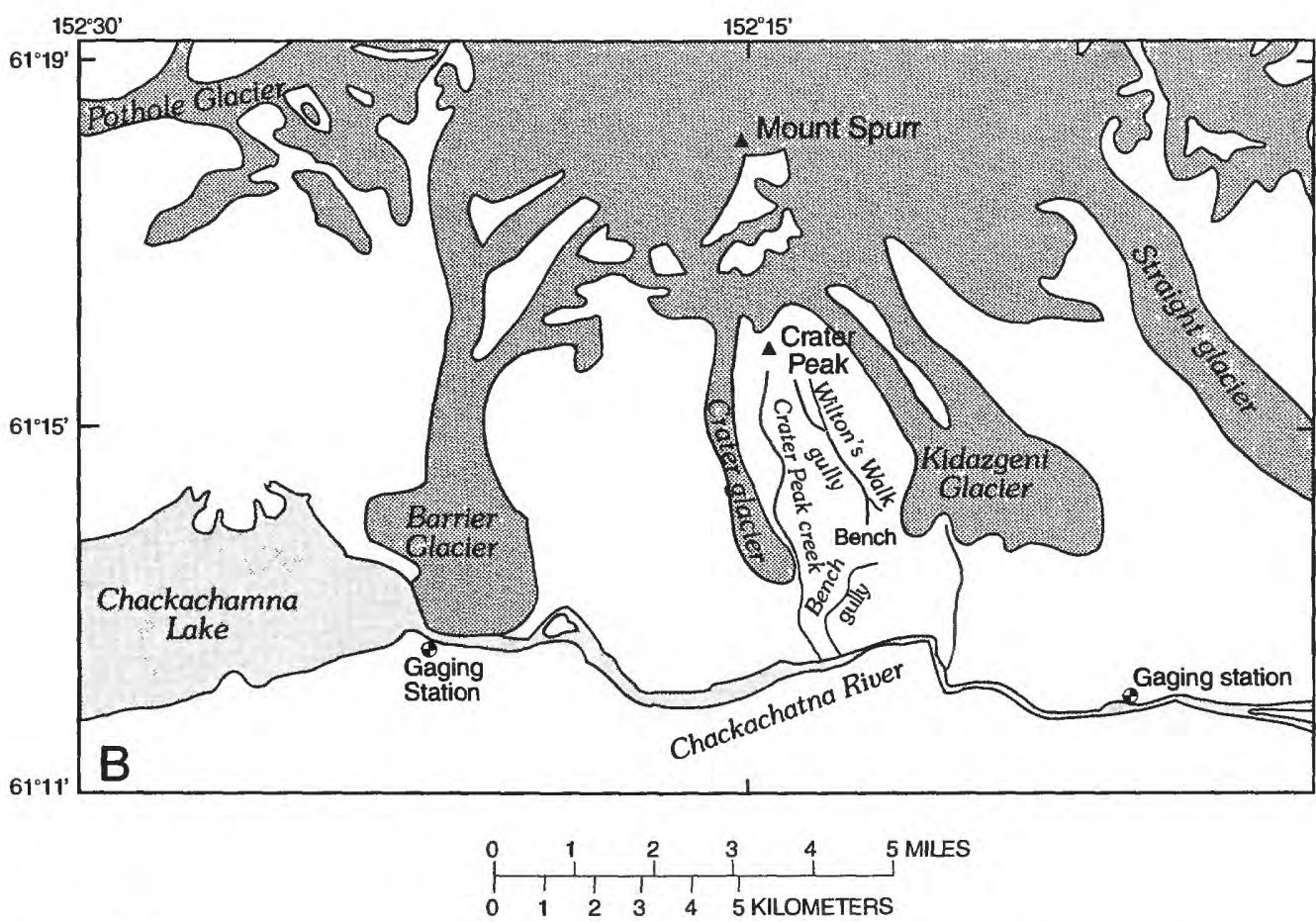

Figure 1. Continued. B, Hydrologic features affected by 1992 eruptions of Crater Peak.

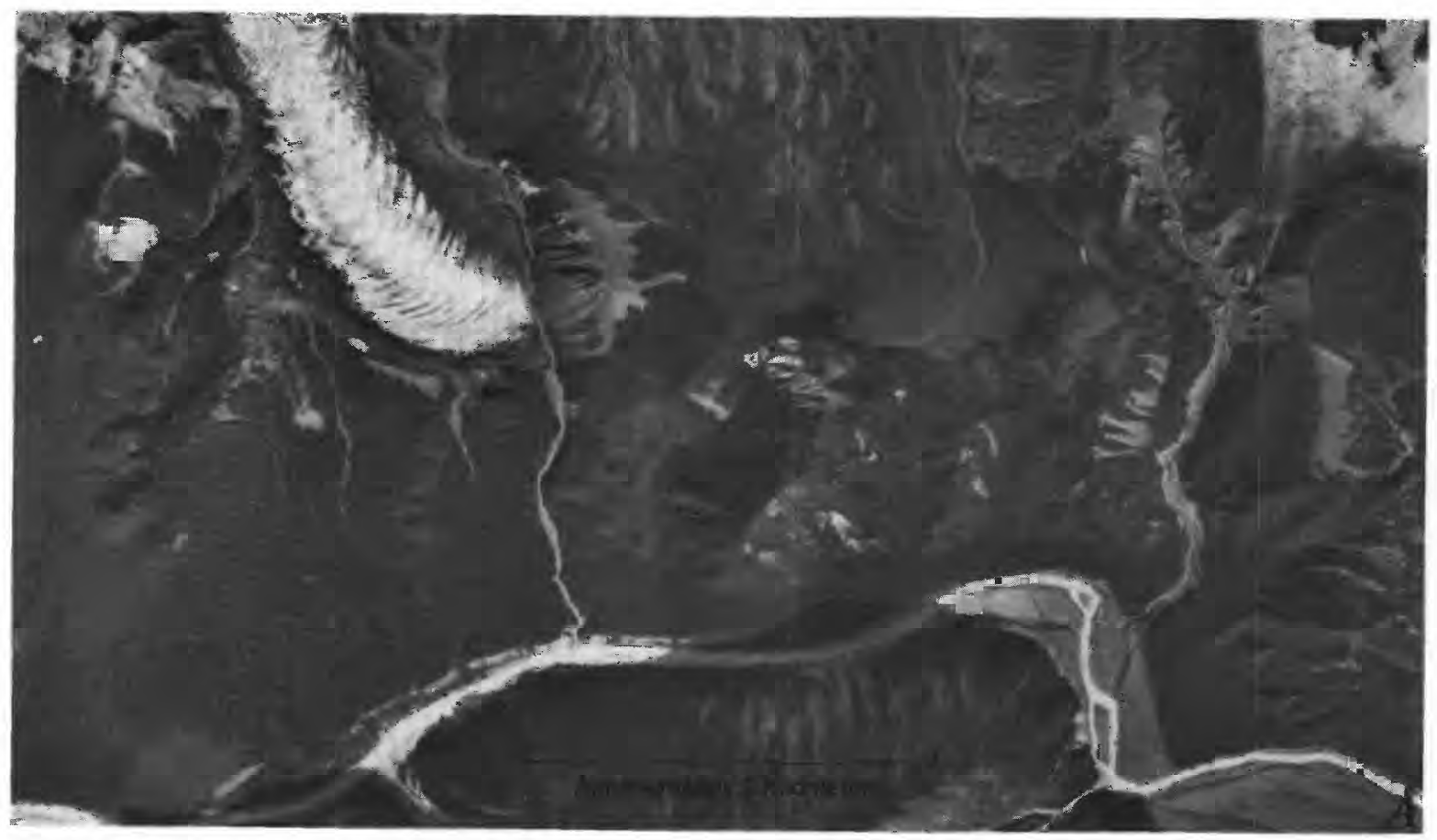

Figure 2. A, South flank of Mount Spurr volcano, southwestern Alaska, on September 2, 1952. 


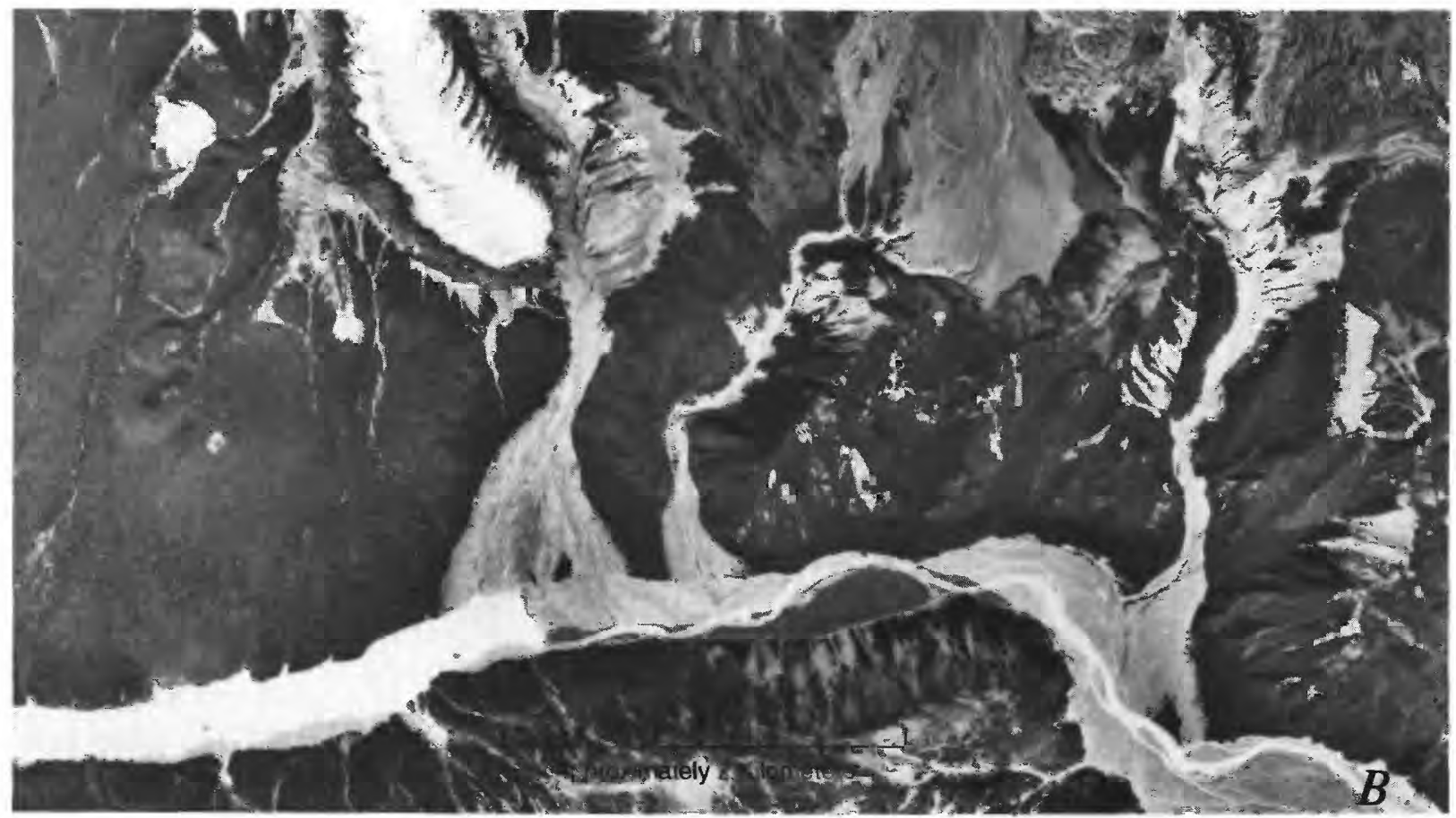

Figure 2. Continued. B, South flank of Mount Spurr volcano, southwestern Alaska, on August 29, 1954. Lahar deposits from July 9, 1953, eruption of Crater Peak visible in center of photograph.

\section{PHYSIOGRAPHY AND HYDROLOGY}

About $67 \mathrm{~km}^{3}$ of snow and ice, covering 360 $\mathrm{km}^{2}$, are stored in the glaciers on Mount Spurr. The main caldera of Mount Spurr is filled by snow and glacier ice and is the source of Kidazgeni Glacier, which flows around the east side of Crater Peak, and of Crater glacier (informal name), which flows around the west side of Crater Peak (fig. 1). Prior to the 1953 eruption of Crater Peak, the crater at its summit was filled with snow and ice that extended a short distance down the flanks (Juhle and Coulter, 1955). Barrier Glacier is the largest glacier in the Chakachatna River drainage and partly obstructs the river southwest of Mount Spurr; this obstruction resulted in the formation of Chakachamna Lake. Barrier Glacier heads on the west flank of the main caldera of Mount Spurr, about $5 \mathrm{~km}$ northwest of Crater Peak.

The Chakachatna River drains the west, south, and east flanks of Mount Spurr, including the areas most affected by the 1992 eruptions of Crater Peak. The largest of numerous canyons and small gullies on the flanks of Crater Peak is Crater Peak creek, a deep, V-shaped gorge cut into pyroclastic and laharic deposits from the Crater Peak vent (Nye and Turner, 1990). Several hot springs are present along the creek. Stream slopes of all of these drainages are steep, rang- ing from 0.3 to 1.1 meters per meter $(\mathrm{m} / \mathrm{m})$ in Crater Peak creek within the first $3 \mathrm{~km}$ from the rim of the crater (fig. 3). At an altitude of about $520 \mathrm{~m}$, Crater Peak creek is bounded by the toe of Crater glacier on the west and by a late Pleistocene debris-avalanche deposit on the east. At this point, channel slopes decrease and range from 0.04 to $0.09 \mathrm{~m} / \mathrm{m}$. Wilton's Walk gully, which drains the south-southeast flank, ranges in slope from 0.3 to $0.8 \mathrm{~m} / \mathrm{m}$ upstream from the point where it drains onto the Bench, a gently sloping plain underlain by late Pleistocene debris-avalanche deposits and late Holocene outwash from Kidazgeni Glacier. Slopes across the Bench range from 0.04 to 0.2 $\mathrm{m} / \mathrm{m}$. The east flank of Crater Peak is drained by a stream that flows on and along the margin of Kidazgeni Glacier, and then through a breach in the Kidazgeni lateral moraine onto the Bench. The Bench is drained by Bench gully, a steep $(0.1$ to $0.6 \mathrm{~m} / \mathrm{m})$ gully that flows onto an alluvial fan in the Chakachatna River valley.

Mean annual precipitation near Mount Spurr ranges from less than $1,000 \mathrm{~mm}$ near the coast to more than $2,000 \mathrm{~mm}$ along the crest of the north end of the Aleutian Range (National Weather Service, 1972); on Mount Spurr, most of the precipitation falls as snow. The snowpack reaches its maximum depth in late May or early June. 


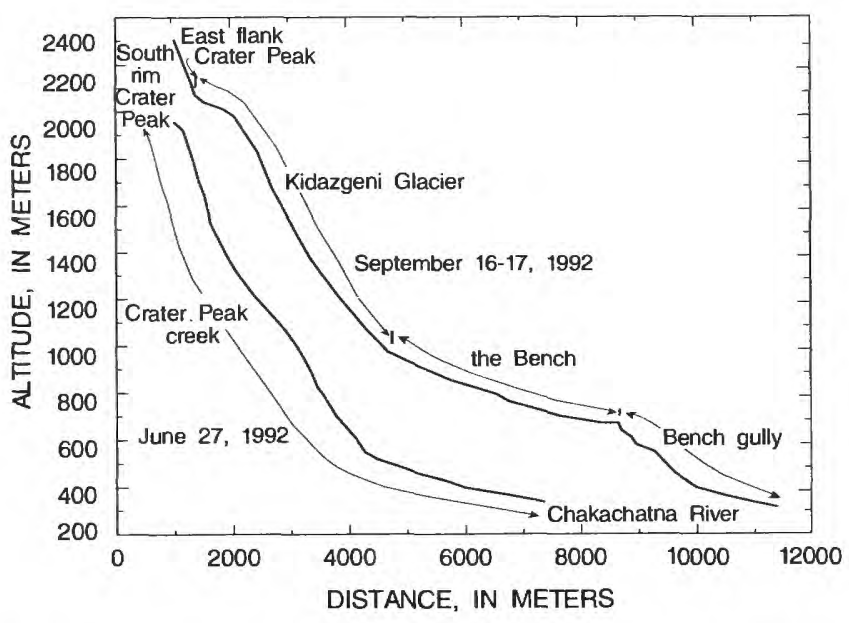

Figure 3. Longitudinal profiles for paths of June 27, 1992, lahar and September 16-17, 1992, lahars produced during eruptions of Crater Peak vent, Mount Spurr volcano, southwestern Alaska.

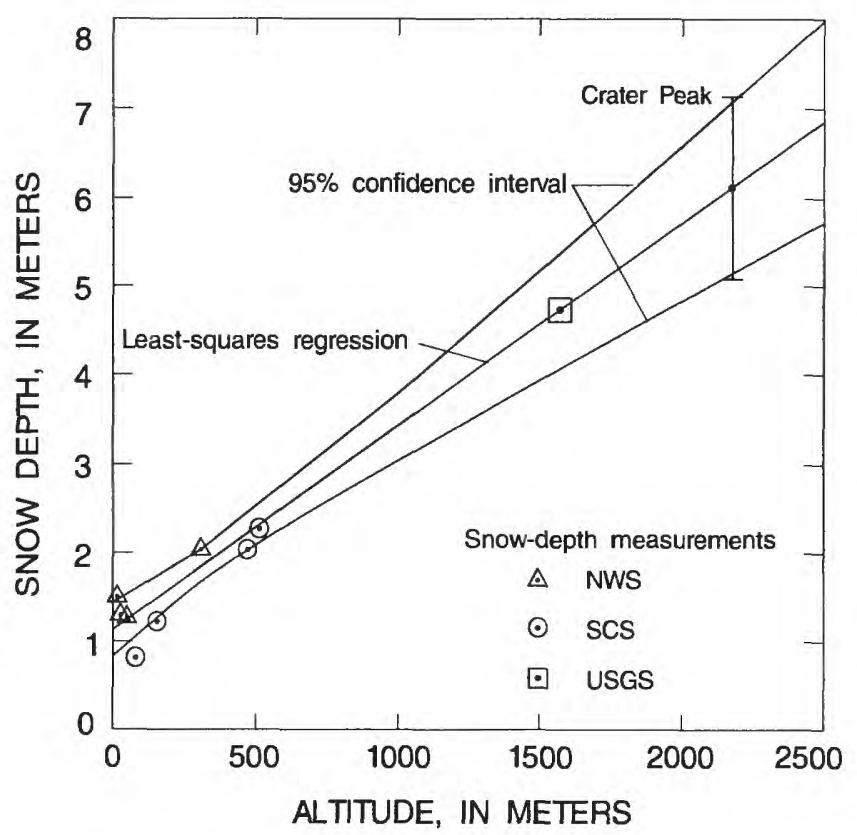

Figure 4. Maximum snow depth versus altitude for four climatological National Weather Service (NWS) stations and four Soil Conservation Service (SCS) snow courses closest to Mount Spurr volcano, southwestern Alaska, and one snowpack measurement from a site on Double Glacier, about 75 $\mathrm{km}$ south of Crater Peak that was taken by U.S. Geological Survey (USGS) scientists. Maximum snow depth was measured during March of 1992 at the low-altitude (NWS and SCS) sites and on April 10, 1991, at Double Glacier site. Extrapolation of regression based on these data indicates that snowpack on south rim of Crater Peak was $6 \pm 1 \mathrm{~m}$ thick.
The mean annual discharge from the $2,900 \mathrm{~km}^{2}$ basin upstream from the mouth of Chakachamna Lake was $107 \mathrm{~m}^{3} / \mathrm{s}$ from 1959 to 1972 , when a streamflow gaging station was operated there. Annual high flow is generated from glacier melt, and streamflow is generally greatest during August; the August mean monthly discharge is $340 \mathrm{~m}^{3} / \mathrm{s}$ (Scully and others, 1978). A flow with a probability of being equaled or exceeded once every 10 years has a magnitude of $595 \mathrm{~m}^{3 / \mathrm{s}}$ (Lamke, 1979). The largest flood measured on the Chakachatna River had a peak discharge of 13,300 $\mathrm{m}^{3} / \mathrm{s}$, and it occurred on August 11, 1971, when part of the Barrier Glacier ice dam was eroded. Barrier Glacier extends most of the way across the Chakachatna River valley. The Chakachatna River occupies a narrow canyon between the toe of Barrier Glacier to the north and the bedrock valley wall to the south. During the period from 1959 to 1971, Barrier Glacier had advanced faster than ice was removed from its toe, and the outlet to the lake became progressively smaller. During high flow generated by a regional rainfall, the toe of the glacier was eroded laterally, which enlarged the outlet of the lake and resulted in the release of about $2.9 \times 10^{8} \mathrm{~m}^{3}$ water (Lamke, 1972; Scully and others, 1978).

\section{JUNE 27, 1992, LAHARS}

The June 27 eruption occurred near the time of the maximum snow accumulation on Crater Peak. The snow depth on relatively flat surfaces, such as glaciers near 2,000 m altitude, is estimated to have been about $6 \mathrm{~m}$ of snow, on the basis of regional extrapolation (fig. 4). The water equivalent of that snowpack is estimated to have been $2.2 \mathrm{~m}$ on the basis of an average density $\left(0.36 \mathrm{~g} / \mathrm{cm}^{3}\right)$ for the five snowpack measurements (made during April 1991 and March 1992) used to construct figure 4 . However, snow was not evenly distributed prior to the eruption, and snow in the avalanche-source areas was probably deeper than $6 \mathrm{~m}$; gullies were filled with snow that had avalanched or blown from the ridges. A small perennial snow and ice layer was present on the east inside wall of the crater prior to the eruption.

The eruption triggered large avalanches of snow, ice, and rock that flowed down the four major drainages on the south and southeast flanks of Crater Peak (fig. 5). Massive tephra deposits blanketed an area of about $0.08 \mathrm{~km}^{2}$ on the crater rim, upstream from the source areas for the avalanches, but no specific evidence of pyroclastic flows was observed (see Miller and others, this volume, fig. 1). The avalanches apparently occurred during the later part of the erup- 


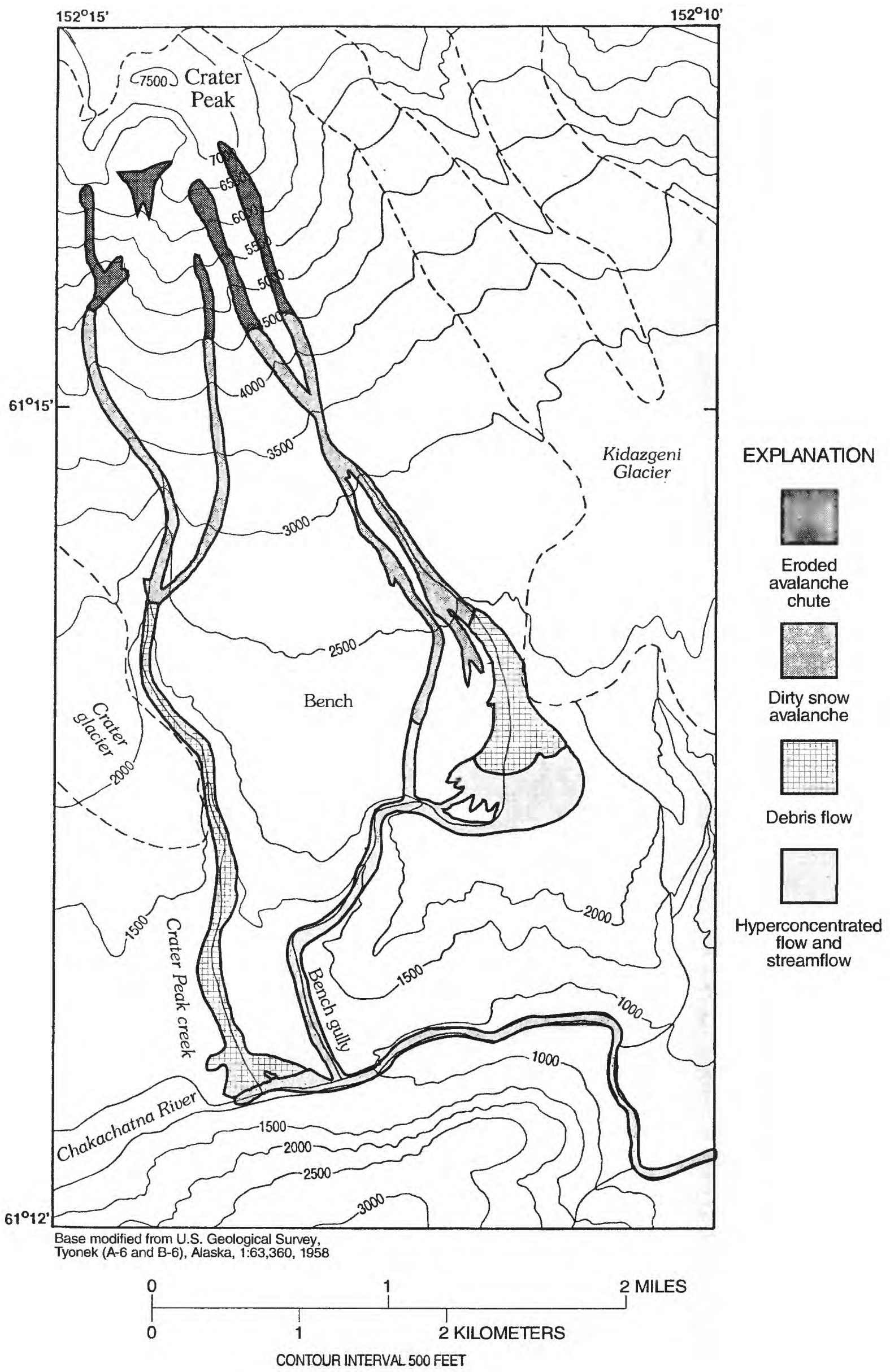


tion, as the avalanche deposits were not extensively covered by fallout tephra, whereas adjacent areas were blanketed by fallout tephra deposits. The avalanches eroded snow, ice, and rock from a reach beginning near the south crater rim at $2,100 \mathrm{~m}$ to $2,000 \mathrm{~m}$ altitude, down to $1,400 \mathrm{~m}$ altitude (fig. 6), and they deposited material along the channel margins from $1,400 \mathrm{~m}$ to $600 \mathrm{~m}$ in altitude in Crater Peak creek, and to at least $800 \mathrm{~m}$ in altitude on the Bench. When fresh, the avalanche deposits had a characteristic dark color, caused by wet rock, relative to adjacent surficial material, and they contained abundant snow and ice particles. After the snow and ice melted and drained away, the avalanche deposits were light-colored, fluffy, and marked by rare small kettle-like pits. These deposits were scoured from the center of the channels by later flows.

The snow, ice, and rock avalanches and the later flows that scoured the center of the channels apparently evolved into debris flows downstream. Debris flows left extensive deposits below an altitude of 430 $\mathrm{m}$ along Crater Peak creek, and across the Bench from $800 \mathrm{~m}$ to about $700 \mathrm{~m}$ in altitude (fig. 5). The massive debris-flow deposits were overlain by well-sorted, waterlaid gravel that had been reworked either by streamflow that followed the debris flows or by flows generated locally as the debris-flow deposit dewatered.
Canyon walls and valley-floor alluvium were eroded along the steep, V-shaped Crater Peak creek canyon. Spring snowmelt probably had saturated the valleyfloor alluvium prior to the eruption, and the eroded material combined with the dirty-snow avalanche to produce the debris flow that left deposits from an altitude of $430 \mathrm{~m}$ down to the Chakachatna River. A 0 to 2.5-m-thick, 100- to 200-m-wide diamict (a nonsorted deposit having a wide range of grain sizes) covered the lower $1 \mathrm{~km}$ of the channel and the alluvial fan at the mouth of Crater Peak creek (fig. 7). Most of the diamict was deposited below the break in slope between $520 \mathrm{~m}$ and $550 \mathrm{~m}$ in altitude. This lower reach, within $2 \mathrm{~km}$ of the mouth of Crater Peak creek, has a channel slope between 0.04 and $0.09 \mathrm{~m} / \mathrm{m}$ (fig. 3).

At a location $0.5 \mathrm{~km}$ upstream from the mouth of Crater Peak creek, the debris flow had an estimated peak discharge of $2,000 \mathrm{~m}^{3} / \mathrm{s}$. This estimate was made using the superelevation of the flow around a bend to estimate the velocity of the flow (Chow, 1959, p. 448). Mid-channel bars in the Chakachatna River at the mouth of Crater Peak creek were veneered by deposits of sand and gravel, but the river was not blocked as it had been during the 1953 Crater Peak eruption. The debris flow did not extend beyond the alluvial fan at the mouth of Crater Peak creek.

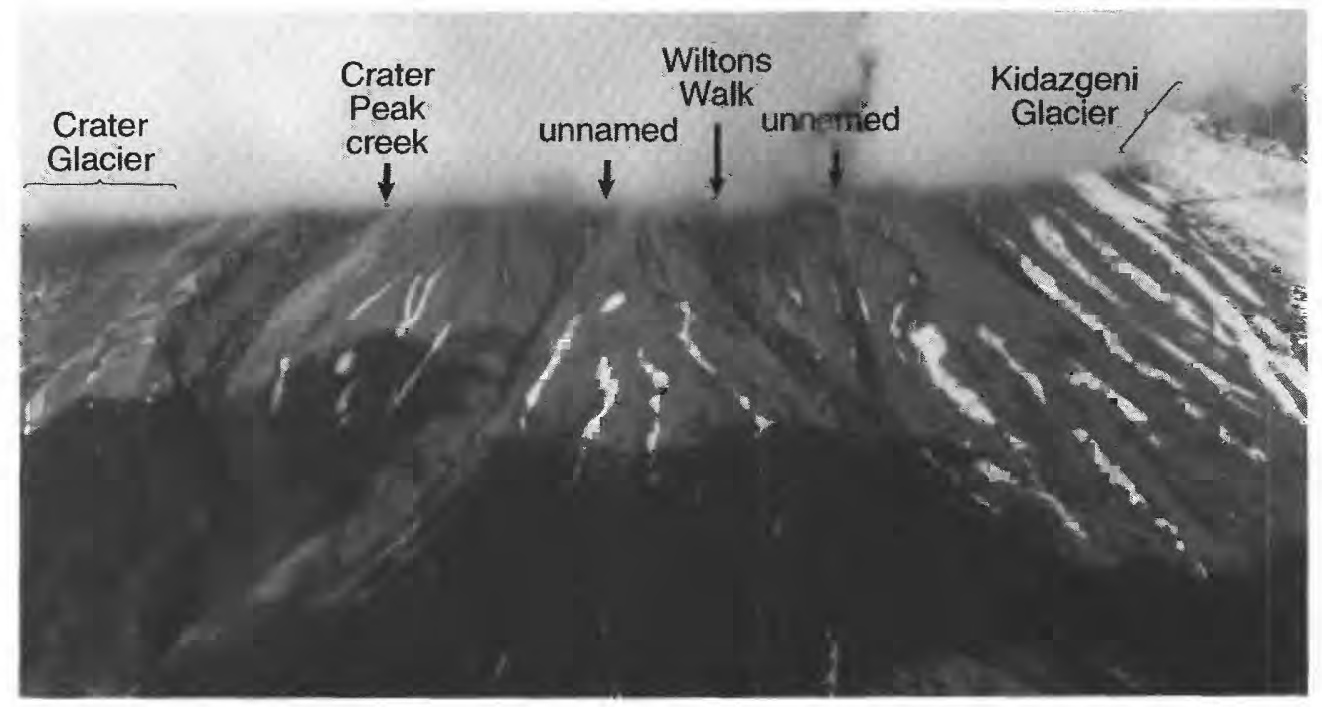

Figure 6. Four large drainage channels on south-southeast flank of Crater Peak vent of Mount Spurr volcano, southwestern Alaska, on June 29, 1992, 2 days after an eruption of Crater Peak. Dark deposits in channels are snow, ice, and rock avalanche deposits. Dark areas covering lower slopes are cloud shadows.

Figure 5. Distribution of deposits from June 27, 1992, Crater Peak (Mount Spurr volcano, Alaska) avalanches and lahars associated with eruption. Dashed lines show approximate boundaries of glaciers. 
In Wilton's Walk gully and two unnamed channels, neither the dirty snow avalanches nor the subsequent flows eroded significant amounts of material from the poorly defined channels. As the flows spread across the Bench, coarse sediment was deposited as a diamict sheet in proximal areas, indicative of a debris flow, but the deposit was thinner, bedded, and better sorted along its margins, indicative of sedimentladen streamflow. Individual units that could be correlated to the dirty snow avalanche or to the later erosive flows upstream could not be distinguished within the diamict on the Bench. The two types of flow evident upstream may have combined to form a single deposit on the Bench or the later erosive flows may not have left deposits on the Bench. Nearly all of the sediment in the flow was deposited on the Bench, and only relatively clear water flowed down Bench gully and into the Chakachatna River. At the mouth of Bench gully, the surface of a fan was covered by thin, waterlaid deposits.

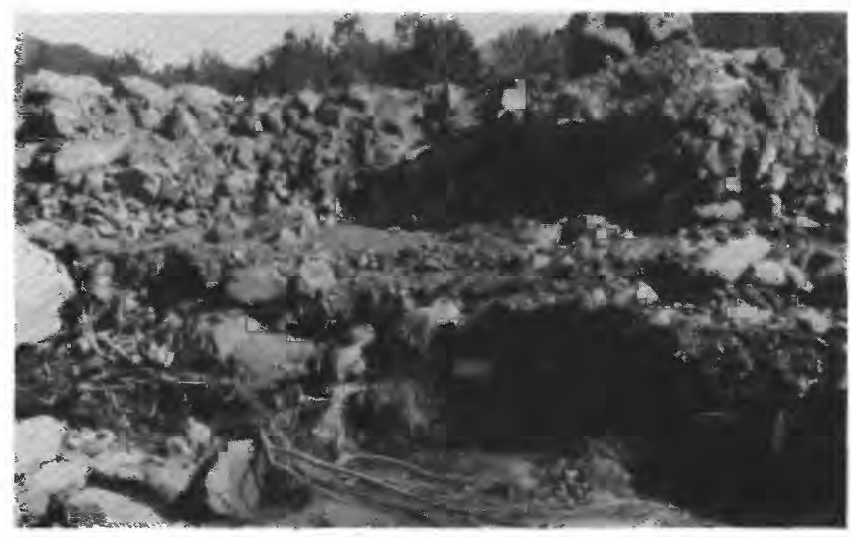

Figure 7. June 27, 1992, debris-flow deposit resulting from eruption of Crater Peak vent (Mount Spurr volcano, Alaska) near mouth of Crater Peak creek, $100 \mathrm{~m}$ upstream from Chakachatna River. Notebook in center of photograph is 20 by $11 \mathrm{~cm}$ and rests on pre-eruption surface. Deposit is about $2.5 \mathrm{~m}$ thick.

Figure 8. Small meltwater channel along west margin of Kidazgeni Glacier, which is covered with wet, dark tephra deposits from August 18, 1992, eruption of Crater Peak vent, Mount Spurr volcano, Alaska. Northeast rim of Crater Peak is in left background. Photograph taken August 20, 1992.

\section{AUGUST 18, 1992, WATERY FLOWS}

Several small pyroclastic flows descended the Wilton's Walk gully on the southeast side of Crater Peak on August 18, but they stopped short of the debris-flow deposits emplaced during the June 27 eruption. Four or more overlapping pyroclastic flows descended the east flank of Crater Peak and covered 0.1 to $0.2 \mathrm{~km}^{2}$ of the western half of the west arm of Kidazgeni Glacier (see Miller and others, this volume, fig. 1). Eight to twelve $\mathrm{cm}$ of fallout tephra was deposited beyond the margins of the pyroclastic-flow deposits, but none was deposited on the pyroclasticflow deposits (see Miller and others, this volume; Neal and others, this volume).

The pyroclastic flows ran onto a relatively smooth glacier surface, except at the highest area of contact with Kidazgeni Glacier, near the extreme northeastern sector of Crater Peak, where some glacier ice was

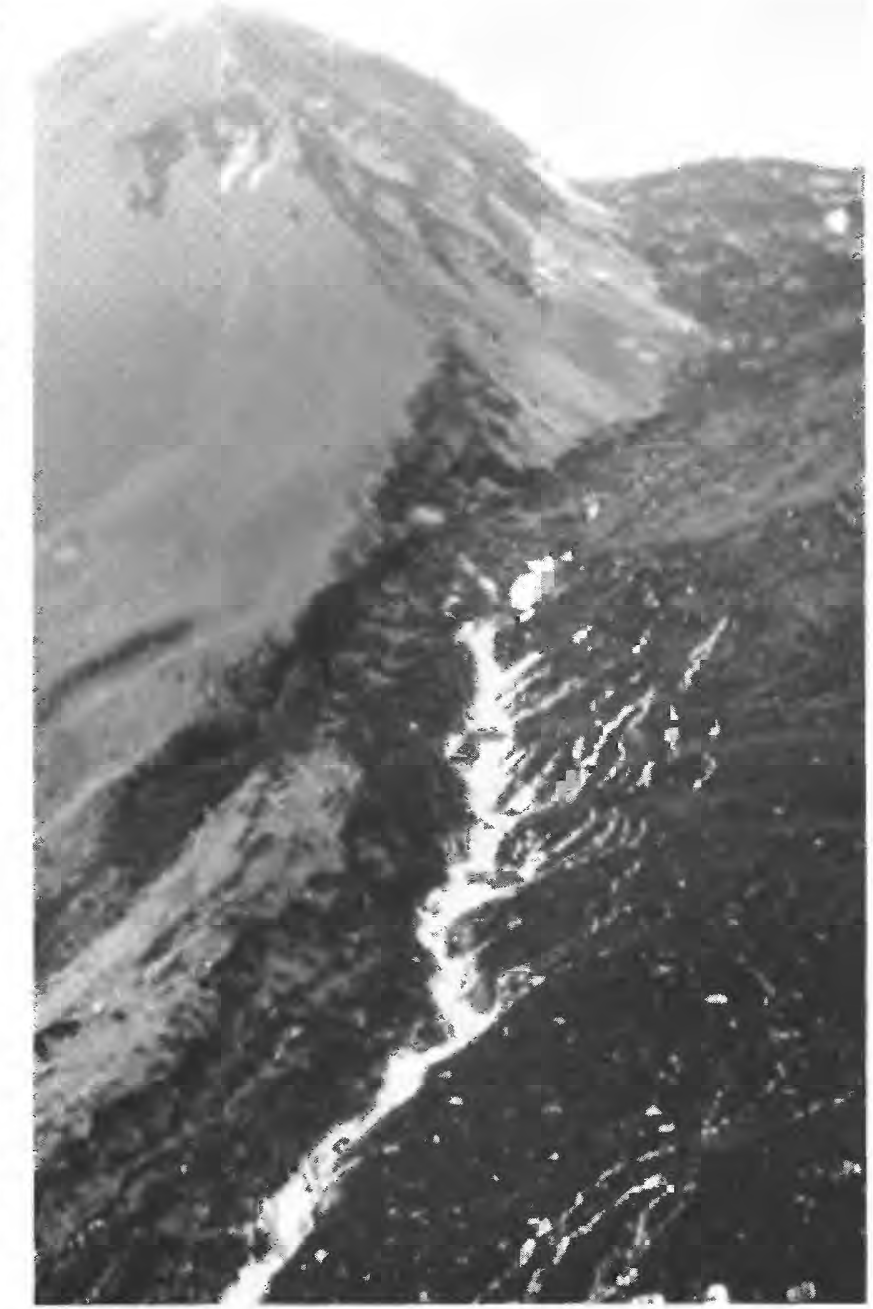


mechanically entrained by the flows. Glacier slopes ranged from 0.21 to $0.26 \mathrm{~m} / \mathrm{m}$. Channels scoured by small watery flows were observed downstream from the multipulsed pyroclastic-flow deposits along both the east and west margins of the lower part of the west arm of Kidazgeni Glacier (fig. 8), but no debris-flow deposits were observed in direct association with either the pyroclastic flows or the watery flows. The water flows were probably generated by melting of small amounts of snow and ice in and under the pyroclastic-flow deposits. The small amount of snow and ice on Crater Peak prior to the August 18 eruption was confined to small patches in gullies. Water flowing down the east margin of the west arm of Kidazgeni Glacier ponded in depressions near the glacier terminus; water flowing down the west margin of the west arm of Kidazgeni Glacier flowed through a small gap in the lateral moraine onto the Bench. Cobble-size bed material was mobilized by these flows, and minor bank erosion occurred within a kilometer of the glacier, but the overall effects were comparable to those from annual glacier-melt generated flows.

\section{SEPTEMBER 16-17, 1992, LAHARS}

Pyroclastic flows generated during the September 16-17 eruption flowed down the northeast flank of Crater Peak and onto the west arm of Kidazgeni Glacier, near the upstream end of a steep icefall (see Miller and others, this volume). These pyroclastic flows were thicker, and they traversed a more extensive and steeper area of the glacier, covering about $0.3 \mathrm{~km}^{2}$ of Kidazgeni Glacier having slopes ranging from 0.25 to $0.38 \mathrm{~m} / \mathrm{m}$. Much of this area was broken by crevasses. Because of the steeper slope, thicker flow, and greater surface roughness, the September 16-17 pyroclastic flows probably showed greater shear at their base than the flows that occurred during the August 18 eruption, and they eroded considerable snow and glacier ice. As the pyroclastic flows incorporated water melted from eroded snow and ice, they were transformed into a lahar that deposited both massive diamicts and bedded streamflow deposits along channels scoured into the glacier surface (see Waitt, this volume).

The lahar fanned across the Bench surface, widening from about $100 \mathrm{~m}$ on the proximal Bench to about a kilometer on the distal Bench (fig. 9). Most of the debris-flow phase of the lahar was deposited as a continuous, 1 - to more than 2.5 -m-thick diamict on the Bench surface. Steep bouldery flow-front lobes formed a few hundred meters upstream from the headcut of Bench gully, which drains the Bench sur- face. The flow-front lobes are depleted in sand- and gravel-size sediment. Deposits of planar- or cross-bedded pebbles and sand cap the surface of the diamict (fig. 10), and they extend downfan from the bouldery flow-front lobes as splay deposits (fig. 11). In some places, the splay deposits extend only a few tens of meters into brushy vegetation; in other places, they extend hundreds of meters into gullies and channels that are tributary to Bench gully (fig. 9).

One lobe of the debris flow extended far enough downstream to flow into Bench gully in a channel 10 $\mathrm{m}$ wide, where it combined with the more watery flows. An estimated 10,000 to $100,000 \mathrm{~m}^{3}$ of material was eroded from the banks of Bench gully by the debris flow and subsequent incision during and following the night of September 16-17 when arcuate failures of 10 - to 20 -m-high banks as thick as $10 \mathrm{~m}$ occurred along a 1,500-m-long reach between the Bench and the Chakachatna River. Large bank failures were still occurring during the afternoon of September 17. An estimated 50,000 to $100,000 \mathrm{~m}^{3}$ of coarse debris was deposited as a 0 - to 3-m-thick diamict over the 50,000 $\mathrm{m}^{2}$ alluvial fan where Bench gully enters the Chakachatna River. This sand and gravel diamict contains boulders as large as $1 \mathrm{~m}$ in diameter, similar on a gross scale to the diamict on the Bench. Subsequent watery flows, probably during the waning stages of the lahar, reworked the surface of the fan and incised a channel 3 to $4 \mathrm{~m}$ deep and less than $100 \mathrm{~m}$ long along the centerline of the fan.

The diamict formed a temporary dam across the Chakachatna River, and so the river rose to depths of 0.5 to $1 \mathrm{~m}$ directly upstream from the fan (fig. 12). A 20-m-wide channel was eroded along the distal margin of the fan by the Chakachatna River; through this channel pulsed a flood wave with an estimated peak discharge of $800 \mathrm{~m}^{3} / \mathrm{s}$ just downstream from the debris fan. Peak discharge estimates $\left(800 \mathrm{~m}^{3} / \mathrm{s}\right.$ and $\left.400 \mathrm{~m}^{3} / \mathrm{s}\right)$ were made using the slope-conveyance technique, which applies the Manning's equation to a single cross section to estimate the flow velocity (Chow, 1959, p. 98). The estimated discharge is larger than the largest measured, meteorologically generated flow on the Chakachatna River, but it was less than one-tenth of the peak discharge that resulted from erosion of the Barrier Glacier ice dam in 1971 (Lamke, 1972; Scully and others, 1978). Deposits downstream from the fan that mark the passage of the flood wave consist of medium- to coarse-grained, planar-bedded sand. The peak attenuated quickly from $800 \mathrm{~m}^{3} / \mathrm{s}$ at the downstream margin of the fan to about $400 \mathrm{~m}^{3} / \mathrm{s}$ at a location $6 \mathrm{~km}$ downstream, where flood deposits were fineto medium-grained, planar-bedded sand. 


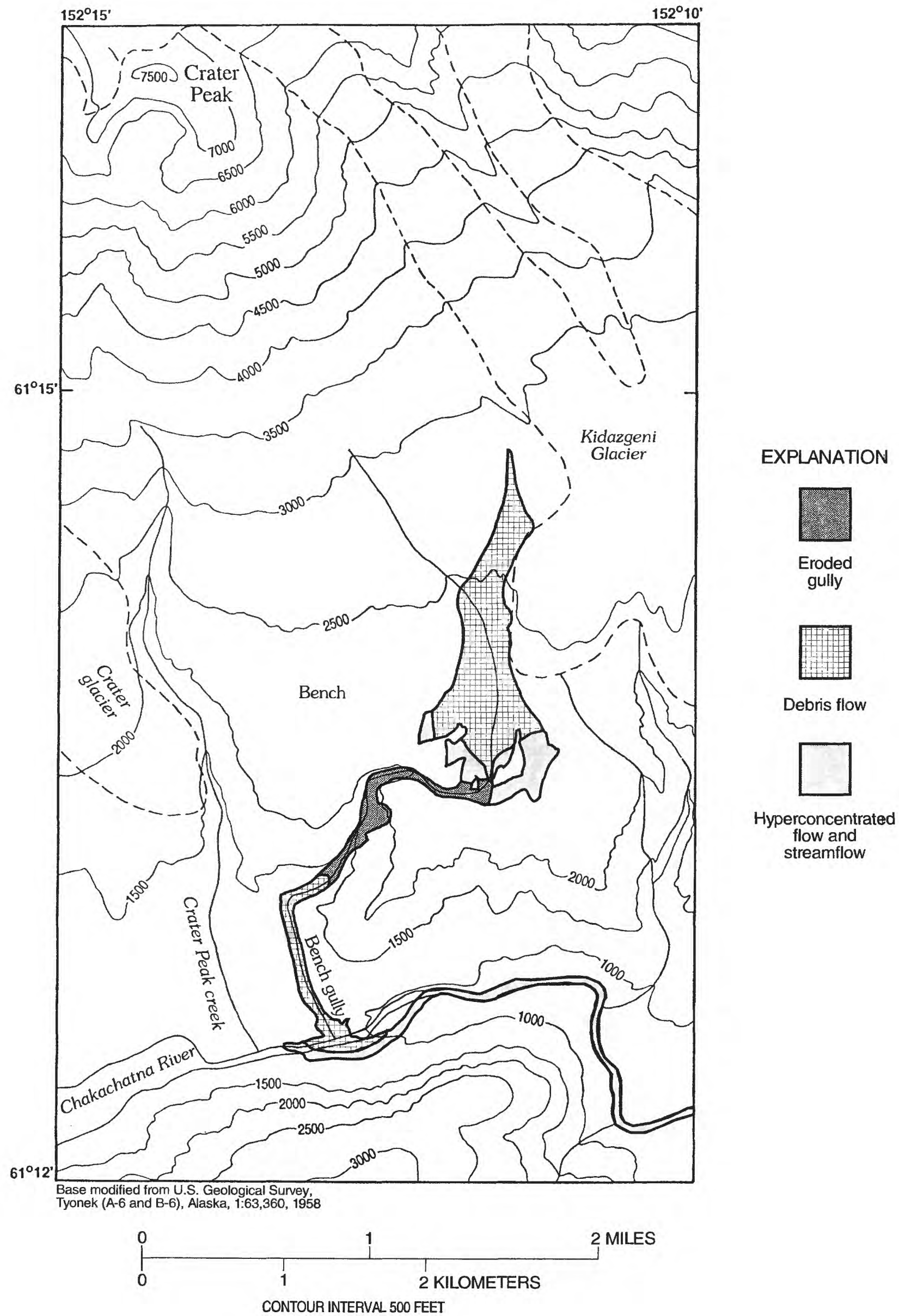




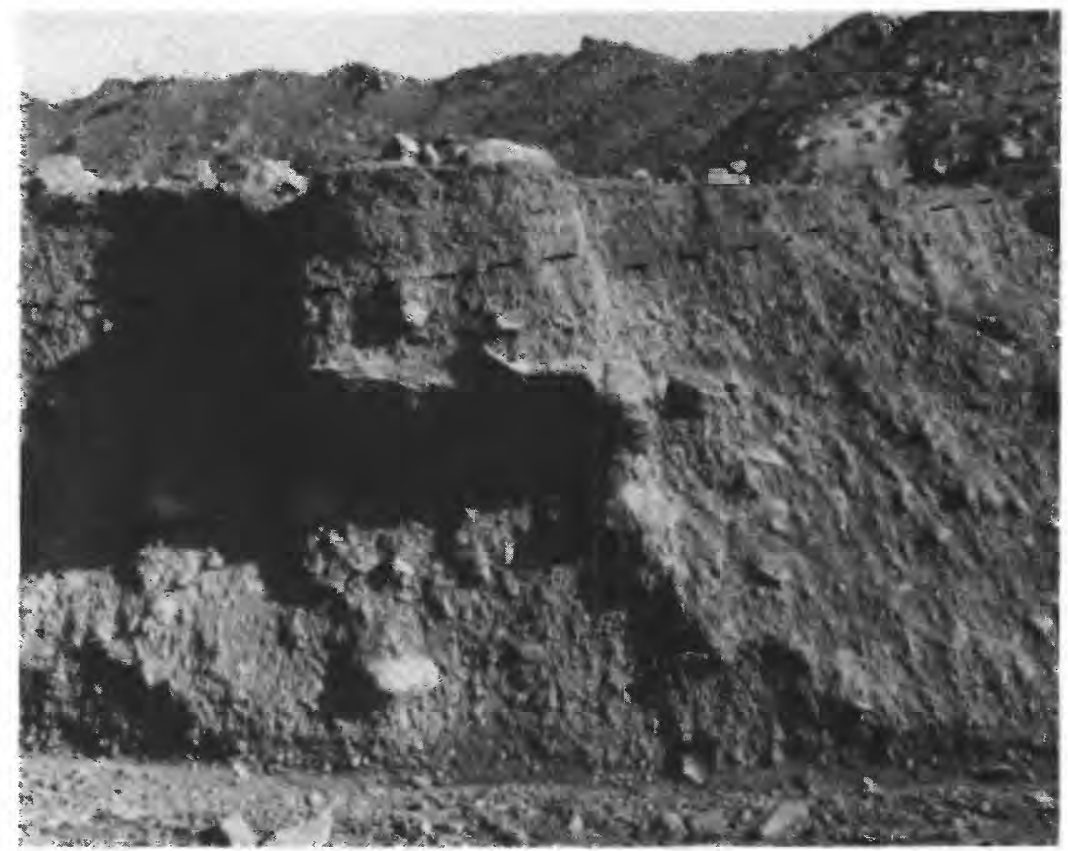

Figure 10. September 16-17, 1992, lahar deposits resulting from Crater Peak vent eruptions, Mount Spurr volcano, Alaska. Deposits are on proximal part of the Bench; they consist of a massive diamict (below dashed line) overlain by planar- and cross-bedded sand and gravel (above dashed line). Shovel in center of photograph is $0.6 \mathrm{~m}$ long.

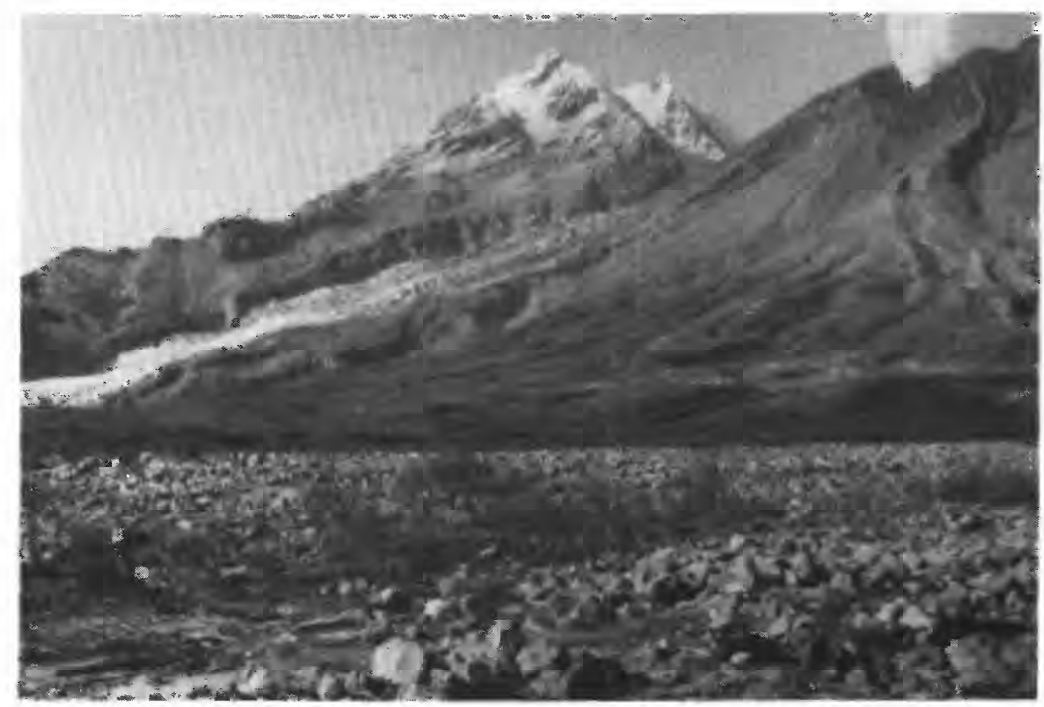

Figure 11. September 16-17, 1992, splay deposits resulting from Crater Peak vent (peak issuing steam in the right background) eruptions, Mount Spurr volcano, Alaska. Deposits crop out along distal part of the Bench just upstream from head of Bench gully and consist of boulders depleted of fine material in the center and right foreground and well-sorted sand and gravel that form flat surfaces in left foreground.

Figure 9. Distribution of deposits from lahars resulting from September 16-17, 1992, eruption of Crater Peak vent, Mount Spurr volcano, Alaska. Dashed lines show approximate boundaries of glaciers. 


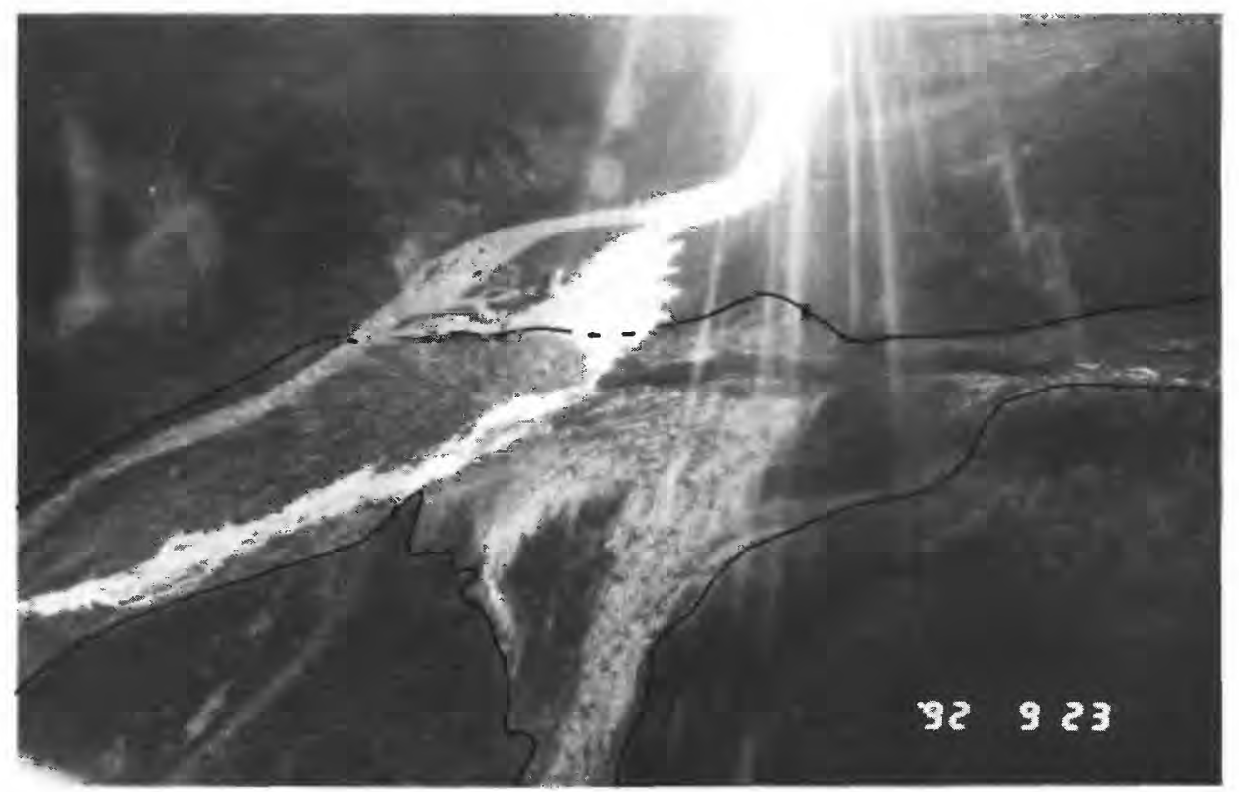

Figure 12. Alluvial fan at mouth of Bench gully, including eroded debris-flow dam (upper left outlined area) across Chakachatna River (light colored river in center). Extent of debris-flow and sediment-laden streamflow deposits indicated by solid lines, dashed where inferred. Channel at toe of alluvial fan (shown at bottom of photograph) is about $20 \mathrm{~m}$ wide. View is upstream.

\section{GRAIN SIZE, LAHAR TRANSFORMATION, AND LAHAR GENERATION}

The behavior of debris flows depends, among other factors, on the grain-size distribution of the material contained in the flow, especially the proportion of clay (Scott, 1988; Scott and others, 1992). Cohesive lahars from Mount St. Helens, Washington, both those that occurred in 1980 and at earlier times, and lahars from Mount Rainier, Washington, maintained fairly constant rheologic and sedimentologic properties when they contained more than 3 percent clay particles (those smaller than $0.004 \mathrm{~mm}$ in diameter). The May 18, 1980, North Fork Toutle River lahar from Mount St. Helens contained more than 3 percent clay, and it flowed as a coherent debris flow more than $100 \mathrm{~km}$ along slopes ranging from 0.007 to $0.002 \mathrm{~m} / \mathrm{m}$. The May 18, 1980, South Fork Toutle River lahar and the March 19, 1982, North Fork Toutle River lahar, both from Mount St. Helens, contained less than 3 percent clay and were noncohesive. They changed from debris flow to hyperconcentrated streamflow along 63 and $58 \mathrm{~km}$ channel reaches, respectively, that ranged from 0.01 to $0.002 \mathrm{~m} / \mathrm{m}$ in slope. However, these transformations occurred as the lahars were diluted when they overrode streamflow. Eventually, the flows were diluted to such an extent that they became sedimentladen streamflow.
The size of the March 19, 1982, North Fork Toutle River lahar on the flanks of Mount St. Helens was similar to the June and September 1992 lahars from Crater Peak. However, as the 1982 lahar spread onto the fan at the base of the north flank of Mount St. Helens, it traversed highly erodible 1980 pyroclasticflow and debris-avalanche deposits, and it not only bulked in volume but also incorporated sediment with a higher proportion of clay-size material (Pierson and Scott, 1985, fig. 9).

The 1992 lahars at Crater Peak contained less than 1 percent clay (fig. 13) and transformed from debris flow to sediment-laden streamflow as they moved downvalley. The flow transformations that were observed within the May 18, 1980, South Fork Toutle River lahar and the March 19, 1982, North Fork Toutle River lahar were quite different than those of the Crater Peak lahars. First, the Crater Peak lahars did not leave extensive deposits of massive, moderately sorted, sand deposits, which are indicative of hyperconcentrated streamflow (Scott, 1988, table 4). Secondly, the Crater Peak lahars moved through dry channels and overbank areas and the transformations could not have resulted from the lahar overriding streamflow. Thirdly, the lahars did leave matrix-poor levees at the distal margins of the flow. Fourth, transformation of the Crater Peak flows resulted in the debris flow coming to rest on slopes as steep as 0.04 to $0.09 \mathrm{~m} / \mathrm{m}$. The extremely low proportions of clay in the 1992 Crater Peak flows may have caused these differences. 


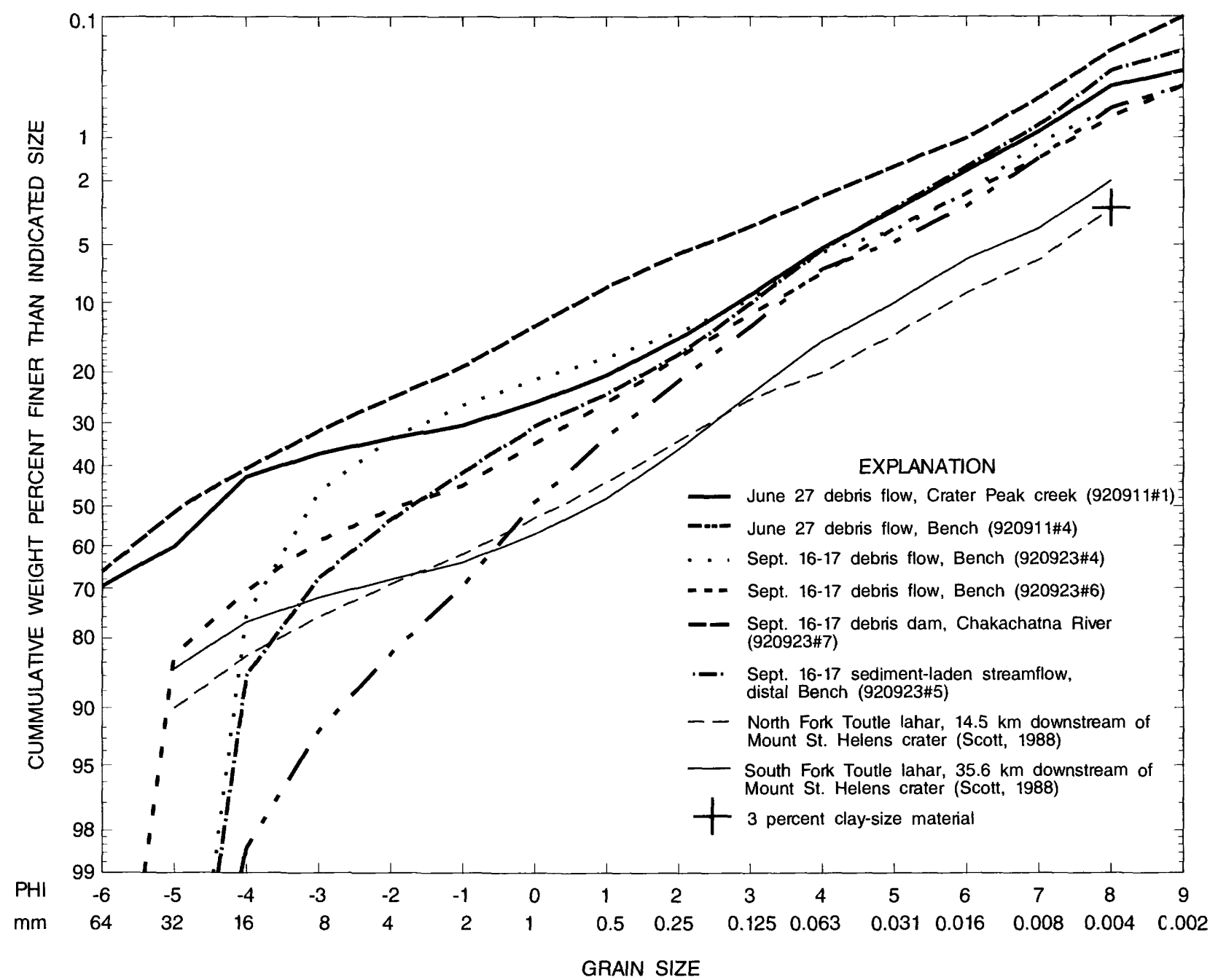

Figure 13. Grain-size distribution of matrix-only samples of June 27, 1992, debris flows and of September 16-17, 1992, debris flows, debris dam, and sediment-laden streamflow deposits from eruptions of Crater Peak vent, Mo'nt Spurr volcano, Alaska. None of the samples include material coarser than $64 \mathrm{~mm}$ in diameter. Material coarser than $64 \mathrm{~mm}$ in diameter composed as much as 50 percent of the Mount Spurr debris-flow deposits but was not present in sediment-laden streamflow deposits. Also shown are grain-size distributions of two lahars from May 18, 1980, er $\lrcorner$ tion of Mount St. Helens (Scott, 1988). Large plus sign is at a point representing 3 percent clay-size material, the percentage of clay-size material thought to distinguish cohesive and noncohesive lahars.

The distal lobes of the 1992 Crater Peak lahar deposits are composed of concentrations of coarse boulders devoid of fine-grained matrix. These lobes are unlike the contemporaneous Crater Peak lahar deposits in the proximal Bench or the 1980 South Fork Toutle River lahar deposits, in which coarse boulders are supported by a finer grained, poorly sorted, but clay-poor matrix. The distal lobes appear to have lost the finegrained sandy matrix during or after deposition of the large boulders. Slurry flows, that is flows that show plastic flow behavior in the field yet become partially liquefied when remolded, commonly consolidate at a rate at which pore fluid can drain out, but most sediment remains in the deposit (Pierson and Costa, 1987, p. 7). This phenomenon is due, in part, to viscous forces, which are dominant over inertial forces in finer grained or slower moving slurry flows. Such was true of the Toutle River lahars, which all contained more than 1 percent clay. The Crater Peak lahars, being generally coarser grained, would have been more dependent (than the Toutle lahars) on inertial forces to sustain plastic fluid flow that characterizes debris flow (Pierson and Costa, 1987, p. 7). When the Crater Peak deposits came to rest, viscous forces were insufficient to hold the matrix in place between the boulders, and the matrix was probably eroded by pore water as it drained rapidly from the deposits. 
Distal lobes were not formed by most of the Mount St. Helens lahars or by the June 27 Crater Peak creek lahar; these lahars were diluted when they overrode streamflow as they flowed downstream and where they entered larger rivers.

Several alternative hypotheses could also explain the boulder levees and lobes that are devoid of matrix:

1. The fine-grained matrix could have been washed from the deposits by waning, watery stages of the lahar. This process probably did account for some of the general reworking of the diamict and the levees. Channels were eroded into the surface of the diamict upstream from the levees and on the glacier. However, these channels were commonly devoid of boulders larger than about $1 \mathrm{~m}$, and they were observed only as discrete channels on the diamict, whereas the matrix-poor boulder levees were common near the distal margins of the diamict.

2. The fine-grained matrix could have been washed out by later rain. The June 27 deposits were not sampled and photographed until September 11, so they would have been reworked to an unknown degree by intervening rainfall and runoff, even though the deposits appeared unaltered where they were sampled. The September 16-17 deposits were sampled and photographed on September 23. Minor amounts of snow and little or no rain fell during the intervening period, and no reworking by surface runoff was observed on fresh, vertical cut banks within the diamict.

3 . The lahar could have transported large concentrations of boulders that were deposited together as the flow traversed the Bench. This process apparently did occur, but it was responsible for deposits unlike the matrix-poor levees. Large (larger than 2 $\mathrm{m})$ boulders were observed in the diamict whose flat surfaces were covered by sand and gravel similar to the reworked matrix deposits. The bases of these boulders were not observed, but similar deposits present in a debris-flow deposit on an alluvial fan at Olancha Creek in southeastern California rest directly on rooted vegetation. As the flow at Olancha Creek spread out over the alluvial fan, increasing in width, it probably became progressively shallower. As its depth became roughly equal to the diameter of the largest boulders, those boulders became grounded, while finer material, although still coarse, continued to flow downfan. At Olancha Creek, very large boulders (larger than 2 m) were grounded near the head of the fan, and grounded boulders are progressively smaller downfan.

At Crater Peak, small flows generated by water draining from the diamict reworked the surface of the deposit (fig. 10). Larger flows, generated from water draining from the distal margins of the diamict, coa- lesced to form flows large enough to erode unconsolidated deposits farther downstream, for example, along Bench gully. Similar flow transition was observed in debris flows having extremely low (less than 1 percent) proportions of clay-size material in $\mathrm{O}^{1}$ ancha Creek, California (D.F. Meyer, unpub. data) and in Ophir Creek, western Nevada, by P.A. Glancy' (oral commun., 1993) of the U.S. Geological Survey.

At Mount St. Helens and at Mount Rainier, cohesive lahars commonly originate as debris avalanches (Janda and others, 1981; Scott, 1988; Scott and others, 1992). Noncohesive lahars have a variety of origins, and some of them are generated by erosion of enough volcaniclastic material that flow concentrations exceed 60 to 80 percent sediment by weight. The higher concentrations are characteristic of coarser material. Some of the initiating flows are water flows generated by lake breakouts (Scott, 1988), pyroclastic flows that have eroded glacier ice (Scott and others, 1992) as did the September 16-17 Crater Peak lahar, and wet snow avalanches similar to the initiation of the June 27 lahar (Waitt and others, 1983; Piersc $\eta$ and Scott, 1985; Waitt, 1989). However, flow dilution (the incorporation of water in the stream channel that is overridden by debris flow) may play an important role in the transformations from debris flow to hyperconcentrated streamflow and from hyperconcentrated streamflow to sediment-laden streamflow (Pierson and Scott, 1985). The Bench at Crater Peak, whero both the June 27 and September 16-17 lahars changed from debris flow to hyperconcentrated flow and from hyperconcentrated flow to sediment-laden streamflow, was not a stream channel. These transformations took place on a broad, vegetated plain (fig. 11), and it was not likely that any water was overridden or incorporated into the flow. Similarly, the Nevada and California debris-flow transformations occurred on alluvial fans, and these flows did not override significant streamflow.

Comparison of the August 18 and September 1617 Crater Peak lahars confirms an observation of the 1989-90 lahars from Redoubt Volcano that ice is most effectively incorporated into pyroclastic flow when its surface is steep and rough. Most of the ice removed from Drift Glacier on Redoubt Volcano was from the steep, narrow canyon on the north breach of the volcano. Where pyroclastic material was deposited on the relatively flatter piedmont lobe of Drift Glacier, little melting occurred (Trabant and Meyer, 1992; Trabant and others, 1994). The August 18 pyroclastic flows were deposited primarily on smooth areas of Kidazgeni Glacier and no lahars were generated. The September 16-17 pyroclastic flows traversed steep, highly crevassed areas of the glacier and generated lahars. 


\section{OTHER HYDROLOGIC EFFECTS OF THE 1992 CRATER PEAK ERUPTIONS}

Increased meltwater runoff can be expected from all glacier areas where ash deposits are less than about $24 \mathrm{~mm}$ in thickness because of decreased albedo, whereas ash thickness of more than a few centimeters can be expected to reduce meltwater runoff because the low heat conductivity of the materials insulates the ice from diurnal temperature fluctuations (Driedger, 1981). The only known ash deposit with thicknesses more than a few centimeters is on the Kidazgeni Glacier and Straight glacier (informal name, fig. 1). Prior to the 1992 eruption, thick, ablationreducing ejecta from the 1953 eruption of Crater Peak mantled Kidazgeni Glacier below the junction of the east and west arms as well as the lower few kilometers of Straight Glacier.

The effects of the 1992 eruption on Barrier Glacier (fig. 1) and its debris-covered piedmont lobe, which dams the Chakachatna River to form Chakachamna Lake, are not expected to be significant. However, these effects need to be considered because release of Chakachamna Lake would be a significant hydrologic hazard. The flow of Barrier Glacier is not likely to have been affected by a change in the heat flow to the bed of the glacier, because the glacier is more than $5 \mathrm{~km}$ from Crater Peak, the active vent. Furthermore, almost no ash was deposited on the glacier, and no pyroclastic flows occurred on or near the glacier. The ice-flow speed of the piedmont lobe fluctuated in the past (G.C. Giles, U.S. Geological Survey, written commun., 1967); however, the single flood release from Chakachamna Lake probably was caused by lateral erosion of the ice dam during rainfall-generated high flow (Lamke, 1972).

Fallout tephra deposits from the three Crater Peak eruptions in 1992 blanketed much of the heaviest populated areas in south-central Alaska (see Neal and others, this volume). After the August 18 eruption deposited several millimeters of ash on Anchorage, both air and water quality were affected. Water use was greater than at any previous time, as businesses, homeowners, and the municipality washed away the ash. (Charley L. Bryant, Anchorage Water and Wastewater Utility, Municipality of Anchorage, written commun., 1992)

\section{CONCLUSIONS}

The interaction between snow and glacier ice and the pyroclastic flows and lahars produced by the 1992 eruptions of Mount Spurr volcano confirm the conclusions drawn from similar occurrences during the
1989-90 eruptions of Redoubt Volcano (Trabant and others, 1994) and the 1985 eruption of Nevado del Ruiz Volcano (Pierson and others, 1990). First, flows generated by mechanical disruption and entrainment of snow and glacier ice by pyroclastic flows are generally larger and more likely to be debris flows than when hot pyroclastic material is deposited more passively over flat surfaces. Second, bulking of lahars by erosion of debris downstream of the initiation point can produce greater hazards than those created by the initial flows. The lahars contained extremely low proportions of clay-size material and came to rest on relatively steep slopes, a behavior more similar to debris flows observed in Nevada and California than to flows observed at other volcanoes.

During the August 18 eruption, when pyrcelastic material was, for the most part, deposited passively on glacier ice, small meltwater flows were produced. During the September 16-17 eruption, more energetic pyroclastic flows traversed a larger and steeper area of the glacier that was broken by crevasses. These flows eroded and melted enough glacier ice to produce large floods downstream. This observation indicates that the largest potential for incorporation of snow and glacier ice by volcanogenic flows is at places where ice surfaces are highly crevassed, steep, and exposed to large volumes of volcanogenic materials.

During the June 27 eruption, the eruption triggered snow, ice, and rock avalanches, but significant amounts of snow and ice were not melted by interaction with hot volcaniclastic material. In many ways, the June 27 lahar was similar to the March 19, 1982, lahar at Mount St. Helens, which began as a snow avalanche, and bulked by eroding volcaniclastic material both on the flank of the volcano and on the 1980 debris-avalanche deposit. The June 27 Crater Peak lahar bulked on the flanks of the volcano, but it was deposited at the base of the volcano where it entered the Chakachatna River valley.

The character of the lahars generated during the 1992 eruptions changed rapidly as they flowed down the flanks of the volcano and into the Chakachatna River valley. Where abundant, readily erodible sediment existed along the channel margins, such as along Crater Peak creek and Bench gully, the lahars incorporated additional sediment and sometimes bulked to debris flows. However, the flows contained very little clay-sized sediment, and most of the gravel in the flows was deposited on fans having slopes between 0.04 and $0.09 \mathrm{~m} / \mathrm{m}$, which is much steeper than depositional areas of lahars having more clay-sized sediment. Because the flows deposited most of their sediment on relatively steep slopes, the hazards resulting directly from the lahars did not extend far beyond the base of the volcano. 


\section{REFERENCES CITED}

Chow, V.T., 1959, Open-channel hydraulics: New York, McGrawHill, $680 \mathrm{p}$.

Driedger, C.L., 1981, Effect of ash thickness on snow ablation, in Lipman, P.W., and Mullineaux, D.R., eds., The 1980 eruptions of Mount St. Helens, Washington: U.S. Geological Survey Professional Paper 1250, p. 757-760.

Janda, R.J., Scott, K.M., Nolan, K.M., and Martinson, H.A., 1981, Lahar movement, effects, and deposits, in Lipman, P.W., and Mullineaux, D.R., eds., The 1980 eruptions of Mount St. Helens, Washington: U.S. Geological Survey Professional Paper 1250 , p. $461-478$.

Juhle, Werner, and Coulter, Henry, 1955, The Mount Spurr eruption, July 9, 1953: Transactions of the American Geophysical Union, v. 36, p. 199.

Lamke, R.D., 1972, Floods of the summer of 1971 in south-central Alaska: U.S. Geological Survey Open-File Report, 88 p. 1979, Flood characteristics of Alaskan streams: U.S. Geological Survey Open-File Report 78-129, 61 p.

National Weather Service, 1972, Mean annual precipitation-inches: National Weather Service [Alaska], map.

Nye, C.J., and Turner, D.L., 1990, Petrology, geochemistry, and age of the Spurr volcanic complex, eastern Aleutian arc: Bulletin of Volcanology, v. 52, p. 205-226.

Pierson, T.C., and Costa, J.E., 1987, A rheologic classification of subaerial sediment-water flows, in Costa, J.E., and Wieczorek. C.F., eds., Debris flows/avalanches-Process, recognition, and mitigation: Geological Society of America Reviews in Engineering Geology, v. VII, p. 1-12.

Pierson, T.C., Janda, R.J., Thouret, J.-C., and Borrero, C.A., 1990, Perturbation and melting of snow and ice by the 13 November 1985 eruption of Nevado del Ruiz, Colombia, and con- sequent mobilization, flow and deposition of lahars: Journal of Volcanology and Geothermal Research, v. 41, p. 17-66.

Pierson, T.C., and Scott, K.M., 1985, Downstream diluti?n of a lahar-transition from debris flow to hyperconcentrated streamflow: Water Resources Research, v. 21, p. 1511-1524.

Scott, K.M., 1988, Origins, behavior, and sedimentology of lahars and lahar-runout flows in the Toutle-Cowlitz River system: U.S. Geological Survey Professional Paper 1447-A. 74 p. 1989, Magnitude and frequency of lahars and lahar-runout flows in the Toutle-Cowlitz River system: U.S. Genlogical Survey Professional Paper 1447-B, 33 p.

Scott, K.M., Pringle, P.T., and Vallance, J.W., 1992, Sedimentology, behavior, and hazards of debris flows at Mount Rainier, Washington: U.S. Geological Survey Open-File Report 90$385,106 \mathrm{p}$.

Scully, D.R., Leveen, L.S., and George, R.S., 1978, Surface-water records of Cook Inlet Basin, Alaska, through September 1975: U.S. Geological Survey Open-File Report 78-498, 102 p.

Trabant, D.C., Waitt, R.B., and Major, J.J., 1994, Disruption of Drift glacier and origin of floods during the 1989-1990 eruptions of Redoubt Volcano, Alaska: Journal of Volcanolcoy and Geothermal Research, v. 62, p. 369-385.

Trabant, D.C., and Meyer, D.F., 1992, Flood generation and destruction of Drift Glacier by the 1989-90 eruption of Redo 'bt Volcano, Alaska: Annals of Glaciology, v. 16, p. 33-38.

Waitt, R.B., 1989, Swift snowmelt and floods (lahars) carised by great pyroclastic surge at Mount St. Helens, Washington, 18 May 1980: Bulletin of Volcanology, v. 52, p. 138-157.

Waitt, R.B. Jr., Pierson, T.C., MacLeod, N.S., Janda, R.J., Voight, Barry, and Holcomb, R.T., 1983, Eruption-triggered avalanche, flood, and lahar at Mount St. Helens-Ef ${ }^{c}$ octs of winter snowpack: Science, v. 221, p. 1394-1397. 


\title{
June 29, 1993, Outburst Flood from Kidazgeni Glacier, Mount Spurr Volcano, Alaska
}

\author{
By Christopher J. Nye, William R. Hammond, Guy C. Tytgat, and Joseph M. Dorava
}

\section{CONTENTS}

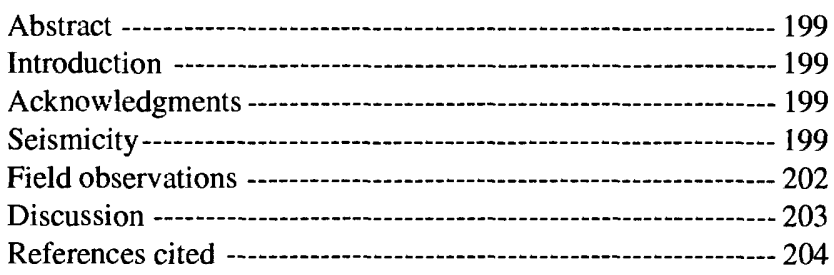

\begin{abstract}
A long, high-amplitude seismic signal caused by an outburst flood from the Kidazgeni Glacier occurred during the late morning of June 29, 1993. This was the longest continuous seismic signal recorded on the Spurr seismic network since the tremor episodes of October 2, 1992, and the earthquake swarm of November 9-10, 1992. The event was significant because visual analysis of helicorder records generated considerable concern that it might have been tremor premonitory to an eruption and because poor weather made direct observation of the Crater Peak vent of Mount Spurr impossible. The seismic signal was different from tremor both in the amplitude ratios between stations and in frequency content. This was not fully, or equally, appreciated by all those involved in the emergency response, and there was protracted discussion about whether or not the Alaska Volcano Observatory (AVO) should raise the level-of-concern color code. Fortuitously, a field crew was in the area during the increased seismicity, and they observed an outburst flood from the terminus of the Kidazgeni Glacier. This flood was the source of the seismicity.
\end{abstract}

\section{INTRODUCTION}

The Kidazgeni Glacier is a valley glacier that drains the southern part of the Mount Spurr amphitheater. The glacier is 1.5 to $3 \mathrm{~km}$ wide and about $7.5 \mathrm{~km}$ long (fig. 1). It averages $125 \mathrm{~m}$ in thickness and covers an area of about 21 square kilometers (R.S. March, oral commun.). It issues from the amphitheater on the east side of Crater Peak, the active vent of Mount Spurr volcano and the source of the 1992 eruptions (Eichelberger and others, this volume). It flows steeply from an altitude of about 2,135 $\mathrm{m}(7,000$ $\mathrm{ft})$ to about $900 \mathrm{~m}(3,000 \mathrm{ft})$ then spreads into a broad, flat lobe that ends at about $700 \mathrm{~m}(2,300 \mathrm{ft})$ elevation (fig. 1).

The Alaska Volcano Observatory currently maintains a local network of about 10 seismometers in the Mount Spurr area. Between 1981 and 1988, only 3 stations were maintained, and during that time the station closest to the terminus of the Kidazgeni Glacier was station CRP, $4 \mathrm{~km}$ to the north. From 1988 through 1992 the network density was increased. Station CKN, $1 \mathrm{~km}$ south of the Kidazgeni Glacier was installed in late 1991 (Power and others, this volume).

This report summarizes the local seismicity and event chronology of a small outburst flood that issued from the terminus of the Kidazgeni Glacier. The event was well recorded on local seismometers. Similar floods or seismic signals had not previously been roted at Mount Spurr, but they have occurred at other snowand ice-covered volcanoes (see Brantley and Power, 1985; Driedger and Fountain, 1989).

\section{ACKNOWLEDGMENTS}

We are grateful to John Power and Dennis Trabant for their reviews and to Carl Benson and Joe Walder for additional comments. Their efforts substantially improved the original version of this paper.

\section{SEISMICITY}

Seismicity associated with the flood began at 9:20 a.m. ADT (Alaska daylight time, Universal Time minus 8 hours) on June 29,1993, with an abrupt increase in amplitude of about two times the background level at station $\mathrm{CKN}$ (figs. 1, 2, 3). Within about 3 min- 


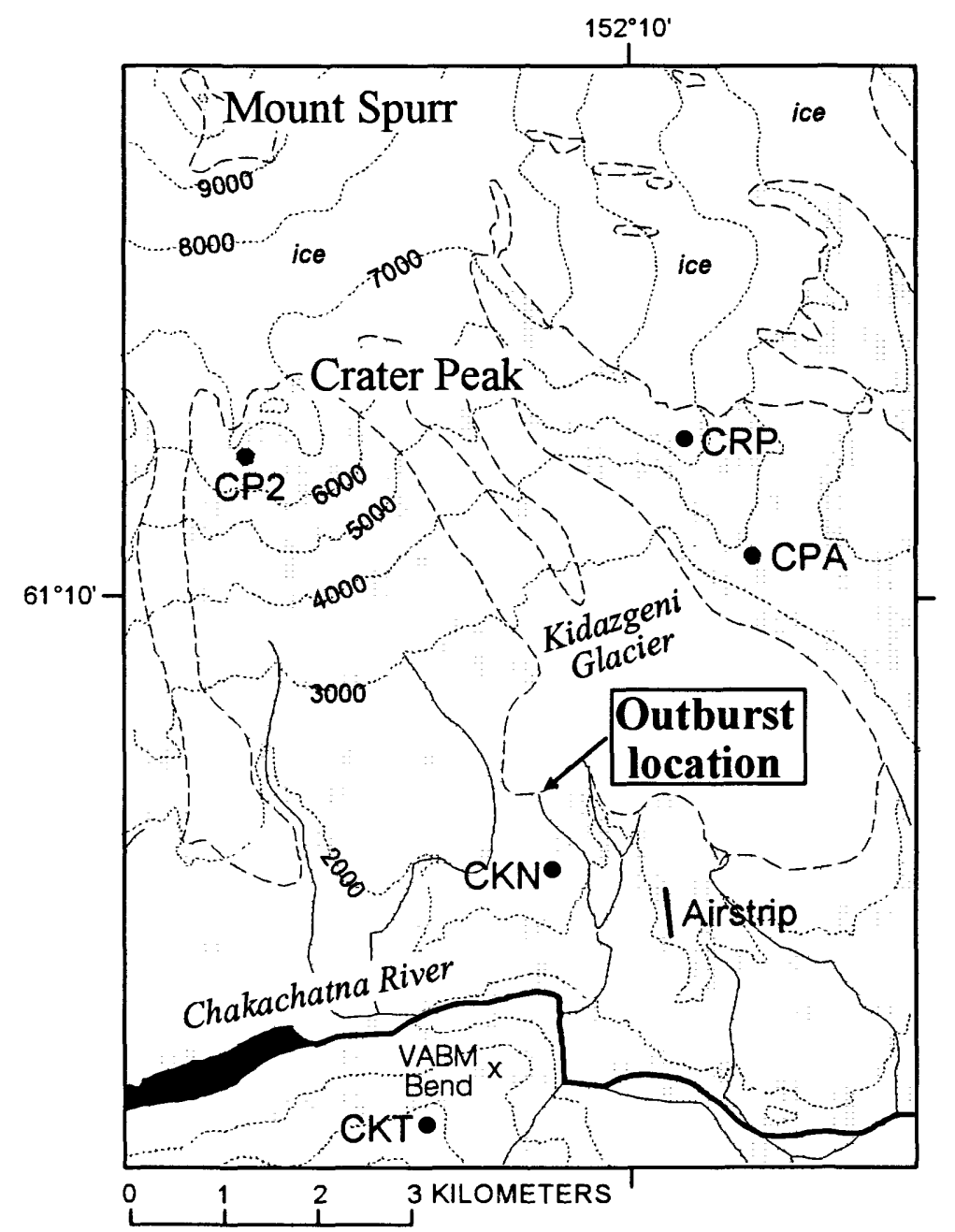

Figure 1. Geography of the Kidazgeni Glacier area of Mount Spurr volcano, Alaska, showing outburst flood location, location of seismic stations (CP2, CRP, CPA, CKN, and CKT), and geographic features referred to in the text. Contour interval 1,000 feet.

utes the seismic signal had begun clipping (some part of the seismometer and telemetry system was saturated). Seven minutes after the initial onset, the amplitude abruptly decayed to nearly background level, where it remained for about 8 minutes. At 9:36 a.m. ADT, a second stronger and longer seismic pulse began (figs. 2, 3). By about 10:11 a.m. ADT, seismicity at CKN was back to two times background level. It remained at this level for about another 9 minutes, when there was a third seismic pulse similar in duration to the initial pulse. Unlike the initial pulse, which stopped abruptly, the third pulse decayed over a period of about 10 minutes. The background seismicity level remained slightly above the pre-event level for the next day or so. The observed frequency of the seismic signal peaked at 4 to $6 \mathrm{~Hz}$, and it had a broad high-frequency tail extending out to about $16 \mathrm{~Hz}$ (fig. 4). This frequency content was distinct from the June
26,1992 , pre-eruptive tremor as recorded at station CKN, which had lower frequencies $(2-4 \mathrm{~Hz})$ and did not have much energy above $5 \mathrm{~Hz}$. Following tha main seismic event on June 29, an increased number of discrete, short duration events were recorded primarily at station CKN. These persisted for a few days (figs. $2,5)$.

Other seismic stations recorded the seismicity associated with the flood, although the peaks in amplitude were shifted in time (fig. 3). These times reflect more than merely greater distance from the source. Instead, they record either a migrating source or the onset of the most energetic seismicity, which could only be sensed at more remote stations. An unequivocal choice between these two possibilities cannot be made because station CKN had clipped so the time of maximum seismic intensity there could not be determined. However, we favor the onset of more energetic seis- 


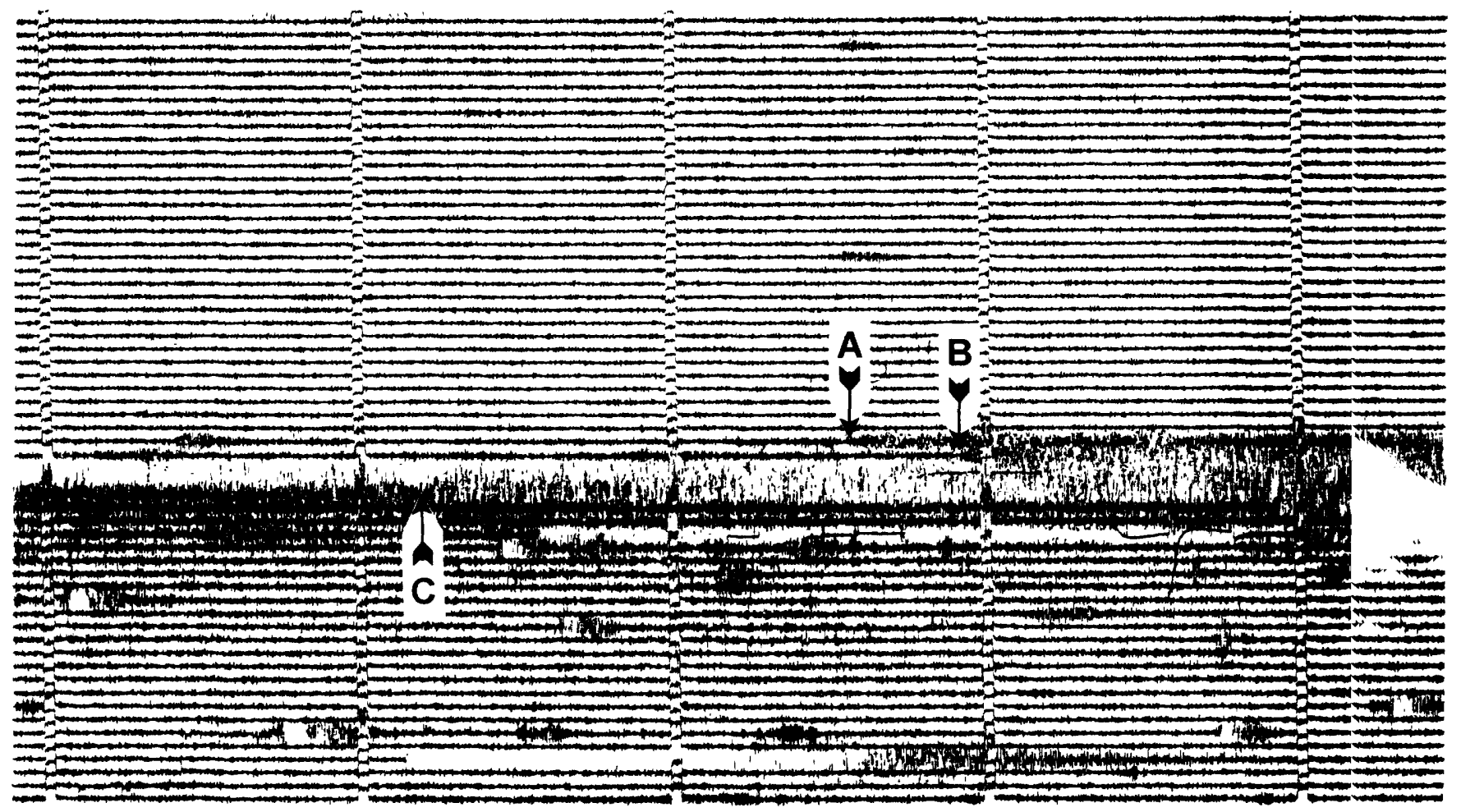

Figure 2. Part of the June 29, 1993, helicorder record for seismic station CKN, (Mount Spurr volcano, Alaska) showing the initial (A), second (B), and third (C) onsets of high-amplitude seismicity and post-outburst discrete events. The background noise preceding the outburst had been typical of station CKN since early June. Tick marks are 1 minute apart.

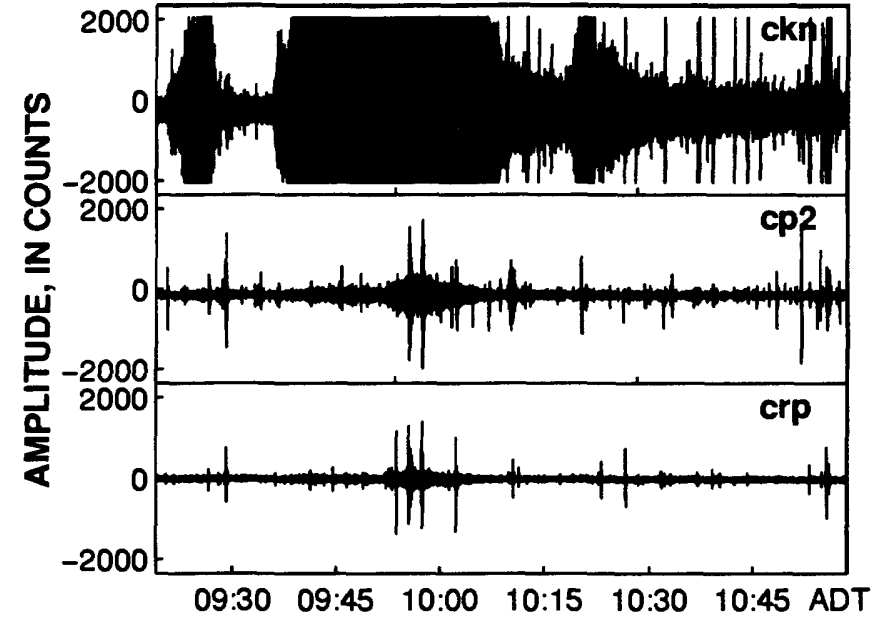

Figure 3. Digital seismic records of the outburst flood at seismic stations CKN (top), CP2 (middle), and CRP (lower) located on or near Mount Spurr volcano, Alaska. Note high intensity and early onset at station CKN.

micity as a possibility. A plot of the envelope of seismicity (not shown) suggests that the maximum energy was released at the time the largest signal was recorded at stations CP2 and CRP.

Station CP2 showed an increase in seismic activity beginning at 9:38 a.m. and ending about 10:05 a.m. ADT. The frequency content was broadly distributed, extending from 2 to greater than $20 \mathrm{~Hz}$ with

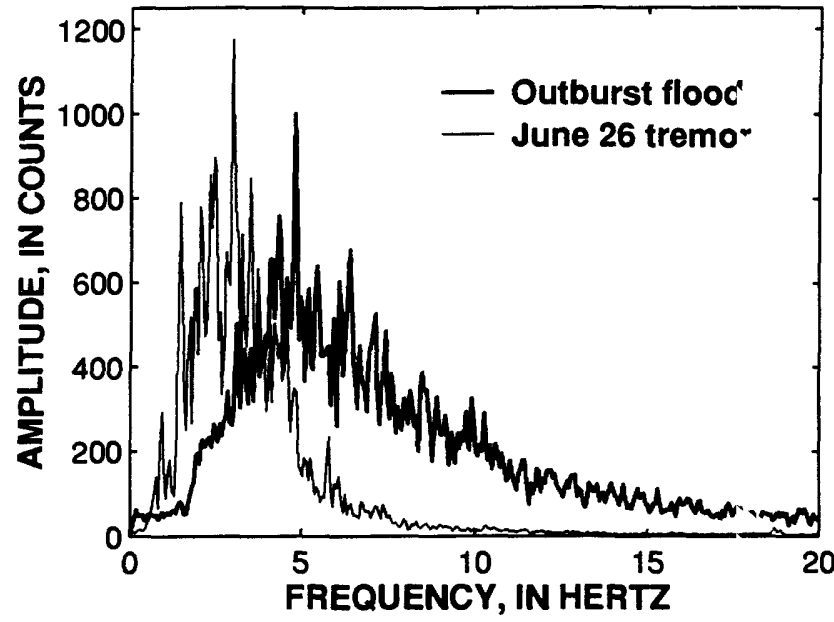

Figure 4. Frequency content of the June 29, 1993, o'tburst flood and June 26, 1992, pre-eruptive tremor as re?orded at station CKN. Each spectrum is constructed from several 10 -second segments, which have been stacked to reduce noise.

no distinct spectral peaks (fig. 6). The signal-to-noise ratio was low, but the signal exceeded the noise for all but the very lowest and very highest frequencies. Station CRP showed an increase in seismic activity beginning at 9:52 a.m. ADT and ending about 10:05 a.m. ADT (fig. 3). The frequency content of the signal was narrow, peaking at $2 \mathrm{~Hz}$, but had a broad, very low-amplitude tail extending to higher frequen- 


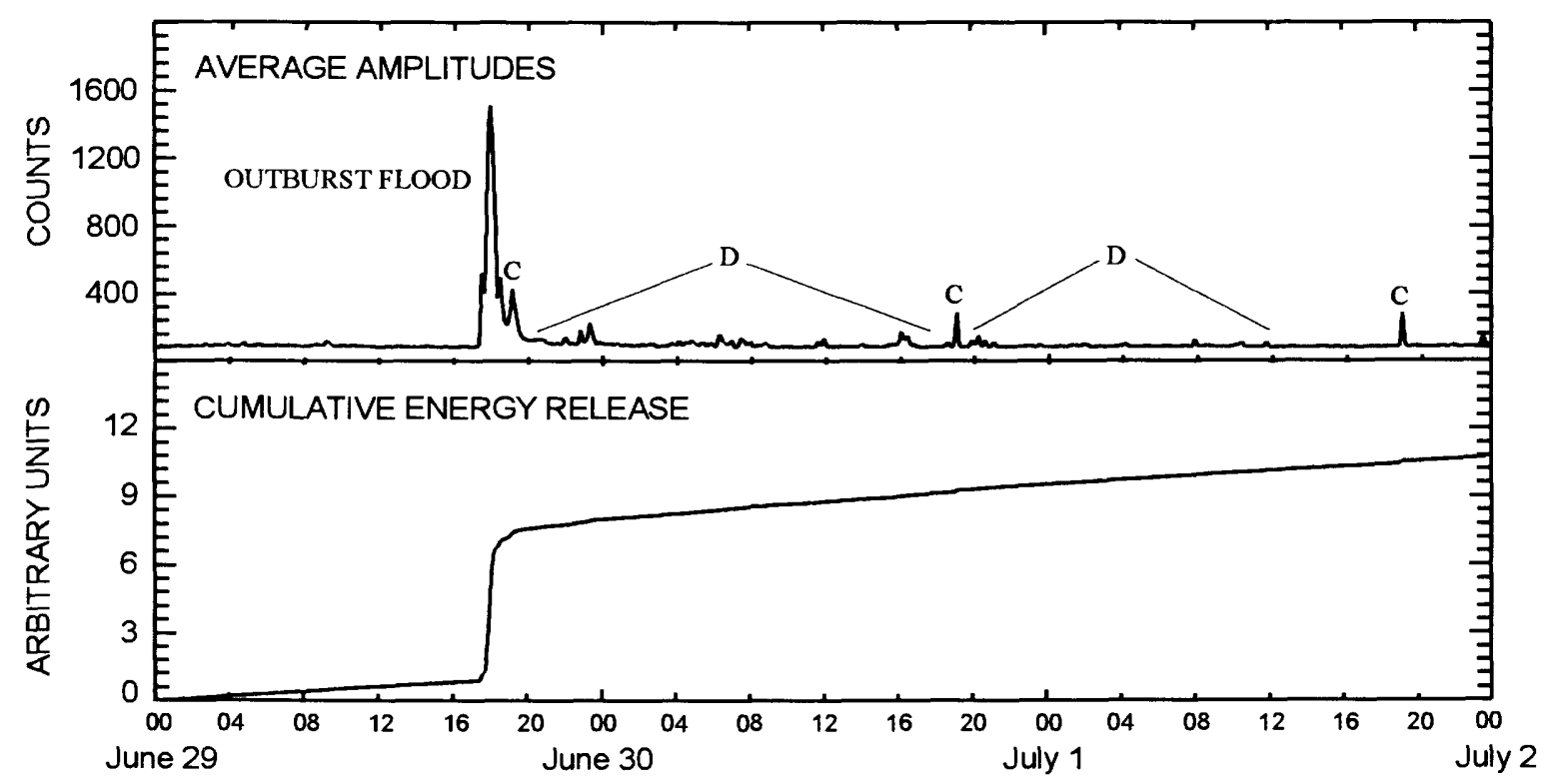

Figure 5. RSAM plots of the outburst flood and succeeding discrete events as recorded at seismic station CKN (located on Mount Spurr volcano, Alaska). In upper plot, discrete events are marked " $D$ " and calibration pulses "C." Upper plot is the average amplitude in counts; lower plot is cumulative energy release in arbitrary units. The graph starts on June 29, 1993, and runs through July 1, 1993. Universal time (intermediate ticks on horizontal axis) expressed in 4-hour increments.

cies (fig. 7). The signal-to-noise ratio was low, however the signal exceeded noise below about $7 \mathrm{~Hz}$. Note that the spectra from stations CP2 and CRP have amplitudes two orders of magnitude lower than those from station CKN. Some aspects of the frequency spectra, particularly high-frequency attenuation, may be artifacts of signal dampening associated with the low energy and greater distances between stations CP2 and CRP and the source and station CKN and the source. Additionally, the low signal-to-noise ratio for these two spectra may significantly reduce the meaningfulness of these data. The June 29 seismic activity at Mount Spurr volcano resembled tremor seen prior to past eruptions with the critical differences that the most energetic signal was not recorded at the station closest to the vent and the frequency content was higher at the station with the highest amplitude signal (CKN).

\section{FIELD OBSERVATIONS}

During the time of increased seismicity, a field party consisting of personnel from AVO, the Cascades Volcano Observatory (CVO), and Carnegie Mellon University was attempting to reach Crater Peak for a reconnaissance in preparation for a robotic mission scheduled for 1994. They approached Crater Peak from the east at about 10:05 a.m. ADT. The cloud base was at about $1,200 \mathrm{~m}$. The field party was informed of the sustained seismicity by AVO Anchorage and landed at the airstrip $1.5 \mathrm{~km}$ east of station CKN (fig. 1) to obtain more information because internal radic communication in the helicopter was not working properly. At the airstrip the field crew was informed of the nature of the seismicity and the concern that it might be tremor premonitory to an eruption. The field crew moved to VABM Bend (fig. 1) by 10:30 a.m.

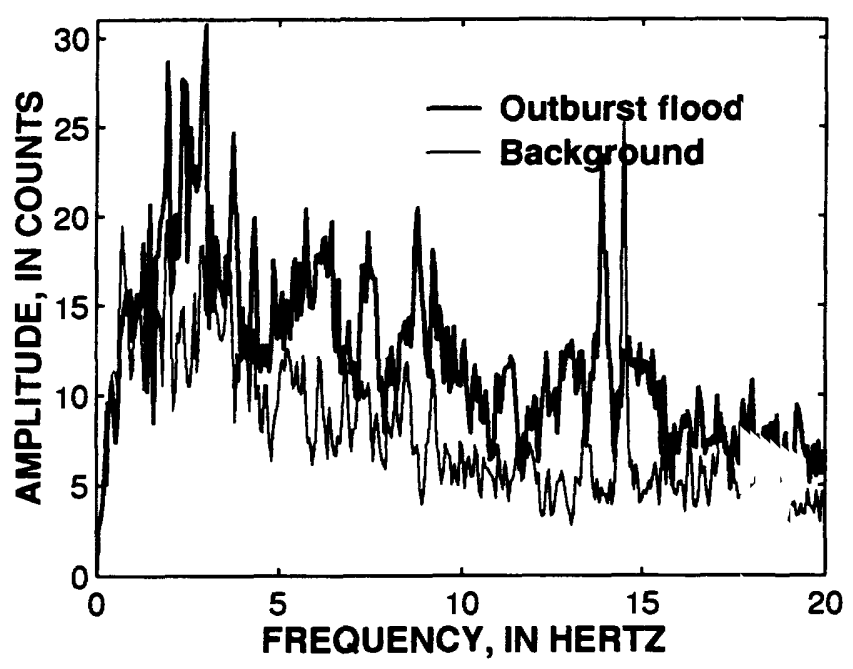

Figure 6. Frequency content of the June 29, 1993, o'tburst flood from Kidazgeni Glacier, Alaska, as recorded at seismic station CP2 on Mount Spurr volcano. Note extremely low amplitude compared to signal recorded at station $\mathrm{CKN}$ (see fig. 4). 
ADT. When leaving the airstrip those members of the field crew familiar with the Mount Spurr area noted that the creek flowing between the airstrip and station CKN (informally called Kidazgeni Creek here) was in flood with dark brown water that was heavily laden with sediment. The water level was higher than had ever been observed previously by those in the field party. Where Kidazgeni Creek entered the Chakachatna River the flow was large enough that mixing was immediate across the entire width $(80-100$ $\mathrm{m})$ of the Chakachatna River. Below the mouth of Kidazgeni Creek, the Chakachatna River was the same shade of dark brown as Kidazgeni Creek. Above Kidazgeni Creek the Chakachatna River was its typical milky blue-green. We estimate that the flow out of Kidazgeni Creek must have been a few tens to several tens of percent of the total flow of the Chakachatna River to so completely and immediately dominate the river's color.

The field crew remained at VABM Bend observing Kidazgeni Creek, waiting for a change in the seismicity, and waiting for the clouds to lift to allow access to Crater Peak. By 12:25 a.m. ADT the flow in Kidazgeni Creek had subsided enough to expose freshly cut and collapsing stream banks with cutbanks on the order of $1 \mathrm{~m}$ high. The field crew conducted an aerial reconnaissance of Kidazgeni Creek and lower Kidazgeni Glacier. Flow into the Chakachatna River was reduced to the point that the muddy brown flood water no longer dominated the Chakachatna River at the confluence with Kidazgeni Creek. Instead, flow from Kidazgeni Creek influenced about one quarter of the width

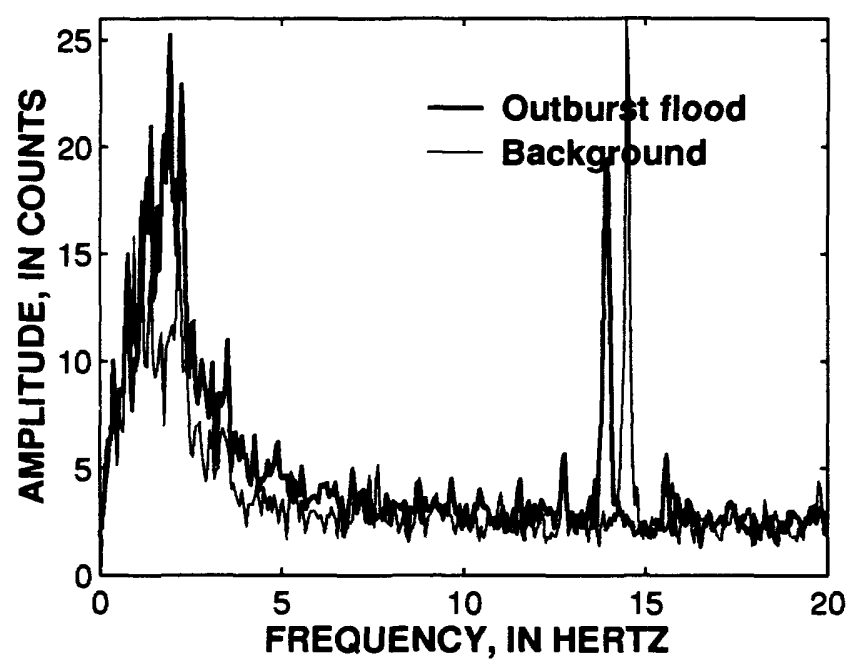

Figure 7. Frequency content of the June 29, 1993, outburst flood from Kidazgeni Glacier, Alaska, as recorded at seismic station CRP on Mount Spurr volcano. Note extremely low amplitude compared to signal at CKN (see fig. 4). Signal-to-noise ratio is small, but signal exceeds noise between about 1.5 and $7 \mathrm{~Hz}$. of the Chakachatna River, and it followed the northeastern bank downstream for a few hundred meters before complete mixing. After mixing with the reduced discharge from Kidazgeni Creek, the Chakachatna Piver was intermediate in color between the dark choc olate brown of Kidazgeni Creek and the milky blue-green of the upper Chakachatna River. The field crew also noted a new stream exit in the western terminus of the Kidazgeni Glacier (fig. 1) surrounded by newly broken ice blocks. It was from this new exit that the dark brown flood waters were issuing. A small superglacial stream a few tens of meters to the west was flowing clear, and another subglacial stream several tens of meters to the east was the typical milky bluegreen of glacial streams. The field crew proce aded up glacier to about the $1,500 \mathrm{~m}$ level looking for major changes to the surface of the glacier but saw rone. There is no indication that the outburst was generated by rapid draining of a superglacial lake. Instead the water storage must have been englacial or subglacial. The glacier in this area is heavily crevassed with a thick cover of debris and 1992 tephra. The field crew returned to the airstrip to observe Kidazgeni Creek and wait for better weather. A small rock slide was correlated with one of the discrete seismic events recorded by station CKN. By 3:50 a.m. ADT the ceiling had lifted to within a hundred meters of the low spot on Crater Peak rim and the field crew flew up along the southern flank of Crater Peak hoping for at least a view into the crater. The ceiling was solid and below the lip of the crater so the field crew returned to Anchorage.

Periodic field investigations of the Kidazgeni Glacier surface were made throughout the 1993 field season to search for evidence that a single subglacial cavity containing the water had drained. However, no surface collapse features were found.

\section{DISCUSSION}

On June 29, 1993, subglacial water burst from a small opening in the terminus of Kidazgeni Glacier and rushed down the steep slopes of Crater Peak to the Chakachatna River. This outburst flood was well recorded seismically and confirmed by field observations. Seismicity at the station nearest the outl 'irst location (CKN, $1 \mathrm{~km}$ south) was distinct from volcanic tremor in its high frequency content (peakirg at $5 \mathrm{~Hz}$ compared to $3 \mathrm{~Hz}$ tremor) and high-frequency tail extending to greater than $20 \mathrm{~Hz}$ (fig. 4). The distinct high-frequency signal was greatly attenuate $f$ by the time outburst seismicity was recorded at stations more distant (but still within $5 \mathrm{~km}$ of the creek). Similar broadband high-frequency seismicity was also observed during floods and lahars at Mount St. Helens, Redoubt 
Volcano, and Mount Pinatubo (Brantley and Power, 1985; Dorava and Meyer, 1994; Bautista and others, 1991). The characteristic frequency of flood events has been recognized by developers of acoustic flow monitoring instruments, which have been used to remotely detect lahars (Hadley and LaHusen, 1991). The increase in discrete events after the June 29 outburst was also recorded most strongly at station $\mathrm{CKN}$, and presumably it reflects settling of the glacial ice after withdrawal of englacial or subglacial water. It is not uncommon to have large quantities of water stored in or under glaciers, especially those on active volcanoes. Post and Mayo (1971) noted that "glaciers with no visible lakes may present unusual flood hazards" and that there is "a common association of glacier outburst floods with glacier-clad volcanoes."

The total discharge of the flood is not precisely known because no flow rate measurements were made during the event and no channel slope and cross-section measurements were made after the event. However, based on the complete and immediate mixing of Kidazgeni Creek and the Chakachatna River, field observers estimated that peak flow from Kidazgeni Creek was a few tens of percent of the total flow of the Chakachatna River. Average June, July, and August flow of the Chakachatna River was about $280 \mathrm{~m}^{3} / \mathrm{s}$ during the period 1959-1972 (U.S. Geological Survey, 1973). If the outburst flood of June 29, 1993, produced a sustained discharge of 20 to 30 percent of this flow during the 66 minutes of seismic shaking at station $\mathrm{CKN}$, then the total flood volume would have been 220,000 to $330,000 \mathrm{~m}^{3}$. This may underestimate the total volume because field observers noted that Kidazgeni Creek flow remained at least somewhat elevated after seismicity at station CKN returned to near-background levels. The volume of this flood is about four orders of magnitude less than more commonly known outburst floods such as the Grimsvotn jökulhlaups in Iceland (Drewry, 1986). If this volume of water was released from a reservoir on the surface of the glacier it would require a pond about $100 \mathrm{~m}$ in diameter and $10 \mathrm{~m}$ deep. No such pond was seen on the surface of the Kidazgeni Glacier at any time during the years of periodic observations prior to the outburst, thus the outburst must have come from englacial or subglacial storage.

The magnitude of this outburst flood is difficult to compare with normal run-off from the glacier because of the scarcity of meteorological data, streamflow data, and comparable basin-characteristic information from similar glacier streams. The probable summer flow from the Kidazgeni Glacier was estimated by dividing the average summer discharge of the Chakachatna River at the gauging station $\left(280 \mathrm{~m}^{3} / \mathrm{s}\right.$; U.S. Geological Survey, 1973) by the $2,900 \mathrm{~km}^{2}$ area of the basin providing that flow, resulting in a unit discharge of $0.0966 \mathrm{~m}^{3} / \mathrm{s} / \mathrm{km}^{2}$. We compare this to the discharge of two unglaciated basins $125 \mathrm{~km}$ to the northeast, which average $0.0366 \mathrm{~m}^{3} / \mathrm{s} / \mathrm{km}^{2}$ and conclude that about 60 percent of the flow of the Chakachatna River is contributed by the 30 percent of the basin covered by glaciers. This analysis suggests that the average discharge from glaciers in the Chakachamna Lake basin is $0.20 \mathrm{~m}^{3} / \mathrm{s} / \mathrm{km}^{2}$. The Kidazgeni Glacier is about $21 \mathrm{~km}^{2}$, and thus should have an average runoff of about $4.3 \mathrm{~m}^{3} / \mathrm{s}$, making the peak outburst flood discharge of $70 \mathrm{~m}^{3} / \mathrm{s}$ about 16 times the mean summer runoff. The estimated flood volume corresponds to about one day of average runoff for the entire glacier at $4.3 \mathrm{~m}^{3} / \mathrm{s}$. We caution that there may be substantial errors in estimating both the flood volume and typical runoff from the Kidazgeni Glacier. We believe, however, that the figures presented here illustrate at least the order of magnitude of volumes involved.

\section{REFERENCES CITED}

Bautista, B.C., Bautista, L.P., Marcial, S.S., Melosantos, A .A., and Hadley, K.C., 1991, Instrumental monitoring of Mount Pinatubo lahars, Philippines: [abs.] Eos Transactions American Geophysical Union, v. 72, no. 44, p. 63.

Brantley, S.R., and Power, J.A., 1985, Reports from the U.S. Geological Survey's Cascades Volcano Observatory at Vancouver, Washington: Earthquake Information Bulletin v. 17, no. 1, p. 21-32.

Dorava, J.M., and Meyer, D.F., 1994. Hydrologic hazards in the lower Drift River associated with the 1989-1990 eruptions of Redoubt Volcano, Alaska: Journal of Volcanology and Geothermal Research, v. 62 , nos. 1-4, p. 387-407.

Drewry, D., 1986, Glacial Geologic Processes: London, Edward Arnold Ltd., p. 31-32.

Driedger, C.L., and Fountain, A.G., 1989, Glacier outburat floods at Mount Rainier, Washington State, U.S.A: Annal ? of Glaciology, v. 13, p. 51-55.

Hadley, K.C., and LaHusen, R.G., 1991, Deployment of an Acoustic Flow Monitoring system and examples of its apslication at Mount Pinatubo, Philippines: [abs.] Eos Transactions, American Geophysical Union, v. 72, no. 44, p. 67.

Post, Austin, and Mayo, L.R., 1971, Glacier dammed lakes and outburst floods in Alaska: U.S. Geological Survey Atlas HA455.

U.S. Geological Survey, 1973, Water resources data for Alaska, water year $1972,389 \mathrm{p}$. 


\title{
Effects of the 1992 Crater Peak Eruptions on Airports and Aviation Operations in the United States and Canada
}

\author{
By Thomas J. Casadevall and M. Dennis Krohn
}

\section{CONTENTS}

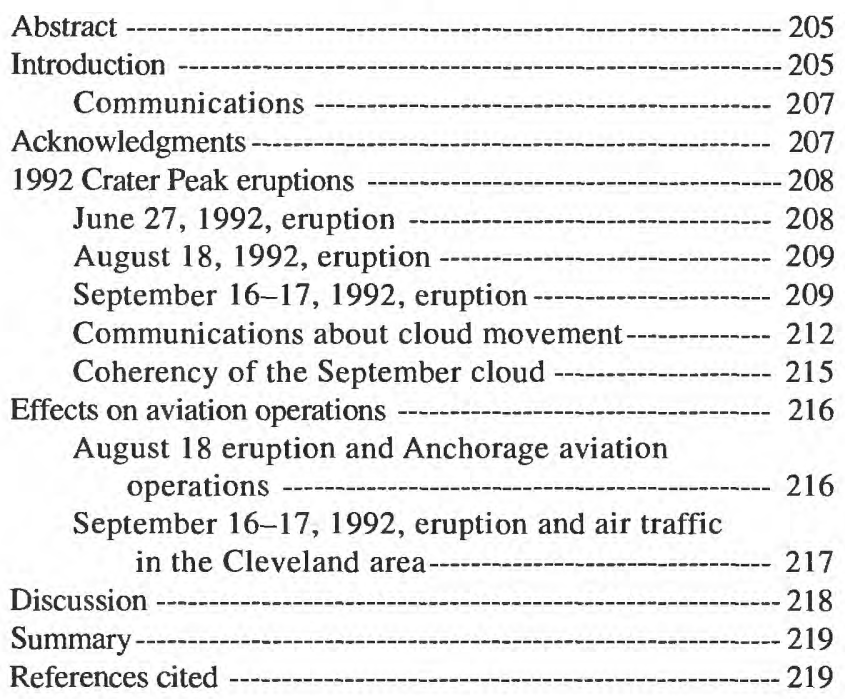

\section{ABSTRACT}

Crater Peak vent on the south side of Mount Spurr volcano, 67 nautical miles $(125 \mathrm{~km})$ west of Anchorage, Alaska, erupted on June 27, August 18, and September 16-17, 1992. Each eruption produced an ash column that rose to between 43,000 and $49,000 \mathrm{ft} \mathrm{(13}$ and $15 \mathrm{~km}$ ) above sea level. Although drifting ash clouds from the three eruptions disrupted air traffic over Alaska, western Canada, and the central conterminous United States, no aircraft were damaged by encounters with the ash clouds.

Ashfall from the August 18 eruption deposited from 1/16" to $1 / 8$ " ( 1 to $3 \mathrm{~mm}$ ) of ash in Anchorage and caused Anchorage airports to close or curtail operations for several days. The cost of removing the ash from the airports, including the cost of protecting and cleaning aircraft caught on the ground in Anchorage is estimated at $\$ 683,000$. The net passenger revenues lost owing to flight cancellations while Anchorage airports were closed are estimated at $\$ 276,000$.
Because encounters with volcanic ash clouds from the 1989-90 eruptions of Redoubt Volcano caused serious damage to five passenger airplanes, there has been a high level of concern in the aviation community about volcanic ash and the threat it presents to aviation safety. The lack of encounters between airplanes and ash clouds from the Mount Spurr eruptions reflects better understanding and increased awareness about the hazards of volcanic ash. Since 1990, a number of improvements have been made to reduce hazards resulting from volcanic ash. These improvements have resulted from major initiatives by Federal and international regulatory agencies and by aviation associations and include: (1) improved warnings of eruptions provided by increased monitoring of Cook Inlet volcanoes, (2) improvements in the detection and tracking of volcanic ash clouds, (3) improved education of pilots and flight dispatchers, and (4) streamlining the ways in which information and warnings are communicated among the agencies concerned with aviation safety.

\section{INTRODUCTION}

Recent eruptions at Redoubt Volcano in Alaska and Pinatubo Volcano in the Philippines provided pilots, aircraft operations personnel, meteorologists, and volcanologists considerable experience in reacting to the presence of volcanic ash clouds and the resulting effects of ash on aviation safety (Casadevall, 1992; 1994a). The 1989-90 eruptions of Redoubt Volcano produced ash clouds which damaged five jet airliners (Casadevall, 1994b). The June 1991 eruptions of Pinatubo produced large ash clouds that were involved in at least 16 damaging encounters with jet airliners (Casadevall and Delos Reyes, 1991).

Mount Spurr $(11,070 \mathrm{ft}, 3,374 \mathrm{~m})$ is one of three volcanoes in the Cook Inlet area of south-central Alaska that have erupted in the past decade. Eruptions of the Crater Peak vent $(6,990 \mathrm{ft}, 2,130 \mathrm{~m})$ on the south side of Mount Spurr on June 27, August 18, and September $16-17,1992$, produced ash columns that rose to 
$43,000$ to $49,000 \mathrm{ft}$ (13 to $15 \mathrm{~km})$ above sea level (Eichelberger and others, this volume). Upper-level winds carried ash from the three eruptions into airspace over south-central and eastern Alaska and western Canada. Ash from the eruptions in June and September was also carried over northern and central parts of the United States (fig. 1). This report evaluates the communication between agencies of information available at the time of the eruptions, describes the movement of the three Mount Spurr ash clouds, and examines the effects of the clouds on aviation operations.

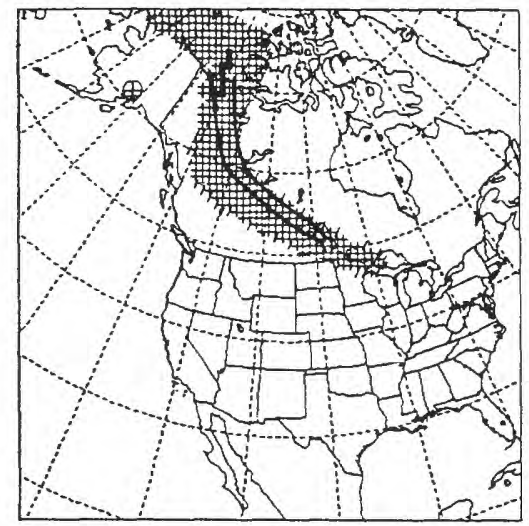

FORECAST CYCLE 92/06/27-12Z

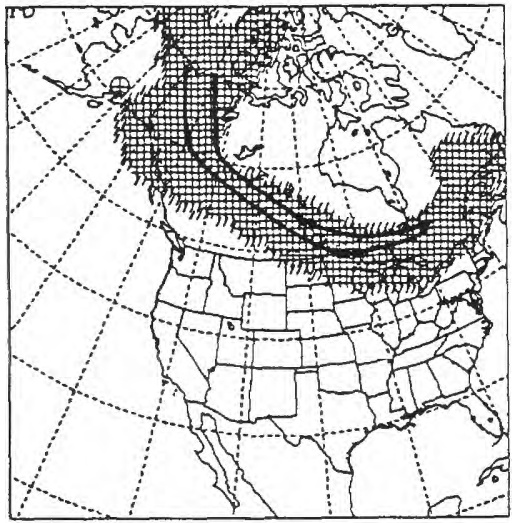

FORECAST CYCLE 92/06/28-12Z

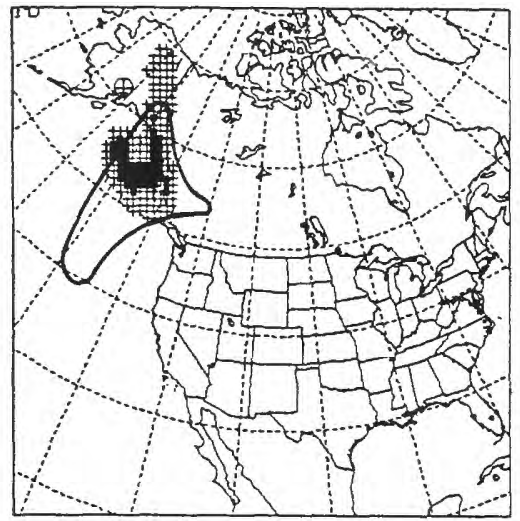

FORECAST CYCLE 92/08/19-00Z

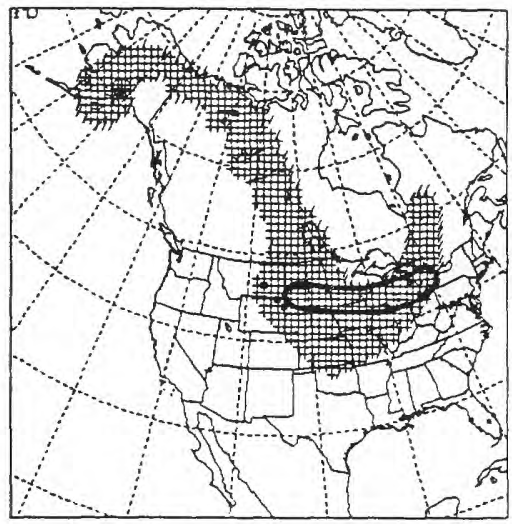

FORECAST CYCLE $92 / 09 / 17-12 Z$

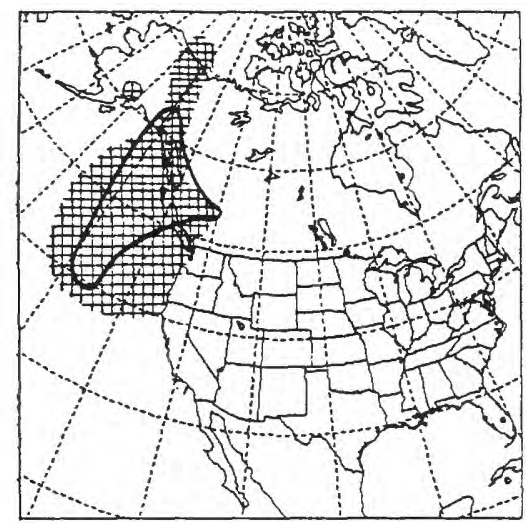

FORECAST CYCLE 92/08/20-00Z

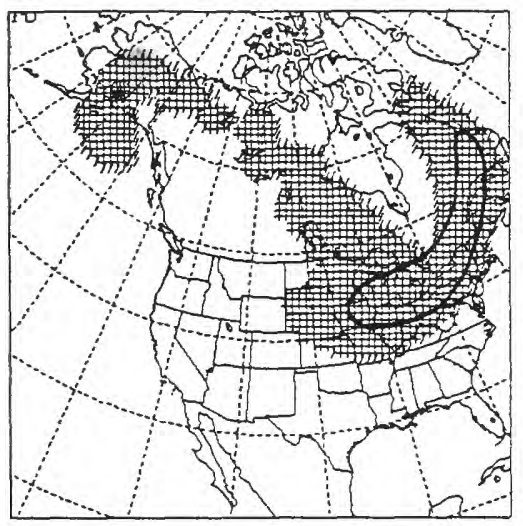

FORECAST CYCLE $92 / 09 / 18-12 Z$
Figure 1. Comparative trajectories of the ash clouds from the June, August and September 1992 eruptions from Mount Spurr volcano, Alaska. Solid lines are ash cloud boundaries determined from composite satellite images. Patterned areas are cloud positions forecast by the volcanic ash forecast transport and dispersion (VAFTAD) model of Heffter and Stunder (1993). Modified from Heffter and Stunder (1993). 
Prior to the 1992 eruptions, Mount Spurr last erupted on July 9, 1953, with a single explosive eruption that sent ash to a maximum estimated elevation of $70,000 \mathrm{ft}(21.3 \mathrm{~km})$ (Juhle and Coulter, 1955). Upper-level winds carried ash from that eruption over Anchorage, 67 nautical miles $(125 \mathrm{~km})$ east of the volcano, and from $1 / 8^{\prime \prime}$ to $1 / 4 "$ ( 3 to $6 \mathrm{~mm}$ ) of ash fell at Anchorage Airport and Elmendorf Air Base; this ashfall resulted in closing the airports for several days and disrupting civilian and military airport operations for several weeks (Juhle and Coulter, 1955; Wilcox, 1959). In addition to the airport closures, at least three F-94 military jets were damaged after flying into the eruption cloud. Ash also covered several C-124 transport aircraft (Globe Trotters) that were parked at Elmendorf; ash removal from these aircraft took 10 days (U.S. Air Force, 1955).

Whereas no damaging encounters between airplanes and ash clouds were reported for the 1992 Crater Peak eruptions, the ash clouds did disrupt air traffic over Alaska, Canada, and the northern and central United States. In addition, the removal of ash and the cleaning of airport facilities and airplanes required temporary suspension of operations at Anchorage airports for several days following the August 18 eruption.

\section{COMMUNICATIONS}

Prompt and direct communication of factual information about Mount Spurr's activity between the aviation community, meteorologists, and volcanologists was a key element in determining pilot response to the eruptions, just as it had been during the 1989-90 Redoubt eruptions (Brantley, 1990; Casadevall, 1994b). Beginning with the Redoubt eruptions, the main source of timely factual information about the activity of Alaskan volcanoes has been the volcano update issued by the Alaskan Volcano Observatory (AVO). The update is normally released weekly and may be supplemented with a level of concern color code that is based primarily on seismic activity and field observations. The color code uses one of four colors (Green, Yellow, Orange, or Red) to succinctly describe the status of the volcano when an eruption is expected or is in progress. Green refers to the normal or noneruptive state of the volcano. Yellow indicates that the volcano is restless with elevated seismic activity and the possibility of a plume of gas and steam rising several thousand feet above the volcano. Orange indicates that a small ash eruption is expected or confirmed with plumes not likely to rise above $25,000 \mathrm{ft}(7.6 \mathrm{~km})$ above sea level. Red indicates that a major explosive eruption is in progress or is expected within the next 24 hours with potentially hazardous ash plumes ex- pected to exceed altitudes of 25,000 feet $(7.6 \mathrm{~km})$ or more. Changes in this information are issued at anytime, 24 hours a day, as events at the volcano demand (Alaska Interagency Operating Plan, 1993).

During an eruption, updates are communicated immediately by telephone to the Anchorage Area Control Center, the Anchorage National Weather Service office, the Alaska Department of Emergency Services, and the U.S. Air Force at Elmendorf Air Base. Simultaneously, the update is sent by telephone facsimile to a wide user community including Anchorage International Airport and the airlines.

Concern that a future eruption of Mount Spurr would affect Anchorage in a manner similar to the 1953 eruption prompted scientists to initiate seismic monitoring of the volcano beginning in 1981. Since 1989 , the AVO has maintained a network of as many as 10 seismometers on the volcano (Power and others, this volume). Beginning in August of 1991, intermittent swarms of small magnitude, shallow earthquakes were detected beneath Crater Peak. After a slightly larger swarm on February 5, 1992, AVO described the increased seismicity in the update of February 7, 1992 (table 1). Between February 7 and June 26, AVO issued 19 additional updates that described the activity of the volcano, including a special update issued on June 8. This special update contained analyses of increased seismicity and other monitoring data then available, such as rates of gas emission (Doukas and Gerlach, this volume) and physical and chemical changes to the small lake within Crater Peak vent (Keith and Thompson, this volume). On June 26, AVO used the color code Yellow to describe the status of the volcano. The 1992 eruptions of Mount Spurr began at 7:04 a.m. ADT (1504 UT) on June 27.

\section{ACKNOWLEDGMENTS}

We would like to express our appreciation for information about the eruptions provided by James Lynch and Grace Swanson of the NOAA-National Environmental Satellite, Data and Information Service, Synoptic Analysis Branch. For the meteorological analysis of the September eruption, we are grateful to David Helms (NASA-Johnson Space Center). For information about the effects on the Cleveland Air Traffic Center, we thank Thomas Howell (FAA). We also greatly appreciate discussions and the unpublished reports provided by Larry Michou (Anchorage International Airport), Captain Terry Spurgeon (Transport Canada), and Carl Shapiro (USGS). Reviews of this paper by John Pallister and Tom Miller of the USGS helped to improve the clarity of the presentation and are appreciated. 
Table 1. Summary of activity from volcano updates issued by the Alaska Volcano Observatory concerning the June 27, 1992, eruption of Mount Spurr volcano.

\begin{tabular}{|c|c|c|}
\hline Date & Time (ADT) & Update \\
\hline $2 / 07 / 92$ & -- & $\begin{array}{l}\text { First mention of increase in seismic activity at Mount Spurr. Minor increase in } \\
\text { seismic activity had been detected previously, starting in August } 1991 .\end{array}$ \\
\hline $3 / 13 / 92-6 / 05 / 92$ & -- & Continuing mention of increased seismic activity made in weekly updates. \\
\hline $6 / 08 / 92$ & -- & Extended update on Mount Spurr seismicity released. \\
\hline $6 / 09 / 92-6 / 26 / 92$ & - & Weekly updates mentioned increased seismicity. \\
\hline $6 / 26 / 92$ & 4:30 p.m. & $\begin{array}{l}\text { At 12:04 p.m. continuous tremor began. Second update issued at 4:30 p.m. on } \\
\text { 6/26/92 describing increased seismicity. Color code Yellow declared. }\end{array}$ \\
\hline $6 / 27 / 92$ & 8:00 a.m. & $\begin{array}{l}\text { Eruption tremor began at 7:04 a.m. Visual verification of ash column to } \\
\text { approximately } 17,000 \mathrm{ft}(5.2 \mathrm{~km}) \text {. Color code raised from Yellow to } \\
\text { Orange. }\end{array}$ \\
\hline $6 / 27 / 92$ & 9:15 a.m. & $\begin{array}{l}\text { Ash column rose to greater than } 30,000 \mathrm{ft}(9 \mathrm{~km}) \text {. Color code raised from } \\
\text { Orange to Red. }\end{array}$ \\
\hline $6 / 28 / 92$ & 9:00 a.m. & Color code reduced from Red to Yellow. \\
\hline $6 / 28 / 92-7 / 07 / 92$ & -- & $\begin{array}{l}\text { Updates issued } 6 / 28,6 / 29,6 / 30,7 / 1,7 / 2,7 / 3,7 / 6,7 / 7 \text {. Color code remained at } \\
\text { Yellow. }\end{array}$ \\
\hline $7 / 08 / 92$ & 3:00 p.m. & Color code reduced to Green. \\
\hline $7 / 10 / 92$ & 3:30 p.m. & Weekly updates resumed; color code remained at Green. \\
\hline
\end{tabular}

\section{CRATER PEAK ERUPTIONS}

The three Crater Peak eruptions in 1992 each lasted from 3.5 to 4 hours, produced pyroclastic material of andesitic composition (Neal and others, this volume), and generated eruption columns that rose to between 43,000 and $49,000 \mathrm{ft}(13$ to $15 \mathrm{~km})$ above sea level (Rose and others, this volume) (table 2). Each eruption also produced large clouds of volcanic ash and gas that affected air traffic and operations over a wide area of the United States and Canada (fig. 1).

\section{JUNE 27, 1992, ERUPTION}

The June 27, 1992, eruption of Mount Spurr's Crater Peak vent produced approximately 12 million cubic meters of andesitic tephra (Neal and others, this volume) and the maximum altitude of the eruption column, as detected by ground-based radar, was approximately $48,000 \mathrm{ft}(14.5 \mathrm{~km})$ (Rose and others, this volume). The forecast movement of the June 27 ash cloud during the first 24 hours was first communicated in the AVO updates issued on June 27 (table 2) and was based on analysis of the forecast upper-level winds. The projected path of the cloud indicated it would travel north of the volcano toward Denali National Park (Mount McKinley) and the Beaufort Sea and remain well clear of the Anchorage area. By June 28, upper-level winds changed direction toward the southeast and by June 29, the cloud had moved southeastward and was transported over western Canada toward the conterminous United States (Heffter and Stunder, 1993) (fig. 1).

On June 27 , shortly after notification of the start of the eruption by AVO, the National Oceanic and Atmospheric Administration (NOAA) and the Federal Aviation Administration (FAA) activated their volca- nic hazards alert plan, which remained in effect for 5 days. The Synoptic Analysis Branch (SAB) of NOAA's National Environmental Satellite, Data, and Information Service (NESDIS) used imagery from the geostationary operational environmental satellite (GOES) and forecast trajectories for the ash clouds (Heffter and Stunder, 1993) to track the June 27 cloud through July 2 when it became indistinguishable from weather clouds over southwestern Canada (J. Lynch, NOAA, written commun., 1992). During this period, SAB issued 19 bulletins about the position and movement of the ash cloud to the Anchorage National Weather Service forecast office, to the National Meteorological Center, to the National Aviation weather advisory unit in Kansas City, to the FAA, and to AVO.

Analysis of images from the advanced very high resolution radiometer (AVHRR) aboard the NOAA-11 polar-orbiting satellite also detected the cloud over western Canada (Aviation Week and Space Technology, 1992). The sulfur dioxide in the eruption cloud was detected using the total ozone mapping spectrometer (TOMS) aboard the Nimbus 7 satellite and the cloud was tracked through July 3 . The eruption cloud contained approximately 200,000 tons of sulfur dioxide gas (Bluth and others, this volume), a mass comparable to the 175,000 tons emitted by the December 15, 1989, eruption of Redoubt Volcano (Schnetzler and others, 1994).

No airplanes flew into the June 27 ash cloud. The only modification of commercial air-traffic patterns in Alaska owing to the eruption was the rerouting of flights from Anchorage to Nome and Anchorage to Kotzebue on June 27 to avoid the ash-contaminated airspace north of Mount Spurr. Several skiequipped charter flights used to service climbers on Mount Denali were canceled on June 27 and 28 because of ashfall on the Denali snowfields. This situation improved by June 29 after fresh snow covered the ash. 
On June 29, the pilot of a daytime domestic flight in Canada reported that he had passed through a 1,000$\mathrm{ft}$ - (300-m)-thick brownish haze layer at $28,000 \mathrm{ft}(8.5$ $\mathrm{km}$ ) altitude as his aircraft descended into Winnipeg (T. Spurgeon, Transport Canada, written commun., 1993). Fortunately, the cloud had been strongly diluted by the time it entered Canadian airspace and there were no reports of ashfall or damage to aircraft in Canada.

\section{AUGUST 18, 1992, ERUPTION}

The first indication of eruptive activity on August 18 was a pilot report received at $3: 48$ p.m. ADT (2348 UT) that ash was rising from 1,000 to $2,000 \mathrm{ft}$ (300-600 m) above Crater Peak. There were no clear seismic precursors to the August eruption, and the eruptive activity reported by the pilot was related to weak tremor that began at 3:41 p.m. ADT (2341 UT) (McNutt and others, this volume). After several additional pilot reports of this low-level ash column and analysis of the weak tremor, AVO raised the color code alert from Green to Yellow at 4:25 p.m. ADT (0025 UT). At 4:42 p.m. ADT (0042 UT), strong eruption-related tremor began to record on the seismic station closest to the vent, and at 4:45 p.m. ADT (0045 UT) AVO telephoned authorities at Anchorage International Airport and Elmendorf Air Base to advise them of the tremor. Authorities at Merrill Field were notified by AVO through the State of Alaska Department of Emergency Services. Following further increase in tremor and notification by the National Weather Service that the Kenai radar had detected an ash column rising above the volcano to more than $35,000 \mathrm{ft}(11 \mathrm{~km})$, AVO issued an update at 4:48 p.m. ADT (0048 UT) and declared color code Red.

The maximum column height of $45,000 \mathrm{ft}(13.7$ $\mathrm{km})$ was detected by radar at 4:55 p.m. ADT (0055 UT) (Rose and others, this volume). The eruption lasted for more than 3 hours and eruption tremor began to decline by $8: 10$ p.m. ADT (0410 UT). AVO lowered the color code from Red to Orange at 9:30 p.m. ADT (0530 UT) on August 18, and further reduced the level to Yellow at 8:30 a.m. ADT (1630 UT) on August 19. During the August eruption, the NOAA SAB issued 21 bulletins that periodically updated the position of the ash cloud and included the trajectory forecasts of cloud position and movement (J. Lynch, NOAA, written commun., 1993).

The August eruption produced 14 million cubic meters of tephra (Neal and others, this volume). The ash column, measured by radar, rose as high as 45,000 ft $(13.7 \mathrm{~km})$ in altitude (Rose and others, this volume), and upper-level winds carried the ash eastward toward Anchorage (table 2). Approximately 1/16" to $1 / 8$ " (1 to $3 \mathrm{~mm}$ ) of fine sand-size ash fell in the Anchorage area between 8:20 p.m. ADT (0420 UT) and 11:00 p.m. ADT (0700 UT); as a result, the three Anchorage airports were closed for several days (figs. 2, 3) (Casadevall, 1993).

\section{SEPTEMBER 16-17, 1992, ERUPTION}

Following the August eruption, AVO maintained a color code of Yellow because levels of seismic activity remained elevated. The update on September 9 drew attention to the first increase in seismic activity since the August eruption, and the update on September 11 stated that an eruption was possible within the next few days or weeks. On September 16, the first phase of a new eruption at 10:36 p.m. ADT (0636 UT) was indicated by increased seismic activity and by pilot reports from Kenai, Alaska (table 3). AVO immediately initiated its calldown and in response to the telephone notification of the eruption from AVO and pilot reports, the National Weather Service issued a notice of significant meteorological event (SIGMET) for the eruption at 10:40 p.m. ADT (0640 UT) (fig-

Table 2. Comparison of the 1992 Mount Spurr volcano eruptions to 1953 Mount Spurr volcano and 1989 Redoubt Volcano eruptions.

[DRE, dense rock equivalent; TOMS, total ozone mapping spectrometer; SAB, Synoptic Analysis Branch, NOAA National Environmental Satellite Data and Information Service (J. Lynch, written commun., 1993)]

\begin{tabular}{|c|c|c|c|c|c|c|}
\hline Date of eruption & $\begin{array}{l}\text { Maximum altitude of } \\
\text { eruption column }(\mathrm{km})\end{array}$ & $\begin{array}{l}\text { Tephra volume } \\
\left(\text { DRE } \times 10^{6} \mathrm{~m}^{3}\right)\end{array}$ & $\begin{array}{l}\text { Sulfur dioxide } \\
\text { (megatons) }\end{array}$ & Traceable on TOMS & $\begin{array}{l}\text { Number of SAB } \\
\text { bulletins issued }\end{array}$ & Pilot reports \\
\hline \multicolumn{7}{|c|}{ Mount Spurr volcano } \\
\hline June 27, 1992 & 14.5 & 12 & $200 \pm 60$ & to $7 / 3$ & 19 & -- \\
\hline August 18,1992 & 13.7 & 14 & $400 \pm 120$ & to $8 / 26$ & 21 &.- \\
\hline September 17-18, 1992 & 13.9 & 15 & $230 \pm 70$ & to $9 / 21$ & 18 & to $9 / 21$ \\
\hline \multicolumn{7}{|c|}{ Mount Spurr volcano } \\
\hline July 9,1953 & $<21.5$ (pilot estimate) & not available & not available & not available & none issued & -- \\
\hline \multicolumn{7}{|c|}{ Redoubt Volcano } \\
\hline December 15,1989 & $>12$ (pilot estimate) & not available & 175 & to $12 / 19$ & 22 & $\overline{--}$ \\
\hline
\end{tabular}




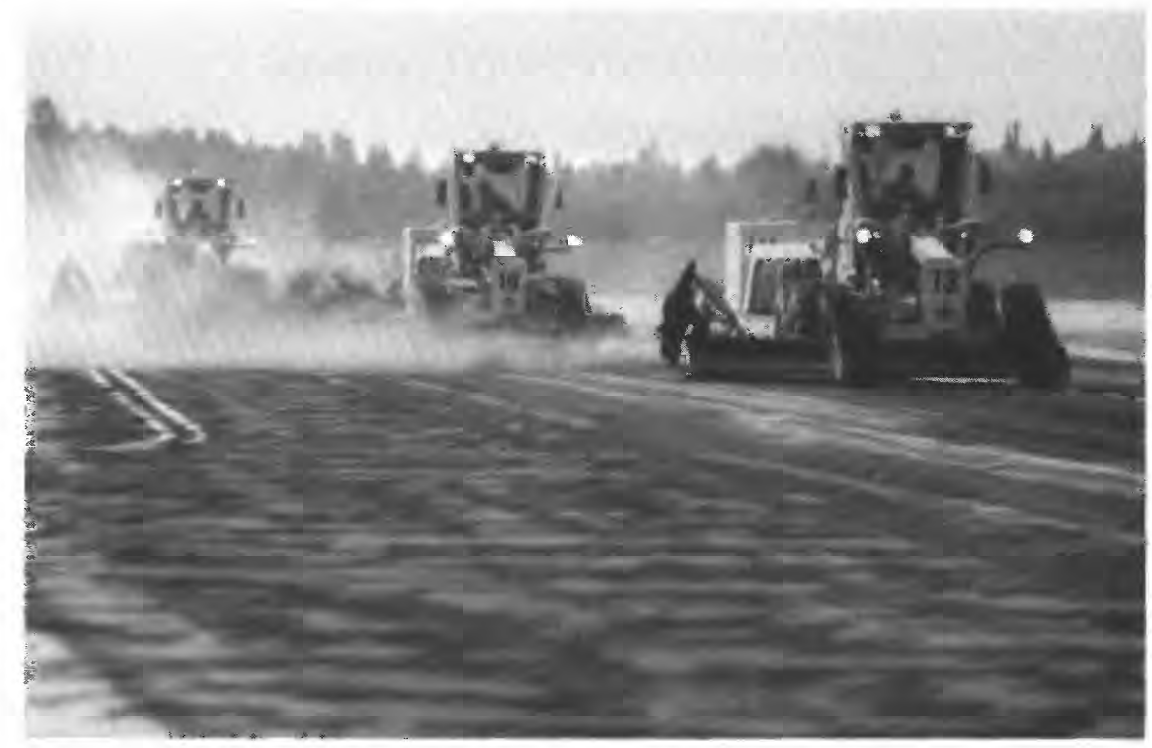

Figure 2. Road graders scrape ash from runways at Anchorage International Airport on August 19, 1992. Road scrapers could effectively move the ash only after it had been sprayed and dampened with water. However, too much water produced a slurry that could not be moved effectively. Dampened ash was scraped into furrows and then scooped up using front-end loaders. Some ash resuspended in the air would settled back onto runways and planes, and thus delayed aircraft cleanup. Photograph by Erik Hill courtesy of Anchorage Daily News.

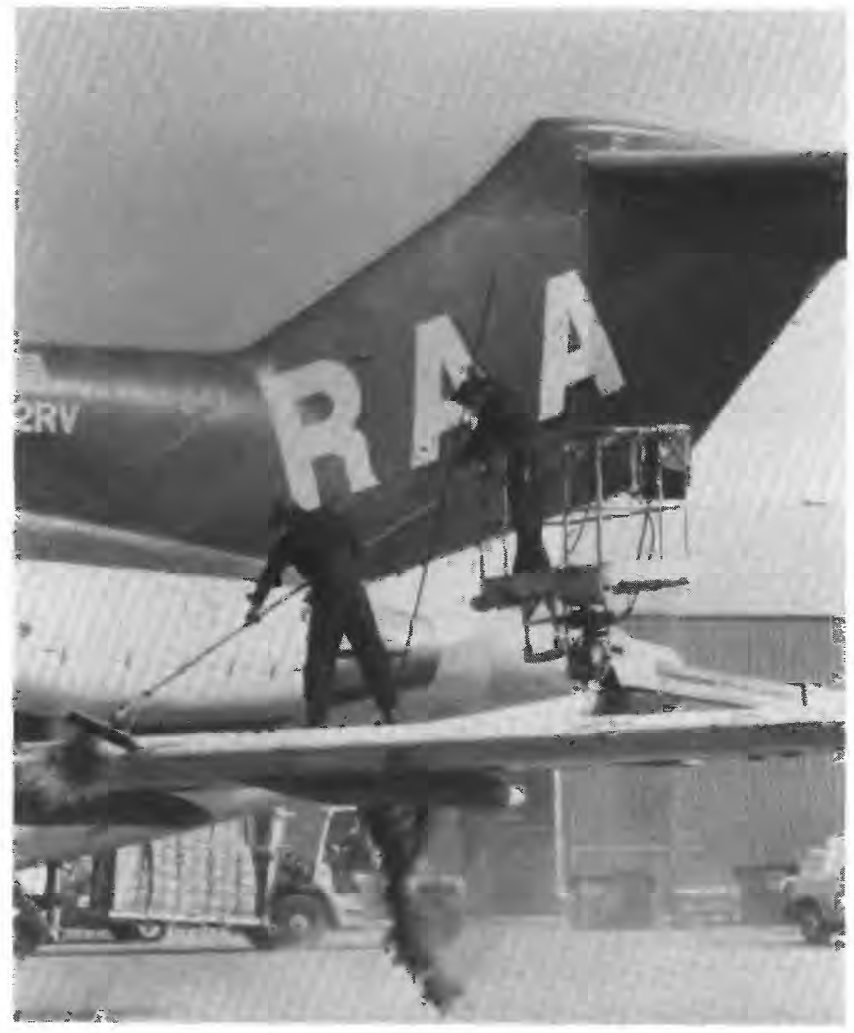

Figure 3. Maintenance crew removing ash from wing of a Reeve Aleutian Airways Boeing 727-100 aircraft on August 19, 1992, at Anchorage International Airport. Photograph by Erik Hill courtesy of Anchorage Daily News. ure 4). AVO increased the color code to Red in the volcano update issued at 10:45 p.m. ADT (0645 UT). The most intense phase of the eruption began shortly before midnight on September 17 and lasted for about 4 hours. At 4:00 p.m. ADT (0000 UT) on September 17 , the color code was reduced to Orange where it remained until September 24 when it was further reduced to Yellow.

The September ash cloud was noteworthy in several ways. Although, the volume of magma erupted, and the basic dimensions of the eruption column and the ash cloud were similar to the two previous eruptions (table 2), the cloud traveled as a coherent mass for 5 days after the eruption. It remained visible during that time to ground observers, pilots, and even to astronauts aboard Space Shuttle mission STS 47. The cloud moved east, passed north of Anchorage and deposited about 1/16" $(1 \mathrm{~mm})$ of ash at Willow, Palmer, and the along Parks Highway in Alaska. It continued across western and south-central Canada, then down into the central United States by September 19 before moving back into eastern Canada and eastward over the North Atlantic by September 21 (fig. 1) (Schneider and others, this volume). 
Table 3. Pilot reports (PIREPs) and ground observations of ash-cloud locations for the September 16-17, 1992, eruption cf Mount Spurr volcano, Alaska.

[Numbers refer to reporting sites shown in fig. 5. AK, Alaska, Yk. Tr., Yukon Territory; Sask, Saskatchewan; Albta., Alberta; SD, South Dakota; ND, North Dakota; NE, Nebraska; IL. Illinois; IA, Iowa; MN, Minnesota; PA. Pennsylvania; OH, Ohio, Ont., Ontario; Wl,

Wisconsin; NY, New York; MI, Michigan, Lab., Labrador, N. Brs., New Brunswick; Latitude and longitudes given in degrees and tenths of degrees. Time given is Universal Coordinated Time (UT). Altitude given in feet above mean sea level, or for values greater than $18,000 \mathrm{ft}$, relative to a barometric pressure of 29.92 inches $\mathrm{Hg}$. Single entries indicate the base of the cloud; second entry indicates top of the cloud. Pilot reports compiled by NOAA Synoptic Analysis Branch (G. Swanson, NOAA, written commun., 1993) and by Transport Canada Aviation (T. Spurgeon, Transport Canada, written commun., 1993)]

\begin{tabular}{|c|c|c|c|c|c|c|c|}
\hline Number & Location & State/ Province & Lat. & Long. & Date & Time & $\begin{array}{l}\text { Altitude/ } \\
\text { Observation }\end{array}$ \\
\hline 1 & Mount Spurr & $\mathrm{AK}$ & 61.3 & 152.2 & $09 / 17$ & 0636 & \\
\hline 2 & Kenai & $\mathrm{AK}$ & 60.62 & 151.19 & $09 / 17$ & 0637 & $\begin{array}{l}\text { ground } \\
\text { observation }\end{array}$ \\
\hline 2 & Kenai & AK & 60.62 & 151.19 & $09 / 17$ & 0646 & $\begin{array}{l}\text { ground } \\
\text { observation }\end{array}$ \\
\hline 3 & Anchorage & $\mathrm{AK}$ & 61.15 & 150.21 & $09 / 17$ & 0713 & \\
\hline 2 & Kenai & $\mathrm{AK}$ & 60.62 & 151.19 & $09 / 17$ & 0745 & $35,0004,0000$ \\
\hline 2 & Kenai & $\mathrm{AK}$ & 60.62 & 151.19 & $09 / 17$ & 0746 & $\begin{array}{l}\text { ground } \\
\text { observation }\end{array}$ \\
\hline 2 & Kenai & $\mathrm{AK}$ & 60.62 & 151.19 & $09 / 17$ & 0757 & \\
\hline 3 & Fire Island & AK & 61.15 & 150.20 & $09 / 17$ & 0800 & \\
\hline 2 & Kenai & $\mathrm{AK}$ & 60.62 & 151.19 & $09 / 17$ & 0804 & $\begin{array}{l}\text { ground } \\
\text { observation }\end{array}$ \\
\hline 3 & Anchorage & $\mathrm{AK}$ & 61.15 & 150.21 & $09 / 17$ & 0821 & $19,00029,000$ \\
\hline 3 & Anchorage & $\mathrm{AK}$ & 61.15 & 150.21 & $09 / 17$ & 0835 & \\
\hline 3 & Anchorage & AK & 61.15 & 150.21 & $09 / 17$ & 0838 & \\
\hline 3 & Anchorage & $\mathrm{AK}$ & 61.15 & 150.21 & $09 / 17$ & 0846 & 10,000 \\
\hline 2 & Kenai & AK & 60.62 & 151.19 & $09 / 17$ & 0846 & $\begin{array}{l}\text { ground } \\
\text { observation }\end{array}$ \\
\hline 3 & Anchorage & AK & 61.15 & 150.21 & $09 / 17$ & 0853 & $21,00037,000$ \\
\hline 3 & Anchorage & $\mathrm{AK}$ & 61.15 & 150.21 & $09 / 17$ & 0900 & $31,00032,000$ \\
\hline 4 & Snowshoe Lake & AK & 62.03 & 146.68 & $09 / 17$ & 1447 & $\begin{array}{l}\text { ground } \\
\text { observation }\end{array}$ \\
\hline 5 & Gulkana & AK & 62.15 & 145.45 & $09 / 17$ & 1449 & $\begin{array}{l}\text { ground } \\
\text { observation }\end{array}$ \\
\hline 3 & Anchorage & $\mathrm{AK}$ & 61.15 & 150.21 & $09 / 17$ & 1452 & $\begin{array}{l}\text { ground } \\
\text { observation }\end{array}$ \\
\hline 2 & Kenai & AK & 60.62 & 151.19 & $09 / 17$ & 1455 & \\
\hline 6 & Talkeetna & $\mathrm{AK}$ & 62.30 & 150.10 & $09 / 17$ & 1457 & $\begin{array}{l}\text { ground } \\
\text { observation }\end{array}$ \\
\hline 1 & Mount Spurr & $\mathrm{AK}$ & 61.3 & 152.2 & $09 / 17$ & 1501 & 35,000 \\
\hline 7 & Watson Lake & Yk. Tr. & 60.07 & 128.48 & $09 / 17$ & 1620 & 35,000 \\
\hline 8 & White River & Yk. Tr. & 61.35 & 139.00 & $09 / 17$ & 1650 & \\
\hline 9 & Beaver Creek & Yk. Tr & 62.45 & 140.62 & $09 / 17$ & 1656 & $\begin{array}{l}\text { ground } \\
\text { observation }\end{array}$ \\
\hline 10 & Lake Laberge & Yk. Tr & 61.17 & 135.17 & $09 / 17$ & 1850 & 6500 \\
\hline 11 & Whitehorse & Yk. Tr. & 60.72 & 135.03 & $09 / 17$ & 2012 & \\
\hline 12 & Dawson & Yk. Tr. & 64.07 & 139.42 & $09 / 17$ & 2141 & 5,000 \\
\hline 13 & Carmacks & Yk. Tr. & 62.10 & 136.32 & $09 / 17$ & $2200^{*}$ & $\begin{array}{l}\text { ground } \\
\text { observation }\end{array}$ \\
\hline 13 & Carmacks & Yk. Tr. & 62.10 & 136.32 & $09 / 17$ & 2300 & 9,000 \\
\hline 14 & Palmer & $\mathrm{AK}$ & 61.59 & 149.08 & $09 / 17$ & 2352 & $\begin{array}{l}\text { ground } \\
\text { observation }\end{array}$ \\
\hline 3 & Anchorage & $\mathrm{AK}$ & 61.15 & 150.21 & $09 / 18$ & 0757 & \\
\hline 15 & Fairbanks & $\mathrm{AK}$ & 64.80 & 148.01 & $09 / 18$ & 0757 & \\
\hline 16 & Lumsden & Sask. & 50.67 & 104.89 & $09 / 18$ & 1250 & $29,00038,000$ \\
\hline 17 & Calgary & Albta. & 51.12 & 113.88 & $09 / 18$ & 1430 & $22,00025,000$ \\
\hline 18 & Pierre & $\mathrm{SD}$ & 44.40 & 100.16 & $09 / 18$ & 1513 & $33,00035,000$ \\
\hline 19 & Swift Current & Sask. & 50.30 & 107.69 & $09 / 18$ & 1520 & $29,00037,000$ \\
\hline 18 & Pierre & $\mathrm{SD}$ & 44.40 & 100.16 & $09 / 18$ & 1528 & $33,00042,000$ \\
\hline 20 & Empress & Albta. & 50.56 & 110.01 & $09 / 18$ & 1650 & 33,500 \\
\hline 3 & Anchorage & $\mathrm{AK}$ & 61.15 & 150.21 & $09 / 18$ & 1705 & $\begin{array}{l}\text { sulfur odor } \\
\text { noted } 7,500\end{array}$ \\
\hline 3 & Anchorage & $\mathrm{AK}$ & 61.15 & 150.21 & $09 / 18$ & 1715 & $\begin{array}{l}\text { sulfur odor } \\
\text { noted } 7,500\end{array}$ \\
\hline 21 & Minot & ND & 48.26 & 101.29 & $09 / 18$ & 1845 & 20,000 \\
\hline 22 & Scottsbluff & NE & 41.90 & 103.48 & $09 / 18$ & 2110 & 37,000 \\
\hline 20 & Empress & Albta. & 50.56 & 110.01 & $09 / 18$ & 2246 & $24,00033,000$ \\
\hline 23 & Northbrook & IL & 42.22 & 87.95 & $09 / 18$ & 2301 & 30,000 \\
\hline 24 & Sioux Falls & SD & 43.65 & 96.78 & $09 / 18$ & 2324 & 27,000 \\
\hline 21 & Minot & ND & 48.26 & 101.29 & $09 / 18$ & 2328 & 33,000 \\
\hline 25 & Cedar Rapids & IA & 41.89 & 91.79 & $09 / 18$ & 2334 & \\
\hline 25 & Cedar Rapids & IA & 41.89 & 91.79 & $09 / 18$ & 2334 & 27,000 \\
\hline 26 & Minneapolis & MN & 44.88 & 93.29 & $09 / 19$ & 0052 & $\begin{array}{l}\text { ground } \\
\text { observation }\end{array}$ \\
\hline
\end{tabular}


Table 3. Pilot reports (PIREPs) and ground observations of ash-cloud locations for the September 16-17, 1992, eruption of Mount Spurr volcano, Alaska-Continued.

\begin{tabular}{|c|c|c|c|c|c|c|c|}
\hline Number & Location & State/ Province & Lat. & Long. & Date & Time & $\begin{array}{l}\text { Altitude/ } \\
\text { Observation }\end{array}$ \\
\hline 27 & Ellwood City & $\overline{\mathrm{PA}}$ & 40.83 & 80.21 & $09 / 19$ & 0116 & 35,000 \\
\hline 28 & Dayton & $\mathrm{OH}$ & 39.90 & 84.22 & $09 / 19$ & 0141 & 11,000 \\
\hline 26 & Minneapolis & $\mathrm{MN}$ & 44.88 & 93.29 & $09 / 19$ & 0154 & $\begin{array}{l}\text { ground } \\
\text { observation }\end{array}$ \\
\hline 29 & Windsor & Ont. & 42.25 & 82.83 & $09 / 19$ & 0200 & 27,000 \\
\hline 30 & Rochester & $\mathrm{MN}$ & 43.78 & 92.60 & $09 / 19$ & 0252 & \\
\hline 26 & Minneapolis & $\mathrm{MN}$ & 44.88 & 93.29 & $09 / 19$ & 0253 & $\begin{array}{l}\text { ground } \\
\text { observation }\end{array}$ \\
\hline 31 & Regina & Sask. & 50.50 & 104.63 & $09 / 19$ & 0320 & $17,30020,500$ \\
\hline 26 & Minneapolis & $\mathrm{MN}$ & 44.88 & 93.29 & $09 / 19$ & 0354 & $\begin{array}{l}\text { ground } \\
\text { observation }\end{array}$ \\
\hline 1 & Mount Spurr & $\mathrm{AK}$ & 61.3 & 152.2 & $09 / 19$ & 0444 & $\begin{array}{l}\text { steam } \\
\text { observed } \\
15,000\end{array}$ \\
\hline 32 & Milwaukee & WI & 42.95 & 87.90 & $09 / 19$ & 0653 & $\begin{array}{l}\text { ground } \\
\text { observation }\end{array}$ \\
\hline 32 & Milwaukee & WI & 42.95 & 87.90 & $09 / 19$ & 0950 & $\begin{array}{l}\text { ground } \\
\text { observation }\end{array}$ \\
\hline 33 & Dunkirk & NY & 42.49 & 79.28 & $09 / 19$ & 1220 & $28,00033,000$ \\
\hline 34 & Rosewood & $\mathrm{OH}$ & 40.29 & 84.04 & $09 / 19$ & 1250 & 23,000 \\
\hline 35 & Flint & MI & 42.97 & 83.74 & $09 / 19$ & 1315 & 28,000 \\
\hline 36 & Waterville & $\mathrm{OH}$ & 41.45 & 83.64 & $09 / 19$ & 1315 & $18,00020,000$ \\
\hline 37 & Buffalo & NY & 42.93 & 78.65 & $09 / 19$ & 1317 & $24,00028,000$ \\
\hline 38 & Dryer & $\mathrm{OH}$ & 41.36 & 82.16 & $09 / 19$ & 1437 & $18,00021,000$ \\
\hline 39 & Hayes Center & NE & 40.45 & 100.92 & $09 / 19$ & 1500 & $35,00037,000$ \\
\hline 38 & Dryer & $\mathrm{OH}$ & 41.36 & 82.16 & $09 / 19$ & 1538 & $18,00023,000$ \\
\hline 40 & Slate Run & PA & 41.51 & 77.97 & $09 / 19$ & 1543 & 21,000 \\
\hline 41 & Tidoute & PA & 41.71 & 79.42 & $09 / 19$ & 1543 & $18,00033,000$ \\
\hline 42 & Clarion & PA & 41.15 & 79.46 & $09 / 19$ & 1543 & $18,00023,000$ \\
\hline 41 & Tidoute & PA & 41.71 & 79.42 & $09 / 19$ & 1543 & $30,00033,000$ \\
\hline 39 & Hayes Center & $\mathrm{NE}$ & 40.45 & 100.92 & $09 / 19$ & 1543 & $31,50037,600$ \\
\hline 43 & McCook & $\mathrm{NE}$ & 40.20 & 100.59 & $09 / 19$ & 1553 & $28,00033,000$ \\
\hline 44 & Ottawa & Ont. & 45.42 & 75.70 & $09 / 20$ & 0123 & $19,00023,000$ \\
\hline 45 & S. Labrador & Lab. & 52.90 & 62.33 & $09 / 20$ & 2025 & 35,000 \\
\hline 46 & London & Ont. & 42.98 & 81.25 & $09 / 20$ & 2230 & $35,00037,000$ \\
\hline 47 & Saint John & N.Brs. & 45.27 & 66.07 & $09 / 21$ & 1123 & $30,00035,000$ \\
\hline 48 & Digby & Nova Scotia & 44.55 & 66.79 & $09 / 21$ & 1825 & 25,000 \\
\hline
\end{tabular}

* report received at 2125 UT noting time of observation was 2200 UT.

\section{COMMUNICATIONS ABOUT CLOUD MOVEMENT}

Pilot reports and ground observations played a critical role in the tracking of the ash cloud from the September 16-17 eruption (table 3; fig. 5). The earliest altitude estimate of $15,000 \mathrm{ft}(4.6 \mathrm{~km})$ for the top of the main eruptive column was made by a pilot and was received at 0637 UT (table 3 ). A pilot report received at 0821 UT estimated the top of the eruption column at between 19,000 and $29,000 \mathrm{ft}(5.8-$ $8.8 \mathrm{~km}$ ); this report corroborated the initial estimates of cloud tops at $28,000 \mathrm{ft}(8.5 \mathrm{~km})$, as determined from C-band radar at Kenai, Alaska (Rose and others, this volume). The ash cloud was tracked using images from the geostationary GOES satellite, images from the TOMS (Bluth and others, this volume), and from the AVHRR (Schneider and others, this volume) detectors aboard polar-orbiting satellites. Pilot reports (table 3; fig. 5), radiosonde analysis, and forecast upperlevel wind data were incorporated from the beginning of the eruption to indicate where the cloud would move (Heffter and Stunder, 1993). These observations were summarized in 18 volcanic hazard alert bulletins issued for the aviation community by NOAA's SAB (J. Lynch, NOAA, written commun., 1993). In addition to written descriptions of the ash cloud, these bulletins contained graphical information showing the location of the ash cloud.

For pilots in the air as well as those preparing for flight, the more succinct SIGMETs were the principal form of information about the ash cloud. These SIGMETs are in an abbreviated text format (fig. 4) and are derived from information in pilot reports, from AVO, from the volcano hazard alert bulletins, and from satellite images. For the September eruption of Crater Peak, the SIGMETs provide a rich source of data about the movement of the ash cloud. The initial SIGMET, ALFA 1, (fig. 4) was issued from Anchorage at 0648 UT on September 16, 12 minutes after the initial eruptive phase and 3 minutes after the AVO color code was changed to Red. That AVO was listed 
WSPN1 PANC 170649

ANCA WS 170648

PAZA SIGMET ALFA 1 VALID 160640/161040 PANC-

ALASKA VOLCANO OBSERVATORY RPTS THAT MT SPURR VOLCANO AT 61.3N LAT/152.2 LONG HAS ERUPTED AT 1036Z.

TOPS INFORMATION NOT YET AVAILABLE. ANY ASH PLUME WL MOV NE-E.

A FOLLOW UP SIGMET TO BE ISSUED ASAP. NC.

WSPN1 PANC 170716

ANCA WS 170716 COR

PAZA SIGMET ALFA 1 VALID 160640/161040 PANC.

ALASKA VOLCANO OBSERVATORY RPTS THAT MT SPURR VOLCANO AT

61.3N LAT/152.2 W LONG HAS ERUPTED AT $0636 Z$.

TOPS INFORMATION NOT YET AVAILABLE. ANY ASH PLUME WL MOVE NE-E.

A FOLLOW UP SIGMET TO BE ISSUED ASAP. NC.

WSPN1 PANC 170844

ANCA WS 170841

PAZA SIGMET ALFA 2 VALID 160840/161240 PANC-

ALASKA VOLCANO OBSERVATORY RPTS THAT MT SPURR VOLCANO AT

61.3N LAT/152.2 W LONG ERUPTED AT 0636Z AND 0804Z. THE 0804Z

ERUPTION WAS MUCH STONGER WITH AN ASH PLUME TO AT LEAST FL400

CONFIRMED BY WEATHER RADAR RHI. WINDS WL MOVE THE ASH TO THE ENE

THEN E. THUS VOLCANIC ASH IS PSBL BLW FL450 WI 9ONM EITHER SIDE OF

A LN FM MT SPUR (61.3N 152.2W) TO ORT. INCRG.

WSPN1 PANC 171225

ANCA WS 171223

PAZA SIGMET ALFA 3 VALID 161240/161640 PANC-

AN ERUPTION OF MT SPURR VOLCANO AT 61.3N LAT/152.2 W LONG CONTINUED

FM $0804 Z$ TILL NEARLY $1100 Z$ WITH WEATHER RADAR INDICATING ASH TO FL 450

THRU THE PD. WINDS WL CONT TO MOVE THE ASH TO THE ENE THEN E.

VOLCANIC ASH IS PSBL BLW FL450 WI 60NM EITHER SIDE OF A LN

FM MT SPUR (61.3N 152.2W) TO GKN TO 62.0N 140.8W WITH THE MAX

CONCENTRATION XPCTD FM FL200-FL350. NC.

Figure 4. Notices of significant meteorological conditions (SIGMETS) issued by Anchorage National Weather Service Office for the September 16-17, 1992, eruption of Mount Spurr volcano, Alaska. Official record compiled by National Climatic Data Center, Asheville, North Carolina.

as the source of the information for the eruption indicates the good coordination between AVO and the National Weather Service during the eruption. No cloudtop information was given because the initial phase was not observed on radar. An error in the start time of eruption was corrected by reissuing SIGMET ALFA 1 at $0716 \mathrm{UT}$.

SIGMET ALFA 2 was issued at $0841 \mathrm{UT}, 38$ minutes after the onset of the main eruptive phase at 0803 UT (fig. 4), and it stayed in effect for the remainder of the eruption. Based on reports from the Kenai radar, SIGMET ALFA 2 informed pilots that the top of the ash cloud had reached $45,00 \mathrm{C}$ feet. This SIGMET also contained a forecast of $a$ 180nautical-mile-wide track for the ash cloud based on the volcanic ash forecast model (Heffter and Stunder, 1993).

The first notification to pilots of the erurtion's end at 1100 UT came from SIGMET ALFA 3 (fig. 4), issued at 1223 UT on September 16. All volcano SIGMET notices from Anchorage were canceled by a SIGMET issued at 0449 UT on September 18, stating that the last reported ash cloud sighting in Alaska was at 2200 UT on September 17. 


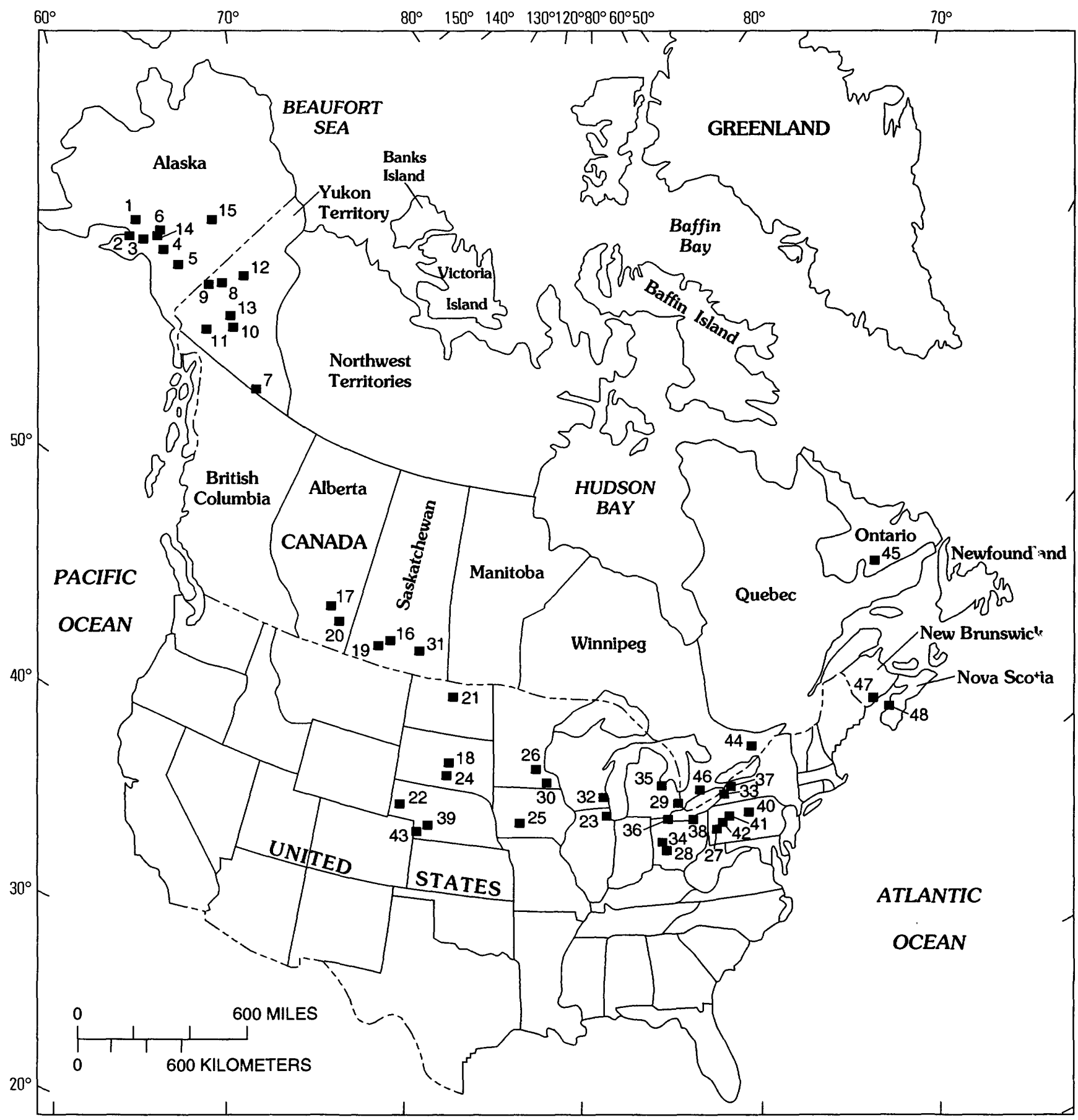

Figure 5. Positions of aircraft reporting visual observations of the September eruption cloud from Mount Spurr volcano, Alaska, as it traveled across North America. Numbers refer to locations of reporting sites listed in table 3 . List compiled from data provided by G. Swanson (NOAA Synoptic Analysis Branch, written commun., 1993) and T. Spurgeon (T. Spurgeon, Transport Canada, written commun., 1993).

Satellite tracking of the cloud in Alaska and in the Yukon Territories was assisted by 24 reports from pilots and ground observers (table 3). At 0400 UT on September 18, after the cloud had been tracked into northwestern Alberta on satellite images, it became obscured by cirrus clouds (G. Swanson, NOAA, written commun., 1993). The next pilot sightings of the cloud were from Lumsden, Saskatchewan, and Calgary, Alberta, at 1250 UT and 1430 UT on September 18 . These reports were followed by observations of the cloud from several sites in South Dakota (table 3; fig. 5). This information was communicated to filots through a series of SIGMETs issued from Canada and from the conterminous United States. 
Eleven SIGMETs were issued by Canadian authorities starting at 1500 UT on September 17 for broad areas of British Columbia, Yukon Territories, Alberta, and Saskatchewan; these SIGMETs were based on computer model predictions for September 17 and 18. These SIGMETs stated that the ash cloud had weakened considerably, but they still advised caution. The Lumsden, Saskatchewan, pilot report (table 3 ) was issued as part of a SIGMET message from Edmonton at 1401 UT on September 18th, a gap of 14 hours from the last pilot report of a visual sighting at 0007 UT.

SIGMET XRAY 1, issued at 1445 UT on September 18 from both Salt Lake City and Chicago, was the first SIGMET issued in the conterminous United States, and was based on analysis of satellite imagery. This SIGMET was followed by SIGMET XRAY 2 issued at 1555 UT that was based on pilot reports over South Dakota that had been received at 1544 UT.

Twenty-five pilot reports of the cloud were recorded in the conterminous United States for September 18 and 19 (table 3), prior to the receipt of the first notification at the Cleveland Air Traffic Control Center at 1000 UT on Saturday September 19 (Howell, 1993). Fourteen additional pilot reports were recorded on September 19, including three from northeastern Nebraska. Additional pilot reports of the ash cloud continued through September 21 (table 3). The pilot reports agree well with satellite observations of ash cloud movement and validate the forecasts of cloud trajectory (Heffter and Stunder, 1993).

\section{COHERENCY OF THE SEPTEMBER CLOUD}

The remarkable coherency of the September ash cloud apparently resulted from meteorological conditions that persisted for several days after the eruption and which prevented the diffusion and dilution of the cloud. The ash cloud was injected into dense cirrostratus and altostratus clouds associated with a surface low-pressure system centered over the eastern Bering Sea. At the time of the eruption, the crest of an upper-level ridge was located at approximately 33,000 $\mathrm{ft}(10 \mathrm{~km})$ over Mount Spurr. Winds at this level carried the ash east and northeast of the volcano (D. Helms, NASA, written commun., 1993).

GOES-7 satellite images showed the ash cloud as it passed beyond the layer of cirrostratus clouds over eastern Alaska and moved southeast in the polar-front jet stream toward Canada. Pilot reports documented the reappearance of the ash cloud during the morning of September 18 at about 1500 UT (figs. 5, 6 ; table 3). At that time, the cloud was observed forming one or more layers between 29,000 and $45,000 \mathrm{ft}$ $(8.8-13.7 \mathrm{~km})$ in the area between western Saskatchewan and Lake Superior where an intensifying low pressure system was located.

On September 19, the ash cloud arrived in the airspace between the Great Lakes and the Mississippi Valley, trapped in the boundary of the polar jet stream. The low-pressure system that was located over Lake Superior on September 18 had moved northeast to-

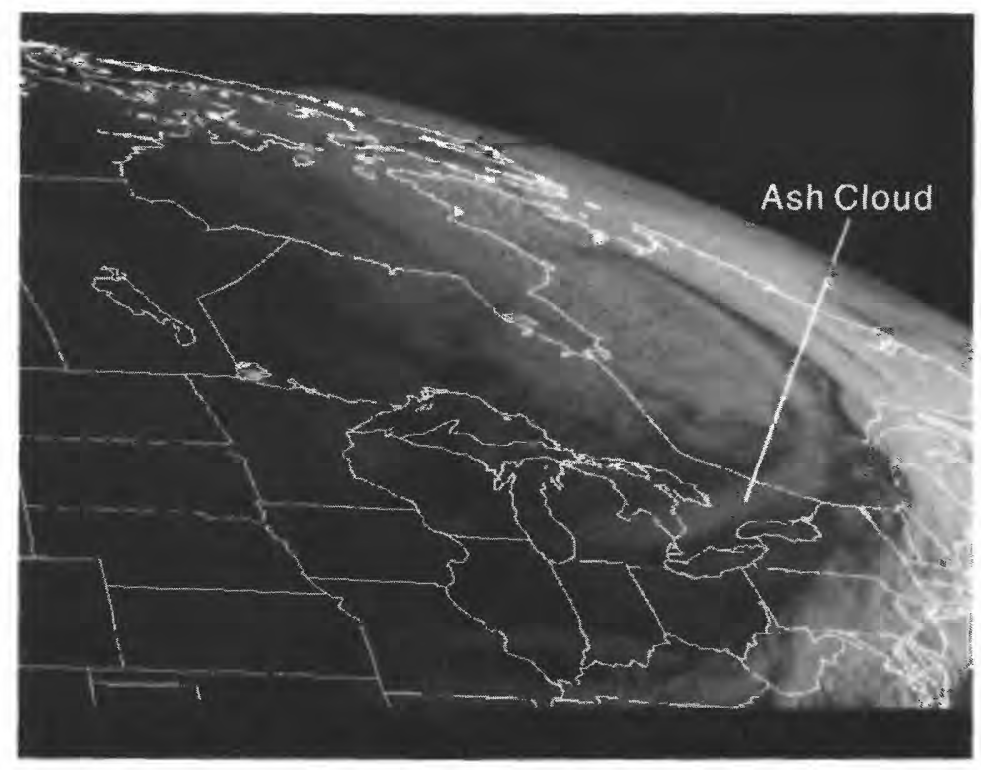

Figure 6. Image from GOES-7 satellite at dawn of September 19, 1992 (1200 UT) showing ash cloud from Mount Spurr volcano, Alaska. Cloud extends from eastern Michigan northeastward into the Canadian Maritime provinces. 
ward Hudson Bay, Canada, and developed into a fully occluded system by September 19. During September 19, the ash cloud moved northeast over the St. Lawrence Seaway and ash particles were apparently concentrated because of the confluent nature of the upper-air flow (D. Helms, NASA, written commun., 1993). Through September 21, the cloud continued to move as a coherent mass visible on GOES-7 images as well as on AVHRR images (Schneider and others, this volume). Occasional pilot reports described the cloud over eastern Canada and even over the North Atlantic region (table 3; fig. 5).

\section{EFFECTS ON AVIATION OPERATIONS}

All three of the 1992 eruptions of Mount Spurr's Crater Peak vent temporarily disrupted air traffic over Alaska and western Canada. The ashfall from the $\mathrm{Au}$ gust 18 eruption caused the temporary closing of the three Anchorage airports. The ash cloud from the September 16-17 eruption disrupted air traffic routing around the volcano, and several days later also disrupted traffic in the congested air corridors of the central United States, especially in the airspace managed by the Cleveland Air Traffic Center (ATC) (Howell, 1993).

\section{AUGUST 18 ERUPTION AND ANCHORAGE AVIATION OPERATIONS}

The August 18 eruption deposited approximately $1 / 16^{\prime \prime}$ to $1 / 8$ " ( 1 to $3 \mathrm{~mm}$ ) of ash in the Anchorage area and resulted in the closing of the three Anchorage airports for several days. The recovery of Anchorage flight operations from the August 18 eruption required that time and money be spent to remove and clean ash from airport facilities and airplanes. The removal of ash from airport facilities and surfaces required a response effort similar to that used for snow removal. Details of the ash-removal operations at the Anchorage airports are reported in Casadevall (1993). In addition to costs associated with ash removal, the cancellation of flights resulted in the loss of revenue to both air carriers and the airport authority.

We tried to establish figures for the costs associated with the August 18 ashfall as one means to evaluate the potential benefits derived from monitoring and surveillance of the volcano as well as mitigation efforts. We report the costs associated with cleaning of the three Anchorage airports to return them to operational status, the costs associated with protecting and cleaning the planes on the ground, and the costs to the air carriers of passenger revenue lost owing to cancellation of flights. Airport officials kept records of the costs associated with the cleanup of buildings and runway and taxiway surfaces at the three Anchorage airports (fig. 2). These costs related largely to employee compensation and minor costs for filters, spare parts, and maintenance of equipment used for cleanup activities and totaled approximately $\$ 653,000$. (L. Michou, Anchorage International Airport, in Casadevall, 1993).

Due to the lack of hanger space, about 30 passenger and cargo aircraft were caught unprotected on the ground at Anchorage International Airport and at Elmendorf. Prior to the ashfall, efforts were made to cover and protect these aircraft, and following the ashfall, the aircraft had to be cleaned (fig. 3) and inspected before they were returned to service. For widebody jets, one manufacturer recommends a total of 30 person hours for preparing an airplane for ashfall (Casadevall, 1993). If a comparable time is spent cleaning an aircraft, the total time spent is approximately 60 person hours, which at a labor rate of $\$ 20$ per hour computes to a cost of approximately $\$ 1,200$ per wide-body airplane. For smaller passenger and cargo jets, we estimate approximately $\$ 900$ per airplane. Labor costs for protecting and cleaning the 20 widebody and 10 smaller aircraft caught on the ground are estimated to total $\$ 33,000$.

The August 18 eruption and ensuing ash cloud caused cancellation of more than 100 domestic and international flights. Unfortunately, we have not been able to recover actual values associated with canceled operations such as the loss of landing fees, fuel-flowage fees, and concession fees. To estimate the revenue lost from these cancellations, we adopted the approach that was developed by Tuck and Huskey (1992) in an analysis of revenue loss attributable to the Redoubt Volcano eruption. In the Redoubt analysis, Tuck and Huskey (1992) calculated the value of $\$ 46.03$ per passenger for net revenues lost to the carriers through flight cancellation. Applying this value to the Mount Spurr situation, using an average of 2,000 passengers per day for the summer tourist season, times 3 days of lost revenue, yields an estimated revenue loss of $\$ 276,000$.

These costs are probably a conservative measure of several costs associated with disruptions to aviation operations due to the August 18 eruption. We have not included costs associated with loss of cargo service, loss of transit of international passengers, and loss of landing fees, fuel flowage fees, and concession fees. Secondary or indirect costs associated with the disruption, such as loss of revenues from car rentals, hotels, and meals were not considered. 


\section{SEPTEMBER 16-17, 1992, ERUPTION AND AIR TRAFFIC IN THE CLEVELAND AREA}

Ash from the September 16-17 eruption caused a major disturbance on September 19 to air traffic managed by the Cleveland Air Traffic Center (ATC) (Howell, 1993). This center is responsible for en-route operations in an area bounded by Saginaw, Michigan; Syracuse, New York; Elkins, West Virginia; and Fort Wayne, Indiana. This airspace includes the major terminal areas of Detroit, Cleveland, and Pittsburgh.

The first report of a volcanic ash cloud was received at Cleveland Center on September 19, 1992 at 1000 UT (6:00 a.m EDT) as a SIGMET from the National Weather Service. The ash cloud was reported to extend from Milwaukee, Wisconsin to Sherbrooke, Quebec, a distance of 710 nautical miles $(1,320 \mathrm{~km})$, at an altitude of $30,000 \mathrm{ft}(9.1 \mathrm{~km}$ ) (figs. 5, 6). Sub- sequent pilot reports through September 19 track the ash cloud moving steadily to the southeast. The last position reported for the cloud was over the Johnstown, Pennsylvania, area at about 1600 UT (table 3). The altitude of the cloud from pilot reports varied from $18,000 \mathrm{ft}$ to $33,000 \mathrm{ft}(5.5$ to $10 \mathrm{~km})$ and higher.

Because the precise altitude of the top of the ash cloud was not well known, aircraft reporting to the Cleveland center elected to descend below the cloud rather than to climb and fly over the cloud. When enroute aircraft were forced to descend below the base of the ash cloud at $18,000 \mathrm{ft}(5.5 \mathrm{~km})$, they entered the low-altitude sectors designed for managing the flow of arriving and departing aircraft. With this influx of aircraft from the high-altitude sectors, the low-altitude sectors quickly became saturated with air traffic (fig. 7). This influx caused numerous delays of as much as 30 minutes for aircraft departing terminals under

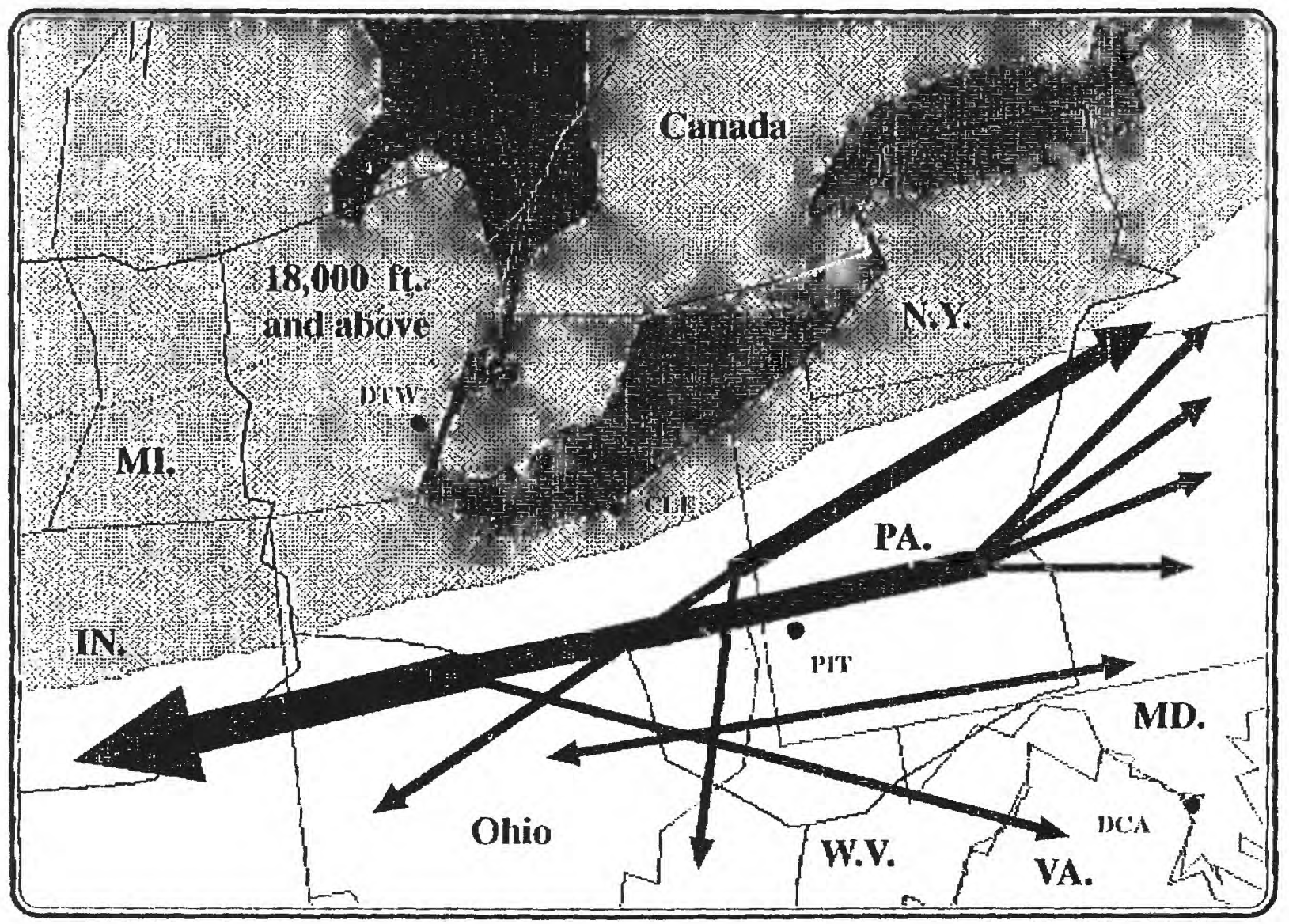

Figure 7. Schematic diagram of airspace around Cleveland Area Traffic Control Center, September 19, 1992 (1317 UT) showing compression of air routes as a result of the southward incursion of the Mount Spurr ash cloud (adapted from Howell, 1993). Dark shaded area shows outlines of Great Lakes. Light shaded area shows extent of ash cloud as interpreted from satellite imagery. Principal air routes are shown with heavy black line; arrows indicate direction of movement; line thickness indicates relative loads along the routes. DTW = Detroit; CLE = Cleveland; PIT = Pittsburgh; DCA = Washington/Dulles. 
the control of the Cleveland ATC. As the ash cloud continued eastward, more pilots requested changes to their flight plans and additional disruptions to normal air-traffic flow took place. Air traffic operations in the airspace controlled by the Cleveland ATC returned to normal by 2300 UT on September 19 (Howell, 1993).

\section{DISCUSSION}

The three ash clouds produced by the Crater Peak vent of Mount Spurr in 1992 were each comparable in size and volume. The effects each cloud had on aviation operations were largely determined by wind dispersal patterns. The June eruption cloud had relatively little effect on air traffic because the southerly winds moved the cloud north away from busy air routes. The August eruption affected Anchorage airports because the west winds carried the ash into the Anchorage area. The September ash cloud affected the busiest en-route region in North America. Fortunately, by the time of the third eruption, the hazard notification system between the ground and air observers in and around Alaska had been used several times and was working efficiently (R. Hutcheon, NOAA, oral commun., 1993). However, in the conterminous United States, where the September ash cloud had not been expected, the air-traffic control system was forced to adjust to the cloud with additional disruption to service. Concerns about the safety aspects of this unique cloud, including its age and far-traveled nature, prompted the FAA to convene a special workshop on volcanic ash clouds held in April 1993 (Federal Aviation Administration, 1993b).

The eruption in September was distinctive because the meteorological conditions kept the ash cloud intact and visible to pilots along major air routes for about 100 hours after the eruption (table 3 ). The September cloud affected the air-traffic system of the conterminous United States as it passed through the heavily traveled north-central air corridor. However, no mechanical problems were recorded and the Cleveland ATC responded in an exemplary way to this major distortion of air routes. Flight delays were the only consequence of the September eruption.

The lack of damaging encounters between aircraft and ash clouds from the 1992 Crater Peak eruptions underscores the recent improvements in the ways that volcanic hazards are being addressed by personnel concerned with aviation operations. Many of the improvements in the hazard warning operations came following the 1989-90 Redoubt eruptions from national and international efforts (Casadevall, 1992, 1994a; ICAO, 1992; Casadevall and Oliveira, 1993; Hickson,
1994) to address the problem of aircraft encounters with volcanic ash. Specific advances include improved monitoring of Cook Inlet volcanoes by the Alaska Volcano Observatory (AVO, 1993); improved monitoring of meteorological conditions in the Cook Inlet region by the National Weather Service (Hufford, 1994); increased awareness and reporting of ash clouds by pilots (Fox, 1994); and refinement and utilization of computer-based forecasting of ash cloud trajectories and particle distribution (Heffter and others, 1990; Heffter and Stunder, 1993; Ellis and others, 1993; Tanaka, 1994).

Since the Redoubt eruptions, the Anchorage office of the National Weather Service has improved its ability to detect and track ash clouds (Hufford, 1994). These improvements include the installation in 1992 of a portable C-band radar on the Kenai Peninsula, which provided immediate detection of the Mount Spurr eruption columns (Rose and others, this volume). Installation of a NEXRAD (WSR-88D) weather radar system (Klazura and Imy, 1993) at Kenai in January 1994, offers several technical advances over conventional C-band weather radar and should enhance the ability to detect the onset of an ash-producing eruption from Cook Inlet volcanoes, the height of the eruption column, and the initial movement of the ash cloud away from the volcano. A newly installed wind profiler at Kenai combined with conventional radiosonde data and with wind data from aircraft overflying the area provide improved wind data for trajectory forecast models. Finally, the satellite downlink capabilities and digital-image processing have been upgraded both at the Anchorage National Weather Service office (Hufford, 1994) and at the University of Alaska in Fairbanks (Dean and Whiting, 1994) for operational application to detect and track ash clouds.

Moreover, the communication of information and warnings among agencies concerned with aviation safety has improved significantly since the 1989-90 eruptions of Redoubt Volcano (Casadevall and others, 1992; FAA, 1993a). In particular, the AVO volcano updates and color code and the volcano hazard bulletins issued by the SAB have been developed and tailored to the requirements of the aviation community in terms of timeliness and message content. In addition, agencies in Alaska have established interagency procedures and operational plans that specifically address the needs of the Alaskan theater of aviation operations (Alaska Interagency Operating Plan, 1993). Recent improvements have also been made in communications between remote field stations and aviation operations in Russia and Alaska (Miller and Kirianov, 1993) in a continuing effort to improve air safety in the North Pacific region. 
Future research to mitigate ash-cloud hazards should include testing of the NEXRAD radar for detecting and tracking ash clouds, validation of remotesensing data such as AVHRR and TOMS data, and validation of trajectory forecast models. This research would benefit from in-situ study of ash clouds, including use of unmanned vehicles to sample ash clouds (Riehle and others, 1994). More attention must be given to improve seismic monitoring of volcanoes in remote areas. Field studies are also needed to evaluate the explosivity of volcanoes, especially in remote regions such as the Kurile-Kamchatka-Aleutian volcanic arc, which parallels some of the world's busiest air routes.

\section{SUMMARY}

Ash clouds produced by the three eruptions of Mount Spurr's Crater Peak vent were comparable in size and volume to the ash clouds from the December 1989 eruptions of Redoubt Volcano (table 2), which damaged five commercial jets. Fortunately, the 1992 Crater.Peak eruptions caused no damage to aircraft en-route. Like several of the Redoubt eruption clouds, the three Mount Spurr clouds also entered Canadian airspace. Two of the clouds entered airspace over the conterminous United States and significantly disrupted the flow of air traffic. This frequent incursion of ash clouds from eruptions of Cook Inlet volcanoes into Canadian and conterminous U.S. airspace highlights the need for timely communications about the threat to aviation safety from drifting ash clouds. In response to these events, U.S. and Canadian meteorologists, volcanologists, and aviation officials continue to develop procedures to provide timely warnings and advisories to pilots about drifting clouds of volcanic ash.

\section{REFERENCES CITED}

Alaska Interagency Operating Plan, 1993, Alaska Interagency Operating Plan for Volcanic Ash Episodes: Alaska Division of Emergency Services, Alaska Volcano Observatory, Department of Defense, Federal Aviation Administration, and National Weather Service, Anchorage, Alaska, June 16, 1993 , $18 \mathrm{p}$.

Alaska Volcano Observatory (AVO), 1993, Mount Spurr's 1992 eruptions: Eos, Transactions of the American Geophysical Union, v. 74, p. 217, 221-222.

Aviation Week and Space Technology, 1992: NOAA satellite helps aviators avoid ash from Alaska volcano: McGraw-Hill, v. 137, , no. 1 , July 6,1992 , p. 31

Brantley, S.R., ed., 1990, The eruption of Redoubt Volcano, Alaska December 14, 1989 - August 31, 1990: U.S. Geological
Survey Circular 1061, $33 \mathrm{p}$.

Casadevall, T.J., 1992, Volcanic Hazards and Aviation Safety, FAA Aviation Safety Journal, v. 2, no. 3, p. 9-17.

Casadevall, T.J., 1993, Volcanic ash and airports: U.S. Geological Survey Open-File Report 93-518, 53 p.

Casadevall, T.J., ed., 1994a, Volcanic ash and aviation safety: U.S. Geological Survey Bulletin 2047, 450 p.

Casadevall, T.J., 1994b, The 1989-1990 Eruption of Redoub+ Volcano, Alaska: Impacts on aircraft operations, in Miller, T.P., and Chouet, B.A., eds., The 1989-90 eruptions of Re toubt Volcano, Alaska, Journal of Volcanology and Geoth rmal Research, v. 62. p. 301-316.

Casadevall, T.J., and Delos Reyes, P., 1991, Impact of June 1991 Pinatubo eruptions on aircraft operations in the western Pacific and Southeast Asia: Eos, Transactions of the American Geophysical Union, v. 72, no. 44 (Supplement), p. 95.

Casadevall, T.J., Matson, M., and Riehle, J., 1992, Volcanic hazards and aviation safety-Minimizing the threat through improved communications: Eos, Transactions, American Geophysical Union, v. 73, no. 43 (Supplement), p. 68.

Casadevall, T.J., and Oliveira, F.A.L., 1993, Special project in the Asia/Pacific region boosts awareness of danger posid by volcanic ash: ICAO Journal, v. 48, no. 8, p. 16-18.

Dean, K.G., and Whiting, L., 1994, Analysis of satellite images of Redoubt Volcano plumes, in Casadevall, T.J., ed., Proceedings, First International Symposium on Volcanic $\mathrm{As}^{\text {h }}$ and Aviation Safety, Seattle, WA, U.S. Geological Survey' Bulletin 2047, p. 333-339.

Ellis, J.S.. Sullivan, T.J., and Vogt, P.J., 1993, Ash cloud transport from the September 17 Mount Spurr eruption: abstract. FAA Workshop on Old Volcanic Ash Clouds, Washington DC, April 22-23, 1993, p. 15.

Federal Aviation Administration, 1993a, Assuring aviation safety after volcanic eruptions: Special Review, Office of the Associate Administrator for Aviation Safety, Washington DC, $35 \mathrm{p}$.

Federal Aviation Administration, 1993b, FAA Workshop on Old Volcanic Ash Clouds, Washington DC, April 22-23, 1993, Office of the Chief Scientist, abstract volume, $37 \mathrm{p}$.

Fox, T., 1994, Volcanic ash-International regulatory aspects, in Casadevall, T.J., ed., Proceedings, First International Symposium on Volcanic Ash and Aviation Safety, Seattle, WA, U.S. Geological Survey Bulletin 2047, p. 169-173.

Heffter, J.L., Stunder, B.J.B., and Rolph, G.D., 1990, Long-range forecast trajectories of volcanic ash from Redoubt Volcano eruptions: Bulletin American Meteorological Society, v. 71, p. $1731-1738$.

Heffter, J.L., and Stunder, B.J.B., 1993, Volcanic ash forecast transport and dispersion (VAFTAD) model: Weather and Forecasting, v. 8, p. 533-541.

Hickson, C.J., 1994, Volcanism in the Canadian Cordillera: Canada's hazard response preparedness, in Casadevall, T.J., ed., Proceedings, First International Symposium on Volcanic Ash and Aviation Safety, Seattle, WA, U.S. Geological Survey Bulletin 2047, p. 47-55.

Howell, T.B., 1993, What happened on September 19, 1992: abstract, FAA Workshop on Old Volcanic Ash Clouds, Washington DC. April 22-23, 1993, p. 18. 
Hufford, G.L., 1994, New technologies to support forecasting volcanic plume movement, in Casadevall, T.J., ed., Proceedings, First International Symposium on Volcanic Ash and Aviation Safety, Seattle, WA, U.S. Geological Survey Bulletin 2047, p. 239-244.

ICAO, 1992, Meteorological Service for International Air Navigation-International standards and recommended practices: Annex III to the convention for international civil aviation, 11 th ed., International Civil Aviation Organization, Montreal, $82 \mathrm{p}$.

Juhle, W., and Coulter, H., 1955, The Mount Spurr eruption, July 9, 1953: Eos, Transactions of the American Geophysical Union, v. 36, p. 199-202.

Klazura, G.E., and Imy, D.A., 1993, A description of the initial set of analysis products available from the NEXRAD WSR-88D system: Bulletin of the American Meteorological Society, v. 74, p. 1293-1311.

Miller, T.P., and Kirianov, V.Y., 1993, Notification procedures for Kamchatka volcanic eruptions: A case history of Sheveluch volcano, April, 1993: U.S. Geological Survey Open-File Report 93-569. 9 p.

Riehle, J.R., Rose, W.I., Schneider, D.J., Casadevall, T.J., and Langsford, J.S., 1994, A proposal for unmanned aerial sampling of a volcanic ash cloud: Eos, Transactions of the American Geophysical Union, v. 75, p. 137-138.

Schnetzler, C.C., Doiron, S.D., Walter, L.S., Krueger, A.J., 1994, Satellite measurements of sulfur dioxide from the Redoubt eruptions of 1989-90, in Miller, T.P., and Chouet. E.A., ed., The 1989-90 eruptions of Redoubt Volcano, Alaska: Journal of Volcanology and Geothermal Research, v. 62, p. 353357.

Tanaka, H.L., 1994, Development of a prediction schem: for the volcanic ash fallout from Mount Redoubt, in Casade"rall, T.J., ed., Proceedings, First International Symposium on Volcanic Ash and Aviation Safety, Seattle, WA, U.S. Geological Survey Bulletin 2047, p. 283-291.

Tuck, B.H., and Huskey, L., 1992, The economic consequences of the 1989-1990 Mount Redoubt eruptions: Institute of Social and Economic Research, University of Alaska, An :horage, $42 \mathrm{p}$.

U.S. Air Force, 1955, History of the Alaskan Air Command, Part 2, Natural Phenomenon, Mt. Spurr Eruption: Alaska Air Command, Elmendorf Air Force Base, Anchorage, p. 73-80.

Wilcox, R.E., 1959, Some effects of recent volcanic ash falls with special reference to Alaska: U.S. Geological Survey Bulletin 1028-N, p. 409-476. 


\section{CLOCK TIME CONVERSION TABLE}

\begin{tabular}{|c|c|c|}
\hline $\begin{array}{c}\text { ALASKA } \\
\text { STANDARD TIME (AST) } \\
\text { (UTC-9 hours) }\end{array}$ & $\begin{array}{l}\text { ALASKA DAYLIGHT } \\
\text { TIME (ADT) } \\
\text { (UTC-8 hours) }\end{array}$ & $\begin{array}{l}\text { UNIVERSAL } \\
\text { TIME (UTC) }\end{array}$ \\
\hline 3:00 p.m. & 4:00p.m. & $00: 00$ \\
\hline 4:00 & $5: 00$ & $01: 00$ \\
\hline 5:00 & $6: 00$ & $02: 00$ \\
\hline $6: 00$ & $7: 00$ & 03:00 \\
\hline 7:00 & $8: 00$ & $04: 00$ \\
\hline 8:00 & 9:00 & $05: 00$ \\
\hline 9:00 & $10: 00$ & 06:00 \\
\hline $10: 00$ & $11: 00$ & 07:00 \\
\hline $11: 00$ & $12: 00 \mathrm{~m}$ & 08:00 \\
\hline $12: 00 \mathrm{~m}$ & 1:00 a.m. & 09:00 \\
\hline 1:00 a.m. & $2: 00$ & $10: 00$ \\
\hline $2: 00$ & 3:00 & $11: 00$ \\
\hline 3:00 & 4:00 & $12: 00$ \\
\hline 4:00 & 5:00 & $13: 00$ \\
\hline $5: 00$ & $6: 00$ & $14: 00$ \\
\hline 6:00 & $7: 00$ & $15: 00$ \\
\hline 7:00 & 8:00 & $16: 00$ \\
\hline $8: 00$ & 9:00 & $17: 00$ \\
\hline 9:00 & $10: 00$ & $18: 00$ \\
\hline $10: 00$ & $11: 00$ & $19: 00$ \\
\hline $11: 00$ & 12:00 p.m. & $20: 00$ \\
\hline 12:00 p.m. & $1: 00$ & 21:00 \\
\hline $1: 00$ & $2: 00$ & $22: 00$ \\
\hline $2: 00$ & 3:00 & $23: 00$ \\
\hline 3:00 & $4: 00$ & $00: 00$ \\
\hline
\end{tabular}




\section{ALASKA VOLCANO OBSERVATORY}

U.S. Geological Survey

4200 University Drive, Anchorage, AK 99508-4667

Dorava, Joe

Doukas, Michael P.

Keith, Terry E.C.

McGimsey, Robert G.

Meyer, David F.

Miller, Thomas $\mathbf{P}$.

Neal, Christina A.

Page, Robert A.

Paskievitch, John F.

Power, John A.

Trabant, Dennis C.

jmdorava@daknet.wr.usgs.gov

fumpd@aurora.alaska.edu

tkeith@tardaddy.wr.usgs.gov

gmcgimsy@ tardaddy.wr.usgs.gov

dfmeyer@daknet.wr.usgs.gov

futpm@aurora.alaska.edu

tneal@tardaddy.wr.usgs.gov

page@ags.wr.usgs.gov

fujfp@aurora.alaska.edu

jp@kiska.gi.alaska.edu

dtrabant@daknet.wr.usgs.gov

University of Alaska, Fairbanks, Geophysical Institute

903 Koyukuk Dr., Fairbanks, AK 99775-7320

Eichelberger, John

eich@dino.gi.alaska.edu

Harbin, Michelle L. mharbin@giseis.alaska.edu

Jolly, Arthur D.

art@kiska.gi.alaska.edu

McNutt, Stephen R.

steve@giseis.alaska.edu

Tytgat, Guy C.

guy@giseis.alaska.edu

State of Alaska Division of Geological and Geophysical Surveys

794 University Ave., Suite 200, Fairbanks, AK 99709

Nye, Christopher J.

cnye @ fm.gi.alaska.edu

\section{OTHER CONTRIBUTORS}

\section{U.S. Geological Survey}

Alaska Earthquake Information Center

University of Alaska, Fairbanks, Geophysical Institute

903 Koyukuk Dr., Fairbanks, AK 99775-7320

Hammond, W.R.

bob@giseis.alaska.edu

\section{U.S. Geological Survey}

Cảscades Volcano Observatory,

5400 MacArthur Blvd., Vancouver, WA 98661-7095

Gardner, Cynthia A.

Gerlach, Terrence M.,

Hoblitt, Richard P.

Murray, Thomas L.

Mastin, Larry G.

Thompson, J. Michael

Waitt, Richard B. cgardner@pwavan.wr.usgs.gov tgerlach@pwavan.wr.usgs.gov rhoblitt@pwavan.wr.usgs.gov tlmurray@pwavan.wr.usgs.gov lgmastin@pwavan.wr.usgs.gov mthompsn@pwavan.wr.usgs.gov waitt@pwavan.wr.usgs.gov 


\title{
OTHER CONTRIBUTORS—Continued
}

\author{
U.S. Geological Survey \\ P.O. Box 25046, MS 903, Denver Federal Center \\ Denver, CO 80225
}

Casadevall, Thomas J.

tcasadev@gccmail.cr.usgs.gov

U.S. Geological Survey, National Center

12201 Sunrise Valley Drive

Reston, VA 22092

Krohn, M. Dennis

Riehle, James R.

dkrohn@aster1.er.usgs.gov

jriehle@isdmnl.wr.usgs.gov

Michigan Technological University

Geological Engineering and Sciences

Houghton, MI 49931

Bluth, Gregg J.S.,

Kostinski, Alexander (Physics Department)

Rose, William I.,

Schneider, David J.,

gbluth@mtu.edu

kostinsk@mtu.edu

raman@mtu.edu

djschnei@mtu.edu

University of Georgia, Franklin College of Arts and Sciences

Department of Geology, 210 Field St., Athens, GA 30602-2501

Swanson, Samuel E.

no email

National Weather Service, Anchorage Region

222 West 7th Ave., \#23, Anchorage, AK 99513-7575

Kelley, Lee

no email

NASA Goddard Space Center, Earth Sciences Directorate, Code 900

NASA Goddard Space Flight Center, Greenbelt, MD 20771

Krueger, Arlin J.

Walter, Louis S.

\section{Hughes STX Corporation}

4400 Forbes Boulevard, Lanham, MD 20706

Scott, Courtney J.

Sprod, Ian E. krueger@chapman.gsfc.nasa.gov lwalter@farside.gsfc.nasa.gov

University of Maryland, Geography Department

University of Maryland, College Park, MD 20742

Schnetzler, Charles C.

cschnetz@ltpsun.gsfc.nasa.gov 


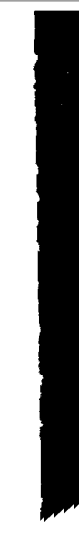





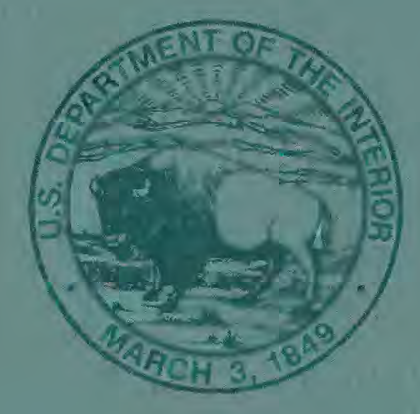

